\title{
Technoeconomic Boundary Analysis of Biological Pathways to Hydrogen Production
}

March 27, 2008 - August 31, 2009

B.D. James, G.N. Baum, J. Perez, and K.N. Baum Directed Technologies, Inc.

Arlington, Virginia

Subcontract Report NREL/SR-560-46674

September 2009

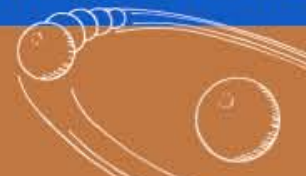




\section{Technoeconomic Boundary Analysis of Biological Pathways to Hydrogen Production}

March 27, 2008 - August 31, 2009

B.D. James, G.N. Baum, J. Perez, and K.N. Baum Directed Technologies, Inc.

Arlington, Virginia

NREL Technical Monitor: Ali Jalalzadeh-Azar

Prepared under Subcontract No. AFH-8-88601-01 
This publication was reproduced from the best available copy Submitted by the subcontractor and received no editorial review at NREL

\section{NOTICE}

This report was prepared as an account of work sponsored by an agency of the United States government. Neither the United States government nor any agency thereof, nor any of their employees, makes any warranty, express or implied, or assumes any legal liability or responsibility for the accuracy, completeness, or usefulness of any information, apparatus, product, or process disclosed, or represents that its use would not infringe privately owned rights. Reference herein to any specific commercial product, process, or service by trade name, trademark, manufacturer, or otherwise does not necessarily constitute or imply its endorsement, recommendation, or favoring by the United States government or any agency thereof. The views and opinions of authors expressed herein do not necessarily state or reflect those of the United States government or any agency thereof.

Available electronically at http://www.osti.gov/bridge

Available for a processing fee to U.S. Department of Energy and its contractors, in paper, from:

U.S. Department of Energy

Office of Scientific and Technical Information

P.O. Box 62

Oak Ridge, TN 37831-0062

phone: 865.576.8401

fax: 865.576.5728

email: mailto:reports@adonis.osti.gov

Available for sale to the public, in paper, from:

U.S. Department of Commerce

National Technical Information Service

5285 Port Royal Road

Springfield, VA 22161

phone: 800.553 .6847

fax: 703.605.6900

email: orders@ntis.fedworld.gov

online ordering: http://www.ntis.gov/ordering.htm 


\section{Preface}

The work described in this report was performed under contract to the National Renewable Energy Lab (NREL), under the technical guidance of members of the Biological Hydrogen Working Group.

The project considered multiple pathways for the biological production of gaseous hydrogen, including photobiological $\mathrm{H}_{2}$ production from a variety of genetically engineered algae and bacteria, dark fermentation of waste photobiological organisms, dark fermentation of lignocellulosic biomass, and the microbial electrolysis of fermentative waste. Additionally, the integration of multiple systems for added hydrogen production and reduced cost was considered. This study was based on the best possible designs using data currently available, and is not inclusive of all potential designs.

Within the photobiological analysis, five different organisms were examined including:

- A truncated antennae Chlamydomonas mutant with an oxygen-tolerant hydrogenase

- A truncated antennae Cyanobacteria mutant with an oxygen-tolerant hydrogenase

- A sulfate-permease Chlamydomonas mutant with a truncated antennae

- An immobilized, sulfur-deprived Chlamydomonas mutant with a truncated antennae

- A truncated antennae Purple Non-Sulfur (PNS) photosynthetic bacterial mutant

For each organism, hydrogen production characteristics were defined, individual reactors conceptually designed, and levelized hydrogen costs calculated. In keeping with a technoeconomic boundary analysis, organism performance was based on the authors projection of future genetically modified organisms rather than current laboratory experimental measurements. Assumptions were carefully stated and compared to current demonstrated performance levels to allow the reader to assess the reasonableness of the future performance levels. Additionally, the hydrogen cost derived from photobiological systems achieving a near term energy efficiency were also computed to assist in bounding the expected future price of hydrogen.

For the fermentative systems, three main systems were examined:

- $\mathrm{H}_{2}$ production using dark fermentation of photobiological systems algal waste

- $\mathrm{H}_{2}$ production using dark fermentation of lignocellulosic feedstock (corn stover)

- $\mathrm{H}_{2}$ production from a Microbial Electrolysis Cell (MEC) using fermentation waste as a feedstock.

While MEC systems produce hydrogen via electrolysis rather than fermentation, we group them with the fermentation systems for convenience as they are linked via a wasteproduct/feedstock relationship. The design and performance of the MEC plant draws heavily from the concepts and laboratory work conducted at Penn State University. The design of the lignocellulosic fermentation plant was based largely on a detailed NREL report analyzing the performance and cost of ethanol production from corn stover. 
Fermentation for ethanol production and fermentation for hydrogen production share many characteristics. Consequently, the current project work product was greatly enhanced by making use of the analogous analysis. For each system, a plant design was selected, its capital cost and performance were estimated, and resulting levelized hydrogen cost computed. The DOE H2A cost estimation spreadsheet tool was used to estimate these levelized hydrogen costs so as to allow easy and transparent comparisons to other production options.

Finally, we integrated the most logical combinations of the above enumerated systems based on synergies in plant design, seeking to realize hydrogen cost reduction through combined utilization of reactor components and potential use of waste products as feedstock. Hydrogen cost from the integrated systems is then compared to hydrogen cost from the stand-alone systems.

Project results were reported in four sequentially prepared reports. This project final report consists of these four reports plus a comprehensive discussion section, all integrated under a common cover. Thus the report consists of five sections:

- Part I: Photobiological $\mathrm{H}_{2}$ Production Systems

- Part II: Algae Fermentative $\mathrm{H}_{2}$ Production Systems

- Part III: Lignocellulosic Fermentative $\mathrm{H}_{2}$ Production Systems \& Microbial Electrolysis Cell Systems

- Part IV: Integrated Systems

- Part V: Discussion of Project Results

Since the individual reports were done sequentially, Part V of the report contains a summary of all contract work, including recommendations for future actions. The reader is advised to look to Part V for an overall project summary and listing of conclusions. 


\section{Acknowledgements}

The authors of this report would like to acknowledge the contributions of the Biological Hydrogen Working Group, whose members provided invaluable technical and/or programmatic guidance throughout the analysis project.

Working Group members included:

Dr. Ali Jalalzadeh-Azar, Senior Engineer II and Technical Monitor, NREL

Dr. Maria L. Ghirardi, Principal Scientist, NREL

Ms. Pin-Ching Maness, Principal Scientist, NREL

Dr. Michael Seibert, Research Fellow, NREL

Dr. Anastasios Melis, Professor, UC Berkeley

Dr. George Sverdrup, Laboratory Program Manager, NREL

Ms. Roxanne Garland, Technology Development Manager, US DOE, EER\&E

Additionally, other members of the hydrogen production community contributed to this analysis through their expert guidance. They are:

Dr. G. Charles Dismukes, Professor, Princeton University

Dr. Bruce E. Logan, Professor, The Pennsylvania State University

The work described in this report was performed under contract to the National Renewable Energy Lab (NREL) with sponsorship provided by the US Department of Energy, Office of Fuel Cell Technologies, DOE Office of Energy Efficiency and Renewable Energy. 


\section{Contents}

PREFACE. III

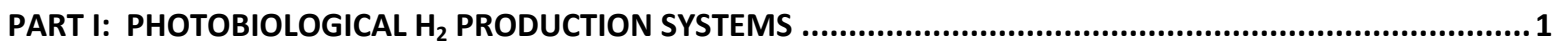

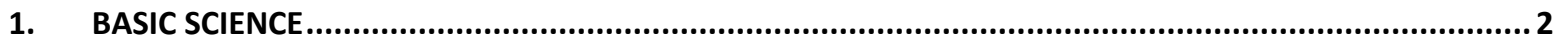

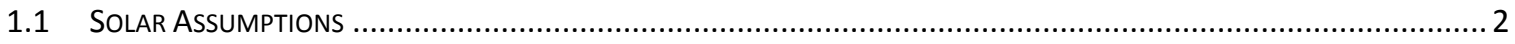

1.2 Bed Depth, Algal Concentration, \& H $\mathrm{H}_{2}$ Production Rate Assumptions ............................................... 4

2. PHOTOBIOLOGICAL SYSTEMS - BIOLOGICAL AND SYSTEM PARAMETERS ...................................13

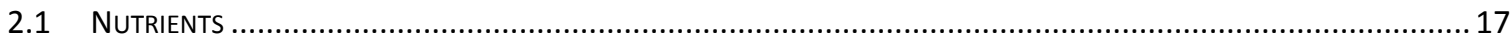

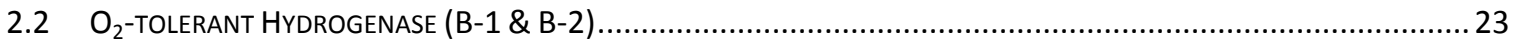

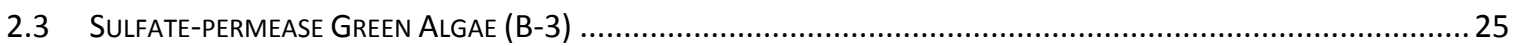

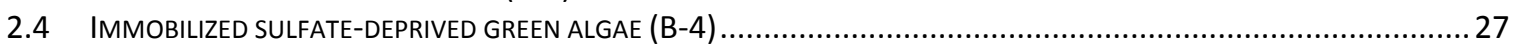

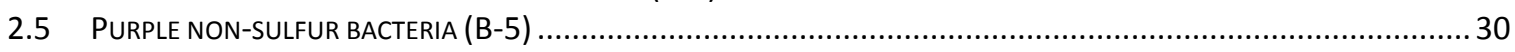

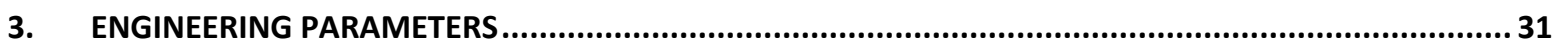

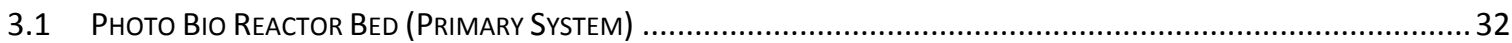

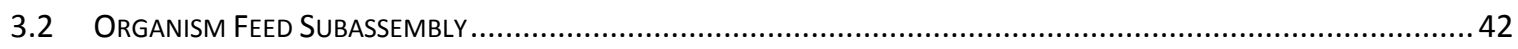

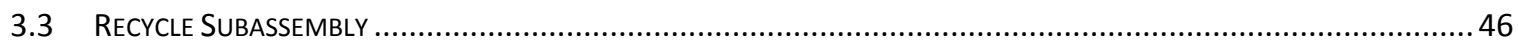

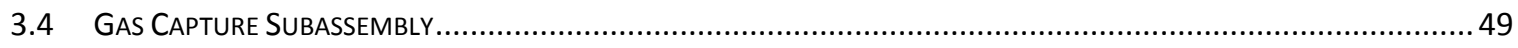

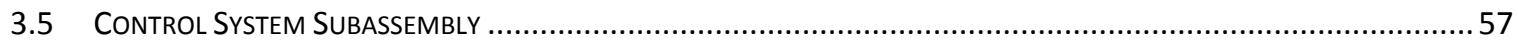

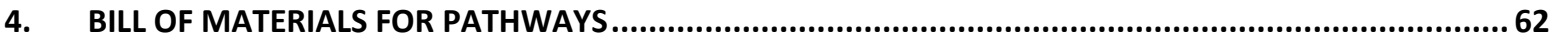

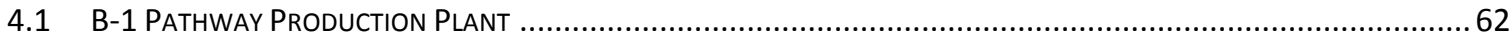

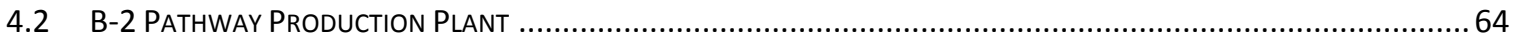

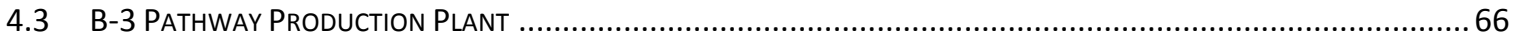

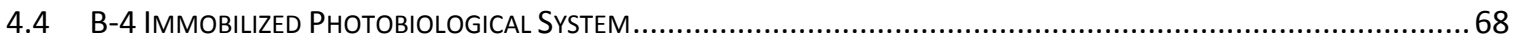

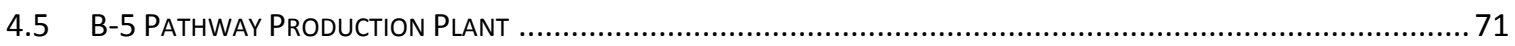

5. CAPITAL COST ASSUMPTIONS AND CALCULATIONS...........................................................73

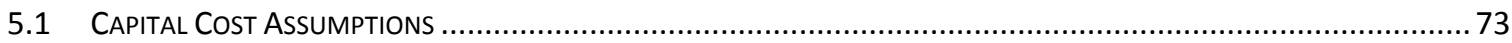

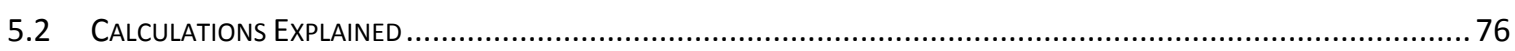

6. LEVELIZED COSTS ASSUMPTIONS \& CALCULATIONS (H2A) ..............................................80

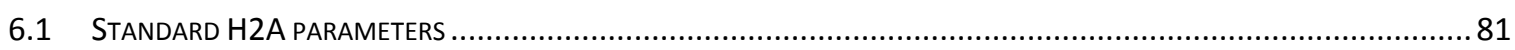

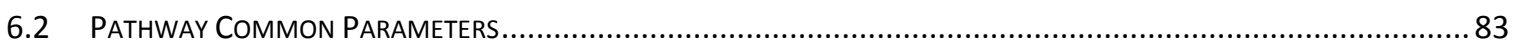

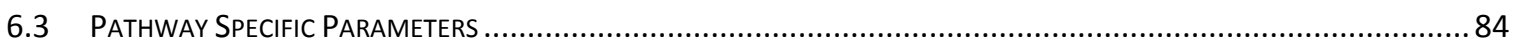

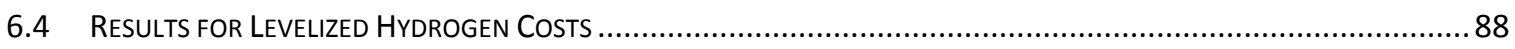

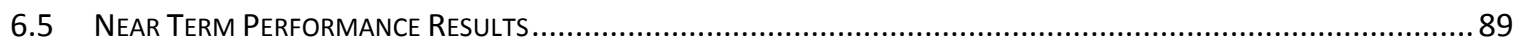

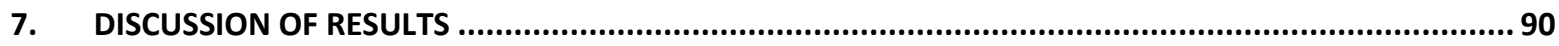

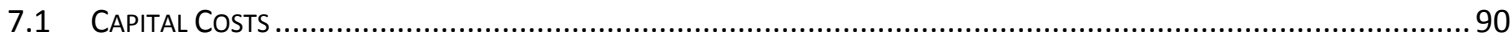

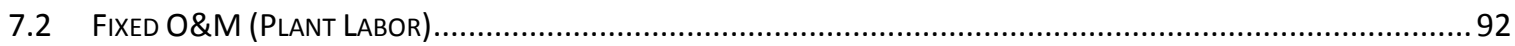

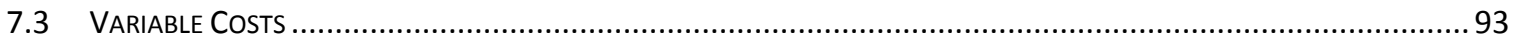

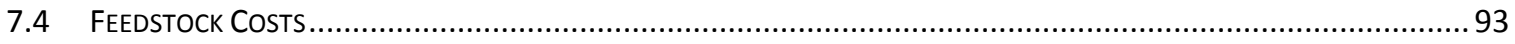

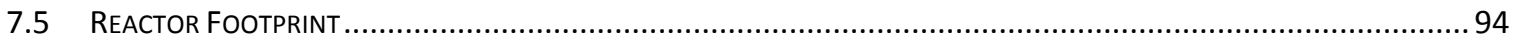

8. PHOTOBIOLOGICAL SYSTEM CONCLUSIONS AND RECOMMENDATIONS .......................................94

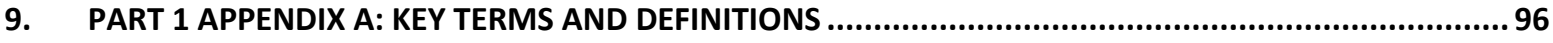

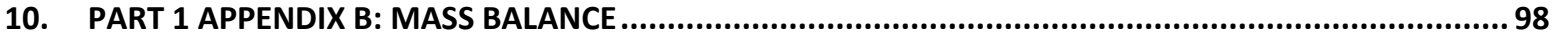




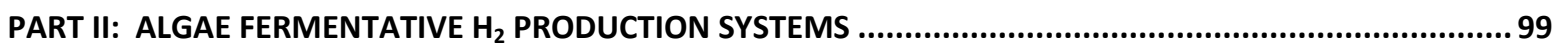

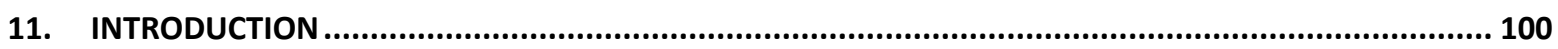

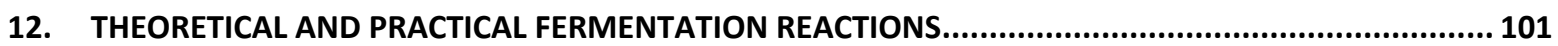

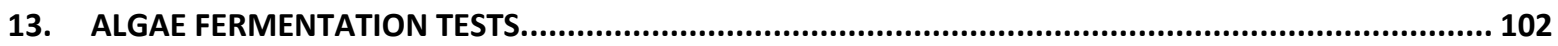

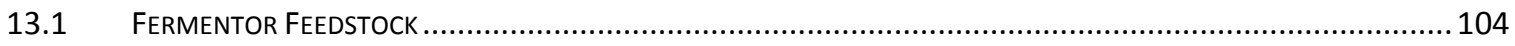

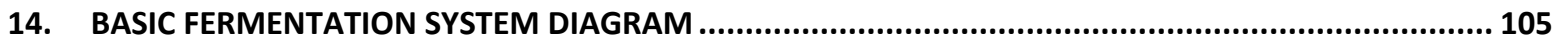

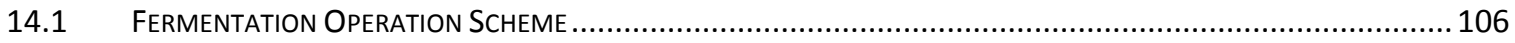

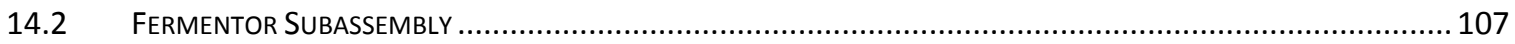

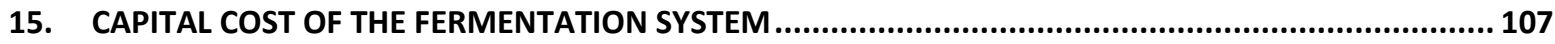

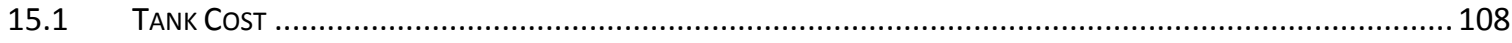

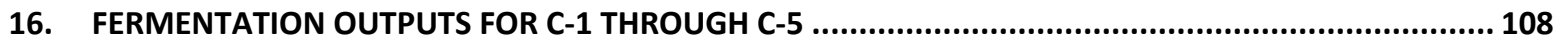

17. LEVELIZED COSTS ASSUMPTIONS \& CALCULATIONS (H2A) ............................................................. 109

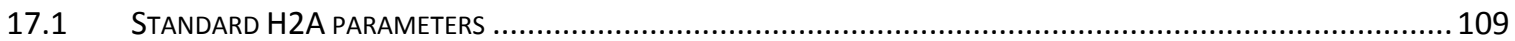

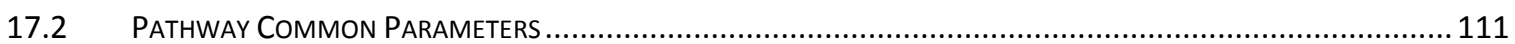

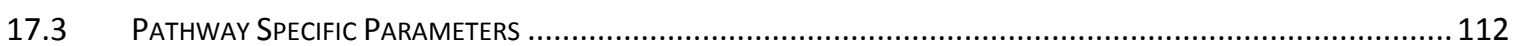

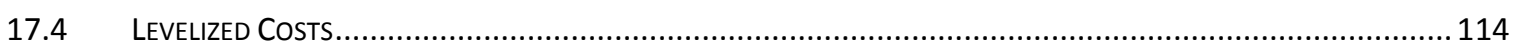

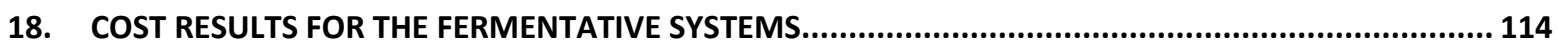

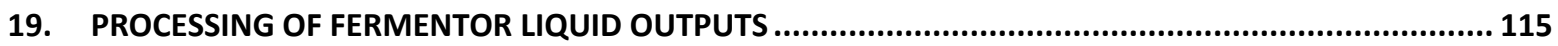

20. ALGAE FERMENTATION SYSTEM CONCLUSIONS AND RECOMMENDATIONS .................................. 117

PART III: LIGNOCELLULOSIC FERMENTATIVE $\mathrm{H}_{2}$ PRODUCTION SYSTEMS................................................ 118

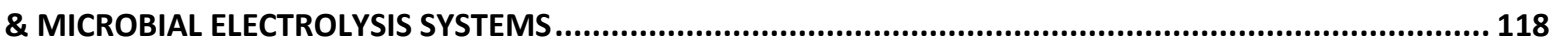

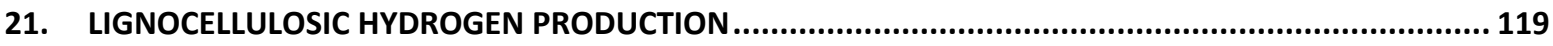

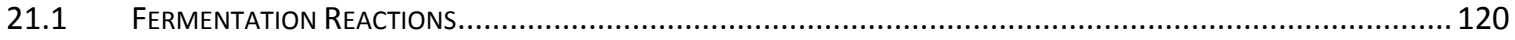

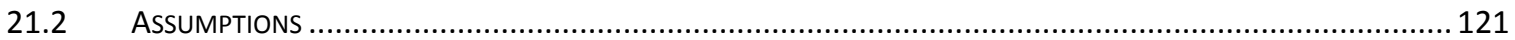

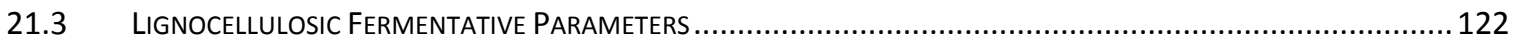

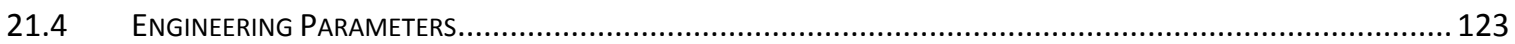

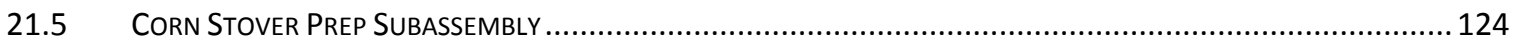

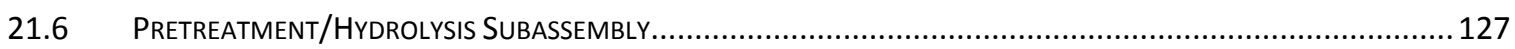

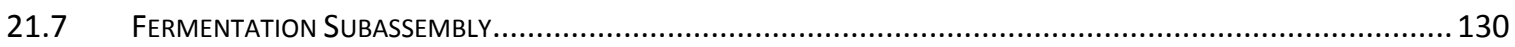

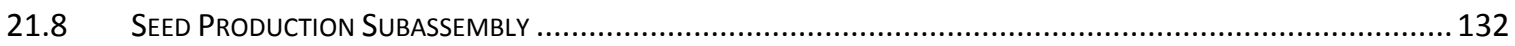

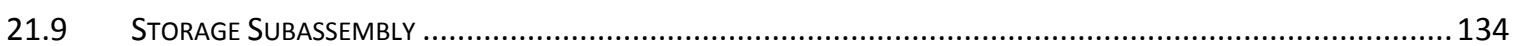

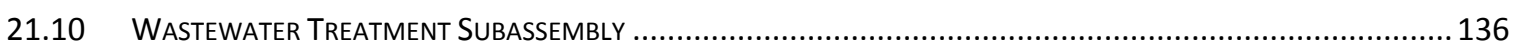

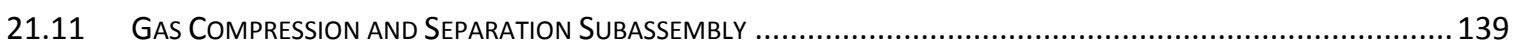

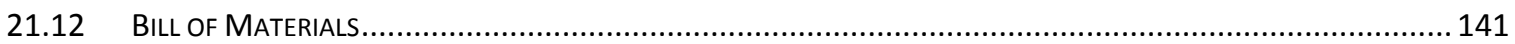

22. MICROBIAL ELECTROLYIS CELL (MEC) HYDROGEN PRODUCTION................................................. 144

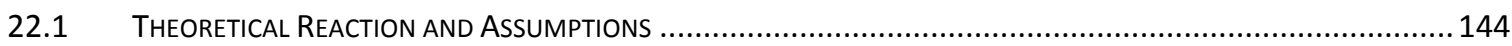

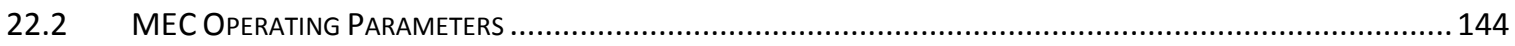

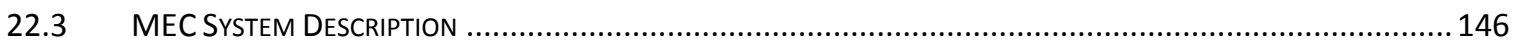

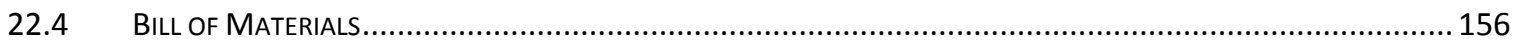

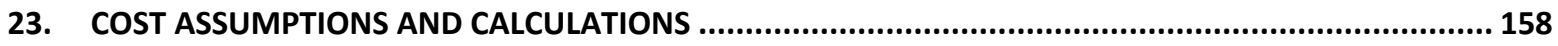

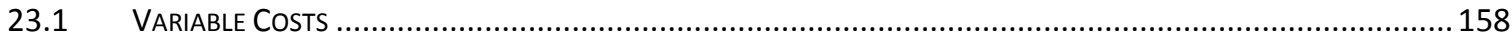

24. HYDROGEN PRODUCTION COSTS FOR FERMENTOR AND MEC ...................................................... 163 
25. LIGNOCELLULOSE FERMENATION AND MEC SYSTEM CONCLUSIONS AND RECOMMENDATIONS..... 164

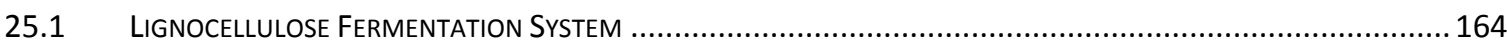

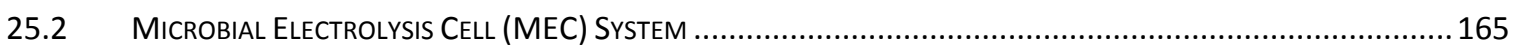

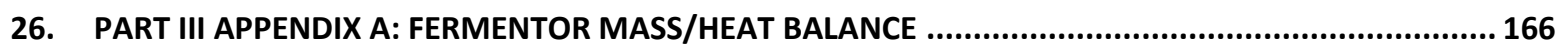

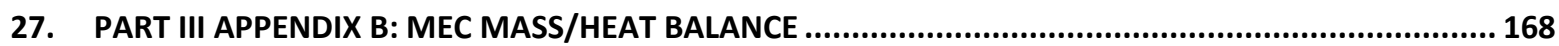

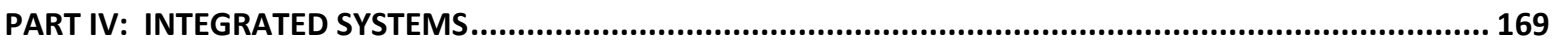

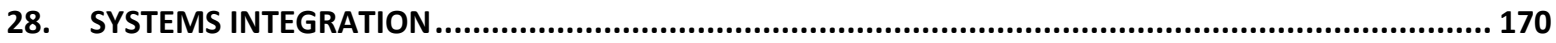

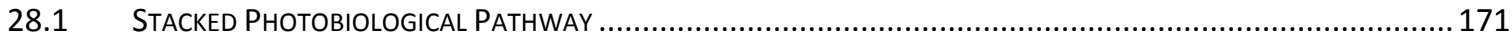

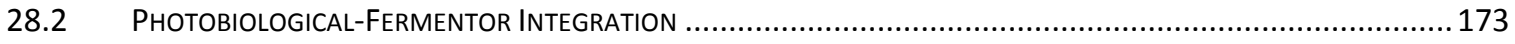

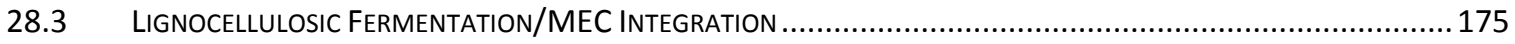

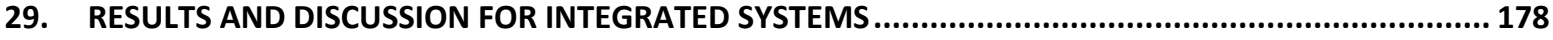

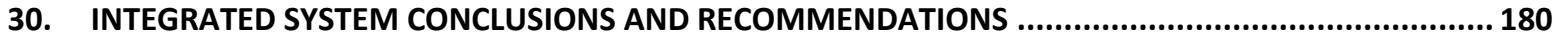

31. PART IV APPENDIX A: INTEGRATED FERMENTOR/MEC MASS/HEAT BALANCE ............................. 181

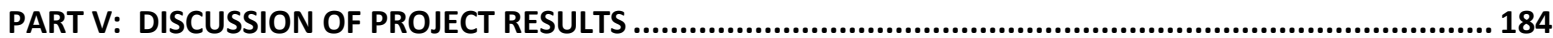

32. SUMMARY OF RESULTS AND CONCLUSIONS ............................................................... 185

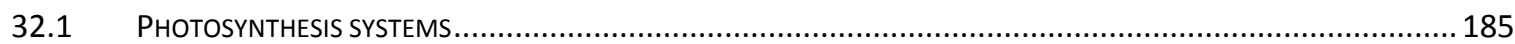

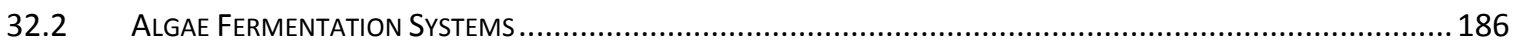

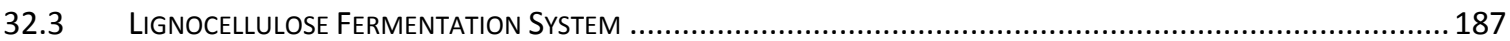

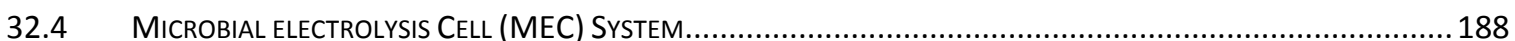

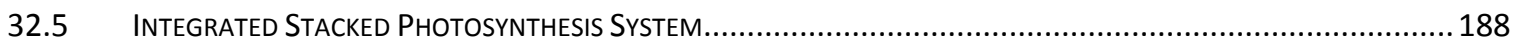

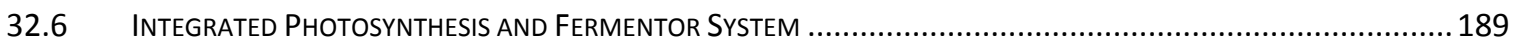

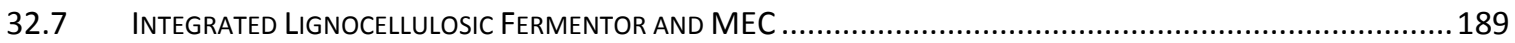

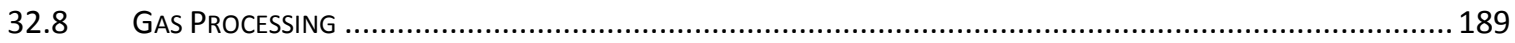

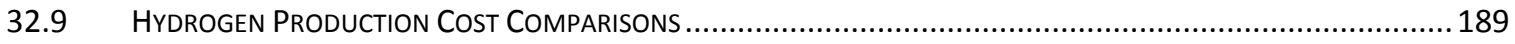

33. RECOMMENDATIONS FOR FUTURE WORK .................................................................. 192 


\section{Figures}

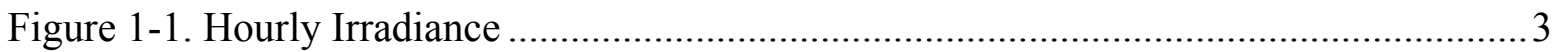

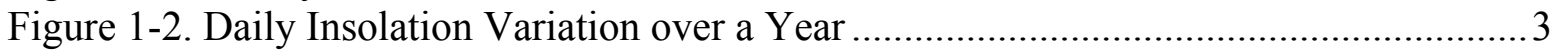

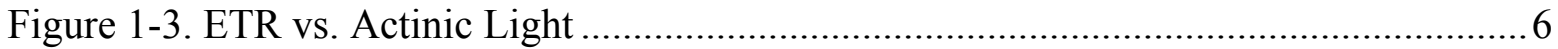

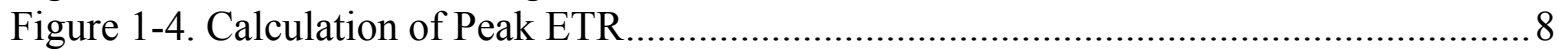

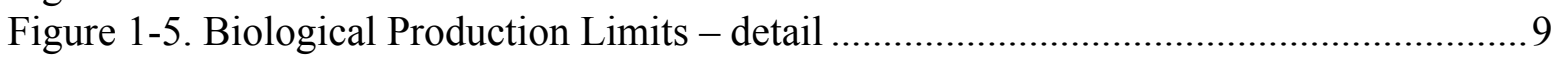

Figure 1-6. Biological Production Limits - total potential ................................................. 9

Figure 1-7. Hydrogen Production Efficiency - Wild-Type (WT) .......................................... 10

Figure 1-8. Hydrogen Production Efficiency - Mutant 1 (MT) ………................................. 10

Figure 1-9. Hydrogen Production Efficiency - Mutant 2 (M2T) ………............................... 10

Figure 1-10. Hydrogen Production - Wild-Type (WT) ...................................................... 11

Figure 1-11. Hydrogen Production - Mutant 1 (MT) ……….............................................11

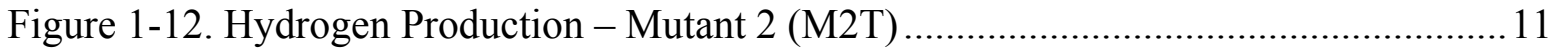

Figure 1-13. Hourly Hydrogen Production Variation - M2T …………............................. 12

Figure 2-1. Biological Parameters of Photobiological Systems ……….................................. 14

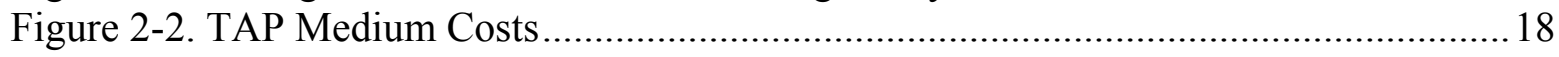

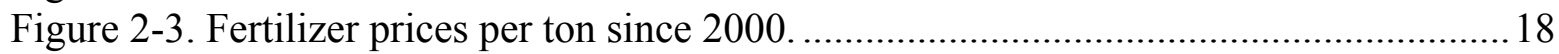

Figure 2-4. Nutrient Rates Computed ......................................................................... 19

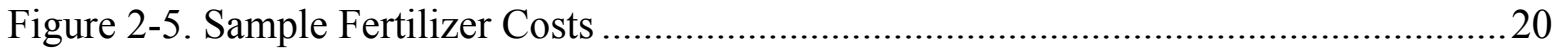

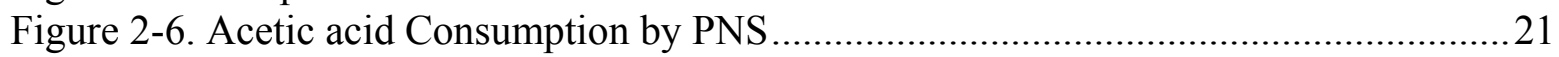

Figure 2-7. Carbon Dioxide Solubility in Water ................................................................2

Figure 2-8. Oxygen-Tolerant Hydrogenase Process ...........................................................2.

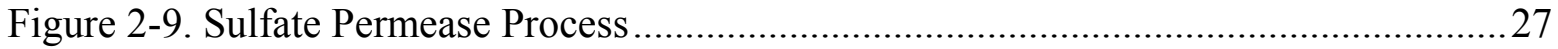

Figure 2-10. Immobilized Sulfur Deprived Process …………..........................................2

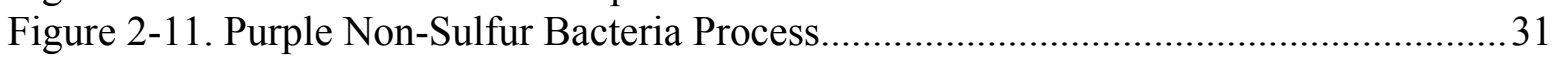

Figure 3-1. Simplified Photobiological Hydrogen Production Plant.........................................32

Figure 3-2. Strengths and Weaknesses of Single Bed Reactors ..............................................33

Figure 3-3. Conceptual Design: Single Bed Reactors ............................................................. 33

Figure 3-4. Strengths and Weaknesses of Dual Bed Reactors................................................34

Figure 3-5. Conceptual Design of Dual Bed Reactors............................................................. 34

Figure 3-6. Strengths and Weaknesses of Chemostat Bed Reactors ...................................... 35

Figure 3-7. Conceptual Design of Chemostat Bed Reactors ................................................. 35

Figure 3-9. Conceptual Design of Chemostat II Bed Reactors................................................36

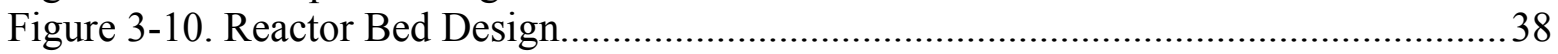

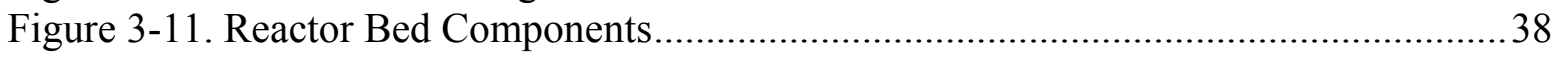

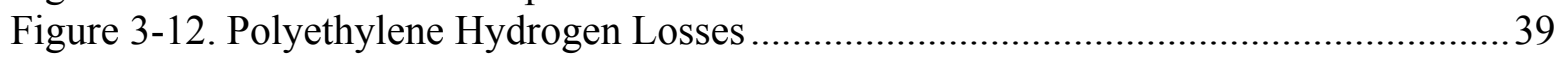

Figure 3-13. Film-Frame interface point ……………….................................................. 40

Figure 3-14. Paddlewheel Electrical Requirements..............................................................4 40

Figure 3-15. Capital Costs of Reactor Bed Components.....................................................4 42

Figure 3-16. Organism Feed Components ..........................................................................4

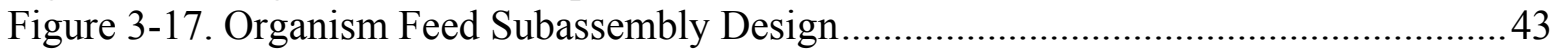

Figure 3-18. Capital Cost of Organism Feed Components..................................................45

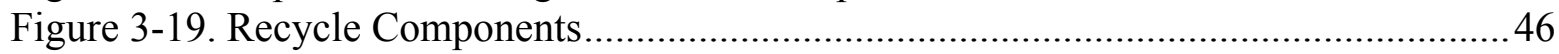

Figure 3-20. Recycle Subassembly Design .....................................................................4 46 


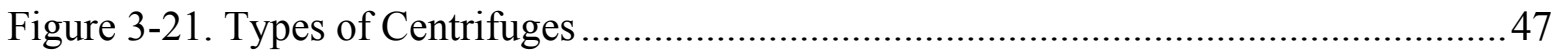

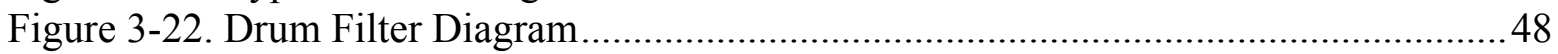

Figure 3-23. Capital Costs of Recycle Components ………………….................................4 49

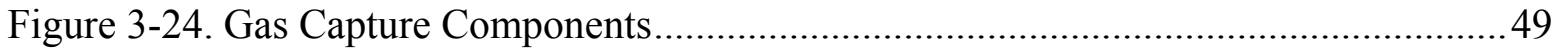

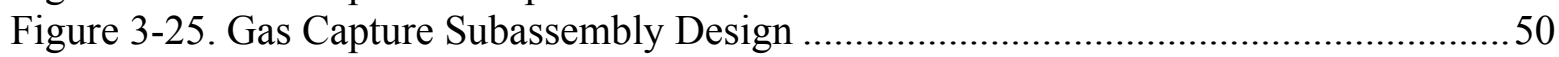

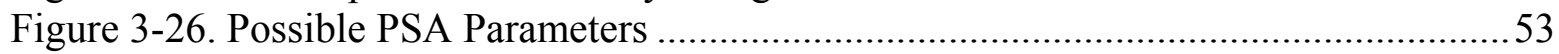

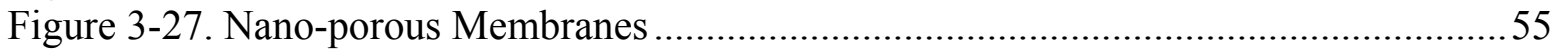

Figure 3-28. Capital Cost of Gas Capture Components ......................................................56

Figure 3-29. Control System Components.......................................................................5

Figure 3-30. Control System Subassembly Design ...........................................................59

Figure 3-31. Control System Wiring and Conduit Quantities for B-1, B-2 ...........................6 60

Figure 3-32. Capital Costs of Control System Components.................................................6 60

Figure 4-1. Production Plant Design for Oxygen-Tolerant Hydrogenase (Chlamy) ..............6 63

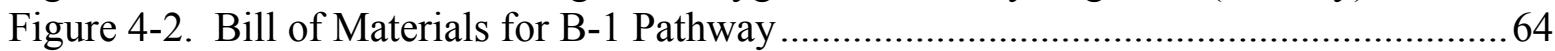

Figure 4-3. Production Plant Design for Oxygen-Tolerant Hydrogenase (Cyanobacteria)... 65

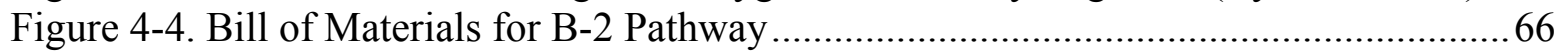

Figure 4-5. Production Plant Design for Sulfate Permease (Chlamy) ....................................67

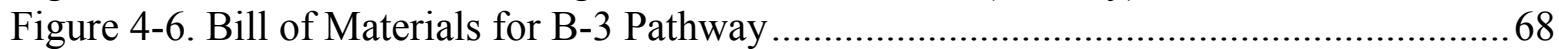

Figure 4-7. Production Plant Design for Immobilized Sulfur Deprived.................................70

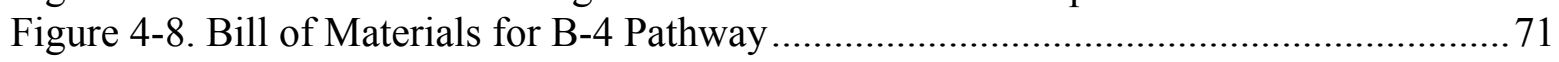

Figure 4-9. Production Plant Design for Purple Non-Sulfur ................................................ 72

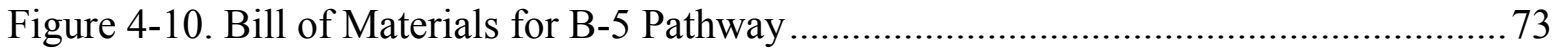

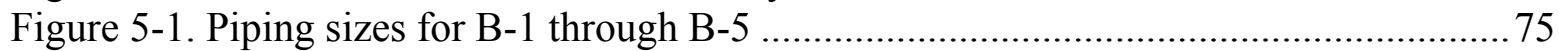

Figure 5-2. Electricity Consumption per Pathway............................................................ 78

Figure 5-3. Davis-Bacon Wage Determinations and Blue Book Rental Costs....................... 79

Figure 5-4. Excavation Cost Estimate for B-1 System using California Costs ......................8 80

Figure 6-1. H2A Default Values and Assumptions used for all Biohydrogen Pathways .......82

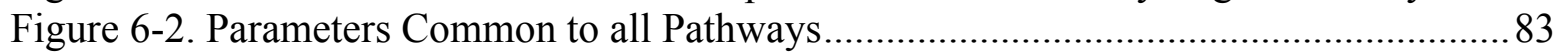

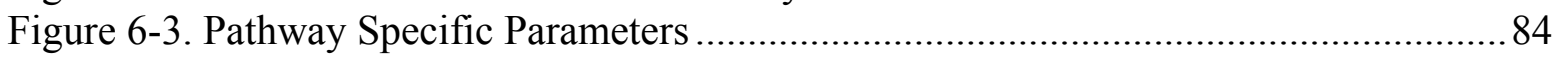

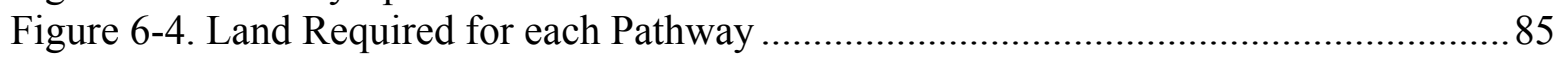

Figure 6-5. Plant Staff Requirements for 1 tonne $\mathrm{H}_{2}$ /day plant............................................... 86

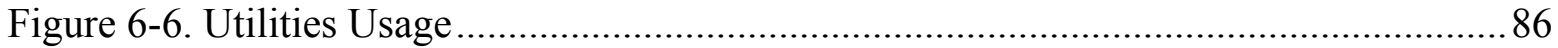

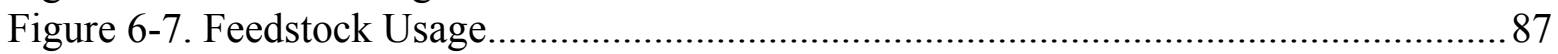

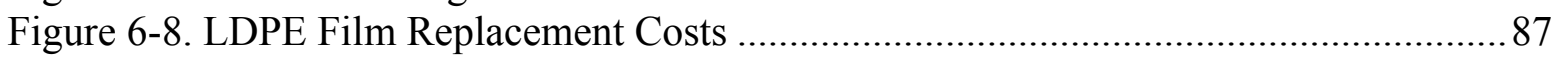

Figure 6-9. Levelized costs for B-1 through B-5 Pathways................................................ 88

Figure 6-10. Comparison of Levelized Cost Components....................................................8

Figure 6-11. Near Term STH Efficiency Assumptions ........................................................ 89

Figure 6-12. Levelized $\mathrm{H}_{2}$ Costs based on Near Term STH Efficiency ................................99

Figure 6-13. Comparison of Levelized Cost Components for Near Term Efficiencies ........ 90

Figure 7-1. Capital Cost Increases from Increased Plant Size............................................... 91

Figure 7-2. Labor Assumptions for Different Plant Sizes ...............................................99

Figure 7-3. Labor Cost Reductions from Increased Plant Size...............................................93

Figure 7-4. Normalized Hydrogen Production .....................................................................99

Figure 8-1. Capital Cost Allocations by Subassembly ……................................................95

Figure 11-1. Fermentation Process within a Biological System.......................................... 101

Figure 12-1. Potential Fermentative Feedstock Materials ..................................................... 102

Figure 13-1. NREL Fermentation Experimental Data ......................................................... 103 
Figure 14-1. Fermentation System Design

Figure 15-1: BOM for Fermentor Systems C-1 and C-2 (sized for the organism wastestream of a 10TPD B-1 or B-2 Photobiological Hydrogen production system) ...... 108

Figure 15-2: BOM for 10 TPD Fermentor System C-5 (sized for the PNS waste-stream of a 10TPD B-5 Photobiological Hydrogen production system) ......................................108

Figure 16-1. Fermentative Hydrogen Ouput (from 10TPD Photobiological System)......... 109

Figure 17-1. H2A Default Values and Assumptions used for all Fermentative Pathways.. 110

Figure 17-2. Parameters Common to all Pathways..........................................................111

Figure 17-3. Pathway Specific Parameters ...................................................................... 112

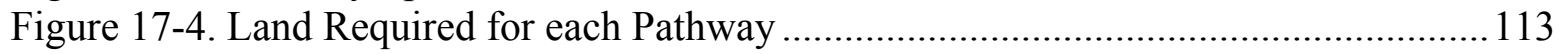

Figure 17-5. Plant Staff Requirements for Fermentor plant ..............................................113

Figure 17-6. Electricity Usage .................................................................................. 113

Figure 18-1: H2A Model Projected Hydrogen Cost per kg from Fermentor Systems C-1,

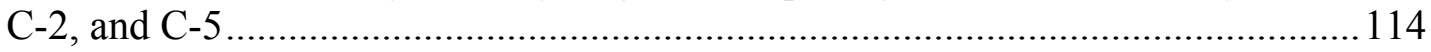

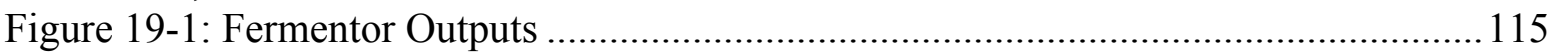

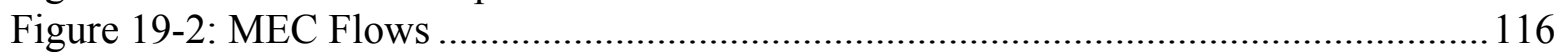

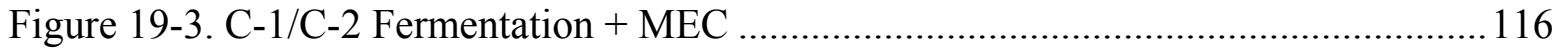

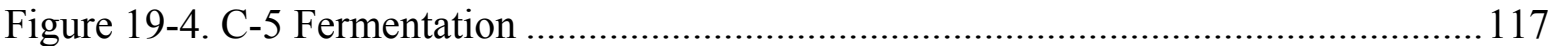

Figure 21-1. Potential Fermentative Feedstock Materials .................................................. 119

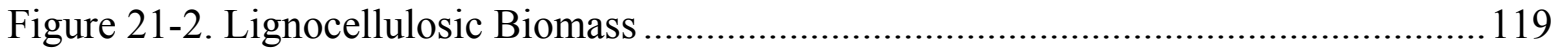

Figure 21-3. Parameters for Fermentation System .......................................................... 122

Figure 21-4. Simplified Lignocellulosic Hydrogen Production Plant .................................. 124

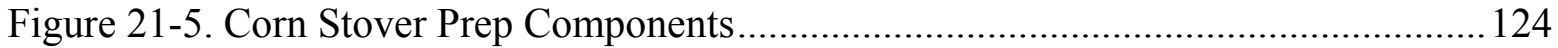

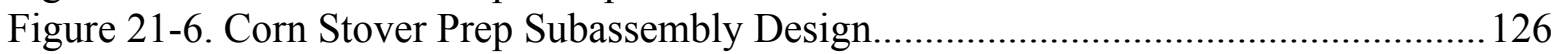

Figure 21-7. Capital Cost of Corn Stover Prep Subassembly............................................... 127

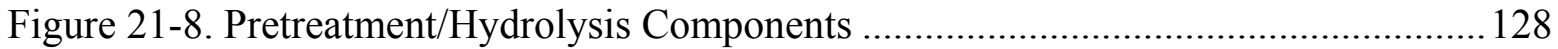

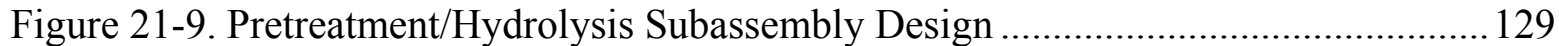

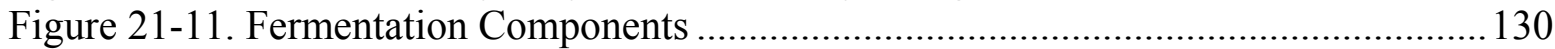

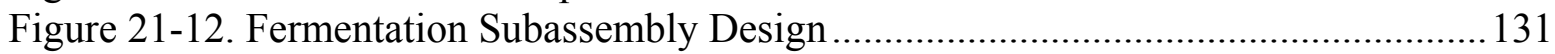

Figure 21-13. Capital Costs of Fermentation Subassembly...................................................132

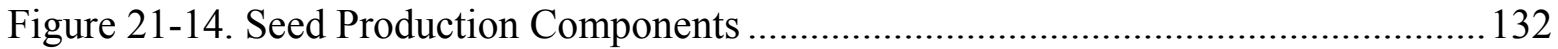

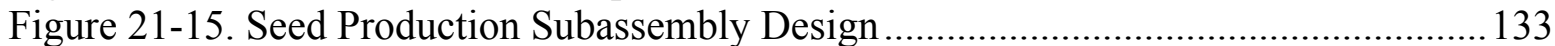

Figure 21-16. Capital Costs of Seed Production Subassembly ………...............................134

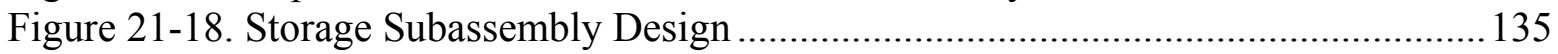

Figure 21-19. Capital Costs of Storage Subassembly......................................................136

Figure 21-20. Wastewater Treatment Subassembly Components .......................................137

Figure 21-21. Wastewater Treatment Subassembly Design .................................................. 138

Figure 21-22. Capital Cost of Wastewater Treatment Subassembly ....................................139

Figure 21-23. Gas Compression and Separation Components …………………............... 140

Figure 21-24. Gas Compression and Separation Subassembly Design ............................... 141

Figure 21-25. Capital Cost of Gas Compression and Separation Subassembly ................... 141

Figure 21-26. Lignocellulosic Fermentation Flow Chart .................................................. 142

Figure 21-27. Bill of Materials Lignocellulosic Fermentation ............................................. 143

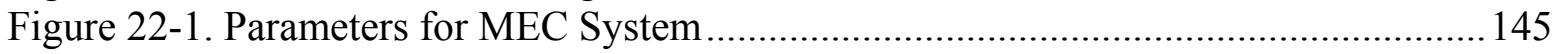

Figure 22-2. Simplified MEC Hydrogen Production Unit................................................. 146

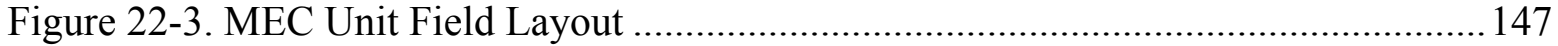

Figure 22-4. MEC Components.................................................................................... 148 
Figure 22-5. MEC Cell 148

Figure 22-6: MEC Operating Performance - Pt Cathode.

Figure 22-7. MEC Operating Performance - Brush Cathode 150

Figure 22-8. MEC Cost Optimization. 151

Figure 22-9: MEC Test Unit Top view with Half-Brush Cathode and Anode. 152

Figure 22-10. Capital Costs of MEC Subassembly 153

Figure 22-11. Storage Components 153

Figure 22-12. Storage Subassembly Design 154

Figure 22-13. Capital Costs of Storage Subassembly..... 154

Figure 22-14. Gas Compression and Separation Components 155

Figure 22-15. Gas Compression and Separation Subassembly Design 156

Figure 22-16. Capital Cost of Gas Compression and Separation Subassembly .................. 156

Figure 22-17. MEC System Flow Chart 157

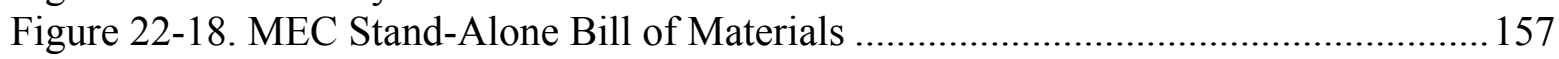

Figure 23-2. Power Requirements MEC System ....................................................... 160

Figure 23-3. Labor Breakdown - Fermentor............................................................ 160

Figure 23-4. Additional Consumables Costs - Fermentation system.............................. 161

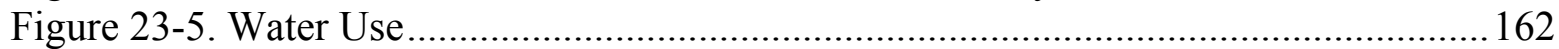

Figure 23-6. Total Variable Costs for Fermentor ...................................................... 162

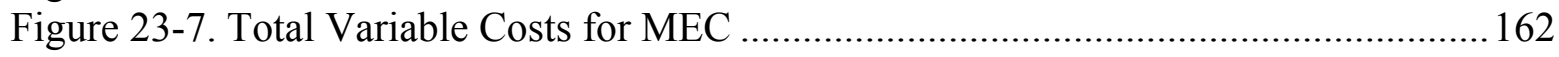

Figure 24-1: Total Hydrogen Cost................................................................................ 163

Figure 24-2. Comparison of Levelized Cost Components............................................ 163

Figure 24-3. Fermentor Liquid-Organic Output Value..................................................... 164

Figure 28-1. Potential Biological Integration Methods ................................................. 170

Figure 28-2. Process Diagram - Integrated Photobiological Systems.............................. 172

Figure 28-3. Tiered Reactor Bed Conceptual Design ................................................ 172

Figure 28-4. Bill of Materials for B-3/B-5 Stacked Beds ............................................. 173

Figure 28-5. Photobio-Fermentor Process Diagram ................................................ 174

Figure 28-6. BOM for B-5/C-5 Integrated System ..................................................... 175

Figure 28-7. Process Diagram for Fermentation-MEC Integration .................................. 176

Figure 28-8. Bill of Materials for Integrated Fermentation-MEC .................................. 177

Figure 28-9. Fermentor/MEC Mass Balance Flow Chart ............................................... 178

Figure 29-2. Comparison of Integrated System Costs ............................................... 179

Figure 32-1. Photobiological System STH Energy Efficiency ..................................... 186

Figure 32-2. $\mathrm{H}_{2}$ Production Costs ............................................................................ 190 


\section{Part I: Photobiological $\mathrm{H}_{2}$ Production Systems}


Introduction

Directed Technologies Inc. (DTI) is under contract to the National Renewable Energy Lab (NREL) to conduct a techno-economic evaluation of photobiological hydrogen production systems. This report documents the biological and engineering characteristics of five algal and bacterial hydrogen production systems selected by DOE and NREL for evaluation. Those characteristics are divided into three areas, namely, basic science, biology, and engineering. Since basic science assumptions are strongly correlated with biological parameters, they are provided first. Hydrogen production capabilities are a function of the reactor bed design so those details are provided in the engineering section of this report. Because product hydrogen product is combined with other gases, the characteristics of a gas separation system will be given additional attention. The last section of this Task B report utilizes the information collected to estimate a final result, given as a cost per unit of produced hydrogen.

\section{Basic Science}

\subsection{Solar Assumptions}

Solar insolation is a key factor in determining algal growth and $\mathrm{H}_{2}$ production rates. Selecting a geographical location provides ambient temperatures, hours of exposure, and amount of irradiance. For the purpose of this study we have based our solar input assumptions on the solar irradiance properties of the Phoenix, AZ area. Hourly solar irradiance $\left(\mathrm{W} / \mathrm{m}^{2}\right.$ striking the horizontal reactor bed) for this area is shown in Figure 1-1. The NREL SOLPOS model is used for solar position angles and intensity ${ }^{1}$. This model calculates extra terrestrial radiation (ETR) by the hour and day throughout the year. The total clearness index, $\mathrm{Kt}$, is multiplied by the ETR to obtain the terrestrial irradiance on the horizontal surface. Kt values for the relevant months in the Phoenix area are obtained from the NASA Atmospheric Data Center / Surface meteorology and Solar Energy (SSE) database $^{2}$. The 3 curves plotted in Figure 1-1 show the solar peak at June 21, the autumnal equinox at September 21, and the solar minimum at December 21. These curves also show the seasonal peak radiation which determines the peak potential $\mathrm{H}_{2}$ production for those periods. The peak June irradiance at $964 \mathrm{~W} / \mathrm{m}^{2}$ is slightly below the nominal peak value of $1,000 \mathrm{~W} / \mathrm{m}^{2}$ due to the sun's maximum elevation angle being 80 degrees above the horizon.

\footnotetext{
${ }^{1}$ NREL MIDS SOLPOS (Solar Position and Intensity) model may be found at http://rredc.nrel.gov/solar/codesandalgorithms/solpos/.

2 NASA Atmospheric Data Center, Langley ASDC User Services, Surface meteorology and Solar Energy (SSE) data base (release 6.0).
} 
Figure 1-1. Hourly Irradiance

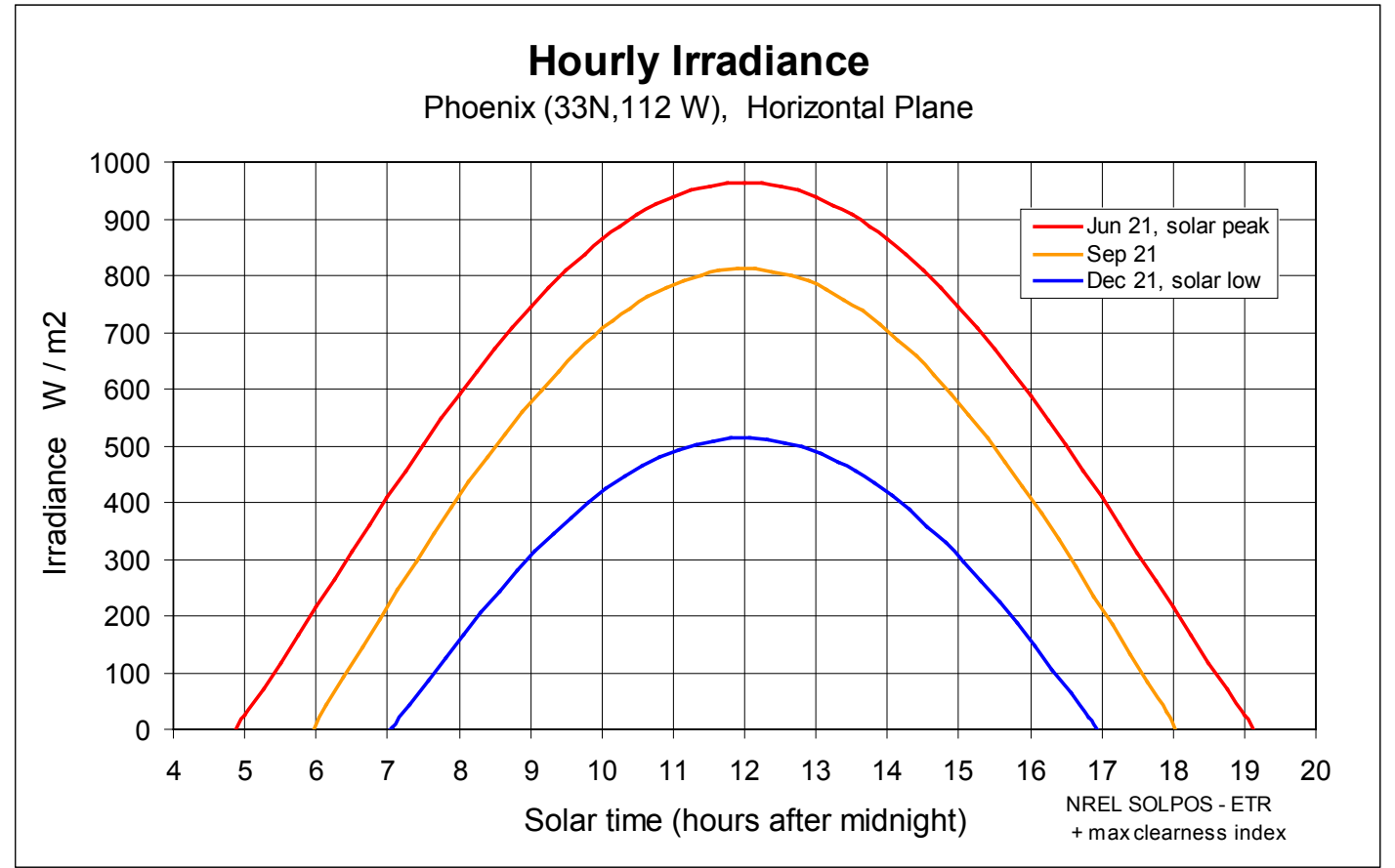

The daily insolation energy $\left(\mathrm{kW}-\mathrm{hr} / \mathrm{m}^{2} /\right.$ day) on a horizontal surface throughout the year for the Phoenix area was obtained from the NASA SSE database, and is plotted in Figure 1-2. These plotted values are averages for the respective months. The yearly mean value of $5.5 \mathrm{~kW}-\mathrm{hr} / \mathrm{m}^{2} /$ day is also shown.

Figure 1-2. Daily Insolation Variation over a Year

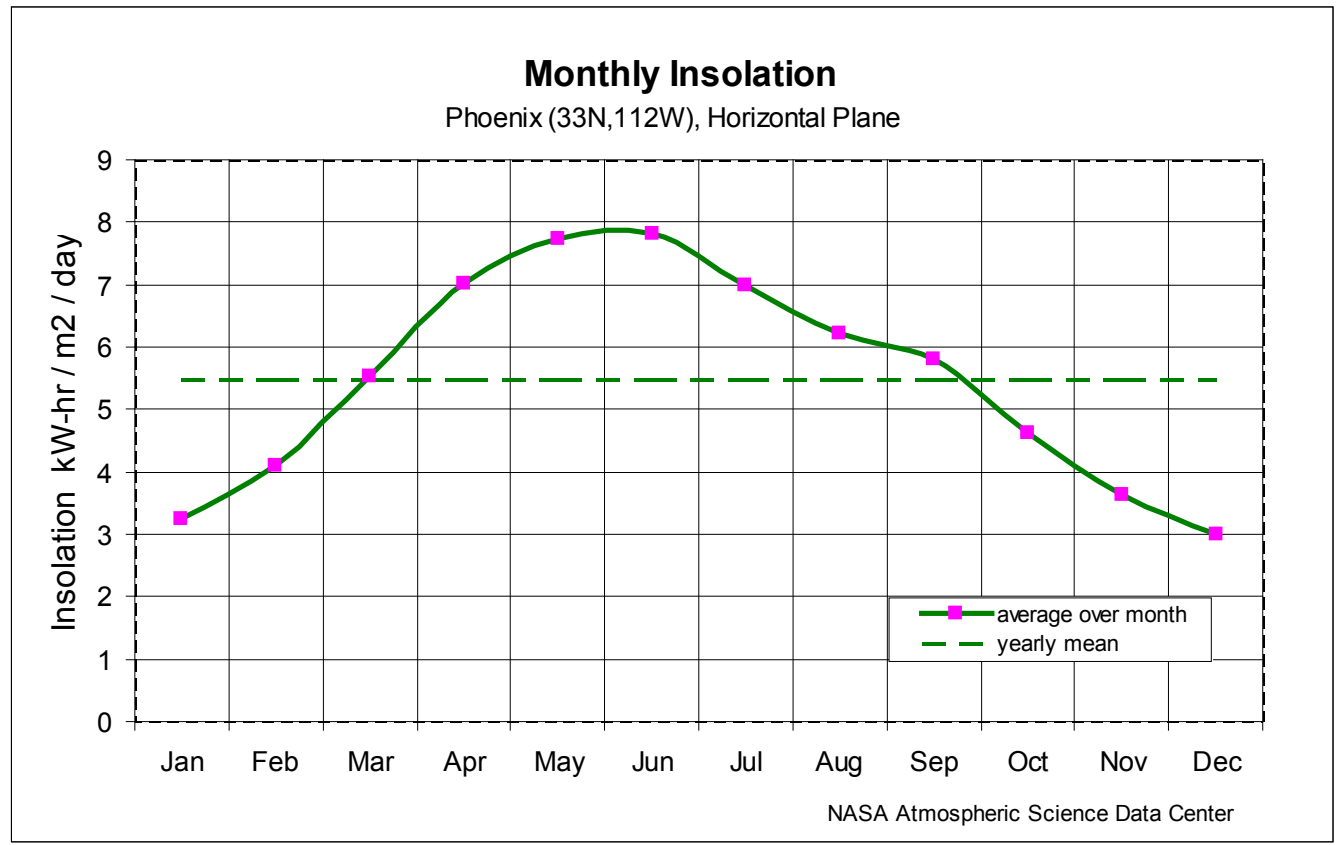


Note that the effects of clouds are implicitly included in these calculations, as the monthly data points are for the average day including the average amount of clouds. The normalized cell growth and hydrogen production parameters used in the following analyses have assumed an average sunlight of $5.5 \mathrm{~kW}-\mathrm{hr} / \mathrm{m}^{2} /$ day to generate a usable hydrogen production rate of $1,000 \mathrm{~kg} /$ day averaged over the year.

\subsection{Bed Depth, Algal Concentration, \& $\mathrm{H}_{2}$ Production Rate Assumptions}

The depth of the reactor bed and algal concentration are matched to ensure full photon capture by the organisms. If organism concentration is too dilute for a given total depth, light will penetrate to the bottom of the bed and photons will be "wasted". Should the organism be too concentrated, photons will be fully absorbed in only the upper layers of the bed potentially "starving" the organisms at the lower depths of photons and adversely affecting their health ${ }^{3}$. The organism concentration and bed depth are also important because they impact specifications for other system components such as pumps and valves, type of solids separation equipment, and type of mixing equipment.

Choice of bed depth and concentration depends on the mode of growth, batch versus continuous dilution. For batch mode, the ideal fixed-volume bioreactor to use for achieving constant light transmission throughout a growing population of dispersed cells would have to allow for continuous decrease in path length as the population grows to higher cell densities. Alternatively, a continuous dilution bioreactor of fixed volume could operate with a fixed cell density after reaching steady-state growth and thus would have constant absorbance. If the latter growth mode is not used and replaced with batch culture growth mode then the bed depth must be chosen so that the absorbance after reaching stationary phase, e.g., at beginning of the photo-hydrogen production stage, produces the maximum rate of hydrogen production.

\subsubsection{Beers Law Photon Absorption Model}

The rate of photon absorption and thus the maximum hydrogen production at a given bed depth increment can be determined by Beer's Law. At each depth increment, $\Delta \mathrm{d}$, one calculates the number of photons absorbed and then multiplies that by the specific rate of $\mathrm{H}_{2}$ production in molecules per photon (this is equivalent to the light saturation curve for photohydrogen production which is an experimental measurement distinct for each cell type or mutant).

Beer's law states that:

$$
\begin{array}{ll}
\mathrm{A}=\mathrm{b} * \mathrm{C}^{*} \varepsilon \text { where } & \mathrm{A}=\text { Absorbance (unitless) } \\
\mathrm{b}=\text { depth into liquid in } \mathrm{cm} \\
\mathrm{C}=\text { cell concentration in } \mathrm{g}_{\mathrm{dryw}} / \mathrm{L} \\
\varepsilon=\text { absorption coefficient in } \mathrm{L} / \mathrm{cm} / \mathrm{g}_{\text {drywt }}
\end{array}
$$

Absorbance is defined as the negative logarithm of the ratio of exiting light intensity to entering (incident) light intensity:

$$
A=-\log (\mathrm{I} / \mathrm{Io})
$$

\footnotetext{
${ }^{3}$ Proper bed mixing can mitigate or potentially eliminate the effects of shallow light penetration.
} 
From this definition, I/Io (light intensity I, at a given bed depth, b) is derived from:

$$
\mathrm{I} / \mathrm{Io}=10^{-\mathrm{zbC}}
$$

To determine the required bed depth and cell concentration to maximize photon capture by the organisms, we integrate the above equation over the depth of the bed. Note that for this approach and Beer's law to be valid, we need to make multiple assumptions:

1. The cell volume and pigment content per cell must not change appreciably during the lifecycle of the sample. While most cells increase pigment content and volume as they age and, therefore, do not strictly obey Beer's law, we assume average rather than instantaneous cellular characteristics for purposes of the calculation. As shall be discussed later in the report, this assumption is most valid for the Chemostat II system, where a constant cell concentration is maintained.

2. The cells must not be allowed to aggregate, as commonly occurs without adequate mixing, resulting in biofilm formation. Consequently, this analysis is most applicable to planktonic (or free-floating) cells. With the exception of the B-4 System (see p. 25), all systems considered are free-floating cells in an actively mixed medium. This analysis is not relevant to the B-4 immobilized system.

3. The cell density must be sufficiently low that cell "shading" does not occur. In the present configuration shading is minimized by dilution: all systems, with the exception of B-3 and B-4 for which this analysis does not apply due to the necessity of higher cell concentration as a feedstock for oxidative respiration, maintain a cell concentration of less than $0.2 \mathrm{~g}_{\text {drywt }} / \mathrm{L}$.

4. Corrections for the light lost from the bioreactor arising from light scattering of cells (turbidity) are generally estimated to be low of order: $10 \%$ for the cell concentrations considered in this report and for a normal incident angle. Generally, visible light scattering by cells of the size of Chlamydomonas (10 microns) is predominantly forward scattering and thus most of the scattered light is retained in the bioreactor. Thus, no correction for light scattering is included in the analysis.

\subsubsection{Light Saturation}

While Beer's Law relates photon absorption to cell and bed characteristics, there is an additional limitation on $\mathrm{H}_{2}$ production due to saturation of photon/electron conversion capability within the cells. There is a charge transfer limitation (alternately called a saturation limit) within the photosynthetic pathway that limits the rate at which photons/electrons can be processed by the PSII reaction. This consequently limits utilization of incident photons, limiting the rate of the PSI reaction and $\mathrm{H}_{2}$ production, and thus lowering the Solar to Hydrogen (STH) energy conversion efficiency. At moderate-tohigh light intensity, this saturation limit is greatly exceeded by wild type organisms and, to a lesser extent, by current truncated antenna mutants. Two analyses of the saturation limit effects are discussed in this and the following section. 
To estimate this charge transfer limitation, we examine the measured quantum efficiency for electron transport by PSII as a function of Actinic Light Photon Flux Density (PFD) for whole cells of the green alga Chlorella. Figure 1-3 displays electron transfer rate (ETR) vs. actinic light for two methods of ETR calculation ${ }^{4}$. Actinic light generally refers to portion of light that causes a chemical change. In this specific case, light refers to the light within the PAR range. These data come from experiments and are qualitatively representative of data in the literature for other algae including Chlamydomonas reinhardtii.

Figure 1-3. ETR vs. Actinic Light
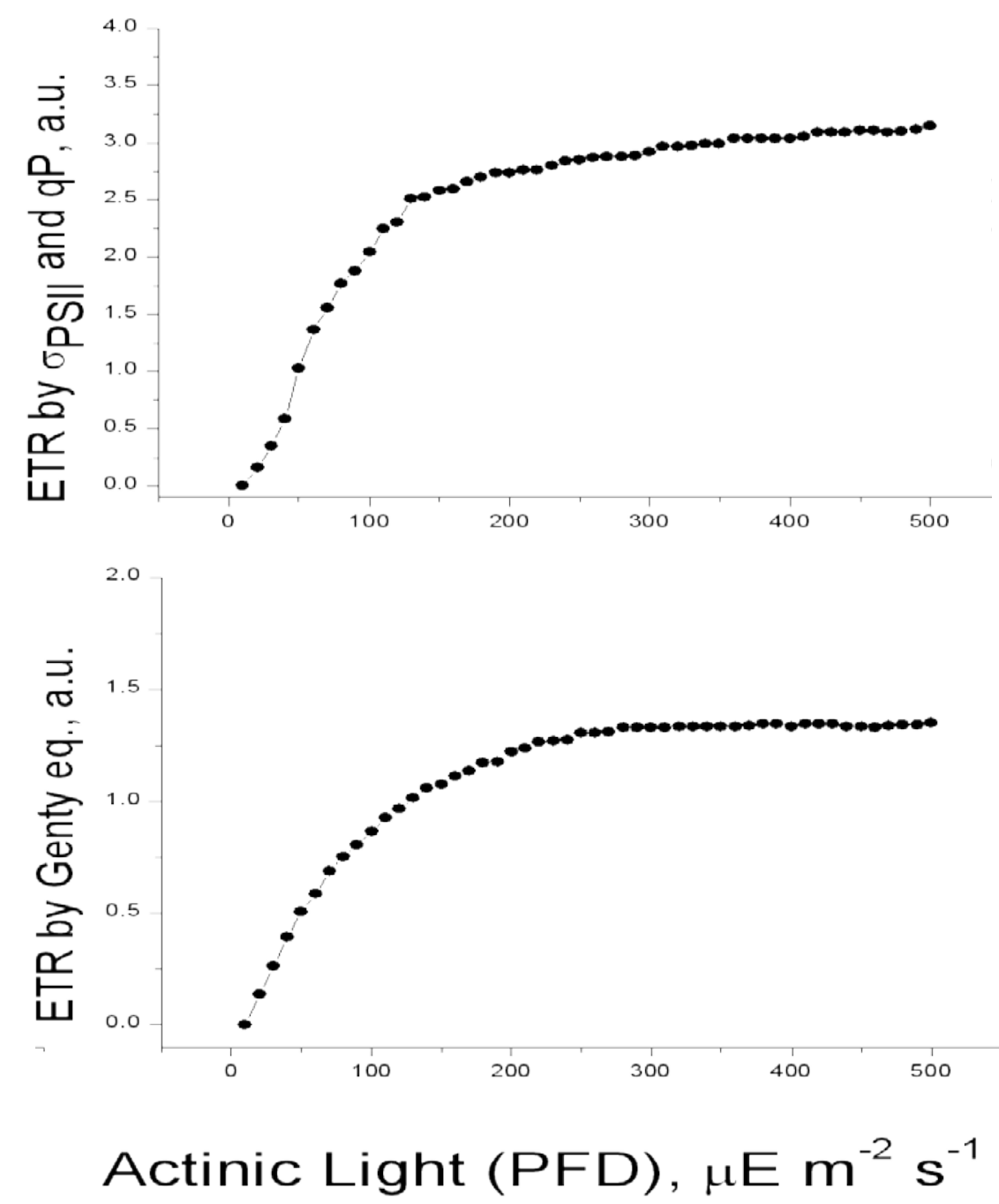

Based on the theory of light absorption and following well-known Poisson statistics ${ }^{5}$ we postulate that the relationship between ETR and light intensity will follow the relationship,

\footnotetext{
${ }^{4}$ Unpublished data from Gennady Ananeyev, Princeton University.

5 "Light Saturation Curves and Quantum Yields in Reaction Centers from Photosynthetic Bacteria", Blankenship et al. Journal of Biophysics, Volume 45 February 1984 455-461.
} 


$$
\begin{aligned}
& \quad \mathrm{Y} / \mathrm{Y}_{\max }=1-\mathrm{e}^{-\sigma \Phi \mathrm{E}} \\
& \text { where; } \\
& \mathrm{Ymax}=\text { Incident light intensity } \\
& \mathrm{Y}=\text { Absorbed light intensity } \\
& \sigma=\text { optical cross section in } \mathrm{cm}^{2} \\
& \Phi=\text { quantum yield, probability of charge separation/photon } \\
& \mathrm{E}=\text { Incident intensity in photons } / \mathrm{cm}^{2} / \mathrm{sec}
\end{aligned}
$$

We next analytically determine the $\sigma \Phi$ value $(\sigma \Phi=0.053346)$ that results in a curve fit to the experimental data. As shown in Figure 1-4, a reasonably good curve fit was obtained. While this form of the data and analytic model indicate that ETR peaks at a light intensity of approximately $60 \mathrm{~W} / \mathrm{m}^{2}$, it does not show the peak ETR. Consequently, to determine the peak ETR, we postulate that there are no charge transfer limitations at very low light levels and thus an extrapolation of the linear portion of the curve will yield an indication of the maximum electron transfer. By extrapolating the linear portion of the curve to its intersection with the maximum electron transfer $\left(\mathrm{Y} / \mathrm{Y}_{\max }=1\right)$, we estimate that the cells would be able to process photons at up to $19 \mathrm{~W} / \mathrm{m}^{2}$ light intensity if they were unencumbered by rate limits. This allows us to compute the peak charge separation rate. Thus we now have a measure of both the peak $\mathrm{H}_{2}$ production rate and shape of the light intensity vs. $\mathrm{H}_{2}$ production rate. The light saturation curve can be used together with Beer's law to determine the rate of charge separation that occurs at every point within the bioreactor. This same approach can be used to calculate the $\mathrm{H}_{2}$ production rate which is assumed to be a fixed fraction of the charge separation rate. Thereby the $\mathrm{H}_{2}$ production rate can be obtained at each depth increment within the bioreactor and the total absorption summed from all such depth increments throughout the bioreactor to obtain the overall $\mathrm{H}_{2}$ production throughout the reactor. The result is a substantial decrease in $\mathrm{H}_{2}$ production rate due to light saturation effects of typical current organisms. 
Figure 1-4. Calculation of Peak ETR

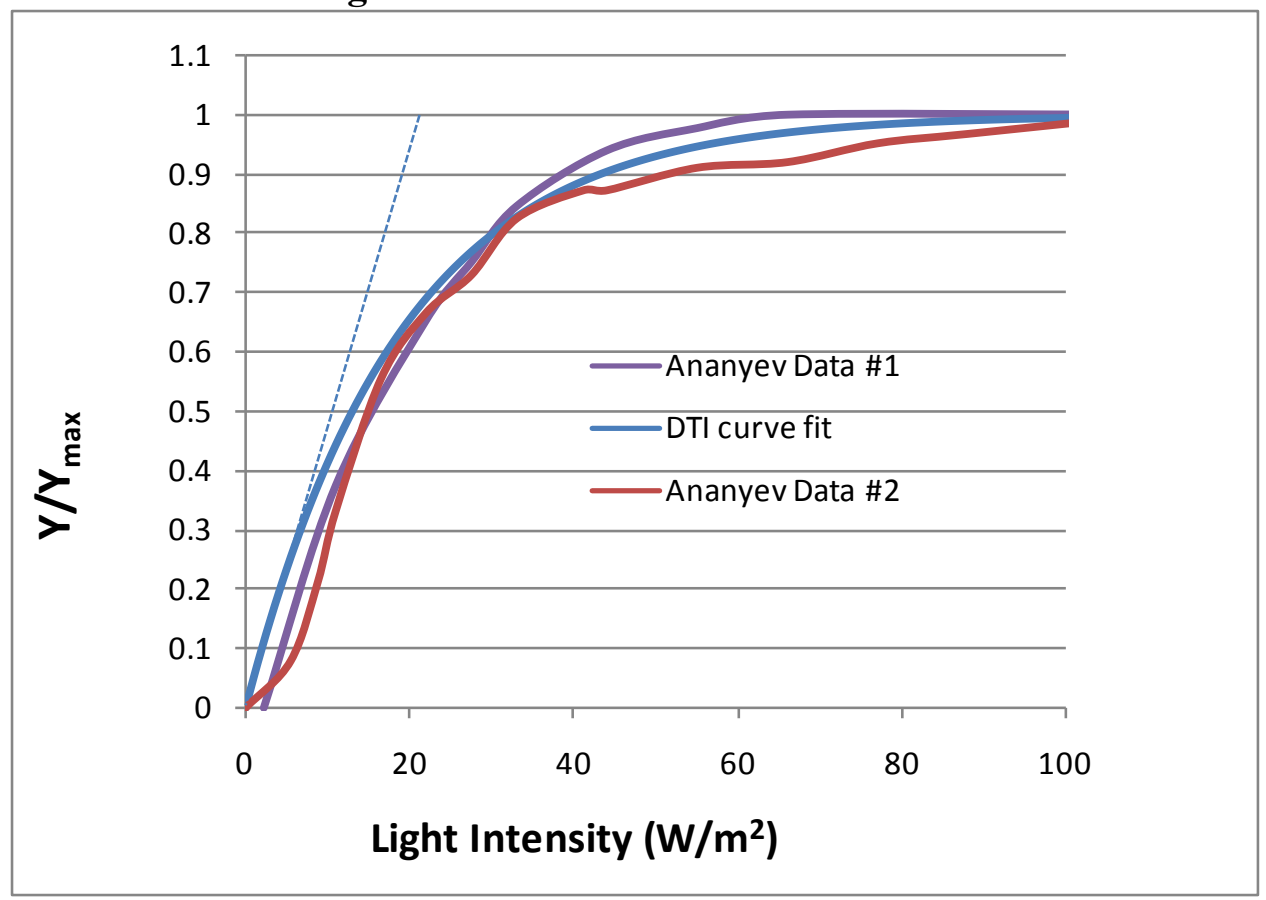

\subsubsection{Alternative Model for Photon Absorption Saturation}

An extensive analysis of saturation effects on hydrogen production was carried out for NREL by Wade Amos in NREL/MP 560-35539 ${ }^{6}$. In this report, the hydrogen production rate in successive $0.2 \mathrm{~mm}$ layers of algae was predicted as a function of depth in the pond, the solar intensity, and the algae antenna saturation characteristics. For reduced antenna mutants, the analysis predicted major reduction in hydrogen production rate at depths shallower than $4 \mathrm{~cm}$ due to photon saturation. The photon saturation criterion assumed by Amos was that the maximum electron current able to be transferred to an external electron acceptor is 1 mole of electrons per gram (dry cell weight) of cells per day.

As an expansion of the Amos saturation analyses, we investigated the saturation effects using a hypothetical mutant (M2T) that had average absorption coefficient $(\varepsilon)$ reduced by a factor of 5 relative to wild-type (WT). Figure 1-5, based on the Figure 15 of NREL/MP 560-35593, plots the rate of hydrogen production per $\mathrm{m}^{2}$ per second for each $0.2 \mathrm{~mm}$ increment of bed depth, for three varieties of algae. The thin green curve represents the rate of hydrogen production per depth layer of wild-type Chlamydomonas reinhardtii which has an average $\varepsilon$ of 5.0, if all absorbed photons were successfully converted to hydrogen. The thick black line plots the analogous production curve for the Amos report Mutant-Type (MT) Chlamydomonas reinhardtii with a reduced antenna, which has an average $\varepsilon$ of 2.07. The blue line plots the analogous production curve for a hypothetical improved Mutant-2Type (M2T) Chlamydomonas reinhardtii with an average $\varepsilon$ of 1.0. Figure 1-6 shows the

6 Amos, Wade, "Updated Cost Analysis of Photobiological Hydrogen Production from Chlamydomonas reinhardtii Green algae", NREL/MP 560-35593, January 2004 at page 7 (Gosset, 1995). 
full extent of these curves. If all of the PAR photons were absorbed and converted to $\mathrm{H}_{2}$ at the rate of 4 photons/one $\mathrm{H}_{2}$ molecule, the hydrogen production would equal the integration of the area under each of these absorption curves and the STH energy efficiency would be $12.2 \%$ (assuming the Lower Heating Value (LHV) of $\mathrm{H}_{2}=33.33 \mathrm{kWh} / \mathrm{kg}$ ).

Figure 1-5. Biological Production Limits - detail

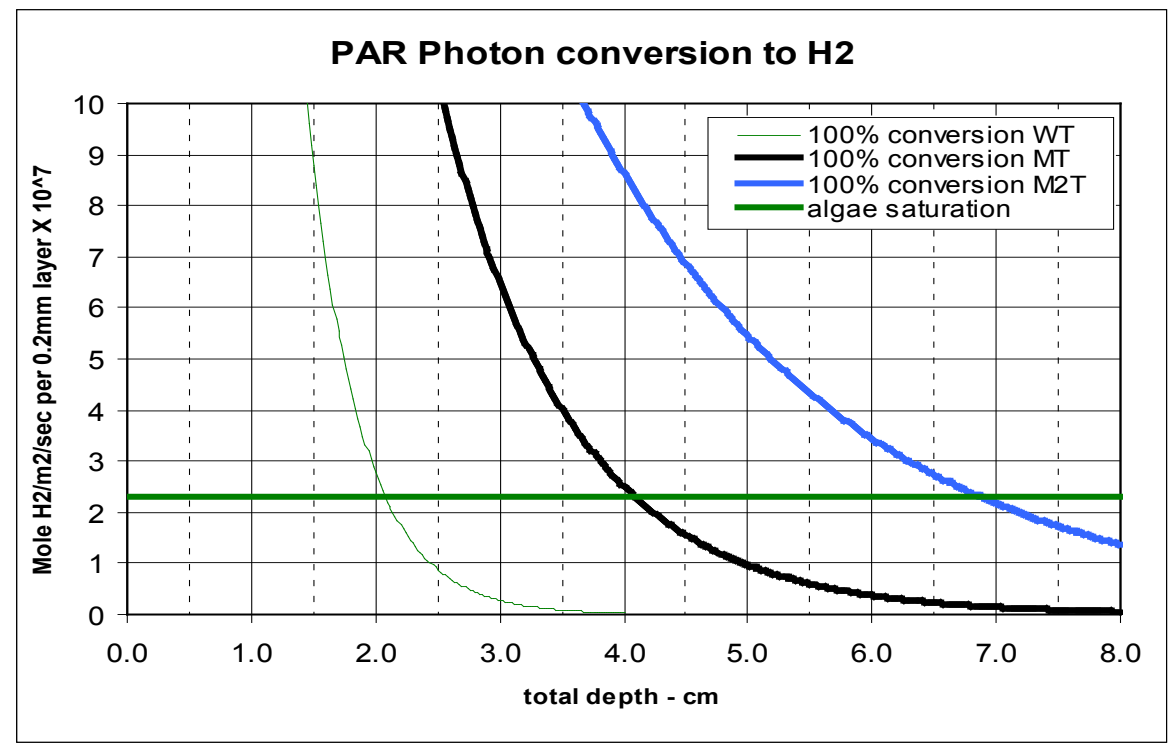

Figure 1-6. Biological Production Limits - total potential

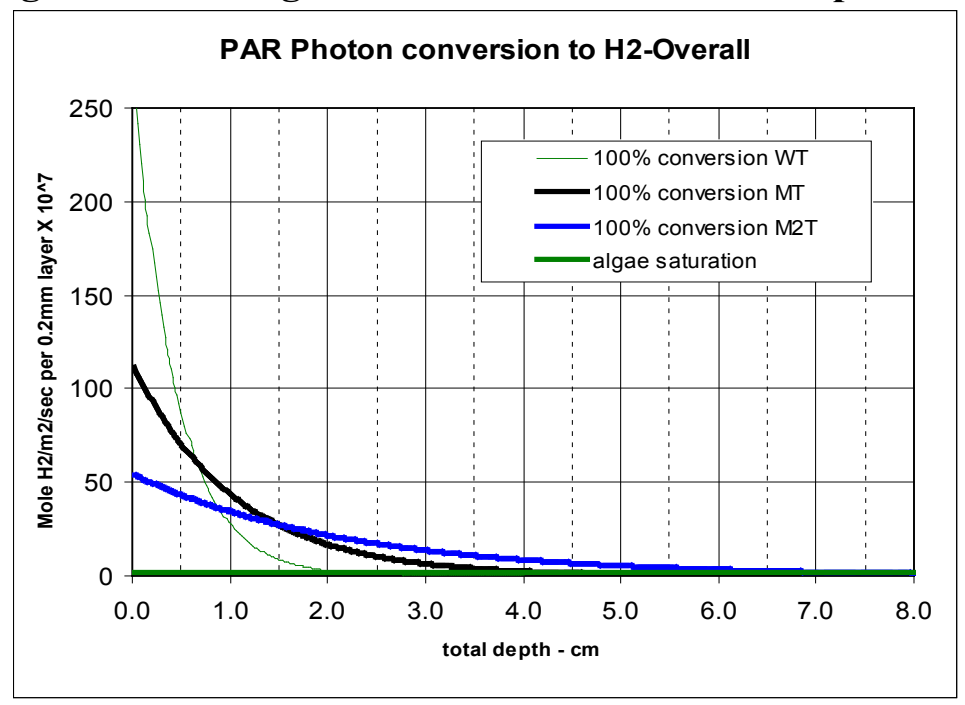

The thick green horizontal line on these curves denotes the algae saturation limit for hydrogen production based on the epsilon assumptions discussed above. Thus, with increasing depth, the actual $\mathrm{H}_{2}$ production rate first follows the saturation thick green line for light intensities exceeding the saturation threshold and then follows the appropriate absorption curve predicted by Beer's Law. The ratio of the area below each set of two limiting curves to the solar photon flux represents the actual fraction of photons captured for $\mathrm{H}_{2}$ production, and thus the process efficiency. 
Shown in Figure 1-7, Figure 1-8 and Figure 1-9 are curves of the $\mathrm{H}_{2}$ production efficiency for the wild-type and two mutant types as solar intensity is increased up to the max intensity of $1000 \mathrm{~W} / \mathrm{m}^{2}$. As can be seen, $100 \%$ photon utilization only takes place at low output for WT and at levels below $21 \mathrm{~W} / \mathrm{m}^{2}$ for MT and $45 \mathrm{~W} / \mathrm{m}^{2}$ for M2T. The higher efficiency of the Mutant-2-Type (M2T) Chlamydomonas reinhardtii results from the increased photon utilization throughout the pond depth.

Figure 1-7. Hydrogen Production Efficiency - Wild-Type (WT)

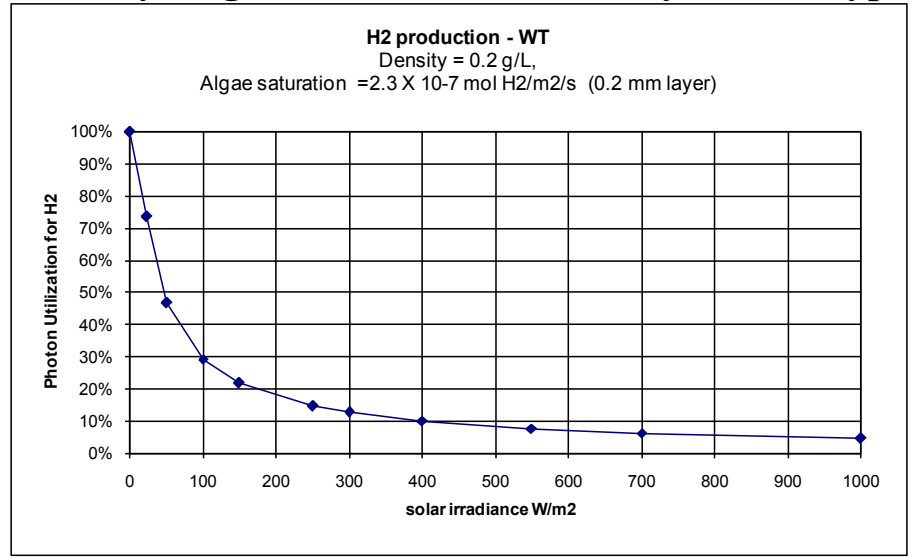

Figure 1-8. Hydrogen Production Efficiency - Mutant 1 (MT)

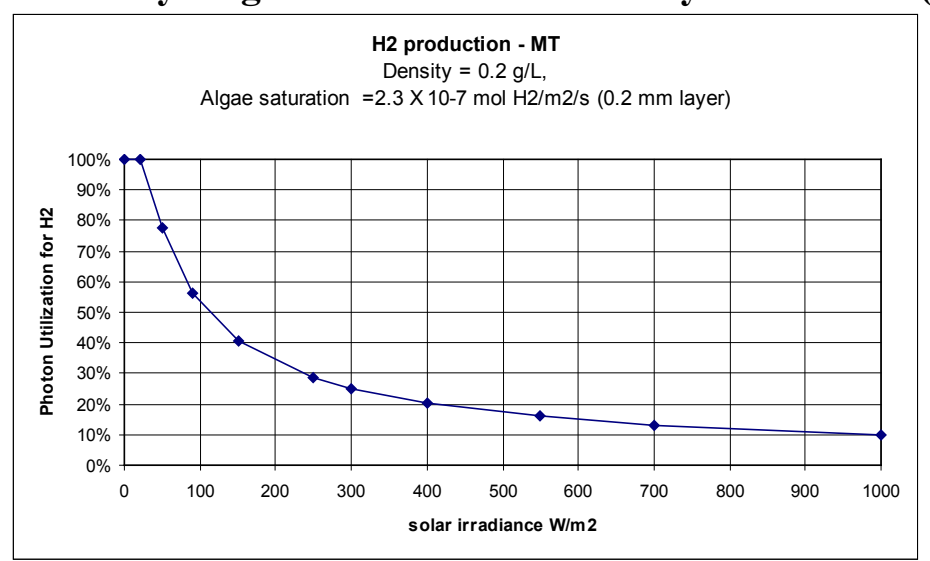

Figure 1-9. Hydrogen Production Efficiency - Mutant 2 (M2T)

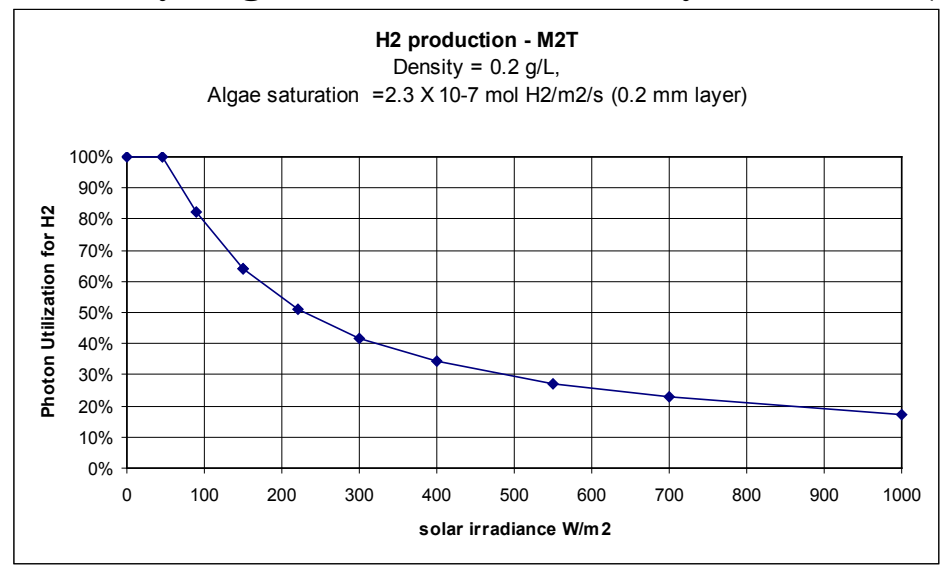


Figure 1-10, Figure 1-11 and Figure 1-12 show resultant hydrogen production rate for both wild-type and mutant types as solar irradiance is increased, with the early linear part of the curve reflecting full conversion. At full conversion intensities, the saturation limit is not exceeded and photon utilization can be $100 \%$ (i.e. $100 \%$ of the photons absorbed are able to be processed by the PSII and PSI reactions.) Output levels off as irradiance increases, with the Mutant-2-Type having significantly higher overall production levels.

Figure 1-10. Hydrogen Production - Wild-Type (WT)

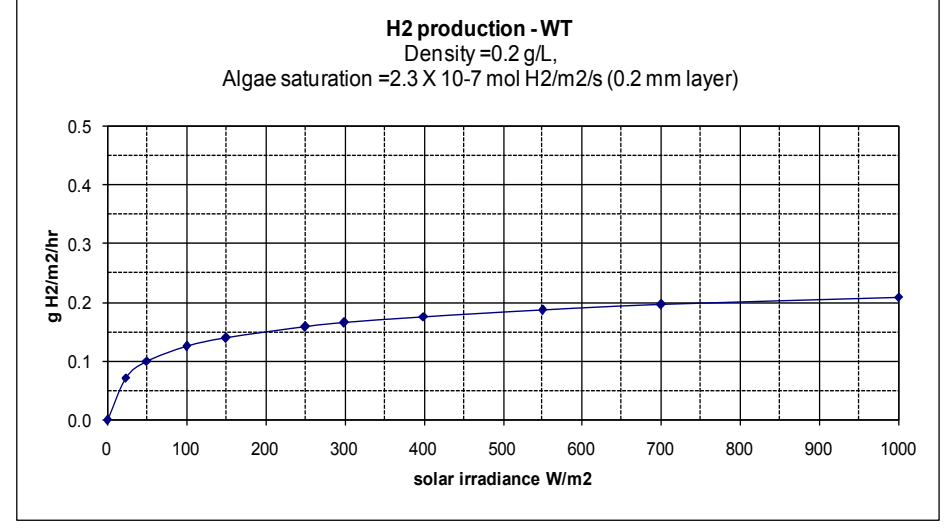

Figure 1-11. Hydrogen Production - Mutant 1 (MT)

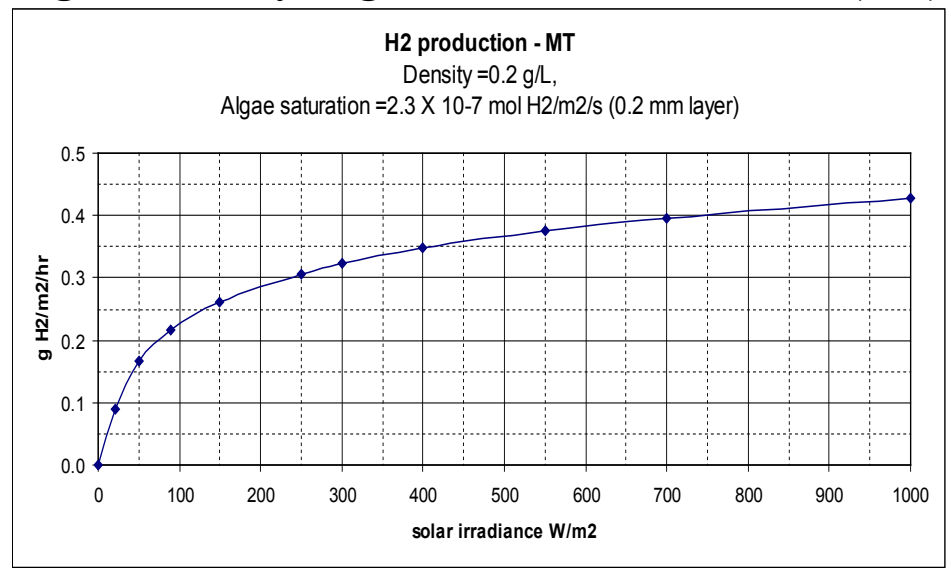

Figure 1-12. Hydrogen Production - Mutant 2 (M2T)

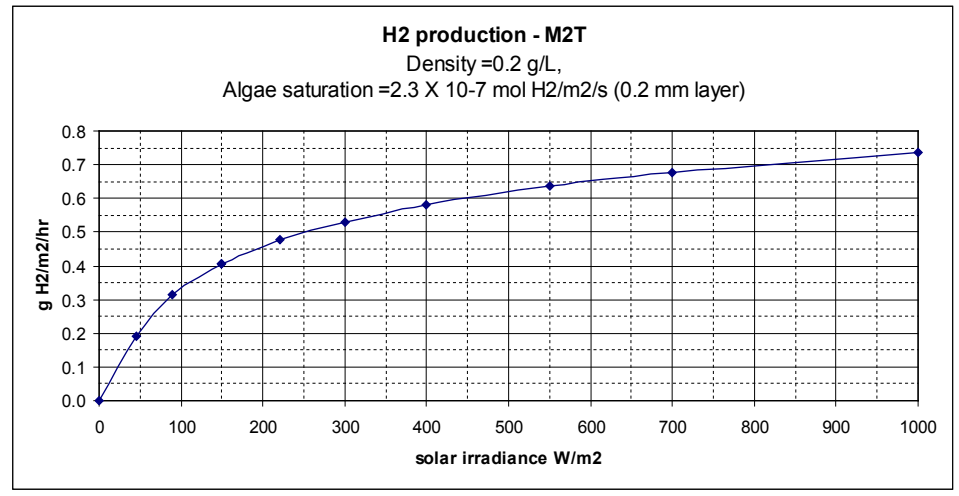


To illustrate the combined effects of cell saturation and seasonal and diurnal variation in light intensity, hourly hydrogen production curves were plotted in Figure 1-13 for June 21, September 21, and December 21. Integrating under the curve gives total daily $\mathrm{H}_{2}$ production and allows an average STH energy conversion efficiency to be calculated. These values are shown in Figure 1-13.

Figure 1-13. Hourly Hydrogen Production Variation - M2T

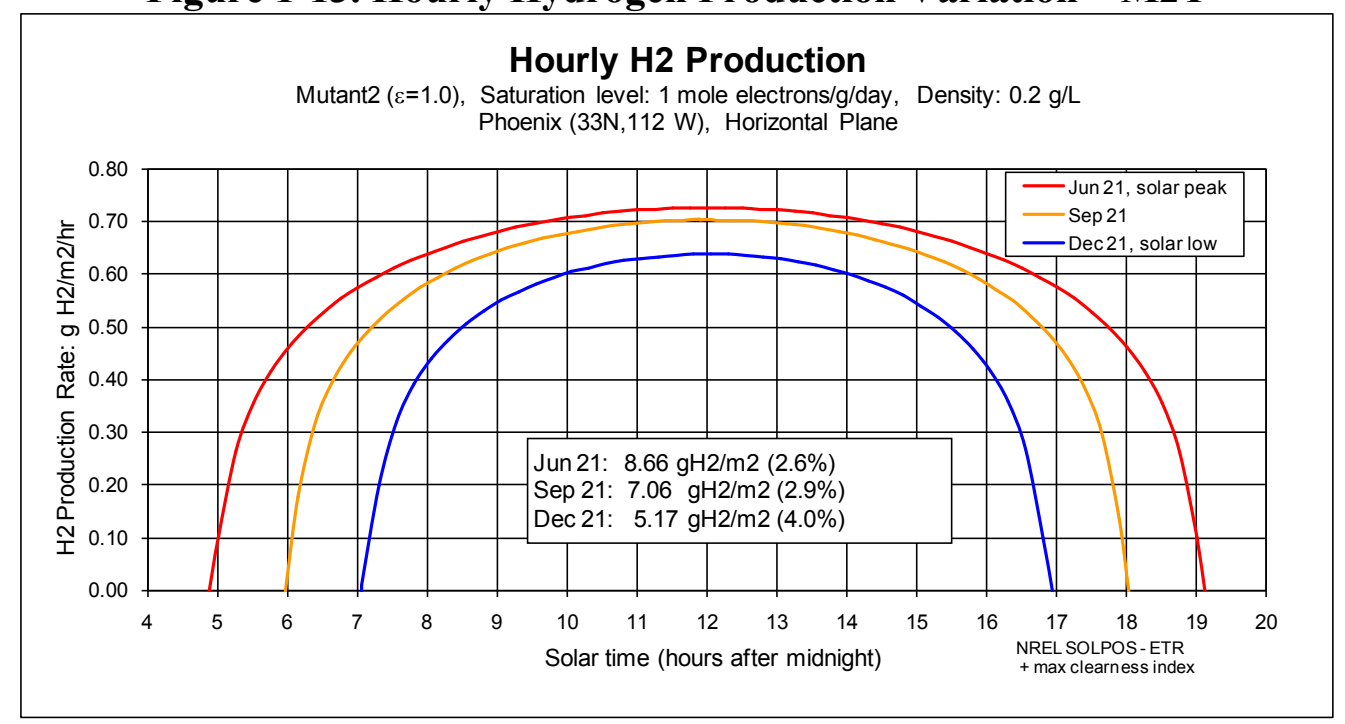

In summary, the above curves show $\mathrm{H}_{2}$ production rate for a hypothetical M2T mutant antenna algae strain at the following conditions:

- An organism that obeys Beer's law

- Chlamydomonas reinhardtii at cell concentration $=0.2 \mathrm{~g} / \mathrm{L}$ and a bed depth $=10 \mathrm{~cm}$

- Mass absorption coefficient $\varepsilon=1 \mathrm{~L} / \mathrm{cm} / \mathrm{g}_{\text {drywt }}$ representing a 5:1 reduced antenna mutant relative to wild type

- Maximum charge transfer saturation limitation of 1 mole electrons per gram cell dry weight of cells per day

- Linear dependence of the $\mathrm{H}_{2}$ production rate on light intensities below those needed to produce electron transfer at the maximum charge transfer limit

- Solar diurnal and yearly fluctuations as described in Section 2.1

- All photons absorbed by the cell are assumed to impact the chlorophyll antenna

- All photons successfully entering the PSII/PSI chain productively produce $\mathrm{H}_{2}$ (i.e., no photons go toward growth, heat or fluorescence)

Integrating over the course of the year, we estimate that the resulting annual average STH energy conversion efficiency is $3.1 \%$.

\subsubsection{Absorption Parameters Used in This Study}

The maximum STH efficiency is highly dependent on the saturation limit assumption. While the limitation mechanism is well understood, the upper saturation limit for future optimized organisms is poorly defined. The saturation model discussed in the prior sections is based on current organism properties. However, this study is focused on potential future 
production using developmental mutants of algae and bacteria which will not have the stringent saturation limits of current algae and bacteria. Consequently for this analysis the saturation limit was not imposed for the following reasons:

1. We wish to parametrically assess the cost of hydrogen resulting from multiple organism systems and configuration. Consequently, we want to establish a true "upper bound" efficiency to gauge the potential of biohydrogen.

2. We are interested in modeling hypothetical mutant strains that have optimized hydrogen generation capability and their exact production characteristics are not known.

3. Mutation of the chlorophyll antenna size is expected to be one approach to optimizing STH efficiency and the limits of antenna truncation are not known.

4. The removal of the saturation limit leads the STH conversion efficiency to be constant with respect to light intensity. This in turn means the STH efficiency is constant throughout the year and greatly simplifies the reactor bed sizing analysis (because it allows us to merely sum total incident photons rather than carefully assessing the incident photon variations over the course of the day and year).

Assumed STH conversion efficiencies for each of the examined biological systems are detailed in the next section.

\section{Photobiological Systems - Biological and System Parameters}

"Certain algae and cyanobacteria photoproduce hydrogen for short times as a way to get rid of excess energy." 7 Recognizing the potential of using these biological systems as a source of energy, scientists have sought out ways to extend and control the duration of hydrogen production from these organisms.

Our analysis focuses on the hydrogen production potential of 5 photobiological systems. These are;

1. green algae that co-produces $\mathrm{H}_{2}$ and $\mathrm{O}_{2}$ gases and possesses an $\mathrm{O}_{2}$-tolerant hydrogenase,

2. cyanobacteria that co-produces $\mathrm{H}_{2}$ and $\mathrm{O}_{2}$ gases and possesses an $\mathrm{O}_{2}$-tolerant hydrogenase ${ }^{8}$,

3. sulfate-permease algal mutants that produce only $\mathrm{H}_{2}$ gas due to the effects of a mutated sulfate permease gene on the chloroplast,

4. immobilized sulfate-deprived green algae that produce $\mathrm{H}_{2}$ for extended periods of time, and

5. purple non-sulfur (PNS) bacteria that produce $\mathrm{H}_{2}$ gas in light.

The baseline conditions that have been used for each of the pathways are summarized in Figure 2-1. The Reactor Bed Mode of Operation refers to the process that is used to grow algae and produce hydrogen. This mode of operation results in different solar to hydrogen (STH) efficiencies for a given organism. The Reactor Bed Mode of Operation is described in more detail in the Engineering Parameters section of this report.

\footnotetext{
${ }^{7}$ Photobiological Production of Hydrogen (Fact Sheet). FS-560-42285. NREL. Colorado. November 2007. http://www.nrel.gov/docs/fy08osti/42285.pdf.

${ }^{8}$ This strain of cyanobacteria does not currently exist and needs to be genetically engineered.
} 
Figure 2-1. Biological Parameters of Photobiological Systems

\begin{tabular}{|c|c|c|c|c|c|}
\hline & $\begin{array}{c}\text { B-1: } \\
\text { Algae } \\
\text { O2-tolerant }_{\text {Hydrogenase }}\end{array}$ & $\begin{array}{c}\text { B-2: } \\
\text { Cyanobacteria } \\
\text { O }_{2} \text {-tolerant } \\
\text { Hydrogenase }\end{array}$ & $\begin{array}{c}\text { B-3: } \\
\text { Algae } \\
\text { Sulfate } \\
\text { Permease }\end{array}$ & $\begin{array}{c}\text { B-4: } \\
\text { Immobilized } \\
\text { Algae, Sulfur } \\
\text { deprived }\end{array}$ & $\begin{array}{c}\text { B-5: } \\
\text { PNS Bacteria }\end{array}$ \\
\hline Organism $^{9}$ & C. reinhardtii & $\begin{array}{l}\text { Synechocystis } \\
\text { Hydrogenase }^{10}\end{array}$ & C. reinhardtii & $\begin{array}{l}\text { C. reinhardtii } \\
\text { cc124 }\end{array}$ & $\begin{array}{c}\text { Rhodobacter } \\
\text { sphaeroides } \\
\text { RV }^{11}\end{array}$ \\
\hline Antennae Type & $\begin{array}{c}\text { LHC (Light } \\
\text { Harvesting } \\
\text { Complex) } \\
\text { deletion Mutant }\end{array}$ & $\begin{array}{c}\text { Phycobilin deletion } \\
\text { Mutant }\end{array}$ & $\begin{array}{l}\text { LHC deletion } \\
\text { Mutant }\end{array}$ & $\begin{array}{l}\text { LHC deletion } \\
\text { Mutant }\end{array}$ & $\begin{array}{l}\text { LHC - II deletion } \\
\text { Mutant }\end{array}$ \\
\hline $\begin{array}{l}\text { Reactor Bed Mode of } \\
\text { Operation. }\end{array}$ & Chemostat II $^{12}$ & Chemostat II & Single-Bed & $\begin{array}{c}\text { Dual-Bed, } \\
\text { Single-Bed }\end{array}$ & Chemostat II \\
\hline \multicolumn{6}{|c|}{ Cell Growth Conditions } \\
\hline Water & Fresh & Fresh & Fresh & Fresh & Fresh \\
\hline Temperature $\left({ }^{\circ} \mathrm{C}\right)$ & $25-35$ & $25-35$ & $25-35$ & $25-35$ & $25-35$ \\
\hline $\begin{array}{l}\text { Final Concentration } \\
\text { in solution }{ }^{14}\end{array}$ & $\begin{array}{c}0.2 \\
\text { (g/L-Dry Wt) }\end{array}$ & $\begin{array}{c}0.2 \\
(\mathrm{~g} / \mathrm{L}-\mathrm{Dry} \mathrm{Wt})\end{array}$ & $\begin{array}{c}4.91^{15} \\
(\mathrm{~g} / \mathrm{L}-\text { Dry Wt) }\end{array}$ & $\begin{array}{c}2.8 \\
(\mathrm{~g} / \mathrm{L}-\mathrm{Dry} \mathrm{Wt})\end{array}$ & $\begin{array}{c}0.2 \\
(\mathrm{~g} / \mathrm{L}-\mathrm{Dry} \mathrm{Wt})\end{array}$ \\
\hline Inorganic nutrients & \multicolumn{5}{|c|}{ Fertilizer containing: Potassium, Phosphorous, Nitrogen and trace elements } \\
\hline $\begin{array}{l}\text { Daily Rates } \\
\text { g/g organism }\end{array}$ & \multicolumn{5}{|c|}{$\mathrm{K}: 3.071 \times 10^{-6}, \quad \mathrm{P}: 4.913 \times 10^{-5}, \mathrm{~N}: 6.142 \times 10^{-6}$} \\
\hline $\begin{array}{l}\text { Daily Rates } \\
\mathrm{g} / \mathrm{m}^{2}\end{array}$ & \multicolumn{5}{|c|}{$\mathrm{K}: 6.14 \times 10^{-5}$ P: $9.83 \times 10^{-4}, \mathrm{~N}: 1.23 \times 10^{-4}$} \\
\hline Organic nutrient & None & None & None & None & Acetic Acid \\
\hline $\begin{array}{l}\text { Daily Rate } \\
\text { g/g organism }\end{array}$ & N/A & N/A & N/A & N/A & 0.624 \\
\hline $\begin{array}{c}\text { Daily Rate } \\
\mathrm{g} / \mathrm{m}^{2}\end{array}$ & $\mathrm{~N} / \mathrm{A}$ & N/A & N/A & N/A & 12.5 \\
\hline $\begin{array}{l}\text { Daily } \mathrm{CO}_{2} \text { Req }^{16} \\
\mathrm{~g} \mathrm{CO}_{2} / \mathrm{g}_{\text {dry mass }}\end{array}$ & 0.73 & 0.73 & 0.73 & 0.73 & None \\
\hline Growth duration & \multicolumn{2}{|c|}{2 days initial } & 4 days & 1 day & 2 days initial \\
\hline
\end{tabular}

${ }^{9}$ We assume an engineered antenna for all organisms. B-1 and B-2 also possess an $\mathrm{O}_{2}$ tolerant hydrogenase, thus creating a "double mutant". While without precedent in the literature, multiple mutations are necessary to achieve high STH conversion efficiencies.

${ }^{10}$ Based on Synechocystis PCC6803 mutant work of Pin-Ching Maness (NREL)

11 Analysis does not rely on a specific strain of PNS proteobacterium. Multiple examples of possible organisms are cited in "Photobiological hydrogen production: photochemical efficiency and bioreactor design," Akkerman et. al., Intl. Journal of Hydrogen Energy 27 (2002) 1195-1208.

${ }^{12}$ Chemostat II is a chemostat with simultaneous growth and $\mathrm{H}_{2}$ production, described in Section 4.1.4

${ }^{13}$ As discussed in Section 3.4, this system utilizes a two day production period, followed by a two day growth period in a single bed. At the end of 180 days of production, the algae grown in a second bed is transferred to the production bed, replacing the spent algae. In this way, it is both a dual-bed and single-bed system

${ }^{14}$ Peak cell concentration in growth bed at end of growth phase, and the target starting concentration for $\mathrm{H}_{2}$ production. For the Chemostat II systems (B-1, B-2, and B-5), this concentration refers to the final concentration at the end of the initial grown phase i.e. the growth phase used to create the initial colony prior to chemostat operation.

15 Concentrations higher than 0.2 are needed for B3 and B4 in order to ensure that enough cell mass is accumulated for respiration to keep the system anaerobic

${ }^{16}$ Four times the sustainment amount used for production conditions in this table. Based on private communication with A. Melis. (University of California-Berkeley) 


\begin{tabular}{|c|c|c|c|c|c|}
\hline & B-1 & B-2 & B-3 & B-4 & B-5 \\
\hline \multicolumn{6}{|c|}{ Hydrogen Production Conditions } \\
\hline Water & Fresh & Fresh & Fresh & Fresh & Fresh \\
\hline Temperature $\left({ }^{\circ} \mathrm{C}\right)$ & $25-35$ & $25-35$ & $25-35$ & $25-35$ & $25-35$ \\
\hline $\begin{array}{l}\text { Cell Concentration } \\
\text { in solution }\end{array}$ & $\begin{array}{c}0.2 \\
(\mathrm{~g} / \mathrm{L}-\mathrm{Dry} \mathrm{Wt})\end{array}$ & $\begin{array}{c}0.2 \\
(\mathrm{~g} / \mathrm{L}-\mathrm{Dry} \mathrm{Wt})\end{array}$ & $\begin{array}{c}0.85 \\
\text { (g/L- Dry Wt) }\end{array}$ & $\begin{array}{l}1.81^{17} \\
\text { (g/L- Dry Wt) }\end{array}$ & $\begin{array}{c}0.2 \\
\text { (g/L - Dry Wt) }\end{array}$ \\
\hline Nutrients & \multicolumn{3}{|c|}{$\begin{array}{c}\text { Fertilizer containing } \\
\text { Potassium, Phosphorous, and Nitrogen and trace elements }\end{array}$} & $\begin{array}{c}\text { Fertilizer } \\
\text { containing } \\
\text { Potassium, and } \\
\text { Nitrogen and trace } \\
\text { elements + Low } \\
\text { Level of Sulfur }\end{array}$ & $\begin{array}{c}\text { Fertilizer } \\
\text { containing } \\
\text { Potassium, } \\
\text { Phosphorous, } \\
\text { and trace } \\
\text { elements + } \\
\text { Acetic Acid }\end{array}$ \\
\hline $\begin{array}{l}\text { Daily Rates } \\
\text { g/g organism }\end{array}$ & \multicolumn{3}{|c|}{$\begin{array}{l}\mathrm{K}: 7.677 \times 10^{-7} \\
\mathrm{P}: 1.228 \times 10^{-5} \\
\mathrm{~N}: 1.535 \times 10^{-6}\end{array}$} & $\begin{array}{c}\mathrm{K}: 7.677 \times 10^{-7} \\
\mathrm{~N}: 1.535 \times 10^{-6} \\
\text { S: very low levels }\end{array}$ & $\begin{array}{l}\mathrm{K}: 3.071 \times 10^{-6} \\
\mathrm{P}: 4.913 \times 10^{-5} \\
\text { Ac acid: } 2.1\end{array}$ \\
\hline $\begin{array}{l}\text { Daily Rates } \\
\mathrm{g} / \mathrm{m}^{2}\end{array}$ & \multicolumn{3}{|c|}{$\begin{array}{l}\text { K: } 1.54 \times 10^{-5} \\
P: 2.46 \mathrm{E} \times 10^{-4} \\
\mathrm{~N}: \quad 3.07 \times 10^{-5}\end{array}$} & $\begin{array}{c}\mathrm{K}: 1.54 \times 10^{-5} \\
\mathrm{~N}: 3.07 \times 10^{-5} \\
\text { S: very low levels }\end{array}$ & $\begin{array}{l}\text { K: } 6.14 \times 10^{-5} \\
\text { P: } 9.83 \times 10^{-4} \\
\text { Ac acid: } 42.15\end{array}$ \\
\hline $\begin{array}{l}\text { Daily } \mathrm{CO}_{2} \text { Req } \\
\mathrm{g} \mathrm{CO}_{2} / \mathrm{g} \text { dry mass }\end{array}$ & $0.16^{18}$ & $0.16^{18}$ & None & None & None \\
\hline Oxygen Tolerance & $\begin{array}{l}\text { Aerobic } / \mathrm{O}_{2} \\
\text { tolerant }\end{array}$ & Aerobic $/ \mathrm{O}_{2}$ tolerant & Anaerobic & Anaerobic $^{19}$ & Anaerobic \\
\hline $\begin{array}{l}\text { Deprivations from } \\
\text { media }\end{array}$ & None & None & None & $\begin{array}{c}\text { Phosphate } \\
\text { deprived, Sulfur } \\
\text { limited }\end{array}$ & $\begin{array}{l}\text { Nitrogen } \\
\text { deprived }\end{array}$ \\
\hline $\begin{array}{l}\text { Production Cycle } \\
\text { Duration }\end{array}$ & $\begin{array}{l}\text { Semi-infinite, } \\
\text { continuous }\end{array}$ & $\begin{array}{l}\text { Semi-infinite, } \\
\text { continuous }\end{array}$ & $\begin{array}{c}3 \text { days } \mathrm{H}_{2} \\
\text { production, } \\
4 \text { days growth }\end{array}$ & $\begin{array}{c}3 \text { days } \mathrm{H}_{2} \\
\text { production, } 1 \text { day } \\
\text { growth for } \sim 180 \\
\text { days total }\end{array}$ & $\begin{array}{l}\text { Semi-infinite, } \\
\text { continuous }\end{array}$ \\
\hline Gases Produced & $\mathrm{H}_{2}, \mathrm{O}_{2}$ & $\mathrm{H}_{2}, \mathrm{O}_{2}$ & $\mathrm{H}_{2}, \mathrm{CO}_{2}$ & $\mathrm{H}_{2}, \mathrm{CO}_{2}$ & $\mathrm{H}_{2}, \mathrm{CO}_{2}$ \\
\hline
\end{tabular}

17 “...the immobilization technique allowed us to increase the cell density about 130-fold compared to a suspension culture" Kosourov, Sergey N. and M. Seibert. Hydrogen Photoproduction by Nutrient-Deprived Chlamydomonas reinhardtii Cells Immobilized within Thin Alginate Films under Aerobic and Anaerobic Conditions. NREL. Colorado. 16 June 2008. p 8. (NREL)

${ }^{18}$ Calculated based on the molar ratios of photosynthesis and the rate of photosynthesis required to support $3 \%$ light conversion into biomass.

19 Operation in aerobic conditions is a possibility but is not postulated for this analysis. "Since this was a critical observation, we further investigated whether alginate-entrapped cells could produce $\mathrm{H}_{2}$ in the presence of air... We in fact observed $\mathrm{H}_{2}$ gas production throughout most of the experiment. However, the final $\mathrm{H}_{2}$ yields were lower than the yields obtained under an argon atmosphere." Kosourov, Sergey N. and M. Seibert. Hydrogen Photoproduction by Nutrient-Deprived Chlamydomonas reinhardtii Cells Immobilized within Thin Alginate Films under Aerobic and Anaerobic Conditions. NREL, Colorado, 16 June 2008. p 10.

${ }^{20}$ Alternating cycles of 2-days growth/2-days $\mathrm{H}_{2}$ production with a total film lifetime of 180 days. 


\begin{tabular}{|c|c|c|c|c|c|}
\hline & B-1 & $B-2$ & B-3 & B-4 & B-5 \\
\hline \multicolumn{6}{|c|}{ Theoretical \& Assumed $\mathrm{H}_{2}$ Production Parameters } \\
\hline Assumed PAR ${ }^{21}$ & $44 \%$ & $44 \%$ & $44 \%$ & $44 \%$ & $71 \%$ \\
\hline Photons $/ \mathrm{H}_{2} \mathrm{~mol}$ & 4 & 4 & 4 & 4 & $11-15$ \\
\hline $\begin{array}{l}\text { Theoretical Product } \\
\text { Ratio }\end{array}$ & \multicolumn{2}{|c|}{$\begin{array}{c}2 \mathrm{~mol} \mathrm{H}_{2}^{22} \\
1 \mathrm{~mol} \mathrm{O}_{2}\end{array}$} & \multicolumn{2}{|c|}{$\begin{array}{c}2 \mathrm{~mol} \mathrm{H}_{2} \\
1 \mathrm{~mol} \mathrm{CO}_{2}\end{array}$} & $\begin{array}{c}2 \mathrm{~mol} \mathrm{H}_{2} \\
1 \mathrm{~mol} \mathrm{CO}_{2}\end{array}$ \\
\hline $\begin{array}{l}\text { Experimental } \\
\text { Product Gas Ratio }\end{array}$ & \multicolumn{2}{|c|}{$\mathrm{H}_{2}$ production not yet demonstrated } & \multicolumn{2}{|c|}{$100 \% \mathrm{H}_{2}^{23}$} & $\begin{array}{l}0.95 \mathrm{~mol} \mathrm{H}_{2} \\
0.05 \mathrm{~mol} \mathrm{CO}_{2}\end{array}$ \\
\hline $\begin{array}{l}\text { Assumed Product } \\
\text { Gas Ratio }\end{array}$ & \multicolumn{2}{|c|}{$\begin{array}{l}2 \mathrm{~mol} \mathrm{H}_{2} \\
1 \mathrm{~mol} \mathrm{O}_{2}\end{array}$} & $\begin{array}{c}2 \mathrm{~mol} \mathrm{H}_{2} \\
0.86 \mathrm{~mol} \mathrm{CO}_{2}\end{array}$ & $\begin{array}{c}2 \mathrm{~mol} \mathrm{H}_{2} \\
0.6 \mathrm{~mol} \mathrm{CO}_{2}\end{array}$ & $\begin{array}{c}2 \mathrm{~mol} \mathrm{H}_{2} \\
0.05 \mathrm{~mol} \mathrm{CO}_{2}\end{array}$ \\
\hline $\begin{array}{l}\text { STH }{ }^{24} \text { Efficiency } \\
\text { (Max Theoretical) }\end{array}$ & $12.2 \%$ & $12.2 \%$ & $12.2 \%$ & $3 \%$ & $6.5 \%$ \\
\hline $\begin{array}{l}\text { Solar energy for } \\
\text { Coincident Cell } \\
\text { Growth }^{25}\end{array}$ & $3 \%$ & $3 \%$ & N/A & N/A & $3 \%$ \\
\hline $\begin{array}{l}\text { STH Efficiency } \\
\text { (Assumed Upper } \\
\text { Bound) }\end{array}$ & $9.2 \%$ & $9.2 \%$ & $\begin{array}{c}5.2 \% \text { (average } \\
\text { over growth \& } \\
\text { production) }\end{array}$ & $\begin{array}{c}2.25 \% \text { (average } \\
\text { over growth \& } \\
\text { production) }\end{array}$ & $3.5 \%$ \\
\hline $\begin{array}{l}\text { STH Efficiency (Near } \\
\text { Term Estimate) }\end{array}$ & $2 \%$ & $2 \%$ & $1.3 \%$ & $1.5 \%$ & $1.5 \%$ \\
\hline $\begin{array}{l}\text { Experimental STH } \\
\text { Efficiency }\end{array}$ & \multicolumn{2}{|c|}{$\mathrm{H}_{2}$ production not yet demonstrated } & $\begin{array}{c}\mathrm{H}_{2} \text { not } \\
\text { demonstrated }\end{array}$ & $0.8 \%$ average & $2.5 \%{ }^{26}$ \\
\hline Bed Depth (cm) & 10 & 10 & 10 & $10^{27}$ & 10 \\
\hline \multicolumn{6}{|c|}{ Reactor Parameters } \\
\hline $\mathrm{H}_{2}$ Rate $\left(\mathrm{kgH}_{2} / \text { day }\right)^{28}$ & 1,111 & 1,111 & 1,176 & 1,176 & 1,111 \\
\hline $\begin{array}{l}\text { Number of } \\
\text { Raceways }\end{array}$ & 20 & 20 & 38 & $\begin{array}{l}90 \text { Production } \\
2 \text { Growth }\end{array}$ & 54 \\
\hline $\begin{array}{l}\text { Raceway LxW: } \\
\text { Raceway D }\end{array}$ & $\begin{array}{c}1090^{\prime} \times 40^{\prime} \\
\times 0.33^{\prime}\end{array}$ & $\begin{array}{c}1090^{\prime} \times 40^{\prime} \\
\times 0.33^{\prime}\end{array}$ & $\begin{array}{c}1090^{\prime} \times 40^{\prime} \\
\times 0.33^{\prime}\end{array}$ & $\begin{array}{c}1060^{\prime} \times 40^{\prime} \\
x 0.33^{\prime}\end{array}$ & $\begin{array}{c}1090^{\prime} \times 40^{\prime} \\
\times 0.33^{\prime}\end{array}$ \\
\hline Reactor Area $\left(\mathrm{m}^{2}\right)$ & 80,968 & 80,968 & 151,754 & 352,070 & 216,228 \\
\hline
\end{tabular}

21 PAR: photosynthetically active radiation

22 Email from Pin-Ching Maness. (NREL) 10 October 2008. “...the gas output should be $1 \mathrm{~mol} \mathrm{O}_{2}$ and 2 mol $\mathrm{H}_{2}$, with no $\mathrm{CO}_{2}$ at all."

${ }^{23}$ While $\mathrm{CO}_{2}$ must be produced by the reaction, it is dissolved in the aqueous media. Consequently no $\mathrm{CO}_{2}$ is experimentally observed in the headspace gas. However, in a potential future system, excess $\mathrm{CO}_{2}$ is expected to exceed the saturation limit and collect as a gas in the reactor bed headspace.

24 STH Efficiency =Solar to Hydrogen conversion efficiency = ratio of hydrogen net energy produced (lower heating value) to total solar energy incident on reactor bed.

${ }^{25}$ This only applies to Chemostat II systems (section 4.1.4), where there is no separate growth stage.

26 Akkerman, Ida, Marcel Janssen, Jorge Rocha, Rene H. Wijffels. Photobiological hydrogen production: photochemical efficiency and bioreactor design. Intl. Journal of Hydrogen Energy. Vol. 27, p 1195-1208, 2002.

27 Thinness of film substrate makes this depth unnecessary for photon capture, but it is still necessary for system temperature modulation.

${ }^{28}$ Beds are sized to meet $1000 \mathrm{kgH}_{2}$ /day out of PSA. PSA recovery is determined by input hydrogen + contaminant gases for all beds, some of which are in growth phase. Calculated by PSA spreadsheet model and confirmed by gas separation experts at UOP LLC. $\mathrm{H}_{2}$ recovery for B1, B2, and B5 estimated at $90 \%$. $\mathrm{H}_{2}$ recovery for B3 and B4 estimated at $85 \%$. 


\section{$2.1 \quad$ Nutrients}

A wild algal colony reaches a final concentration in the photoautotrophic growth stage of $>1$ $\mathrm{g} / \mathrm{L}$ if allowed to grow to stationary phase. Thus, each system must be diluted through algae filtering to achieve a cell density of $0.2 \mathrm{~g} / \mathrm{L}$. The bed depth is chosen so that, following transition to the hydrogen production mode, the absorbance achieves the highest yield of hydrogen at this density. For the chemostat systems, a final cell concentration of $0.2 \mathrm{~g}$ dry weight/L (WT cells) was recommended by NREL before transition to hydrogen production mode ${ }^{29}$. This concentration can be achieved either by dilution of the stationary phase culture or by earlier commencement of transition to hydrogen producing conditions.

The concentration of algae is important because it determines how several other items are sized in our analysis. It impacts the amount of nutrients and input gases required. Later in the engineering parameters section we will analyze how it can affect pump and valve sizes as well.

\subsubsection{Chlamydomonas reinhardtii Nutrients}

In most laboratory environments, Chlamydomonas nutrient requirements are fulfilled by the tris-acetate-phosphate (TAP) medium with Hunter Trace Elements or other custom mixes of common lab chemicals. While ideal for a laboratory where these chemicals are readily available and only used in small quantities, on a production scale the costs are extraordinarily expensive. Even in large quantities and at technical grade, the manufacturing that goes into laboratory quality chemicals substantially increases the price. A cost breakdown of the TAP medium can be seen in Figure 2-2. Prices are based on quotes from Spectrum Chemical Corporation and Eastern Chemical Corporation.

\footnotetext{
${ }^{29}$ What we desire is an appropriate matching of organism density and bed depth so that full photon capture is achieved. Full photon capture will lead to maximum hydrogen production. Amos suggests that $0.2 \mathrm{~g} / \mathrm{L}$ is a feasible and practical organism density. Consequently, we have adopted that density and have adjusted bed depth based on the specific organism absorption properties to achieve full photon capture.
} 
Figure 2-2. TAP Medium Costs

\begin{tabular}{|c|c|c|c|c|c|c|}
\hline Compound & Symbol & Price & Quantity & Concentration & Price & Cost/ Liter \\
\hline \multicolumn{7}{|c|}{ TAP Medium } \\
\hline Tris & $(\mathrm{HOCH} 2) 3 \mathrm{CNH} 2$ & $\$ 13,480.00$ & $907 \mathrm{~kg}$ & $2.43 \mathrm{~g} / \mathrm{L}$ & $\$ 14.86 / \mathrm{kg}$ & 0.03612 \\
\hline Ammonium Chloride & $\mathrm{NH} 4 \mathrm{Cl}$ & $\$ 102.00$ & $23 \mathrm{~kg}$ & $.4 \mathrm{~g} / \mathrm{L}$ & $\$ 4.5 / \mathrm{kg}$ & 0.00180 \\
\hline Magnesium Sulfate, Heptahydrate & $\mathrm{MgSO} 4.7 \mathrm{H} 2 \mathrm{O}$ & $\$ 2,160.00$ & $500 \mathrm{~kg}$ & $.1 \mathrm{~g} / \mathrm{L}$ & $\$ 4.32 / \mathrm{kg}$ & 0.00043 \\
\hline Calcium Chloride, Dihydrate & $\mathrm{CaCl} 2.2 \mathrm{H} 2 \mathrm{O}$ & $\$ 583.00$ & $50 \mathrm{~kg}$ & $.05 \mathrm{~g} / \mathrm{L}$ & $\$ 11.66 / \mathrm{kg}$ & 0.00058 \\
\hline Potassium Phosphate, Dibasic & K2HPO4 & $\$ 216.00$ & $23 \mathrm{~kg}$ & $108 \mathrm{~g} / \mathrm{L}$ & $\$ 9.52 / \mathrm{kg}$ & 0.00103 \\
\hline Potassium Phosphate Monobasic & KH2PO4 & $\$ 3,300.00$ & $225 \mathrm{~kg}$ & $.056 \mathrm{~g} / \mathrm{L}$ & $\$ 14.67 / \mathrm{kg}$ & 0.00082 \\
\hline Acetic Acid & СH3 $3 \mathrm{COOH}$ & $\$ 558.00$ & $208 \mathrm{~L}$ & 1. $\mathrm{m} / \mathrm{L}$ & $\$ 2.68 / \mathrm{L}$ & 0.00268 \\
\hline \multicolumn{7}{|c|}{ Hunter Trace Elements } \\
\hline EDTA Disodium Salt & Na2EDTA & $\$ 1,402.74$ & $12 \mathrm{~kg}$ & 50. $\mathrm{g} / \mathrm{L}$ & $\$ 116.9 / \mathrm{kg}$ & 0.00584 \\
\hline Zinc Sulfate, Heptahydrate & $\mathrm{ZnSO} 4.7 \mathrm{H} 2 \mathrm{O}$ & $\$ 709.80$ & $12 \mathrm{~kg}$ & 22. $\mathrm{g} / \mathrm{L}$ & $\$ 59.15 / \mathrm{kg}$ & 0.00130 \\
\hline Boric Acid & Н3B⿱一⿻上丨 & $\$ 531.54$ & $12 \mathrm{~kg}$ & $11.4 \mathrm{~g} / \mathrm{L}$ & $\$ 44.3 / \mathrm{kg}$ & 0.00050 \\
\hline Manganese Chloride, 4- Hydrate & $\mathrm{MnCl} 2.4 \mathrm{H} 2 \mathrm{O}$ & $\$ 1,227.78$ & $12 \mathrm{~kg}$ & $5.06 \mathrm{~g} / \mathrm{L}$ & $\$ 102.32 / \mathrm{kg}$ & 0.00052 \\
\hline Ferrous Sulfate, Heptahydrate & $\mathrm{FeSO} 4.7 \mathrm{H} 2 \mathrm{O}$ & $\$ 865.44$ & $12 \mathrm{~kg}$ & $4.99 \mathrm{~g} / \mathrm{L}$ & $\$ 72.12 / \mathrm{kg}$ & 0.00036 \\
\hline Cobalt Chloride, Hexahydrate & $\mathrm{CoCl} 2.6 \mathrm{H} 2 \mathrm{O}$ & $\$ 2,683.50$ & $12 \mathrm{~kg}$ & $1.61 \mathrm{~g} / \mathrm{L}$ & $\$ 223.63 / \mathrm{kg}$ & 0.00036 \\
\hline Cupric Sulfate, Pentahydrate & $\mathrm{CuSO} 4.5 \mathrm{H} 2 \mathrm{O}$ & $\$ 716.82$ & $12 \mathrm{~kg}$ & $1.57 \mathrm{~g} / \mathrm{L}$ & $\$ 59.74 / \mathrm{kg}$ & 0.00009 \\
\hline Ammonium Molybdate, Tetrahydrate & (NH4)6Mo7O24.4H2O & $\$ 2,509.13$ & $12 \mathrm{~kg}$ & $1.1 \mathrm{~g} / \mathrm{L}$ & $\$ 209.09 / \mathrm{kg}$ & 0.00023 \\
\hline Total Cost TAP Medium/ Liter & & & & & & 0.0435 \\
\hline Total Cost Hunter Elements/Liter & & & & & & 0.0092 \\
\hline Total Cost/ Liter Solution & & & & & & 0.05267 \\
\hline Total Cost/ Reactor (B1) & & & & & & $\$ 427,037.50$ \\
\hline $\begin{array}{l}\text { Total Cost/ Year } \\
\text { (assuming } 12 \text { reactor changes per yr) }\end{array}$ & & & & & & $\$ 5,124,450.00$ \\
\hline
\end{tabular}

Due to the prohibitive cost of the TAP medium, we investigated alternative nutrient sources. Fish aquaculture provides an excellent case study for large-scale algae production since algae is the primary food source for most fish, and an effective nutrient source is integral to the success of the culture. The standard source of nutrients for algal based aquaculture is liquid or solid farm fertilizer. The most effective fertilizers are ones that contain all three of the major fertilizer nutrients: Potassium, Phosphorous, and Nitrogen. Commercial fertilizers also come with a wide variety of available trace elements that can be added in any number of custom blends. The prices for commercial fertilizers that would be adequate for effective algae growth are substantially cheaper than those of the TAP medium or other similar media. Information from the US Dept. of Agriculture (USDA) indicates the cost of fertilizers ranges generally between $\$ 150$ and $\$ 550$ per ton, depending on the type of fertilizer and the quantity being purchased. Some of the more common fertilizers and their prices over the past seven years can be seen Figure 2-3.

Figure 2-3. Fertilizer prices per ton since 2000.

\begin{tabular}{|c|c|c|c|c|c|c|c|c|c|}
\hline Year & Month & $\begin{array}{l}\text { Anhydrous } \\
\text { ammonia }\end{array}$ & $\begin{array}{c}\text { Nitrogen } \\
\text { solutions }(30 \%)\end{array}$ & $\begin{array}{l}\text { Urea } 45-46 \% \\
\text { nitrogen }\end{array}$ & $\begin{array}{c}\text { Ammonium } \\
\text { nitrate }\end{array}$ & $\begin{array}{c}\text { Sulfate of } \\
\text { ammonium }\end{array}$ & $\begin{array}{c}\text { Super-phosphate } \\
44-46 \% \\
\text { phosphate }\end{array}$ & $\begin{array}{l}\text { Diammonium } \\
\text { phosphate } \\
(18-46-0)\end{array}$ & $\begin{array}{l}\text { Potassium } \\
\text { chloride } 60 \% \\
\text { potassium }\end{array}$ \\
\hline 2000 & Apr. & $\$ 227$ & $\$ 131$ & $\$ 200$ & $\$ 194$ & $\$ 167$ & $\$ 233$ & $\$ 240$ & $\$ 165$ \\
\hline 2001 & Apr. & $\$ 399$ & $\$ 189$ & $\$ 280$ & $\$ 260$ & $\$ 192$ & $\$ 236$ & $\$ 244$ & $\$ 170$ \\
\hline 2002 & Apr. & $\$ 250$ & $\$ 127$ & $\$ 191$ & $\$ 195$ & $\$ 187$ & $\$ 221$ & $\$ 227$ & $\$ 164$ \\
\hline 2003 & Apr. & $\$ 373$ & $\$ 161$ & $\$ 261$ & $\$ 243$ & $\$ 195$ & $\$ 243$ & $\$ 250$ & $\$ 165$ \\
\hline 2004 & Apr. & $\$ 379$ & $\$ 178$ & $\$ 276$ & $\$ 263$ & $\$ 205$ & $\$ 266$ & $\$ 276$ & $\$ 181$ \\
\hline 2005 & Apr & $\$ 416$ & $\$ 215$ & $\$ 332$ & $\$ 292$ & $\$ 244$ & $\$ 299$ & $\$ 303$ & $\$ 245$ \\
\hline 2006 & Apr & $\$ 521$ & $\$ 232$ & $\$ 362$ & $\$ 366$ & $\$ 266$ & $\$ 324$ & $\$ 337$ & $\$ 273$ \\
\hline 2007 & Apr & $\$ 523$ & $\$ 277$ & $\$ 453$ & $\$ 382$ & $\$ 288$ & $\$ 418$ & $\$ 442$ & $\$ 280$ \\
\hline
\end{tabular}

According to US Patent \#5,567,221 from OMS Investments Inc., the suggested aquaculture algae nutrient rates for the three major fertilizer nutrients is 100 pounds/acre per production cycle for nitrogen, 800 pounds/acre per production cycle for phosphorous, and 50 pounds/acre per production cycle for potassium. Average production cycles vary depending on the species of fish from as much as 18 months to as little as 6 months. If we average that 
range to a year, and estimate the algal concentration for these fertilizer quantities we can compute the necessary fertilizer for our application.

The biodiesels industry indicates concentrations of $1 \mathrm{~g} / \mathrm{L}$ to $10 \mathrm{~g} / \mathrm{L}$ of algae in solution are normally achieved. Taking the average we assume that the nutrient rates suggested by the OMS patent are based on an algae concentration of $5 \mathrm{~g} / \mathrm{L}$, compared to our colony concentration of $0.2 \mathrm{~g} / \mathrm{L}$. The bed depth in the OMS patent is $1 \mathrm{~m}$ compared to our pond depth of $0.1 \mathrm{~m}$. The rate of nutrients of interest is $g$ Nutrient $/ g$ algae $/ \mathrm{m}^{2} /$ day. In order to compute this we first convert the rate given to $\mathrm{g} / \mathrm{m}^{2} /$ day using the conversion factors below.

\begin{tabular}{|rl|}
\hline \multicolumn{2}{|c|}{ Conversion Factors } \\
4046.9 & $\mathrm{~m}^{2} / \mathrm{acre}$ \\
365 & days/yr \\
453.592 & $\mathrm{~g} / \mathrm{lb}$ \\
\hline
\end{tabular}

\begin{tabular}{|lccc|}
\cline { 2 - 4 } \multicolumn{1}{c|}{} & Nitrogen & Potassium & Phosphorus \\
\hline $\mathrm{lb} /$ acre $/ \mathrm{yr}$ & 100 & 50 & 800 \\
$\mathrm{~g} / \mathrm{m}^{2} / \mathrm{day}$ & 0.031 & 0.015 & 0.246 \\
\hline
\end{tabular}

Then using the concentration values and bed depths we can compute the $\mathrm{g}$ algae $/ \mathrm{m}^{2}$ for the reference and for our plant.

\begin{tabular}{|lrl|}
\hline Conversion Factors & & \\
\hline Volume & 1000 & $\mathrm{~L} / \mathrm{m}^{3}$ \\
Bed Depth (Aqua) & 1 & $\mathrm{~m}$ \\
Bed Depth (Photobio) & 0.10 & $\mathrm{~m}$ \\
\hline & Aquaculture & Photobio \\
\hline $\mathrm{g} / \mathrm{L}$ & 5 & 0.2 \\
$\mathrm{~g} / \mathrm{m}^{2}$ & 5000 & 20 \\
\hline
\end{tabular}

Lastly, we compute the daily mass ratio of nutrients to algae in the aquaculture then convert to an areal density given the Photobiological algae concentration. This leads us to the values provided in the Biological Parameters table above (Figure 2-1) for colony growth. Naturally, this amount would be less at the start of the colony. However, given the extremely small level of nutrients and the short growth time, we took this nutrient rate as a constant value during the growth phase. During $\mathrm{H}_{2}$ production the nutrient rates decrease as specified by other sources.

Figure 2-4. Nutrient Rates Computed

\begin{tabular}{|l|l|ccc|}
\cline { 2 - 3 } \multicolumn{1}{c|}{} & Nutrient --> & Nitrogen & Potassium & Phosphorus \\
\hline Aquaculture & g Nutrient $/ \mathrm{m}^{2} /$ day & 0.031 & 0.015 & 0.246 \\
\cline { 1 - 2 } Aquaculture/Photobio & g Nutrient/g algae/day & $6.142 \mathrm{E}-06$ & $3.071 \mathrm{E}-06$ & $4.913 \mathrm{E}-05$ \\
\cline { 1 - 2 } Photobio & g Nutrient $/ \mathrm{m}^{2} /$ day & $1.228 \mathrm{E}-04$ & $6.142 \mathrm{E}-05$ & $9.827 \mathrm{E}-04$ \\
\hline
\end{tabular}


If we average the production cycle range to a year with rates computed, the cost of nutrients drops significantly when compared with the TAP medium. An example of possible nutrient cost for the B-1 system using three different fertilizers, each rich in one of the nutrients, is shown in Figure 2-5. The costs were calculated using the Nitrogen solutions, Super Phosphate, and Potassium Chloride prices from the USDA. While costs may vary and more accurate testing of the adequate fertilizer mix and the appropriate rate still need to be done, these costs are indicative of the cost for using fertilizer as a nutrient source.

Figure 2-5. Sample Fertilizer Costs

\begin{tabular}{|lcccc|} 
Nutrient & Cost/Lb & Lb/Acre/Yr. & Cost/Acre/Yr. & $\begin{array}{c}\text { Cost/1 TPD } \\
\text { Module/Year }\end{array}$ \\
\hline Nitrogen & $\$ 0.14$ & 0.4 & $\$ 0.06$ & $\$ 0.80$ \\
\hline Potassium & $\$ 0.14$ & 0.2 & $\$ 0.03$ & $\$ 0.40$ \\
\hline Phosphorous & $\$ 0.21$ & 3.2 & $\$ 0.67$ & $\$ 9.63$ \\
\hline Total & $\$ 0.49$ & 3.8 & $\$ 0.76$ & $\$ 14.65$ \\
\hline
\end{tabular}

It should be noted that this price and nutrient breakdown are merely representative. In hydrogen production mode, a fertilizer without phosphorous would be used for the B-4 system, while in the B-5 system, a fertilizer that is nitrogen deprived would be ideal. Additionally, small amounts of sulfur would be added to the B-4 system in order to maintain the cell during long hydrogen production periods. Since the cost of nutrients is insignificant, more accurate costing of each nutrient system was not necessary for this report.

\subsubsection{Bacteria Nutrients}

Cyanobacteria (blue-green algae) are a diverse branch of prokaryotic oxygenic photoautotrophs that, like algae, oxidize water as electron donor and fix $\mathrm{CO}_{2}$ using light. They produce energy during the night by consumption of energy reserves, mainly glycogen, under aerobic conditions (respiration) or anaerobically (fermentation). They differ from algae in using a phycobilin pigment system for antenna. There are many thousands of different genera and strains with vastly different requirements for water, salinity, $\mathrm{pH}$, temperature and nutrients. The native cyanobacterial strain serving as background for the genetic alterations considered above in B-2 is Synechocystis PCC6803. This unicellular strain grows in freshwater media similar to that used with $C$. reinhardtii. In our analysis, Cyanobacteria nutrients and nutrient rates are the same as for the $C$. reinhardtii.

\subsubsection{PNS Bacteria Nutrients}

Purple Non-Sulfur (PNS) photosynthetic bacteria are very different organisms than algae and cyanobacteria and have different nutrient requirements. In previous studies concerning PNS, the primary source of nutrition was a combination of laboratory chemicals; however, organic acids such as acetic acid combined with agricultural fertilizer containing the three major macronutrients are hypothesized for mass production. Acetic acid consumption 
during hydrogen production of PNS bacteria has been demonstrated experimentally ${ }^{30}$. Based on the assumed PNS hydrogen production reaction ${ }^{31}$ of $\mathrm{C}_{2} \mathrm{H}_{4} \mathrm{O}_{2}+2 \mathrm{H}_{2} \mathrm{O}+$ Light Energy $=>2 \mathrm{CO}_{2}+4 \mathrm{H}_{2}, 4$ moles of hydrogen gas are formed for each mole of acetic acid. Using this ratio, along with the ratio of acetic acid to PNS cell mass (modeled as $\mathrm{C}_{5} \mathrm{H}_{8} \mathrm{O}_{2}$ ) needed for the assumed 3\% of photons dedicated to growth, we can calculate the overall acetic acid consumption rate shown in Figure 2-6.

Figure 2-6. Acetic acid Consumption by PNS

\begin{tabular}{|llr|}
\hline \multicolumn{2}{|c|}{ PNS Acetic Acid Consumption (Based on Theoretical Mass Balance) } \\
\hline Molar Ratio of Acetic Acid to PNS Mass (Section 3.5) & 3 \\
Molecular Weight of Acetic Acid & $\mathrm{g} / \mathrm{mol}$ & 60.032 \\
Molecular Weight of PNS Mass & $\mathrm{g} / \mathrm{mol}$ & 100.064 \\
Mass of PNS Grown (3\% of photons) & $\mathrm{kg} / \mathrm{day}$ & 468 \\
\hline Acetic Acid Needed for Growth & $\mathrm{kg} / \mathrm{day}$ & 842 \\
\hline Molar Ratio of Acetic Acid to $\mathrm{H}_{2}$ & & 0.25 \\
Molecular Weight of $\mathrm{H}_{2}$ & $\mathrm{~g} / \mathrm{mol}$ & 2.016 \\
$\mathrm{H}_{2}$ Produced & $\mathrm{kg} / \mathrm{day}$ & 1111 \\
\hline Acetic Acid Needed for $\mathrm{H}_{2}$ Production & $\mathrm{kg} / \mathrm{day}$ & 8272 \\
\hline Total Acetic Acid Needed & $\mathrm{kg} / \mathrm{day}$ & $\mathbf{9 1 1 3}$ \\
\hline
\end{tabular}

According to data from the Chemical Journal (Korea) the international market price for acetic acid is $\$ 0.595 / \mathrm{kg}^{32}$. As an alternative, in an integrated system, the waste product of a fermentor can potentially be used as an organic acid feedstock for the PNS bacteria.

\subsection{4 $\mathrm{pH}$ of Solution}

The $\mathrm{pH}$ of the solution in the reactor beds should be maintained near 7 to ensure optimal organism growth. In systems B-3, B-4 and B-5, there will be trapped $\mathrm{CO}_{2}$ released by the organisms in the process water. In the B-3 and B-4 systems this $\mathrm{CO}_{2}$ is needed as a feedstock for the algae during the growth stage to return the cell concentration to a level high enough to support the respiration needed to keep the system anaerobic during hydrogen production. Approaches to maintaining targeted $\mathrm{pH}$ levels have not been considered in detail within this report. Further investigation of the effects of $\mathrm{pH}$ should be considered in future work.

\subsubsection{Carbon Dioxide}

In addition to fertilizer and acetate, these organisms utilize carbon dioxide to make both structural biomass and energy reserves. The gas rate requirements have been determined using the stoichiometric ratios of photosynthesis. Additional $\mathrm{CO}_{2}$ will only need to be added to the B-1 and B-2 systems to support the minimal growth required to keep the system alive. Systems B-3 and B-4 will be producing all of the $\mathrm{CO}_{2}$ necessary for the

${ }^{30}$ Barbosa, Maria, Johannes Tramper Jorge Rocha, Rene H. Wijffels. Acetate as a carbon source for hydrogen production by photosynthetic bacteria. Journal of Biotechnology. Vol 85, p 25-33. 2000.

31 Akkerman, Ida, Marcel Janssen, Jorge Rocha, Rene H. Wijffels. Photobiological hydrogen production: photochemical efficiency and bioreactor design. International Journal of Hydrogen Energy. Vol 27, p 11951208. 2002

${ }^{32}$ Lee, Sang Y. Plastic Bacteria? Progress and prospects for polyhydroxyalkanoate production in bacteria. Trends in Biotechnology Vol 14, p 431-438. 1996. 
system, and the B-5 system will utilize acetate as its carbon source. The amount of carbon dioxide required was checked against the amount soluble in water. The amount of $\mathrm{CO}_{2}$ used should be well below saturation to avoid excess $\mathrm{CO}_{2}$ bubbling out into the $\mathrm{H}_{2}$ product gas. Using the CRC Handbook of Chemistry and Physics, we obtained the solubility of $\mathrm{CO}_{2}$ in water. We will maintain a $\mathrm{CO}_{2}$ partial pressure that will assure adequate $\mathrm{CO}_{2}$ supply. In the B-3 and B-4 systems the $\mathrm{CO}_{2}$ produced by the algae will be far above the solubility threshold, and the gaseous $\mathrm{CO}_{2}$ produced will be filtered out through PSA and added to the system after the dissolved level of $\mathrm{CO}_{2}$ drops through algae consumption. Since each system consists of numerous beds, their growth and production cycles will be appropriately staggered to ensure that there are always beds in need of the $\mathrm{CO}_{2}$ that is being filtered by the PSA. A constant slip stream of water will be removed and run through a $\mathrm{CO}_{2}$ saturation vessel and returned to raceways that are low on $\mathrm{CO}_{2}$. The only addition of $\mathrm{CO}_{2}$ necessary for B-3 and B-4 is the initial amount needed at the initial colony growth. B-5 has no $\mathrm{CO}_{2}$ needs.

The B-1 and B-2 organism needs for normal growth conditions are $31.66 \mathrm{mg} / \mathrm{L} / \mathrm{day}$ and for reduced growth conditions are $146.57 \mathrm{mg} / \mathrm{L} /$ day $^{18}$. Figure 2-7Figure 2-7. Carbon Dioxide Solubility in Water shows that these $\mathrm{CO}_{2}$ concentrations are well below the maximum solubility of $\mathrm{CO}_{2}$ in water at one atmosphere and that the $\mathrm{CO}_{2}$ input will remain in solution.

The $\mathrm{CO}_{2}$ needs for sustainment for the entire system amounts to only $257 \mathrm{kgCO}_{2} /$ day $\left(17,560 \mathrm{ft}^{3} /\right.$ day at $\left.1 \mathrm{~atm}\right)$. The $\mathrm{CO}_{2}$ can be readily provided by maintaining a $\mathrm{CO}_{2}$ partial pressure of $0.5 \mathrm{psia}$. This partial pressure will also minimize the $\mathrm{CO}_{2}$ dilution of the product $\mathrm{H}_{2}$ in the headspace of the reactor. 
Figure 2-7. Carbon Dioxide Solubility in Water

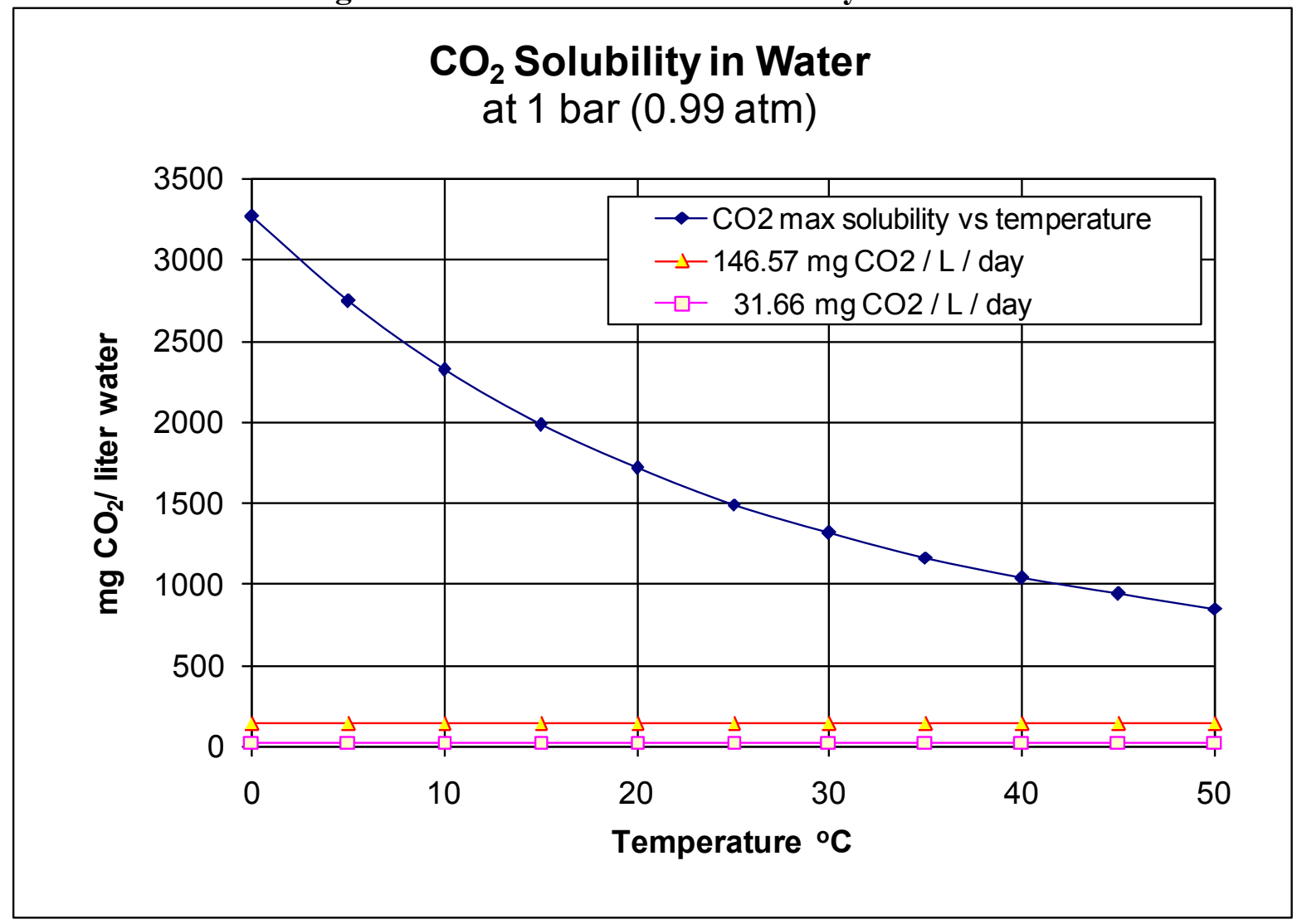

\section{$2.2 \quad O_{2}$-tolerant Hydrogenase $(B-1 \& B-2)$}

The B-1 and B-2 systems utilize organism mutants that are $\mathrm{O}_{2}$-tolerant, with B-1 using the algae strain C. reinhardtii and the B-2 system using the cyanobacterium Synechocystis PCC6803. The $\mathrm{O}_{2}$-tolerant hydrogenase pathway in both organisms is comprised of theoretical mutants with truncated Ch1 antennae (Light Harvesting Complex, or LHC, mutants) to minimize excess absorption of solar energy beyond what is needed for maximal $\mathrm{H}_{2}$ production. Two research groups have reported mutants in $\mathrm{C}$. reinhardtii that have reduced $\mathrm{Chl}$ content associated with truncated antenna complexes. ${ }^{33},{ }^{34}$ In both cases, the cells exhibit a reduced optical cross section and a higher growth rate at full solar light intensity. Factors of two have been reported. However, in both cases, reports on hydrogen production from these mutants have not been published, since research is ongoing.

A number of oxygen tolerant hydrogenases have been identified in bacteria as potential enzymes in algal hosts; bioengineering has yet to produce a mutant that exhibits stable $\mathrm{H}_{2}$ output over extended periods.

\footnotetext{
33 Melis, A. (2007) Photosynthetic H-2 metabolism in Chlamydomonas reinhardtii (unicellular green algae), Planta 226, 1075-1086.

34 Mussgnug, J. H., Thomas-Hall, S., Rupprecht, J., Foo, A., Klassen, V., McDowall, A., Schenk, P. M., Kruse, O., and Hankamer, B. (2007) Engineering photosynthetic light capture: impacts on improved solar energy to biomass conversion, Plant Biotechnology Journal 5, 802-814.
} 
The current best solar-to-hydrogen (STH) energy conversion efficiency of non-tolerant C. reinhardtii is ca. $0.8 \%$ for immobilized cells ${ }^{35}$. The theoretical prediction for algae assuming $100 \%$ flux of photoelectrons going solely into $\mathrm{H}_{2}$ production and without any loss or competition with other processes predicts an STH of $\sim 12.2 \%$. However, a certain amount of energy must be diverted for homeostasis, the regulation of the general health and functioning of the cell, regardless of the outside environment. Allowing for energy losses required for homeostasis, but assuming no competition with other pathways for utilization of light energy, our analysis assumes that hypothetical mutant B-1 algae will produce hydrogen at 9.2\% STH efficiency, while growing at approximately $1 / 4$ of the normal growthonly doubling rate (i.e. the doubling rate of algae that is not producing $\mathrm{H}_{2}$ ). Because the growth rate during production is assumed to be $1 / 4$, the carbon dioxide and nutrients during this condition is also assumed to be $1 / 4$.

For the B-2 system, Cyanobacteria do not produce significant levels of hydrogen upon illumination, even those strains which possess a native hydrogenase. However, hydrogenase-containing strains can produce hydrogen upon incubation under dark anaerobic conditions which induces autofermentation. In order to produce significant levels of photohydrogen with cyanobacteria, an engineered strain will need to be derived in which the native $[\mathrm{NiFe}]$-hydrogenase is replaced with one capable of utilizing the same photoreductant produced in algae, ferredoxin. Though deemed possible, no such bacteria have been reported to date in the literature. Therefore, extrapolations made herein are based on predictions provided by the NREL staff. The algae assumptions of a theoretically possible $12.2 \% \mathrm{STH}$ for the B-1 pathway are also applied to the B-2 pathway.

Pathways B-1 and B-2 are expected to produce hydrogen indefinitely unless the colony is spoiled by external factors. Since these mutants are still in a research stage, our analysis will assume that the amount of energy spent on hydrogen production can be regulated somewhat by controlling $\mathrm{CO}_{2}$ or ferredoxins (controlling how much energy goes to cell maintenance and cell growth). ${ }^{36}$ Although the organism is different for photobiological system B-1 and B-2, we assume their growth rates and calculated parameters to be identical in Figure 2-1, as the systems are future projections of yet undeveloped strains. Cyanobacteria may have an advantage to algae as their native hydrogenase is less sensitive to oxygen ${ }^{7}$. However, as noted above they produce $\mathrm{H}_{2}$ most efficiently in the dark and would require an algal-like hydrogenase if photohydrogen was the primary goal. As more data become available for these systems, the STH performance can be modified to assess the impact on hydrogen production capabilities and system costs.

Photobiological Systems B-1 and B-2 are modeled by the following reactions:
$\mathrm{H}_{2}$ Production:
$2 \mathrm{H}_{2} \mathrm{O}+$ Light Energy $\rightarrow 2 \mathrm{H}_{2}+\mathrm{O}_{2}$
Respiration:
$6 \mathrm{O}_{2}+\mathrm{C}_{6} \mathrm{H}_{12} \mathrm{O}_{6} \rightarrow 6 \mathrm{CO}_{2}+6 \mathrm{H}_{2} \mathrm{O}$
Photosynthesis/Growth:
$6 \mathrm{CO}_{2}+6 \mathrm{H}_{2} \mathrm{O}+$ Light Energy $\rightarrow \mathrm{C}_{6} \mathrm{H}_{12} \mathrm{O}_{6}+6 \mathrm{O}_{2}$

The inputs and outputs of the system are depicted in Figure 2-8.

35 Kosourov, Sergey N. and Michael Seibert. Hydrogen Photoproduction by Nutrient-Deprived Chlamydomonas reinhardtii Cell Immobilized within Thin Alginate Films under Aerobic and Anaerobic Conditions. Basic Sciences Center, NREL, Golden Colorado. 16 June 2008.

${ }^{36}$ Telecom. 09JUL08 Mtg Minutes. Technoeconomic Analysis of Bio-Hydrogen Program. NREL Contract \# AFH-8-88601-01. Revision 10 July 2008. 
Figure 2-8. Oxygen-Tolerant Hydrogenase Process

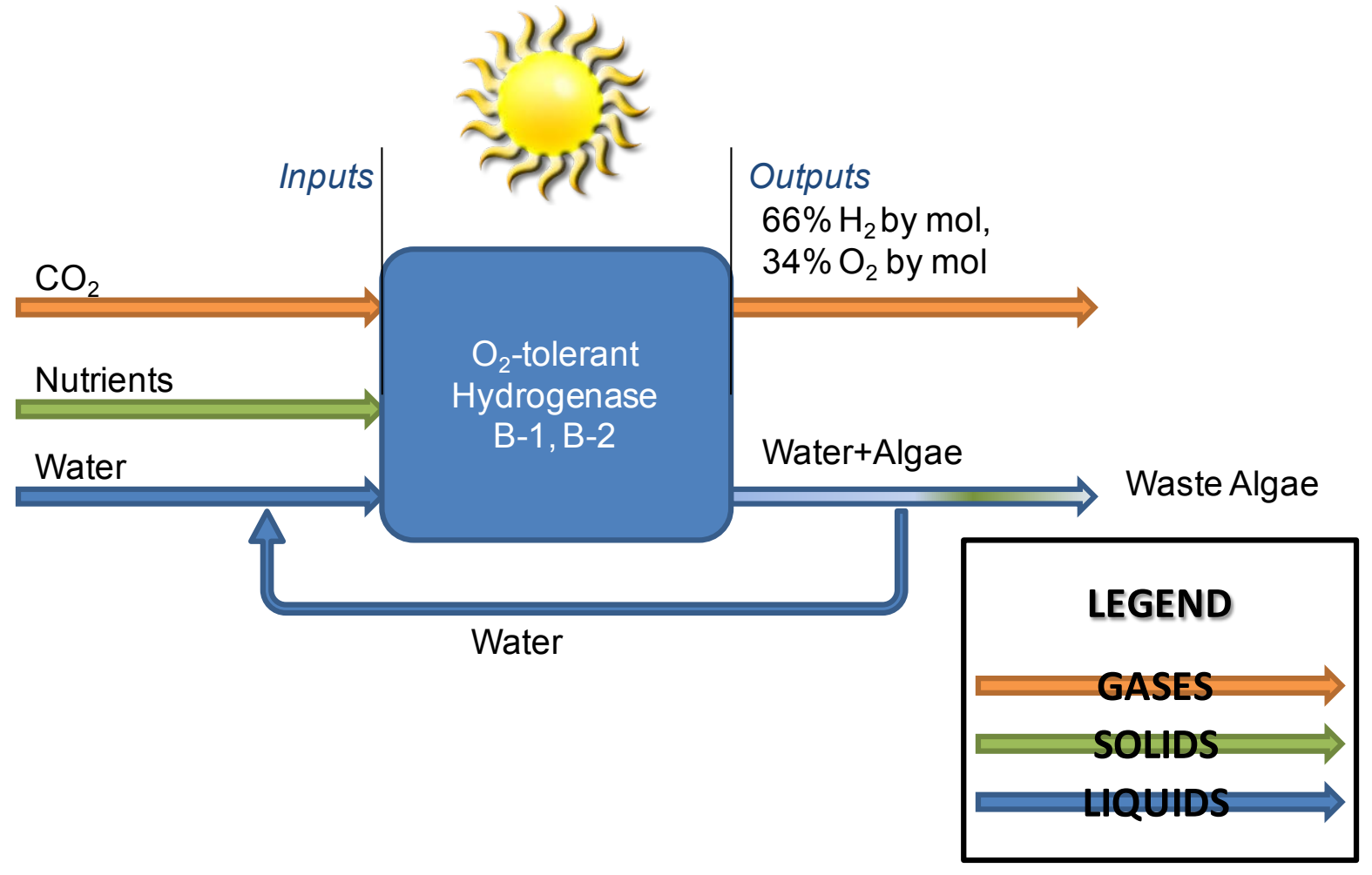

The product gases from this system are hydrogen and oxygen. In certain ratios, those gases can be a highly combustive mixture. The gas mixture would be located above the reactor bed. The engineering analysis portion of this report addresses ways to separate this mixture to obtain the pure product hydrogen.

\subsection{Sulfate-permease Green Algae (B-3)}

Like the B-1 pathway the sulfate-permease pathway utilizes algae mutants with truncated antennae. However, the algae in this pathway lack the mutated $\mathrm{O}_{2}$-tolerant hydrogenase of B-1. Hydrogen production is controlled through genetic mutation of the chloroplast sulfur uptake mechanism, reducing the rate of oxygenic photosynthesis. Sulfur is necessary for the regeneration of proteins damaged by photo-oxidation. Over time, the build-up of damaged photosynthetic proteins in the chloroplast will lead to a reduction in oxygen evolution. As the rate of oxygen evolution falls below the rate of oxidative respiration, the system will become anaerobic, leading to the induction of the hydrogenase pathway and continuous hydrogen production. The level of respiration needed to eliminate the high levels of oxygen produced by the water splitting hydrogen production reaction will necessitate a large amount of starch that must be produced by the cells prior to hydrogen production. Therefore, this organism is operated in a cyclic manner, with: (1) a growth/regeneration leading to starch buildup and (2) a hydrogen production phase which is anaerobic. In order to achieve the required level of starch mass, the starting concentration of the cells at the end of the hydrogen production phase will be $0.85 \mathrm{~g} / 1$ and will increase rapidly over the course of the regeneration phase to ensure enough mass exists to keep the system anaerobic when subsequently producing the necessary volume of hydrogen gas. Over time, however, the lack of starch production and the loss of cell mass due to respiration keeping the system 
anaerobic will inhibit cellular function, necessitating the regeneration phase where the system is bubbled with $\mathrm{CO}_{2}$ and air. For phase transition, adding small amounts of air to the system will shut down the hydrogenase enzyme, ceasing $\mathrm{H}_{2}$ production and directing photosynthesis towards algae mass production.

During the production phase, the carbon dioxide production from respiration will rapidly saturate the process water and be released into the headspace. This $\mathrm{CO}_{2}$ will be removed from of the product gasses using a PSA and then returned to other beds in the system that are in growth phase, and thus need $\mathrm{CO}_{2}$ (the individual raceways will be staggered so that not all of them will be in the same phase of the cycle at once). Data has indicated that a system like this can engage in continuous hydrogen production for 80-100 hours. Experimental data are lacking for hydrogen production rates since research is ongoing and data has yet to be published. Theoretically, while in hydrogen production mode, the sulfate permease mutant could convert $100 \%$ of photoelectrons into $\mathrm{H}_{2}$ production without any loss or competition with other processes. However, the maximal 12.2\% STH efficiency of the photohydrogen production must be averaged over both phases, and thus is reduced by a factor of 3/7, given the need for a 3-day hydrogen production period followed by a 4-day recovery and regeneration period.

Photobiological System B-3 is modeled by the following reactions:

$\mathrm{H}_{2}$ Production Phase

$\mathrm{H}_{2}$ Production Reaction: $\quad 2 \mathrm{H}_{2} \mathrm{O}+$ Light Energy $\rightarrow 2 \mathrm{H}_{2}+\mathrm{O}_{2}$

Respiration Reaction: $\quad 6 \mathrm{O}_{2}+\mathrm{C}_{6} \mathrm{H}_{12} \mathrm{O}_{6} \rightarrow 6 \mathrm{CO}_{2}+6 \mathrm{H}_{2} \mathrm{O}$

Growth/Regeneration Phase:

Photosynthesis Reaction: $6 \mathrm{CO}_{2}+6 \mathrm{H}_{2} \mathrm{O}+$ Light Energy $\rightarrow \mathrm{C}_{6} \mathrm{H}_{12} \mathrm{O}_{6}+6 \mathrm{O}_{2}$

Respiration Reaction: $\quad 6 \mathrm{O}_{2}+\mathrm{C}_{6} \mathrm{H}_{12} \mathrm{O}_{6} \rightarrow 6 \mathrm{CO}_{2}+6 \mathrm{H}_{2} \mathrm{O}$

The inputs and outputs of the system for both production and growth phase are depicted in Figure 2-9. 
Figure 2-9. Sulfate Permease Process

Hydrogen Production Phase

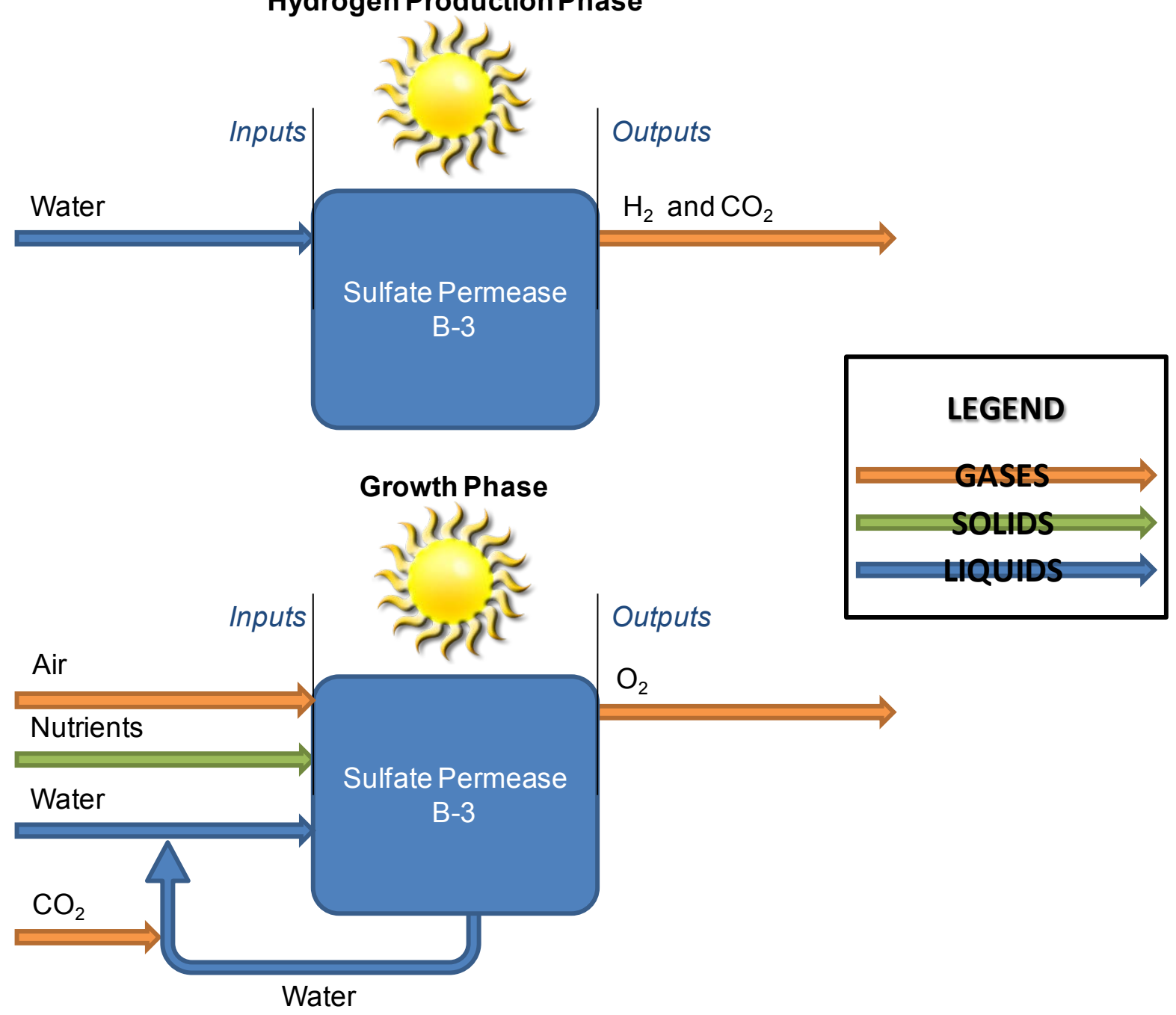

\subsection{Immobilized sulfate-deprived green algae (B-4)}

In this photobiological pathway the basic system concept utilizes mutant, truncated-antenna Chlamydomonas reinhardtii algae. It involves use of a designated bed for algal growth followed by immobilization of the algae by attachment to a thin film in the growth bed. The film with immobilized algae is transferred to a production bed for the $\mathrm{H}_{2}$ production mode, which is initiated by sulfur deprivation. Sulfur deprivation leads to the gradual and reversible reduction of $\mathrm{O}_{2}$ evolution in algae. As the rate of $\mathrm{O}_{2}$ evolution falls below the rate of oxidative respiration, the system goes anaerobic, leading to $\mathrm{H}_{2}$ production. The benefit of thin film immobilization is a substantial increase in duration of the $\mathrm{H}_{2}$ production mode as compared to non-immobilized sulfate-deprived algae systems due to the reduced energy requirements of the cells for movement and increased cell density. Unlike the B-1 and B-2 pathways, the immobilized system has been successfully tested in a laboratory environment. 
Data for the immobilized, sulfate-deprived green algae are based on an NREL study by Kosourov and Seibert ${ }^{37}$. The NREL study utilized a thin alginate film as the immobilization substrate; however other types of films have also been used in analogous applications. For example, nitrogen-fixing blue-green algae have been attached using their heterocyst cells to cellulose sheets and to spunbond and meltblown polypropylene web sheets for use in stimulating agricultural plant growth ${ }^{38}$. In order to improve the affinity of the algae to the polypropylene film, the film surface energy will probably need to be increased to a level of 40 dynes/cm using corona treatment, or an alternative material having higher inherent surface energy, such as polyester can be used. With any man-made polymer, it is ultraimportant to steam clean or otherwise treat the material to eliminate the manufacturing process substances that would be deleterious to the algae.

In other research work, cyanobacteria have been immobilized on polyurethane foam sheets (as well as alginate) for hydrogen production purposes at King's College in London ${ }^{39}$. As noted therein, polyurethane foam was also used to immobilize the algae Chlorella vulgaris.

In this report, we have chosen to use meltblown polypropylene web sheets for minimum cost immobilization. The Kosourov report uses an alginate/plastic screen configuration. This alginate has advantages if the immobilized algae are later used in a fermentation process, since the alginate film will also ferment. However, the higher cost of the screen along with the cost associated with impregnating the screen with alginate increases the levelized hydrogen cost of the B-4 system. Conversations with NREL have also indicated that on substrates other than alginate, hydrogen production periods of up to six months can be maintained with the addition of minimal amounts of sulfur ${ }^{40}$. This increase in hydrogen production time will reduce the labor requirement for film replacement.

As with the B-3 system, there will be a hydrogen production phase followed by a growth/regeneration phase in which the concentration and mass of algae will increase enough to allow adequate starch for the respiration necessary to keep the system anaerobic during the production phase. This growth/regeneration phase will be triggered by the addition of sulfur to the nutrient medium. Sulfur deprivation will then be used to trigger the hydrogen production phase. At the end of a two day hydrogen production phase, the concentration of algae will be at $1.81 / \mathrm{L}$, the concentration needed for the necessary mass growth to allow enough respiration for anaerobic hydrogen production. Also like the B-3 system, the beds will be staggered to allow excess $\mathrm{CO}_{2}$ separated through PSA to be added to a slip stream of water removed from raceways during the regeneration phase. After 180 days of cycling between growth and production, the algae films will need replacement from mats being created in the two designated growth beds.

37 Kosourov, Sergey N. and Michael Seibert. Hydrogen Photoproduction by Nutrient-Deprived Chlamydomonas reinhardtii Cell Immobilized within Thin Alginate Films under Aerobic and Anaerobic Conditions. Basic Sciences Center, NREL, Golden Colorado. 16 June 2008.

${ }^{38}$ U.S. Patent 4,879,232, Nov 7, 1989, "Multilayered Structure Containing Immobilized Blue-Green Algae".

39 Muallem, Bruce, and Hall, "Photoproduction of $\mathrm{H}_{2}$ and $\mathrm{NADPH}_{2}$ by Polyurethane Immobilized Cyanobacteria", King's College, London.

40 Private communication with Dr. Mike Seibert of NREL, 29 May 2009. 
Theoretically, the algae can be separated from the binder and rejuvenated but, since the algae growth costs are low, it is not worth the complexity of the separation system. Figure 2-10 shows the growth and production modes of this pathway.

Figure 2-10. Immobilized Sulfur Deprived Process

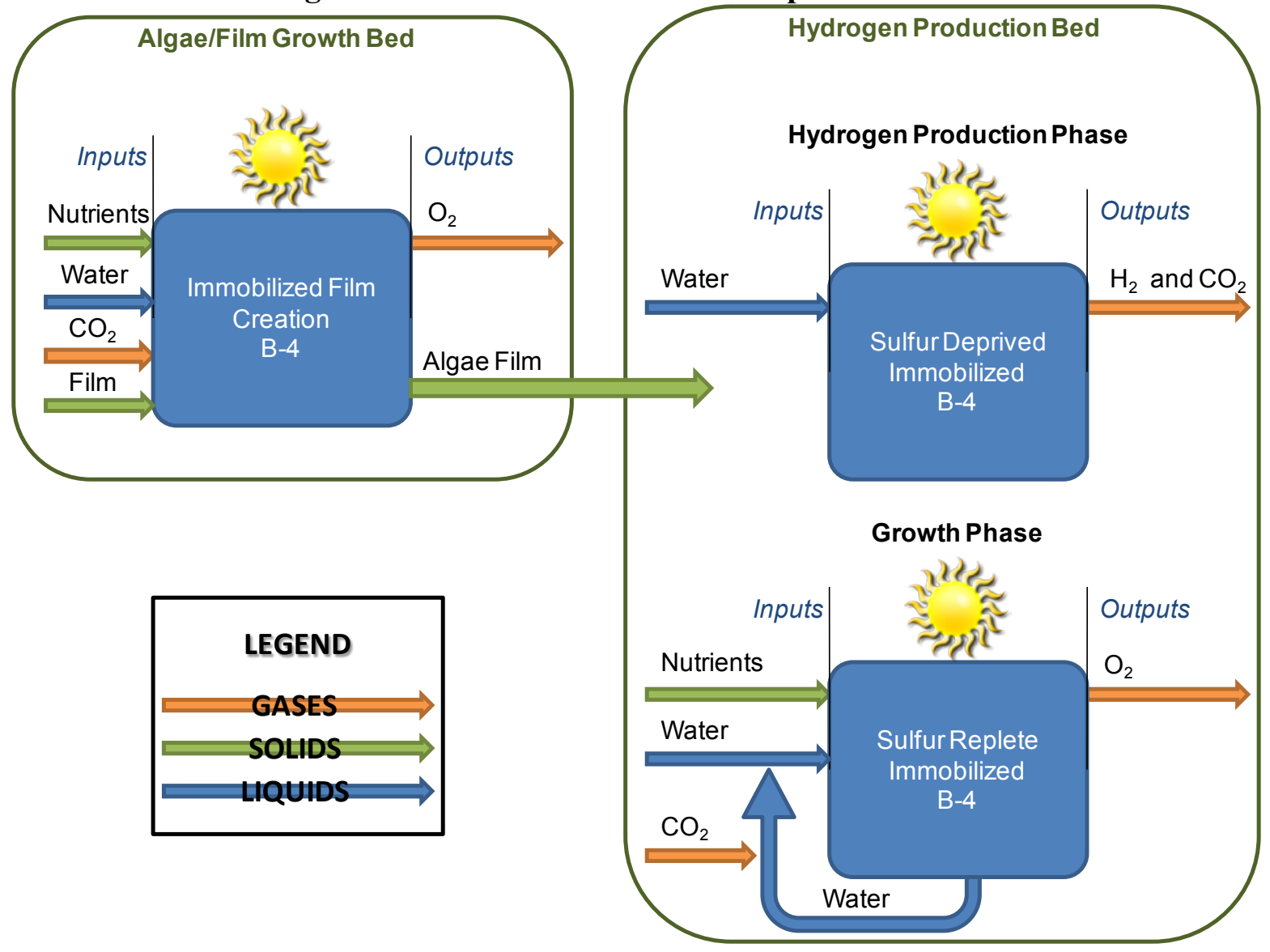

In this system we assume the same growth rate as other Chlamydomonas systems. To ensure that the growth beds are fully utilized, we will use two algae film/growth beds to produce algae for the 68 production beds. The $\mathrm{H}_{2}$ production cycles of each bed will be staggered appropriately, so that each day the growth beds will be utilized to replenish a spent production bed.

Compared to $\mathrm{O}_{2}$-tolerant algal systems (B-1, B-2), cellular maintenance energy requirements are substantially lower due to the immobilization of the algae on thin films. The theoretical STH efficiency is 3\%; however, the laboratory tests have only achieved $0.8 \% \mathrm{STH}$ efficiency ${ }^{37}$. Since this is an actual data point, it is not reasonable to compare it to other systems that only have theoretical values. For comparison purposes we will use the STH efficiency of the assumed reactor operation of $2.25 \%$, due to the one day of production for every three days of growth. 
Photobiological System B-4 is modeled by the following reactions:

$\mathrm{H}_{2}$ Production Phase

$\mathrm{H}_{2}$ Production Reaction: $\quad 2 \mathrm{H}_{2} \mathrm{O}+$ Light Energy $\rightarrow 2 \mathrm{H}_{2}+\mathrm{O}_{2}$

Respiration Reaction: $\quad 6 \mathrm{O}_{2}+\mathrm{C}_{6} \mathrm{H}_{12} \mathrm{O}_{6} \rightarrow 6 \mathrm{CO}_{2}+6 \mathrm{H}_{2} \mathrm{O}$

Growth Phase:

Photosynthesis Reaction: $\quad 6 \mathrm{CO}_{2}+6 \mathrm{H}_{2} \mathrm{O}+$ Light Energy $\rightarrow \mathrm{C}_{6} \mathrm{H}_{12} \mathrm{O}_{6}+6 \mathrm{O}_{2}$

Respiration Reaction: $\quad 6 \mathrm{O}_{2}+\mathrm{C}_{6} \mathrm{H}_{12} \mathrm{O}_{6} \rightarrow 6 \mathrm{CO}_{2}+6 \mathrm{H}_{2} \mathrm{O}$

\subsection{Purple non-sulfur bacteria (B-5)}

Unlike the carbon-fixing organisms in the previous systems, these bacteria are photoheterotrophic, nitrogen-fixing organisms. Under anaerobic conditions and using simple organic acids or glycerol as an electron donor, these bacteria produce hydrogen gas from the light driven, ATP-dependent reduction of protons to $\mathrm{H}_{2}$ in the absence of nitrogen ${ }^{41}$. In this mode they require removal of $\mathrm{N}_{2}$ and $\mathrm{O}_{2}$ and require a supply of organic acids. The photosynthetically active radiation, or PAR, for purple bacteria is $400-950 \mathrm{~nm}$, compared to $400-700 \mathrm{~nm}$ for green algae. However, the PNS organism requires 11 to 15 photons (depending on wavelength) per hydrogen molecule rather than the 4 photons required in the algal systems. As a result of the wavelength energy span and the required photon ratio, the maximum solar-to-hydrogen conversion efficiency is $6.5 \%$. Due to the $3 \%$ of photons needed for cell maintenance, the assumed reactor $\mathrm{STH}$ is $3.5 \%$.

Since the PAR wavelength of PNS is shifted relative to algae, there is an opportunity to capture a fuller spectrum of light energy by "stacking" an algae system on top of a PNS system. This concept will be further described in Part IV (System Integration).

Photobiological System B-5 is modeled by the following reactions:

$\mathrm{H}_{2}$ Production Reaction: $\quad \mathrm{C}_{2} \mathrm{H}_{4} \mathrm{O}_{2}+2 \mathrm{H}_{2} \mathrm{O}+$ Light Energy $\rightarrow 2 \mathrm{CO}_{2}+4 \mathrm{H}_{2}$

Fermentation Reaction $^{42}: \quad 2 \mathrm{C}_{6} \mathrm{H}_{12} \mathrm{O}_{6}+2 \mathrm{H}_{2} \mathrm{O} \rightarrow 5 \mathrm{C}_{2} \mathrm{H}_{4} \mathrm{O}_{2}+2 \mathrm{CO}_{2}+4 \mathrm{H}_{2}$

Growth Reaction ${ }^{43}$ : $\quad 3 \mathrm{C}_{2} \mathrm{H}_{4} \mathrm{O}_{2} \rightarrow\left(\mathrm{C}_{5} \mathrm{H}_{8} \mathrm{O}_{2}\right)_{\mathrm{n}}+\mathrm{CO}_{2}+2 \mathrm{H}_{2} \mathrm{O}$

The inputs and outputs of the system are depicted in Figure 2-11.

\footnotetext{
41 Akkerman, Ida, Marcel Janssen, Jorge Rocha, Rene H. Wijffels. Photobiological hydrogen production: photochemical efficiency and bioreactor design. International Journal of Hydrogen Energy. Vol 27, p 11951208. 2002.

42 The fermentation reaction produces additional hydrogen as well as organic acids (here modeled as acetate). However, it doesn't produce these in appreciable quantities and is thus ignored in this analysis.

43 The actual PNS growth reaction is complex and involves ammonia $\left(\mathrm{NH}_{3}\right)$ and multiple intermediaries. For simplicity and clarity, we base our analysis on the displayed simplified net reaction. This photosynthesic growth reaction produces a variety of organic products, including the glucose utilized in fermentation. Ashing analysis (from Van Gemerden H. 1968. Utilization of reducing power in growing cultures of Chromatium. Arch. Mikrobiol. 64:111) shows that the molecular ratio is represented as $\left(\mathrm{C}_{5} \mathrm{H}_{8} \mathrm{O}_{2}\right)_{\mathrm{n}}$.
} 
Figure 2-11. Purple Non-Sulfur Bacteria Process

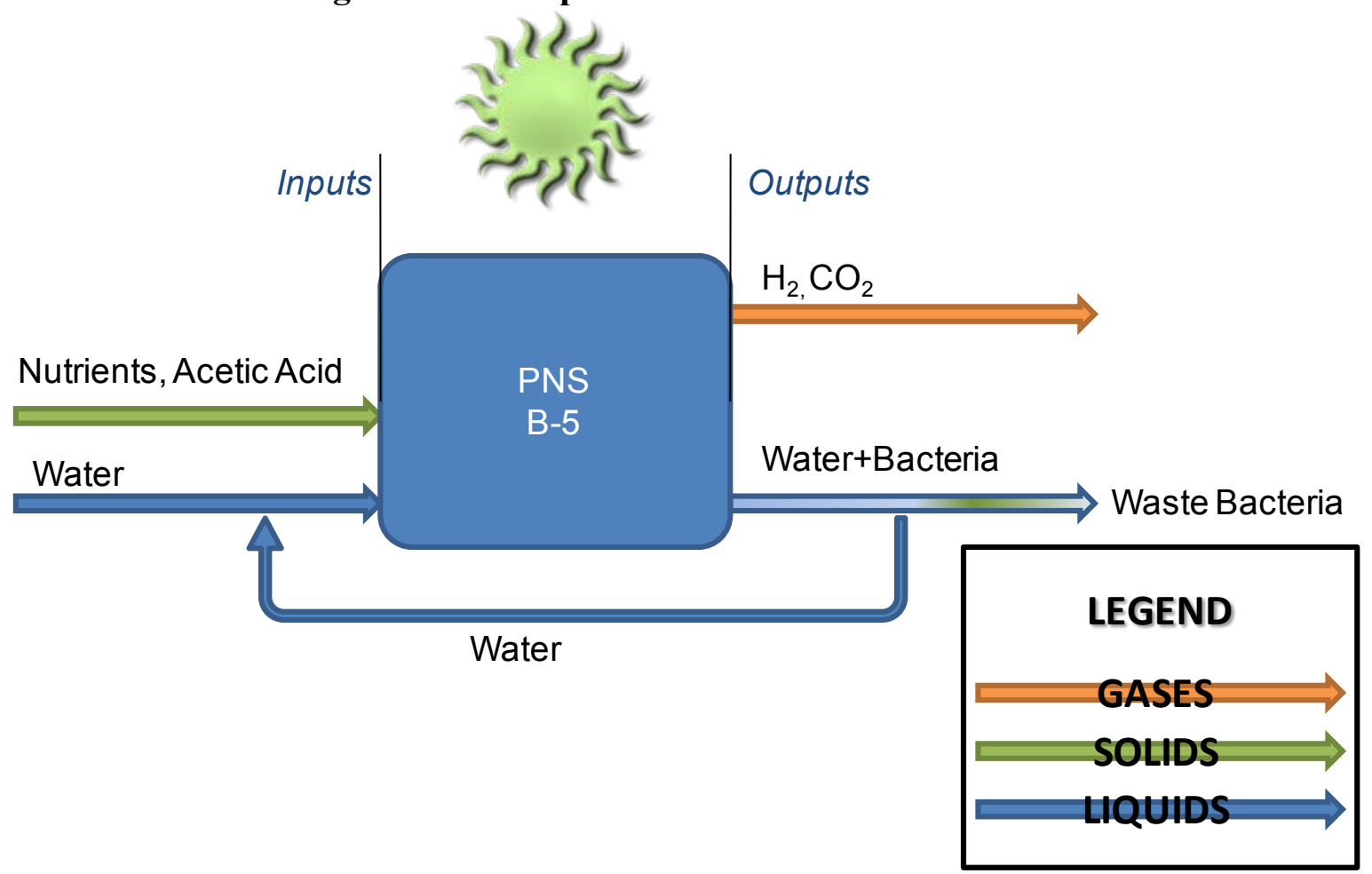

\section{Engineering Parameters}

The production plant has been divided into the Photobiological Reactor Bed and 4 auxiliary or balance of plant (BOP) subassemblies, namely,

- Organism Feed Subassembly,

- Recycle Subassembly,

- Gas Capture Subassembly, and

- Control System Subassembly

The interfaces between the primary system and its BOP subassemblies are shown in Figure 3-1. Each subassembly is depicted in a different color. The Photo Bio Reactor Bed can take on several forms. The subassemblies have several components that will be identified in later sections of this document. 
Figure 3-1. Simplified Photobiological Hydrogen Production Plant

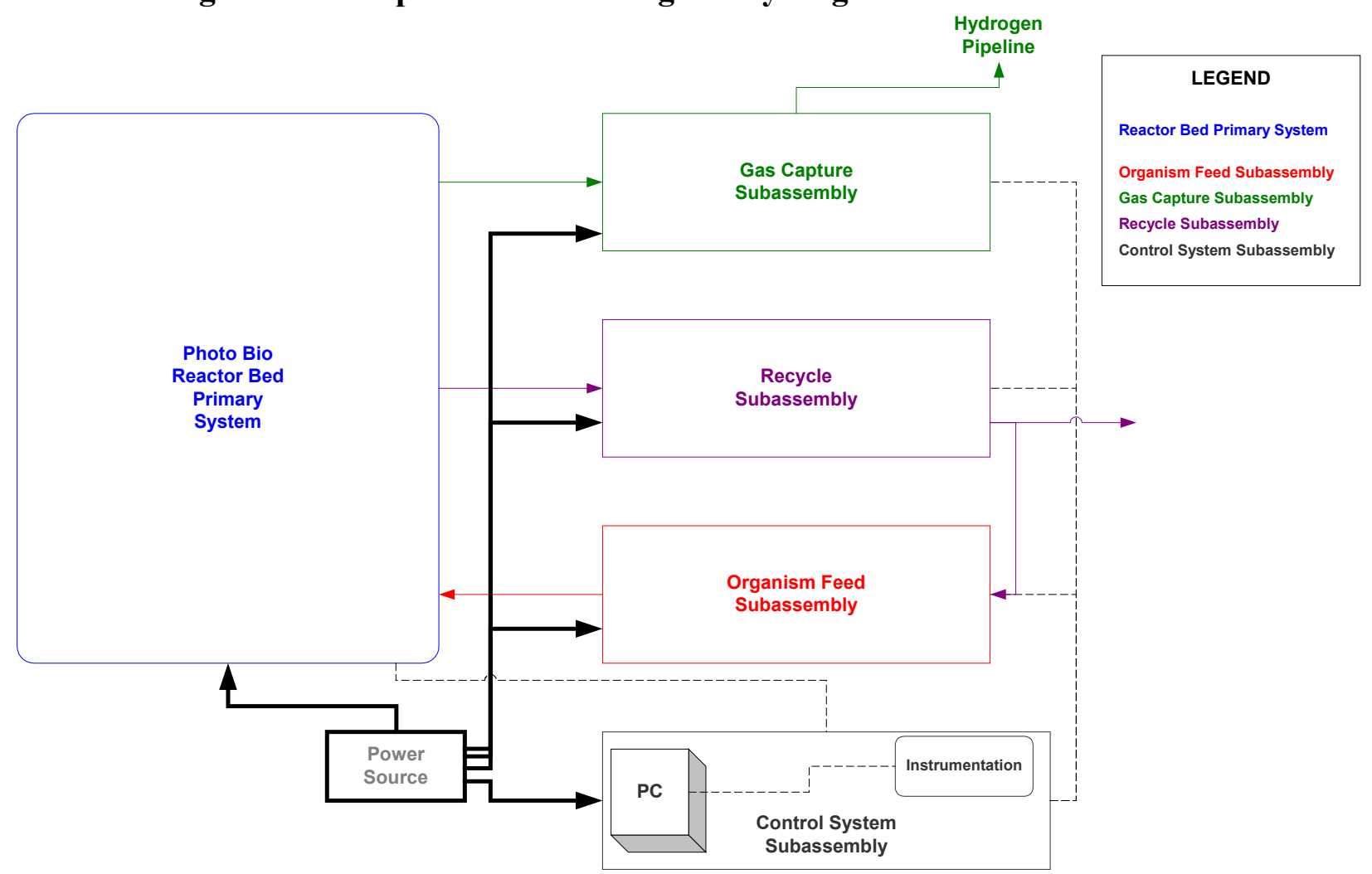

A modular design philosophy was used in the design of the production plant. Each function that needs to be performed in the plant is treated as an independent subassembly and is sized appropriately so that multiple systems can be arranged in parallel within a production plant. The subassemblies are designed such that a single module produces $1,000 \mathrm{kgH}_{2} /$ day at the boundary limits of the production facility. As will be discussed in the results section, the baseline cost estimates correspond to a 10 tonne/day plant consisting of ten $1,000 \mathrm{kgH}_{2} /$ day modules.

\subsection{Photo Bio Reactor Bed (Primary System)}

Several designs for reactors beds have been developed to enhance performance of these photobiological systems. Each system has both strengths and weaknesses. Our study reviewed four different forms for reactor beds. Each form was then applied to a specific organism to determine which was more or less suitable for the different algae and bacteria. The reactor bed form was selected based on the author's initial judgment of cost effectiveness and because an analysis of all five pathways with all bed form options was beyond the scope of the project.

\subsubsection{Single Reactor Bed}

The simplest form for a bed is the single reactor. In this bed there is one pond where all photobiological processes occur. The processes occur sequentially, not simultaneously. Thus, if algae are in the growth phase they cannot produce hydrogen and vice versa. The strengths and weaknesses of this system are listed in Figure 3-2. 
Figure 3-2. Strengths and Weaknesses of Single Bed Reactors

\section{Single Bed Reactor Design}

\begin{tabular}{|ll|}
\hline \multicolumn{1}{|c|}{ Strengths } & \multicolumn{1}{c|}{ Weaknesses } \\
\hline $\begin{array}{l}\text { Organisms are working at their most } \\
\text { efficient point during each process. }\end{array}$ & Batch process \\
\hline Single pond; less area, lower cost & $\begin{array}{l}\text { Time split between production and growth } \\
\text { not most efficient. }\end{array}$ \\
\hline & $\begin{array}{l}\text { Requires more area for a given hydrogen } \\
\text { production }\end{array}$ \\
\hline
\end{tabular}

A conceptual design of the single reactor bed is shown in Figure 3-3. The blue box represents the reactor bed. The dotted line separates the different processes that occur in the same bed but at different times. The organisms transition from one photobiological process to another by a manipulation of the inputs and climate conditions. Sunlight is required during both photobiological phases.

\section{Figure 3-3. Conceptual Design: Single Bed Reactors}

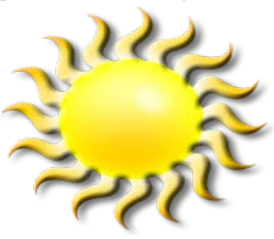

Duration: Phase 2 = Phase 1

\section{Single Bed Reactor}

\subsubsection{Dual Reactor Bed}

The next form for a bed is the dual reactor. In this reactor there are two ponds; one where all photobiological growth occurs and another where photobiological hydrogen production occurs. Because there are separate beds for each process, growth and production can occur simultaneously. The strengths and weaknesses of this system are listed in Figure 3-4. 
Figure 3-4. Strengths and Weaknesses of Dual Bed Reactors

\section{Dual Bed Reactor Design}

Strengths

Simultaneous growth and production

Growth and production bed sizes can be

optimized for maximum utilization

No mixing of nutrients or gases from

production and growth stages

Weaknesses

Cost of two reactor beds

Batch process

Large flow pumps required under

intermittent operation (transfer process)

A conceptual design of the dual reactor bed is shown in Figure 3-5. The blue boxes represent the reactor beds. The organisms are transferred from the growth reactor bed to the production bed when the colony reaches a given concentration. Although growth and production occur simultaneously this is still essentially a batch process. Sunlight is required during both photobiological phases. This dual bed concept is useful when growth and production conditions are different, such as when growth can occur aerobically but production cannot.

Figure 3-5. Conceptual Design of Dual Bed Reactors

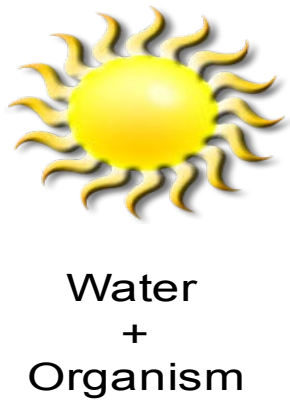

Batch

\section{Dual Bed Reactor}

\subsubsection{Chemostat Reactor Bed}

A chemostat system requires two reactor beds. Like the dual bed reactor, there is one pond where all photobiological growth occurs and another where photobiological hydrogen production occurs. Because there are separate beds for each process, growth and production occurs simultaneously. A chemostat system seeks to maintain a constant volume in the reactor bed. This is accomplished by a continuous slip stream of volume being removed while simultaneously being replenished from the growth reactor bed. The volume of slip stream is computed such that the hydrogen production is constant. Because of the constant volume criteria, chemostat reactors continuously grow algae and produce hydrogen (as long as sunlight is available). The strengths and weaknesses of this system are listed in Figure 3-6. 
Figure 3-6. Strengths and Weaknesses of Chemostat Bed Reactors

\begin{tabular}{|ll|}
\multicolumn{1}{|c|}{ Strengths } & \multicolumn{1}{c|}{ Weaknesses } \\
\hline $\begin{array}{l}\text { Simultaneous and continuous growth and } \\
\text { production }\end{array}$ & Large slip stream volumes of up to 25\% /day \\
\hline Isolation of growth and production products & $\begin{array}{l}\text { No means of selectively separating algae } \\
\text { such that slip stream contains waste algae }\end{array}$ \\
\hline $\begin{array}{l}\text { Smaller pumps required and operate } \\
\text { continuously (their preferred mode) }\end{array}$ & \\
\hline
\end{tabular}

A conceptual design of the chemostat reactor bed is shown in Figure 3-7. Conceptually, the chemostat form looks identical to the dual reactor bed however the water + organism flow between the two reactors is continuous rather than intermittent. Sunlight is required during both photobiological phases.

Figure 3-7. Conceptual Design of Chemostat Bed Reactors
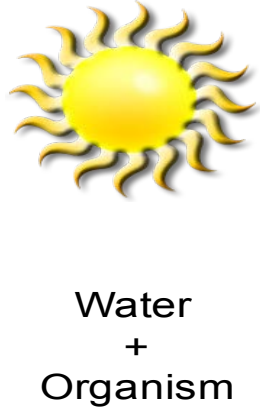

Continuous

\section{Chemostat Bed Reactor}

\subsubsection{Chemostat II Reactor Bed}

The Chemostat II's chief characteristic is a single reactor bed that, after the initial growth of the colony, is used simultaneously for both growth and production. The system operates similarly to a chemostat system however it does so in a single reactor bed. During initial growth no production occurs. The bed is filled with the appropriate nutrients required for algae colony to achieve a target algal concentration. Afterwards, climate conditions are adjusted such that algae grow at a $1 / 4$ of their normal rate and maintain cell functions while producing hydrogen.

In $\mathrm{H}_{2}$ production mode, the organisms use a limited amount of their energy to complete cell maintenance functions and the remainder of the energy is spent producing hydrogen. By simultaneously doing growth and production, the Chemostat II system allows for continuous hydrogen production without having to stop and replenish algae. The strengths and weaknesses of this system are listed in

Figure 3-8. 
Figure 3-8. Strengths and Weakness of Chemostat II Bed Reactors

\section{Chemostat II Bed Reactor Design}

Strengths

Weaknesses

Single pond; less area, lower cost

Continuous supply of nutrient may result in diluted product stream

Lower nutrient requirement

A conceptual design of the Chemostat II reactor bed is shown in Figure 3-9. The Chemostat II looks similar to the single bed reactor, however growth and production occur simultaneously and continuously. Sunlight is required during both the growth and reduced growth with production processes.

Figure 3-9. Conceptual Design of Chemostat II Bed Reactors

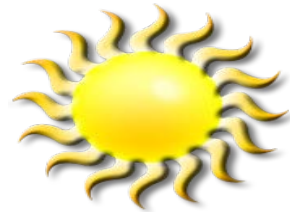

Duration: Phase $2>$ Phase 1

\section{Chemostat II Bed Reactor}

For this system to be feasible the number of days spent growing the culture must be insignificant when compared to the number of hydrogen production days. The colony concentration will increase slightly every hour and therefore a slip stream of the algal solution will be removed from the bed on a continuous basis. As that stream is being drawn, the reactor bed will be dosed with additional water and nutrients to maintain the colony at constant concentration, size, and $\mathrm{pH}$ levels.

\subsubsection{Reactor Bed Embodiment}

The reactors forms were mapped against the biological parameters of each photobiological system and the best form was selected for each process. The forms selected are listed in Figure 2-1. A complete bill of materials for each pathway is provided in section 4 of this report. Here is included a lengthy description of the physical embodiment of these reactor beds. The components of the reactor bed are described and materials selected for the bed are listed in this section. 
A reactor bed could be open or closed to the environment. While an open pond would provide direct access to sunlight, it also leaves our algae colony susceptible to contamination and provides no means of collecting the production hydrogen. A closed pond with a translucent cover allows light to penetrate while protecting the algae from weather conditions (wind, temperature) that may harm them. It also contains any gases produced by the algae. For these reasons all reactor beds in this analysis will be of the closed pond variety.

The reactor bed serves 4 basic functions: fluid containment, product gas containment, access to sunlight, and algal mixing (to avoid stratification). The bed can be a single monolithic structure, such as a pond, or several smaller beds, such as raceways, connected by a piping system. Since typical reactor bed areas are quite large $\left(\sim 20-87\right.$ acres for a $\left.1,000 \mathrm{kgH}_{2} / \mathrm{day}\right)$, a modular concept was chosen where the reactor bed is comprised of smaller raceways. This facilitates ease of access, ease of maintenance, isolation of any contaminants, and economies of scale in equipment purchases. The reactor bed is sketched in Figure 3-10 and the components are listed in Figure 3-11.

The reactor bed we have chosen is comprised of several raceways, each measuring between $1060^{\prime}$ and 1090' in length, 40' in width, and $10 \mathrm{~cm}$ in depth. Raceways are designed in an oval shape so that a system of paddlewheels creates a flow in the bed to evenly disperse nutrients and prevent cell coagulation. Each raceway has inlet and outlet ports for the slurry and a separate outlet port for the product gases. Raceway widths are limited by the translucent film dimensions. The film is attached to a frame to maintain a gas-tight seal in the system. Driveways are interspersed between the raceways to provide vehicular access. The quantity of raceways is driven by daily hydrogen production rate and STH of the organism. For our systems there will be between 20 and 90 raceways.

In concept B-4, immobilized organisms are grown on an inert mat which floats upon the surface of the raceway. Circulation of the water/nutrient mixture via paddlewheels is not needed nor is it feasible. Consequently, an oval reactor bed is not needed, and a "runway" configuration is instead used. A "runway" is merely a single side of the oval raceway, without the paddlewheels and without fluid connection between the two sides. 
Figure 3-10. Reactor Bed Design

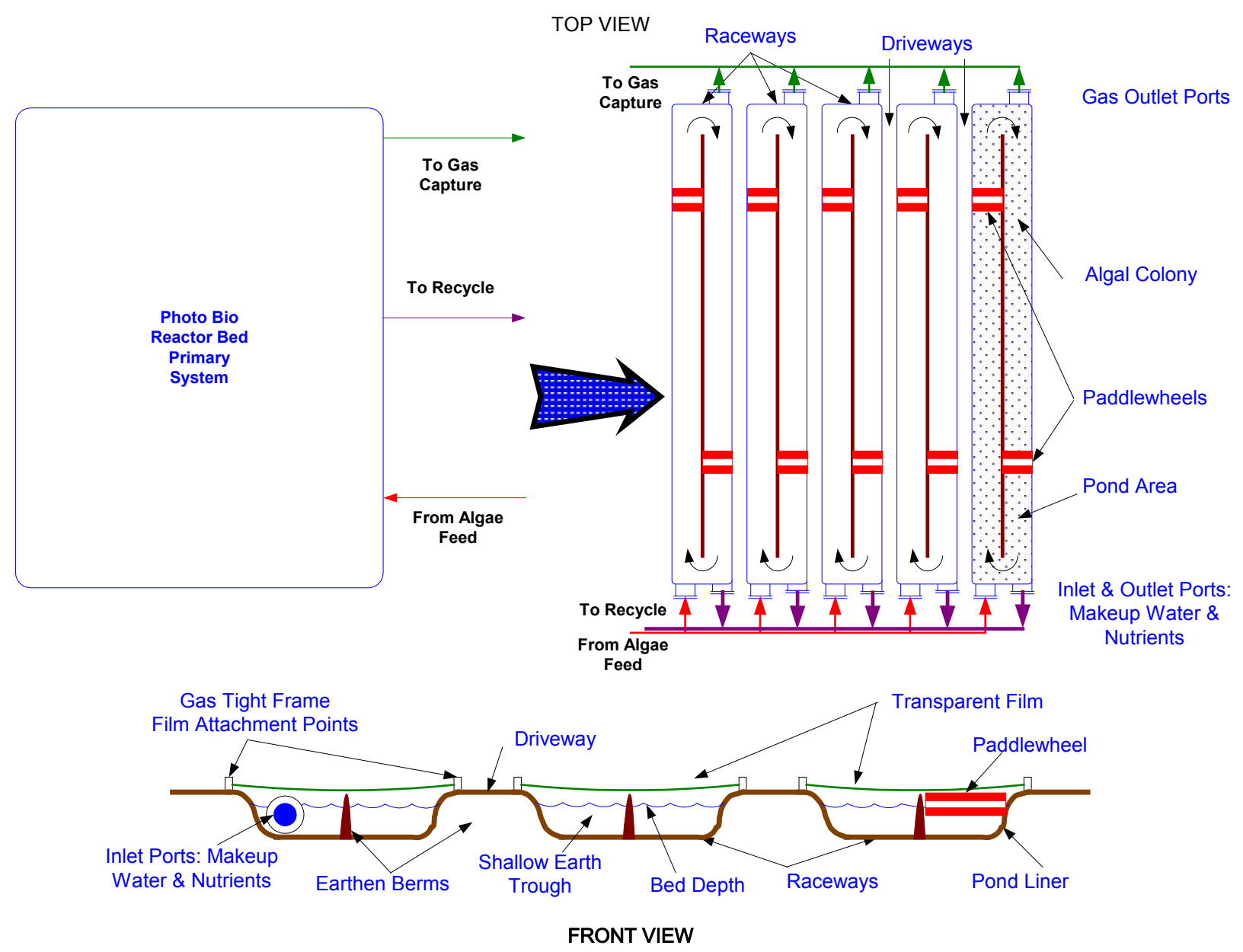

Figure 3-11. Reactor Bed Components

\begin{tabular}{|l|} 
Reactor Bed Components \\
\hline Transparent Film \\
\hline Pond Lining \\
\hline Pond Edging \\
\hline Paddlewheel \& Motor \\
\hline Gas Valves \\
\hline Gas Ports (Flanges) \\
\hline Water Valves \\
\hline Water Ports (Flanges) \\
\hline
\end{tabular}

\subsubsection{Films, Edging, and Lining}

In the Front View one can see that the bed itself is not made with any solid materials but rather shaped from earthen berms and lined with a suitable pond liner material that will keep the system gas tight. Pond liner material is available in roll sizes of $50^{\prime} \mathrm{x} 100^{\prime}$ on www.justliners.com. To achieve the necessary pond dimensions the material will be heatsealed to itself, which is a common practice when creating any kind of retention pond. 
Above the raceways a low density polyethylene (LDPE) transparent film $(6 \mathrm{~mm})$ is used to allow sunlight in and keep the product hydrogen gas from escaping. A presentation from Daniel Blake at NREL concerning Hydrogen reactor development indicates that the hydrogen permeability coefficient for polyethylene is fairly low (near 200

$\mathrm{cm}^{3} \bullet \mathrm{mm} / \mathrm{m}^{2} \bullet$ atm $\bullet$ day $)^{44}$. Based on our calculations, show in Figure $3-12$, the volume of hydrogen lost through the film is negligible.

Figure 3-12. Polyethylene Hydrogen Losses

\begin{tabular}{|c|c|c|c|c|c|}
\hline \multicolumn{6}{|c|}{ Polyethylene Hydrogen Losses } \\
\hline & Units & $\mathrm{B} 1 / \mathrm{B} 2$ & B3 & B4 & B5 \\
\hline Hydrogen Permeability Coefficient & $\begin{array}{c}\mathrm{cm}^{3} \bullet \mathrm{mm} / \mathrm{m}^{2} \bullet \\
\text { atm } \bullet \text { day }\end{array}$ & 200 & 200 & 200 & 200 \\
\hline Total Area & $\mathrm{m}^{2}$ & 80,968 & 151,035 & 352,070 & 216,228 \\
\hline Film Thickness & $\mathrm{mm}$ & 6 & 6 & 6 & 6 \\
\hline Partial Pressure Differential & atm & 0.67 & 1.00 & 1.00 & 0.95 \\
\hline $\mathrm{kg} / \mathrm{cm}^{3}$ Hydrogen & & 0.00000009 & 0.00000009 & 0.00000009 & 0.00000009 \\
\hline $\mathrm{H}_{2}$ lost & $\mathrm{kg} /$ day & 0.16 & 0.45 & 1.06 & 0.61 \\
\hline$\% \mathrm{H}_{2}$ lost from system & $\%$ & $0.016 \%$ & $0.045 \%$ & $0.106 \%$ & $0.061 \%$ \\
\hline
\end{tabular}

According to conversations with Berry Plastics, the LDPE film allows $90 \%$ of available light through. It is available in rolls 56' wide and more than 1000' long and, therefore, a single continuous roll is able to stretch over an entire raceway ${ }^{45}$. The film attaches to a frame structure along the edges of the raceway so that a gas tight compartment is formed. Notice that the film is not taught over the top of the berms, but rather is slack. This is to allow for variations in hydrogen production rate which is expected with varying solar insolation. The number of raceways for a given reactor bed will depend on hydrogen production rate. Thus far it appears that the limiting factor is the width of the transparent roll sizes. We do not want to bond multiple sheets of LDPE as it will only provide additional leakage points for our product gas.

The Pond Edging envisioned would be a mechanical fixture that would seal the transparent film to the pond lining as shown in Figure 3-13.

\footnotetext{
44 Blake, Daniel M. "Hydrogen Reactor Development and Design for Photofermentation and Photolytic Processes". NREL Project PD19. May 23-26, 2005.

45 Agriculture Films by Berry Plastics. http://www.covalenceplastics.com/site/content/agricultural/agricultural.asp\#gh. Date Accessed 18 July 2008.
} 


\section{Figure 3-13. Film-Frame interface point \\ Gas Tight Frame \\ Film Attachment Points}

Inlet Ports: Makeup

Water \& Nutrients

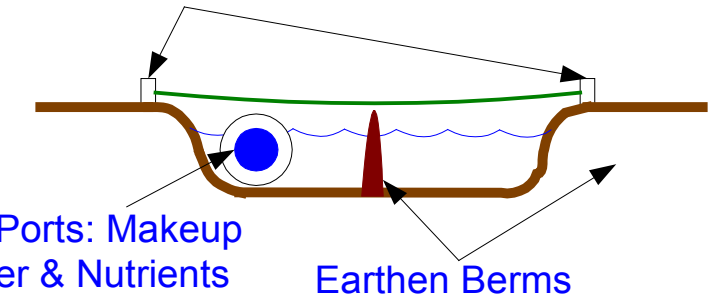

\subsubsection{Paddlewheel Mixers}

Two paddlewheels and a center berm are located in each raceway to provide circulation of the algae solution for proper mixing. The paddlewheel mixer would look similar to a water wheel at a mill. Our analysis for the amount of mixing necessary is based on typical mixing parameters for algal growth in the biodiesel industry. Using that data and resizing to our raceway configuration, we obtained comparable parameters which are listed in Figure 3-14. Paddlewheels with higher flow rates of up to $60 \mathrm{~cm} / \mathrm{s}$ and larger may be necessary to assist in the thermal control of the pond. ${ }^{46}$ The B-4 system consists of immobilized mats of algae, and, therefore, will not need paddlewheels for mixing. The nutrients will be provided through a perforated PVC tube that travels the length of the raceway to ensure adequate nutrient dispersal.

\begin{tabular}{l} 
Figure 3-14. Paddlewheel Electrical Requirements \\
\begin{tabular}{|lrl|}
\hline \multicolumn{3}{|c|}{ Biodiesel Equipment for Algal Growth } \\
\hline Algae Concentration & $1 \%$ & volume of pond \\
\hline Flowrate & $20 \mathrm{~cm} / \mathrm{s}$ \\
\hline Pond Size & $1000 \mathrm{~m}^{2}$ \\
\hline Paddle Wheel (single) & $1.23 \mathrm{kWh} /$ day \\
\hline
\end{tabular} \\
Source: http://www.bioking.lv/algae cultivated in raceway ponds.html \\
\hline
\end{tabular}

\begin{tabular}{|c|c|c|}
\hline \multicolumn{3}{|c|}{ Reactor Raceway } \\
\hline Algae Concentration & 0.02 & volume of pond \\
\hline Flowrate & 20 & $\mathrm{~cm} / \mathrm{s}$ \\
\hline Pond Size & 4050 & $\mathrm{~m}^{2}$ \\
\hline Size Factor & 4.05 & \\
\hline Paddle Wheel (two) & 2.46 & kWh/day \\
\hline
\end{tabular}

\subsubsection{Ports and Valves}

In the Top View of Figure 3-10 one can see that the bed is made up of several raceways, each with an inlet and two outlet ports. At each of these ports are manual valves to isolate individual raceways or regulate the flow to or from each raceway. From our research it is possible for the daily water level drop due to evaporation to be as much as $6.2 \mathrm{~mm}$ for a

\footnotetext{
${ }^{46}$ R. Vitale. Waterwheel Factory Inc. Telephone Interview. 08 October 2008.
} 
$1,000 \mathrm{~m}^{2}$ pond. $^{47}$ This would translate into makeup water requirements of $28.8 \mathrm{~m}^{3} /$ day in our raceway without including the slip stream flow rates that are part of the Chemostat II and Chemostat reactor bed forms. In this subassembly we only consider the costs of the flanges and valves. All piping runs are accounted for in the subassemblies they support.

\subsubsection{Capital Costs}

The materials selected and unit costs of the components are listed in Figure 3-15. The plant is anticipated to operate for 20 years. However, the transparent film is susceptible to UV damage which causes the film to haze and thereby become non-transparent. Thus the costs of that material shown below are only for the initial material. Replacements costs of the film are considered an operational expense. In our cost analysis (to be described) we will assume the polyethylene is good for 5 years. All other components of this subassembly are anticipated to last the entire plant life.

${ }^{47}$ http://www.bioking.lv/algae cultivated_in_raceway_ponds.html. Date Accessed 08 October 2008. 


\begin{tabular}{|c|c|c|}
\hline $\begin{array}{l}\text { Reactor Bed } \\
\text { System }\end{array}$ & Material Chosen & Unit Pricing \\
\hline Transparent Film & $\begin{array}{l}\text { Tufflite Brand Products, available up to } 56 \text { ' wide, } \\
\text { Polyethylene, } 4-6 \text { mil } \\
\text { Source: Berry Plastics } \\
\text { (http://www.covalenceplastics.com/site/content/ag } \\
\text { ral.asp\#gh) }\end{array}$ & $\$ \$ 0.54 / \mathrm{m}^{2}$ \\
\hline Pond Lining & $\begin{array}{l}\text { Either Butyl rubber, PVC, or LDPE (low density } \\
\text { polyethylene), } 30-40 \text { mil } \\
\text { Source: }\end{array}$ & $\$ 0.47 / \mathrm{m}^{2}$ \\
\hline Pond Edging & $\begin{array}{l}\text { Hard Plastic } \\
\text { Source: DTI Estimate }\end{array}$ & $\$ 7 / m$ \\
\hline $\begin{array}{l}\text { Paddlewheel Mixer } \\
\text { with Motor }\end{array}$ & $\begin{array}{l}14 \text { blades ( } 6^{\prime} \text { long } \times 6^{\prime \prime} \text { wide), } 3 / 4 \mathrm{hp} \text { motor, capable } \\
\text { of } 1 \mathrm{ft} / \mathrm{s} \text { flow } \\
\text { Source: Waterwheel Factory, Inc. }\end{array}$ & $\$ 5000$ ea. \\
\hline Manual Gas Valve & $\begin{array}{l}\text { IPEX VKD series PVC Ball Valve Part\# VKDBV108, } \\
\text { EPDM/Teflon Seals 2" } \\
\text { Source: } \underline{\text { http://www.valvestore.com }}\end{array}$ & $\$ 67.23$ \\
\hline Manual Water Valve & $\begin{array}{l}\text { IPEX VKD series PVC Ball Valve Part\# VKDBV108, } \\
\text { EPDM/Teflon Seals 2" } \\
\text { Source: http://www.valvestore.com }\end{array}$ & $\$ 43.46$ \\
\hline Water Port & $\begin{array}{l}\text { ISO-QF flange, Schedule } 80 \text { Polyvinyl Chloride, Ref } \\
\text { \#PVC50-SF } \\
\text { Source: http://www.ancorp.com/line.aspx?id=819 }\end{array}$ & $\$ 8$ \\
\hline Gas Port & $\begin{array}{l}\text { ISO-QF flange, Schedule } 80 \text { Polyvinyl Chloride, Ref } \\
\text { \#PVC50-SF } \\
\text { Source: http://www.ancorp.com/line.aspx?id=819 }\end{array}$ & $\$ 8$ \\
\hline Excavation/Installation & $\begin{array}{l}\text { Based on } 5 \text { day excavation, } 6 \text { workers, medium } \\
\text { sized equipment and no dirt removal. } \\
\text { Source: Dept of Labor, Davis Bacon Wage Determin } \\
\text { Rates) \& The Blue Book of Building \& Construction }\end{array}$ & $\begin{array}{l}\$ 26,083 / \text { raceway } \\
\text { ations (CA Labor }\end{array}$ \\
\hline
\end{tabular}

\subsubsection{Heat Exchangers}

The covered reactor area in direct sunlight could increase bed temperatures significantly. Heat exchangers would require large electricity and/or water requirements. In order to keep costs low we are assuming that the earth will provide a sufficient heat sink for this system so no heat exchangers would be required.

\subsection{Organism Feed Subassembly}

The organism feed subassembly provides the necessary nutrients, medium and gases to grow and maintain a hydrogen producing algal or bacteria colony. The components of this subassembly are listed in Figure 3-16 and shown in Figure 3-17. The components of the subassembly can be further specified for a given organism and reactor bed form. A variation of this system will be required in the B-4 pathway, where algae growth beds and hydrogen production beds require different nutrients simultaneously. 
Figure 3-16. Organism Feed Components

\begin{tabular}{|ll|}
$\begin{array}{l}\text { Organism Feed Subassembly } \\
\text { Components }\end{array}$ & $\begin{array}{l}\text { Organism Feed Subassembly } \\
\text { Consumables } \\
\mathrm{CO}_{2}\end{array}$ \\
\hline Nutrient/Fertilizer Tank & Nutrients/Fertilizer \\
\hline Metering Pump & Water (Initial Fill) \\
\hline Mixing Pump & \\
\hline $\mathrm{CO}_{2}$ Cylinder & \\
\hline $\mathrm{CO}_{2}$ Saturation Vessel & \\
\hline Transfer In Pump & \\
\hline Piping & \\
\hline
\end{tabular}

Figure 3-17. Organism Feed Subassembly Design

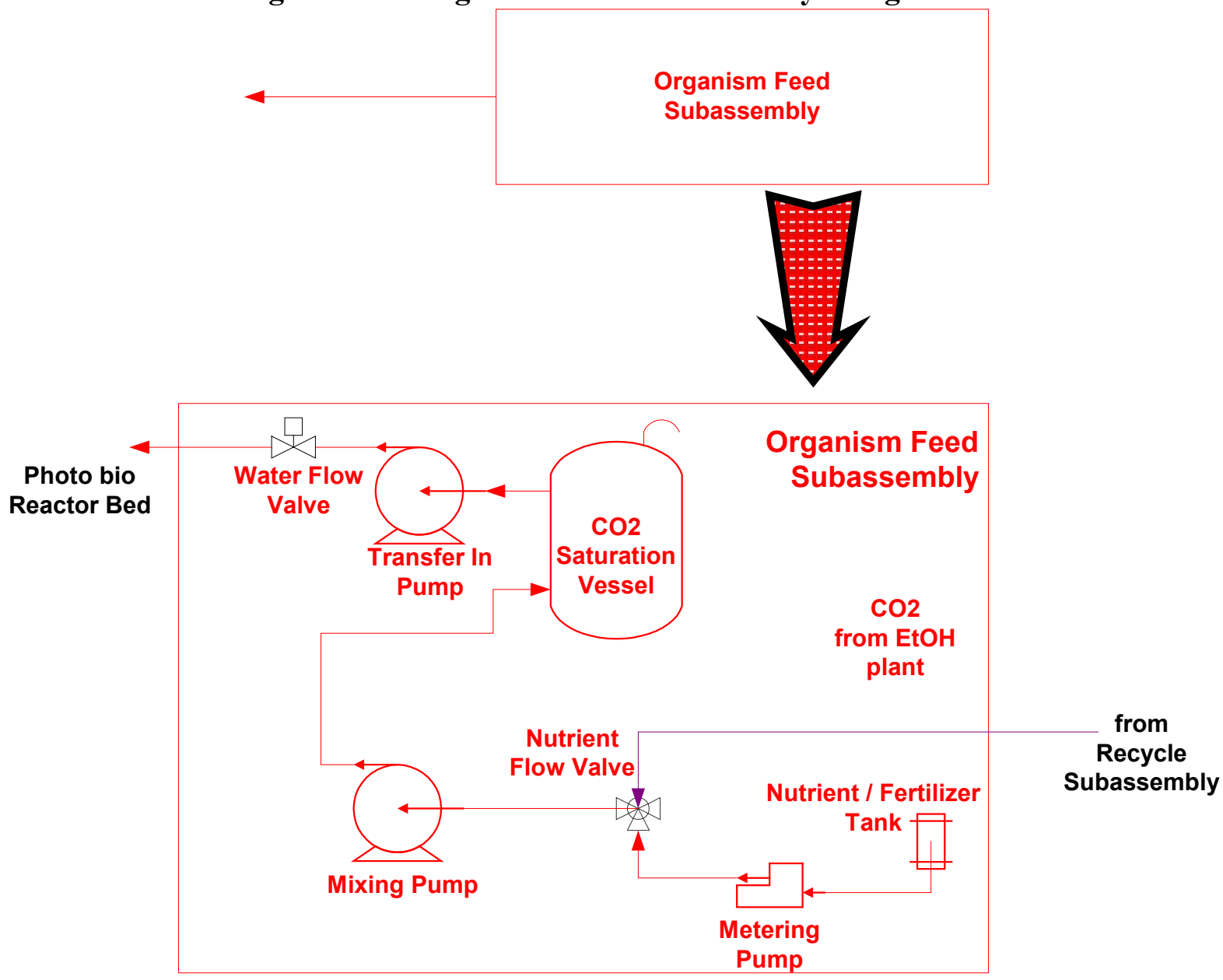

\subsubsection{Flow Valves}

The flow valves are shown in this flow diagram because they are located within the area of the organism feed subassembly. However because they will be monitored and operated remotely, their costs are accounted for in the control system subassembly. For further description of what types of valves are selected refer to that section of the document. 


\subsubsection{Vessels and Tanks}

There are three vessels in this subassembly. The $\mathrm{CO}_{2}$ Cylinder is a standard off the shelf item from one of the gas producer such as Air Products which supplies to industrial plants. The fertilizer is envisioned to be in aqueous form. The fertilizer will arrive at the facility pre-mixed for our application. The tank can be a stationary item on its own concrete pad that is refilled as necessary. The alternative would be a trailer provided by the fertilizer supplier which is dropped off when the trailer on site is dry.

\subsubsection{Pumps}

This subassembly has several pumps. After further research, centrifugal pumps were considered the most cost effective and appropriate pumps for our application. The pumps are sized based on the flow rates required to operate the reactor. Thus given a fixed hydrogen production rate of $1,000 \mathrm{kgH}_{2} /$ day, pump size will vary depending on the form of the reactor bed.

\subsubsection{Capital Costs}

The capital costs associated with this subassembly have been identified in Figure 3-18. A distinction is made between the consumables needed to establish the initial colony (which are included in capital costs of the Organism Feed Subassembly) and consumables needed for subsequent operation of the production plant (which will be included as feedstock costs under plant operation expenses). In a Chemostat II reactor bed, we postulate that $\mathrm{CO}_{2}$ gas will be necessary during the initial growth stage of the algae and, thus, are included in the plant capital costs. The costs of $\mathrm{CO}_{2}$ required during the reduced growth stage will be accounted for in plant operational expenses. The fertilizer will need to be continually fed to the colony during hydrogen production. Transporting liquids into and out of the reactor bed will require piping which is considered part of this subassembly. Pump sizes are a representative average in Figure 3-18. Actual sizes are in the Bill of Materials in section 4. 


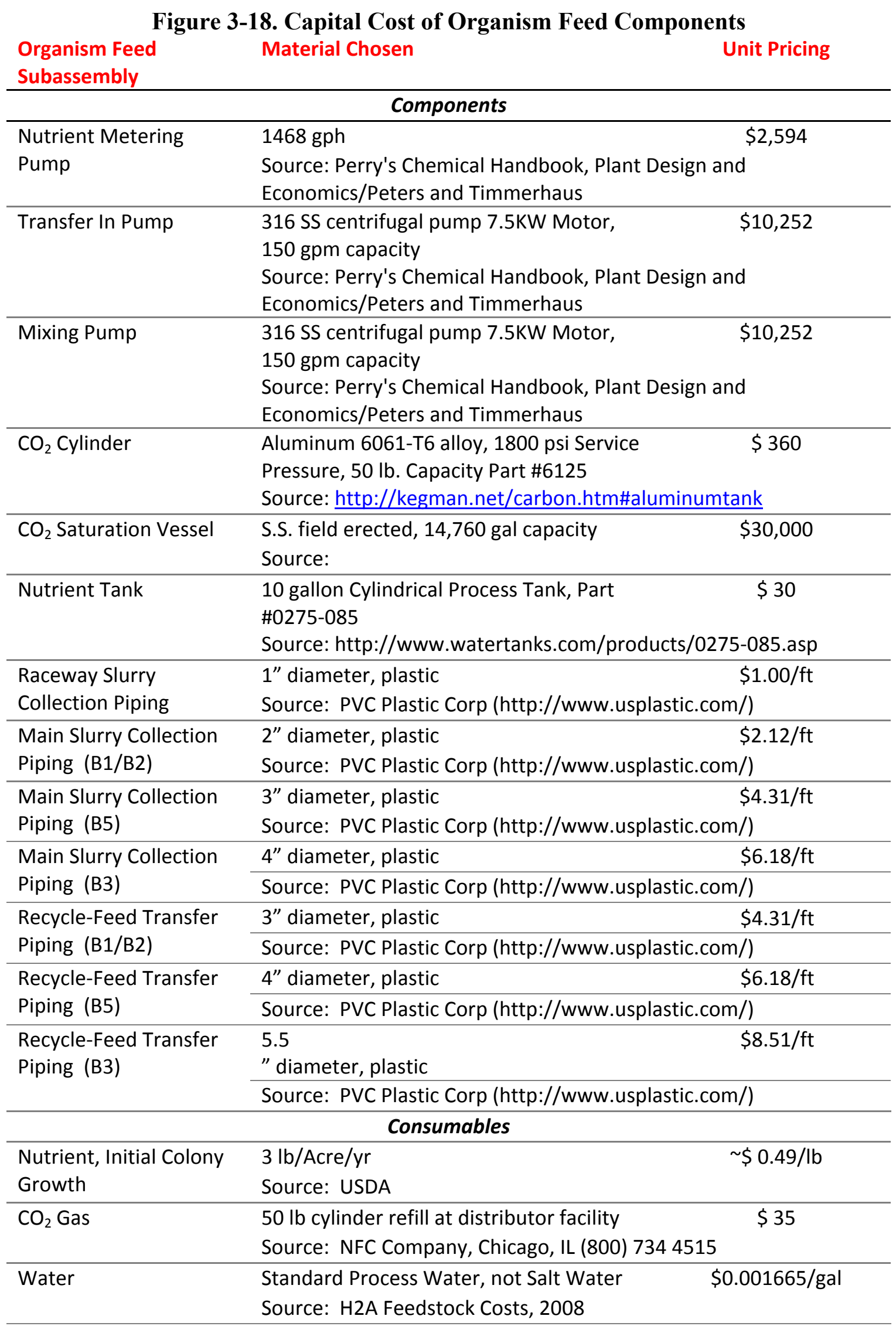




\subsection{Recycle Subassembly}

The purpose of the recycle subassembly is to separate waste organisms from water so that the water can be reused in the reactor bed. The components of this subassembly in general terms are listed in Figure 3-19 and shown in Figure 3-20.

\section{Figure 3-19. Recycle Components}

\begin{tabular}{|l|} 
Recycle Subassembly Components \\
\hline Transfer Out Pump \\
\hline Algal Separation Unit \\
\hline Piping \\
\hline
\end{tabular}

In this subassembly the organism solution is pumped to a device capable of separating the organism from the water. This is envisioned as a rotary drum filter. However, several other systems were considered. The organism-water separator will result in both organism and water outflows. The water outflow is recycled and combined with new water to make up for the amount that has evaporated, consumed in the production of hydrogen, or could not be separated from the organism. That water is sent back to the Organism Feed Subassembly to be combined with nutrients prior to being re-injected into the Photo-bio reactor bed. The subassembly components are all shown in Figure 3-20.

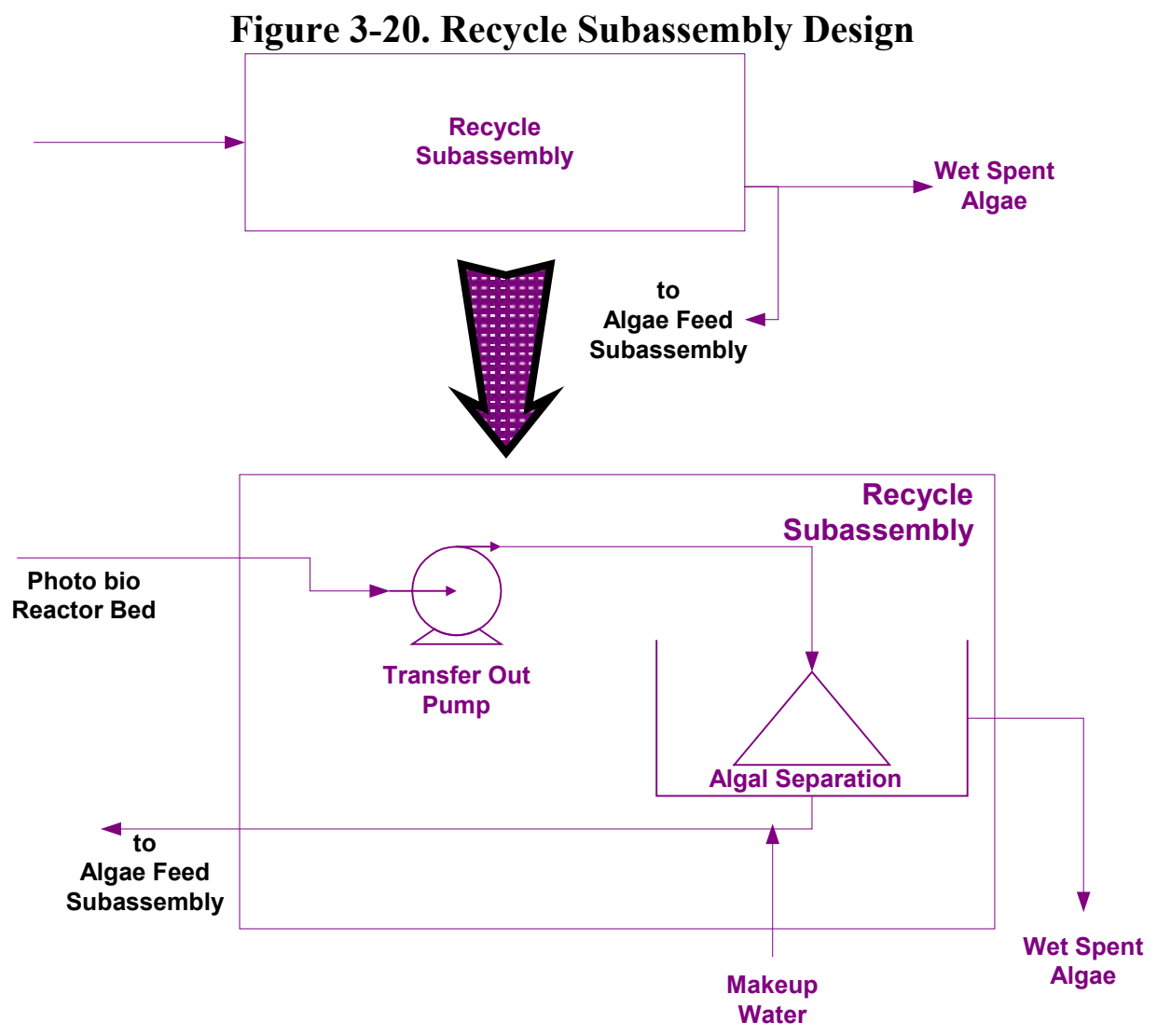




\subsubsection{Organism Separation Concepts}

In order to maintain a constant volume of living organisms in the system, it will be necessary to remove both dead and excess living organisms stemming from the continual growth of the culture. It is also imperative to separate the organisms from the water to allow for maximum water recycling. Two different concepts for organism separation were examined: industrial centrifuges and rotary drum filters. In the end, rotary drum filters are the most economically and technically viable option, due to their lower capital cost and much higher rate of water return.

\subsubsection{Centrifuges}

In most of the research concerning photobiological production of hydrogen using algae or bacteria, a laboratory centrifuge is used to separate the organisms from the nutrient medium. Owing to this precedent, we initially investigated industrial sized centrifuges as a means of algae separation. Consultation with many centrifuge manufacturers including Alfa Laval, Westphalia, US Centrifuge, and Centrifuge Experts International indicated that while centrifuges are able to handle large flow rates, the extremely low concentration of organisms in the mixture would prove difficult to separate well. Capital costs for this system would also be fairly expensive since many machines running at flow rates far below their rated capacity would be necessary to effectively separate the organisms.

After consultation, the two kinds of industrial centrifuges considered were vertically spun and decanter centrifuges. Conversations with representatives from the aforementioned companies all suggested that vertically spun centrifuges would be more adept at algae/bacteria separation than decanter. The decanter centrifuges generally offered higher flow rates, but extremely poor separation performance. Dialogue with representatives from Centrifuge Experts International indicated that in order to get an appreciable percentage of water return from a vertically spun centrifuge, the machines would have to be run at $15 \%$ of rated capacity, necessitating multiple machines. One potential avenue for increasing the flow rate while maintaining a high water recovery percentage would be through the use of chemical flocculants. The drawback of this method is the contamination of the water, a solution to which is still being developed. At nearly $\$ 400,000$ each, with the necessity for a minimum of four machines, the capital costs for this system are fairly high, especially given the water recovery rate of only $90 \%$. Westphalia centrifuges yielded similar results with slightly higher capital costs. Details about the various types of centrifuges can be seen in Figure 3-21.

Figure 3-21. Types of Centrifuges

\begin{tabular}{|c|c|c|c|c|c|c|c|}
\hline \multicolumn{7}{|c|}{ Algae Separation } \\
\hline Company & Type of Filtration & Flow Rate (GPH) & Motor Required & Type & Cost & $\begin{array}{c}\text { Quantity } \\
\text { needed }\end{array}$ & Drawbacks \\
\hline $\begin{array}{c}\text { Centrifuge Experts } \\
\text { International }\end{array}$ & Vertically Spun & 24,000 & $50 \mathrm{HP}$ & Seital SE 10 & $\$ 400,000$ & $2-4$ & $\begin{array}{c}\text { Unable to run at full flow } \\
\text { rate }\end{array}$ \\
\hline Westphalia & Vertically Spun & 15,600 & $75 \mathrm{KW}$ & HSB 400 & 550,000 & $2-4$ & $\begin{array}{c}\text { Unable to run at full flow } \\
\text { rate }\end{array}$ \\
\hline US Centrifuge & Decanter & 22,500 & $150 \mathrm{HP} / 25 \mathrm{HP}$ & Model CQ 7 & $\$ 400,000$ & 1 & $\begin{array}{c}\text { Not able to separate algae } \\
\text { well }\end{array}$ \\
\hline Alfa Laval & Decanter & 30,000 & $250 \mathrm{HP} / 50 \mathrm{HP}$ & Aldec G2 & $\begin{array}{c}\$ 750,000-\$ 800, \\
000\end{array}$ & 1 & $\begin{array}{c}\text { Not able to separate algae } \\
\text { well }\end{array}$ \\
\hline
\end{tabular}




\subsubsection{Rotary Drum Filters}

Considering the limitations of conventional centrifuge separation, research was done into the aquaculture industry, which deals heavily with algae and algae separation. Discussions with Advanced Aquaculture Systems Inc. and information from www.phyco.org indicated that rotary drum filters are far superior to centrifuges for organism separation. In rotary drum separation the input water from the pond is pumped into the filter. The organisms catch on the inside of a $<10$ micron screen in the rotating drum and the clean water passes through the screen as a backwash system rinses the solids of the screen into a sludge trough. A diagram of a drum filter can be seen in Figure 3-22. Expected water return from such a system is greater than $99 \%$. The capital costs are also lower. Three Hydrotech drum filters will be needed to handle the flow rate of one B-1 module, but are only $\$ 87,000$ per drum, substantially lower than the centrifuges.

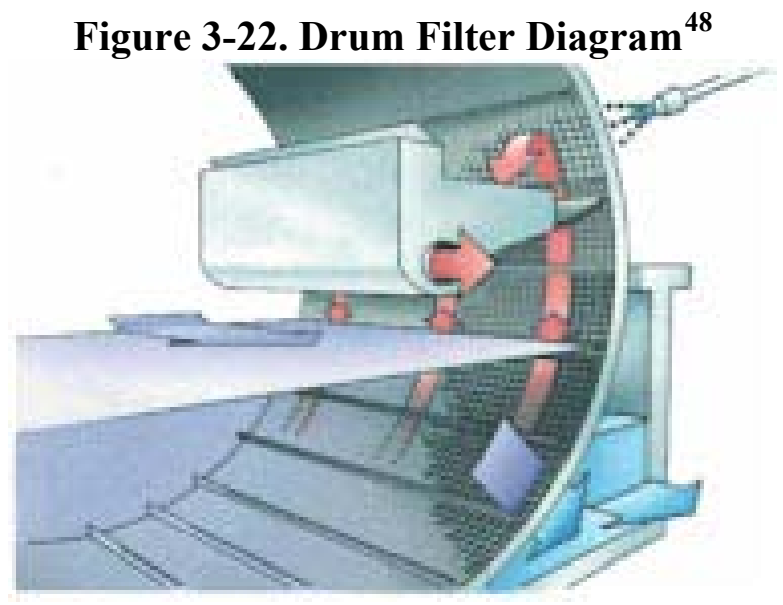

\subsubsection{Pumps}

This subassembly has a single pump. A centrifugal pump was considered the most cost effective and appropriate for our application. The pump is sized based on the flow rates required to operate the reactor. Thus given a fixed hydrogen production rate of $1,000 \mathrm{kgH}_{2} /$ day, pump size will be different depending on the form of the reactor bed. The materials selected and unit costs of the components needed for this subassembly are listed in Figure 3-23

\footnotetext{
${ }^{48}$ Email from Dana Kent. (Advanced Aquaculture Inc.) 19 August 2008.
} 
Figure 3-23. Capital Costs of Recycle Components

\begin{tabular}{|c|c|c|}
\hline $\begin{array}{l}\text { Recycle } \\
\text { Subassembly }\end{array}$ & Material Chosen & Unit Pricing \\
\hline \multirow[t]{2}{*}{ Rotary Drum filter } & Hydrotech Drum Filter - 3750 gph & \multirow[t]{2}{*}{$\$ 87,000$ ea. } \\
\hline & Source: Advanced Aquaculture Inc. & \\
\hline \multirow[t]{3}{*}{ Transfer Out Pump } & 316 SS centrifugal pump 7.5KW Motor, & \multirow[t]{3}{*}{$\$ 10,252$} \\
\hline & 150 gpm capacity & \\
\hline & $\begin{array}{l}\text { Source: Perry's Chemical Handbook, Plant Design and } \\
\text { and Timmerhaus }\end{array}$ & \\
\hline \multirow{2}{*}{$\begin{array}{l}\text { Main Slurry Feed Piping } \\
\text { (B1/B2) }\end{array}$} & 2" diameter, plastic & $\$ 2.12 / \mathrm{ft}$ \\
\hline & \multicolumn{2}{|c|}{ Source: PVC Plastic Corp (http://www.usplastic.com/) } \\
\hline \multirow{2}{*}{$\begin{array}{l}\text { Main Slurry Feed Piping } \\
\text { (B5) }\end{array}$} & 3" diameter, plastic & \multirow{2}{*}{$\$ 4.31 / \mathrm{ft}$} \\
\hline & Source: PVC Plastic Corp (http://www.usplastic.com/) & \\
\hline \multirow{2}{*}{$\begin{array}{l}\text { Main Slurry Feed Piping } \\
\text { (B3) }\end{array}$} & 4" diameter, plastic & \multirow[t]{2}{*}{$\$ 6.18 / \mathrm{ft}$} \\
\hline & Source: PVC Plastic Corp (http://www.usplastic.com/) & \\
\hline \multirow{2}{*}{$\begin{array}{l}\text { Raceway Slurry Feed } \\
\text { Piping }\end{array}$} & 1" diameter, plastic & \multirow{2}{*}{$/{ }^{\$ 1.00 / f t}$} \\
\hline & Source: PVC Plastic Corp (http://www.usplastic.com/) & \\
\hline
\end{tabular}

\subsection{Gas Capture Subassembly}

The function of gas capture subassembly is to compress and separate our product hydrogen and deliver it to the production facility limits. The components of this subassembly in general terms are listed in Figure 3-24.

Figure 3-24. Gas Capture Components

\begin{tabular}{|l|} 
Gas Capture Subassembly Components \\
\hline Compressor \\
\hline Gas Separation \\
\hline Piping \\
\hline
\end{tabular}

The outlet pressure of hydrogen at the plant gate is 300 psi. This pressure was selected to provide a system comparable to other DOE H2A Production Plants. Those cases have been normalized to an outlet pressure of 300psi. The hydrogen is at atmospheric pressure when released by the organisms. The Hydrogen Flow Meter is located at this subassembly but it is accounted for in the control system subassembly. Between these two points in the subassembly there is minimally a compressor and a gas separation unit. The compressor will need to bring the gas mixture to the pressures required for separation and transport to the plant gate. Pressure losses are possible in the gas separation unit and the pipeline runs so compression may be higher than $300 \mathrm{psi}$. The subassembly components are all shown in Figure 3-25. 
Figure 3-25. Gas Capture Subassembly Design
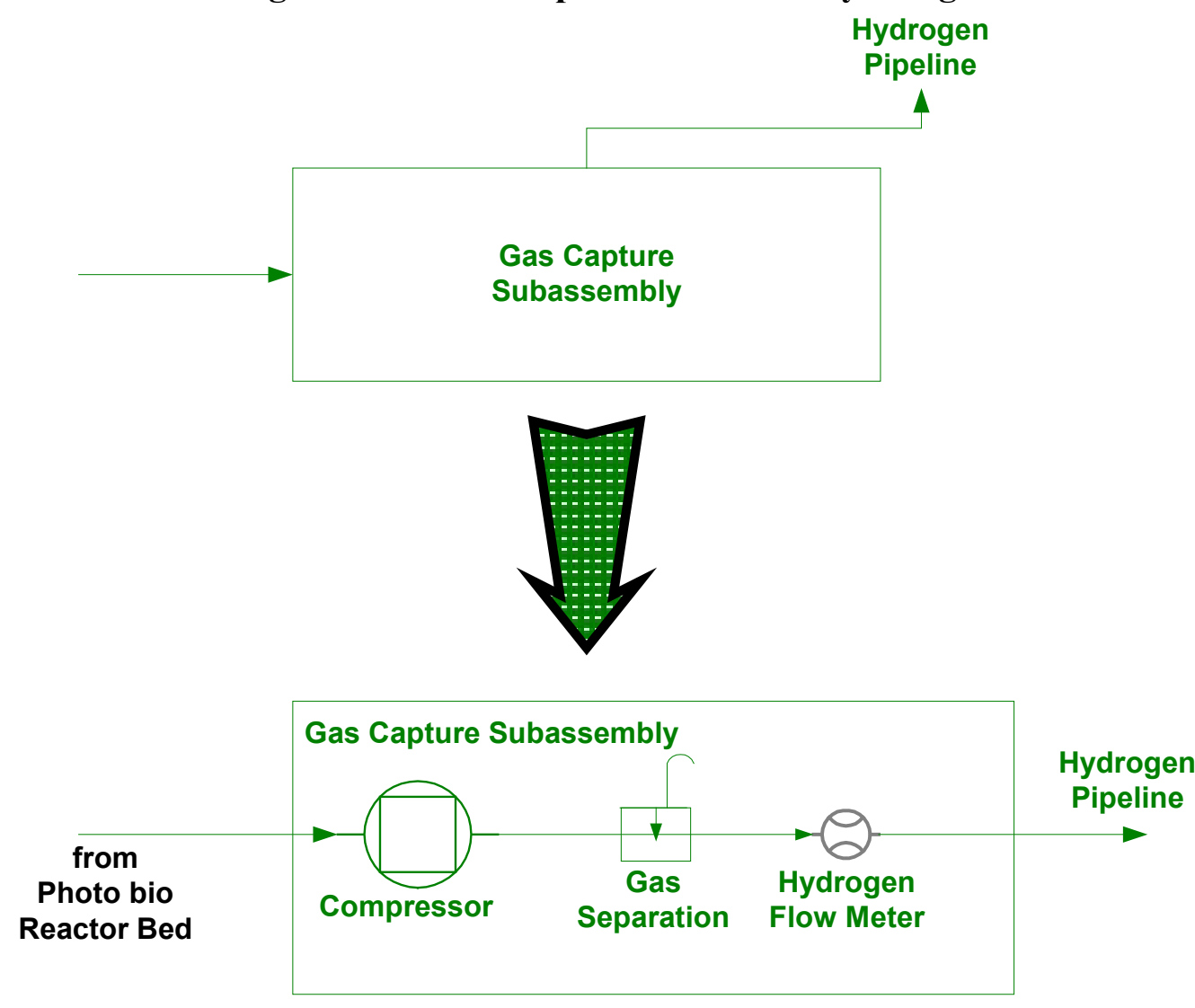

\subsection{1 $\mathrm{H}_{2}-\mathrm{O}_{2}$ Gas Mixture Safety}

Since the organisms create hydrogen via water splitting, oxygen is necessarily created as a byproduct of hydrogen production. For the systems that must maintain anaerobic conditions for hydrogen production (B3, B4, and B5), a separate reaction (i.e. respiration) occurs to virtually instantaneously consume the oxygen, so that $\mathrm{O}_{2}$ levels are maintained at very low levels. However, the B1 and B2 pathways use oxygen tolerant organisms that can carry out water splitting without a separate respiration reaction to absorb the $\mathrm{O}_{2}$, and thus they generate substantial $\mathrm{O}_{2}$, at a stoichiometric ratio with the produced hydrogen. This $2: 1$ molar ratio of hydrogen to oxygen is a flammability concern and therefore precautions must be taken to eliminate any potential ignition source. $\mathrm{H}_{2}$ safety precautions are important to all the systems, however, the issue particularly affects the B-1 and B-2 pathways where a stoichiometric $\mathrm{H}_{2} / \mathrm{O}_{2}$ mixture is stored, i.e., in raceways, headspaces, and gas processing systems. For this analysis, the requisite safety sensors and controls are used to assure safe plant operation with this gas mixture. These kinds of safety measures are also routinely dealt with in other industrial systems using $\mathrm{H}_{2}$.

\subsubsection{Compressors}

Conversations with Norwalk Compressors of Norwalk CT suggest that an oil-free, balancedopposed, 3-stage piston compressor can be used to safely compress the hydrogen or hydrogen/oxygen gas stream prior (or after) gas separation. Particular care must be taken when compressing flammable gas mixtures to avoid sparking or exceeding temperature 
limits. However, compression of flammable mixtures is a routine industrial process conducted safely every day.

Pursuant to the modular concept, the compression system is scaled for the gas flows of a $1,000 \mathrm{kgH}_{2} /$ day module. The compression module is sized for the average hydrogen production for the longest day of the year: the summer solstice (June $21^{\text {st }}$ ). At all other times, the compressor is operated at reduced capacity. Power for the compressor is based on mass flow rate and compression ratio ${ }^{49}$ which are both modest by industrial standards. Consequently, compressor power is moderate: approximately $78-123 \mathrm{~kW}$ depending on system. However, due to the low hydrogen pressure generated above the raceways (1atm), compressor piston diameter for the first stage will be quite large. For this reason, diaphragm compressors, which would normally be attractive for their longer life and non-leak attributes, are not viewed as viable candidates.

Since the biohydrogen compressors are similar in type (piston compressors) and compression ratio $(\sim 20)$ to the compressors used in the DOE's H2A forecourt analyses ${ }^{50}$, we have adopted the $\mathrm{H} 2 \mathrm{~A}$ compressor cost algorithm of $\$ 4,580 /\left(\mathrm{kgH}_{2} / \mathrm{h}\right)$. However, since this algorithm is based on hydrogen compression and the biohydrogen systems produce a mixture of gases, we convert the costing algorithm to a molar basis: $\$ 9,233 /(\mathrm{kgmol} / \mathrm{h})$.

\subsubsection{Gas Separation Concepts}

There are several commercial means available for separating hydrogen gas from a gas mixture. In this analysis we have focused our attention on pressure swing adsorption (PSA), temperature swing adsorption (TSA), membranes, electrochemical pumps and combinations of these methods.

\subsubsection{Pressure Swing Adsorption}

A pressure swing adsorption (PSA) system is preliminarily selected as the $\mathrm{H}_{2}$ separation system. PSA technology takes advantage of a materials affinity to preferentially adsorb a particular gas species at high gas pressure. PSA systems are commonly used in the petroleum industry to purify a variety of gases. Separation of hydrogen gas from steam methane reforming (SMR) product gases $\left(\mathrm{H}_{2}, \mathrm{CO}, \mathrm{CO}_{2}, \mathrm{H}_{2} \mathrm{O}, \mathrm{CH}_{4}\right)$ is common. We propose to use PSA to separate hydrogen from a $\mathrm{H}_{2}, \mathrm{O}_{2}, \mathrm{H}_{2} \mathrm{O}$ mixture, a much less frequently encountered application. Dialogue with Adsorption Research, Inc. indicated that it was feasible to use PSA to separate such a mixture. ${ }^{51}$

PSA operate by flowing a pressurized stream of gases across a multi-component adsorbent bed (commonly layers of activated carbon, zeolite, silica gel, etc.) to preferentially capture an undesired gaseous species on the surface of the adsorbent. By careful selection of adsorbent materials, all undesirable species may be captured in the bed so that only high purity gas (often greater than 5 nines purity) exits the bed. PSA systems are inherently cyclic with a series of bed (typically $4,6,8$ or 12 ) operating out of phase. After a bed is

\footnotetext{
${ }^{49}$ Compression ratio is $300 \mathrm{psi} / 14.7 \mathrm{psi}=20.4$.

50 The standard DOE H2A forecourt analysis assumes a 4-stage, piston compressor, 300psi inlet, 6250psi outlet, and approximate $1500 \mathrm{kgH} 2 /$ day flow rate.

${ }^{51}$ Knaebel, Kent. Phone conversation. 20 Oct 2008
} 
"full" (i.e. the adsorbent material no longer has open sites on which to further adsorb contaminant gases), the bed goes into a "vent' cycle where pressure is decreased (typically to $1 \mathrm{~atm}$ but sometimes $<1 \mathrm{~atm})$ to desorb the contaminants. This vent gas stream is typically vented to the atmosphere or fed to a burner if it contains fuel value. After venting, the bed is purged with pure gas stream reserve flowed i.e. fed from the exit of the bed to drive any residual containment gas back towards the inlet. After purging, the bed enters an "equalization" cycle where gas pressure is raised to full operating pressure in preparation for the resumption of contaminant gas flow.

Hydrogen recovery is a key metric of PSA performance. Hydrogen recovery is defined as the fraction of inlet gas hydrogen that is captured in the pure gas stream. There are two main sources of hydrogen loss. The first is hydrogen that is contained in the bed at the beginning of the vent cycle. As the bed is depressurized, this hydrogen is expelled and lost to recovery. The second source of loss is during the purge cycle when pure hydrogen is used to actively vent the system of impurities. By summing these two losses, an accurate measure of hydrogen recovery can be attained.

To determine $\mathrm{H}_{2}$ recovery for an $\mathrm{H}_{2} / \mathrm{O}_{2}$ mixed gas system, we have ascertained the packing density and adsorption performance of carbon (for $\mathrm{O}_{2}$ adsorption) and silica gel (for water adsorption). These parameters are listed in Figure 47. By carefully modeling the desired flow rates and calculating the hydrogen contained in the bed during the various cycles, the hydrogen recovery is calculated.

Key parameters of the PSA system are shown in Figure 3-26. Parameters are listed for the adsorption of water, methane, carbon dioxide, carbon monoxide, nitrogen, and oxygen. Although oxygen is the primary species for adsorption, the other gases are included both because they were used in validation of the modeling approach and may be present in low quantities due to the decomposition of algae. For each adsorbent there are two values of interest; the amount of gas that adheres to the adsorbent at high pressure, and the amount of gas that adheres to the absorbent at low pressure. It is the difference in adsorption levels between the two pressures that is of interest. Although not necessarily linear, we have assumed that the adsorption data varies linearly between the two data points listed.

Capital costs for the individual PSA systems are estimated based on both the performance model described above and on a scaling factor approach. The performance model is used to calculate the approximate bed size of the PSA vessels for the particular flow rates and gas compositions of each system. Once this PSA bed size is determined, a scaling factor approach is used to ratio the cost relative to a H2A model PSA system. A 0.5 scaling factor is assumed resulting in the following equation:

$$
\text { NewCost }=\text { BaseCost } * \sqrt{\frac{\text { NewBedSize }}{\text { BaseBedSize }}}
$$

The base PSA system cost assumed is based on an $\mathrm{H} 2 \mathrm{~A} 1500 \mathrm{kgH}_{2} /$ day SMR PSA having $6,065 \mathrm{~L}$ of total absorbent and a $\$ 100,000$ total price. 
Figure 3-26. Possible PSA Parameters

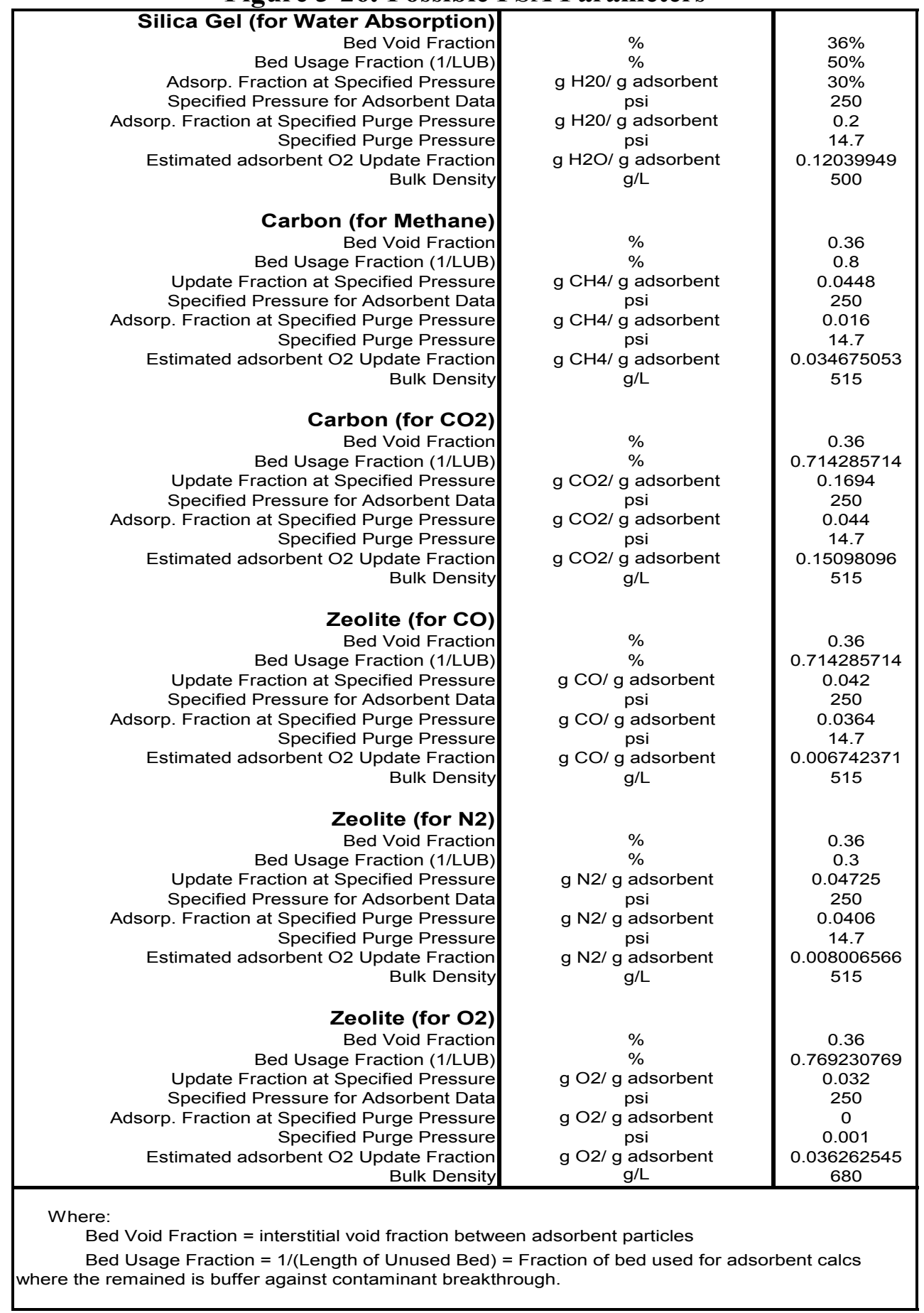

\subsubsection{Temperature Swing Adsorption}

Temperature swing adsorption (TSA) systems are analogous to PSA systems except they use differences in temperature rather than pressure to preferentially adsorb and desorb contaminant species. While used industrially, TSA systems are not as prevalent in process plants as PSA systems. The main advantage of a TSA system is that it would not require compression of the $\mathrm{H}_{2}$-rich gas thereby avoiding the safety concerns of compressing $\mathrm{H}_{2} / \mathrm{O}_{2}$ 
gas mixtures and potentially lowering electrical requirements. However, separation of $\mathrm{H}_{2}$ and $\mathrm{O}_{2}$ via TSA requires a significant temperature swing with a refrigeration system required to achieve the lower temperature bound. Was "waste" cooling or heating available from an adjacent process, TSA would be an attractive option. However, as currently configured such "waste" thermal energy is not readily available and thus the refrigeration system would be a substantial energy and cost element. Additionally, conversations with Kent Knaebel from Adsorption Research Incorporated, a gas separation consulting company, indicated that PSA was a far superior option, given its vastly reduced cycle time. The cycle for a TSA system would be measured in hours, as opposed to minutes for PSA, necessitating a much larger bed size in order to separate the same amount of gas. This increased capital cost of the beds and cooling system makes TSA less economically practical than PSA. Consequently, we have not pursued further TSA system analysis for any of the bio-hydrogen systems.

\subsubsection{Membrane Separation}

Membrane separation units are of two main types: metallic membranes and nano-porous membranes. Metallic membranes typically use palladium (Pd), Pd-alloys, or layered $\mathrm{Pd}$ /alloy to allow the diffusion of $\mathrm{H}+$ ions through the membrane. $\mathrm{Pd}$ membranes are characterized by very high hydrogen selectivity (typically $<10,000$ ), high cost (due to the inherent Pd material cost), and moderate hydrogen permeability that is primarily a function of temperature and membrane thickness. Hydrogen flux through the membrane follows Boyds Law and is proportional to the difference of the square root of the reformate (upstream) hydrogen partial pressure and the square root of the permeate (downstream) hydrogen partial pressure. Consequently, Pd-membrane systems work best with highly pressurized inlet streams and low pressure $\mathrm{H}_{2}$ product streams. While a few small scale Pdmembrane commercial products are on the market (e.g. IdaTech), large scale Pd-membrane hydrogen purification systems are not employed industrially due to performance and cost concerns. Based on membrane system modeling for a bio-hydrogen system with $60 \% \mathrm{H}_{2}$ at $20 \mathrm{~atm}(300 \mathrm{psi})$ and a $1 \mathrm{~atm}$ permeate $\left(\right.$ pure $\left.\mathrm{H}_{2}\right)$ outlet pressure, hydrogen recoveries in excess of $90 \%$ are theoretically possible.

Drawbacks of Pd-membrane separation systems include:

- the necessity to heat the membrane (and hydrogen) to $250-350^{\circ} \mathrm{C}$ to ensure adequate hydrogen permeability

- the requirement to compress the $\mathrm{H}_{2}$-rich feedstream to high pressure thereby raising safety concerns related to $\mathrm{H}_{2} / \mathrm{O}_{2}$ compression

- the low pressure of the pure $\mathrm{H}_{2}$ product stream thereby requiring additional $\mathrm{H}_{2}$ compression to achieve a pipeline transport pressure

- uncertainty of using $\mathrm{Pd}$ membrane with $\mathrm{H}_{2} / \mathrm{O}_{2}$ gas mixtures (the $\mathrm{Pd}$ may oxidize or be an $\mathrm{H}_{2} / \mathrm{O}_{2}$ combustion catalyst)

- the general immaturity of the technology.

For these reasons, Pd-membranes are not selected for further analysis.

The other broad class of membrane separation systems is based on nano-porous materials. Nano-porous materials function as molecular sieves and use pore size to preferentially pass 
molecular hydrogen. As reproduced in Figure 3-27, Phair and Badwal ${ }^{52}$ have surveyed the range of nano-porous membrane options. Of these, we judge polymeric membrane to be most applicable to bio-hydrogen gas separation due to their low temperature of operation. However, polymer membranes are not highly selective and thus would require additional downstream purification. Additionally, hydrogen flow is driven by differences in hydrogen partial pressure across the membrane. Consequently, compression of the unseparated gas is required once again raising safety concern for $\mathrm{H}_{2} / \mathrm{O}_{2}$ gas mixtures. A detailed analysis beyond the scope of this project is required to optimize pressure level, permeate purity, and recover $\mathrm{H}_{2}$. For these reasons, polymer membranes don't appear to offer substantially superior benefits over PSA systems. Consequently, polymer membranes are not selected for further analysis.

Figure 3-27. Nano-porous Membranes

\begin{tabular}{lllllll}
\hline & Polymeric & Carbon & Glass & Aluminosilicate & Oxides \\
\hline Pore size $^{\mathrm{a}}$ & Meso-macro & Micro-meso & Meso-macro & Micro-meso & Micro-meso \\
Surface area/porosity & Low $>0.6$ & High 0.3-0.6 & Low 0.3-0.6 & High 0.3-0.7 & Medium 0.3-0.6 & Meso-macro \\
Permeability & Low-medium & Low-medium & High & Low & Low-medium \\
Strength & Medium & Low & Strong & Weak & High \\
Thermal stability & Low & High & Good & Medium-high & Medium-high \\
Chemical stability & Low-medium & High & High & High & Very high & High \\
Costs & Low & High & High & Low-medium & Medium & High \\
Life & Short & Long & Long & Medium-long & Long & Long \\
\hline
\end{tabular}

${ }^{\mathrm{a}}$ Micoporous $=$ pore radius $<1 \mathrm{~nm}$, mesoporous $=1 \mathrm{~nm}<$ pore radius $<25 \mathrm{~nm}$, macroporous $=$ pore radius $>25 \mathrm{~nm}$.

\subsubsection{Electrochemical Pumps}

Electrochemical purification of hydrogen is possible using an applied voltage to drive hydrogen across a separation membrane. Such systems have been demonstrated at small scale but are not currently in industrial use. In addition to the gas separation function, electrochemical pumps can be used to pressure the hydrogen stream thereby eliminating or reducing the need for mechanical $\mathrm{H}_{2}$ gas compression. In theory, a mixed gas stream could enter the electrochemical pump at 1atm and a high $\mathrm{H}_{2}$ purity gas stream could exit at pressure (10-100atm).

Conversations with Glen Eiseman of Hydrogen Pump LLC preliminarily explored the use of electrochemical pumps for biohydrogen purification. Current products from Hydrogen Pumps use a PBI membrane, operate at $\sim 160^{\circ} \mathrm{C}$, employ a Pt catalyst, compress the $\mathrm{H}_{2}$ stream to several atmospheres, and contain a supplementary gas cleanup system since only $98 \%$ pure $\mathrm{H}_{2}$ is passed across the membrane. Since exposure of a $\mathrm{H}_{2} / \mathrm{O}_{2}$ gas mixture to $\mathrm{Pt}$ would result in catalyst combustion of the gases, such a combination is unacceptable. Development of alternate non-Pt catalyst is theoretically possible, but the authors know of no such development efforts.

\footnotetext{
52 "Materials for separation membranes in hydrogen and oxygen production and future power generation", J.W. Phair, S.P.S. Badwal, (CSIRO Manufacturing and Infrastructure Technology, Victoria, Australia) Science and Technology of Advanced Materials 7 (2006) 792-805.
} 
Electrochemical pumps could be used for separation of non- $\mathrm{O}_{2}$ containing gas mixtures. However, the systems would incur the following disadvantages:

- the necessity to heat the membrane (and hydrogen) to $160^{\circ} \mathrm{C}$

- the need for a secondary gas cleanup system (such as PSA) to further purify the $\mathrm{H}_{2}$ product gas to five 9's purity

- the electrical consumption to power the device

For these reasons, electrochemical pumps are not selected for further analysis.

\subsubsection{Capital Costs}

The components of the subassembly can be further specified for a given organism and reactor bed form. However we have included in Figure 3-28 materials selected and unit costs of components.

Figure 3-28. Capital Cost of Gas Capture Components

\begin{tabular}{|c|c|c|}
\hline $\begin{array}{l}\text { Gas Capture } \\
\text { Subassembly }\end{array}$ & Material Chosen & Init Pricing \\
\hline Compressor & $\begin{array}{l}142 \mathrm{kgH}_{2} / \mathrm{hr} \text { size for } 1000 \mathrm{kgH}_{2} / \text { day plant } \\
\text { Source: Using } \mathrm{H} 2 \mathrm{~A} \text { Cost guidelines }\end{array}$ & $33 / \mathrm{kgmol} / \mathrm{hr}$ \\
\hline Gas Separation & $\begin{array}{l}\text { Pressure Swing Adsorption } \$ 30 \text {, } \\
\text { Source: Using H2A Cost guidelines and scaling factors }\end{array}$ & $542-\$ 119,408$ \\
\hline $\begin{array}{l}\text { Gas Capture Collection } \\
\text { Piping }\end{array}$ & $\begin{array}{l}\text { 5.5" diameter, plastic, } 100 \mathrm{ft} / \mathrm{s} \text { velocity, } \\
\text { Source: PVC Plastic Corp (http://www.usplastic.com/) }\end{array}$ & $\$ 8.51 / \mathrm{ft}$ \\
\hline $\begin{array}{l}\text { Gas Capture Collection } \\
\text { Piping }\end{array}$ & $\begin{array}{l}\text { 4.5" diameter, plastic, } 100 \mathrm{ft} / \mathrm{s} \text { velocity, } \\
\text { Source: PVC Plastic Corp (http://www.usplastic.com/) }\end{array}$ & $\$ 6.18 / \mathrm{ft}$ \\
\hline Main Collection Piping & $\begin{array}{l}\text { 4" diameter, plastic, 100ft/s velocity, } \\
\text { Source: PVC Plastic Corp (http://www.usplastic.com/) }\end{array}$ & $\$ 6.18 / \mathrm{ft}$ \\
\hline Main Collection Piping & $\begin{array}{l}\text { 3" diameter, plastic, 100ft/s velocity, } \\
\text { Source: PVC Plastic Corp (http://www.usplastic.com/) }\end{array}$ & $\$ 4.31 / \mathrm{ft}$ \\
\hline $\begin{array}{l}\text { Raceway Collection } \\
\text { Piping }\end{array}$ & $\begin{array}{l}\text { 1.5" diameter, plastic, } 100 \mathrm{ft} / \mathrm{s} \text { velocity, } \\
\text { Source: PVC Plastic Corp (http://www.usplastic.com/) }\end{array}$ & $\$ 1.57 / \mathrm{ft}$ \\
\hline $\begin{array}{l}\text { Raceway Collection } \\
\text { Piping }\end{array}$ & $\begin{array}{l}\text { 1" diameter, plastic, 100ft/s velocity, } \\
\text { Source: PVC Plastic Corp (http://www.usplastic.com/) }\end{array}$ & $\$ 1.00 / f t$ \\
\hline
\end{tabular}

\subsubsection{Piping}

Transporting gases out of the reactor bed and the product hydrogen to the facility limits will require several hundred feet of piping which are included as part of the subassemblies cost. For the B-3 and B-4 systems, the piping lengths needed must be doubled to account for the piping needed to bring $\mathrm{CO}_{2}$ to the $\mathrm{CO}_{2}$ saturation vessel. There is no drum filter for these systems. 


\subsubsection{Additional Gas Capture Subassembly Components}

It is possible for the product gas to have water saturation. In this case, a dryer may be needed to remove water from the gas mixture. A slight vacuum might be required to draw the gas mixture out of the pond network and into the gas capture subassembly. These components are not part of the system yet but as we finalize our analysis we'll be able to determine if these components are necessary.

\subsection{Control System Subassembly}

Plant control systems serve many functions including local and remote monitoring, alarming and controlling of plant equipment and functions. The more functions the system performs, the more costly and complex the system becomes. A very simple system may provide only local indication or monitoring of equipment operation. A complex system would include all three functions for each piece of equipment from a remote facility and some logic for how to operate each piece under a given set of conditions. Automating plant operations can increase the cost of the control system. These costs need to be evaluated against the operational labor savings.

\subsubsection{Components}

For this subassembly the design approach was to create a very basic system which is practical enough to provide some savings in operational labor. Because of the reactor bed's large area requirements remote capabilities are essential. This will require electrical conduit and wiring to be laid out between the plant components and the primary control area. Monitoring of only the most primary indicators will be included. Alarming capabilities of only the most hazardous conditions will be required. Control will only be available for flow valves. No automation is assumed thus a PLC will not be included. For the basic control system described the components and instrumentation for each function are listed in Figure 3-29. 
Figure 3-29. Control System Components

\begin{tabular}{|c|c|c|}
\hline \multicolumn{3}{|l|}{ Control System Subassembly } \\
\hline \multirow{2}{*}{\multicolumn{3}{|c|}{$\begin{array}{l}\text { Components } \\
\text { Control Room }\end{array}$}} \\
\hline & & \\
\hline \multicolumn{3}{|l|}{$\begin{array}{l}\text { Control Room Wiring Panel } \\
\text { Raceway Wiring Panel }\end{array}$} \\
\hline \multicolumn{3}{|c|}{ Computer, Monitor, Labview software } \\
\hline \multicolumn{3}{|c|}{ Electrical Conduit (power and instrumentation) } \\
\hline \multicolumn{3}{|c|}{ Instrumentation Wiring } \\
\hline \multicolumn{3}{|l|}{ Instrumentation } \\
\hline Monitor & Alarm & Control \\
\hline Level Indicators & Pressure Sensors & Nutrient Flow Valve \\
\hline \multicolumn{2}{|c|}{ Hydrogen Area Sensors } & Water Flow Valve \\
\hline Air Temperature Indicator & Oxygen Area Sensors & \\
\hline \multicolumn{3}{|l|}{ Water Temperature Indicator } \\
\hline \multicolumn{3}{|l|}{ Hydrogen Flow Meter } \\
\hline & & \\
\hline \multicolumn{3}{|l|}{$\begin{array}{l}\text { pH level indicator } \\
\text { Consumables }\end{array}$} \\
\hline Electricity & & \\
\hline
\end{tabular}

While the control system is relatively simple, the subassembly is complicated by the sheer size of the reactor beds and the modular nature of the raceways. Each raceway must be individually monitored and controlled, leading to a large number of replicated sensors. Additionally, the instruments are dispersed over this area, 20-66 acres in size, leading to very long runs of wiring and conduit. Signal boosting may be required. To simplify the system all instrumentation will operate on electricity rather than instrument air, so that an air compressor is not required. There is no power transformer considered here, rather electricity will be treated as a plant operating expense and bought off the grid at the typical $\$ / \mathrm{kWh}$ for the region.

\subsubsection{Wiring and Conduit}

Because of the large size of our plant there is significant amount of wiring involved with conveying power to each raceway for the paddlewheels and instrumentation as well as bringing back signal wiring for instrumentation. Figure 3-30 shows a possible layout of the production facility where growth and production are carried out in a single bed. Some key dimensions are identified so that approximate lengths of wiring and conduit can be computed. The number of wires required to each raceway panel is shown in the Raceway Wiring Panel. All panels are assumed to be at the near end of each raceway and subassembly center for conceptual design calculations. The hydrogen flow meter has a single signal and power wire. The flow valves have 1 power wire but need 2 signal wires; 1 for actuating valve and 1 for status of valve. The remaining equipment at each subassembly has power wires but no signal wires. Since this is a simple control system other equipment (pumps, compressor, and algal separation unit) will only have local control and monitoring. All monitoring and sensor instrumentation has a single power and a single signal wire with the exception of the hydrogen area sensor. It requires two signal wires for monitoring 
hydrogen and alarming at certain conditions. Water flow control into and out of each individual raceway will be done with manual valves so they do not factor into the control system. The additional power wires are for the paddlewheel motors. There is no signal indicating the operation of these motors to the control room. Based on the other signals the operator should be able to infer the operating status of the paddlewheels.

Figure 3-30. Control System Subassembly Design

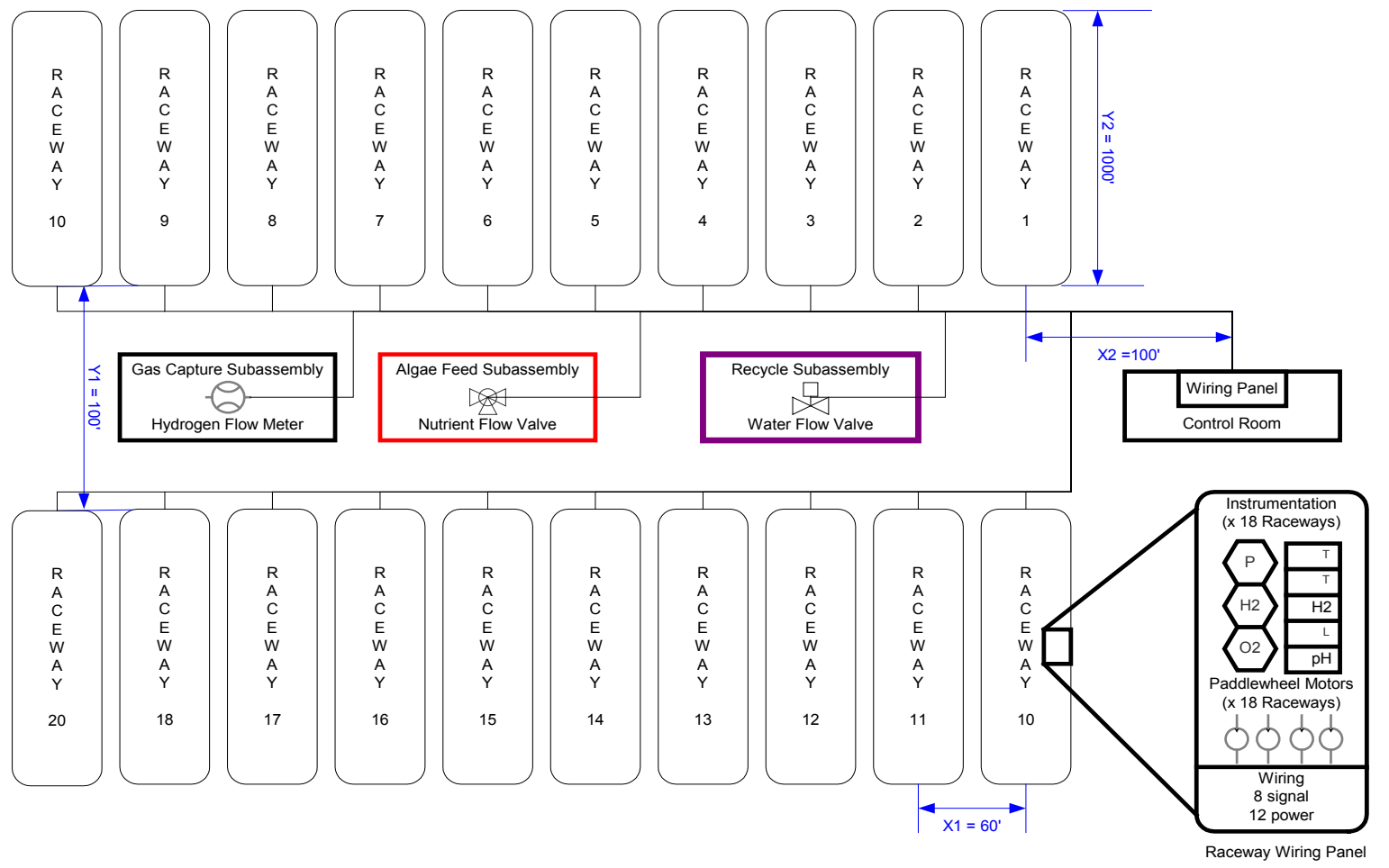

For the B-1 and B-2 systems, a plant layout like this yields the lengths of conduit and wiring shown in Figure 3-31. Signal and power wiring will be run in separate conduits. This is done to ensure that there is no interference in the signal data from voltage associated with the power wiring. In the diagram above one can see there are two main horizontal conduits runs (above and below the subassemblies). That route will be used for both power and signal wiring. Each individual raceway will have its own conduit run along the length of the raceway for the raceway wiring panel located at the near end of the raceway. Each subassembly will have its own conduit run off the main horizontal conduit lines for its wiring. 
Figure 3-31. Control System Wiring and Conduit Quantities for B-1, B-2

\begin{tabular}{|lr|rr|} 
Components & $\begin{array}{c}\text { Signal Wiring Qty } \\
\text { (ft) }\end{array}$ & $\begin{array}{r}\text { Power Wiring Qty } \\
\text { (ft) }\end{array}$ & $\begin{array}{r}\text { Conduit Qty (ft) } \\
\text { Raceways }\end{array}$ \\
\hline $\begin{array}{l}\text { Organism Feed } \\
\text { Subassembly }\end{array}$ & 67,200 & 84,000 & 4,560 \\
\hline $\begin{array}{l}\text { Recycle } \\
\text { Subassembly }\end{array}$ & 500 & 270 & 100 \\
\hline $\begin{array}{l}\text { Gas Capture } \\
\text { Subassembly }\end{array}$ & 640 & 630 & 100 \\
\hline Totals & 630 & $\mathbf{8 5 , 3 5 0}$ & $\mathbf{4 , 8 6 0}$ \\
\hline
\end{tabular}

The raceways category in Figure 3-31 above is a summation of all the wiring required for each of the 20 raceway wiring panels needed in the B-1 and B-2 systems. The flow valve and flow meter wiring requirements are included in the appropriate subassembly line. The additional power wiring in those subassembly lines are for the other equipment (pumps, compressors, etc) that require power but are not monitored and operated remotely. The control system wiring could have been done overhead with cable trays, however, since some level of excavation will already take place to create raceways, this analysis assumes underground lines. The installation costs of buried conduit in this case will be lower because it is included in the excavation of the raceways.

\subsubsection{Capital Costs}

The analysis above provides a fairly extensive bill of materials for a typical control system. All of the instrumentation, wiring and conduit is assumed to be commercially on the shelf and readily available. The costs of those components are summarized in Figure 3-32.

Figure 3-32. Capital Costs of Control System Components

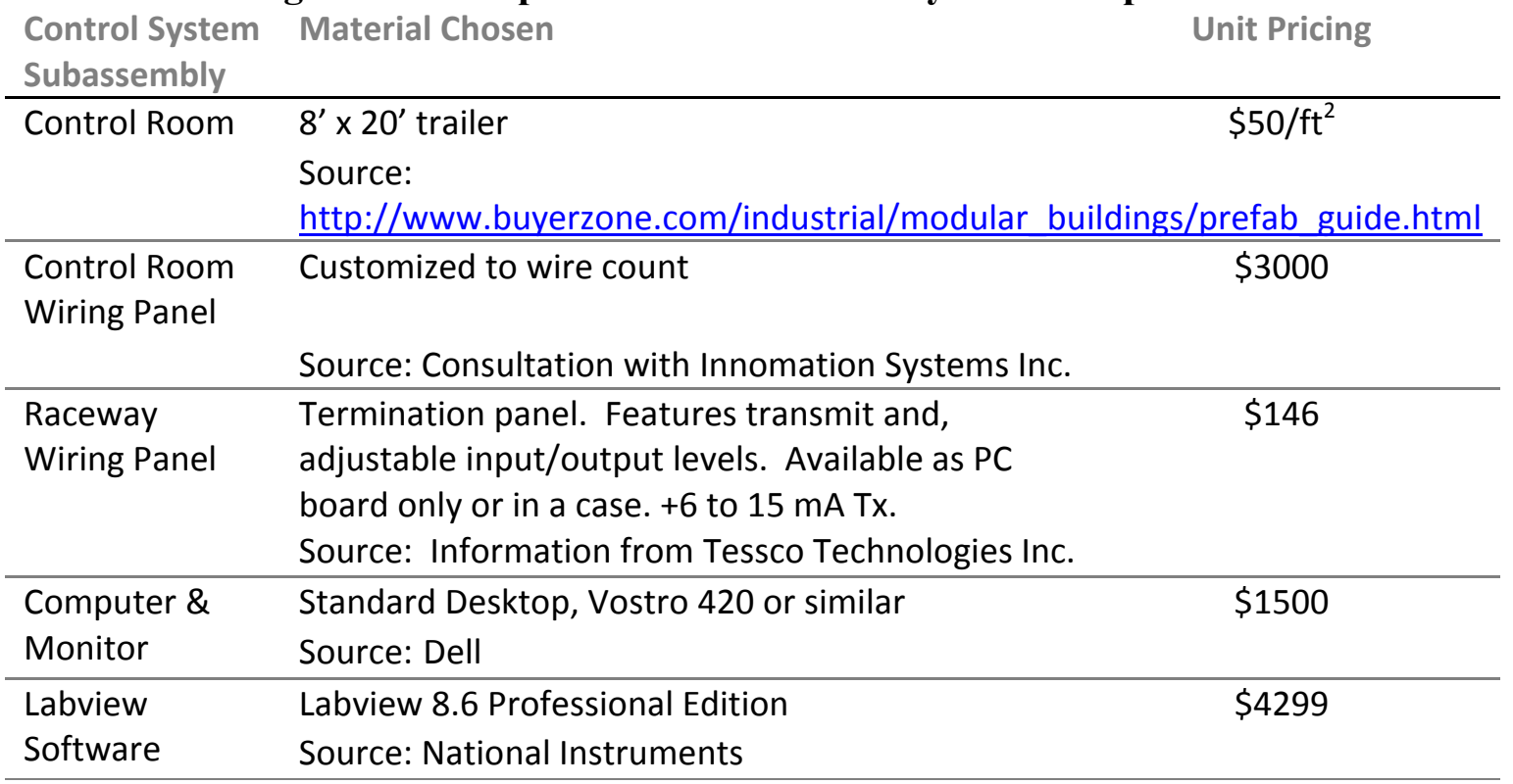




\begin{tabular}{|c|c|c|}
\hline $\begin{array}{l}\text { Control System } \\
\text { Subassembly }\end{array}$ & Material Chosen & Unit Pricing \\
\hline Level Indicators & $\begin{array}{l}\text { Flanged, Float level, } 316 \text { SST components, } \\
\text { displays, } 4 \text { to } 20 \text { ma output, standard process } \\
\text { connection } \\
\text { Source: Omega Engineering Inc. }\end{array}$ & $\$ 714$ \\
\hline $\begin{array}{l}\text { Pressure } \\
\text { Sensors }\end{array}$ & $\begin{array}{l}\text { Solid State Pressure Transducer and meter, } 316 \\
\text { SST components, displays, } 4 \text { to } 20 \text { ma output, } \\
\text { standard process connection } \\
\text { Source: Omega Engineering Inc. }\end{array}$ & $\$ 345$ \\
\hline $\begin{array}{l}\text { Hydrogen Area } \\
\text { Sensors }\end{array}$ & $\begin{array}{l}\text { Thermal Conductivity Gas Analyzer, } 316 \text { SST } \\
\text { components, displays, } 4 \text { to } 20 \text { ma output, } \\
\text { standard process connection } \\
\text { Source: Lesman Instrument Company }\end{array}$ & $\$ 7,600$ \\
\hline $\begin{array}{l}\text { Air } \\
\text { Temperature } \\
\text { Indicator }\end{array}$ & $\begin{array}{l}\text { Thermistor, } 316 \text { SST components, } 4 \text { to } 20 \text { ma } \\
\text { output, standard process connection } \\
\text { Source: Omega Engineering Inc. }\end{array}$ & $\$ 38$ \\
\hline $\begin{array}{l}\text { Air } \\
\text { Temperature } \\
\text { Meter }\end{array}$ & $\begin{array}{l}\text { Panel Meter, single width, up to } 24 \text { inputs } \\
\text { Source: Omega Engineering Inc. }\end{array}$ & $\$ 599$ \\
\hline $\begin{array}{l}\text { Water } \\
\text { Temperature } \\
\text { Indicator }\end{array}$ & $\begin{array}{l}\text { Comes with } \mathrm{pH} \text { sensor } \\
\text { Source: Information from Emerson Process Management }\end{array}$ & $\$ 0$ \\
\hline $\begin{array}{l}\mathrm{pH} \text { level } \\
\text { Indicator }\end{array}$ & $\begin{array}{l}\text { CPVC components, displays, } 4 \text { to } 20 \text { ma output, } \\
\text { standard process connection } \\
\text { Source: Omega Engineering Inc. }\end{array}$ & $\$ 435$ \\
\hline $\begin{array}{l}\text { Oxygen Area } \\
\text { Sensors }\end{array}$ & $\begin{array}{l}\text { Comes with Hydrogen Sensor } \\
\text { Source: Omega Engineering Inc. }\end{array}$ & $\$ 0$ \\
\hline $\begin{array}{l}\text { Nutrient Flow } \\
\text { Valve }\end{array}$ & $\begin{array}{l}\text { 6" vortex type, } 316 \text { SST components, displays, } 4 \\
\text { to } 20 \text { ma output, standard process connection } \\
\text { Source: Information from Emerson Process Management }\end{array}$ & $\$ 5,500$ \\
\hline $\begin{array}{l}\text { Water Flow } \\
\text { Valve }\end{array}$ & $\begin{array}{l}\text { 6" vortex type, } 316 \text { SST components, displays, } 4 \\
\text { to } 20 \text { ma output, standard process connection } \\
\text { Source: Information from Emerson Process Management }\end{array}$ & $\$ 5,500$ \\
\hline $\begin{array}{l}\text { Hydrogen Flow } \\
\text { Meter }\end{array}$ & $\begin{array}{l}\text { 6" vortex type, } 316 \text { SST components, displays, } 4 \\
\text { to } 20 \text { ma output, standard process connection } \\
\text { Source: Information from Emerson Process Management }\end{array}$ & $\$ 5,500$ \\
\hline $\begin{array}{l}\text { Instrument } \\
\text { Wiring }\end{array}$ & $\begin{array}{l}22 \text { GA Copper wire UL1007/UL1569 } \\
\text { Source: Waytek Inc. at www.waytekwire.com @ 500' qty }\end{array}$ & $\$ 0.02 / \mathrm{ft}$ \\
\hline Power Wiring & $\begin{array}{l}22 \text { GA Copper wire UL1007/UL1569 } \\
\text { Source: Waytek Inc. at www.waytekwire.com @ 500' qty }\end{array}$ & $\$ 0.02 / \mathrm{ft}$ \\
\hline Conduit & $\begin{array}{l}1 / 2 \prime \prime, 100^{\prime} \text { pack, Highly flexible black PVC tubing, } \\
\text { resistant to oil, water, and corrosion } \\
\text { Source: Waytek Inc. at www.waytekwire.com @ 550’ qty }\end{array}$ & $\$ 0.58 / \mathrm{ft}$ \\
\hline
\end{tabular}




\section{Bill of Materials for Pathways}

While most of the photobiological work has been done in a laboratory scaled environment under conditions uneconomical for large-scale production, the food industry has some experience at growing these organisms at larger scales. Looking at both sources, we have determined that the most practical means of hydrogen production with a photobiological system for each of the 5 photobiological pathways.

\subsection{B-1 Pathway Production Plant}

The B-1 Pathway is a Chemostat II photobiological reactor system using a mutant-antenna Chlamydomonas reinhardtii oxygen-tolerant variant as the $\mathrm{H}_{2}$ production microorganism. As a Chemostat II, the initial algal colony is grown at the normal cell growth rate until final colony concentration is reached, and then the process is switched over to steady-state mode where simultaneous growth and hydrogen production occur in the reactor beds. This is achieved by manipulating the nutrients and carbon dioxide provided. $\mathrm{H}_{2}$ production is projected at $9.2 \%$ solar-to-hydrogen efficiency and corresponds to a future optimized organism. Sufficient cellular activity to keep the micro-organism during $\mathrm{H}_{2}$ production healthy is assumed to occur with new cell growth taking place at a reduced rate compared to wild-type organisms ( $20 \%$ per day vs. $\sim 80 \%$ per day).

Twenty racetrack raceways of approximately $40 \mathrm{ft}$ width by $1090 \mathrm{ft}$ length are used to produce an average of $1,000 \mathrm{kgH}_{2} /$ day throughout the year. The raceways have a liquid depth of $10 \mathrm{~cm}$ to correspond to full photon capture at a cell concentration of $0.2 \mathrm{~g} / \mathrm{L}$. Paddlewheels circulate the water/Chlamydomonas reinhardtii slurry. A slip stream of water/micro-organisms slurry is drawn off continuously to maintain the $0.2 \mathrm{~g} / \mathrm{L}$ microorganism concentration. Micro-organisms are removed from the recycle stream by a rotary drum filter. The slip stream volume removed is carefully matched to the growth rate to maintain a constant organism mass within the system (assuming a constant concentration of algae within the bed). The removed micro-organisms are taken to a land-fill, used in a subsequent fermentor, or otherwise disposed. Nutrients in the form of commercial grade fertilizer are mixed with the returning water to provide required nourishment to the microorganisms. $\mathrm{CO}_{2}$ is bubbled into a reservoir tank of the returning water to dissolve $\mathrm{CO}_{2}$ into the water for use by the micro-organisms. Only a very low amount of $\mathrm{CO}_{2}$ is needed to maintain cell health; thus $\mathrm{CO}_{2}$ does not appreciably accumulate in the headspace of the reactor beds.

The Chlamydomonas reinhardtii micro-organism produces a net product gas of $33.33 \% \mathrm{O}_{2}$ and $66.66 \% \mathrm{H}_{2}$ (plus water vapor). A piston compressor is used to compress the gas mixture to 300psi prior to separation. A pressure swing adsorption (PSA) system is used to purify the hydrogen gas stream.

Further details of the B-1 pathway are specified in Figure 2-1. The subassemblies of this pathway are shown in Figure 4-1. The complete bill of materials and capital costs of this production plant are shown in Figure 4-2. The total system cost is $\$ 2,164,488$. 
Figure 4-1. Production Plant Design for Oxygen-Tolerant Hydrogenase (Chlamy)

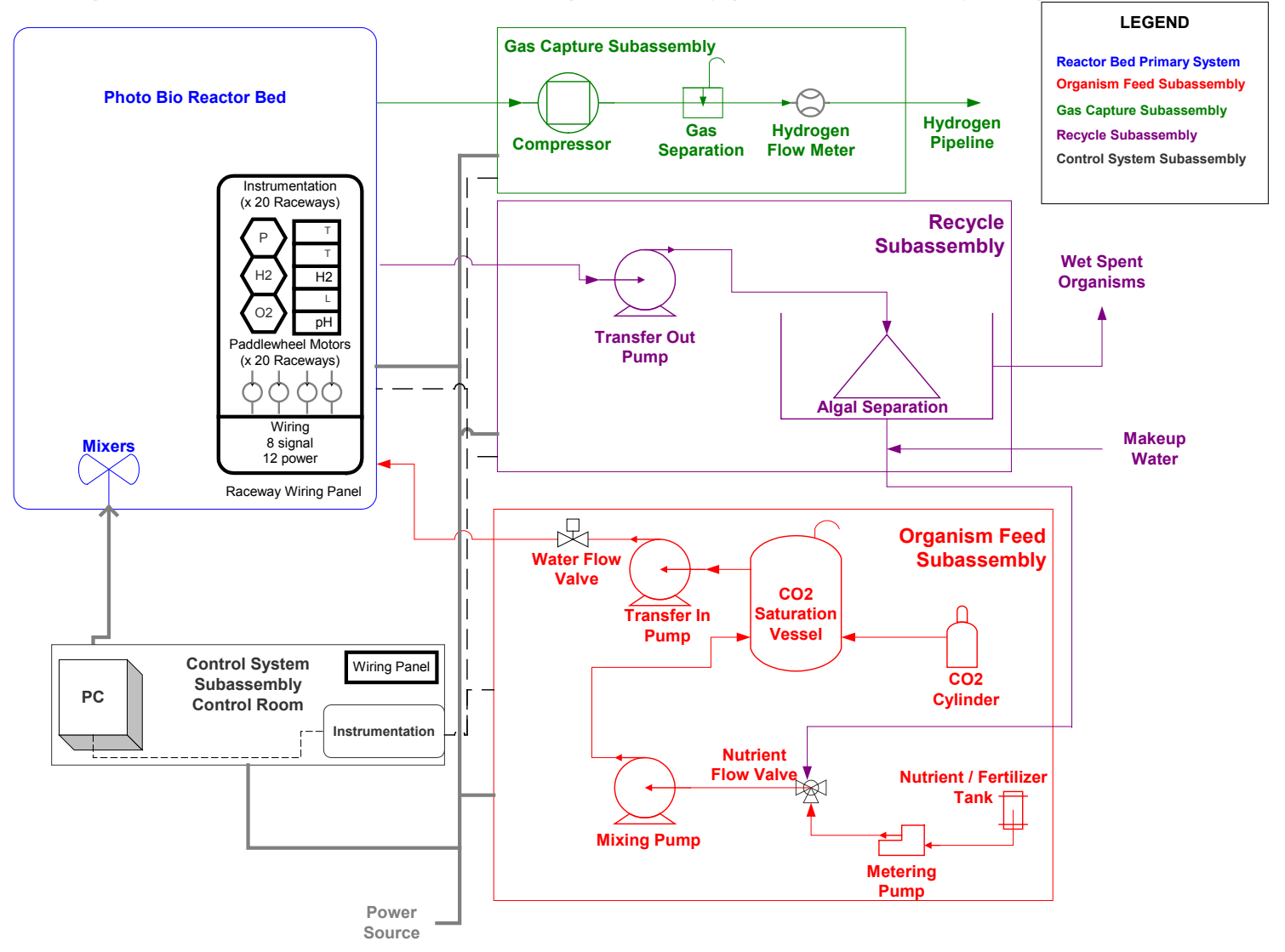


Figure 4-2. Bill of Materials for B-1 Pathway

\begin{tabular}{|c|c|c|c|c|c|c|c|c|}
\hline Description & Size Req'd & Unit Size & Units & & Unit cost & Qty Req'd & Total cost & Material / Part Description \\
\hline \multicolumn{9}{|l|}{ Photo Bio Reactor Bed Subassembly } \\
\hline Transparent Film & $87,080 \mathrm{~m} 2$ & 1 & $\mathrm{~m} 2$ & $\$$ & 0.54 & $87,080 \$$ & 46,871 & Polyethylene price quote at $\$ 0.54 / \mathrm{m2}(\$ 0.05 / \mathrm{ft} 2)$ \\
\hline Pond Lining & $93,998 \mathrm{~m} 2$ & 1 & $\mathrm{~m} 2$ & $\$$ & 0.47 & $93,998 \quad \$$ & 44,412 & Butyl Iubber, PVC, and LDPE (low density polyethylene)based on quote of $\$ 175.56$ for 4,000 oftz. \\
\hline Pond Edging & $13,982 \mathrm{~m}$ & 1 & $\mathrm{~m}$ & $\$$ & 7.00 & $13,982 \$$ & 97,876 & Unit Cost is engineering estimate at $\$ 7 / \mathrm{m}$ \\
\hline Installation of Ponds & & 1 & raceway & $\$$ & $26,083.00$ & $20 \$$ & 521,660 & Based on California labor rates. \\
\hline Paddlewheel Mixers & & 1 & each & $\$$ & $5,000.00$ & $40 \$$ & 200,000 & Est. paddlewheel cost. 4 per raceway. 18 raceways. \\
\hline Inlet Water Valve & 0.5 in & 1 & each & $\$$ & 43.46 & $20 \$$ & 869 & Price from Valvestore.com (http:///www.valvestore.com/prodinfo.asp?number=551032) \\
\hline Outlet Water Valve & $0.5 \mathrm{in}$ & 1 & each & $\$$ & 43.46 & $20 \$$ & 869 & Price from Valvestore.com (http:///www.valvestore.com//rodinfo.asp?number=551032) \\
\hline Outlet Gas Valve & $1.0 \mathrm{in}$ & 1 & each & $\$$ & 67.23 & $20 \$$ & 1,345 & Price from Valvestore.com (http://www.valvestore.com/prodinfo.asp?number=551032) \\
\hline Flanges & 0.5 in & 1 & each & $\$$ & 8.00 & $60 \$$ & 480 & Price from http://www.ancorp.com/line.aspx?:id=819 \\
\hline \multicolumn{9}{|l|}{ Gas Capture Subassembly } \\
\hline Compressor & $66 \mathrm{kgmol} / \mathrm{hr}$ & 66 & $\mathrm{kgmol} / \mathrm{hr}$ & $\$$ & $9,233.00$ & $1 \$$ & 606,207 & Using H2A Unit cost \\
\hline PSA & & & & $\$$ & $119,407.39$ & $1 \$$ & 119,407 & Using H2A scaling \\
\hline Raceway Collection Pipe & $40 \mathrm{ft}$ & 1 & $\mathrm{ft}$ & $\$$ & 1.57 & $40 \$$ & 63 & Sized for Peak Hydrogen production. Assuming Plastic Gas piping, $100 \mathrm{ft} /$ s velocity, uniform pipe diameter Ican be \\
\hline Main Collection Pipe & $1080 \mathrm{ft}$ & 1 & $\mathrm{ft}$ & $\$$ & 6.18 & $1080 \$$ & 6,674 & Sized for Peak Hydrogen production. Assuming Plastic Gas piping, $100 \mathrm{ft} /$ s velocity, uniform pipe diameter (can be \\
\hline Gas Capture Pipe & $50 \mathrm{ft}$ & 1 & $\mathrm{ft}$ & $\$$ & 6.18 & $50 \$$ & 309 & Sized for Peak Hydrogen production. Assuming Plastic Gas piping, $100 \mathrm{ft} /$ s velocity, uniform pipe diameter (can be \\
\hline \multicolumn{9}{|l|}{ Organism Feed Subassembly } \\
\hline $\begin{array}{l}\text { Transfer In Pump } \\
\text { The }\end{array}$ & $150 \mathrm{gpm}$ & 150 & $\mathrm{gpm}$ & $\$$ & 10,252 & $2 \$$ & 20,503 & Est. Based on Perry's chemical Handbook, Plant Design and Economics/Peters and Timmerhaus \\
\hline Nutrient Metering Pumps & $1468 \mathrm{gph}$ & 1 & each & $\$$ & 2,594 & $1 \$$ & 2,594 & Est. Based on Perry's chemical Handbook, Plant Design and Economics. Pumps nutrients into return flow \\
\hline Mixing Pump & $150 \mathrm{gpm}$ & 150 & $\mathrm{gpm}$ & $\$$ & 10,252 & $2 \$$ & 20,503 & Est. Based on Perry's Chemical Handbook, Plant Design and Economics/Peters and Timmerhaus \\
\hline $\mathrm{CO} 2$ Cylinder & $50 \mathrm{lb}$ & 50 & $\mathrm{lb}$ & $\$$ & 360 & $1 \$$ & 360 & Aluminum 6061-T6 alloy, 1800 psi Service Pressure, 50 lb. Capacity Part \#6125 (http:///kegman.net/carbon.htm) \\
\hline CO2 Saturation Vessel & $15000 \mathrm{gal}$ & 15000 & gal & $\$$ & 30,000 & $1 \$$ & 30,000 & Field erected Stainless Steel tank from Perry's chemical Handbook, Plant Design and Economics \\
\hline Nutrient Tank & $8 \mathrm{gal}$ & 10 & gal & $\$$ & 30.00 & $1 \$$ & 30 & 10 gallon Cylindrical Process Tank, Part \#0275-085 (http://www.watertanks.com/products/0275-085.asp) \\
\hline Raceway Slurry Collection Pipe & $40 \mathrm{ft}$ & 1 & $\mathrm{ft}$ & $\$$ & 1.00 & $40 \$$ & 40 & Pricing based off of Estimates from PVC Plastic Corp. Assumes $10 \mathrm{ft} / \mathrm{second}$ flow rate and Density of $1 \mathrm{~g} / \mathrm{ml}$ \\
\hline Main Slurry Collection Pipe & $1080 \mathrm{ft}$ & 1 & $\mathrm{ft}$ & $\$$ & 2.12 & $1080 \$$ & 2,290 & Pricing based off of Estimates from PVC Plastic Corp. Assumes $10 \mathrm{ft} / \mathrm{sec}$ cond flow rate and Density of $1 \mathrm{~g} / \mathrm{ml}$ \\
\hline Recycle-Feed Transfer Pipe & $180 \mathrm{ft}$ & 1 & $\mathrm{ft}$ & $\$$ & 4.31 & $180 \$$ & 776 & Pricing based off of Estimates from PVC Plastic Corp. Assumes $10 \mathrm{ft} / \mathrm{sec}$ cond flow rate and Density of $1 \mathrm{~g} / \mathrm{ml}$ \\
\hline \multicolumn{9}{|l|}{ Recycle Subassembly } \\
\hline Rotary Drum filter & $9639 \mathrm{gph}$ & 3750 & $\mathrm{gph}$ & $\$$ & $87,000.00$ & $3 \$$ & 261,000 & Information from Dana Kent at Advanced Aquaculture Inc. on Hydrotech Drum Filter \\
\hline Transfer Out Pump & $150 \mathrm{gpm}$ & 150 & $\mathrm{gpm}$ & $\$$ & 10,252 & $2 \$$ & 20,503 & Est. Based on Perry's chemical Handbook, Plant Design and Economics/Peters and Timmerhaus \\
\hline Main Slurry Feed Pipe & $1080 \mathrm{ft}$ & 1 & $\mathrm{ft}$ & $\$$ & 2.12 & $1080 \$$ & 2,290 & Pricing based off of Estimates from PVC Plastic Corp. Assumes $10 \mathrm{ft} / \mathrm{sec}$ cond flow rate and Density of $1 \mathrm{~g} / \mathrm{ml}$ \\
\hline Raceway Slurry Feed Pipe & $40 \mathrm{ft}$ & 1 & $\mathrm{ft}$ & $\$$ & 1.00 & $40 \$$ & 40 & Pricing based of of Estimates from PVC Plastic Corp. Assumes $10 \mathrm{ft} / \mathrm{sec}$ end flow rate and Density of $1 \mathrm{~g} / \mathrm{ml}$ \\
\hline \multicolumn{9}{|r|}{ 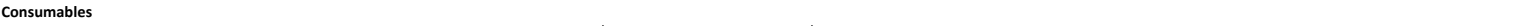 } \\
\hline Initial $\mathrm{CO} 2$ & $5241 \mathrm{lb}$ & 50 & Ib & $\$$ & 35.00 & $105 \$$ & 3,675 & Cost based on average fertilizer use for Aquaculture and average fertilizer costs from the USDA \\
\hline Initial Nutrients & $0.42 \mathrm{lb}$ & 1 & $\mathrm{lb}$ & $\$$ & 0.20 & $0 \$$ & 0 & NFC Company, Chicago, IL (800) 7344515 \\
\hline Initial Water & $2,142,278 \mathrm{gal}$ & 1 & gal & $\$$ & 0.0017 & $2,142,278 \$$ & 3,567 & H2A Feedstock Costs \\
\hline \multicolumn{9}{|l|}{ Control System } \\
\hline Control Room & $160 \mathrm{ft} 2$ & 1 & $\mathrm{ft} 2$ & $\$$ & 50.00 & $160 \$$ & 8,000 & comes from price quote of $\$ 50 / f t 2$ from http://www.buyerzone.com/industrial/modular_buildings/prefab__uuide.htm \\
\hline Control Room Wiring Panel & & 1 & & $\$$ & $3,000.00$ & $1 \$$ & $3,000.00$ & Consultation with Innomation Systems Inc. \\
\hline Raceway wiring Panel & & 1 & & $\$$ & 146.00 & $20 \$$ & 2,920 & Information from Tessco Technologies Inc. \\
\hline Computer and Monitor & & 1 & & $\$$ & $1,500.00$ & $1 \$$ & $1,500.00$ & Information from Emerson Process Management \\
\hline Labview Software & & 1 & & $\$$ & $4,299.00$ & $1 \$$ & $4,299.00$ & Information from Emerson Process Management \\
\hline Level Indicators & & 1 & & $\$$ & 714.00 & $20 \$$ & $14,280.00$ & Omega Engineering Inc. LVR51 Liquid Level Float Transmitter + DP i32 Meter \\
\hline Pressure Sensors & & 1 & & $\$$ & 345.00 & $20 \$$ & $6,900.00$ & Omega Engineering Inc. PX209 Pressure Trnasducer + DPi32 Meter \\
\hline Hydrogen Area Sensors & & 1 & & $\$$ & $7,600.00$ & $10 \$$ & $76,000.00$ & Honeywell 7866 Gas Analyzer (http://www.lesmman.com/unleashd//catalog/analytical/analyt_hwhydrogengas.htm) \\
\hline Air Temperature Meter & & 1 & & $\$$ & 599.00 & $1 \$$ & 599.00 & Omega DP81T Meter \\
\hline Air Temperature Indicator & & 1 & & $\$$ & 38.00 & $20 \$$ & 760.00 & Omega TH-10-44000 Thermistor Probe \\
\hline Water Temperature Indicator & & 1 & & $\$$ & - & $20 \$$ & - & Comes with the PH sensor \\
\hline $\mathrm{pH}$ level Indicator & & 1 & & $\$$ & 435.00 & $20 \$$ & $8,700.00$ & Omega Engineering IInc. PHE - 6510 PH electrode + DP24-PH Meter \\
\hline Oxygen Area Sensors & & 1 & & $\$$ & - & $20 \$$ & - & Comes with H2 Sensor \\
\hline Nutrient Flow Valve & & 1 & & $\$$ & $5,500.00$ & $1 \$$ & $5,500.00$ & Information from Emerson Process Management \\
\hline Water Flow Valve & & 1 & & $\$$ & $5,500.00$ & $1 \$$ & $5,500.00$ & Information from Emerson Process Management \\
\hline Hydrogen Flow Meter & & 1 & & $\$$ & $5,500.00$ & $1 \$$ & $5,500.00$ & Information from Emerson Process Management \\
\hline Instrument Wiring & $69270 \mathrm{ft}$ & 1 & $\mathrm{ft}$ & $\$$ & 0.02 & $69270 \$$ & $1,343.84$ & Information from Waytek Inc. at waytekwire.com \\
\hline Power Wiring & $85350 \mathrm{ft}$ & 1 & $\mathrm{ft}$ & $\$$ & 0.02 & $85350 \$$ & $1,655.79$ & Information from Waytek Inc. at waytekwire.com \\
\hline Conduit & $4860 \mathrm{ft}$ & 1 & $\mathrm{ft}$ & $\$$ & 0.58 & $4860 \$$ & $2,817.83$ & Information from Waytek Inc. at waytekwire.com \\
\hline
\end{tabular}

\subsection{B-2 Pathway Production Plant}

The B-2 pathway is a Chemostat II photobiological reactor system using a mutant-antenna cyanobacteria (often called blue-green algae) oxygen-tolerant variant as the $\mathrm{H}_{2}$ production microorganism. As a Chemostat II, the initial bacteria colony is grown at the normal cell growth rate until final colony concentration is reached, and then the process is switched over to steady-state mode where simultaneous growth and hydrogen production occur in the reactor beds. This is achieved by manipulating the nutrients and carbon dioxide provided. $\mathrm{H}_{2}$ production is projected at $9.2 \%$ solar-to-hydrogen efficiency and corresponds to a future optimized organism. Sufficient cellular activity to keep the micro-organism healthy during $\mathrm{H}_{2}$ production is assumed to occur with new cell growth taking place at a reduced rate compared to wild-type organisms (20\% per day vs. $\sim 80 \%$ per day). The B-2 pathway is very similar to the B-1 pathway with the primary difference being type of micro-organism.

Twenty racetrack raceways of approximately $40 \mathrm{ft}$ width by $1090 \mathrm{ft}$ length are used to produce an average of $1,000 \mathrm{kgH}_{2}$ /day over the year. The raceways have a liquid depth of $10 \mathrm{~cm}$ to correspond to full photon capture at a cell concentration of $0.2 \mathrm{~g} / \mathrm{L}$. Paddlewheels circulate the water/bacteria slurry. A slip stream of water/micro-organisms slurry is drawn off continuously to maintain the $0.2 \mathrm{~g} / \mathrm{L}$ micro-organism concentration. Micro-organisms 
are removed from the recycle stream by a rotary drum filter. The slip stream volume removed is carefully matched to the growth rate to maintain a constant organism mass within the system (assuming a constant concentration of algae within the bed). The removed micro-organisms are taken to a land-fill, used in a subsequent fermentor, or otherwise disposed. Nutrients in the form of commercial grade fertilizer are mixed with the returning water to provide required nourishment to the micro-organisms. $\mathrm{CO}_{2}$ is bubbled into a reservoir tank of the returning water to dissolve $\mathrm{CO}_{2}$ into the water for use by the micro-organisms. Only a very low amount of $\mathrm{CO}_{2}$ is needed to maintain cell health; thus $\mathrm{CO}_{2}$ does not appreciably accumulate in the headspace of the reactor beds.

The cyanobacteria micro-organisms produce a net product gas of $33.33 \% \mathrm{O}_{2}$ and $66.66 \% \mathrm{H}_{2}$ (plus water vapor). A piston compressor is used to compress the gas mixture to 300psi prior to separation. A pressure swing adsorption (PSA) system is used to purify the hydrogen gas stream.

Further details of the B-2 pathway are specified in Figure 2-1. The subassemblies of this pathway are shown in Figure 4-3. The complete bill of materials and capital costs of this production plant are shown in Figure 4-4. The total system cost is $\$ 2,164,488$.

\section{Figure 4-3. Production Plant Design for Oxygen-Tolerant Hydrogenase} (Cyanobacteria)

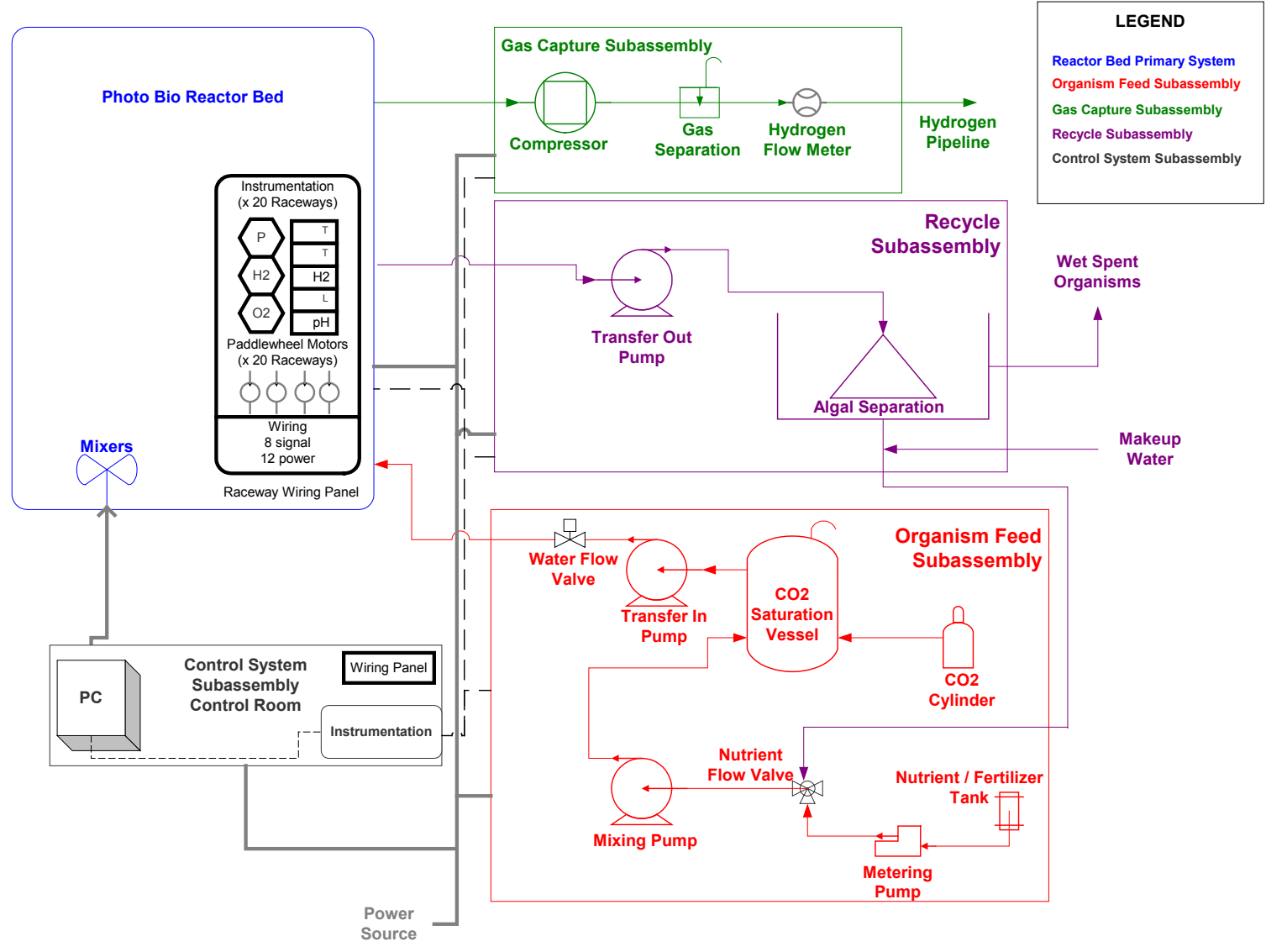


Figure 4-4. Bill of Materials for B-2 Pathway

\begin{tabular}{|c|c|c|c|c|c|c|c|c|}
\hline Description & Size Req'd & Unit Size & Units & & Unit cost & Qty Req'd & Total Cost & Material / Part Description \\
\hline \multicolumn{9}{|l|}{ Photo Bio Reactor Bed Subassembly } \\
\hline Transparent Film & $87,080 \mathrm{~m} 2$ & 1 & $\mathrm{~m} 2$ & $\$$ & 0.54 & $87,080 \$$ & 46,871 & Polyethylene price quote at $50.54 / \mathrm{m} 2(50.05 / \mathrm{tt} 2)$ \\
\hline Pond Lining & $93,998 \mathrm{~m} 2$ & 1 & $\mathrm{~m} 2$ & $\$$ & 0.47 & $93,998 \$$ & 44,412 & Butyl rubber, PVC, and LDPE (low density polyethylene)based on quote of $\$ 175.56$ for 4,000 ftz. \\
\hline Pond Edging & $13,982 \mathrm{~m}$ & 1 & $\mathrm{~m}$ & $\$$ & 7.00 & $13,982 \$$ & 97,876 & Unit cost is engineering estimate at $\$ 7 / \mathrm{m}$ \\
\hline Installation of Ponds & & 1 & raceway & $\$$ & $26,083.00$ & $20 \$$ & 521,660 & Based on California labor rates. \\
\hline Paddlewheel Mixers & & 1 & each & $\$$ & $5,000.00$ & $40 \$$ & 200,000 & Est. paddlewheel cost. 4 per raceway. 18 raceways. \\
\hline Inlet Water Valve & $0.5 \mathrm{in}$ & 1 & each & $\$$ & 43.46 & $20 \$$ & 869 & Price from ValveStore.com (http://wwww.valvestore.com/prodinfo.asp?number=551032) \\
\hline Outlet Water Valve & $0.5 \mathrm{in}$ & 1 & each & $\$$ & 43.46 & $20 \$$ & 869 & Price from ValveStore.com (http:///www.valvestore.com/prodinfo.asp?number=551032) \\
\hline Outlet Gas Valve & $1.0 \mathrm{in}$ & 1 & each & $\$$ & 67.23 & $20 \$$ & 1,345 & Price from Valvestore.com (http:///www.valvestore.com/prodinfo.asp?number=551032) \\
\hline Flanges & 0.5 in & 1 & each & $\$$ & 8.00 & $60 \$$ & 480 & Price from http://www.ancorp.com/line.aspx?:id=819 \\
\hline \multicolumn{9}{|l|}{ Gas Capture Subassembly } \\
\hline Compressor & $66 \mathrm{kgmol} / \mathrm{hr}$ & 66 & $\mathrm{kgmol} / \mathrm{hr}$ & $\$$ & $9,233.00$ & $1 \$$ & 606,207 & Using HZA Unit cost \\
\hline PSA & & & & $\$$ & $119,407.39$ & $1 \$$ & 119,407 & Using H2A scaling \\
\hline Raceway Collection Pipe & $40 \mathrm{ft}$ & 1 & $\mathrm{ft}$ & $\$$ & 1.57 & $40 \$$ & 63 & Sized for Peak Hydrogen production. Assuming Plastic Gas piping, $100 \mathrm{ft} / \mathrm{s}$ velocity, uniform pipe diameter Ican be \\
\hline Main Collection Pipe & $1080 \mathrm{ft}$ & 1 & $\mathrm{ft}$ & $\$$ & 6.18 & $1080 \$$ & 6,674 & Sized for Peak Hydrogen production. Assuming Plastic Gas piping, $100 \mathrm{ft} /$ /s velocity, uniform pipe diameter (can be \\
\hline Gas Capture Pipe & $50 \mathrm{ft}$ & 1 & $\mathrm{ft}$ & \$ & 6.18 & $50 \$$ & 309 & Sized for Peak Hydrogen production. Assuming Plastic Gas piping, $100 \mathrm{ft} / \mathrm{s}$ velocity, uniform pipe diameter Ican be \\
\hline \multicolumn{9}{|l|}{ Organism Feed Subassembly } \\
\hline Transfer In Pump & $150 \mathrm{gpm}$ & 150 & $\mathrm{gpm}$ & $\$$ & 10,252 & $2 \$$ & 20,503 & Est. Based on Perry's Chemical Handbook, Plant Design and Economics/Peters and Timmerhaus \\
\hline Nutrient Metering Pumps & $1468 \mathrm{gph}$ & 1 & each & $\$$ & 2,594 & $1 \$$ & 2,594 & Est. Based on Perry's chemical Handbook, Plant Design and Economics. Pumps nutrients into return flow \\
\hline Mixing Pump & $150 \mathrm{gpm}$ & 150 & gpm & $\$$ & 10,252 & $2 \$$ & 20,503 & Est. Based on Perry's Chemical Handbook, Plant Design and Economics/Peters and Timmerhaus \\
\hline CO2 Cylinder & $50 \mathrm{lb}$ & 50 & $\mathrm{lb}$ & $\$$ & 360 & $1 \$$ & 360 & Aluminum 6061-T6 alloy, 1800 psi Service Pressure, 50 lb. Capacity Part \#6125 (http:///kegman.net/carbon.htm) \\
\hline CO2 Saturation Vessel & $15000 \mathrm{gal}$ & 15000 & gal & $\$$ & 30,000 & $1 \$$ & 30,000 & Field erected Stainless Steel tank from Perry's chemical Handbook, Plant Design and Economics \\
\hline Nutrient Tank & $8 \mathrm{gal}$ & 10 & gal & $\$$ & 30.00 & $1 \$$ & 30 & 10 gallon Cylindrical Process Tank, Part \#0275-085 (http://www.watertanks.com/products/0275-085.asp) \\
\hline Raceway Slurry Collection Pipe & $40 \mathrm{ft}$ & 1 & $\mathrm{ft}$ & $\$$ & 1.00 & $40 \$$ & 40 & Pricing based off of Estimates from PVC Plastic Corp. Assumes $10 \mathrm{ft} / \mathrm{sec}$ end flow rate and Density of $1 \mathrm{~g} / \mathrm{ml}$ \\
\hline Main Slurry Collection Pipe & $1080 \mathrm{ft}$ & 1 & $\mathrm{ft}$ & $\$$ & 2.12 & $1080 \$$ & 2,290 & Pricing based off of Estimates from PVC Plastic Corp. Assumes $10 \mathrm{ft} / \mathrm{second}$ flow rate and Density of $1 \mathrm{~g} / \mathrm{ml}$ \\
\hline Recycle-Feed Transfer Pipe & $180 \mathrm{ft}$ & 1 & $\mathrm{ft}$ & $\$$ & 4.31 & $180 \$$ & 776 & Pricing based off of Estimates from PVC Plastic Corp. Assumes $10 \mathrm{ft} / \mathrm{sec}$ ond flow rate and Density of $1 \mathrm{~g} / \mathrm{ml}$ \\
\hline \multicolumn{9}{|l|}{ Recycle Subassembly } \\
\hline Rotary Drum filter & $9639 \mathrm{gph}$ & 3750 & $\mathrm{gph}$ & $\$$ & $87,000.00$ & $3 \$$ & 261,000 & Information from Dana Kent at Advanced Aquaculture Inc. on Hydrotech Drum Filter \\
\hline Transfer Out Pump & $150 \mathrm{gpm}$ & 150 & $\mathrm{gpm}$ & $\$$ & 10,252 & $2 \$$ & 20,503 & Est. Based on Perry's Chemical Handbook, Plant Design and Economics/Peters and Timmerhaus \\
\hline Main Slurry Feed Pipe & $1080 \mathrm{ft}$ & 1 & $\mathrm{ft}$ & $\$$ & 2.12 & $1080 \$$ & 2,290 & Pricing based off of Estimates from PVC Plastic Corp. Assumes $10 \mathrm{ft} / \mathrm{sec}$ cond flow rate and Density of $1 \mathrm{~g} / \mathrm{ml}$ \\
\hline Raceway Slurry Feed Pipe & $40 \mathrm{ft}$ & 1 & $\mathrm{ft}$ & $\$$ & 1.00 & $40 \$$ & 40 & Pricing based off of Estimates from PVC Plastic Corp. Assumes $10 \mathrm{ft} / \mathrm{sec}$ ond flow rate and Density of $1 \mathrm{~g} / \mathrm{ml}$ \\
\hline \multicolumn{9}{|l|}{ Consumables } \\
\hline Initial CO2 & $5241 \mathrm{lb}$ & 50 & Ib & $\$$ & 35.00 & $105 \$$ & 3,675 & Cost based on average fertilizer use for Aquaculture and average fertilizer costs from the USDA \\
\hline Initial Nutrients & $0.42 \mathrm{lb}$ & 1 & lb & $\$$ & 0.20 & $0 \$$ & 0 & NFC Company, Chicago, IL (800) 7344515 \\
\hline Initial Water & $2,142,278$ gal & 1 & gal & $\$$ & 0.0017 & $2,142,278 \$$ & 3,567 & HZA Feedstock Costs \\
\hline \multicolumn{9}{|l|}{ Control System } \\
\hline Control Room & $160 \mathrm{ft} 2$ & 1 & $\mathrm{ft} 2$ & $\$$ & 50.00 & $160 \$$ & 8,000 & comes from price quote of $\$ 50 / \mathrm{ftz}$ from http://www.buyerzone.com/industrial//modular_buildings//refab__guide.html \\
\hline Control Room Wiring Panel & & 1 & & $\$$ & $3,000.00$ & $1 \$$ & $3,000.00$ & Consultation with Innomation Systems Inc. \\
\hline Raceway wiring Panel & & 1 & & $\$$ & 146.00 & $20 \$$ & 2,920 & Information from Tessco Technologies Inc. \\
\hline Computer and Monitor & & 1 & & $\$$ & $1,500.00$ & $1 \$$ & $1,500.00$ & Information from Emerson Process Management \\
\hline Labview Software & & 1 & & $\$$ & $4,299.00$ & $1 \$$ & $4,299.00$ & Information from Emerson Process Management \\
\hline Level Indicators & & 1 & & $\$$ & 714.00 & $20 \$$ & $14,280.00$ & Omega Engnineering Inc. LVR51 Liquid Level Float Transmitter + DP 332 Meter \\
\hline Pressure Sensors & & 1 & & $\$$ & 345.00 & $20 \$$ & $6,900.00$ & Omega Engineering Inc. PX209 Pressure Trnasducer + DPi32 Meter \\
\hline Hydrogen Area Sensors & & 1 & & $\$$ & $7,600.00$ & $10 \$$ & $76,000.00$ & Honeywell 7866 Gas Analyzer (http://www.lesman.com/unleashd/catalog/analytical//analyt_hwhydrogengas.htm) \\
\hline Air Temperature Meter & & 1 & & $\$$ & 599.00 & $1 \$$ & 599.00 & Omega DP81T Meter \\
\hline Air Temperature Indicator & & 1 & & $\$$ & 38.00 & $20 \$$ & 760.00 & Omega TH-10-44000 Thermistor Probe \\
\hline Water Temperature Indicator & & 1 & & $\$$ & - & $20 \$$ & $\cdot$ & Comes with the PH sensor \\
\hline $\mathrm{pH}$ level Indicator & & 1 & & $\$$ & 435.00 & $20 \$$ & $8,700.00$ & Omega Engineering Inc. PHE - 6510 PH electrode + DP24-PH Meter \\
\hline Oxygen Area Sensors & & 1 & & $\$$ & - & $20 \$$ & - & Comes with H2 Sensor \\
\hline Nutrient Flow Valve & & 1 & & $\$$ & $5,500.00$ & $1 \$$ & $5,500.00$ & Information from Emerson Process Management \\
\hline Water Flow Valve & & 1 & & $\$$ & $5,500.00$ & $1 \$$ & $5,500.00$ & Information from Emerson Process Management \\
\hline Hydrogen Flow Meter & & 1 & & $\$$ & $5,500.00$ & $1 \$$ & $5,500.00$ & Information from Emerson Process Management \\
\hline Instrument Wiring & $69270 \mathrm{ft}$ & 1 & $\mathrm{ft}$ & $\$$ & 0.02 & $69270 \$$ & $1,343.84$ & Information from Waytek Inc. at waytekwire.com \\
\hline Power Wiring & $85350 \mathrm{ft}$ & 1 & $\mathrm{ft}$ & $\$$ & 0.02 & $85350 \$$ & $1,655.79$ & Information from Waytek Inc. at waytekwire.com \\
\hline Conduit & $4860 \mathrm{ft}$ & 1 & $\mathrm{ft}$ & $\$$ & 0.58 & $4860 \$$ & $2,817.83$ & Information from Waytek Inc. at waytekwire.com \\
\hline
\end{tabular}

\subsection{B-3 Pathway Production Plant}

The B-3 pathway is a single-bed photobiological reactor system using a mutant-antenna Chlamydomonas reinhardtii sulfate permease variant as the $\mathrm{H}_{2}$ production micro-organism. As a single bed reactor, the initial algal colony is grown at the normal cell growth rate until final colony concentration is reached. After sealing the system, the oxygen evolution rate, reduced due to the mutation in the sulfate permease proteins, falls below the rate of oxidative respiration, leading to an anaerobic system that produces hydrogen for a period of roughly 3 days. When the organism's capability to produce hydrogen under these conditions has diminished, the system undergoes a 4-day regeneration/growth phase wherein $\mathrm{O}_{2}$ is given to the micro-organisms, halting $\mathrm{H}_{2}$ production through hydrogenase inhibition and encouraging cellular growth. This is followed by another 3-day $\mathrm{H}_{2}$ production phase under anaerobic conditions, when the outside $\mathrm{O}_{2}$ addition is stopped. $\mathrm{H}_{2}$ production is projected at $5.2 \%$ average solar-to-hydrogen efficiency and corresponds to a future optimized organism.

Thirty-eight raceways of approximately $40 \mathrm{ft}$ width by $1090 \mathrm{ft}$ length are used to produce an average of $1,000 \mathrm{kgH}_{2} /$ day throughout the year. The raceways have a liquid depth of $10 \mathrm{~cm}$ to correspond to full photon capture at a cell concentration of $0.2 \mathrm{~g} / \mathrm{L}$. In order to allow 
enough growth during the regeneration phase, however, the concentration will be higher during reactor operation. Paddlewheels circulate the water/Chlamydomonas reinhardtii slurry. Nutrients in the form of commercial grade fertilizer are mixed with make-up water stream to provide required nourishment to the microorganisms.

The Chlamydomonas reinhardtii sulfate permease mutant will produce a large amount of carbon dioxide that will quickly saturate the process water and begin filling the headspace. A piston compressor is used to compress the hydrogen to 300psi. A pressure swing adsorption (PSA) system is used to purify the hydrogen gas stream to five nines purity and return the $\mathrm{CO}_{2}$ to the $\mathrm{CO}_{2}$ saturation vessel where it will be mixed with a slipstream of water that has been removed from raceways low in saturated $\mathrm{CO}_{2}$ during their regeneration phase. During the regeneration phase all product gases will be vented.

Further details of the B-3 pathway are specified in Figure 2-1. The subassemblies of this pathway are shown in Figure 4-5. The complete bill of materials and capital costs of this production plant are shown in Figure 4-6. The total system cost is $\$ 3,562,117$.

Figure 4-5. Production Plant Design for Sulfate Permease (Chlamy)

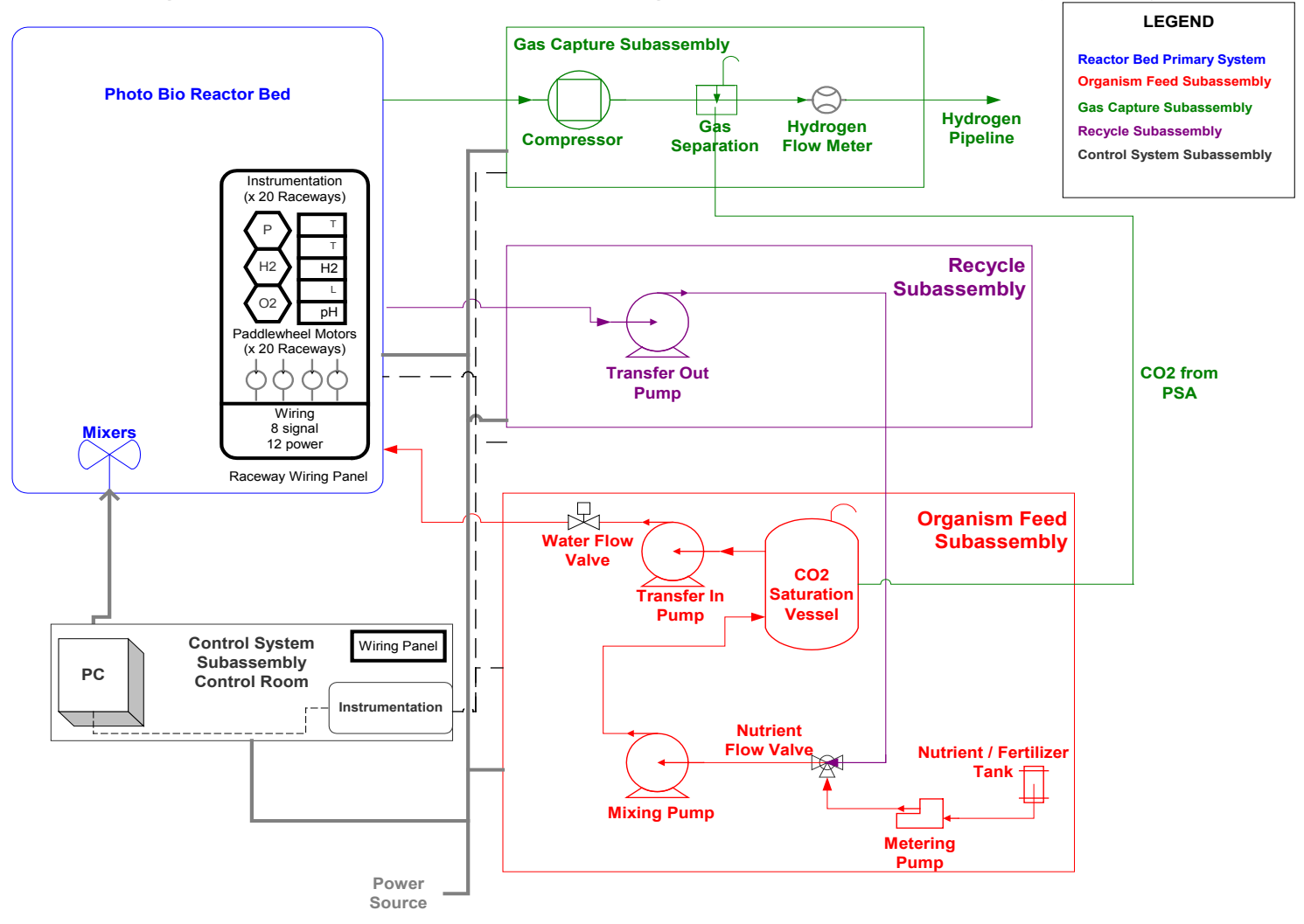




\section{Figure 4-6. Bill of Materials for B-3 Pathway}

\begin{tabular}{|c|c|c|c|c|c|c|c|c|}
\hline Description & Size Req'd & Unit Size & Units & \multicolumn{2}{|r|}{ Unit cost } & Qty Reg'd & Total Cost & \multirow{2}{*}{ Material / Part Description } \\
\hline \multirow[t]{2}{*}{$\begin{array}{l}\text { Photo Bio Reactor Bed Subassembly } \\
\text { Transparent Film }\end{array}$} & & & & & & & & \\
\hline & $165,452 \mathrm{~m} 2$ & 1 & $\mathrm{~m} 2$ & $\$$ & 0.54 & $165,452 \$$ & $89,054 \mathrm{P}$ & Polyethylene price quote at $50.54 / \mathrm{m} 2(50.05 / \mathrm{tr} 2)$ \\
\hline Pond Lining & $178,597 \mathrm{~m} 2$ & 1 & $\mathrm{~m} 2$ & $\$$ & 0.47 & $178,597 \$$ & 84,382 в & Butyl rubber, PVC, and LDPE (low density polyethylene)based on quote of $\$ 175.56$ for 4,000 oftz. \\
\hline Pond Edging & $26,566 \mathrm{~m}$ & 1 & $\mathrm{~m}$ & $\$$ & 7.00 & $26,566 \$$ & 185,965 & Unit Cost is sengineering estimate at $\$ 7 / \mathrm{m}$ \\
\hline Installation of Ponds & & 1 & raceway & $\$$ & $26,083.00$ & $38 \$$ & 991,154 в & Based on California labor rates. \\
\hline Paddlewheel Mixers & & 1 & each & $\$$ & $5,000.00$ & $76 \$$ & 380,000 e & Est. paddlewheel cost. 4 per raceway. 18 raceways. \\
\hline Inlet Water Valve & $0.5 \mathrm{in}$ & 1 & each & \$ & 43.46 & 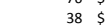 & $1,651 \mathrm{P}$ & Price from Valvestore.com (http://www.valvestore.com/prodinfo.asp?number= $=551032$ ) \\
\hline Outlet Water Valve & 0.5 in & 1 & each & $\$$ & 43.46 & $38 \$$ & $1,651 \mathrm{p}$ & Price from Valvestore.com (http:///www.valvestore.com/prodinfo.asp??number=551032) \\
\hline Outlet Gas Valve & $1.0 \mathrm{in}$ & 1 & each & $\$$ & 67.23 & $38 \$$ & $2,555 \mathrm{p}$ & Price from ValveStore.com (http:///www.valvestore.com//rodinfo.asp?number=551032) \\
\hline Flanges & $0.5 \mathrm{in}$ & 1 & each & $\$$ & 8.00 & $114 \$$ & $912 \mathrm{P}$ & Price from http://www.ancorp.com/line.aspx?id=819 \\
\hline \multicolumn{9}{|l|}{ Gas Capture Subassembly } \\
\hline Compressor & $65 \mathrm{kgmol} / \mathrm{hr}$ & 65 & $\mathrm{kgmol} / \mathrm{hr}$ & $\$$ & $9,233.00$ & $1 \$$ & 602,582 u & Using H2A Unit cost \\
\hline PSA & & & & $\$$ & $80,034.78$ & $1 \$$ & 80,035 & Using HZA scaling \\
\hline Raceway Collection Pipe & $76 \mathrm{ft}$ & 1 & $\mathrm{ft}$ & $\$$ & 2.80 & $76 \$$ & $213 \mathrm{~s}$ & Sized for Peak Hydrogen production. Assuming Plastic Gas piping, $100 \mathrm{ft}$ /s velocity, uniform pipe diameter (can be \\
\hline Main Collection Pipe & $2160 \mathrm{ft}$ & 1 & $\mathrm{ft}$ & \$ & 6.18 & $2160 \$$ & $13,349 \mathrm{~s}$ & Sized for Peak Hydrogen production. Assuming Plastic Gas piping, $100 \mathrm{ott} / \mathrm{s}$ velocity, uniform pipe diameter (can be \\
\hline Gas Capture Pipe & $350 \mathrm{ft}$ & 1 & $\mathrm{ft}$ & $\$$ & 6.18 & $350 \$$ & $2,163 \mathrm{~s}$ & Sized for Peak Hydrogen production. Assuming Plastic Gas piping, $100 \mathrm{ft} / \mathrm{s}$ velocity, uniform pipe diameter (can be \\
\hline \multicolumn{9}{|l|}{ Organism Feed Subassembly } \\
\hline Transfer In Pump & $150 \mathrm{gpm}$ & 150 & $\mathrm{gpm}$ & $\$$ & 10,252 & $16 \$$ & $164,027 \mathrm{E}$ & Est. Based on Perry's Chemical Handbook, Plant Design and Economics/Peters and Timmerhaus \\
\hline Nutrient Metering Pumps & $1468 \mathrm{gph}$ & 1 & each & $\$$ & 2,594 & $1 \$$ & 2,594 & Est. Based on Perry's Chemical Handbook, Plant Design and Economics. Pumps nutrients into return flow \\
\hline Mixing Pump & $150 \mathrm{gpm}$ & 150 & $\mathrm{gpm}$ & $\$$ & 10,252 & $16 \$$ & $164,027 \mathrm{E}$ & Est. Based on Perry's Chemical Handbook, Plant Design and Economics/Peters and Timmerhaus \\
\hline CO2 Cylinder & $50 \mathrm{lb}$ & 50 & lb & s & $\begin{array}{l}10,252 \\
360\end{array}$ & $1 \$$ & $360 \mathrm{~A}$ & Aluminum 6061 -T6 alloy, 1800 psi Service Pressure, 50 lb. Capacity Part \#6125 (http://kegman.net/carbon.htm) \\
\hline CO2 Saturation Vessel & $15000 \mathrm{gal}$ & 15000 & gal & $\begin{array}{c}3 \\
\$\end{array}$ & 30,000 & $\begin{array}{c}10 \\
10\end{array}$ & $300,000 \mathrm{~F}$ & Field erected Stainless steel tank from Perry's chemical Handbook, Plant Design and Economics \\
\hline Nutrient Tank & 15 gal & 10 & gal & $\$$ & 30.00 & $2 \$$ & 601 & 10 gallon CVyindrical Process Tank, Part t0275-085 (http:///www.watertanks.com/products $0275-085$.asp) \\
\hline Raceway Slurry Collection Pipe & $76 \mathrm{ft}$ & 1 & $\mathrm{ft}$ & s & 2.12 & $76 \$$ & $161 \mathrm{p}$ & Pricing based of of Estimates from PVC Plastic Corp. Assumes $10 \mathrm{t} / \mathrm{sec}$. \\
\hline $\begin{array}{l}\text { Main Slurry Collection Pipe } \\
\text { Mipe }\end{array}$ & $2160 \mathrm{ft}$ & 1 & $\mathrm{ft}$ & s & 8.51 & $2160 \$$ & $18,382 \mathrm{p}$ & 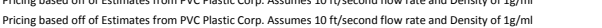 \\
\hline Recycle-Feed Transfer Pipe & $180 \mathrm{ft}$ & 1 & $\mathrm{ft}$ & $\$$ & 8.51 & $180 \$$ & $1,532 \mathrm{p}$ & Pricing based of of Estimates from PVC Plastic Corp. Assumes $10 \mathrm{t} / \mathrm{s} / \mathrm{scond}$ fllow rate and Density of $1 \mathrm{~g} / \mathrm{ml}$ \\
\hline \multicolumn{9}{|l|}{ Recycle Subassembly } \\
\hline Transfer Out Pump & $150 \mathrm{gpm}$ & 150 & $\mathrm{gpm}$ & $\$$ & 10,252 & $16 \$$ & 164,027 E & Est. Based on Perry's Chemical Handbook, Plant Design and Economics/Peters and Timmerhaus \\
\hline Raceway Slurry Collection Pipe & $76 \mathrm{ft}$ & 1 & $\mathrm{ft}$ & $\$$ & 8.51 & $76 \$$ & $647 \mathrm{p}$ & Pricing based off of Estimates from PVC Plastic Corp. Assumes $10 \mathrm{t} / \mathrm{s} / \mathrm{scond}$ fllow rate and Density of $1 \mathrm{~g} / \mathrm{ml}$ \\
\hline Main Slurry Collection Pipe & $2160 \mathrm{ft}$ & 1 & $\mathrm{ft}$ & $\$$ & 8.51 & $2160 \$$ & $18,382 \mathrm{p}$ & Pricing based of of Estimates from PVC Plassic Corp. Assumes $10 \mathrm{t} / \mathrm{sec}$. \\
\hline \multicolumn{9}{|l|}{ Consumables } \\
\hline Initial CO2 & $41629 \mathrm{lb}$ & 50 & lb & $\$$ & 35.00 & $833 \$$ & $29,155 \mathrm{c}$ & Cost based on average fertilizer use for Aquaculture and average fertilizer costs from the USDA \\
\hline Initial Nutrients & $0.78 \mathrm{lb}$ & 1 & $\mathrm{lb}$ & s & 0.20 & $1 \$$ & $\begin{aligned} 0 \\
29,103\end{aligned}$ & $\begin{array}{l}\text { NFC Company, Chicago, IL ( } 800 \text { ) } 7344515 \\
\text { S }\end{array}$ \\
\hline Initial Water & $3,997,674$ gal & 1 & gal & $\$$ & 0.0017 & $3,997,674 \$$ & 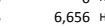 & H2A Feedstock Costs \\
\hline \multicolumn{9}{|r|}{ 然 } \\
\hline Control Room & $160 \mathrm{ft} 2$ & 1 & $\mathrm{ft} 2$ & $\$$ & 50.00 & $160 \$$ & $8,000 \mathrm{c}$ & comes from price quote of $\$ 50 /$ trt from http://www.buyerzone.com/industrial/modular_buildings/prefab_guide.html \\
\hline Control Room Wiring Panel & & 1 & & s & $3,000.00$ & $1 \$$ & $3,000.00 \mathrm{c}$ & 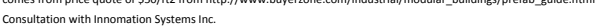 \\
\hline Raceway wiring Panel & & 1 & & \$ & 146.00 & $38 \$$ & 5,548 & Information from Tessco Technologies Inc. \\
\hline Computer and Monitor & & 1 & & $\$$ & $1,500.00$ & $1 \$$ & $1,500.00$ & Information from Emerson Process Management \\
\hline Labview Software & & 1 & & s & $4,299.00$ & $1 \$$ & $4,299.00$ & Information from Emerson Process Management \\
\hline Level Indicators & & 1 & & \$ & 714.00 & $38 \$$ & $27,132.00 \mathrm{o}$ & Omega Engineering Inc. LVR51 Liquid Level Float Transmitter + DPi32 Meter \\
\hline Pressure Sensors & & 1 & & \$ & 345.00 & $38 \$$ & $13,110.00$ & Omega Engineering Inc. PX209 Pressure Trnasducer + DPi32 Meter \\
\hline Hydrogen Area Sensors & & 1 & & \$ & $7,600.00$ & $19 \$$ & $144,400.00$ & Honeywell 7866 Gas Analyzer (http://www.lesman.com/unleashd/catalog/analytical//analyt hwhhdrogengas.htm) \\
\hline Air Temperature Meter & & 1 & & s & 599.00 & $1 \$$ & 599.00 & Omega DP81T Meter \\
\hline Air Temperature Indicator & & 1 & & $\$$ & 38.00 & $38 \$$ & $1,444.00 \mathrm{c}$ & $\begin{array}{l}\text { Omega TH-10-44000 Thermistor Probe } \\
\text { The }\end{array}$ \\
\hline Water Temperature Indicator & & 1 & & \$ & & $38 \$$ & $1,-1.0$ & Comes with the PH sensor \\
\hline $\mathrm{pH}$ level Indicator & & 1 & & $\$$ & 435.00 & $38 \$$ & $16,530.00 \mathrm{c}$ & Omega Engineering Inc. PHE- 6510 PH electrode + DP24-PH Meter \\
\hline Oxygen Area Sensors & & 1 & & s & 43.00 & 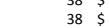 & 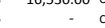 & 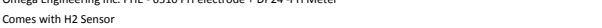 \\
\hline Nutrient Flow Valve & & 1 & & \$ & $5,500.00$ & $1 \$$ & $5,500.00$ & Information from Emerson Process Management \\
\hline Water Flow Valve & & 1 & & $\$$ & $5,500.00$ & $1 \$$ & $5,500.00$ & Information from Emerson Process Management \\
\hline Hydrogen Flow Meter & & 1 & & $\$$ & $5,500.00$ & $1 \$$ & $5,500.00$ & Information from Emerson Processs Management \\
\hline Instrument Wiring & $213180 \mathrm{ft}$ & 1 & $\mathrm{ft}$ & s & 0.02 & $213180 \$$ & $4,135.69 \mathrm{nt}$ & Information from Waytek Inc. at waytekwire.com \\
\hline Power Wiring & $264360 \mathrm{ft}$ & 1 & $\mathrm{ft}$ & \$ & 0.02 & $264360 \$$ & $5,128.58$ & Information from Waytek Inc. at waytekwire.com \\
\hline Conduit & $8820 \mathrm{ft}$ & 1 & $\mathrm{ft}$ & s & 0.58 & $8820 \mathrm{~S}$ & $5,113.84$ & Information from Waytek Inc. at wavtekwire.com \\
\hline
\end{tabular}

\subsection{B-4 Immobilized Photobiological System}

The B-4 pathway is a dual-bed photobiological reactor system using a sulfur-deprived, immobilized, mutant-antenna Chlamydomonas reinhardtii as the $\mathrm{H}_{2}$ production microorganism. $\mathrm{H}_{2}$ production is projected at 3\% solar-to-hydrogen conversion efficiency, corresponding to a future optimized organism. However, laboratory testing has only yielded $0.8 \%$ conversion efficiency.

The dual-bed system consists of 2 growth reactors and $90 \mathrm{H}_{2}$ production reactors. Each reactor is approximately $40 \mathrm{ft}$ wide by $1060 \mathrm{ft}$ long. Reactors are large rectangular beds without a middle divider because there is no need to direct circular flow. Unlike reactor systems which use paddlewheels for circulation, these reactors will use a perforated pipeline system and central pump to distribute nutrients and provide mixing. The entire system is scaled to produce an average of $1,000 \mathrm{kgH}_{2} /$ day over the year. All reactors have a liquid depth of $10 \mathrm{~cm}^{53}$ to ensure full photon capture, moderate temperature swings by adding heat capacity to the system, and allow for sufficient circulation of nutrients. A thriving algal

${ }^{53} 10 \mathrm{~cm}$ depth at $1 \mathrm{~g} / \mathrm{L}$ is not needed for full photon capture. However, the bed is made this deep to provide commonality with the other pathways studied, to provide temperature moderation, and to relax construction tolerances on the bed itself. 
culture is maintained in the growth reactors at an enhanced concentration of $>1 \mathrm{~g} / \mathrm{L}$. Two porous, fibrous substrates ( 2 mil spin-molded polypropylene sheets) each $20 \mathrm{ft}$ wide and the length of the reactor are floated in the growth reactor for 2 days. During this time, the newly grown algae attach to the substrate and grow, forming an immobilized biofilm ${ }^{54}$. Commercial fertilizer and $\mathrm{CO}_{2}$ are fed to the growth reactors to ensure micro-organism health and growth. After 2 days, the film substrate is transferred to the $\mathrm{H}_{2}$ production reactors.

The substrate then begins to cycle between two days of hydrogen production and two days of regenerative growth to keep the culture alive for an extended period of time and to allow enough biomass to accumulate as substrate for the respiration needed to keep the system anaerobic during hydrogen production. Sulfur deprivation will lead to $\mathrm{H}_{2}$ production, and adding sulfur will begin the regeneration phase. During the growth stage, all product gases will be vented to the outside.

The $\mathrm{H}_{2}$ production phase is $\sim 180$ days in duration before the film needs replacing. Like in the growth beds, the biofilm containing immobilized algae floats to the top of the $10 \mathrm{~cm}$ reactor liquid layer. A custom blend of commercial fertilizer nutrients with a minimal amount of sulfur is added to the reactors via a water recirculation system. Sulfur deprivation will trigger hydrogen production. As in the growth reactors, a central pump and pipeline system circulates nutrients.

The biofilm substrate from the growth reactors are rolled up and then unrolled into the $\mathrm{H}_{2}$ production reactors using an industrial unwind machine that is attached to the front end of a forklift truck. The unwind machine, as quoted by Powell Engineering, costs around $\$ 37,000$ and winds the film onto a one foot diameter aluminum core. The Forklift is an $\$ 18,571$ Caterpillar C3000 lift. By using the forklift to transport the unwind machine, a single device can be used for all biofilm transfers. At the end of the 180-day production cycle, the biofilm substrate is discarded. The forklift mounted wind machine is again used to collect the substrate.

The Chlamydomonas reinhardtii micro-organism in sulfur-deprived mode produces a nominally pure hydrogen product gas (plus water vapor). A piston compressor is used to compress the hydrogen to 300psi. A small pressure swing adsorption (PSA) system is used to polish the hydrogen gas stream to five nines purity and return the $\mathrm{CO}_{2}$ to the $\mathrm{CO}_{2}$ saturation vessel where it will be mixed with a slipstream of water that has been removed from raceways low in saturated $\mathrm{CO}_{2}$ during their regeneration phase. During the regeneration phase all product gases will be vented.

Further details of the B-4 pathway are specified in Figure 2-1. The subassemblies of this pathway are shown in Figure 4-7. The complete bill of materials and capital costs of this production plant are shown in Figure 4-8. The total system cost is $\$ 4,843,599$.

\footnotetext{
${ }^{54}$ While a biofilm is "grown" on the substrate, the algae are actually a combination of the free-floating algae that clings to the substrate and new algae that blooms during the 2 days of incubation.
} 
Figure 4-7. Production Plant Design for Immobilized Sulfur Deprived

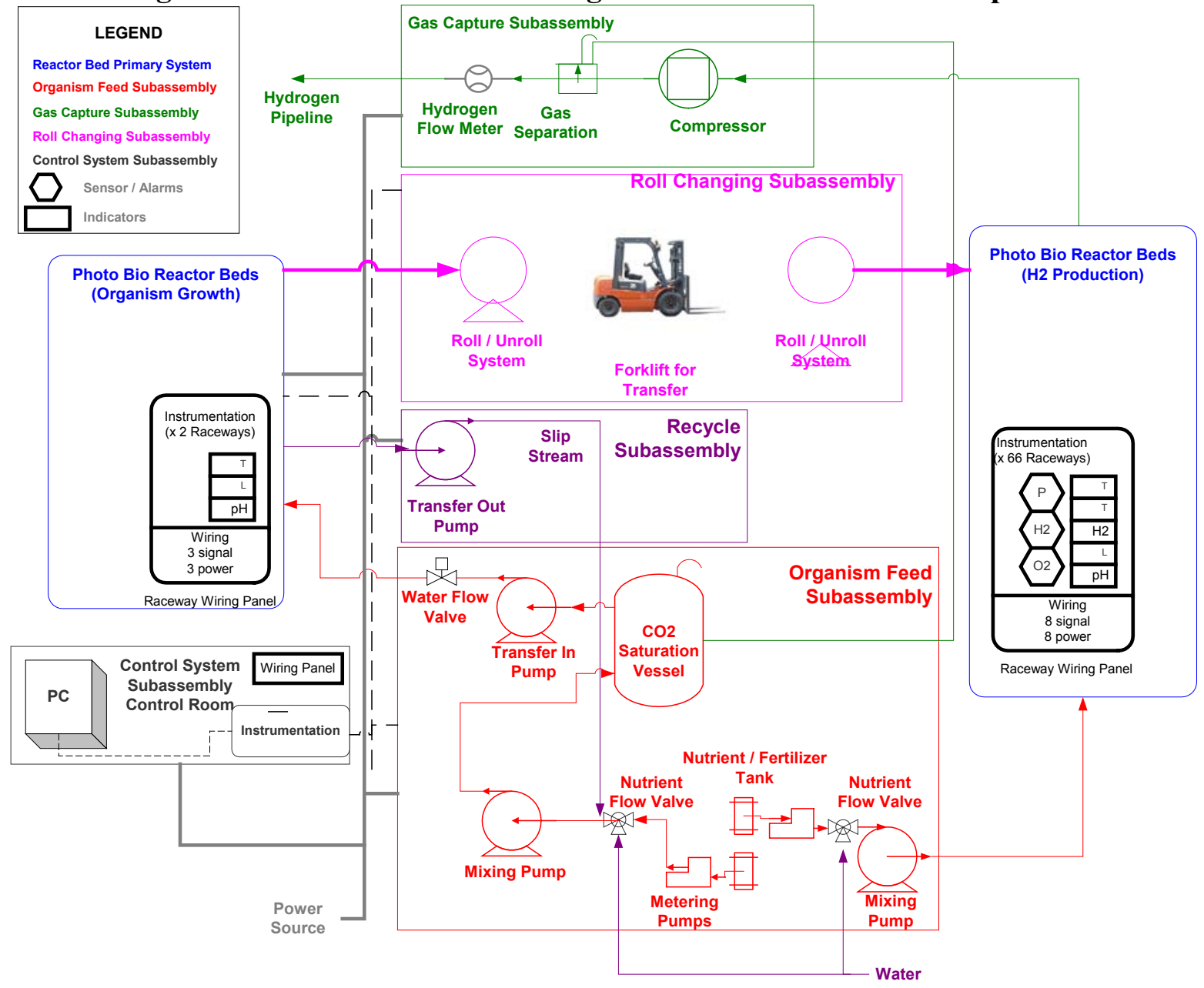


Figure 4-8. Bill of Materials for B-4 Pathway

\begin{tabular}{|c|c|c|c|c|c|c|c|c|}
\hline Description & Size Req'd & Unit Size & Units & & Unit cost & Qty Req'd & Total Cost & Material / Part Description \\
\hline Photo Bio Reactor Bed Subassembly & & & & & & & & \\
\hline Transparent Film & $381,075 \mathrm{~m} 2$ & 1 & $\mathrm{~m} 2$ & $\$$ & 0.54 & $381,075 \$$ & 205,113 & Polyethylene price quote at $50.54 / \mathrm{m} 2(\$ 0.05 / \mathrm{ft} 2)$ \\
\hline Pond Lining & $411,355 \mathrm{~m} 2$ & 1 & $\mathrm{~m} 2$ & $\$$ & 0.47 & $411,355 \$$ & 194,354 & Buty I rubber, PVC, and LDPE (low density polyethylene) based on quote of $\$ 175.56$ for 4,000 oftz. \\
\hline Pond Edging & $61,258 \mathrm{~m}$ & 1 & $\mathrm{~m}$ & $\$$ & 7.00 & $61,258 \$$ & 428,807 & Unit cost is enginering estimate at $57 / \mathrm{m}$ \\
\hline Installation of Ponds & & 1 & raceway & $\$$ & $26,083.00$ & $92 \$$ & $2,399,636$ & Based on Callifornia labor rates. \\
\hline Inlet Water Valve & 0.5 in & 1 & each & $\$$ & 43.46 & $90 \$$ & 3,911 & Price from Valvestore.com (http:///www.valvestore.com//rodinfo. asp??number=551032) \\
\hline Outlet Water Valve & 0.5 in & 1 & each & $\$$ & 43.46 & $90 \$$ & 3,911 & Price from Valvestore.com (http:///www.valvestore.com/rrodinfo.asp??number=551032) \\
\hline Outlet Gas Valve & $1.0 \mathrm{in}$ & 1 & each & $\$$ & 67.23 & $90 \$$ & 6,051 & Price from Valvestore.com (http:-//www.valvestore.com//rodinfo. asp? ?number=551032) \\
\hline Flanges & 0.5 in & 1 & each & $\$$ & 8.00 & $270 \$$ & 2,160 & Price from http://www.ancorp.com/line.aspx:id=819 \\
\hline \multicolumn{9}{|l|}{ Gas Capture Subassembly } \\
\hline 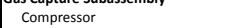 & $56 \mathrm{kgmol} / \mathrm{hr}$ & 56 & $\mathrm{kgmol} / \mathrm{hr}$ & $\$$ & $9,233.00$ & $1 \$$ & 521,146 & Using H2A Unit cost \\
\hline PSA & & & & $\$$ & $60,970.48$ & $1 \$$ & 60,970 & Using H2A scaling \\
\hline Raceway Collection Pipe & $180 \mathrm{ft}$ & 1 & $\mathrm{ft}$ & $\$$ & 1.00 & $180 \$$ & 180 & Sized for Peak Hydrogen production. Assuming Plastic Gas piping, $100 \mathrm{ft}$ /s velocity, uniform pipe diameter (can be \\
\hline Main Collection Pipe & $5280 \mathrm{ft}$ & 1 & $\mathrm{ft}$ & $\$$ & 6.18 & $5280 \$$ & 32,630 & Sized for Peak Hydrogen production. Assuming Plastic Gas piping, $100 \mathrm{ot} /$ / velocity, uniform pipe diameter (can be \\
\hline Gas Capture Pipe & $460 \mathrm{ft}$ & 1 & $\mathrm{ft}$ & $\$$ & 6.18 & $460 \$$ & 2,843 & Sized for Peak Hydrogen production. Assuming Plastic Gas piping, $100 \mathrm{oft} / \mathrm{s}$ velocity, uniform pipe diameter (can be \\
\hline \multicolumn{9}{|l|}{ Organism Feed Subassembly } \\
\hline Transfer In Pump & $150 \mathrm{gpm}$ & 150 & $\mathrm{gpm}$ & $\$$ & 10,252 & $1 \$$ & 10,252 & Est. Based on Perry's Chemical Handbook, Plant Design and Economics/Peters and Timmerhaus \\
\hline Nutrient Metering Pumps & $1468 \mathrm{gph}$ & 1 & $\begin{array}{l}\text { each } \\
\text { each }(1) ~\end{array}$ & $\$$ & 2,594 & $1 \$$ & 2,594 & Est. Based on Perry's Chemical Handbook, Plant Design and Economics. Pumps nutrients into return flow \\
\hline Mixing Pump & $150 \mathrm{gpm}$ & 150 & $\mathrm{gpm}$ & $\$$ & 10,252 & $1 \$$ & 10,252 & Est. Based on Perry's Chemical Handbook, Plant Design and Economics/Peters and Timmerhaus \\
\hline CO2 Cylinder & $50 \mathrm{lb}$ & 50 & $\mathrm{lb}$ & $\$$ & 360 & $1 \$$ & 360 & Aluminum 6061 -T6 alloy, 1800 psi Service Pressure, 50 lb. Capacity Part \#6125 (httpt://kegman.net/carbon.htm) \\
\hline CO2 Saturation Vessel & 15000 gal & 15000 & gal & $\$$ & 30,000 & $1 \$$ & 30,000 & Field erected Stainless Steel tank from Perry's chemical Handbook, Plant Design and Economics \\
\hline Nutrient Tank & 35 gal & 10 & gal & $\$$ & 30.00 & $4 \$$ & 120 & 10 gallon Cylindrical Process Tank, Part \#0275-085 (http://www.watertanks.com/products/0275-085.asp) \\
\hline Nutrient Piping & $90000 \mathrm{ft}$ & 1 & $\mathrm{ft}$ & $\$$ & 0.58 & $90000 \$$ & 52,200 & \\
\hline Raceway Slurry Collection Pipe & $180 \mathrm{ft}$ & 1 & $\mathrm{ft}$ & $\$$ & 0.52 & $180 \$$ & 94 & Pricing based off of Estimates from PVC Plastic Corp. Assumes $10 \mathrm{ft} / \mathrm{sec}$ end flow rate and Density of $1 \mathrm{~g} / \mathrm{ml}$ \\
\hline Main Slurry Collection Pipe & $5280 \mathrm{ft}$ & 1 & $\mathrm{ft}$ & $\$$ & 2.12 & $5280 \$$ & 11,194 & Pricing based off of Estimates from PVC Plastic Corp. Assumes $10 \mathrm{ft} / \mathrm{sec}$ cond fllow rate and Density of $1 \mathrm{~g} / \mathrm{ml}$ \\
\hline Recycle-Feed Transfer Pipe & $180 \mathrm{ft}$ & 1 & $\mathrm{ft}$ & $\$$ & 2.80 & $180 \$$ & 504 & Pricing based off of Estimates from PVC Plastic Corp. Assumes $10 \mathrm{ft} / \mathrm{sec}$ - nd fllow rate and Density of $1 \mathrm{~g} / \mathrm{ml}$ \\
\hline \multirow{2}{*}{\multicolumn{9}{|c|}{ Roll Changing Subassembly }} \\
\hline Roll-Unroll System & $20 \mathrm{ft}$ & 1 & Roller & & $\$ 37,000$ & $1 \$$ & 37,000 & Information from conversations with Powell Engineering $\$ 29,500$ for base, $\$ 4,000$ for motor, and $\$ 3,500$ for Core \\
\hline Polypropylene Film & $352070 \mathrm{~m} 2$ & 1 & m2 & $\$$ & 0.12 & $352070 \$$ & 42,248 & \\
\hline Forklift & & 1 & Forklift & \$ & $18,571.00$ & $1 \$$ & 18,571 & Price Quote from Atlantic Lift Truck inc. \\
\hline \multicolumn{9}{|l|}{ Recycle Subassembly } \\
\hline Transfer Out Pump & $150 \mathrm{gpm}$ & 150 & $\mathrm{gpm}$ & $\$$ & 10,252 & $1 \$$ & 10,252 & Est. Based on Perry's Chemical Handbook, Plant Design and Economics/Peters and Timmerhaus \\
\hline Main Slurry Feed Pipe & $5280 \mathrm{ft}$ & 1 & $\mathrm{ft}$ & $\$$ & 2.12 & $5280 \$$ & 11,194 & Pricing based off of Estimates from PVC Plastic Corp. Assumes $10 \mathrm{ft} / \mathrm{sec}$ cond flow rate and Density of $1 \mathrm{1} / \mathrm{ml}$ \\
\hline Raceway Slurry Feed Pipe & $180 \mathrm{ft}$ & 1 & $\mathrm{ft}$ & $\$$ & 0.52 & $180 \$$ & 94 & Pricing based off of Estimates from PVC Plastic Corp. Assumes $10 \mathrm{ft} / \mathrm{sec}$ cond flow rate and Density of $1 \mathrm{~B} / \mathrm{ml}$ \\
\hline \multicolumn{9}{|l|}{ Consumables } \\
\hline Initial CO2 & $206180 \mathrm{lb}$ & 50 & lb & $\$$ & 35.00 & $4124 \$$ & 144,340 & Cost based on average fertilizer use for Aquaculture and average fertilizer costs from the USDA \\
\hline Initial Nutrients & $1.81 \mathrm{lb}$ & 1 & $\mathrm{lb}$ & $\$$ & 0.20 & $2 \$$ & & NFC Company, Chicago, IL (800) 7344515 \\
\hline Initial Water & $9,324,121 \mathrm{gal}$ & 1 & gal & $\$$ & 0.0017 & $9,324,121 \$$ & 15,525 & H2A Feedstock costs \\
\hline \multicolumn{9}{|l|}{ Control System } \\
\hline Control Room & $160 \mathrm{ft} 2$ & 1 & $\mathrm{ft} 2$ & $\$$ & 50.00 & $160 \$$ & 8,000 & comes from price quote of $\$ 50 / / t 2$ from $h$ htp:-//www.buyerzone.com/industrial/modula_buildings/prefab__uuide.htm! \\
\hline Control Room Wiring Panel & & 1 & & $\$$ & $3,000.00$ & $1 \$$ & 3,000 & Consultation with innomation Systems inc. \\
\hline Raceway wiring Panel & & 1 & & $\$$ & 146.00 & $90 \$$ & 13,140 & Information from Tessco Technolggies inc. \\
\hline Computer and Monitor & & 1 & & $\$$ & $1,500.00$ & $1 \$$ & 1,500 & Information from Emerson Process Management \\
\hline Labview Software & & 1 & & $\$$ & $4,299.00$ & $1 \$$ & 4,299 & Information from Emerson Process Management \\
\hline Level Indicators & & 1 & & $\$$ & 714.00 & $90 \$$ & 64,260 & Omega Engineering Inc. LVR51 Liquid Level Float Transmitter + DP 32 Meter \\
\hline Pressure Sensors & & 1 & & $\$$ & 345.00 & $90 \$$ & 31,050 & Omega Engineering Inc. PX209 Pressure Trnasducer + DP132 Meter \\
\hline Hydrogen Area Sensors & & 1 & & $\$$ & $7,600.00$ & $45 \$$ & 342,000 & Honeywell 7866 Gas Analyzer (http:///www.lesman.com/unleashd/catalog/analytical/analyt_hwhydrogengas.htm) \\
\hline Air Temperature Meter & & 1 & & $\$$ & 599.00 & $1 \$$ & 599 & Omega DP81T Meter \\
\hline Air Temperature Indicator & & 1 & & $\$$ & 38.00 & $90 \$$ & 3,420 & Omega TH-10-44000 Thermistor Probe \\
\hline Water Temperature Indicator & & 1 & & $\$$ & & $90 \$$ & & Comes with the PH sensor \\
\hline $\mathrm{pH}$ level Indicator & & 1 & & $\$$ & 435.00 & $90 \$$ & 39,150 & 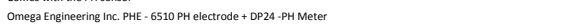 \\
\hline Oxygen Area Sensors & & 1 & & $\$$ & & $90 \$$ & & Comes with $\mathrm{H} 2$ Sensor \\
\hline Nutrient Flow Valve & & 1 & & $\$$ & $5,500.00$ & $1 \$$ & 5,500 & Information from Emerson Process Management \\
\hline Water Flow Valve & & 1 & & $\$$ & $5,500.00$ & $1 \$$ & 5,500 & Information from Emerson Process Management \\
\hline Hydrogen Flow Meter & & 1 & & $\$$ & $5,500.00$ & $1 \$$ & 5,500 & Information from Emerson Process Management \\
\hline Instrument Wiring & $1065720 \mathrm{ft}$ & 1 & $\mathrm{ft}$ & $\$$ & 0.02 & $1065720 \$$ & 20,675 & Information from Waytek inc. at waytekwire.com \\
\hline Power Wiring & $1327500 \mathrm{ft}$ & 1 & $\mathrm{ft}$ & $\$$ & 0.02 & $1327500 \$$ & 25,754 & Information from Waytek inc. at waytekwire.com \\
\hline Conduit & $20260 \mathrm{ft}$ & 1 & $\mathrm{ft}$ & $\$$ & 0.58 & $20260 \$$ & 11,747 & Information from Waytek Inc. at waytekwire.com \\
\hline
\end{tabular}

\subsection{B-5 Pathway Production Plant}

The B-5 pathway is a Chemostat II photobiological reactor system using a mutant-antenna purple-non-Sulfur (PNS) proteobacteria as the $\mathrm{H}_{2}$ production micro-organism. As a Chemostat II, the initial bacterial culture is grown at the normal cell growth rate until final colony concentration is reached, and then the process is switched over to steady-state mode where simultaneous growth and hydrogen production occur in the reactor beds. This is achieved by manipulating the nutrients. $\mathrm{H}_{2}$ production is projected at $3.5 \%$ solar-tohydrogen efficiency and corresponds to a future optimized organism. Current PNS systems have been demonstrated at only $2.5 \%$ conversion efficiency in the laboratory. Sufficient cellular activity to keep the micro-organism healthy is assumed to occur during $\mathrm{H}_{2}$ production with new cell growth taking place at a reduced rate compared to wild-type organisms ( $20 \%$ per day vs. $\sim 80 \%$ per day). Since the system functions as a Chemostat II with $20 \%$ daily organism renewal, an effectively infinite $\mathrm{H}_{2}$ production phase duration is achieved.

Fifty-four raceways of approximately $40 \mathrm{ft}$ width by $1090 \mathrm{ft}$ length are used to produce an average of $1,000 \mathrm{kgH}_{2} /$ day throughout the year. The raceways have a liquid depth of $10 \mathrm{~cm}$ to correspond to full photon capture at a cell concentration of $0.2 \mathrm{~g} / \mathrm{L}$. Paddlewheels circulate the water/PNS slurry. A slip stream of water/micro-organism slurry is drawn off 
continuously to maintain the $0.2 \mathrm{~g} / \mathrm{L}$ micro-organism concentration. Micro-organisms are removed from the recycle stream by a rotary drum filter. The micro-organism mass removed is carefully matched to the growth rate to maintain a constant organism mass within the system. The removed micro-organisms are taken to a land-fill, used in a subsequent fermentor, or otherwise disposed. Nutrients in the form of acetate are mixed with the returning water to provide required nourishment to the micro-organisms and as a substrate in the hydrogen production reaction.

The PNS micro-organisms produce a net product gas of $95 \% \mathrm{H}_{2}$ and $5 \% \mathrm{CO}_{2}$ (plus water vapor). A piston compressor is used to compress the gas mixture to 300psi prior to separation. A pressure swing adsorption (PSA) system is used to purify the hydrogen gas steam.

Further details of the B-5 pathway are specified in Figure 2-1. The subassemblies of this pathway are shown in Figure 4-9. The complete bill of materials and capital costs of this production plant are shown in Figure 4-10. The total system cost is $\$ 4,034,192$.

Figure 4-9. Production Plant Design for Purple Non-Sulfur

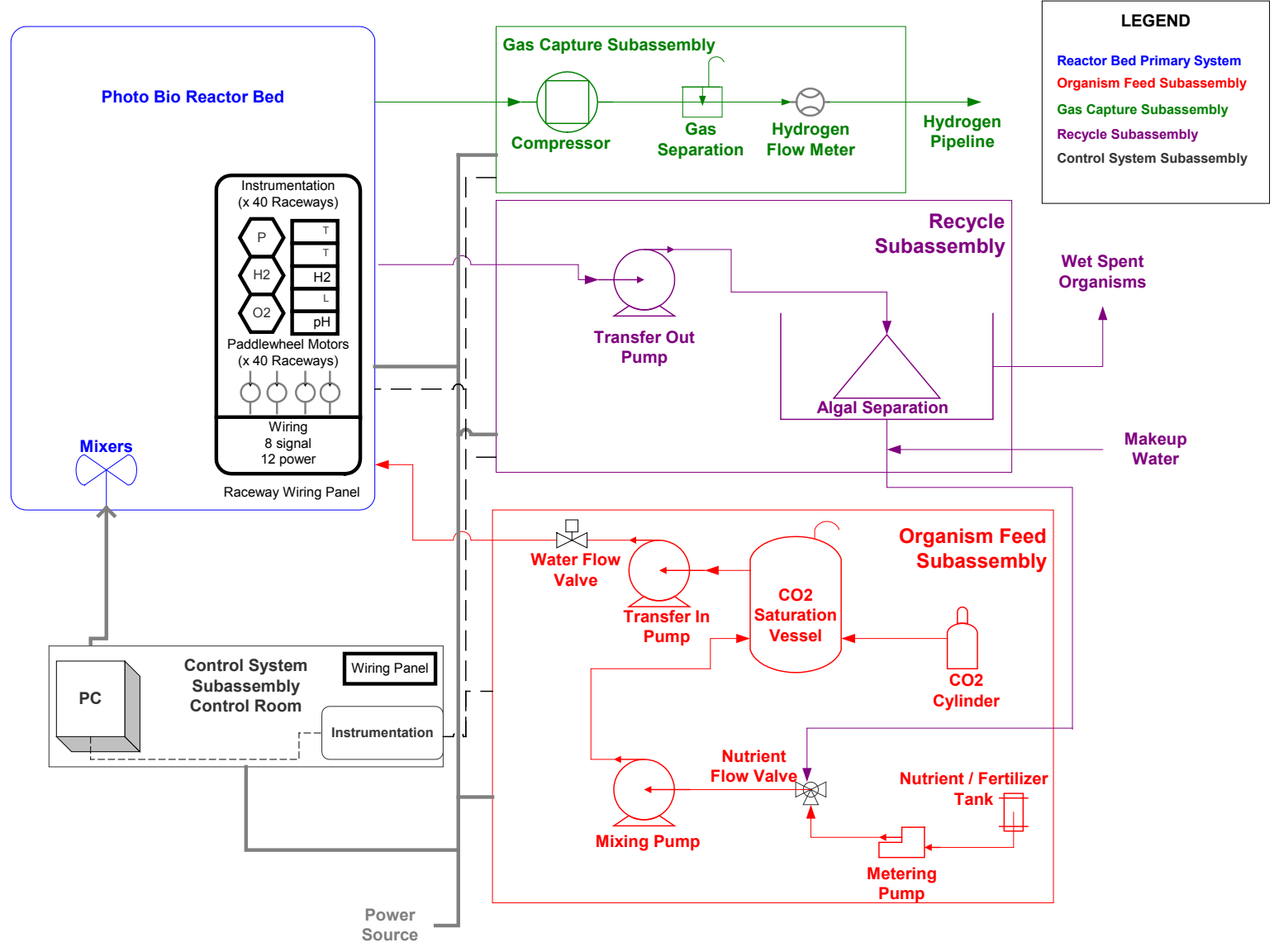


Figure 4-10. Bill of Materials for B-5 Pathway

\begin{tabular}{|c|c|c|c|c|c|c|c|c|}
\hline Description & Size Req'd & Unit Size & Units & & Unit cost & aty Req'd & Total Cost & Material / Part Description \\
\hline \multirow{2}{*}{\multicolumn{9}{|c|}{ Photo Bio Reactor Bed Subassembly }} \\
\hline & & & & & & & & Polyethylene price quote at $50.54 / \mathrm{m} 2(50.05 / \mathrm{ft} 2)$ \\
\hline Pond Lining & $253795 \mathrm{~m} 2$ & 1 & $\mathrm{~m} 2$ & $\$$ & 0.47 & 253,795 & 119,912 & Butyl rubber, PVC, and LDPE (low density polyethylene) based on quote of $\$ 175.56$ for 4,000 oft2. \\
\hline Pond Edging & $37752 \mathrm{~m}$ & 1 & $\mathrm{~m}$ & $\$$ & 7.00 & 37,752 & 264,266 & Unit cost is engineering estimate at $57 / \mathrm{m}$ \\
\hline Installation of Ponds & & 1 & raceway & $\$$ & $26,083.00$ & 54 & $1,408,482$ & Based on California labor rates. \\
\hline Paddlewheel Mixers & & 1 & each & $\$$ & $5,000.00$ & 108 & 540,000 & Est. paddlewheel cost. 4 per raceway. 18 raceways. \\
\hline Inlet Water Valve & $0.5 \mathrm{in}$ & 1 & each & $\$$ & 43.46 & 54 & 2,347 & Price from Valvestore.com (http://wwww.valvestore.com/prodinfo.asp? ?umber=551032) \\
\hline Outlet Water Valve & 0.5 in & 1 & each & $\$$ & 43.46 & 54 & 2,347 & Price from Valvestore.com (http://wwww.valvestore.com/prodinfo.asp? ?umber=551032) \\
\hline Outlet Gas Valve & 1.0 in & 1 & each & $\$$ & 67.23 & 54 & 3,630 & Price from Valvestore.com (http://wwww.valvestore.com/rododinfo.asp? ?umber=551032) \\
\hline Flanges & 0.5 in & 1 & each & $\$$ & 8.00 & 162 & 1,296 & Price from http://www.ancorp.com/line.asppxidid=819 \\
\hline \multicolumn{9}{|l|}{ Gas Capture Subassembly } \\
\hline $\begin{array}{l}\text { Compressor } \\
\text { Costinty }\end{array}$ & $45 \mathrm{kgmol} / \mathrm{hr}$ & 45 & $\mathrm{kgmol} / \mathrm{hr}$ & $\$$ & $9,233.00$ & 1 & 414,241 & Using H2A Unit cost \\
\hline PSA & $45 \mathrm{~kg}$ & 45 & mgrivirim & $\$$ & $30,541.73$ & 1 & 30,542 & Using H2A scaling \\
\hline Raceway Collection Pipe & $108 \mathrm{ft}$ & 1 & $\mathrm{ft}$ & $\$$ & 1.00 & 108 & 108 & Sized for Peak Hydrogen production. Assuming Plastic Gas piping, $10 \mathrm{oft} / \mathrm{s}$ velocity, uniform pipe diameter (can be \\
\hline Main Collection Pipe & $3120 \mathrm{ft}$ & 1 & $\mathrm{ft}$ & $\$$ & 6.18 & 3120 & 19,282 & Sized for Peak Hydrogen production. Assuming Plastic Gas piping, $10 \mathrm{ft} / \mathrm{s}$ velocity, unfform pipe diameter (can be \\
\hline Gas Capture Pipe & $50 \mathrm{ft}$ & 1 & $\mathrm{ft}$ & $\$$ & 6.18 & 50 & 309 & Sized for Peak Hydrogen production. Assuming Plastic Gas piping, $100 \mathrm{ft} /$ / v velocity, uniform pipe diameter (can be \\
\hline \multicolumn{9}{|l|}{ Organism Feed Subassembly } \\
\hline $\begin{array}{l}\text { Transfer In Pump } \\
\text { Theming }\end{array}$ & $150 \mathrm{gpm}$ & 150 & $\mathrm{gpm}$ & $\$$ & 10,252 & 3 & 30,755 & Est. Based on Perry's Chemical Handbook, Plant Design and Economics/Peters and Timmerhaus \\
\hline Nutrient Metering Pumps & $1468 \mathrm{gph}$ & 1 & each & $\$$ & 2,594 & 13 & 2594 & Est. Based on Perry's Chemical Handbook, Plant Design and Economics. Pumps nutrients into return flow \\
\hline Mixing Pump & $150 \mathrm{gpm}$ & 150 & $\mathrm{gpm}$ & $\$$ & 10,252 & 3 & 30,755 & Est. Based on Perry's Chemical Handbook, Plant Design and Economics/Peters and Timmerhaus \\
\hline Nutrient Tank & $21 \mathrm{gal}$ & 10 & gal & $\$$ & 30.00 & 3 & 90 & 10 gallon Cylindrical Process Tank, Part \#0275-085 (http://www.watertanks.com/products/0275-085.asp) \\
\hline Raceway Slurry Collection Pipe & $108 \mathrm{ft}$ & 1 & ${ }_{\mathrm{ft}}^{\mathrm{gat}}$ & $\$$ & 1.00 & 108 & 108 & Pricing based of of Estimates from PVC Plastic Corp. Assumes $10 \mathrm{ft} / \mathrm{sec}$. \\
\hline Main Slurry Collection Pipe & $3120 \mathrm{ft}$ & 1 & $\mathrm{ft}$ & $\$$ & 4.31 & 3120 & 13,447 & Pricing based of of Estimates from PVC Plastic Corp. Assumes $10 \mathrm{ft} /$ second flow rate and Density of $1 \mathrm{~g} / \mathrm{ml}$ \\
\hline Recycle-Feed Transfer Pipe & $180 \mathrm{ft}$ & 1 & $\mathrm{ft}$ & $\$$ & 6.18 & 180 & 1,112 & Pricing based of of Estimates from PVC Plastic Corp. Assumes $10 \mathrm{ft} / \mathrm{sec}$ cond flow rate and Density of $1 / \mathrm{gl} / \mathrm{ml}$ \\
\hline \multicolumn{9}{|l|}{ Recycle Subassembly } \\
\hline Rotary Drum filter & $25741 \mathrm{gph}$ & 3750 & $\mathrm{gph}$ & $\$$ & $87,000.00$ & 7 & 609,000 & Information from Dana Kent at Advanced Aquaculture Inc. on Hydrotech Drum Filter \\
\hline Transfer Out Pump & $150 \mathrm{gpm}$ & 150 & $\mathrm{gpm}$ & $\$$ & 10,252 & 3 & 30,755 & Est. Based on Perry's Chemical Handbook, Plant Design and Economics/Peters and Timmerhaus \\
\hline Main Slurry Feed Pipe & $3120 \mathrm{ft}$ & 1 & $\mathrm{ft}$ & $\$$ & 4.31 & 3120 & 13,447 & Pricing based off of Estimates from PVC Plastic Corp. Assumes $10 \mathrm{ft} / \mathrm{sec}$ cond fllow rate and Density of $1 \mathrm{~g} / \mathrm{ml}$ \\
\hline Raceway Slurry Feed Pipe & $108 \mathrm{ft}$ & 1 & $\mathrm{ft}$ & $\$$ & 1.00 & 108 & 108 & Pricing based off of Estimates from PVC Plastic Corp. Assumes $10 \mathrm{ft} / \mathrm{sec}$ cond flfow rate and Density of $1 \mathrm{~g} / \mathrm{ml}$ \\
\hline \multicolumn{9}{|l|}{ Consumables } \\
\hline Initial Nutrients & $1.11 \mathrm{lb}$ & 1 & $\mathrm{lb}$ & $\$$ & 0.20 & 1 & & NFC Company, Chicago, IL L 8000$) 7344515$ \\
\hline Initial Water & $5,720,312$ gal & 1 & gal & $\$$ & 0.0017 & $5,720,312$ & 9,524 & H2A Feedstock Kosts \\
\hline Initial Acetate & $7,793 \mathrm{~kg}$ & 1 & $\mathrm{~kg}$ & $\$$ & 0.5950 & 7,793 & 4,637 & Chemical Journal of Korea. Assumes consumption to be four times more to account for full groweth conditions. \\
\hline \multicolumn{9}{|l|}{ Control System } \\
\hline Control Room & $160 \mathrm{ft} 2$ & 1 & $\mathrm{ft} 2$ & $\$$ & 50.00 & 160 & 8,000 & 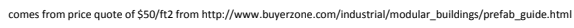 \\
\hline Control Room Wiring Panel & & 1 & & $\$$ & $3,000.00$ & 1 & $3,000.00$ & Consultation with Innomation Systems inc. \\
\hline Raceway wiring Panel & & 1 & & $\$$ & 146.00 & & 7,884 & Information from Tessco Technologies Inc. \\
\hline Computer and Monitor & & 1 & & $\$$ & $1,500.00$ & 1 & $1,500.00$ & Information from Emerson Process Management \\
\hline Labview Software & & 1 & & $\$$ & $4,299.00$ & 1 & $4,299.00$ & Information from Emerson Process Management \\
\hline Level Indicators & & 1 & & $\$$ & 714.00 & 54 & $38,556.00$ & Omega Engineering Inc. LVRS1 L Liquid Level Float Transmitter + DP P32 Meter \\
\hline Pressure Sensors & & 1 & & $\$$ & 345.00 & 54 & $18,630.00$ & Omega Engineering Inc. PX209 Pressure Trnasducer + DPi32 Meter \\
\hline Hydrogen Area Sensors & & 1 & & $\$$ & $7,600.00$ & 27 & $\$ 205,200.00$ & 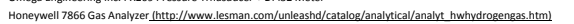 \\
\hline Air Temperature Meter & & 1 & & $\$$ & 599.00 & 1 & $\$ 599.00$ & Omega DPQ1T Meter \\
\hline Air Temperature Indicator & & 1 & & $\$$ & 38.00 & 54 & $2,052.00$ & Omega TH-10-44000 Thermistor Probe \\
\hline Water Temperature Indicator & & 1 & & $\$$ & & 54 & & Comes with the PH sensor \\
\hline $\mathrm{pH}$ level Indicator & & 1 & & $\$$ & 435.00 & 54 & $23,490.00$ & Omega Engineering Inc. PHE- 6510 PH electrode + DP24-PH Meter \\
\hline Oxygen Area Sensors & & 1 & & $\$$ & - & & & Comes with H2 Sensor \\
\hline Nutrient Flow Valve & & 1 & & $\$$ & $5,500.00$ & 1 & $5,500.00$ & Information from Emerson Process Management \\
\hline Water Flow Valve & & 1 & & $\$$ & $5,500.00$ & 1 & $5,500.00$ & Information from Emerson Process Management \\
\hline Hydrogen Flow Meter & & 1 & & $\$$ & $5,500.00$ & 1 & $5,500.00$ & Information from Emerson Process Managemenent \\
\hline Instrument Wiring & $406380 \mathrm{ft}$ & 1 & $\mathrm{ft}$ & $\$$ & 0.02 & 406380 & $7,883.77$ & Information from Waytek inc. at waytekwire.com \\
\hline Power Wiring & $505080 \mathrm{ft}$ & 1 & $\mathrm{ft}$ & $\$$ & 0.02 & 505080 & $9,798.55$ & Information from Waytek Inc. at wayt tekwire.com \\
\hline Conduit & $12340 \mathrm{ft}$ & 1 & $\mathrm{ft}$ & $\$$ & 0.58 & 12340 & $7,154.73$ & Information from Waytek Inc. at waytekwire.com \\
\hline
\end{tabular}

\section{Capital Cost Assumptions and Calculations}

Thus far in the report we have discussed the basic science that applies to photobiological systems as well as the biological parameters of micro-organisms and the engineering design conditions which were used in the analysis. This section of the document is dedicated to financial and engineering assumptions that have been made in order to evaluate the economics of each of the bio-hydrogen solutions under review. The assumptions have been divided between those necessary to develop capital costs and those essential to determining levelized hydrogen costs. That is followed by computation of the levelized hydrogen costs and a discussion of the results and how they may be improved.

\subsection{Capital Cost Assumptions}

A bill of materials for each pathway outlining the capital costs associated with the construction and components of that photobiological hydrogen production facility is provided in the previous section. That section characterized the basic operation and configuration assumptions but many other assumptions relating to the capital cost were not defined. This section outlines and defines the other underlying assumptions used in determining the capital costs associated with the individual cost components. 


\subsubsection{Material Margins}

When calculating the size of the Low Density Polyethylene (LDPE) film needed to cover the top of the raceways, it was necessary to add an extra margin to account for ease of assembly and the potential for misalignment as the film is unrolled. We assumed an additional one foot would be more than sufficient to cover the pond edging and leave extra material for sealing against the edging. In addition, we calculate that an additional six inches on either side and on either end will be necessary to give room for the accumulation of gas at times of day when production of gas exceeds removal. Excess gas accumulation is covered in Section 5.2.3.

\subsubsection{Bed Dimensions}

In choosing the dimensions of the raceways, polyethylene manufacturers were consulted to determine the manufacturing constraints of polyethylene film production. Since the LDPE is intended as an impermeable hydrogen gas barrier, it is desirable to avoid seams between sheets as those are at higher risk for leakage. While sealing on the edges of the raceways is unavoidable, the difficulty of sealing against hydrogen loss led us to size the raceways based on the largest single sheet of LDPE that could be produced. Conversations with Berry Plastics indicated that the maximum width for a roll of LDPE film is 56 feet. However, we recognized the constraints of transporting such a large roll, and assumed a maximum width that could fit onto a truck to be roughly 50 feet. To allow for the overage mentioned in the previous section, we assume a roll width of 43 feet, leaving a 40 foot wide raceway. Berry Plastics also indicated that roll lengths of over 1000 feet are feasible. To ensure impermeability to hydrogen, Berry Plastics recommended $6 \mathrm{~mm}$ thick film. We desired an even number of raceways to make material cost calculations and system design easier. Therefore, to determine the length of raceways for each system, we chose a round number of feet near 1000 that, with a 40 foot active width, would cover the necessary production area with an even number of raceways. For all systems, raceway length is between 1060 and 1090ft. In addition to these physical dimension parameters, the LDPE also impacts bed dimension because it is a barrier to the full solar insolation reaching the algae. Data from manufacturer indicates that the transmission of sunlight is $90 \%$ across the film. That has been taken into consideration in sizing the raceways.

\subsubsection{Gas Capture Sizing}

Due to yearly variation in insolation, it is necessary to size the elements of the gas capture subassembly for the projected peak day of production, June 21. Sizing for the average would lead to extreme $\mathrm{H}_{2}$ accumulation of during the days where insolation is higher than the average (March 21 to September 21). Thus, the gas capture subassembly will be operating below rated capacity for most of the year.

\subsubsection{Pipe Sizing}

Pipe sizing was achieved through the use of the continuity equation $\dot{m}=\rho A v$. For gas piping, we assumed a maximum gas velocity of $100 \mathrm{ft} / \mathrm{second}$ to limit pressure loss due to pipe flow. For water piping, we assumed a maximum velocity of $15 \mathrm{ft} / \mathrm{second}$. The exact physical layout of the piping systems is needed to accurately assess the velocity and pressure drop relationship. Since a detailed piping layout is beyond the scope of this project, the specific velocity cannot be known. Consequently, the number computed is used as a surrogate for more detailed analysis and we judge it to be adequate given the low costs 
associated with small changes in PVC pipe diameter. We rounded our pipe diameter calculated to the nearest nominal size for cost analysis purpose.

There were three different pipe sizes calculated for the various stages of liquid removal and recycling. The pipes that transfer the water out to and back from the individual raceways are sized for individual raceway requirements. Each of these individual raceway pipes comes from or combines with a collection manifold sized for half of the overall volume, since the raceways are placed in two even rows with the recycle and algae feed subassemblies in the middle. Finally, one pipe combines flow from the two collection manifolds and feeds it to the recycle subassembly and out of the algae feed subassembly. This manifold must be sized to contain the entire flow volume. The pipe sizes for each system are given in Figure 5-1. Similarly, gas piping was sized both for individual outlets on each raceway, and then the main collection lines that lead to the Gas Capture Subassembly.

Figure 5-1. Piping sizes for B-1 through B-5

\begin{tabular}{|c|c|c|c|c|c|}
\hline & $\begin{array}{c}\text { Algal 02- } \\
\text { tolerant } \\
\text { Hydrogenase }\end{array}$ & $\begin{array}{c}\text { Cyanobacterium } \\
\text { O2-tolerant } \\
\text { Hydrogenase }\end{array}$ & $\begin{array}{c}\text { Algal } \\
\text { Sulfate } \\
\text { Permease }\end{array}$ & $\begin{array}{l}\text { Immobilized } \\
\text { Algal, Sulfur } \\
\text { deprived }\end{array}$ & $\begin{array}{c}\text { PNS } \\
\text { bacteria }\end{array}$ \\
\hline & B-1 & B-2 & B-3 & B-4 & B-5 \\
\hline \multicolumn{6}{|c|}{ Gas Piping } \\
\hline $\begin{array}{l}\text { Raceway } \\
\text { Collection Pipe }\end{array}$ & $1.5 \%$ & $1.5 \%$ & $1 "$ & $1 "$ & $1 "$ \\
\hline $\begin{array}{l}\text { Main Collection } \\
\text { Pipe }\end{array}$ & $4 ”$ & $4 "$ & $4 "$ & $3.5 \%$ & $3.5 \%$ \\
\hline $\begin{array}{l}\text { Gas Capture } \\
\text { Collection Pipe }\end{array}$ & $5.5 \%$ & $5.5^{\prime}$ & $5.5 \%$ & $5.0 "$ & $4.5 \%$ \\
\hline \multicolumn{6}{|c|}{ Slurry Piping } \\
\hline $\begin{array}{l}\text { Raceway Slurry } \\
\text { Collection }\end{array}$ & $1 ”$ & $1 "$ & $2 "$ & $0.5 "$ & $1 "$ \\
\hline $\begin{array}{l}\text { Main Slurry } \\
\text { Collection }\end{array}$ & $2 "$ & $2 ”$ & $7 "$ & $2 "$ & $3 "$ \\
\hline $\begin{array}{l}\text { Recycle-Feed } \\
\text { Transfer Pipe }\end{array}$ & $3 "$ & $3 "$ & $10 ”$ & $2.5 "$ & $4.5 \%$ \\
\hline $\begin{array}{l}\text { Main Slurry } \\
\text { Feed Pipe }\end{array}$ & $2 "$ & $2 "$ & $7 ”$ & $2 "$ & $3 "$ \\
\hline $\begin{array}{l}\text { Raceway Slurry } \\
\text { Feed Pipe }\end{array}$ & $1 "$ & $1 "$ & $2 ”$ & $0.5 \%$ & $1 "$ \\
\hline
\end{tabular}

\subsubsection{Equipment Duty Cycles}

Given that the biological production of hydrogen gas can only occur during sunlight, it was originally assumed that the operation cycles of the gas capture subassembly equipment would match the production cycle. However this would necessitate sizing the compressor and the PSA for the maximum gas production rate. Considering the substantial capital and operation costs associated with the compressor and the PSA, it is more cost effective to size the compressor and the PSA for average daily gas production and have it run 24 hours a day so the last of the product gases are removed from the bed as a new production day begins. 
The organisms require nutrients even though they may not be producing hydrogen. Because of this the replenishment supply and slip stream removal must be continuous. Thus the pumps and drum filters are also expected to operate 24 hours a day and sized as such. Paddlewheel operation is not continuous because the mixing of the micro-organisms is only required during sunlight hours.

\subsubsection{Operational Cycle}

While ideally the hydrogen production bioreactor would operate all days of the year, it will be necessary to shut down the reactor at times for maintenance or to flush out and restart individual raceway colonies in case of culture contamination. With these considerations in mind, we have assumed a plant operation time of $90 \%$.

In a given day, the production cycle will be entirely determined by the duration of sunlight, which varies throughout the year. To simplify the equipment sizing procedure we have assumed that on average, there will be 12 hours of sunlight per day throughout the year.

\subsection{Calculations Explained}

Many of the calculations used for the sizing of elements in the raceway are explained in the following sections. They are based on assumptions stated in the previous section or elsewhere in this report.

\subsubsection{Quantity of Raceways}

As mentioned in Section 1.1.2 the dimensions of the raceways are determined largely by the constraints of the LDPE film production and practical considerations such as ease of truck transport. We slightly tweaked the length in order to obtain an even number of raceways. However, with these numbers relatively constrained, the determining factor for quantity of raceways is the area of bed required to produce $1,000 \mathrm{~kg}$ of usable hydrogen gas per day. According to PSA modeling and conversations with PSA manufacturer UOP, PSA systems operating on $\mathrm{H}_{2} / \mathrm{O}_{2}$ gas mixtures can achieve approximately $90 \%$ hydrogen recovery. As mentioned earlier, the LDPE film is only $90 \%$ transparent as well. Thus we must oversize the reactor bed in order to account for both this photon loss and PSA hydrogen losses and achieve the target net $1,000 \mathrm{kgH}_{2} /$ day. Based on the efficiency assumptions of the particular system involved, the average insolation data referenced earlier, and the assumed conversion efficiency of photons to hydrogen also mentioned earlier, we integrated the hourly $\mathrm{H}_{2}$ production to get a daily $\mathrm{gH}_{2} / \mathrm{m}^{2}$ rate. This, combined with our desired $\mathrm{H}_{2}$ production level, allowed us to calculate the total production area required. Knowing the constraints of our raceway size mentioned earlier, we determined the quantity of raceways by dividing the total area needed by the size of an individual raceway.

\subsubsection{Water Slip Stream Volume or Rates}

Although organisms in hydrogen production mode generally grow at a reduced rate, there is some continual growth occurring. In order to maintain a constant concentration of organisms within the bed it is necessary to draw off a specific volume of water/organism solution to filter out the excess organisms. The specific slip stream volume required is based on the average doubling rate of our organisms. Using hourly solar intensity data and the corresponding organism growth rate, an iterative process determines that a removal rate 
of $0.45 \%$ /hour of the total bed aqueous volume is needed to ensure that concentration is constant throughout the day. Each system has a different total reactor volume depending on the assumed efficiency of hydrogen production in the system. Making use of $0.45 \%$ of the overall volume of the system as the hourly removal mass fraction, the hourly slip stream volume is computed. This volume value is employed to size pumps, pipes, and saturation vessels. In the B-3 and B-4 system a slip stream of water will be pumped to the $\mathrm{CO}_{2}$ saturation vessel for $\mathrm{CO}_{2}$ addition necessary for the growth and regeneration phase. The volume of water drawn off was calculated by determining how much water is needed each day of the regeneration phase to fully absorb all the $\mathrm{CO}_{2}$ that was bubbled into the headspace during the hydrogen production phase based on the $\mathrm{CO}_{2}$ saturation rate of $1.4 \mathrm{~g} / \mathrm{L}$.

\subsubsection{Product gas storage under Film}

As mentioned in Section 1.1.4, to keep compressor and PSA size down, the rate of gas drawn off of the raceways will not necessarily match the rate of gas production. As a consequence, excess gas will accumulate underneath the LDPE film. This accumulation will necessitate a surplus headspace volume above the liquid level of the bed and below the LDPE film. The LDPE film above the bed will rise as the gas accumulates during the day and fall as the gas is drawn out during the night. An excess of film material is needed to accommodate this film motion and avoid stretching of the film. In order to calculate the amount of extra film necessary, we used data from the NREL SOLPOS model combined with data from the NASA Atmospheric Data Center to calculate the amount of hydrogen gas being produced at 15 minute intervals during the month of June where insolation and corresponding hydrogen production will be at its peak ${ }^{55,56}$. Based on the molar ratios of each system, we calculated the amount of total gas produced for each 15 minute interval. Knowing the density and the molar ratios of the gas we calculated the volume. Using the volume of gas and the area of the raceway, we computed the total height required of the film to achieve that volume. Lastly, by subtracting a specific rate of gas every 15 minutes, we determined the minimum rate of gas removal that will leave no gas accumulated by the following dawn. According to our calculations, approximately $6 \mathrm{~cm}$ of headspace is required to account for gas accumulation. The resulting gas removal rate is then used in PSA sizing.

\subsubsection{Electricity Consumption}

The power consumption of the system primarily comes from the Gas Capture Subassembly, with slight contributions elsewhere. The items consuming power are the compressor, PSA, pumps, nutrient metering pumps, rotary drum filters, paddlewheels and the control room. PSA power is minimal as it is only needed for air compression to actuate pneumatic valves. The power consumption of the pumps, nutrient metering pumps, rotary drum filters and paddlewheels all come from quotes we have received concerning these items and have been documented previously in this report. The gas compressor is assumed to be a 2-stage piston compressor $(\mathrm{N}=2)$ with interstage cooling. Its power was calculated by assuming isentropic compression from $20^{\circ} \mathrm{C}$ ambient temperature with efficiency, $\eta$, of $75 \%$. Overall pressure ratio was 20.4 for an outlet pressure of 300 psi.

\footnotetext{
${ }^{55}$ NREL MIDS SOLPOS (Solar Position) model.

56 NASA Atmospheric Data Center, Langley ASDC User Services, Surface meteorology and Solar Energy (SSE) data base (release 6.0).
} 


$$
P=\frac{d m}{d t} \operatorname{CpTN} \frac{1}{\eta}\left(\frac{P 2}{P 1}^{\frac{\gamma-1}{\gamma \mathrm{N}}}-1\right)
$$

Lastly, the power consumption of the control room was calculated by taking $5 \%$ of the overall power consumption of the plant. Given the relatively low power consumption of the control room and the ambiguity of all the different power consuming devices it might contain, this fairly conservative estimate is adequate. Figure 5-2 lists the electricity usage anticipated for each of the components previously described and provides a total consumption value to be used in further analysis. The previously mentioned duty cycles and operational cycle have been taken into account in these computations.

Figure 5-2. Electricity Consumption per Pathway ${ }^{57}$

\begin{tabular}{|c|c|c|c|c|c|c|}
\hline & & B1 & B2 & B3 & B4 & B5 \\
\hline Compressor & $\mathrm{kW}$ & 123 & 123 & 78 & 78 & 83 \\
\hline PSA & $\mathrm{kW}$ & 1 & 1 & 1 & 1 & 1 \\
\hline Pumps (3) & kW & 18 & 18 & 96.0 & 9 & 27 \\
\hline Nutrient Pump & $\mathrm{kW}$ & 1.5 & 1.5 & 1.5 & 1.5 & 1.5 \\
\hline Control Room & kW & 9.8 & 9.8 & 13.5 & 4.5 & 12.7 \\
\hline Rotary Drum Filters & $\mathrm{kW}$ & 3.9 & 3.9 & 0.0 & 0 & 9.1 \\
\hline Paddlewheels & $\mathrm{kW}$ & 49.2 & 49.2 & 93.5 & 0 & 132.8 \\
\hline Total & $\mathrm{kW}$ & 206.4 & 206.4 & 283.7 & 94.2 & 267.0 \\
\hline Total Usage & $\mathrm{kWh} / \mathrm{yr}$ & $1,433,023$ & $1,433,023$ & $2,041,916$ & 742,765 & $1,581,043$ \\
\hline Usage Rate & $\mathrm{kWh} / \mathrm{kg} \mathrm{H}$ & 4.36 & 4.36 & 6.22 & 2.26 & 4.81 \\
\hline Cost & $\$ / y r$ & $\$ 70,957$ & $\$ 70,957$ & $\$ 101,106$ & $\$ 36,778$ & $\$ 78,286$ \\
\hline Cost & $\$ / \mathrm{kg} \mathrm{H}_{2}$ & $\$ 0.20$ & $\$ 0.20$ & $\$ 0.28$ & $\$ 0.10$ & $\$ 0.22$ \\
\hline
\end{tabular}

\subsubsection{Excavation of Land for Reactor Bed Placement}

Because of the considerable size of the raceways, detailed attention was given to calculating an accurate cost for the construction of the reactor ponds. Consultation with Mark Dormsteader from Metro Earth Works, a company that focuses solely on earth moving projects, suggested that our project would require a loader, a dozer, and a roller. He said that medium sized equipment would be adequate for such a shallow pool depth. The project would also require a foreman and two laborers on foot. No dump truck for dirt removal will be necessary since all dirt excavated will be used in construction of the side and central berms. Assuming a standard 8 hour work day, it was estimated to take 5 days to construct one raceway. Since multiple teams of workers would be working simultaneously to build all the raceways necessary for a plant, the time per raceway constructed would be significantly reduced, however, the overall cost per raceway would remain the same, since increased workforce brings increased cost.

To calculate the wages of the workers, we used the Department of Labor's Davis-Bacon Wage Determinations for 2008, as referenced in the US Department of Agriculture's "Cost Estimating Guide for Road Construction", which provide a state by state breakdown of

${ }^{57}$ Equipment consumptions rates are based on producing of $1,111 \mathrm{kgH}_{2} /$ day. Yearly Consumption is based on all equipment operating 360days/yr, 24hrs/day, with the exception of paddlewheels, which operate only $12 \mathrm{hrs} /$ day. Consumption Rate/Hydrogen Product is based on final product of $1,000 \mathrm{kgH}_{2} /$ day over previously stated 360 days. 
average wages for various jobs ${ }^{58}$. We also used equipment rental costs referenced by this report taken from The Blue Book of Building and Construction. The cost for equipment rental and the wages vary widely, causing substantial variability in the construction price depending on location. Figure 5-3 shows some examples of wages and rental costs in the American Southwest. We chose the numbers corresponding to Californian wages and rental rates. Given the fact that the organisms involved in biohydrogen production are sensitive to temperature, we decided that a location with more moderate temperatures, yet still high levels of sunlight would be ideal. Thus, southern California, which has more moderate temperatures due to its proximity to the ocean, would be more ideal than desert areas in Arizona or Nevada. Although not considered in our analysis, the proximity to the ocean could also provide an added benefit: an endless supply of water for the system ${ }^{59}$. Figure 5-4 shows the cost estimation for the B-1 system, which requires 20 raceways. Were the plant built in some other state, such as New Mexico, there would be up to a $50 \%$ reduction in construction costs.

Figure 5-3. Davis-Bacon Wage Determinations and Blue Book Rental Costs

TABLE 1 - HOURLY WAGE RATES
\begin{tabular}{|l|l|l|l|l|l|l|l|l|l|l|}
\hline JOB CLASSIFICATION & AZ & CA & CO & ID & KS & NE & NV \\
\hline ZONE & & & 1 & 2 & 1 & 2 & & & LV & $\begin{array}{c}\text { CAR- } \\
\text { SON } \\
\text { CITY }\end{array}$ \\
\hline Foreman & & & & & & & & & & \\
\hline General Laborer & 44.44 & 78.84 & 43.87 & 45.46 & 45.73 & 47.91 & 23.89 & 23.84 & 71.06 & 63.33 \\
\hline Chainsaw Operator & 25.69 & 49.97 & 22.15 & 28.63 & 39.75 & 41.93 & 13.76 & 13.06 & 50.89 & 38.71 \\
\hline Powderman & 26.05 & 52.97 & 25.98 & 29.69 & 40.26 & 42.44 & 15.20 & 17.63 & 51.28 & 39.09 \\
\hline Wagon Drill Operator & 28.71 & 52.97 & 40.88 & 40.65 & 40.04 & 42.23 & 17.74 & 18.26 & 51.48 & 39.46 \\
\hline Asphalt Spreader Operator & 40.02 & 69.43 & 40.88 & 41.10 & 43.55 & 45.74 & 17.01 & 18.26 & 51.35 & 39.09 \\
\hline Backhoe Operator & 41.57 & 67.40 & 40.65 & 40.65 & 43.06 & 45.24 & 19.55 & 19.44 & 62.10 & 56.12 \\
\hline Dozer Operator (1) & 40.80 & 69.51 & 29.00 & 29.00 & 43.42 & 45.61 & 18.10 & 15.50 & 66.45 & 57.48 \\
\hline Dozer Operator (2) & 35.33 & 71.38 & 40.65 & 40.65 & 43.51 & 45.69 & 18.10 & 18.26 & 66.95 & 56.23 \\
\hline Front End Loader Operator (1) & 40.02 & 71.38 & 40.65 & 40.65 & 43.51 & 45.69 & 18.10 & 20.15 & 66.95 & 58.55 \\
\hline Front End Loader Operator (2) & 41.57 & 71.38 & 40.65 & 40.65 & 43.06 & 45.24 & 18.10 & 17.94 & 66.45 & 58.01 \\
\hline Grader Operator & 41.57 & 75.77 & 40.88 & 40.88 & 43.31 & 45.49 & 18.10 & 19.04 & 67.13 & 58.65 \\
\hline Heavy Duty Mechanic/Welder & 35.56 & 71.38 & 29.25 & 41.10 & 43.51 & 45.69 & 21.00 & 20.38 & 68.60 & 57.48 \\
\hline Hydraulic Excavator Operator & 41.57 & 75.77 & 40.88 & 40.88 & 44.09 & 46.28 & 19.55 & 19.75 & 67.38 & 61.11 \\
\hline Truck Driver (1) & 31.94 & 56.92 & 25.01 & 27.62 & 41.13 & 43.31 & 17.38 & 15.19 & 54.29 & 34.67 \\
\hline Truck Driver (2) & 32.83 & 57.38 & 25.01 & 28.12 & 41.39 & 43.57 & 18.10 & 17.08 & 55.26 & 40.48 \\
\hline Roller Operator Compaction & 35.33 & 68.31 & 40.65 & 40.65 & 42.61 & 44.79 & 17.38 & 15.19 & 54.29 & 34.67 \\
\hline
\end{tabular}

LOADERS:

Crawler type, diesel powered, with EROPS:

\begin{tabular}{|l|c|c|c|c|}
\hline Model & Bucket Size & \multicolumn{3}{|c|}{ Hourly Rate (\$) } \\
\hline & Cubic Yards & AZ,NM,UT & CO,ID,KS,NE,NV & CA,SD,WY \\
\hline Caterpillar 933C & 1.30 & 41.72 & 43.33 & 45.42 \\
\hline Deere 555G & 1.50 & 51.52 & 53.56 & 56.21 \\
\hline Caterpillar 953C & 2.42 & 84.96 & 88.76 & 93.68 \\
\hline Caterpillar 963C & 3.20 & 110.46 & 115.20 & 121.34 \\
\hline Caterpillar 973C & 4.19 & 161.25 & 168.29 & 177.42 \\
\hline
\end{tabular}

58 Moll, Jeff, Marjorie Apodaca, Ken Goddard, Jon Stites, Andrea Glover. Cost Estimating Guide for Road Construction. US Forest Service, USDA, Washington DC. April 2008.

${ }^{59}$ While some organism may flourish in saltwater, we assume fresh water for all of the biohydrogen systems under analysis. Consequently, a desalination plant would be necessary to achieve unlimited water from the ocean. 
Figure 5-4. Excavation Cost Estimate for B-1 System using California Costs

\begin{tabular}{|c|c|c|}
\hline \multicolumn{3}{|c|}{ Excavation Cost Estimation for California } \\
\hline Equinment Cost- L oader & & $93.68 \$ / h r$ \\
\hline Equipment Cost- Dozer & & $94.25 \$ / h r$ \\
\hline Equipment Cost- Roller & & $74.3 \$ / \mathrm{hr}$ \\
\hline Operator Cost- Loader & & $71.38 \$ / h r$ \\
\hline Operator Cost- Dozer & & $71.38 \$ / h r$ \\
\hline Operator Cost- Roller & & $68.31 \$ / \mathrm{hr}$ \\
\hline Laborer Cost & & $49.97 \$ / h r$ \\
\hline Foreman Cost & & $78.84 \$ / h r$ \\
\hline Number of Laborers & & 2 \\
\hline Number of Operators & & 3 \\
\hline Total Cost/ day & $\$$ & 5,217 \\
\hline Total Cost/ pool & $\$$ & 26,083 \\
\hline Total Cost/ system & $\$$ & 521,664 \\
\hline
\end{tabular}

The excavation costs calculated concern only the construction of the raceways and the berms. The installation costs of the other components in the system are computed using the H2A methodology.

\section{Levelized Costs Assumptions \& Calculations (H2A)}

Thus far, this report has discussed the capital cost and expenditures associated with building a photobiological-to-hydrogen plant. While this is critical and valuable information, the build decision is ultimately based on the financial and economic benefits of these capital expenditures. The investment is quite large and cannot be properly evaluated without some knowledge of the expected return on that investment. In order to evaluate the return, DTI performed a discounted cash flow (DCF) analysis using the H2A Production Model, Version 2.0.

The H2A model provides a structured format for a user to enter in parameters which impact cash inflows and outflows associated with the construction and operation of the plant. There are H2A Default values for several of the parameters which can be selected as part of the analysis. Additionally, there are plant specific parameters which the analyst must enter. 
Once all parameters have been entered the $\mathrm{H} 2 \mathrm{~A}$ model computes the levelized cost of hydrogen in $\$ / \mathrm{kgH}_{2}{ }^{60}$

\subsection{Standard H2A parameters}

In order to develop levelized costs, several parameters must be defined. Because this analysis focuses on a plant which is still in its conceptual stage, many of the values for these parameters must be assumed. The assumptions are documented in this section. These are meant to represent a baseline system and analysis. Later in the discussion portion of this report, the assumed values can be altered for sensitivity analyses.

Standard H2A financial values and assumptions shown in Figure 6-1 apply to all biohydrogen pathways. This list does not encompass all parameters which must be defined in order to run the analysis; just those were there is an H2A Default value which has been accepted for this analysis. The remaining parameters are defined later in this section. Some of those parameters are common to all biohydrogen pathways and others are pathway specific. No dispensing parameters are listed here because the biohydrogen plants are central type plants and thus dispensing is not factored into the analysis.

${ }^{60}$ For further description of the H2A Model reference, D. Steward, T. Ramsden, and J. Zuboy. H2A Production Model, Version 2 User Guide. NREL/TP-560-43983. Golden, CO. September 2008. 
Figure 6-1. H2A Default Values and Assumptions used for all Biohydrogen Pathways ${ }^{61}$

\begin{tabular}{|c|c|}
\hline Parameter & Assumptions \\
\hline Analysis Period & 20 years \\
\hline Burdened Labor Rate for Staff & $\$ 50 /$ hour \\
\hline CO2 Capture Credit & $\begin{array}{l}\text { Not included in base cases (default } \\
\text { value }=0 \text { ) }\end{array}$ \\
\hline CO2 Production Taxes & $\begin{array}{l}\text { Not included in base cases (default } \\
\text { value }=0 \text { ) }\end{array}$ \\
\hline Construction Period and Cash Flow & 1 year \\
\hline $\begin{array}{c}\text { Co-produced and Cogenerated Electricity } \\
\text { Price }\end{array}$ & $\$ 30 / \mathrm{MWh}$ \\
\hline Decommissioning & $10 \%$ of initial capital \\
\hline $\begin{array}{l}\text { Depreciation Type and Schedule for Initial } \\
\text { Depreciable Capital Cost }\end{array}$ & MACRS: 20 years for central model \\
\hline Facility Life & 20 years \\
\hline G\&A Rate & $20 \%$ of the staff labor costs \\
\hline Hydrogen Pressure at Central Gate & 300 psig \\
\hline Hydrogen Purity ${ }^{62}$ & $\begin{array}{l}98 \% \text { minimum; } \mathrm{CO}<10 \mathrm{ppm} \text {, sulfur }< \\
10 \mathrm{ppm}\end{array}$ \\
\hline Income Taxes & $35 \%$ federal; $6 \%$ state; $38.9 \%$ effective \\
\hline Inflation Rate & $\begin{array}{l}1.9 \% \text {, but with resultant price of } \\
\text { hydrogen in reference year constant } \\
\text { dollars }\end{array}$ \\
\hline Installation Cost Factor & 1.3 \\
\hline Land Cost & $\$ 5,000 /$ acre purchased \\
\hline Licensing, Permits and fees & $\$ 1000$ \\
\hline O2 Credit & Not included in base cases \\
\hline Production Maintenance \& Repairs & $1 / 2 \%$ of direct capital cost \\
\hline Property Taxes and Business Insurance & $2 \% /$ year of the total initial capital cost \\
\hline Reference Financial Structure & $\begin{array}{l}100 \% \text { equity with } 10 \% \text { IRR; includes } \\
\text { levelized hydrogen price plot for } 0 \%- \\
25 \% \text { IRR; model allows debt financing }\end{array}$ \\
\hline Sales Tax & $\begin{array}{l}\text { Not included on basis that facilities and } \\
\text { related purchases are wholesale and } \\
\text { through a general contractor entity }\end{array}$ \\
\hline Salvage Value & $10 \%$ of initial capital \\
\hline Working Capital Rate & $\begin{array}{l}15 \% \text { of the annual change in total } \\
\text { operating costs }\end{array}$ \\
\hline
\end{tabular}

${ }^{61}$ D. Steward, T. Ramsden, and J. Zuboy. H2A Production Model, Version 2 User Guide. Appendix 3: Default Values and Assumptions. NREL/TP-560-43983. Golden, CO. September 2008. p. 60.

62 Purity levels are driven by $\mathrm{H}_{2}$ vehicle consumption requirements. 


\subsection{Pathway Common Parameters}

In addition to the financial parameters defined by $\mathrm{H} 2 \mathrm{~A}$ in the previous section there are other project inputs which must be quantified in order to carry out the DCF analysis. All inputs can be found on the following worksheets in the H2A model;

- Input_Sheet_Template

- ReplacementCosts

- CapitalCosts

Many of these parameters are specific to the location, operation, and type of plant. In the case of our biohydrogen pathways there are some parameters that are the same for all pathways and some that vary by pathway. The parameters in Figure 6-2 are common to all pathways.

Figure 6-2. Parameters Common to all Pathways

\begin{tabular}{|lll|}
\hline \multicolumn{1}{|c}{ Parameter } & \multicolumn{1}{c|}{ Assumed Value } & \multicolumn{1}{c|}{ Worksheet } \\
\hline Operating Capacity Factor & $90 \%$ & Input_Sheet_Template \\
Reference Year Dollars & 2005 & Input_Sheet_Template \\
Site Preparation & $\begin{array}{l}1 \% \text { of direct costs minus } \\
\text { raceway excavation }\end{array}$ & Input_Sheet_Template \\
& costs & \\
Engineering \& design & $7 \%$ of direct costs & Input_Sheet_Template \\
Process Contingency & $20 \%$ of direct costs & Input_Sheet_Template \\
Project Contingency & $\$ 0$ & Input_Sheet_Template \\
Up-Front Permitting Costs & $0.5 \%$ of direct costs & Input_Sheet_Template \\
Production Maintenance \& & $0.5 \%$ of direct costs & Input_Sheet_Template \\
Repairs & & \\
\hline
\end{tabular}

\subsubsection{Operating Capacity Factor}

The operating capacity factor can be found on the Input_Sheet_Template worksheet of the model. This analysis assumes that the plant and dispensing station have a $90 \%$ operating capacity. This capacity factor takes into considering things such as planned maintenance outages, forced outages, etc. Thus, if the plant is capable of producing $1,111 \mathrm{kgH}_{2} /$ day, only $1,000 \mathrm{kgH}_{2}$ will be dispensed and all economic benefit analysis is based on the amount dispensed or sold.

\subsubsection{Reference Year Dollars}

The reference year dollars parameter is the year dollars in which the cost of hydrogen is reported. The H2A standard is to report out hydrogen costs in 2005 dollars. The model expects capital costs to be entered in 2005 dollars. In this analysis Reference Year 2005 was selected.

\subsubsection{Site Preparation}

The site preparation parameter can be found on the Input_Sheet_Template worksheet of the model. In central plants, $\mathrm{H} 2 \mathrm{~A}$ defaults this value to $1 \%$ of direct costs. This analysis uses the same default value; however, the cost basis is slightly altered. Our direct costs include excavation for raceways. We excluded that from the cost basis in this calculation since it is 
not a piece of equipment, but rather a separately computed type of site preparation. Excavation is not all inclusive as site preparation is still required for things such as driveways, control building and algae feed subassembly.

\subsubsection{Engineering \& design}

The engineering \& design parameter can be found on the Input_Sheet_Template worksheet of the model. In central plants, $\mathrm{H} 2 \mathrm{~A}$ defaults this value to $13 \%$ of direct costs. This analysis uses $7 \%$ of direct costs due to the modularity of the design.

\subsubsection{Process Contingency}

The process contingency parameter can be found on the Input_Sheet_Template worksheet of the model. In central plants, H2A defaults this value to $15 \%$ of direct costs. This analysis uses $20 \%$ of direct costs due to uncertainties in the system configuration.

\subsubsection{Project Contingency}

The process contingency parameter can be found on the Input_Sheet_Template worksheet of the model. In our analysis we have chosen to include all contingency factors in the process contingency parameter, thus the project contingency is set to $\$ 0$.

\subsubsection{Up-Front Permitting Costs}

The up-front permitting cost parameter can be found on the Input_Sheet_Template worksheet of the model. The H2A default for this parameter is $9 \%$ of direct costs. This analysis uses $0.5 \%$ of direct costs due to the modularity of the design and its environmental benefits.

\subsection{Pathway Specific Parameters}

The last types of parameters we identify are those which are specific to each pathway analyzed. Figure 6-3 lists these parameters and rules of thumb applied in computing their values. These are pathway specific because they are associated with feedstock, process design and plant design.

Figure 6-3. Pathway Specific Parameters

\begin{tabular}{|lll|}
\hline \multicolumn{1}{|c|}{ Parameter } & \multicolumn{1}{c|}{ Rule Applied } & \multicolumn{1}{c|}{ Worksheet } \\
\hline Land Required & $\begin{array}{l}30 \% \text { greater than reactor } \\
\text { bed area }\end{array}$ & Input_Sheet_Template \\
Production facility plant staff & $\begin{array}{l}\text { 1 worker per shift per } \\
100 \text { raceways }+0.5\end{array}$ & Input_Sheet_Template \\
& $\begin{array}{l}\text { Workers for winders } \\
\text { Electricity and water }\end{array}$ & Input_Sheet_Template \\
Utility Usage & $\begin{array}{l}\text { costs use H2A pricing } \\
\text { As required by organism }\end{array}$ & Input_Sheet_Template \\
Feedstock Usage & LDPE every 5 yrs & ReplacementCosts \\
Specified Yearly Replacement & & \\
Costs & & \\
\hline
\end{tabular}




\subsubsection{Land Required}

The land required parameter can be found on the Input_Sheet_Template worksheet of the model. In developing the plant design, a land area for the reactor bed was computed. The analysis assumes that the total land required for this design is $30 \%$ greater than the reactor bed. The $30 \%$ factor is meant to encompass area requirements for pump skids, compressors, gas and algae separators and a small control room. The total land requirement for each pathway is shown in Figure 6-4.

Figure 6-4. Land Required for each Pathway

\begin{tabular}{|lccccc|} 
& $\begin{array}{c}\text { Algal } \mathbf{2}^{-} \\
\text {tolerant } \\
\text { Hydrogenase } \\
\text { (1) }\end{array}$ & $\begin{array}{c}\text { Cyanobacterium } \\
\mathbf{O}_{2} \text {-tolerant } \\
\text { Hydrogenase (2) }\end{array}$ & $\begin{array}{c}\text { Algal } \\
\text { Sulfate } \\
\text { Permease }\end{array}$ & $\begin{array}{c}\text { Immobilize } \\
\text { d Algal, } \\
\text { Sulfur } \\
\text { deprived }\end{array}$ & $\begin{array}{c}\text { PNS } \\
\text { bacteria }\end{array}$ \\
\hline $\begin{array}{l}\mathrm{B}-1 \\
\text { Bed Area } \\
\left(\mathbf{m}^{2}\right)\end{array}$ & 80,968 & 80,968 & 151,035 & 352,070 & 216,228 \\
$\begin{array}{l}\text { \% increase } \\
\text { for } \\
\text { auxiliaries }\end{array}$ & $30 \%$ & $30 \%$ & $30 \%$ & $30 \%$ & $30 \%$ \\
$\begin{array}{l}\text { Total Land } \\
\text { Required } \\
\left(\mathbf{m}^{2}\right)\end{array}$ & 105,259 & 105,259 & 196,345 & 457,691 & 281,096 \\
\hline
\end{tabular}

\subsubsection{Production facility plant staff}

The production facility plant staff parameter can be found on the Input_Sheet_Template worksheet of the model. This represents the number of full-time employees required to operate the plant. There is no H2A default value for this. Our analysis for each of the pathways is shown in Figure 6-5. From our analysis we suggest 3 employees are needed for each $1,000 \mathrm{kgH}_{2}$ module of the B-1, B-2, B-3, and B-5 system design. This is based on the assumptions that each worker can operate 5 of these modules simultaneously but the plant operates $24 \mathrm{hrs} /$ day so three shifts are needed. In the case of the B-4 pathway, an additional employee is required for the manual transfer of algae films between ponds. However, the films only need replacement once every six months, limiting the overall labor needed.. We have assumed a wind and unwind speed of $0.5 \mathrm{ft} / \mathrm{second}$ for the polypropylene films. Two old films per raceway will need to be wound and unwound along with new films that will be wound and unwound for replacement. Additionally, we have assumed it will take 15 minutes to reposition and prepare the winder for each wind/unwind cycle. We calculated that it will take about eight hours, or one full FTE for a worker to complete the task of exchanging the mats in one raceway. Thus, the total labor need is the total number of raceways (90) divided by the number of work days in 6 months (120), giving us $\sim 0.75$ FTE in addition to the daily raceway operators. 
Figure 6-5. Plant Staff Requirements for 1 tonne $\mathrm{H}_{2}$ /day plant

\begin{tabular}{|c|c|c|c|c|c|}
\hline & $\begin{array}{c}\text { Algal 02- } \\
\text { tolerant } \\
\text { Hydrogenase } \\
\text { (1) }\end{array}$ & $\begin{array}{c}\text { Cyanobacterium } \\
\text { O2-tolerant } \\
\text { Hydrogenase (2) }\end{array}$ & $\begin{array}{c}\text { Algal } \\
\text { Sulfate } \\
\text { Permease }\end{array}$ & $\begin{array}{l}\text { Immobilized } \\
\text { Algal, } \\
\text { Sulfur } \\
\text { deprived }\end{array}$ & $\begin{array}{c}\text { PNS } \\
\text { bacteria }\end{array}$ \\
\hline & B-1 & B-2 & B-3 & B-4 & B-5 \\
\hline Modules & 1 & 1 & 1 & 1 & 1 \\
\hline $\begin{array}{l}\text { Raceways/ } \\
\text { Module }\end{array}$ & 20 & 20 & 38 & 68 & 54 \\
\hline $\begin{array}{l}\text { Raceways/ } \\
\text { Worker }\end{array}$ & 100 & 100 & 100 & 100 & 100 \\
\hline Shifts/Day & 3 & 3 & 3 & 3 & 3 \\
\hline $\begin{array}{l}\text { Workers } \\
\text { FTE }^{63}\end{array}$ & 3 & 3 & 3 & 3 & 3 \\
\hline $\begin{array}{l}\text { Winder } \\
\text { Workers }\end{array}$ & N/A & N/A & $\mathrm{N} / \mathrm{A}$ & $0.5 \mathrm{FTE}$ & $\mathrm{N} / \mathrm{A}$ \\
\hline Total FTE & 3 & 3 & 3 & 3.75 & 3 \\
\hline
\end{tabular}

\subsubsection{Energy Usage}

The usage of utilities, feedstocks and creation of byproducts can be found on the Input_Sheet_Template worksheet of the model. There are no H2A default values for these. We are not aware of any Byproducts associated with the bio-hydrogen pathways. In the case of utilities, the utility (electricity, natural gas, steam) of interest is selected from a dropdown box. The amount consumed is based on the plant design and thus varies. For our $1,000 \mathrm{kgH}_{2} /$ day system those quantities are shown in Figure 6-6. The model has a cost rate for each utility and thus computes the total costs of utilities.

Figure 6-6. Utilities Usage

\begin{tabular}{|lccccc|} 
& $\begin{array}{c}\text { Algal O2- } \\
\text { tolerant } \\
\text { Hydrogenase } \\
(\mathbf{1})\end{array}$ & $\begin{array}{c}\text { Cyanobacterium } \\
\text { O2-tolerant } \\
\text { Hydrogenase (2) }\end{array}$ & $\begin{array}{c}\text { Algal } \\
\text { Sulfate } \\
\text { Permease }\end{array}$ & $\begin{array}{c}\text { Immobilized } \\
\text { Algal, Sulfur } \\
\text { deprived }\end{array}$ & $\begin{array}{c}\text { PNS } \\
\text { bacteria }\end{array}$ \\
\hline $\begin{array}{l}\text { Electricity } \\
\text { (kWh/kgH2) }\end{array}$ & 4.36 & B-2 & B-3 & B-4 & B-5 \\
$\begin{array}{l}\text { Water } \\
\left(\mathbf{g a l} / \mathbf{k g H}_{2}\right)\end{array}$ & 2.900 & 2.36 & 6.22 & 2.26 & 4.81 \\
\hline
\end{tabular}

In our bio-hydrogen pathways the feedstocks are nutrients and $\mathrm{CO}_{2}$ which are not $\mathrm{H} 2 \mathrm{~A}$ options that can be selected from the drop-down box. Therefore the usage, price and heating value of each feedstock must be entered manually. Those pathway specific required inputs are shown in Figure 6-7.

${ }^{63}$ Full Time Equivalent 
Figure 6-7. Feedstock Usage

\begin{tabular}{|c|c|c|c|c|c|}
\hline \multicolumn{6}{|c|}{ Carbon Dioxide } \\
\hline Value & Unit & B1 & B2 & B3 & B4 \\
\hline Lower Heating Value & mmBTU/ Short Ton & 9.37 & 9.37 & 9.37 & 9.37 \\
\hline Price Startup Year & \$/Dry Short Ton & 1,400 & $\$ 1,400$ & $\$ 1,400$ & 1,400 \\
\hline Startup CO2 & lb & 5,241 & 5,241 & 41,629 & 206,180 \\
\hline Usage & Ib/day & 566 & 566 & - & - \\
\hline Usage & DryTon/kg H2 & $2.83 \mathrm{E}-04$ & 2.83E-04 & $0.00 E+00$ & $0.00 \mathrm{E}+00$ \\
\hline
\end{tabular}

\begin{tabular}{|l|c|c|c|c|c|c|}
\hline \multicolumn{1}{|c|}{ Nutrients } & B1 & B2 & B3 & B4 & B5 \\
\hline \multicolumn{1}{|c|}{ Value } & Unit & 28.44 & 28.44 & 28.44 & 28.44 & 28.44 \\
\hline Lower Heating Value & mmBTU/ Short Ton & 400 & 400 & 400 & 400 & 400 \\
Price Startup Year & \$/Dry Short Ton & $1.16 \mathrm{E}-07$ & $1.16 \mathrm{E}-07$ & $2.16 \mathrm{E}-07$ & $5.03 \mathrm{E}-07$ & $3.09 \mathrm{E}-07$ \\
Usage & DryTon/kg H2 & & &
\end{tabular}

\subsubsection{Specified Yearly Replacement Costs}

The specified yearly replacement costs can be found on the Replacement Costs worksheet of the model. There is no H2A default value for this. This analysis recognizes that the transparent film which serves to capture product gas, permit sunlight, and keep culture free of contamination will need periodic replacement. The film is made of LDPE and over time will degrade such that less sunlight will enter the system thereby lowering plant efficiency. This analysis assumes that a 5-yr replacement cycle for the LDPE film is sufficient to keep system performing at acceptable levels. All other components are anticipated to operate for 20 years. There are no other specified replacement costs over the twenty year analysis period for any of the pathways. Figure 6-8 lists the pathway specific costs associated with replacement components.

Figure 6-8. LDPE Film Replacement Costs

\begin{tabular}{|c|c|c|c|c|c|}
\hline & $\begin{array}{l}\text { Algal 02- } \\
\text { tolerant } \\
\text { Hydrogenase } \\
\text { (1) }\end{array}$ & $\begin{array}{c}\text { Cyanobacterium } \\
\text { O2-tolerant } \\
\text { Hydrogenase (2) }\end{array}$ & $\begin{array}{c}\text { Algal } \\
\text { Sulfate } \\
\text { Permease }\end{array}$ & $\begin{array}{l}\text { Immobilized } \\
\text { Algal, Sulfur } \\
\text { deprived }\end{array}$ & $\begin{array}{c}\text { PNS } \\
\text { bacteria }\end{array}$ \\
\hline & B-1 & B-2 & B-3 & B-4 & B-5 \\
\hline $\begin{array}{l}\text { Quantity of } \\
\text { Film }^{64}\left(\mathrm{~m}^{2}\right)\end{array}$ & 87,080 & 87,080 & 165,452 & 381,075 & 235,116 \\
\hline $\begin{array}{l}\text { Costs } \\
\text { (yrs. 5, 10, } \\
\text { 15) }\end{array}$ & $\$ 60,932$ & $\$ 60,932$ & $\$ 115,770$ & $\$ 205,113$ & $\$ 164,516$ \\
\hline
\end{tabular}

\subsubsection{Baseline Uninstalled Costs}

The baseline uninstalled costs can be found on the Capital Costs worksheet of the model. There is no H2A default value for this. These are the capital costs of the equipment that were computed in an earlier part of this project. Those separately calculated values will be imported into this area of the H2A Production Model to access the economic benefit of the capital expenditure. These costs are provided in the bill of materials for each pathway.

${ }^{64}$ Quantity includes pathway area and overages explained in Section 5.1.2. 


\subsubsection{Installation Cost Factor}

The installation cost factor parameter can be found on the Capital Costs worksheet of the model. The default value for this is 1.3 , however there is an exception. The installation of the reactor beds doesn't rely on a cost factor but rather performs a separate excavation cost calculation which was described above.

\subsection{Results for Levelized Hydrogen Costs}

The results from the $\mathrm{H} 2 \mathrm{~A}$ model are provided in tabular form. The total cost of produced hydrogen in a 10 tonne per day (TPD) plant ${ }^{65}$ is provided as well as the cost breakdown of that value over several cost components. Our analysis indicates that for a 10 TPD plant the B-1 and B-2 pathways produce the lowest cost hydrogen as shown in Figure 6-9. B-1 and B-2 provide identical cost of hydrogen because the key assumptions effecting cost are the same for these two pathways. The primary components of the levelized cost of hydrogen are capital costs, fixed O\&M and other variable costs as shown in Figure 6-10. The discussion section of this report will delve further into the costs included in these components.

Figure 6-9. Levelized costs for B-1 through B-5 Pathways

\begin{tabular}{|r|c|c|c|c|c|}
\hline \multicolumn{7}{|c|}{ Total Cost of Produced $\mathbf{~}_{\mathbf{2}}$} \\
\hline Cost Component & \multicolumn{2}{|c|}{ Hydrogen Production Cost Contribution (\$/kg) } \\
\hline System & $\mathbf{B 1}$ & $\mathbf{B 2}$ & $\mathbf{B 3}$ & $\mathbf{B 4}$ & $\mathbf{B 5}$ \\
\hline Capital Costs & $\$ 1.74$ & $\$ 1.74$ & $\$ 2.82$ & $\$ 3.87$ & $\$ 3.37$ \\
\hline Decommissioning Costs & $\$ 0.02$ & $\$ 0.02$ & $\$ 0.03$ & $\$ 0.04$ & $\$ 0.03$ \\
\hline Fixed O\&M & $\$ 0.60$ & $\$ 0.60$ & $\$ 0.99$ & $\$ 1.99$ & $\$ 1.27$ \\
\hline Feedstock Costs & $\$ 0.40$ & $\$ 0.40$ & $\$ 0.00$ & $\$ 0.00$ & $\$ 5.43$ \\
\hline Other Raw Material Costs & $\$ 0.00$ & $\$ 0.00$ & $\$ 0.00$ & $\$ 0.00$ & $\$ 0.00$ \\
\hline Byproduct Credits & $\$ 0.00$ & $\$ 0.00$ & $\$ 0.00$ & $\$ 0.00$ & $\$ 0.00$ \\
\hline $\begin{array}{r}\text { Other Variable Costs } \\
\text { (including utilities) }\end{array}$ & $\$ 0.23$ & $\$ 0.23$ & $\$ 0.33$ & $\$ 0.12$ & $\$ 0.25$ \\
\hline Total & $\mathbf{\$ 2 . 9 9}$ & $\mathbf{\$ 2 . 9 9}$ & $\mathbf{\$ 4 . 1 7}$ & $\mathbf{\$ 6 . 0 2}$ & $\mathbf{\$ 1 0 . 3 6}$ \\
\hline
\end{tabular}

${ }^{65}$ Cost results are based on a 10 metric ton per day hydrogen plant composed of ten 1 metric ton per day modules. 
Figure 6-10. Comparison of Levelized Cost Components

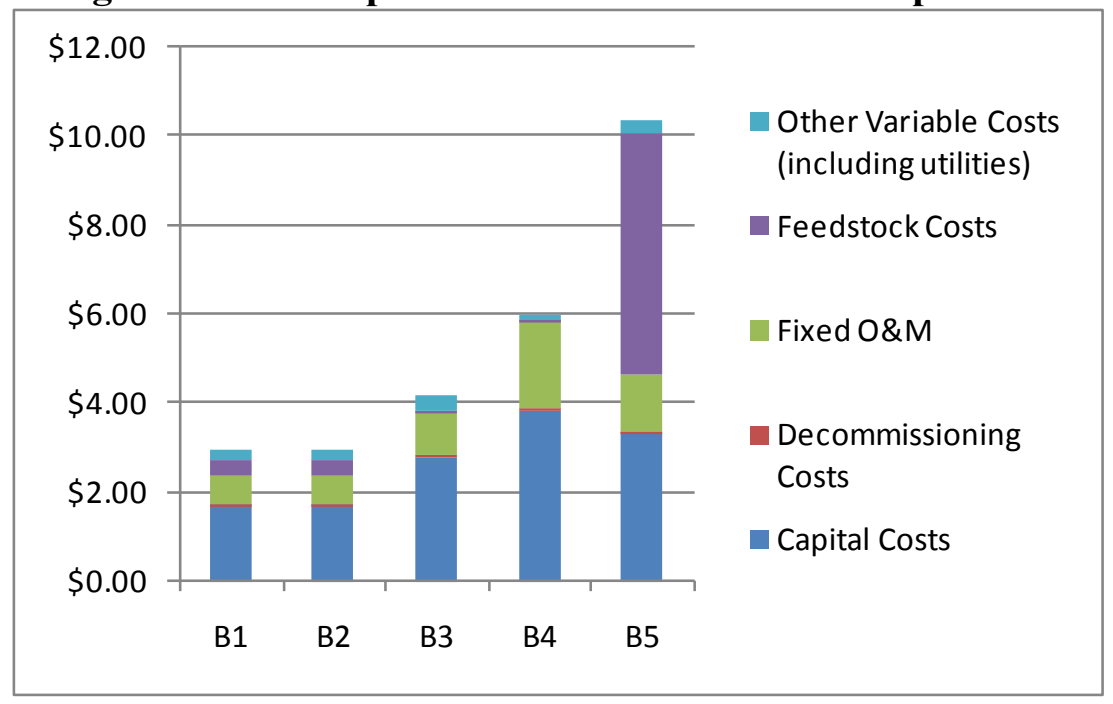

\subsection{Near Term Performance Results}

In addition to calculating the results for the upper bound solar-to-hydrogen (STH) conversion efficiencies, which has been explicated thus far in the report, we also calculated levelized hydrogen costs for "near term" STH efficiencies.

The upper bound performance projections for the B-1, B-2, B-3, and B-5 assume that there is full utilization of the solar photons for hydrogen production due to development of mutants that have reduced antennas and do not have saturation and other electron transfer limits. For near term organisms, utilization will be significantly less than $100 \%$, but is expected to be better than the current status. Based on these anticipated developments, we have made estimates of the organisms' near term properties and estimated the consequent near term production capabilities.

Assumed near term solar-to-hydrogen (STH) conversion efficiencies are shown in Figure 6-11 along with the previously discussed upper bound efficiencies for convenient comparison. . For B-4, the upper bound solar utilization comes from the NREL extrapolation of experimental results to generate a model of the best possible future performance level of B-4. For the B-4 near term projection, we have assumed a reduction in utilization from that best future performance upper bound.

Levelized $\mathrm{H}_{2}$ costs corresponding to the near term efficiencies are shown in Figure 6-12. The primary components of the levelized cost of hydrogen are capital costs, fixed O\&M, and "Other Variable Costs".

Figure 6-11. Near Term STH Efficiency Assumptions

\begin{tabular}{|lccccc|}
\hline STH Efficiency & B1 & B2 & B3 & B4 & B5 \\
\hline Upper Bound & $9.2 \%$ & $9.2 \%$ & $5.2 \%$ & $2.25 \%$ & $3.5 \%$ \\
\hline Near Term & $2 \%$ & $2 \%$ & $1.3 \%$ & $1.5 \%$ & $1.5 \%$ \\
\hline
\end{tabular}


Figure 6-12. Levelized $\mathrm{H}_{2}$ Costs based on Near Term STH Efficiency

\begin{tabular}{|r|c|c|c|c|c|}
\hline \multicolumn{6}{|c|}{ Total Cost of Produced H } \\
\hline Cost Component & \multicolumn{6}{|c|}{ Hydrogen Production Cost Contribution (\$/kg) } \\
\hline System & B1 & B2 & B3 & B4 & B5 \\
\hline Capital Costs & $\$ 5.61$ & $\$ 5.61$ & $\$ 7.04$ & $\$ 5.36$ & $\$ 7.10$ \\
\hline Decommissioning Costs & $\$ 0.06$ & $\$ 0.06$ & $\$ 0.07$ & $\$ 0.05$ & $\$ 0.07$ \\
\hline Fixed O\&M & $\$ 2.08$ & $\$ 2.08$ & $\$ 2.96$ & $\$ 2.92$ & $\$ 2.62$ \\
\hline Feedstock Costs & $\$ 0.00$ & $\$ 0.00$ & $\$ 0.00$ & $\$ 0.00$ & $\$ 3.73$ \\
\hline Other Raw Material Costs & $\$ 0.00$ & $\$ 0.00$ & $\$ 0.00$ & $\$ 0.00$ & $\$ 0.00$ \\
\hline Byproduct Credits & $\$ 0.00$ & $\$ 0.00$ & $\$ 0.00$ & $\$ 0.00$ & $\$ 0.00$ \\
\hline $\begin{array}{r}\text { Other Variable Costs } \\
\text { (including utilities) }\end{array}$ & $\$ 0.41$ & $\$ 0.41$ & $\$ 0.41$ & $\$ 0.11$ & $\$ 0.44$ \\
\hline Total & $\$ \mathbf{\$ 8 . 1 5}$ & $\mathbf{\$ 8 . 1 5}$ & $\$ 10.48$ & $\$ 8.44$ & $\$ 13.95$ \\
\hline
\end{tabular}

Figure 6-13. Comparison of Levelized Cost Components for Near Term Efficiencies

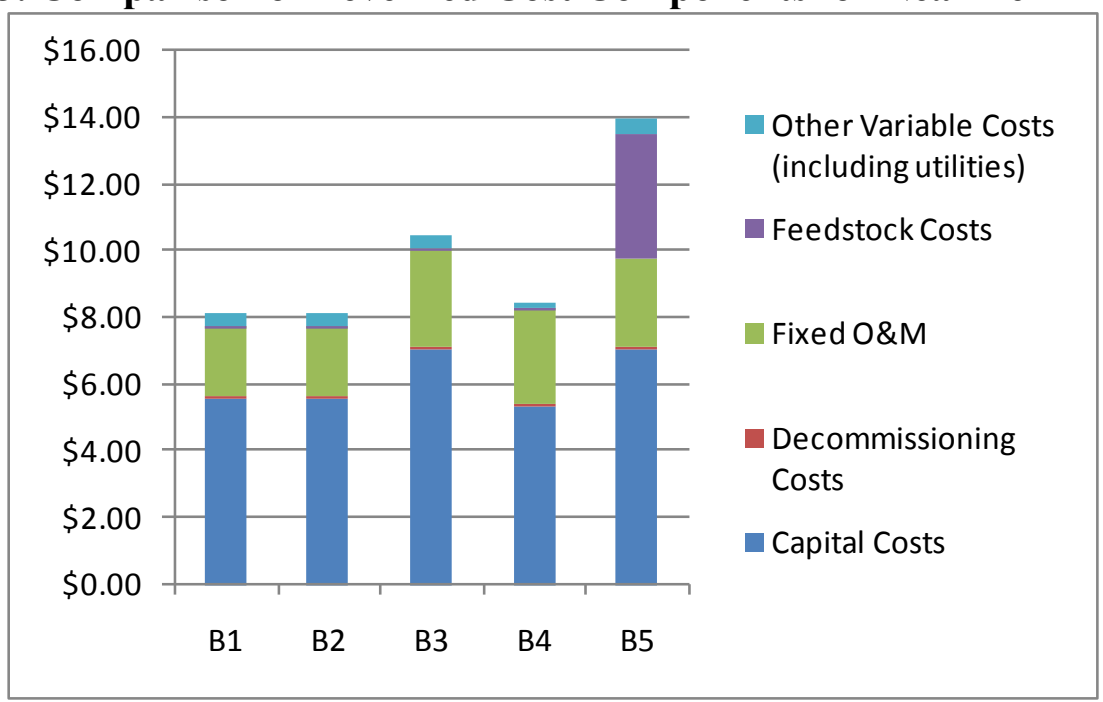

\section{Discussion of Results}

The results discussion will look at how plant sizing impacts the key costs components of levelized costs, namely, capital costs, fixed O\&M, and variable costs. An explanation for the low feedstock costs is also provided.

This report's baseline cost analysis assumes a 10 TPD plant consisting of ten 1 TPD modules. One would expect that the levelized costs results from $\mathrm{H} 2 \mathrm{~A}$ would be different if the plant size chosen was different. Plant sizes of 1TPD, 50TPD and 100TPD were reviewed and our analysis shown below indicates that the 10TPD facility was appropriate for this analysis.

\subsection{Capital Costs}

Because this analysis is developing a large plant size from several smaller modules, one would expect equipment cost advantages based on modularity. However, recall that each 1 
TPD module already has multiple raceways resulting in large quantities of similar components within a single module. Additional capital cost reductions as a result of increased purchase quantity are likely to be minimal since the quantity of most materials is already substantial for one module. The smallest module considered amongst our five pathways has twenty raceways, and the costing already employs a significant economy of scale. Further scaling of lower quantity, larger items, such as drum filters could result in further cost reduction, but has not been considered in this report primarily because low yearly sales of these items makes scaling data unavailable.

Additionally, most components selected are available commercially off the shelf (COTS) and costs were obtained using vendor quotations. Because of this, the capital costs for each module already take into account commodity; high volume pricing and thus capital costs due to large plant size are expected to increase linearly. Figure 7-1 demonstrates the relationship between capital costs and plant size.

Figure 7-1. Capital Cost Increases from Increased Plant Size ${ }^{66}$

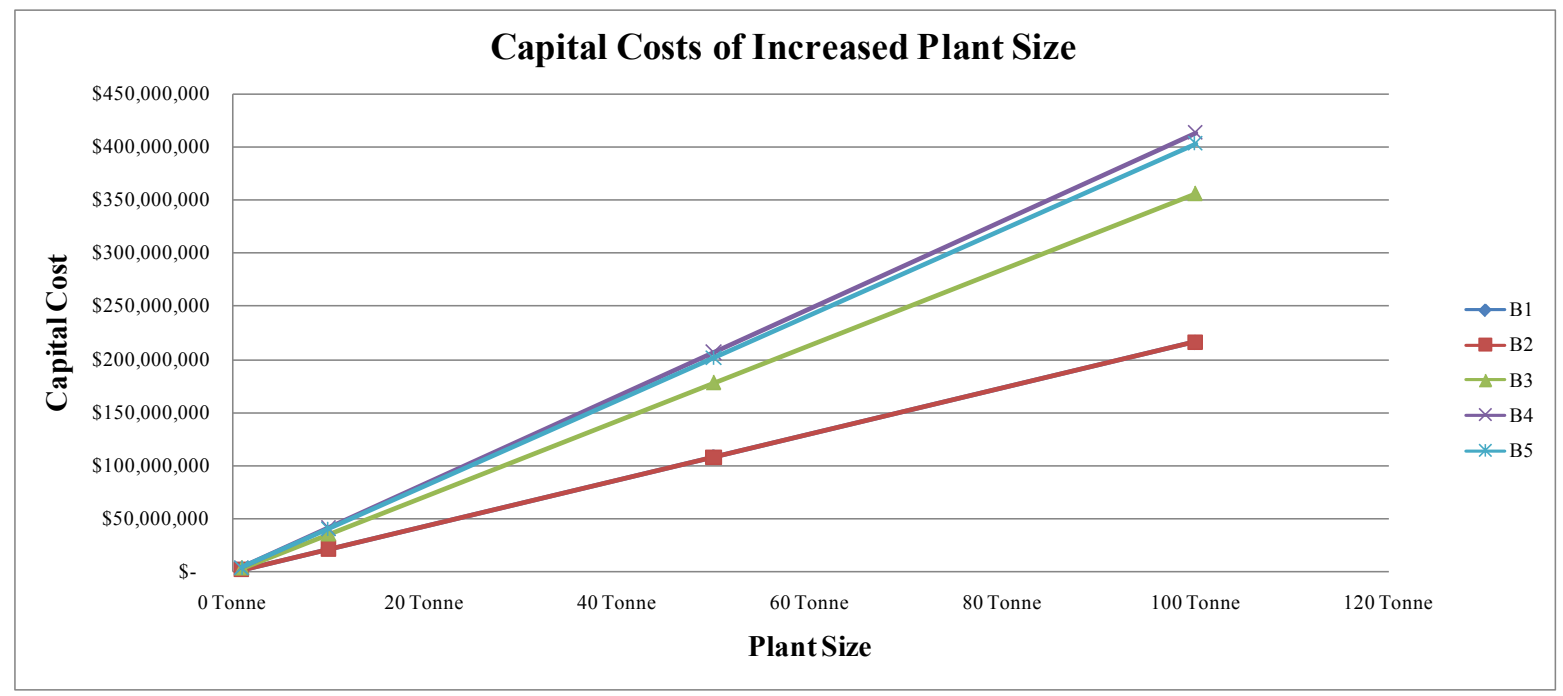

Exceptions to this COTS and high volume logic are the compressors and PSAs that are sized for 1TPD modules. Given the extremely large areas of a single module, we chose not to combine several modules into a common compressor and PSA due to the difficulty of transporting low pressure gas over long distances. Furthermore, unlike the other equipment whose costs were obtained from vendor quotes, the cost of compressors and PSAs are derived from H2A unit costing models. However those models already have built in assumptions to provide an $\mathrm{n}^{\text {th }}$ unit cost so again no economy of scale can be assumed for these components.

Because the capital costs do not achieve economy of scales we explored fixed O\&M for an indication of optimal plant size.

${ }^{66} \mathrm{~B} 1$ and $\mathrm{B} 2$ are the exact same and overlap on the graph, which is why B1 does not show up on the graph 


\subsection{Fixed O\&M (Plant Labor)}

After capital cost component, fixed O\&M is the next largest cost component of the levelized hydrogen cost. Within H2A the fixed O\&M consists of primary of labor, G\&A (which is a percentage of labor), Property Taxes (which is a percentage of capital costs), and Production Maintenance and Repair (which is a percentage of capital costs). Since we have already established that capital costs scale linearly, we focus on plant labor costs.

One of the most significant differences in plant sizes is the amount of labor needed. Labor rates for a 1, 10, 50, and 100 TPD plant were examined. A summary of the assumed labor requirements and rates is shown in Figure 7-2. The analysis assumes that the plant will need constant supervision (3shifts/day) from workers who can fix any equipment malfunction and monitor plant operation. We assume one worker can effectively watch over 100 raceways working a standard 8-hour shift. Additionally, for the multiple module plants, an overall supervisor will be needed. For the 100 TPD plant, an assistant supervisor is added due to the extremely large area of such the plant. The B-4 system requires an extra worker in order to change one roll of immobilized algae film per day.

Figure 7-2. Labor Assumptions for Different Plant Sizes

\begin{tabular}{|c|c|c|c|c|c|c|c|c|}
\hline & \multicolumn{4}{|c|}{ B1/B2 } & \multicolumn{4}{|c|}{ B3 } \\
\hline & 1 ton & 10 ton & 50 ton & 100 ton & 1 ton & 10 ton & 50 ton & 100 ton \\
\hline Modules & 1 & 10 & 50 & 100 & 1 & 10 & 50 & 100 \\
\hline Total Raceways & 20 & 200 & 1000 & 2000 & 38 & 380 & 1900 & 3800 \\
\hline Raceways/Worker & 100 & 100 & 100 & 100 & 100 & 100 & 100 & 100 \\
\hline Shifts/Day & 3 & 3 & 3 & 3 & 3 & 3 & 3 & 3 \\
\hline Workers FTE & 3 & 6 & 30 & 60 & 3 & 12 & 57 & 114 \\
\hline Roll/Unroll Workers & $\mathrm{N} / \mathrm{A}$ & $\mathrm{N} / \mathrm{A}$ & $\mathrm{N} / \mathrm{A}$ & N/A & N/A & $\mathrm{N} / \mathrm{A}$ & $\mathrm{N} / \mathrm{A}$ & $\mathrm{N} / \mathrm{A}$ \\
\hline Supervisor FTE & 0 & 3 & 3 & 3 & 0 & 3 & 3 & 3 \\
\hline Asst. Super. FTE & 0 & 0 & 0 & 1 & 0 & 0 & 0 & 1 \\
\hline Total FTE & 3 & 9 & 33 & 64 & 3 & 15 & 60 & 118 \\
\hline \multirow[t]{3}{*}{ FTE/1TPD Module } & 3 & 0.9 & 0.66 & 0.64 & 3 & 1.5 & 1.2 & 1.18 \\
\hline & \multicolumn{4}{|c|}{ B4 } & \multicolumn{4}{|c|}{ B5 } \\
\hline & 1 ton & 10 ton & 50 ton & 100 ton & 1 ton & 10 ton & 50 ton & 100 ton \\
\hline Modules & 1 & 10 & 50 & 100 & 1 & 10 & 50 & 100 \\
\hline Total Raceways & 90 & 900 & 4500 & 9000 & 54 & 540 & 2700 & 5400 \\
\hline Raceways/Worker & 100 & 100 & 100 & 100 & 100 & 100 & 100 & 100 \\
\hline Shifts/Day & 3 & 3 & 3 & 3 & 3 & 3 & 3 & 3 \\
\hline Workers FTE & 3 & 27 & 135 & 270 & 3 & 18 & 81 & 162 \\
\hline Roll/Unroll Workers & 0.8 & 8 & 38 & 75 & N/A & $\mathrm{N} / \mathrm{A}$ & $\mathrm{N} / \mathrm{A}$ & $\mathrm{N} / \mathrm{A}$ \\
\hline Supervisor FTE & 0 & 3 & 3 & 3 & 0 & 3 & 3 & 3 \\
\hline Asst. Super. FTE & 0 & 0 & 0 & 1 & 0 & 0 & 0 & 1 \\
\hline Total FTE & 4 & 38 & 176 & 349 & 3 & 21 & 84 & 166 \\
\hline FTE/1TPD Module & 3.8 & 3.8 & 3.5 & 3.5 & 3 & 2.1 & 1.68 & 1.66 \\
\hline
\end{tabular}


When these plant sizes are analyzed in $\mathrm{H} 2 \mathrm{~A}$, hydrogen costs decrease with plant size as shown in Figure 7-3. This study indicates labor cost reductions are achieved through increasing plant size. In all cases most of the cost benefit is gained in the initial increase in plant size, with the curve flattening towards a 100TPD system. Therefore, it is appropriate to choose the 10TPD plant for analysis. This is also intuitive from the labor assumptions in Figure 7-2 where a comparison in Total Raceways and Raceways/Worker shows that in the 1 ton module workers are underutilized.

Figure 7-3. Labor Cost Reductions from Increased Plant Size

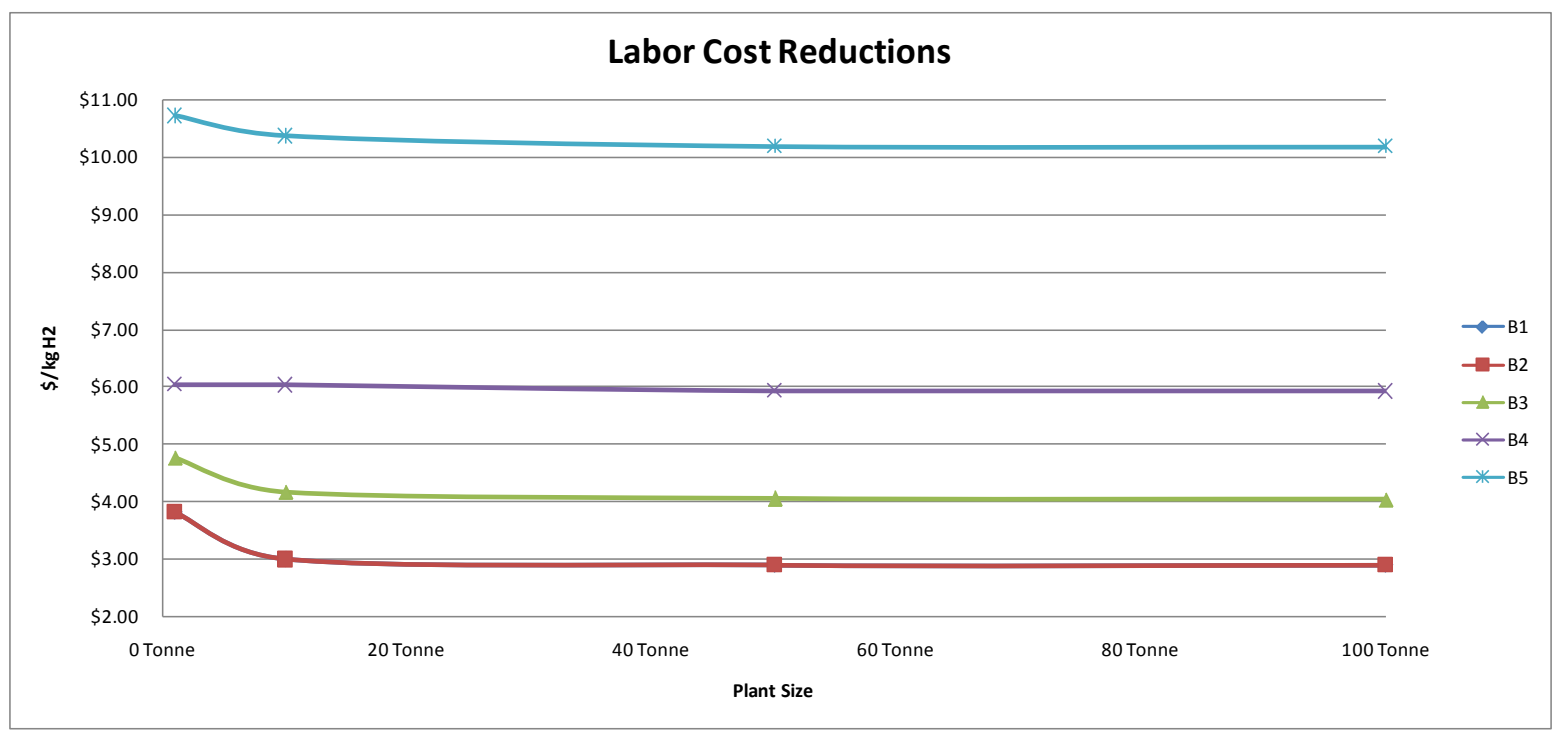

\subsection{Variable Costs}

The third largest cost component of the levelized hydrogen cost is variable cost. Within $\mathrm{H} 2 \mathrm{~A}$ the variable costs consists of utilities, byproduct credits, waste costs, and tax incentives. In our analysis only utilities (specifically electricity) are considered. Since electricity consumption is based on the equipment and we have chosen to duplicate modules and therefore equipment in the larger plants, variable costs are expected to be constant per $\mathrm{kgH}_{2}$ produced regardless of plant size.

\subsection{Feedstock Costs}

Feedstock Costs are essentially the cost of nutrients. As we can see they are minimal in all pathways except B-5, where the cost of acetate is substantial. Since nutrient quantity is based on algae and area then we expect the relationship with plant size to be linear. Nutrient costs are currently derived from price quotes for high-quantity agriculture fertilizer purchases and data on international market prices for acetate. Considering the low level of nutrients consumed compared to conventional agriculture, change in pricing due to increased plant size is negligible and ignored. 


\subsection{Reactor Footprint}

The above cost analysis uses a baseline 10 TPD plant consisting of ten 1 TPD modules. Thus all systems produce the same amount of hydrogen. However, due to varying efficiencies, the five systems result in vastly different land area requirements. If we were to normalize based on the land area, or reactor footprint, for the 1 TPD module we can analyze the production data in a different way. Choosing the area of the B-4 systems which has the largest reactor footprint, in Figure 7-4 we show the hydrogen outputs of each system if scaled to match the land area of B-4. This is an important consideration in areas where land may be in short supply.

Figure 7-4. Normalized Hydrogen Production

\begin{tabular}{|c|c|c|c|c|c|}
\hline System & B-1 & B-2 & B-3 & B-4 & B-5 \\
\hline Reactor Size $\left(\mathrm{m}^{2}\right)$ & 352,070 & 352,070 & 352,070 & 352,070 & 352,070 \\
\hline $\begin{array}{l}\text { Algae Removed } \\
\text { (kg/day) }\end{array}$ & 175 & 175 & NA & NA & 468 \\
\hline $\begin{array}{l}\text { Hydrogen } \\
\text { Production } \\
\left(\mathrm{kgH}_{2} / \text { day) }\right.\end{array}$ & 4,348 & 4,348 & 2,331 & 1,000 & 1,628 \\
\hline
\end{tabular}

\section{Photobiological System Conclusions and Recommendations}

Under the premise that low cost hydrogen is the most important factor, then the H2A analysis points us to B-1 and B-2 pathways as the best photobiological pathways. However, one engineering concern for B-1 and B-2, which produce stoichiometric mixtures of hydrogen and oxygen, is to assure that the gases are isolated from any potential ignition sources. Before moving forward with any given system further, additional sensitivities should be done on key assumptions in this analysis. In the previous section we explored the assumptions of plant size and modular design. One parameter that could be further tested is the impact of plant efficiency on levelized costs. The characterization section of this report identified 3 efficiencies for each system: maximum theoretical, assumed reactor operation, and current experimental data. This baseline analysis is based on the assumed reactor operation. However if that value cannot be reached, the impact on cost can be great. Another parameter to consider is component lifetime, which impact replacement costs. Sensitivities on labor rates for plant personnel could also be performed. Furthermore, the probability of success and commercialization timeline of all systems should be considered prior to eliminating any pathway from further analysis.

As mentioned in Section 6.4, a large portion of the levelized cost is from the capital costs of the plant. Figure 8-1 shows the contribution of each subassembly to the overall plant costs. The most costly subsystems are the Photobioreactor and Control System. 
Figure 8-1. Capital Cost Allocations by Subassembly

\begin{tabular}{|c|c|c|c|}
\hline & B1 & & \\
\hline
\end{tabular}

Within the photobioreactor subassembly the largest cost contributors are the pond installation and paddlewheel mixers. The pond installation is directly proportional to the number of raceways. The costs of the installation were well vetted as described in Section 5.2.5. The plant location could affect labor costs associated with installation and could "provide some relief to capital cost. The second largest cost contributors to this subassembly are the paddlewheel mixers. These costs are well known. The quantities required are conservative estimates based on the land area and water depth. Further research could be done in this area to see if more cost effective mixing solutions are available for our area and bed depth. Any other solutions should have a similar lifetime to be cost effective or significantly cheaper to offset replacement costs.

The control system subassembly has two items which are of large costs. These are the gas analyzers and level indicators. Rather than placing a gas analyzer in each raceway $\mathrm{H} 2$ outlet pipe, we group the outlet of two raceways into one analyzer to reduce cost. If the sensor indicates a problem with the gas steam, a worker would need to identify which of the two raceways is affected using a handheld gas analyzer: this approach is considerably less expensive. An important consideration with this equipment is that each raceway contains one of these items thus a cost savings in a single unit is magnified by the number of raceways. Currently the lifetime on all this instrumentation is equal to the plant life so any substitute equipment should have similar lifetimes or take into account replacement costs. Rather than assume that each raceway is instrumented, a separate analysis could consider these instruments as portable. In that way there would be 1 of each sensor per worker rather than per raceway. This method would rely more heavily on the plant personnel which may diminish the number of raceways that can be monitored per worker. This tradeoff could be considered as a separate sensitivity study. 


\section{Part 1 Appendix A: Key Terms and Definitions}

Solar-to-Hydrogen (STH) Efficiency (in \%): This is the ratio of the Lower Heating Value (LHV) of the net hydrogen produced from the system divided by the total solar energy input striking the biological beds. Hydrogen LHV is defined to be $33.33 \mathrm{kWh} / \mathrm{kg}^{67}$. Solar input is defined as total photon energy striking the bed measured in $\mathrm{W} / \mathrm{m}^{2}$. We typically use daily averages and thus base efficiency calculations on the average Southwest US insolation (average over the year) of $5.5 \mathrm{~kW} / \mathrm{m}^{2} /$ day.

Maximum Theoretical Solar-to-Hydrogen (STH) Efficiency (in \%): Converting all of this $5.5 \mathrm{~kW} / \mathrm{m}^{2} /$ day insolation into electrons used for $\mathrm{H}_{2}$ production yields a $12.2 \% \mathrm{STH}$ efficiency. Thus our nominal $9.2 \% \mathrm{STH}$ is close to the theoretical maximum. The $12.2 \%$ max efficiency is based on:

$1000 \mathrm{~W} / \mathrm{m}^{2}$ full sunlight intensity with $44 \%$ PAR (photosynthetically active radiation) and an average wavelength of $550 \mathrm{~nm}$ (average of 400-700nm)

$=>$ Photon density of $2.024 \times 10^{-3} \mathrm{ein} / \mathrm{m}^{2} / \mathrm{s}$ hitting the surface of the water.

Since it takes 4 photons to make an $\mathrm{H}_{2}$, the maximum energy of $\mathrm{H}_{2}$ produced from conversion of all of the photons is:

$\left(2.024 \times 10^{-3} \mathrm{ein} / \mathrm{m}^{2} / \mathrm{s}\right) \times(\mathrm{mol} \mathrm{H} / 4 \mathrm{~mol}$ photons $) \times\left(2.016 \mathrm{~g} \mathrm{H}_{2} / \mathrm{mol} \mathrm{H}_{2}\right) \times\left(\mathrm{kg} \mathrm{H}_{2} / 1000 \mathrm{~g} \mathrm{H}_{2}\right)$ $\mathrm{x}(33.33 \mathrm{kWh} \mathrm{H} / \mathrm{kg} \mathrm{H}$ ) x $(3600 \mathrm{~s} / \mathrm{hr})$

$$
=0.122 \mathrm{kWH} / \mathrm{m}^{2}
$$

Taking the ratio of hydrogen energy to the photon energy yields the maximum Solar-toHydrogen efficiency:

$$
\left(0.122 \mathrm{kWH}_{2} / \mathrm{m}^{2}\right) /\left(1.0 \mathrm{~kW} \text { photon } / \mathrm{m}^{2}\right)=12.2 \%
$$

Solar Peak Intensity and Daily Variation $\left(\mathbf{W} / \mathbf{m}^{2}\right)$ : Based on actual daily intensity data with amplitude varied to achieve the target total solar daily insolation $\left(5.5 \mathrm{kWh} / \mathrm{m}^{2} /\right.$ day $)$.

Doubling Time (in hours): The time, for an algal colony to double in concentration. Typically based on constant $1000 \mathrm{~W} / \mathrm{m}^{2}$ sunlight irradiance.

Hourly Algae Renewal Fraction (in \%): This term is the reactor bed volume fraction that is removed every hour. Removal of algae is necessary to maintain a constant colony of living algae both to remove dead/unproductive algae and/or to remove new growth. It is assumed that all algae (dead, young, and old) are evenly mixed together and preferential removal is not possible. Thus all performance numbers are based on average algae performance.

Growth Reactor: A bioreactor with the main function of promoting algae growth.

Production Reactor: A bioreactor with the main function of promoting hydrogen production.

${ }^{67}$ The HHV is defined to be $39.4 \mathrm{kWh} / \mathrm{kgH} 2$. 
Four types of Systems are analyzed:

Single Bed: In this cyclic bioreactor, a single bed first functions as a growth reactor (typically 1-4 days) and then switches to a production reactor (for $1+$ day). The end of the production phase is determined by the $\mathrm{H}_{2}$ production rate dropping below a threshold limit due to death or other impairment of the algae. At the end of the production phase, the bed either returns to the growth phase to rejuvenate the algae or becomes partially or completely removed from the reactor and replaced with fresh, healthy algae.

Dual Bed: In the cyclic bioreactor system, a first bed serves as a growth reactor to supply algae to the production reactor second bed. After the algae in the production reactor reaches the end of its useful life, the algae is removed from the reactor.

Chemostat: Derived from Chemical environment is static, a chemostat system is one in which fresh medium is continuously added to the reactor and "old" reactor medium is continuously removed, so that the reactor volume remains constant. In this embodiment, two reactors are used, a growth reactor and a production reactor, but their operation is constant rather than cyclic. The growth reactor continuously produces new algae at a rate that is fed into the production reactor. The production reactor has the same mass rate removed to maintain the mass balance. A centrifuge separates the water from the "dead" algae with the water being recycled back to the growth reactor and the algae going to a landfill or fermentation unit.

Chemostat II: The Chemostat II is a single bed chemostat system in which growth and production occur simultaneously in the same reactor. In this yet unproven, idealized system, a portion of the incident photon energy (ideally 22\%) is used for cell maintenance (i.e. to keep the algae cells unstressed and healthy) and the remaining photon energy (78\%) is used for $\mathrm{H}_{2}$ production for a net Solar-to-Hydrogen efficiency of $9.2 \%$.

Algae Capture Fraction (in \%): The mass capture fraction of algae that is separated by the filter (centrifuge or drum filters). This is nominally $99 \%$. Once separated, the algae enter a fermentation unit or are sent to a landfill.

Algae Water Content (in \%): This refers to the water fraction of the algae after it is separated from the renewal fraction by the filters. This is nominally $90 \%$. 


\section{Part 1 Appendix B: Mass Balance}

\begin{tabular}{|c|c|c|c|c|c|}
\hline \multicolumn{6}{|c|}{ Mass Balance $\mathrm{H}_{2}$ Production Phase } \\
\hline & B1 (daily) & B2 (daily) & B3 (3 days) & B4 ( 2 days) & B5 (daily) \\
\hline \multicolumn{6}{|l|}{ Start Conditions $-\mathrm{H}_{2}$ Produdction } \\
\hline \multicolumn{6}{|l|}{ Inputs - $\mathrm{H}_{2}$ Production } \\
\hline Process Water & 10,985 & 10,985 & 38,807 & 22,367 & 5,614 \\
\hline Nutrients & 0 & 0 & - & - & 9,113 \\
\hline $\mathrm{CO}_{2}$ & 257 & 257 & - & - & - \\
\hline Total & 12,863 & 12,863 & 112,994 & 121,188 & 19,058 \\
\hline \multicolumn{6}{|l|}{ Outputs - $\mathrm{H}_{2}$ Production } \\
\hline $\mathrm{H}_{2}$ & 1,111 & 1,111 & 8,235 & 4,706 & 1,111 \\
\hline $\mathrm{O}_{2}$ & 9,005 & 9,005 & - & - & - \\
\hline $\mathrm{H}_{2} \mathrm{O}$ & - & - & - & - & 168 \\
\hline $\mathrm{H}_{2} \mathrm{O}$ Vapor (Evaporation) & 951 & 951 & 2,010 & 1,340 & 650 \\
\hline $\mathrm{CO}_{2}$ & - & - & 68,696 & 1,999 & 606 \\
\hline Dissolved $\mathrm{CO}_{2}$ & - & - & 21,173 & 49,355 & 11,725 \\
\hline Waste Algae & 175 & 175 & - & - & 468 \\
\hline Algae & 1,622 & 1,622 & 12,879 & 63,789 & 4,330 \\
\hline Total & 12,863 & 12,863 & 112,994 & 121,188 & 19,058 \\
\hline Balance & 0.0 & 0.0 & 0.0 & 0.0 & 0.0 \\
\hline \multicolumn{6}{|c|}{ Mass Balance Growth Phase } \\
\hline & B1 & $\mathrm{B} 2$ & B3 (4 days) & B4 (2 day) & B5 \\
\hline \multicolumn{6}{|l|}{ Start Conditions - Growth } \\
\hline $\mathrm{CO}_{2}$ (Dissolved in water) & & & 21,173 & 1,999 & \\
\hline Algae & & & 12,879 & 63,789 & \\
\hline \multicolumn{6}{|l|}{ Inputs - Growth } \\
\hline $\mathrm{CO}_{2}$ (from PSA) & & & 68,695 & 49,354 & \\
\hline Process Water & & & 39,477 & 22,367 & \\
\hline Nutrients & & & 1 & 1 & \\
\hline Total & & & 142,225 & 137,509 & \\
\hline \multicolumn{6}{|l|}{ Outputs Growth } \\
\hline Algae & & & 74,187 & 98,821 & \\
\hline $\mathrm{H}_{2} \mathrm{O}$ Vapor (Evaporation) & & & 2,680 & 1,340 & \\
\hline $\mathrm{O}_{2}$ & & & 65,359 & 37,347 & \\
\hline Total & & & 142,225 & 137,509 & \\
\hline Balance & & & 0.0 & 0.3 & \\
\hline
\end{tabular}

\begin{tabular}{|c|c|c|c|c|c|}
\hline \multicolumn{6}{|c|}{ Mass Balance Initial Growth Phase } \\
\hline & B1 (2 days) & B2 (2 Days) & B3 (2 days) & B4 (2 days) & B5 (2 days) \\
\hline \multicolumn{6}{|c|}{ Inputs - Initial Colony Growth } \\
\hline Algae & - & - & - & - & - \\
\hline Process Water & 973 & 973 & 7,730 & 38,286 & - \\
\hline Nutrients & 0 & 0 & 0 & 1 & 7,793 \\
\hline $\mathrm{CO}_{2}$ & 2,377 & 2,377 & 18,879 & 93,505 & o \\
\hline Total & 3,350 & 3,350 & 26,610 & 131,793 & 7,793 \\
\hline \multicolumn{6}{|c|}{ Outputs - Initial Colony Growth } \\
\hline Algae & 1,622 & 1,622 & 12,879 & 63,789 & 4,330 \\
\hline $\mathrm{H}_{2} \mathrm{O}$ & - & - & - & - & 1,559 \\
\hline $\mathrm{O}_{2}$ & 1,728 & 1,728 & 13,730 & 68,004 & 1,904 \\
\hline Total & 3,350 & 3,350 & 26,610 & 131,793 & 7,793 \\
\hline Balance & 0.0 & 0.0 & 0.0 & 0.0 & 0.0 \\
\hline
\end{tabular}

\begin{tabular}{|lc|}
\hline Days of B3 Growth Mode & 4 \\
Days of B4 Growth Mode & 1 \\
Overall Growth of B3 in Full Growth Mode & 5.76 \\
Overall Growth of B4 in Full Growth Mode & 1.55 \\
Starting Concentration of Algae in B3 & $0.85 \mathrm{~g} / \mathrm{l}$ \\
Starting Concentration of Algae in B4 & $1.81 \mathrm{~g} / \mathrm{l}$ \\
\hline End Concentration of Algae in B3 & $4.91 \mathrm{~g} / \mathrm{l}$ \\
End Concentration of Algae in B4 & $2.80 \mathrm{~g} / \mathrm{l}$ \\
\hline
\end{tabular}




\section{Part II: Algae Fermentative $\mathrm{H}_{2}$ Production Systems}




\section{Introduction}

As mentioned previously in this report, a constant slip stream will be removed from the raceways in the B-2, B-2, and B-5 systems to ensure that the organism concentration remains static. There is no way to ensure that the organisms removed in the slip stream are all exhausted organisms, thus the slip stream volume will be a mix of old exhausted and new replete organisms. The organisms removed from this slip stream will from here on be referred to as waste organisms. These organisms, while spent of their photo-hydrogen capabilities can still produce hydrogen through a fermentation process. In order to obtain maximal $\mathrm{H}_{2}$ production, Part II of this report addresses use of the waste organisms as feedstock to a fermentation process using hydrogen-generating bacteria to produce additional $\mathrm{H}_{2}$. The process yields and economics will build on the analysis already completed for the Part I photobiological systems.

In Part I of this report, five photobiological hydrogen production systems were defined: three of the five pathways generate a stream of waste organisms suitable for subsequent fermentation. For the B-3 system, an increase in organism mass in the growth stage is needed to provide enough mass for consumption in the oxidative respiration needed to consume the oxygen produced by water splitting to keep the system anaerobic. This mass consumption through respiration will return the system back to its original concentration by the end of the production stage. Thus, no additional mass need be removed.

For the B-4 system, the algae were immobilized on a non-fermentable polypropylene substrate to reduce cost. For this embodiment, feeding the waste organisms to a fermentor would be too costly and cumbersome, and thus the waste organisms from this system are not used for fermentation. In contrast, NREL research for immobilized algae utilizes an alginate film for immobilization. Use of the fermentable alginate film in B-4 would increase B-4 cost but also increase the potential C-4 fermentation $\mathrm{H}_{2}$ production, and that is an option that could be considered in the future.

Subsequent to this fermentation process, liquid fermentation products, such as acetate, can be recycled into a PNS photobiological reactor bed, or they can be transferred to a Microbial Electrolysis Cell (MEC) for additional hydrogen-production. Figure 11-1 below shows process alternatives considered. 
Figure 11-1. Fermentation Process within a Biological System

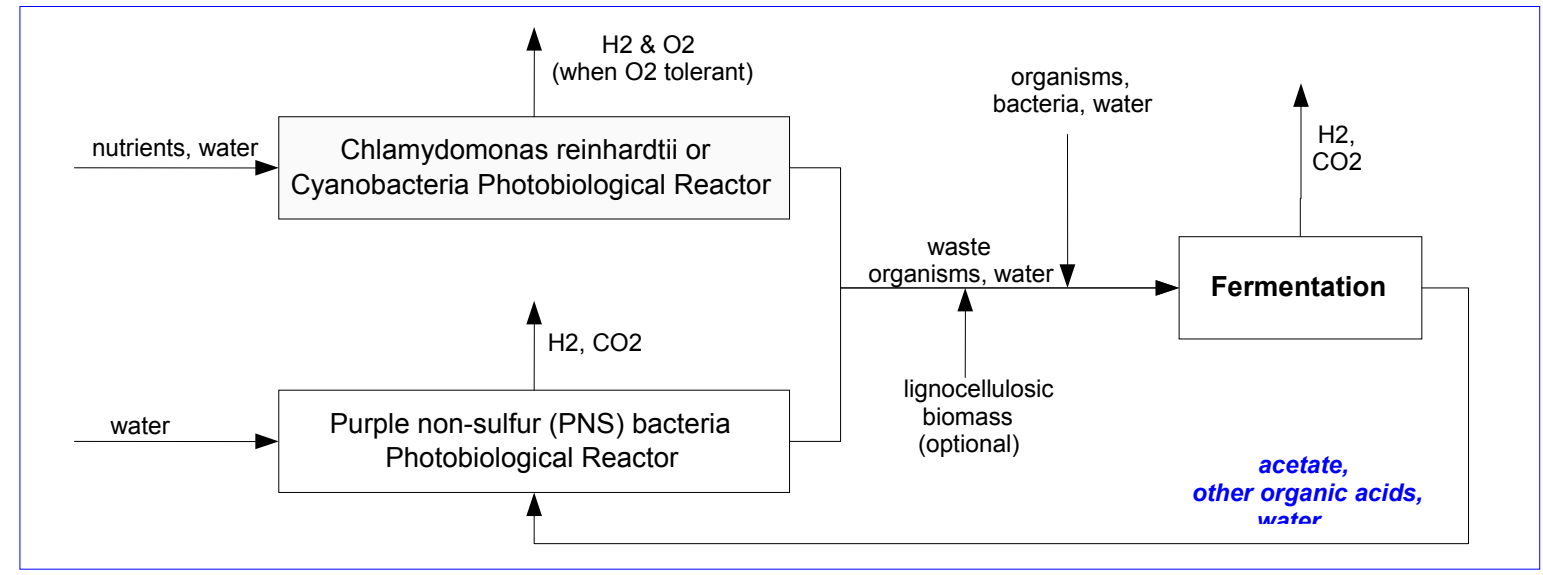

\section{OR}

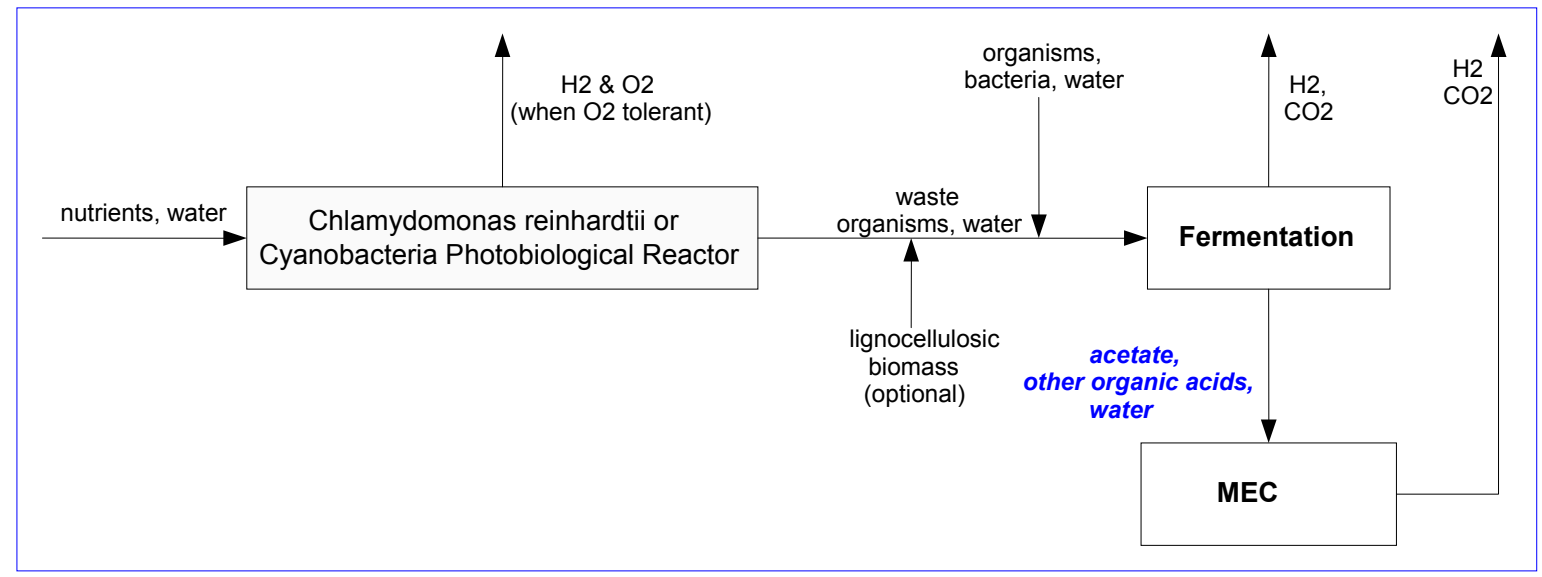

\section{Theoretical and Practical Fermentation Reactions}

Fermentation is the process of deriving energy from the oxidation of organic compounds, such as carbohydrates. Dark fermentation reactions, as the name suggests, do not require light energy, so they are capable of constantly producing hydrogen from organic compounds throughout the day and night. In theory, any carbohydrate source could be used as a feedstock for fermentation. Algae and other biomass listed in Figure 12-1 are representative fermentation feedstocks. 


\section{Figure 12-1. Potential Fermentative Feedstock Materials \\ Algae and other biomass \\ Corn stover hydrolyzate \\ Sugar cane juices \\ Wood fiber hydrolyzates from pulp mills \\ Biomass hydrolyzates from agricultural resides \\ Energy crops}

The feedstock is composed of a starch/glucose component as well as proteins and lipids and other components. If it were possible to convert all of the waste organism starch entering the fermentation processes to hydrogen, the stoichiometric result, using glucose as a representative of starch feedstock, would be:

$$
\mathrm{C}_{6} \mathrm{H}_{12} \mathrm{O}_{6}+6 \mathrm{H}_{2} \mathrm{O}=>12 \mathrm{H}_{2}+6 \mathrm{CO}_{2} \text {. }
$$

However, this theoretical limit does not naturally occur ${ }^{68}$. Instead, the observed glucose reactions are a conversion to $\mathrm{H}_{2}, \mathrm{CO}_{2}$, and acetate which is represented as:

$$
\mathrm{C}_{6} \mathrm{H}_{12} \mathrm{O}_{6}+2 \mathrm{H}_{2} \mathrm{O}=>4 \mathrm{H}_{2}+2 \mathrm{CO}_{2}+2 \mathrm{C}_{2} \mathrm{H}_{4} \mathrm{O}_{2} .
$$

This is known as the Thauer limit and results in $4.5 \% \mathrm{H}_{2}$ output by mass relative to the glucose component ${ }^{68}$. An alternative, less complete, reaction that also takes place forms $\mathrm{H}_{2}$, $\mathrm{CO}_{2}$, and butyl acid:

$$
\mathrm{C}_{6} \mathrm{H}_{12} \mathrm{O}_{6}=>2 \mathrm{H}_{2}+2 \mathrm{CO}_{2}+\mathrm{C}_{4} \mathrm{H}_{8} \mathrm{O}_{2}
$$

In actual practice, a combination of these reactions takes place, yielding between 2 and 4 moles of hydrogen per mole of glucose.

\section{Algae Fermentation Tests}

The organisms under consideration consist primarily of starches, lipids, and proteins. Multiple tests have been run by researchers with NREL support on fermentation of Chlamydomonas reinhardtii. The consortium ferments the starch and lipid and protein components, at least partially. However, that research is not yet complete ${ }^{69}$.

The most directly applicable data for starch fermentation is from Project 3.3, Photobiological Systems for Hydrogen Photoproduction, Task 3 - Integrated Systems. Test results from this project for FY2007 and FY2008 were provided as references for the design of the fermentation system. The First Quarter FY08 results are summarized in Figure 13-1. These results have a comprehensive compilation of algae components and hydrogen outputs and were used as guidelines for the fermentation analysis along with the more recent data from the emails referenced.

\footnotetext{
${ }^{68}$ Benemann, John R. and Paola M. Pedroni. 4.3 Biological production of $\mathrm{H}_{2}$ : mechanisms and processes.

69 Maria Ghirardi. Project 3.3:Photobiological systems for Hydrogen Photoproduction. $1^{\text {st }}$ Quarter 2008 Report.
} 
Figure 13-1. NREL Fermentation Experimental Data ${ }^{70}$

\begin{tabular}{|c|c|c|c|c|c|c|c|c|}
\hline \multirow[b]{2}{*}{$\begin{array}{c}\text { Algae } \\
\text { Characteristics }\end{array}$} & \multicolumn{4}{|c|}{ Input mass - Algae } & \multirow[b]{2}{*}{$\begin{array}{c}\text { Dwell } \\
\text { time } \\
\text { [hr] }\end{array}$} & \multicolumn{3}{|c|}{$\mathrm{H}_{2}$ Output } \\
\hline & $\begin{array}{c}\text { Total } \\
\text { mass } \\
{[\mathrm{mg}]}\end{array}$ & $\begin{array}{l}\text { Starch } \\
\text { mass } \\
{[\mathrm{mg}]}\end{array}$ & $\begin{array}{l}\text { Starch } \\
\text { [\% of } \\
\text { algae] }\end{array}$ & $\begin{array}{l}\text { lipid + } \\
\text { protein } \\
\% \%\end{array}$ & & $\begin{array}{c}\mathrm{H}_{2} \\
{[\mu \mathrm{mol}]}\end{array}$ & $\begin{array}{c}\text { weight } \% \\
\text { per algae } \\
\text { [g/g] }\end{array}$ & $\begin{array}{l}\text { Mole \% } \\
\text { H2 to } \\
\text { glucose }\end{array}$ \\
\hline \multicolumn{9}{|c|}{ January 2008} \\
\hline sulfur deprived, $21 \mathrm{hr}$ & 5.77 & 1.87 & $32.4 \%$ & NA & \multirow{3}{*}{$\begin{array}{c}120 \\
\mathrm{hr} \\
\max \end{array}$} & 17.68 & $0.618 \%$ & 1.70 \\
\hline sulfur deprived,142 hr & 29.8 & 1.79 & $6.0 \%$ & NA & & 22.97 & $0.155 \%$ & 2.31 \\
\hline $\begin{array}{c}\text { sulfur and phosphate } \\
\text { deprived, } 142 \mathrm{hrs}\end{array}$ & 86.2 & 1.76 & $2.0 \%$ & NA & & 38.44 & $0.090 \%$ & 3.93 \\
\hline
\end{tabular}

Results $^{69}$ show that the extent of algal sulfur deprivation has a direct effect on the algae's total glucan content (glucose, starch, and glycogen), with the percentage mass of starch in the tested algae varying from $32 \%$ at 21 hours of sulfur deprivation, to $6 \%$ at 142 hours of sulfur deprivation, to $2 \%$ at 142 hours of sulfur and phosphate deprivation. The bacteria used in fermentation tests with these algae samples carried out fermentation mainly on the starch component, so the $\mathrm{H}_{2}$ outputs were dependent on the starch percentages. For these 3 samples, test results yielded $\mathrm{H}_{2}$ masses that were respectively $0.618 \%, 0.155 \%$, and $0.090 \%$ of the algae cdw. The results from the tests referenced are described in Figure 13-1. Note that in the last case, the molar yield of $\mathrm{H}_{2}$ to glucose is 3.93 , very close to the Thauer limit of 4.0, indicating that some $\mathrm{H}_{2}$ was generated from lipid and protein components.

Previous work on the sulfur deprivation of $C$. reinhadtii ${ }^{71}$ indicated that the starch content of cells grown under sulfur replete conditions and resuspended in a sulfur-deprived medium $(t=0)$ is similar to that of cells deprived of sulfur for 142 hours. For the purposes of this analysis, thus, we used the data from the second row of Figure 89 to represent the starch amount of cultures in the three photobiological systems. The data shown in the third row reflects the starch amount of cultures that are immobilized in alginate films (not addressed in this analysis).

Current NREL research with different bacteria consortia have shown that $\mathrm{H}_{2}$ can also be generated from the lipid and protein content of the algae. Therefore, it is expected that future research will raise $\mathrm{H}_{2}$ output from this algae, and it was assumed that an $\mathrm{H}_{2}$ output between the $0.62 \%$ level and the $0.16 \%$ level would be representative of future capabilities, and a level of $0.4 \% \mathrm{H}_{2}$ /algae cdw was used in this analysis.

Though First Quarter FY08 results were for a test time of 120 hours, other tests (Fourth Quarter FY07 and Fourth Quarter FY08) indicate that cumulative $\mathrm{H}_{2}$ production plateaus after 72 hours into a fermentative cycle. Thus, it was assumed that the fermentation process took 72 hours.

\footnotetext{
${ }^{70}$ Maria Ghirardi. Project 3.3: Photobiological Systems for Hydrogen Photoproduction. $1^{\text {st }}$ Quarter Report. 22 January 2008.

${ }^{71}$ Kosourov, S.; Seibert, M.; Ghirardi, M. L. (2003). Effects of Extracellular pH on the Metabolic Pathways in Sulfur-Deprived H2-Producing Chlamydomonas Reinhardtii Cultures. Plant and Cell Physiology. Vol. 44(2), 2003; pp. 146-155; NREL Report No. JA-590-34437.
} 


\subsection{Fermentor Feedstock}

As discussed above, feedstock of interest is waste organisms from photobiological processes. To facilitate the integration system task that comes after this fermentation analysis, the feedstock quantities and composition evaluated here are those identified in the Photobiological Characterization Report. ${ }^{72}$ Based on the previous photobiological systems examined, three possible fermentor feedstocks are shown in Figure 89. These are the waste algae or bacteria from photobiological systems B-1, B-2, and B-5. For the sake of consistency, the fermentor systems will be tagged C-1, C-2, and C-5 to correspond with the photobiological system from which it obtains its feedstock. Because the efficiencies and composition of each of photobiological systems vary, the slurry feedstock to the fermentor will differ. Note that there is no C-3 or C-4 fermentation pathway for reasons discussed earlier.

Figure 13-2. Analysis Feedstocks Defined (from 10TPD Photobiological System)

\begin{tabular}{|c|c|c|c|c|}
\hline & & C-1 & C-2 & $C-5$ \\
\hline $\begin{array}{l}\text { Photobiological Reactor Bed } \\
\text { Type }\end{array}$ & & Chemostat II & Chemostat II & Chemostat II \\
\hline Organism & & $\begin{array}{l}\text { Chlamydomonas } \\
\text { reinhardtii }\end{array}$ & $\begin{array}{c}\text { Cyanobacteri } \\
\text { a } \\
\end{array}$ & $\begin{array}{c}\text { purple non-sulfur } \\
\text { proteobacterium (PNS) }\end{array}$ \\
\hline $\begin{array}{l}\text { Slurry extracted from } 10 \text { TPD } \\
\text { photobio reactor bed } \\
(0.2 \mathrm{~g} / \mathrm{L} \text { organism density) }\end{array}$ & $\begin{array}{l}\% / \text { day } \\
\text { gal/hr } \\
\text { L/hr }\end{array}$ & $\begin{array}{c}10 \% \\
96,391 \\
364,840\end{array}$ & $\begin{array}{c}10 \% \\
96,391 \\
364,840\end{array}$ & $\begin{array}{c}10 \% \\
257,414 \\
974,312\end{array}$ \\
\hline $\begin{array}{l}\text { Organism mass extracted } \\
\text { (organism dry mass) }\end{array}$ & $\begin{array}{l}\mathrm{kg} / \mathrm{hr} \\
\mathrm{kg} / \text { day }\end{array}$ & $\begin{array}{c}73 \\
1,751\end{array}$ & $\begin{array}{c}73 \\
1,751\end{array}$ & $\begin{array}{c}195 \\
4,677\end{array}$ \\
\hline $\begin{array}{l}\text { Fermentor Input } \\
\% \text { organism/water by } \\
\text { weight }{ }^{73,74} \\
\text { Mass organism / liter } \\
\text { Daily Quantity } \\
\text { Fermentation time }\end{array}$ & $\begin{array}{c}\% \\
\text { g/L } \\
\text { L/day } \\
\text { hrs } \\
\text { days }\end{array}$ & $\begin{array}{c}20 \% \\
200 \\
8,756 \\
72 \\
3\end{array}$ & $\begin{array}{c}20 \% \\
200 \\
8,756 \\
72 \\
3\end{array}$ & $\begin{array}{c}20 \% \\
200 \\
23,383 \\
72 \\
3\end{array}$ \\
\hline
\end{tabular}

\subsubsection{C-1 Feedstock}

The organism in the $\mathrm{C}-1$ system is an oxygen-tolerant hydrogenase, Chlamydomonas reinhardtii $c c 124$ as defined in the B-1 Photobiological Pathway. These algae have been cultivated in a Chemostat II reactor bed ${ }^{75}$ which is continuously extracting a slipstream of organism/water slurry to maintain a constant cell concentration. As mentioned previously, since there is no way to sort the organisms so that only exhausted ones are expunged from

\footnotetext{
${ }^{72}$ James, Brian D. Task B: Photobiological $\mathrm{H}_{2}$ Production Subsystems Characterization Report. NREL Contract\# AFH-8-88601-01. 24 December 2008.

73 Aden, A. et al.. Lignocellulosic Biomass to Ethanol Process Design and Economics Utilizing Co-Current Dilute Acid Prehydrolysis and Enzymatic Hydrolysis for Corn Stover. NREL Contract\# DE-AC36-99GO10337. June 2002, NREL/TP-510-32438.

${ }^{74}$ Remainder is water.

75 While a generic chemostat system in defined as a reactor in which a constant volume of medium is maintained, the Characterization Report defines a Chemostat II as a chemostat system in which organism growth and hydrogen production simultaneously occur.
} 
the reactor bed, we must assume a normally distributed cell age within the slurry. The quantities listed in the table above are computed based on the slipstream amount from a standard reactor bed size.

\subsubsection{C-2 Feedstock}

The organism in the $\mathrm{C}-2$ system is cyanobacteria, an oxygen-tolerant hydrogenase, based on the Synechocystis PCC6803 mutant from the B-2 Photobiological Pathway. These organisms have also been cultivated in a Chemostat II reactor bed which is continuously extracting a slipstream of organism/water slurry to maintain a constant cell concentration.

Certain filamentous cyanobacteria acquire both longer filament lengths with age and develop gas vacuoles with age leading to compulsory flotation, while younger less buoyant cells remain dispersed. Separation of organisms by age may thus be more readily carried out for these bacteria, allowing removal of only the old organisms. This attribute could be exploited in a future design

The quantities listed in Figure 13-2 above are computed based on the slipstream amount from a standard reactor bed size. However there is no data on the fermentation of these organisms, thus we assume the organism fermentation is similar to Chlamydomonas reinhardtii.

\subsubsection{C-5 Feedstock}

The organism in the C-5 system is a purple non-sulfur proteobacterium from the B-5 Photobiological Pathway. These bacteria have been cultivated in a Chemostat II reactor bed which is continuously extracting a slipstream of organism/water slurry to maintain a constant cell concentration. Since there is no way to sort these organisms, we assume a normally distributed cell age. The quantities listed in the table above are computed based on the slipstream amount from a standard reactor bed size.

\section{Basic Fermentation System Diagram}

In Figure 11-1 the fermentation system within a biological process is shown. This section of the report will delve into that portion of the system and describe in detail the components and the operation. Figure 14-1 shows the fermentation system is made of two subassemblies, fermentation and gas capture. Each of these subassemblies is described further below. 


\section{Figure 14-1. Fermentation System Design}

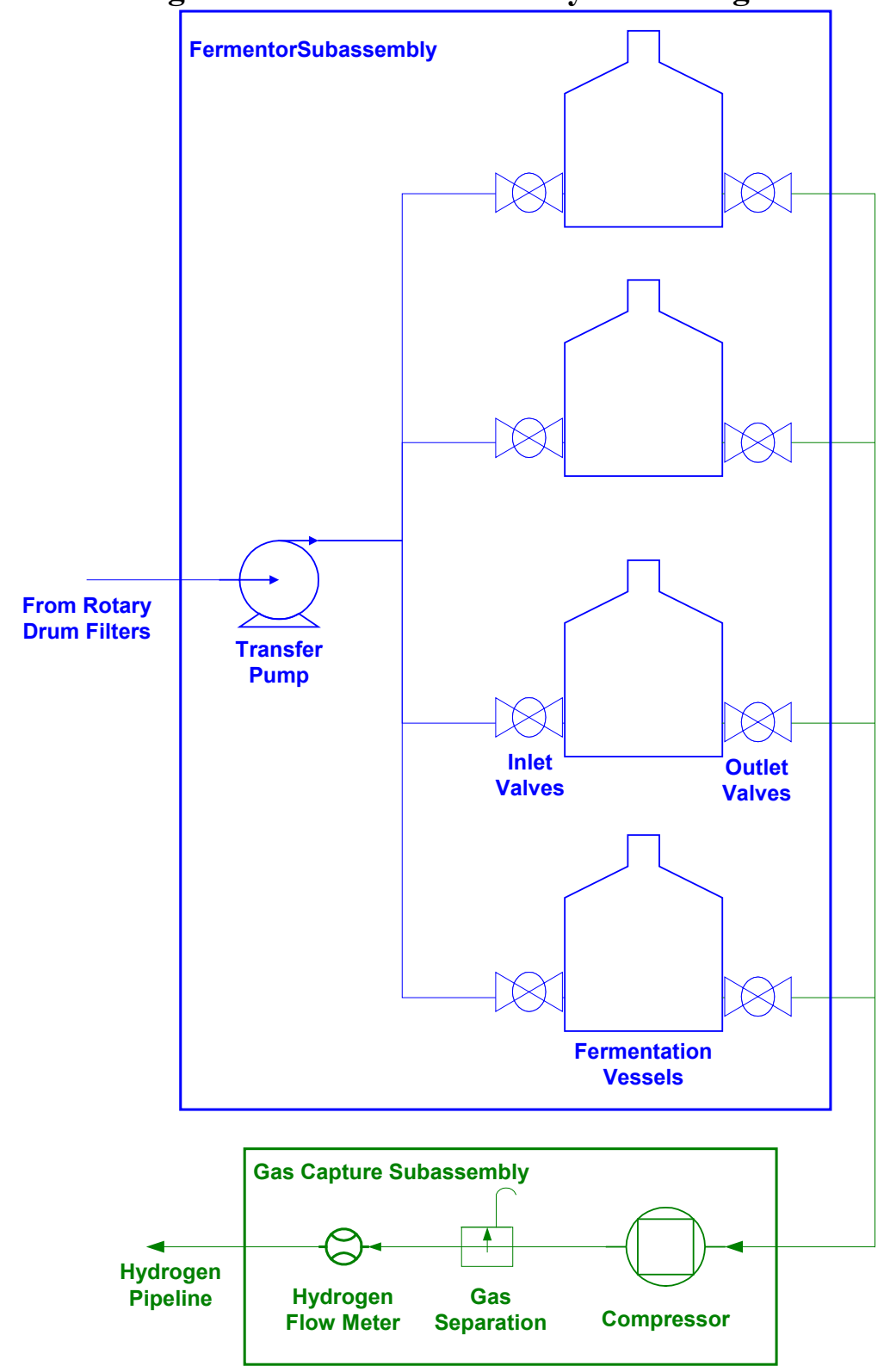

\subsection{Fermentation Operation Scheme}

In a prior section, it was mentioned that $\mathrm{H}_{2}$ cumulative production at lab scale tests plateaus in a 72 hour cycle. Thus we have taken 72 hours to be the duration of the fermentation process. Data indicates that the production rate over the 72 hours is not constant, but varies from minimal output for the first 24 hours, to max rate over the next 44 hours, and drops down to zero over the next 4 hours.

In the fermentation process at larger scales, mixing will be a major concern to remove oxygen and to control variables such as $\mathrm{pH}$ and residual oxidants (oxygen and nitrate). For this purpose, the fermentation tanks each include a tank agitator. In addition, it will be needed to continuously monitor and control variables such as $\mathrm{pH}$. 
Because of the 3 day fermentation period, there are 3 fermentors running in parallel, with a fourth in recharging status or in reserve. At the end of the 72 hour process the vessel will contain solids residue which will need to be cleaned out prior to beginning the next batch. The fourth vessel will be cleaned while the other three are used.

There are two options available to handle the variability. First, downstream equipment can be sized for peak rates and operate at reduced capacity during non-peak production. Second, the downstream equipment can be sized for average rates, and the plant design and operation adjusted to accommodate the variable gas production. The decision of which route to take is an economic one. In our case the downstream components are a compressor, gas separation system, and a flow meter. The flow meter operation is not impacted by the variability in hydrogen production, however the compressor and gas separator are. We choose to operate the downstream equipment at steady-state conditions and accommodate the variable gas production.

There are several ways the plant design could be modified to ensure the gas capture subassembly encounters a constant and continuous flow of output gas. The most direct would be to install a buffer storage tank between the two subassemblies. While simple in practice, storage of hydrogen at low pressures is voluminous. Thus in our design we have opted to build several fermentation vessels and stage the start of the fermentation process in each so that the cumulative hydrogen production from all vessels is leveled.

\subsection{Fermentor Subassembly}

The fermentor subassembly conveys algae into the fermentors and processes it at the necessary conditions to produce hydrogen. In order to accomplish this, the subassembly is comprised of a pump, inlet valves, fermentation vessels, outlet valves, and piping. The pump transfers wet organisms and bacteria into the subassembly. In an integrated system one could assume that the organisms are collected from the rotary drum filters described in the photobiological systems report. The inlet and outlet valves are considered manual and necessary to isolate each vessel. The need to isolate each vessel will be evident when the operation scheme is described. Piping is needed to move material into the vessels. Because the quantities are low, pipe cross-sectional area is also low. Only short piping runs are needed due to the relatively low diameter of the fermentation tanks and the resulting close spacing of the tanks.

The last piece of equipment in this system is the fermentation vessel itself. These vessels are designed for atmospheric pressure and temperature.

\section{Capital Cost of the Fermentation System}

Based on the system configurations described above, bills of material (BOM's) were prepared for each of the fermentative systems. These BOM's appear in Figure 15-1 through Figure 15-2. 
Figure 15-1: BOM for Fermentor Systems C-1 and C-2 (sized for the organism wastestream of a 10TPD B-1 or B-2 Photobiological Hydrogen production system)

\begin{tabular}{|c|c|c|c|c|c|c|c|}
\hline Description & Size Req'd & Unit Size & Units & Unit cost & Qty Req'd & Total Cost & Material / Part Description \\
\hline \multicolumn{8}{|l|}{ Fermentation Subassembly } \\
\hline Tank & $2312 \mathrm{gal}$ & 1 & gal & 2.00 & 9,247 & 18,493 & This is a scaled cost based on the capital costs from NREL Report TP-510-32438 \\
\hline Slurry Piping - 0.5" & $500 \mathrm{ft}$ & 1 & $\mathrm{ft}$ & 0.52 & 500 & 260 & Sized using Continuity Equation. Assumed a velocity of $1 \mathrm{ft} / \mathrm{sec}$. \\
\hline Slurry Piping - 1" & $3734 \mathrm{ft}$ & 1 & $\mathrm{ft}$ & 1.00 & 3,734 & 3,734 & Sized using Continuity Equation. Assumed a velocity of $1 \mathrm{ft} / \mathrm{sec}$. \\
\hline Pump & $2312 \mathrm{gal} / \mathrm{day}$ & 4 & $\mathrm{gal} / \mathrm{min}$ & 198.50 & 1 & 199 & http://www.grainger.com/Grainger/items/1P795 \\
\hline Inlet Valves & 1 in & 1 & each & 67.23 & 4 & 269 & http://www.valvestore.com/rroducts.asp?dept=1485 \\
\hline Outlet Valves & 0.5 in & 1 & each & 46.85 & 4 & 187 & http://www.valvestore.com/products.asp?dept=1485 \\
\hline Water & $18,493 \mathrm{gal}$ & 1 & gal & $\$ 0.001665$ & 18,493 & 30.79 & H2A Costing \\
\hline \multicolumn{8}{|l|}{ Gas Capture Subassembly } \\
\hline Compressor & $0.29 \mathrm{kgmol} / \mathrm{h}$ & 0.29 & $\mathrm{kgmol} / \mathrm{hr}$ & $\$ 9,233.00$ & & 2,679 & H2A Costing \\
\hline PSA & & & & $\$ \quad 5,738$ & 1 & 5,738 & HZA Costing \\
\hline Gas Piping - 0.5" & $100 \mathrm{ft}$ & 1 & $\mathrm{ft}$ & 0.52 & 100 & 52 & Sized using the Continuity Equation. Assumes $1 \mathrm{~mol}$ of $\mathrm{H} 2,0.5 \mathrm{Mol}$ of CO@, and water vapor \\
\hline Hydrogen Flow Meter & & 1 & & $\$ 5,500.00$ & 1 & $5,500.00$ & Information from Emerson Process Management \\
\hline
\end{tabular}

Figure 15-2: BOM for 10 TPD Fermentor System C-5 (sized for the PNS waste-stream of a 10TPD B-5 Photobiological Hydrogen production system)

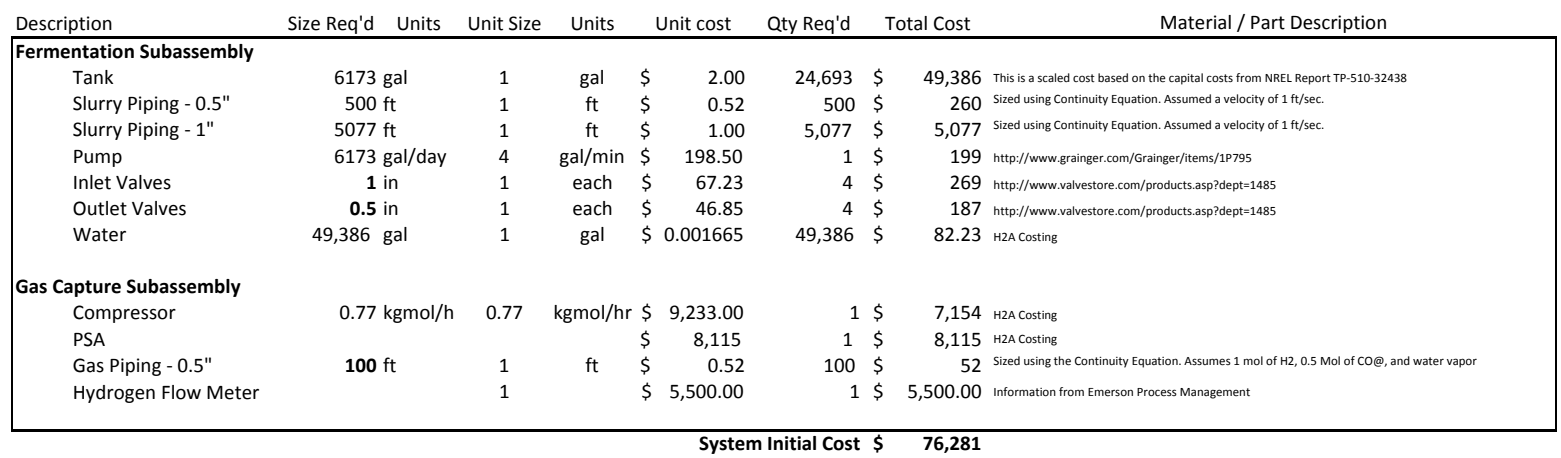

As shall be noted when examining the cost results, tank capital cost and labor assumptions play an important role in the cost examination. For this reason, they are discussed in more detail below.

\subsection{Tank Cost}

Capital cost of the stainless steel fermentation vessels is based on data from an NREL report $^{76}$ by Aden et al that gives us a $\$ 2.00 /$ gallon cost for fermentor tanks in this size range operating at atmospheric pressure. As shown in the system bills of material, typical fermentor tank size for systems C-1, C-2, and C-5 is around 2,000-7,000 gallons. .

\section{Fermentation Outputs for $\mathrm{C}-1$ through $\mathrm{C}-5$}

Based on the above assumptions, the daily hydrogen output resulting from fermentation of algae from the photobiological pathways (B-1, B-2 and B-5) was calculated.

76 Aden, A. et al.. Lignocellulosic Biomass to Ethanol Process Design and Economics Utilizing Co-Current Dilute Acid Prehydrolysis and Enzymatic Hydrolysis for Corn Stover. NREL Contract\# DE-AC36-99GO10337. June 2002, NREL/TP-510-32438. 
Figure 16-1. Fermentative Hydrogen Ouput (from 10TPD Photobiological System)

\begin{tabular}{|l|c|c|c|c|}
\hline \multicolumn{2}{|c|}{$\begin{array}{c}\text { Photobiological } \\
\text { Reactor Bed Type }\end{array}$} & Chemostat II & Chemostat II & Chemostat II \\
\hline Organism & & $\begin{array}{c}\text { Chlamydomonas } \\
\text { reinhardtii }\end{array}$ & Cyanobacteria & $\begin{array}{c}\text { purple non-sulfur } \\
\text { proteobacterium (PNS) }\end{array}$ \\
\hline $\begin{array}{l}\text { Hydrogen Produced } \\
\text { weight \% relative to } \\
\text { organism }=\mathbf{0 . 4 \%}\end{array}$ & $\mathrm{kg} / \mathrm{day}$ & 7.0 & 7.0 & 18.7 \\
\hline
\end{tabular}

For the $\mathrm{C}-1 / \mathrm{C}-2$ process this amounts to only $7.0 \mathrm{~kg} \mathrm{H}_{2} /$ day for the system producing 10,000 $\mathrm{kg} /$ day from the photobiological process.

\section{Levelized Costs Assumptions \& Calculations (H2A)}

Thus far, this report has discussed the capital cost and expenditures associated with building a fermentative hydrogen plant. While this is critical and valuable information, the build decision is ultimately based on the financial and economic benefits of these capital expenditures. The investment is quite large and cannot be properly evaluated without some knowledge of the expected return on that investment. In order to evaluate the return, DTI has performed a discounted cash flow (DCF) analysis using the H2A Forecourt Production Model, Version 2.0.

Discounted cash flow is a method of evaluating an investment by estimating the present value of future cash flows and taking into consideration the time value of money. The method uses future free cash flow projections and discounts them using the weighted average cost of capital (WACC) to arrive at a present value (PV). Two basic DCF methods are the net present value (NPV) method and the internal rate of return (IRR) method, both of which take into account the time-value of money, and are similar to the methods used in computing interest-income on bank deposits. This analysis uses the IRR method. Recall that IRR is the discount rate where the PV of total cash inflows equals the PV of the total cash outflows.

The H2A model uses the DCF methodology described above. However future cash inflows from sale of the hydrogen are highly speculative. Thus, the DCF results in this analysis are presented in a slightly different manner. Rather than predict cash inflows from sales and compute the IRR, our analysis pre-selects an IRR value which would be agreeable to investors. It then assumes sales are equal to the amount of product that can be produced over the analysis period. With those two values in places, this analysis computes the price of hydrogen necessary for the IRR at the given sales volume. This price is expressed in $\$ / \mathrm{kgH}_{2}$. This is often referred to as the levelized cost of hydrogen. Levelized cost is the PV of the all costs associated with building and operating a generating plant over its economic life, converted to equal payments.

\subsection{Standard H2A parameters}

In order to develop levelized costs, several parameters must be defined. Because this analysis focuses on a plant which is still in its conceptual stage, many of the values for these parameters must be assumed. The assumptions are documented in this section. These are meant to represent a baseline system and analysis. Later in the discussion portion of this report, the assumed values can be altered for sensitivity analyses. 
Standard H2A values and assumptions shown in Figure 17-1 apply to all biohydrogen pathways. This list does not encompass all parameters which must be defined in order to run the analysis; just those were there is an H2A Default value which has been accepted for this analysis. The remaining parameters are defined later in this section. Some of those parameters are common to all fermentative pathways and others are pathways specific. No dispensing parameters are listed here because they are not factored into the analysis.

Figure 17-1. H2A Default Values and Assumptions used for all Fermentative Pathways $^{77}$

\begin{tabular}{|ll|}
\hline \multicolumn{1}{|c|}{ Parameter } & \multicolumn{1}{c|}{ Assumptions } \\
\hline Operating Period & 20 years \\
Burdened Labor Rate for Staff & $\$ 50 /$ hour for central model \\
CO2 Capture Credit & Not included in base cases (default value $=0)$ \\
CO2 Production Taxes & Not included in base cases (default value $=0)$ \\
Construction Period and Cash Flow & 1 year modeled after forecourt \\
Co-produced and Cogenerated & $\$ 30 /$ MWh \\
Electricity Price & $10 \%$ of initial capital for forecourt model \\
Decommissioning & MACRS: 20 years for central model \\
Depreciation Type and Schedule for & \\
Initial Depreciable Capital Cost & 20 years for forecourt model \\
Facility Life & $20 \%$ of the staff labor costs \\
G\&A Rate & 300 psig \\
Hydrogen Pressure at Central Gate & $98 \%$ minimum; CO $<10$ ppm, sulfur $<10$ ppm \\
Hydrogen Purity & $35 \%$ federal; $6 \%$ state; $38.9 \%$ effective \\
Income Taxes & $1.9 \%$, but with resultant price of hydrogen in \\
Inflation Rate & reference year constant dollars \\
\hline Installation Cost Factor & 1.3 for all models \\
\hline Land Cost & $\$ 5,000 /$ acre purchased for central model; \\
\hline Licensing, Permits and fees & $\$ 1000$ for forecourt model \\
\hline O2 Credit & Not included in base cases \\
\hline Production Maintenance \& Repairs & $1 / 2 \%$ of direct capital cost for central model \\
\hline Property Taxes and Business & $2 \% /$ year of the total initial capital cost \\
Insurance & $100 \%$ equity with $10 \%$ IRR; includes levelized \\
\hline Reference Financial Structure & hydrogen price plot for $0 \%-25 \%$ IRR; model \\
& allows debt financing \\
\hline Sales Tax & Not included on basis that facilities and related \\
& purchases are wholesale and through a general \\
& $10 \%$ of initial capital for central model \\
\hline Salvage Value & $15 \%$ of the annual change in total operating costs \\
\hline Working Capital Rate & \\
\hline
\end{tabular}

77 Appendix 3: Default Values and Assumptions. H2A Production Model, Version 2.0 User Guide, Rev. DRAFT, June 2008, p. 63. 


\subsection{Pathway Common Parameters}

In addition to the financial parameters defined by $\mathrm{H} 2 \mathrm{~A}$ in the previous section there are other inputs which must be quantified in order to carry out the DCF analysis. All inputs can be found on the following worksheets in the H2A model;

- Input_Sheet_Template

- ReplacementCosts

- CapitalCosts

Many of these parameters are specific to the location, operation, and type of plant. In the case of our biohydrogen pathways there are some parameters that are the same for all pathways and some that vary by pathway. The parameters in Figure 17-2 are common to all pathways.

Figure 17-2. Parameters Common to all Pathways

\begin{tabular}{|lll|}
\hline \multicolumn{1}{|c|}{ Parameter } & \multicolumn{1}{c|}{ Assumed Value } & \multicolumn{1}{c|}{ Worksheet Name } \\
\hline Operating Capacity Factor & $90 \%$ & Input_Sheet_Template \\
Reference Year Dollars & 2005 & Input_Sheet_Template \\
Site Preparation & $\begin{array}{l}1 \% \text { of direct costs minus } \\
\text { raceway excavation } \\
\text { costs }\end{array}$ & Input_Sheet_Template \\
Engineering \& design & $1 \%$ of direct costs & Input_Sheet_Template \\
Process Contingency & $20 \%$ of direct costs & Input_Sheet_Template \\
Project Contingency & $\$ 0$ & Input_Sheet_Template \\
Up-Front Permitting Costs & $0.5 \%$ of direct costs & Input_Sheet_Template \\
Licensing, Permits, and Fees & $\$ 1000$ & Input_Sheet_Template \\
Production Maintenance \& & $0.5 \%$ of direct costs & Input_Sheet_Template \\
Repairs & & \\
\hline
\end{tabular}

\subsubsection{Operating Capacity Factor}

The operating capacity factor can be found on the Input_Sheet_Template worksheet of the model. This analysis assumes that the plant and dispensing station have a $90 \%$ operating capacity. This capacity factor takes into considering things such as planned maintenance outages, forced outages, etc.

\subsubsection{Reference Year Dollars}

The reference year dollars parameter is the year dollars in which the cost of hydrogen is reported. The H2A standard is to report out hydrogen costs in 2005 dollars. The model expects capital costs to be entered in 2005 dollars. In this analysis Reference Year 2005 was selected.

\subsubsection{Site Preparation}

The site preparation parameter can be found on the Input_Sheet_Template worksheet of the model. In central plants, $\mathrm{H} 2 \mathrm{~A}$ defaults this value to $1 \%$ of direct costs. This analysis uses the same default value. 


\subsubsection{Engineering \& design}

The engineering \& design parameter can be found on the Input_Sheet_Template worksheet of the model. In central plants, $\mathrm{H} 2 \mathrm{~A}$ defaults this value to $13 \%$ of direct costs. This analysis uses the same default value.

\subsubsection{Process Contingency}

The process contingency parameter can be found on the Input_Sheet_Template worksheet of the model. In central plants, $\mathrm{H} 2 \mathrm{~A}$ defaults this value to $15 \%$ of direct costs. This analysis uses $20 \%$ of direct costs due to uncertainties in the system configuration.

\subsubsection{Project Contingency}

The process contingency parameter can be found on the Input_Sheet_Template worksheet of the model. In our analysis we have chosen to include all contingency factors in the process contingency parameter, thus the project contingency is set to $\$ 0$.

\subsubsection{Up-Front Permitting Costs}

The up-front permitting cost parameter can be found on the Input_Sheet_Template worksheet of the model. The H2A default for this parameter is $9 \%$ of direct costs. This analysis uses the same default value.

\subsection{Pathway Specific Parameters}

The last type of parameters we identify are those which are specific to each pathway analyzed. Figure 17-3 lists these parameters and rules of thumb applied in computing their values. These are pathway specific because they are associated with feedstock, process design and plant design.

Figure 17-3. Pathway Specific Parameters

\begin{tabular}{|lll|}
\hline \multicolumn{1}{|c}{ Parameter } & \multicolumn{1}{c|}{ Rule Applied } & \multicolumn{1}{c|}{ Worksheet Name } \\
\hline $\begin{array}{l}\text { Land Required } \\
\text { Production facility plant staff }\end{array}$ & & Input_Sheet_Template \\
Utility Usage & Electricity and water & Input_Sheet_Template \\
& Input_Sheet_Template \\
Feedstock Usage & None & Input_Sheet_Template \\
$\begin{array}{l}\text { Specified Yearly Replacement } \\
\text { Costs }\end{array}$ & None & ReplacementCosts \\
\hline
\end{tabular}

\subsubsection{Land Required}

The land required parameter can be found on the Input_Sheet_Template worksheet of the model. In developing the plant design, a land area for the fermentor system was computed and then increased by $30 \%$ for conservatism. The 30\% factor is meant to encompass area requirements for pump skids, compressors, gas and other process flow components and a small control room. The total land requirement for each pathway is shown in Figure 17-4. 
Figure 17-4. Land Required for each Pathway

\begin{tabular}{|l|l|}
\hline \multicolumn{1}{|c|}{ Pathway } & Area $\left(\mathbf{m}^{2}\right)$ \\
\hline C-1 & 1,012 \\
\hline C-2 & 1,012 \\
\hline C-5 & 1,012 \\
\hline
\end{tabular}

\subsubsection{Production facility plant staff}

The production facility plant staff parameter can be found on the Input_Sheet_Template worksheet of the model. This represents the number of full-time employees required to operate the plant. There is no H2A default value for this. Our analysis for each of the pathways is shown in Figure 17-5.

Figure 17-5. Plant Staff Requirements for Fermentor plant

\begin{tabular}{|l|l|}
\hline \multicolumn{1}{|c|}{ Pathway } & Total Workers Needed \\
\hline $\mathrm{C}-1$ & $1 \mathrm{man} / 3$ shifts/day \\
\hline $\mathrm{C}-2$ & $1 \mathrm{man} / 3 \mathrm{shifts} /$ day \\
\hline $\mathrm{C}-5$ & $1 \mathrm{man} / 3 \mathrm{shifts} /$ day \\
\hline
\end{tabular}

\subsubsection{Energy Usage}

The usage of utilities, feedstocks and creation of byproducts can be found on the Input_Sheet_Template worksheet of the model. There are no H2A default values for these.

Figure 17-6. Electricity Usage

\begin{tabular}{|l|l|}
\hline \multicolumn{1}{|c|}{ Pathway } & Electricity $\left(\mathrm{kWh} / \mathrm{kg} \mathrm{H}_{2}\right)$ \\
\hline $\mathrm{C}-1$ & 6.15 \\
\hline $\mathrm{C}-2$ & 6.15 \\
\hline $\mathrm{C}-5$ & 3.90 \\
\hline
\end{tabular}

\subsubsection{Specified Yearly Replacement Costs}

The specified yearly replacement costs can be found on the Replacement Costs worksheet of the model. There is no H2A default value for this and no fermentative system component replacements are assumed.

\subsubsection{Baseline Uninstalled Costs}

The baseline uninstalled costs can be found on the Capital Costs worksheet of the model. There is no H2A default value for this. These are the capital costs of the equipment that were computed in an earlier part of this project. Those separately calculated values will be imported into this area of the H2A Production Model to access the economic benefit of the capital expenditure. These costs are provided in the bill of materials for each pathway.

\subsubsection{Installation Cost Factor}

The installation cost factor parameter can be found on the Capital Costs worksheet of the model. The default value for this is 1.3 . 


\subsection{Levelized Costs}

Once all the cost parameters are specified, the H2A Production Model can perform levelized cost calculations. Parameters can be changed in a sensitivity analysis to access the impact on the cost per kilogram of hydrogen.

\section{Cost Results for the Fermentative Systems}

Based on the system diagrams, performance, and capital cost presented above, the projected hydrogen cost was next calculated using the $\mathrm{H} 2 \mathrm{~A}$ analysis model ${ }^{78}$. The total levelized cost of hydrogen for each fermentative pathway is shown in Figure 18-1.

Figure 18-1: H2A Model Projected Hydrogen Cost per kg from Fermentor Systems C-1, C-2, and C-5

\begin{tabular}{|r|c|c|}
\hline \multicolumn{3}{|c|}{ Total Cost of Produced $\boldsymbol{H}_{\mathbf{2}}$} \\
\hline Cost Component & \multicolumn{2}{|c|}{ Hydrogen Production Cost Contribution (\$/kg) } \\
\hline System & C1/C2 & C5 \\
\hline Capital Costs & $\$ 6.69$ & $\$ 2.91$ \\
\hline Decommissioning Costs & $\$ 0.03$ & $\$ 0.01$ \\
\hline Fixed O\&M & $\$ 165.70$ & $\$ 62.10$ \\
\hline Feedstock Costs & $\$ 0.00$ & $\$ 0.00$ \\
\hline Other Raw Material Costs & $\$ 0.00$ & $\$ 0.00$ \\
\hline Byproduct Credits & $\$ 0.00$ & $\$ 0.00$ \\
\hline Other Variable Costs (including utilities) & $\$ 0.32$ & $\$ 1.14$ \\
\hline Total & $\$ 172.73$ & $\$ 66.17$ \\
\hline
\end{tabular}

Note that the project cost of hydrogen is quite high $(\sim \$ 70-\$ 170 / \mathrm{kg})$ due to two primary factors. The first is the low $\mathrm{kg} /$ day of hydrogen production being produced from the system: 7-19 $\mathrm{kg} \mathrm{H} /$ day. This has an amplifying affect since all costs must be amortized over a small amount of hydrogen. The second factor is labor cost, which is reflected under fixed O\&M (operating and maintenance) cost. Labor cost is set at 1 laborer per shift, for each of the three shifts per day. Sensitivity to production scale and labor costs is examined in the next section.

\footnotetext{
${ }^{78}$ H2A Forecourt Production Model, Version 2.0.
} 


\section{Processing of Fermentor Liquid Outputs}

For the 3 photobiological systems feeding the fermentor, each system producing 10 tonnes/day, the major useful outputs from the fermentor are shown in Figure 19-1.

Figure 19-1: Fermentor Outputs

\begin{tabular}{|c|c|c|c|c|c|}
\hline \multirow{2}{*}{$\begin{array}{c}\text { Fermentor } \\
\text { System }\end{array}$} & \multirow{2}{*}{$\begin{array}{c}\text { Fermentor } \\
\text { Feedstock } \\
\text { Source }\end{array}$} & \multicolumn{4}{|c|}{ Output from Fermentor (kg/day) } \\
\cline { 3 - 6 } & & $\mathbf{H}_{2}$ & $\mathrm{CO}_{2}$ & Acetate & $\begin{array}{c}\text { Lipid,Protein } \\
\text { \& Other }\end{array}$ \\
\hline $\mathrm{C}-1, \mathrm{C}-2$ & $\mathrm{~B}-1, \mathrm{~B}-2$ & 7.01 & 76.5 & 104.3 & 1563.6 \\
\hline $\mathrm{C}-5$ & $\mathrm{~B}-5$ & 18.7 & 204.1 & 278.6 & 4175.2 \\
\hline
\end{tabular}

For the C-5 system, the acetate is used as feedstock to the ponds for PNS organism growth. It is not determined whether the acetate would be separated from the other fermentation byproducts or whether the entire byproduct stream could be used. At any rate, at the quantities produced in the fermentor, the acetate is only $3 \%$ of the B-5 system requirements.

One alternative for obtaining additional gaseous products from the unused fermentation byproduct is a separate fermentation step. The remaining unreacted lipids and proteins could potentially be converted to gases $\left(\mathrm{H}_{2}, \mathrm{CO}_{2}, \mathrm{CH}_{4}\right.$, and $\left.\mathrm{NH}_{3}\right)$ in additional fermentation reactions with different bacteria. Research work is ongoing to examine capabilities in those areas.

Another post-processing alternative for the acetate and other simple organic liquids from C1 and C-2 is the use of a Microbial Electrolysis Cell (MEC) system. The MEC is an electrolysis unit that uses bacteria on the anode along with a moderate electrode voltage to carry out an electrolysis reaction of acetate (and other organic acids and alcohols) with water, producing $\mathrm{H}_{2}$ at the cathode and $\mathrm{CO}_{2}$ at the anode. The details of the MEC are discussed in a following section on lignocellulose fermentation and processing.

The MEC sizing is determined by the volume of the diluted liquid organic input stream and the required residence time of the reaction. We assumed an acetate concentration of 2.0 gram acetate per liter. Residence time in the MEC depends on the voltage applied, with MEC size and cost decreasing with increased voltage up to a maximum of around 0.9-1.0 volt. For these algae reactions a voltage of 0.9 Volts was assumed, which requires a 1 day residence time. For systems $\mathrm{C}-1$ and $\mathrm{C}-2$, (corresponding to biological pathways B-1 and B2 ), the processing of the liquid streams and the $\mathrm{H}_{2}$ output is shown in Figure 19-2. 
Figure 19-2: MEC Flows

\begin{tabular}{|l|c|c|}
\hline \multicolumn{1}{|c|}{ Parameters } & Units & System C-1 and C-2 \\
\hline Acetate Flow Rate & $\mathrm{kg} /$ day & 104.3 \\
\hline Reactant water & $\mathrm{kg} /$ day & 56.3 \\
\hline MEC - $\mathrm{H}_{2}$ output & $\mathrm{kg} /$ day & 12.6 \\
\hline MEC Flow Rate & gal/day & 13,782 \\
\hline MEC Residence Time & days & 1 \\
\hline Total MEC Volume & gal & 13,782 \\
\hline Number of MECs & tanks & 1 \\
\hline
\end{tabular}

Mass Balances summarizing the flows for C-1/C-2 and C-5 are shown in Figure 19-3 and Figure 19-4:

Figure 19-3. C-1/C-2 Fermentation + MEC

\section{C-1/C-2 Fermentation + MEC}

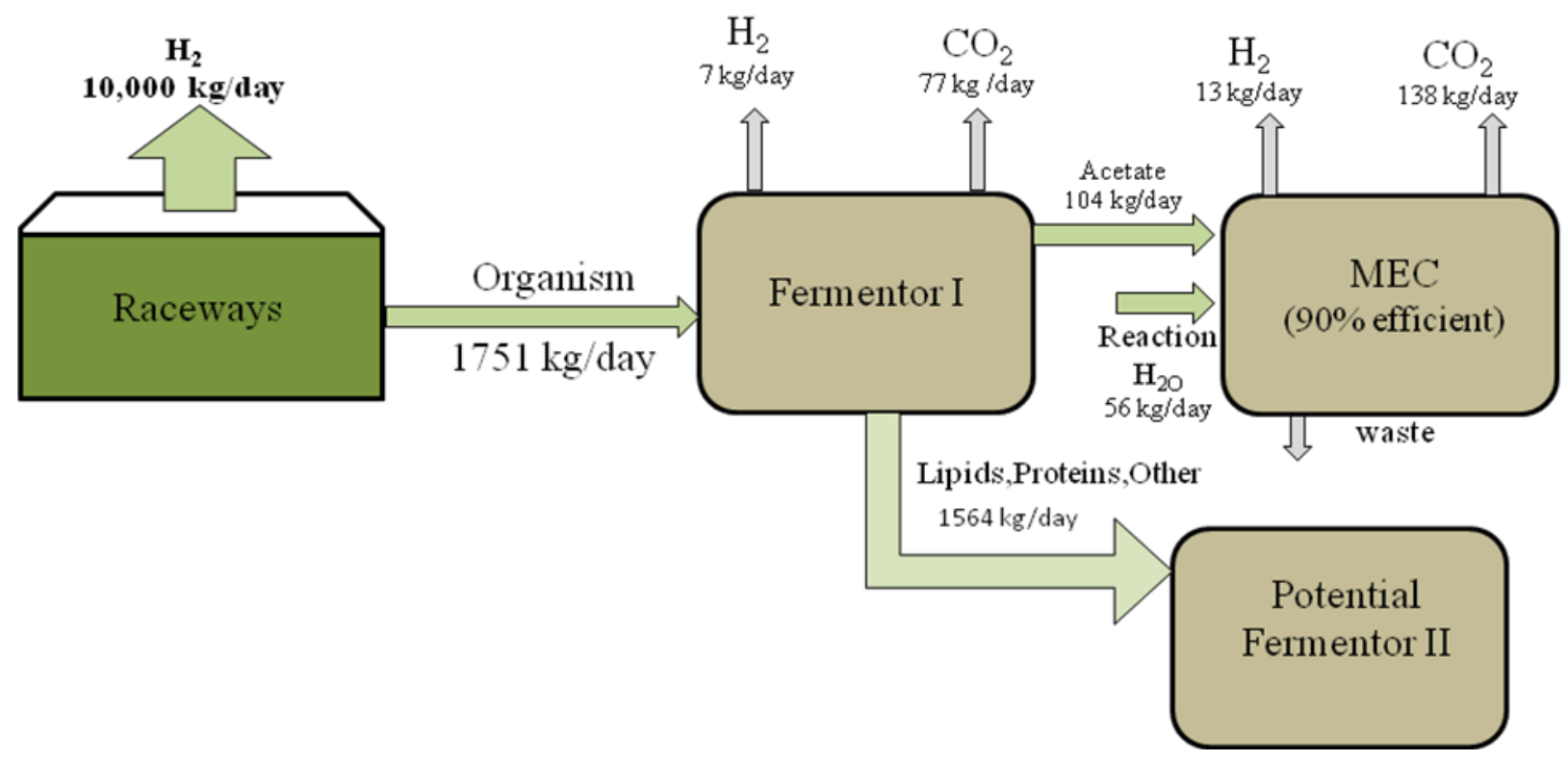


Figure 19-4. C-5 Fermentation

\section{C-5 Fermentation}

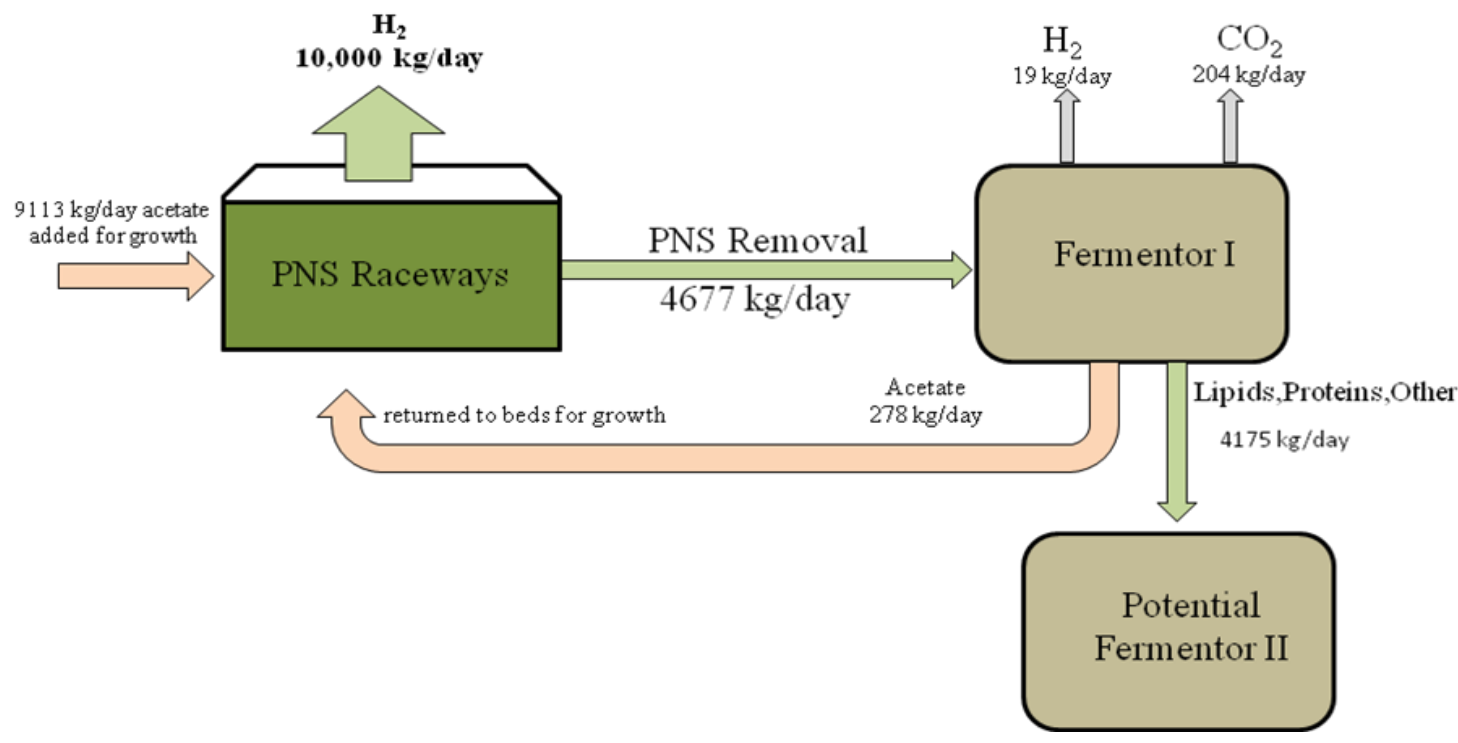

The heat balance will involve heating/cooling to maintain fermentation temperature. At the current stage of the algae fermentation research, this requirement has not been quantified.

\section{Algae Fermentation System Conclusions and Recommendations}

It is apparent that the initial fermentation step doesn't produce much $\mathrm{H}_{2}\left(\sim 7-19 \mathrm{~kg} \mathrm{H}_{2} /\right.$ day) when compared to the $10,000 \mathrm{~kg} \mathrm{H}_{2}$ /day photobiological system production rate from which it draws its organism feedstock.

If the full stoichiometric level of $\mathrm{H}_{2}$ fermentation of algal glucose were achievable through use of additional processing systems, one could potentially obtain three times more hydrogen. However, this is still only a small fraction of the targeted production rate of $10,000 \mathrm{~kg} \mathrm{H}_{2} /$ day. It is also possible that a substantial amount of hydrogen can be obtained from the protein and lipid components, which constitute about $67 \%$ of the waste algae mass. Research is being carried out to optimize the fermentative process and to assess how much additional hydrogen might be available in these components.

For the C-5 system, the fermentor byproduct acetate can be used as nutrient to the photobiological beds, providing $3 \%$ of the requirement. Future research might bring about a more complete fermentation reaction that would produce more acetate, more in line with the B-5 bed needs.

The algal fermentor may also be useful to produce acetate for an MEC. Addition of the MEC provides an additional $180 \% \mathrm{H}_{2}$, raising total $\mathrm{C}-1 / \mathrm{C}-2$ output from $7 \mathrm{~kg} /$ day to 20 $\mathrm{kg}$ /day, but that is still a small amount compared with the photobiological production of $10,000 \mathrm{~kg} /$ day. MEC operation is discussed in detail in the section on Lignolcellulosic fermentation and postprocessing. Integrated operation of a Fermentor and an MEC is discussed in the section on integrated system. 


\title{
Part III: Lignocellulosic Fermentative $\mathbf{H}_{2}$ Production Systems
}

\author{
\& Microbial Electrolysis Systems
}




\section{Lignocellulosic Hydrogen Production}

An important pathway available for production of renewable hydrogen is fermentation of carbohydrate-rich feedstock. Fermentation is the process of oxidation of organic compounds, such as carbohydrates. Dark fermentation reactions with select bacteria are capable of producing hydrogen from organic compounds throughout the day and night. In theory, any carbohydrate source could be used as a feedstock. Examples of potential lignocelluloses fermentative feedstocks are shown in Figure 21-1. The rate of $\mathrm{H}_{2}$ production via fermentation is relatively fast, and the reaction takes place continuously ${ }^{79}$. These features simplify reactor design and operation compared to photobiological pathways.

\section{Figure 21-1. Potential Fermentative Feedstock Materials}

\begin{tabular}{|l|}
\hline Algae and other biomass \\
Corn Stover \\
Switchgrass \\
Wood fiber \\
\hline
\end{tabular}

The lignocellulosic biomass feedstocks of concern in this section of the report consist of cellulose, hemicellulose, and lignin components as shown in Figure 21-2.

\section{Figure 21-2. Lignocellulosic Biomass}

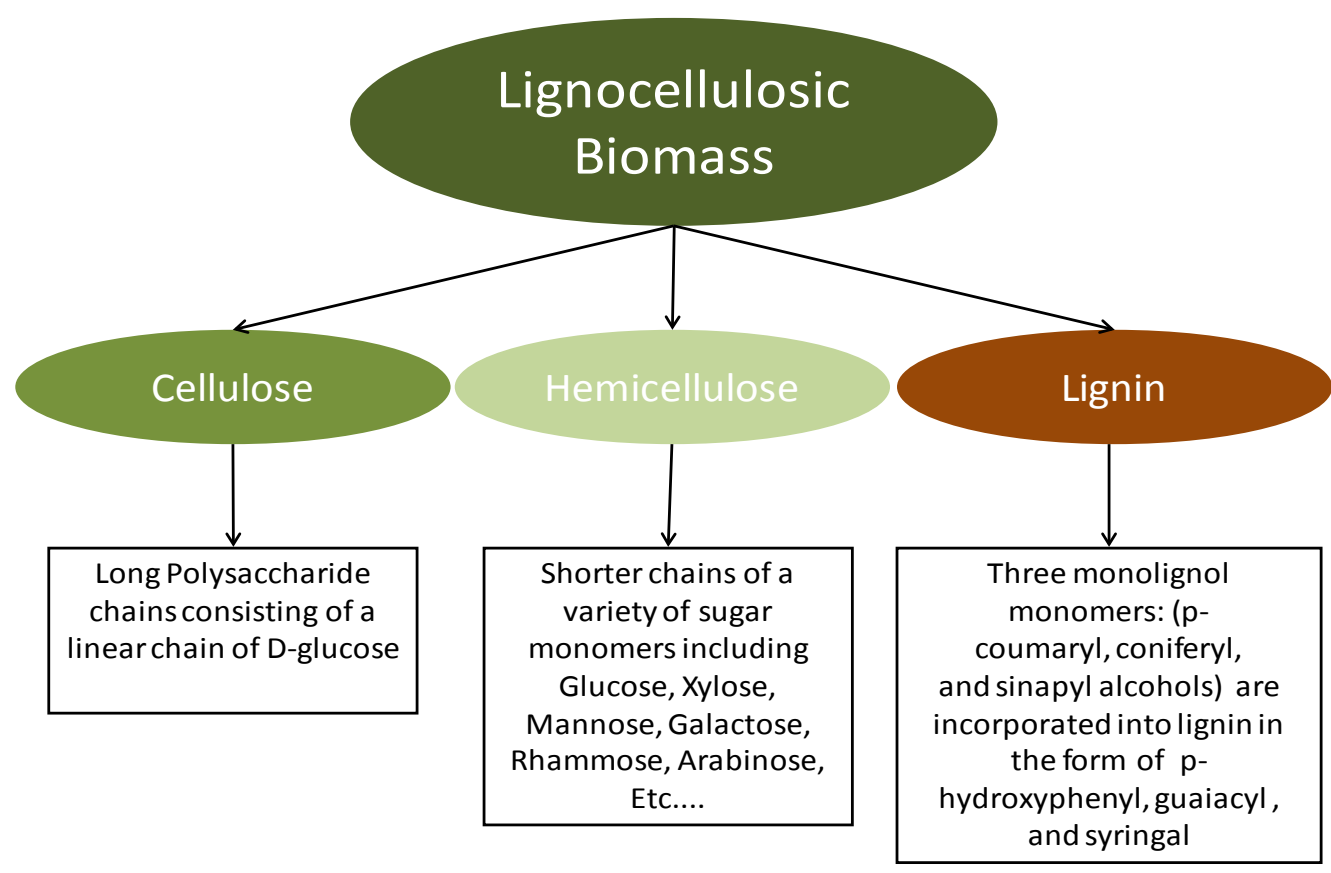

\footnotetext{
${ }^{79}$ Hawkes, F.R, Dinsdale, R., Hawkes, D.L., and Hussy, I. 2002. Sustainable fermentative hydrogen production: challenges for process utilization. Intl. J. Hydrogen Energy 27, 1339-1347.
} 
Several technical issues are concerns relative to the economic feasibility of the fermentation process. Those identified by the HFC\&IT Program ${ }^{80}$ are:

- Glucose feedstock cost (barrier AT);

- $\mathrm{H}_{2}$ molar yield ( $\mathrm{mol} \mathrm{H} / \mathrm{mol}$ hexose) (AR); and

- Waste acid accumulation (AS)

The cost of feedstock and $\mathrm{H}_{2}$ molar yield thus play important roles in determining the viability of this process. This was confirmed by a preliminary boundary analysis for $\mathrm{H}_{2}$ production by fermentation, conducted by Tim Eggeman ${ }^{81}$ for a DOE Workshop on "Hydrogen Production via Direct Fermentation."

\subsection{Fermentation Reactions}

As cellulose and hemicellulose feedstock consist of long chains of glucose, xylose, and other sugar compounds, they can generally be represented in a reaction equation as glucose. If it were possible to convert all of the glucose in the fermentation processes to hydrogen, the stoichiometric result would be:

$$
\mathrm{C}_{6} \mathrm{H}_{12} \mathrm{O}_{6}+6 \mathrm{H}_{2} \mathrm{O}=>12 \mathrm{H}_{2}+6 \mathrm{CO}_{2}
$$

However, this theoretical limit does not occur in vivo because the overall energetics is not favorable. The complete set of enzymes needed for this multi-step conversion does not function in vivo toward hydrogen production. Instead microbes opt to produce a mixture of organic acids including acetic acid and butyric acid thus lowering the yield of hydrogen ${ }^{82}$. In an "ideal" fermentation reaction, the glucose reacts with water to produce $\mathrm{H} 2$ and $\mathrm{CO} 2$ gas plus acetic acid as the only non-gaseous by-product:

\section{$\mathrm{C}_{6} \mathrm{H}_{12} \mathrm{O}_{6}+2 \mathrm{H}_{2} \mathrm{O}=>4 \mathrm{H}_{2}+2 \mathrm{CO}_{2}+2 \mathrm{CH}_{3} \mathrm{COOH}$}

This is known as the Thauer limit and results in a maximal $4.5 \% \mathrm{H}_{2}$ output by mass relative to the glucose component ${ }^{68}$. No known single microbe is able to achieve this yield. An alternative, less favorable, reaction could also take place and form $\mathrm{H}_{2}$ with butyrate as the organic acid product:

\section{$\mathrm{C}_{6} \mathrm{H}_{12} \mathrm{O}_{6}=>2 \mathrm{H}_{2}+2 \mathrm{CO}_{2}+\mathrm{CH}_{3} \mathrm{CH}_{2} \mathrm{CH}_{2} \mathrm{COOH}$}

\footnotetext{
80 “Hydrogen, Fuel Cells \& Infrastructure Technologies Program, Multi-Year Research, Development and Demonstration Plan," Section 3.1 Hydrogen Production, U.S. Department of Energy: Energy Efficiency and Renewable Energy; Hydrogen, Fuel Cells, and Infrastructure Technology Program. April 2007. www.eere.energy.gov/hydrogenandfuelcells/mypp/

${ }^{81}$ Eggeman, T. "Boundary Analysis for H2 Production by Fermentation, Neoterics International, Prepared for the National Renewable Energy Laboratory, March 12, 2004. Accessible from Proceedings of Workshop on "Hydrogen Production via Direct Fermentation." http://www1/eere.energy.gov/hydrogenandfuelcells/wkshp_proceedings.html\#hydrogen

${ }^{82}$ Benemann, John R. and Paola M. Pedroni. 4.3 Biological production of $\mathrm{H}_{2}$ : mechanisms and processes.
} 
To breakdown the cellulose and hemicelluloses, the fermentation process includes a hydrolysis step, a saccharification step, and, finally, a fermentation step for reacting the various sugars produced in the initial steps. In actual practice, the saccharification and fermentation reactions take place in the fermentor. In our analysis we assumed $90 \%$ efficiency of the hydrolysis step and $90 \%$ efficiency in the saccharification/fermentation step. This leads to 3.2 moles of hydrogen, 1.6 moles of carbon dioxide and byproducts consisting of organic acids and alcohols plus unreacted glucose and other solids (lignin, xylane, etc.). This has been demonstrated in experiments.

Production of 3.2 moles of hydrogen per mole of glucose leads to a mass conversion efficiency in the fermentation process of $3.6 \%$ (gram $\mathrm{H}_{2} /$ gram cellulose and hemicellulose). The feedstock chosen for this analysis is corn stover which is only $64 \%$ cellulose and hemicellulose, leading to an estimated corn stover hydrogen conversion efficiency of $2.32 \%$ (gram $\mathrm{H}_{2} /$ gram corn stover).

\subsection{Assumptions}

While much of the process design for our hydrogen fermentation plant is derived from a Lignocellulosic ethanol report ${ }^{83}$, there are some important assumptions in the bacteria performance and process parameters that differentiate the two.

\subsubsection{Bacteria Assumptions}

While testing for bacteria optimization is ongoing, we are hypothesizing performance based on hypothetical genetically engineered organisms capable of a fermentation $\mathrm{H}_{2}$ molar yield approaching 4. We assume in our analysis that rates of $\mathrm{H}_{2}$ production are stable for long duration. There will be two types of organisms used concurrently that will carry out saccharification and fermentation of the cellulose and the hemicellulose, avoiding the need for separation and independent reactors. The organism that ferments the cellulose will create its own cellulase enzyme which obviates the need for an outside cellulase source. Finally, we are assuming that the non-gas products of the fermentation reaction are primarily acetic acid with lignins not reacting.

\subsubsection{Process Assumptions}

Several of the processes involved in the ethanol fermentation report have been combined or eliminated in our version, simplifying the overall process. First, we assume that hydrolysis pretreatment breaks down the hemicellulose and cellulose inputs into reactable products. This pretreatment relies on high temperature acid hydrolysis alone, rather than the steam explosion process used in the ethanol report. We are using a feedstock cost that is minimal compared to a pure glucose feedstock. We have also assumed that saccharification and fermentation can occur in the same reactor. In our process, liming is done in the hydrolysis tank without any detrimental effect to the rest of the process. Lastly, we have assumed $20 \%$ solids content in the processed feedstock.

83 Aden A. et al. Lignocelulosic Biomass to Ethanol Process Design and Economics Utilizing Co-Current Dilute Acid Prehydrolysis and Enzymatic Hydrolysis for Corn Stover. NREL/TP-510-32438, June 2002 


\subsection{Lignocellulosic Fermentative Parameters}

The baseline conditions that have been used for a fermentative pathway for hydrogen production using a lignocellulosic feedstock are summarized in Figure 21-3.

Figure 21-3. Parameters for Fermentation System

\begin{tabular}{|c|c|}
\hline \multicolumn{2}{|c|}{ System Parameters } \\
\hline Corn Stover Usage (MT/day) & $2352^{84}$ \\
\hline \multicolumn{2}{|l|}{$\mathrm{H}_{2}$ Production Rate $\left(\mathrm{kgH}_{2} /\right.$ day $)$} \\
\hline At Fermentor outlet & 46,477 \\
\hline At PSA outlet & $37,181^{85}$ \\
\hline Plant Area (Acres) & 11 \\
\hline Land Utilization ( $\mathrm{kg} \mathrm{H}_{2} /$ acre/year) & $1,112,422$ \\
\hline \multicolumn{2}{|l|}{ Water Usage } \\
\hline (gal/day) & 10,539 \\
\hline$\left(\mathrm{gal} / \mathrm{kgH}_{2}\right)$ & 0.28 \\
\hline \multicolumn{2}{|l|}{ Electricity Required } \\
\hline $\mathrm{kWhr} /$ day & 152,389 \\
\hline $\mathrm{kWh} / \mathrm{kgH}_{2}$ & 4.10 \\
\hline $\mathrm{kWh} / \mathrm{kWh} \mathrm{H}_{2}$ & 0.12 \\
\hline \multicolumn{2}{|c|}{ Fermentor Parameters } \\
\hline Bacteria Cell lines & $\begin{array}{l}\text { Clostridium Consortium and Clostridium } \\
\text { thermocellum }\end{array}$ \\
\hline Duration of Cycle (hrs) & 36 \\
\hline Target Temperature $\left({ }^{\circ} \mathrm{C}\right)$ & 55 \\
\hline \multicolumn{2}{|l|}{ Assumed Reaction Efficiency } \\
\hline Hydrolysis & $90 \%$ \\
\hline $\begin{array}{l}\text { Saccharification and } \\
\text { Fermentation }\end{array}$ & $90 \%$ \\
\hline \multicolumn{2}{|l|}{ Feedstock - to $-\mathrm{H}_{2}$ Conversion } \\
\hline Efficiency & $3.6 \%$ \\
\hline $\begin{array}{l}\text { gram } \mathrm{H}_{2} / \text { gram glucose } \\
\text { gram } \mathrm{H}_{2} \text { /gram corn stover }\end{array}$ & $2.3 \%$ \\
\hline \multicolumn{2}{|l|}{ Reactor Volume $^{86}$} \\
\hline Gallons & $4,813,255$ \\
\hline Liters & $18,220,095$ \\
\hline Theoretical Product Ratio & $\begin{array}{l}4 \mathrm{~mol} \mathrm{H}_{2} \\
2 \mathrm{~mol} \mathrm{CO}_{2} \\
2 \mathrm{~mol} \mathrm{Acetate}\end{array}$ \\
\hline Assumed Goal Product Ratio & $\begin{array}{l}3.2 \mathrm{~mol} \mathrm{H}_{2} \\
1.6 \mathrm{~mol} \mathrm{CO}_{2} \\
1.6 \mathrm{~mol} \mathrm{Acetate}\end{array}$ \\
\hline
\end{tabular}

Note that in current tests the molar yield of $\mathrm{H}_{2}$ is closer to 2.0 mole $\mathrm{H}_{2}$ per mole of glucose.

\footnotetext{
${ }^{84}$ Assumes $15 \%$ water weight, for dry Corn Stover mass of 2,000 Metric Tonnes (MT)/day

${ }^{85}$ Assumes $80 \% \mathrm{H}_{2}$ recovery in the PSA.

${ }^{86}$ Volume is main fermentation tanks only- does not include pre-treatment tank volume.
} 


\subsection{Engineering Parameters}

The lignocellulosic hydrogen production plant has been divided into 7 interconnected subassemblies, namely,

- Corn Stover Prep Subassembly,

- Pretreatment/Hydrolysis Subassembly,

- Fermentation Subassembly,

- Seed Production Subassembly,

- Storage Subassembly,

- Wastewater Treatment Subassembly, and

- Gas Compression and Separation Subassembly

A general diagram showing the basic flow of this system is shown in Figure 21-4. This diagram does not include all of the subassemblies. For a more detailed look at the interaction between the subassemblies please refer to the individual assembly diagrams shown in the subsequent sections. The subassemblies have several components that will also be identified in later sections of this document.

Plant design was based upon a prior NREL report analyzing the design and costs of a lignocellulosic ethanol producing plant ${ }^{87}$. Using information from this report we extrapolated the costs and material requirements into a simplified, future hydrogen production plant using the same feedstock and similar processes. Hydrogen production involves different fermentative bacteria than ethanol production, and there are some additional assumptions made concerning potential advances in fermentation that will allow us to combine processes into one tank. These assumptions have been outlined previously in this report. Given the complexity of scaling such a complex system, we chose to emulate the ethanol plant's scale. Therefore, all components in the following subassemblies are sized and priced analogous to the corresponding ethanol plant components. The volume of hydrogen produced is based upon the fermentation of 2,000 Metric Tons (MT) of corn stover (dry weight), which was determined by the ethanol report to be the most cost-effective volume of feedstock.

Altering certain materials from the NREL report was considered for capital cost savings. Specifically, we analyzed use of concrete tanks instead of stainless steel. The Philadelphia Suburban Water Company conducted a life cycle analysis of concrete tanks and stainless steel tanks used in their water treatment system ${ }^{88}$. The conclusion drawn was that, the long-term durability of stainless steel made it the more cost effective tank solution. Coupled with the NREL reports decision to use stainless steel, we felt that there was no compelling reason to switch tank materials.

\footnotetext{
87 Aden A. et al. Lignocelulosic Biomass to Ethanol Process Design and Economics Utilizing Co-Current Dilute Acid Prehydrolysis and Enzymatic Hydrolysis for Corn Stover. NREL/TP-510-32438, June 2002

${ }^{88}$ Philadelphia Suburban Water Co. Steel vs. Concrete - A Life Cycle Analysis. http://www.steeltank.com/LinkClick.aspx?fileticket=L1jYUfta9aw\%3D\&tabid=219\&mid=701
} 
Figure 21-4. Simplified Lignocellulosic Hydrogen Production Plant

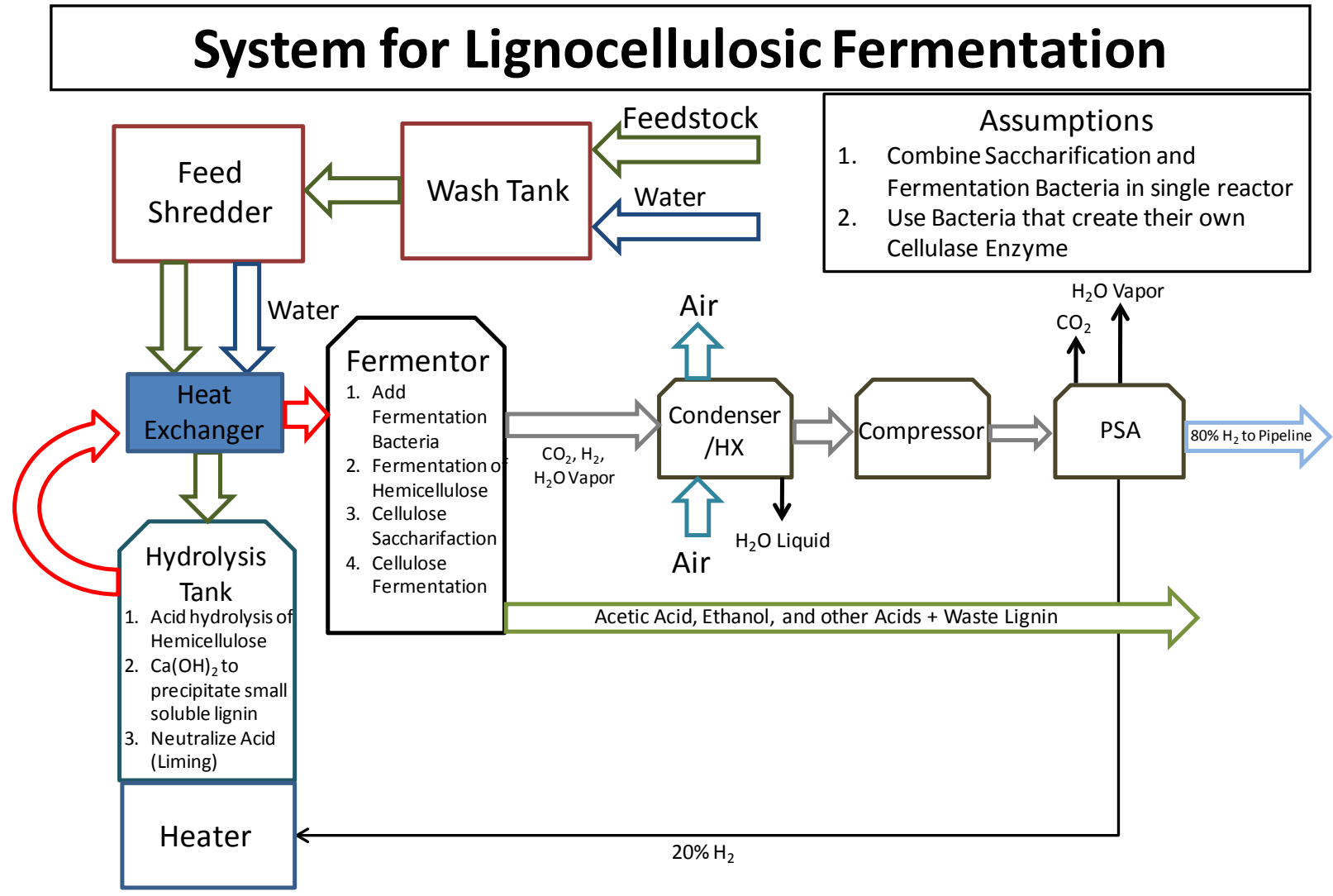

\subsection{Corn Stover Prep Subassembly}

The corn stover prep subassembly processes bales of corn stover in preparation for hydrolysis. The components of this subassembly in general terms are listed in Figure 21-5 and shown in Figure 21-6.

Figure 21-5. Corn Stover Prep Components

\begin{tabular}{|l|}
\hline Organism Feed Subassembly Components \\
\hline Bale Unwrapping Conveyor \\
\hline Belt Press Discharge Conveyor \\
\hline Shredder Feed Conveyor \\
\hline Truck Scales \\
\hline Truck Unloading Forklift \\
\hline Bale Moving Forklift \\
\hline Corn Stover Wash Table \\
\hline Shredder \\
\hline Concrete Feedstock-Storage Slab \\
\hline Polymer Feed System \\
\hline Wash Table Pump \\
\hline Wash Water Pump \\
\hline
\end{tabular}




\begin{tabular}{|l|}
\hline Clarifier Underflow Pump \\
\hline Clarified Water Pump \\
\hline Belt Press Sump Pump \\
\hline Clarifier Thickener \\
\hline Belt Press \\
\hline Magnetic Separator \\
\hline Wash Water Tank \\
\hline Clarifier Thickener Tank \\
\hline
\end{tabular}

Bales of corn stover are received by the plant on trucks. The trucks are weighed and unloaded by forklifts. Some bales are sent to storage while the rest are taken directly to conveyors. From there, the bales travel to an automatic unwrapping system that cuts away the plastic wrapping. Unwrapped bales are conveyed to a wash table, which starts breaking up bales and washes dirt from the corn stover. The washed stover is then conveyed past a magnetic separator which removes metal. Then, the stover is passed through primary and secondary shredders which shred the stover into a smaller, more easily processed size. Finally, the processed stover is conveyed to the pretreatment/hydrolysis subassembly.

Dirty wash water is recycled and cleaned utilizing a clarifier-thickener system. The wash water is pumped to the clarifier where clean water is drawn off and recycled back to the wash tables. The underflow from the clarifier is then dewatered in a belt press. Because most of the wash water is recycled through this system, the fresh water requirement is low. 
Figure 21-6. Corn Stover Prep Subassembly Design
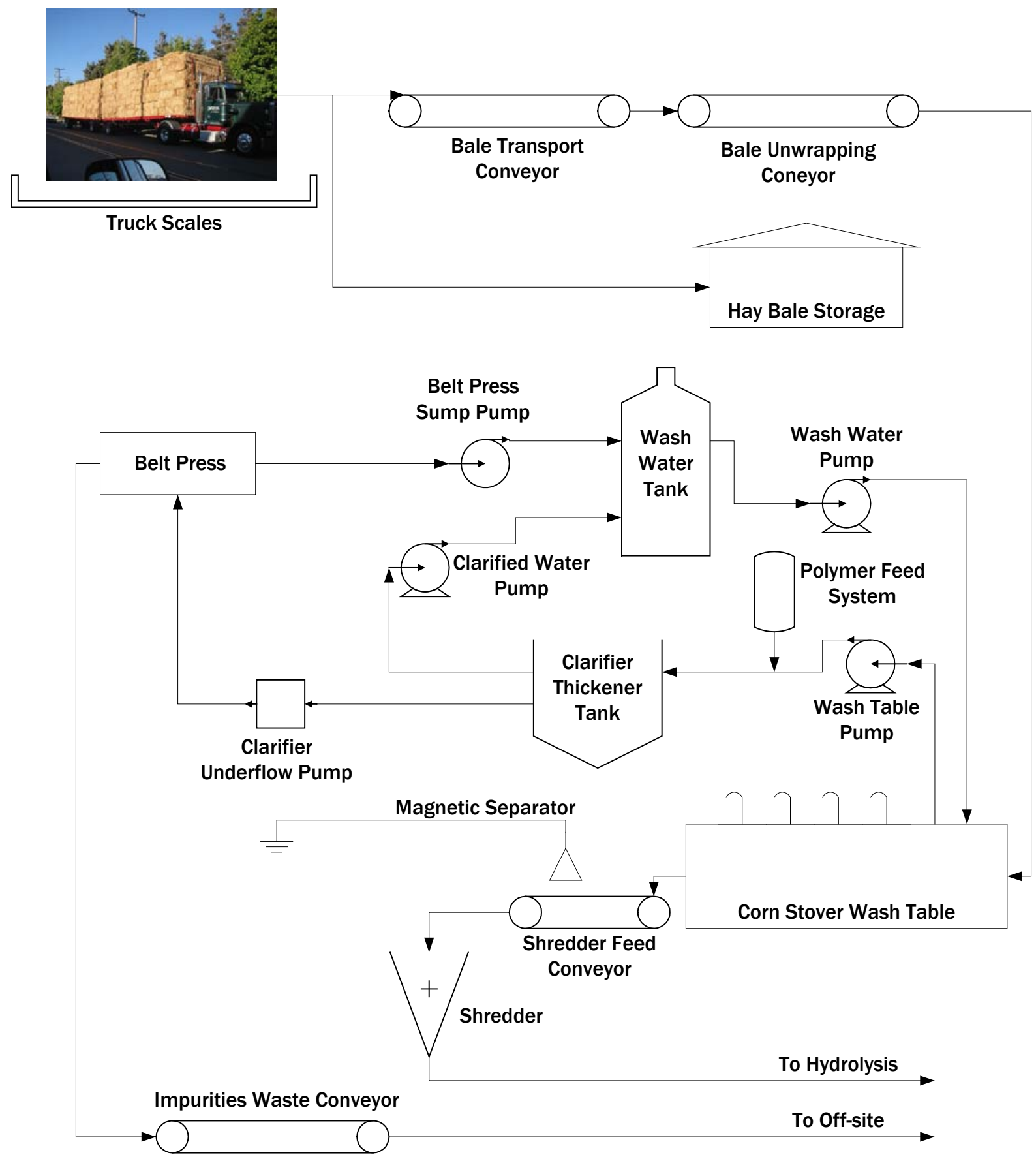

The equipment in Figure 21-6 is all very commonly available within the agricultural industry. Thus pricing for the equipment was easily located in reference documents and through discussions with suppliers. The capital cost of the subassembly is $\$ 4,038,990$ as shown in Figure 21-7. 
Figure 21-7. Capital Cost of Corn Stover Prep Subassembly

\begin{tabular}{|c|c|c|c|}
\hline $\begin{array}{l}\text { Corn Stover Prep } \\
\text { Components }\end{array}$ & Material Chosen & Total Pr & ing \\
\hline $\begin{array}{l}\text { Bale Transport } \\
\text { Conveyor }\end{array}$ & $400 \mathrm{ft}$ long, 8 wide, $50 \mathrm{HP}$ motor & $\$$ & 800,000 \\
\hline $\begin{array}{l}\text { Bale Unwrapping } \\
\text { Conveyor }\end{array}$ & 90 bale $/ \mathrm{hr}$ & $\$$ & 300,000 \\
\hline $\begin{array}{l}\text { Belt Press Discharge } \\
\text { Conveyor }\end{array}$ & 3' wide X 50' long. & $\$$ & 50,000 \\
\hline $\begin{array}{l}\text { Shredder Feed } \\
\text { Conveyor }\end{array}$ & $8^{\prime}$ wide $\mathrm{X} 30^{\prime}$ long. $6001 \mathrm{lbs} 31 \mathrm{fpm}$ & $\$$ & 240,000 \\
\hline Truck Scales & $\begin{array}{c}\text { Concrete. } 8^{\prime} \text { wide X 30' long. } 6001 \text { lbs } 31 \\
\text { fpm }\end{array}$ & $\$$ & 68,000 \\
\hline $\begin{array}{l}\text { Truck Unloading } \\
\text { Forklift }\end{array}$ & Propane Gas Forklift & $\$$ & 72,000 \\
\hline Bale Moving Forklift & Propane Gas Forklift & $\$$ & 72,000 \\
\hline $\begin{array}{l}\text { Corn Stover Wash } \\
\text { Table }\end{array}$ & $\mathrm{A} 238.55 \mathrm{ton} / \mathrm{hr}$ & $\$$ & 208,000 \\
\hline Shredder & Alloy Steel. 55 ton $/ \mathrm{hr}$ & $\$$ & $1,208,000$ \\
\hline $\begin{array}{l}\text { Concrete Feedstock- } \\
\text { Storage Slab }\end{array}$ & Concrete Slab. 350' X538' & $\$$ & 450,655 \\
\hline Polymer Feed System & & $\$$ & 30,000 \\
\hline Wash Table Pump & Rubber. $2500 \mathrm{gpm}, 50 \mathrm{ft}$ head & $\$$ & 40,000 \\
\hline Wash Water Pump & SS316. $5000 \mathrm{gpm}, 50 \mathrm{ft}$ head & $\$$ & 30,000 \\
\hline $\begin{array}{l}\text { Clarifier Underflow } \\
\text { Pump }\end{array}$ & $\begin{array}{l}\text { Rubber. MOD SRL 2X3-10 } 100 \text { GPM -- } \\
50 \text { TDH }\end{array}$ & $\$$ & 6,000 \\
\hline Clarified Water Pump & SS316.5000 gpm, $50 \mathrm{ft}$ head & $\$$ & 15,000 \\
\hline Belt Press Sump Pump & VJC 1.5X2.11 100 GPM -- 40 TDH & $\$$ & 19,000 \\
\hline Clarifier Thickener & 5000 GPM mechanism & $\$$ & 135,000 \\
\hline Belt Press & 304 SS. 1.5 meter & $\$$ & 100,000 \\
\hline Magnetic Separator & Tramp iron magnet separator & $\$$ & 10,355 \\
\hline Wash Water Tank & (20' Diameter X 22' Tall, 50,000 gal) & $\$$ & 50,000 \\
\hline $\begin{array}{l}\text { Clarifier Thickener } \\
\text { Tank }\end{array}$ & Cement. (80' diameter) & $\$$ & 135,000 \\
\hline TOTAL & \multicolumn{3}{|c|}{$\$ 4,038,990$} \\
\hline
\end{tabular}

\subsection{Pretreatment/Hydrolysis Subassembly}

The feedstock corn stover consists primarily of three components: cellulose, hemicelluloses, and lignin. Based on the Aden et al. report we have assumed a composition by weight of $36.7 \%$ cellulose, $27.4 \%$ hemicellulose, $30.8 \%$ lignin, and $5.1 \%$ other non-reacting matter. The feedstock is mixed with water to the ratio of $20 \%$ dry weight and $80 \%$ liquid. The purpose of the pretreatment/hydrolysis subassembly is to break down the components of the corn stover into complex sugars on which bacteria are capable of carrying out saccharification and 
fermentation. The components of this subassembly in general terms are listed in Figure 21-8 and shown in Figure 21-9.

Figure 21-8. Pretreatment/Hydrolysis Components

\begin{tabular}{|l|}
\multicolumn{1}{c|}{$\begin{array}{c}\text { Pretreatment/Hydrolysis Subassembly } \\
\text { Components }\end{array}$} \\
\hline Hydrozylate Mix Tank Agitator \\
\hline Hydrozylate Mixing Tank \\
\hline In-line Sulfuric Acid Mixer \\
\hline Sulfuric Acid Pump \\
\hline Sulfuric Acid Tank \\
\hline Lime Solids Feeder \\
\hline Lime Unloading Blower \\
\hline Lime Dust Vent Baghouse \\
\hline Lime Storage Bin \\
\hline Hydrolysis Tank Pump \\
\hline Hydrolysis Feed Boiler \\
\hline
\end{tabular}

The pretreatment/hydrolysis subassembly utilizes dilute acid hydrolysis reactions at $150{ }^{\circ} \mathrm{C}$ and 4.7 atmospheres to convert the washed and cleaned corn stover feedstock into hemicellulosederived soluble sugars and crystalline cellulose that allow for subsequent bacterial sacchrification and fermentation. Cleaned corn stover from the corn stover prep subassembly mixed with water is heated by two heat exchangers, HX-1 and HX-2, and then heated in a boiler to $150{ }^{\circ} \mathrm{C}$. In the boiler, heat is added to the mixture by burning the byproduct $\mathrm{H}_{2} / \mathrm{CO}_{2}$ mixture coming from the waste side of the PSA separator. The heated slurry is then pumped into the hydrolysis reactor. The hydrolysis reaction hydrolyzes and breaks down the hemicelluloses portion of the feedstock by adding dilute $(1.1 \%)$ sulfuric acid at $150{ }^{\circ} \mathrm{C}$. The slurry is treated in this way for two minutes before the overliming process begins. This process raises the $\mathrm{pH}$ and re-solidifies the soluble lignin components for later separation. The subassembly components are shown in Figure 21-9. 
Figure 21-9. Pretreatment/Hydrolysis Subassembly Design

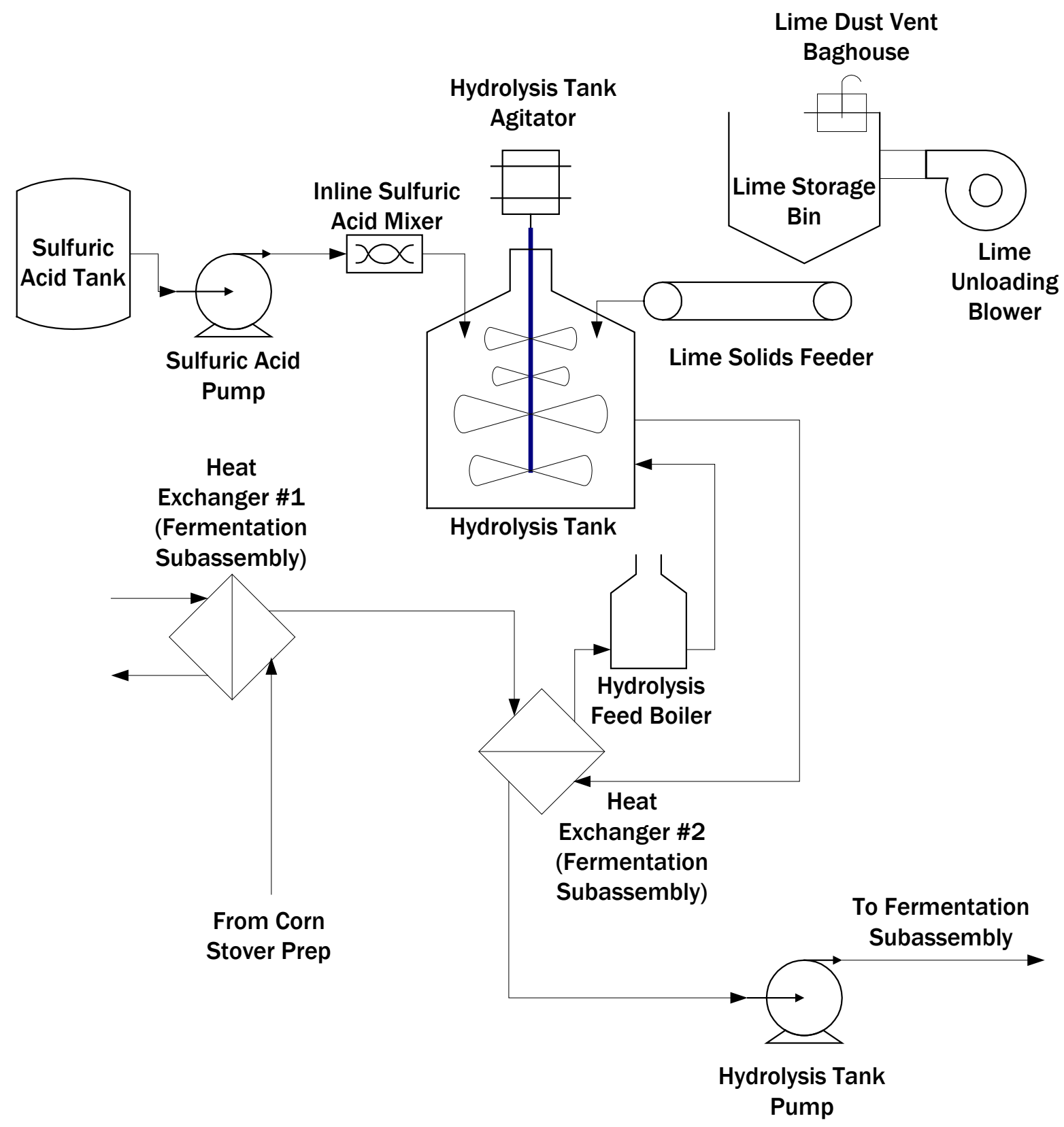

The equipment in Figure 21-9 is all very commonly available within the agricultural industry. Thus pricing for the equipment was easily located in reference documents and through discussions with suppliers. The capital cost of the subassembly is $\$ 847,017$ as shown in Figure 21-10. 
Figure 21-10. Capital Costs of Pretreatment/Hydrolysis Subassembly

\begin{tabular}{|c|c|c|}
\hline $\begin{array}{l}\text { Pretreatment/Hydrolysis } \\
\text { Components }\end{array}$ & Material Chosen & Total Pricing \\
\hline Hydrozylate Mix Tank & SS. Top-Mounted, $1800 \mathrm{rpm}, 50 \mathrm{hp}$ & \\
\hline Agitator & & $\$ 28,421$ \\
\hline Hydrozylate Mixing Tank & $\begin{array}{l}\text { SS304. } 24770 \text { gal., } 13 \text { ' dia. X 25' high, } 15 \\
\text { min. res. time, } 90 \% \text { wv, atmospheric }\end{array}$ & $\$ 32,237$ \\
\hline In-line Sulfuric Acid Mixer & SS304. Static Mixer, 248 gpm total flow. & $\$ 2,542$ \\
\hline Sulfuric Acid Pump & SS304. 4 gpm, $245 \mathrm{ft}$. head & $\$ 8,289$ \\
\hline Sulfuric Acid Tank & $\begin{array}{c}\text { Plastic. } 6444 \text { gal., } 24 \mathrm{hr} \text {. residence time, } \\
90 \% \mathrm{wV}\end{array}$ & $\$ 9,441$ \\
\hline Lime Solids Feeder & $\begin{array}{l}\text { A285C. 8" dia., } 140 \mathrm{cfh}, 7000 \mathrm{lb} / \mathrm{hr} \max \\
\text { flow conveyor }\end{array}$ & $\$ 3,900$ \\
\hline Lime Unloading Blower & C.S. $7425 \mathrm{cfm}, 6 \mathrm{psi}, 22275 \mathrm{lb} / \mathrm{hr}$ & $\$ 99,594$ \\
\hline Lime Dust Vent Baghouse & $\begin{array}{c}\text { A285C, Polyester. } 8333 \mathrm{cfm}, 1389 \text { sf, } 6 \\
\mathrm{cfm} / \mathrm{sf}\end{array}$ & $\$ 140,707$ \\
\hline Lime Storage Bin & $\begin{array}{c}4455 \mathrm{cf}, 14 \text { ' dia x } 25^{\prime} \text { high, } 1.5 \mathrm{x} \text { rail car vol., } \\
\text { atmospheric }\end{array}$ & $\$ 136,370$ \\
\hline Hydrolysis Tank Pump & SS304. $737 \mathrm{gpm}, 200 \mathrm{ft}$ head & $\$ 69,516$ \\
\hline Hydrolysis Feed Boiler & 6000 kW Boiler, 200 PSI. SS304 & $\$ 316,000$ \\
\hline TOTAL & & $\$ 847,017$ \\
\hline
\end{tabular}

\subsection{Fermentation Subassembly}

The fermentation subassembly carries out two processes: Saccharification and fermentation. The sacharification converts the hydrolyzer complex sugars into simple sugars using enzymes. Fermentation describes the subsequent conversion of these simple sugars into hydrogen gas by carefully designed fermentative organisms. As mentioned earlier, these organisms will produce a cellulase enzyme for the saccharification of the cellulose component of the feedstock. The components of this subassembly in general terms are listed in Figure 21-11 and shown in Figure 21-12.

Figure 21-11. Fermentation Components

\begin{tabular}{|l|}
\multicolumn{1}{|c|}{ Fermentation Subassembly Components } \\
\hline Fermentation Tank \\
\hline Fermentation Agitator \\
\hline Fermentation Recirculation Pump \\
\hline Lignin Wet Cake Screw \\
\hline Acetate Product Storage Tank \\
\hline Acetate Transfer Pump \\
\hline Pneumapress Filter \\
\hline Heat Exchanger \#1 \\
\hline Heat Exchanger \#2 \\
\hline Fermentor Temperature Control \\
\hline
\end{tabular}

In this subassembly the pretreated slurry is pumped into the saccharification/fermentation tank and inoculated with bacteria produced in the seed production subassembly, which will be 
discussed later in this report. A fraction of the pretreated slurry will also be routed to the seed production subassembly for use in the cultivation of fermentative organisms. To maintain the temperature most conducive to fermentation, a portion of the slurry will be removed from the reactor, cycled through the fermentor temperature control heat exchanger for cooling, and returned to the tank. Residence time for one saccharification and fermentation cycle is a total of 40 hours.

In addition to hydrogen and carbon dioxide gases, the fermentation reaction will also produce acetic acid, which may be further processed into hydrogen by separate bacteria in a subsequent MEC system. This acetate is then pumped from the fermentation tank into temporary storage before being sent on for further hydrogen production or discarded. The subassembly components are all shown in Figure 21-12.

Figure 21-12. Fermentation Subassembly Design

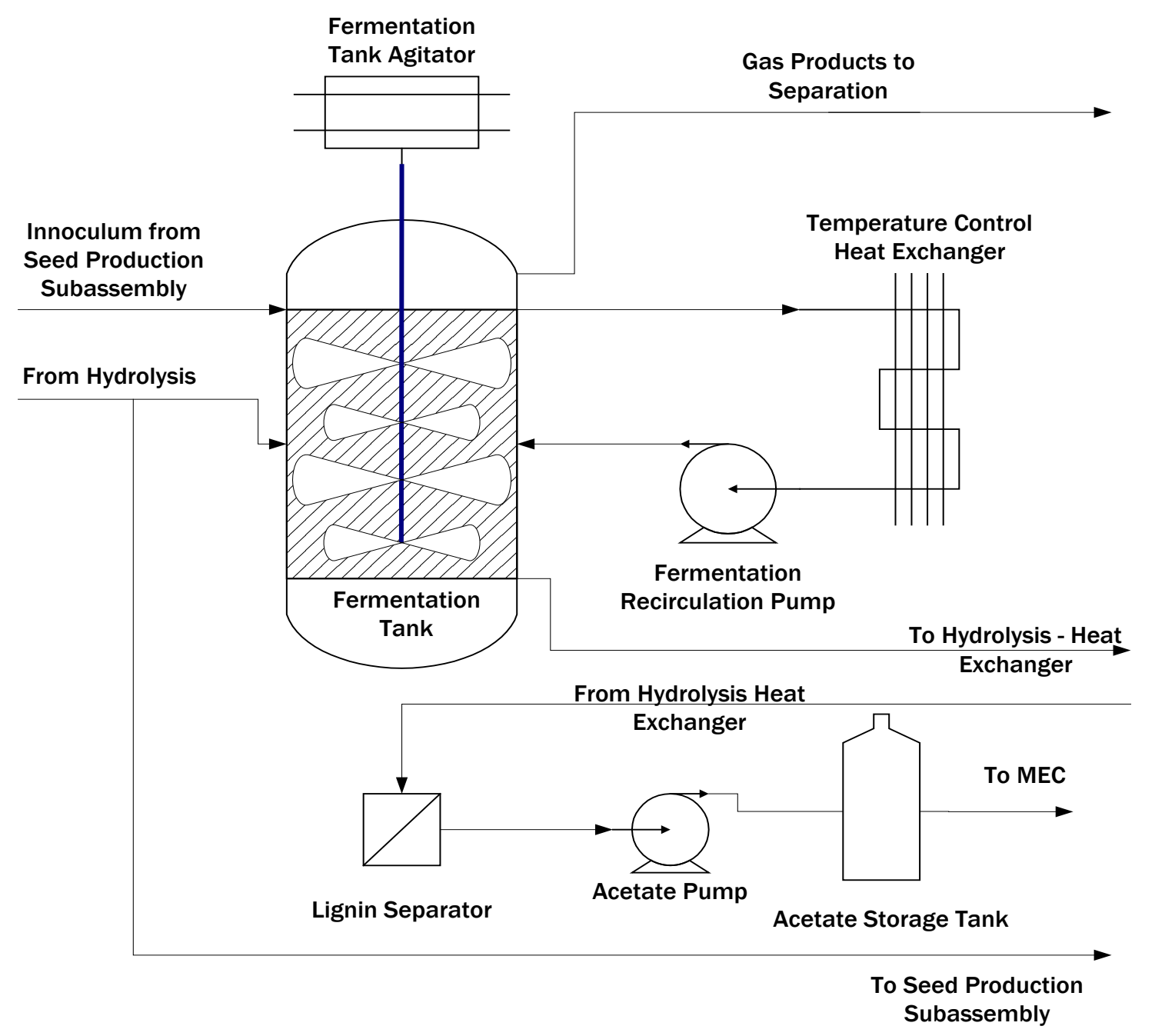

The equipment in Figure $21-12$ is all very commonly available within the agricultural industry. Thus pricing for the equipment was easily located in reference documents and through discussions with suppliers. The capital cost of the subassembly is $\$ 8,458,507$ as shown in Figure 21-13. 
Figure 21-13. Capital Costs of Fermentation Subassembly

\section{Fermentation Components Material Chosen Total Pricing}

Fermentation Tank

Fermentation Agitator

Fermentation Recirculation Pump

Lignin Wet Cake Screw

Acetate Product Storage Tank

Acetate Transfer Pump

Fermentor Temperature Control

Heat Exchanger \#1

Heat Exchanger \#2

TOTAL
SS304. 962,651 gal. each, 90\% wv, API, atmospheric

SS304. Side Mounted, 2 per vessel, $75 \mathrm{hp}$ each, $0.15 \mathrm{hp} / 1000 \mathrm{gal}$

SS304. $1060 \mathrm{gpm}, 150 \mathrm{ft}$ head 14" Dia X 100' Long

SS304. 456617 gal., 45' dia x 40' high, 4 hr res. Time, $90 \% \mathrm{wv}$, atmospheric

SS304. 1231 gpm total, 615 gpm each, 100 $\mathrm{ft}$ head

Plate-Frame, SS304, atmospheric

Plate-Frame, SS304, atmospheric

Plate Frame, SS304, 4.68 atmospheres
$\$ 2,466,955$

\$ 196,760

$\$ 68,330$

$\$ 84,185$

$\$ 160,829$

$\$ 53,737$

$\$ 33,905$

$\$ 22,346$

$\$ 194,905$

$\$ 8,424,607$

\subsection{Seed Production Subassembly}

The purpose of the seed production subassembly is to breed hydrogen producing fermentative bacteria for use in the fermentation reactor. The components of this subassembly in general terms are listed in Figure 21-14 and shown in Figure 21-15.

\section{Figure 21-14. Seed Production Components}

Seed Production Subassembly Components

Seed Hold Tank

Seed Hold Tank Agitator

Seed Hold Transfer Pump

1st Seed Fermentor

2nd Seed Fermentor

3rd Seed Fermentor

4th Seed Fermentor

5th Seed Fermentor

4th Seed Agitator

5th Seed Agitator

4th Seed Fermentor Coil

5th Seed Fermentor Coil

Seed Transfer Pump

The bacteria is grown in a series of seed fermentation vessels. Hydrolyzed slurry and nutrients, such as corn steep liquor (CSL) and Diammonium Phosphate (DAP) are combined with an initial seed inoculum grown in a very small vessel in a laboratory. The result of each seed batch is used as the inoculum for the next size seed increment. This series of scale-ups is continued until the last step is large enough to support fermentation. Finally, the seed inoculum, nutrients, and saccharified slurry are combined in each fermentation tank. The number of fermentors will 
be five 1-million gallon vessels in a line with a 40 hour reaction residence time in each. The subassembly components are shown in Figure 21-15.

Figure 21-15. Seed Production Subassembly Design

\section{Seed Production Subassembly}

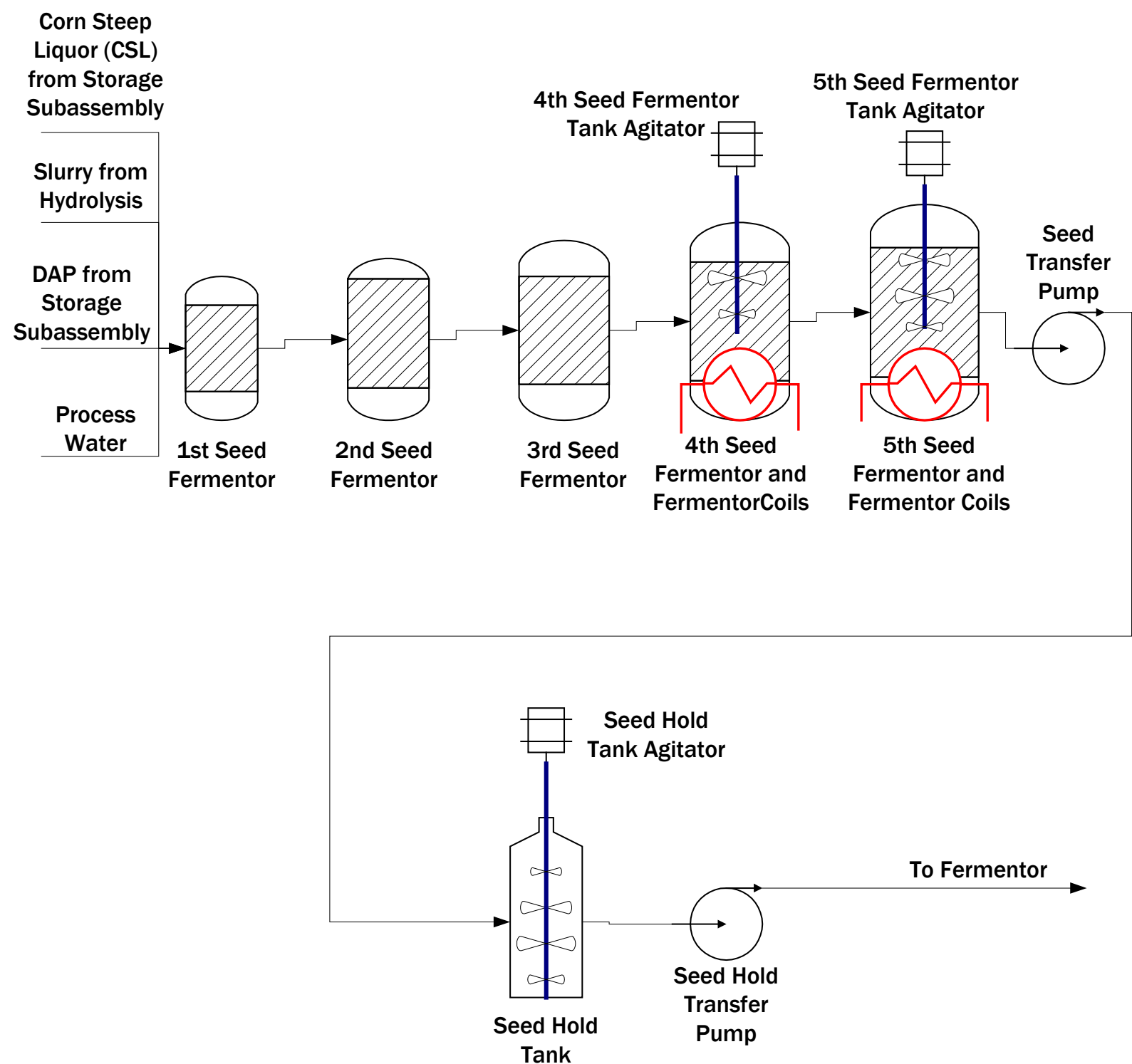

The equipment in Figure 21-15 is all very commonly available within the agricultural industry. Thus pricing for the equipment was easily located in reference documents and through discussions with suppliers. The capital cost of the subassembly is $\$ 1,007,829$ as shown in Figure 21-16. 
Figure 21-16. Capital Costs of Seed Production Subassembly

\begin{tabular}{|c|c|c|}
\hline $\begin{array}{c}\text { Seed Production } \\
\text { Components } \\
\end{array}$ & Material Chosen & Total Pricing \\
\hline Seed Hold Tank & SS304. 233,333 gal., API atmospheric & $\$ 160,829$ \\
\hline Seed Hold Tank Agitator & $\begin{array}{l}\text { SS304. Top Mounted, } 1800 \mathrm{rpm}, 23 \mathrm{hp}, 0.1 \\
\text { hp/1000 gal }\end{array}$ & $\$ 12,492$ \\
\hline Seed Hold Transfer Pump & SS304. $172 \mathrm{gpm}, 150 \mathrm{ft}$ head & $\$ 22,050$ \\
\hline 1st Seed Fermentor & $\begin{array}{c}\text { SS304. } 20 \text { gal, jacketed, agitated, 1.3' dia., } \\
\text { 2' high, } 15 \text { psig }\end{array}$ & $\$ 29,400$ \\
\hline 2nd Seed Fermentor & $\begin{array}{c}\text { SS304. } 194 \text { gal., jacketed, agitated, 3' dia., } \\
\text { 4' high, } 2.5 \text { psig }\end{array}$ & $\$ 65,200$ \\
\hline 3rd Seed Fermentor & $\begin{array}{c}\text { SS304. } 1950 \text { gal., jacketed, agitated, 6.5' } \\
\text { dia, 8' high, } 2.5 \text { psig }\end{array}$ & $\$ 162,200$ \\
\hline 4th Seed Fermentor & $\begin{array}{c}\text { SS304. } 19444 \text { gal., 12' dia x 23' high, } \\
\text { atmospheric }\end{array}$ & $\$ 78,320$ \\
\hline 5th Seed Fermentor & SS304. 194500 gal., API, atmospheric & $\$ 293,097$ \\
\hline 4th Seed Agitator & $\begin{array}{l}\text { SS. Top Mounted, } 1800 \mathrm{rpm}, 6 \mathrm{hp}, 0.3 \\
\text { hp/1000 gal }\end{array}$ & $\$ 23,289$ \\
\hline 5th Seed Agitator & $\begin{array}{l}\text { SS. Top Mounted, } 1800 \mathrm{rpm}, 19 \mathrm{hp}, 0.1 \\
\text { hp/1000 gal }\end{array}$ & $\$ 20,582$ \\
\hline 4th Seed Fermentor Coil & SS. 27 sf, 1" sch 40 pipe, 105 BTU/hr sf F & $\$ 4,658$ \\
\hline 5th Seed Fermentor Coil & SS. 307 sf, 3" sch 40 pipe, 92 BTU/hr sf F & $\$ 28,238$ \\
\hline Seed Transfer Pump & $\begin{array}{c}\text { SS304. } 1231 \mathrm{gpm} \text { total, } 615 \mathrm{gpm} \text { each, } 100 \\
\mathrm{ft} \text { head }\end{array}$ & $\$ 107,474$ \\
\hline TOTAL & & $\$ 1,007,829$ \\
\hline
\end{tabular}

\subsection{Storage Subassembly}

The purpose of the storage subassembly is to provide bulk storage of chemicals used in the hydrogen production process. It also serves as the location for the main process water tank, which provides water needed in the various subassemblies of the system. The components of this subassembly in general terms are listed in Figure 21-17 and shown in Figure 21-18.

Figure 21-17. Storage Components

\begin{tabular}{|l|}
\multicolumn{1}{l}{ Storage Subassembly Components } \\
\hline CSL Storage tank Agitator \\
\hline CSL Pump \\
\hline CSL Storage Tank \\
\hline CSL/DAP Day Tank \\
\hline CSL/DAP Pump \\
\hline CSL/DAP Day Tank Agitator \\
\hline DAP Solids Feeder \\
\hline DAP Unloading Blower \\
\hline DAP Vent Baghouse \\
\hline DAP Storage Bin \\
\hline Sulfuric Acid Pump \\
\hline Sulfuric Acid Storage Tank \\
\hline
\end{tabular}




\begin{tabular}{|l|}
\multicolumn{1}{|c|}{ Storage Subassembly Components } \\
\hline Propane Storage Tank \\
\hline Cooling Water Pump \\
\hline Make-up Water Pump \\
\hline Process Water Circulating Pump \\
\hline Process Water Tank \\
\hline
\end{tabular}

In addition to the main process water tank, stored chemicals include sulfuric acid, of which a five day supply is held, Corn Steep Liquor (CSL), a by-product of the corn wet-milling industry, and Diammonium Phosphate (DAP), both nutrient sources for fermentation seed growth. Propane gas for use in the bale handling forklifts. The subassembly components are all shown in Figure 21-18.

Figure 21-18. Storage Subassembly Design

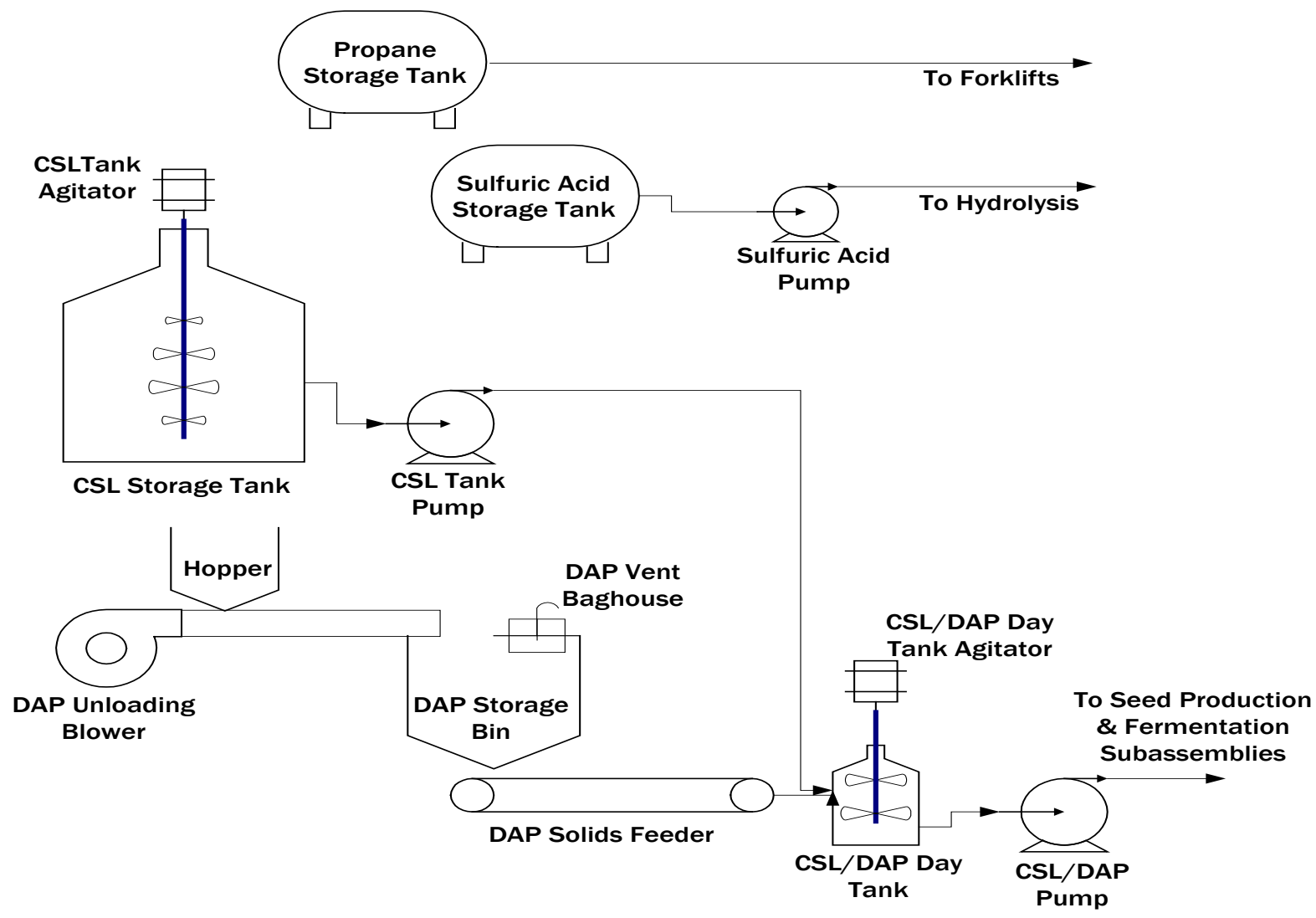

The equipment inFigure 21-18 is all very commonly available within the agricultural industry. Thus pricing for the equipment was easily located in reference documents and through discussions with suppliers. The capital cost of the subassembly is $\$ 924,749$ as shown in Figure 21-19. 
Figure 21-19. Capital Costs of Storage Subassembly

\section{Storage Components}

CSL Storage tank Agitator

CSL Pump

CSL Storage Tank

CSL/DAP Day Tank

CSL/DAP Pump

CSL/DAP Day Tank Agitator

DAP Solids Feeder

DAP Unloading Blower

DAP Vent Baghouse

DAP Storage Bin

Sulfuric Acid Pump

Sulfuric Acid Storage Tank

Propane Storage Tank

Cooling Water Pump

Make-up Water Pump

Process Water Circulating Pump

Process Water Tank

TOTAL

\section{Material Chosen}

Total

Pricing

SS304. Top Mounted, 1800 rpm, 23 hp, 0.1 hp/1000

gal

$\$ 2,143$

SS304. Top Mounted, 1800 rpm, 23 hp, 0.1 hp/1000

gal

$\$ 6,188$

Cs. 431 gpm, $150 \mathrm{ft}$ head

SS304. 10,000 gal, $24 \mathrm{hr}$ res time, 90\% wv, 9.5' dia

$\mathrm{x} 18.9^{\prime}$ high, atmospheric

$\$ 61,949$

CS. $431 \mathrm{gpm}, 150 \mathrm{ft}$ head

SS304. Top Mounted, 1800 rpm, 5 hp, 0.5 hp/1000

$$
\text { gal }
$$

$\$ 28,470$

$\$ 6,188$

$\$ 12,348$

A285C. 8" dia., $140 \mathrm{cfh}, 7000 \mathrm{lb} / \mathrm{hr}$ max flow

CS. $7425 \mathrm{cfm}, 6 \mathrm{psi}, 22275 \mathrm{lb} / \mathrm{hr}$

$\$ 3,900$

$\$ 49,014$

A285C, Polyester. $8333 \mathrm{cfm}, 1389$ sf, $6 \mathrm{cfm} / \mathrm{sf}$

CS. 1425 cf, 9' dia x 19.5' high, 1.5x vessel vol.

Req. for 7-day res time, atmospheric

$\$ 9,595$

$\$ 34,255$

SS316. 215 gpm, $150 \mathrm{ft}$ head

SS316. 18697 gal, $120 \mathrm{hr}$ res time, 90\% wv, 12' dia x 22 ' high, atmospheric

$\$ 13,814$

$\$ 60,470$

A515. 2000 gal, 10 day res time, $90 \% \mathrm{wv}, 4$ ' dia $x$ 23.6 length, $250 \mathrm{psig}$

$\$ 30,825$

CS. 41000 gpm, $70 \mathrm{ft} \mathrm{head.}$

$\$ 242,216$

CS. 1083 gpm, 75 ft. head

$\$ 8,735$

CS. 1199 gpm ea, 75 ft. head

$\$ 17,635$

CS. 756000 gal. $8 \mathrm{hr}$ res time

$\$ 337,004$

$\$ 924,749$

\subsection{Wastewater Treatment Subassembly}

The function of the wastewater treatment subassembly is to treat process water for reuse to reduce the plant makeup water. The waste water is first screened, removing large particles to be subsequently sent to a landfill. Following screening, the organic matter in the water is then removed with anaerobic and aerobic digestion. This digestion produces a waste sludge and methane gas that could be used as a fuel for heating, however, we will not consider this further in this report. The components in this subassembly in general terms are listed in Figure 21-20. 
Figure 21-20. Wastewater Treatment Subassembly Components

Wastewater Treatment Subassembly Components

Equalization Basin Agitator

Anaerobic Agitator

Anaerobic Digester Feed Cooler

Nutrient Feed System

Biogas Emergency Flare

Anaerobic Reactor Feed Pump

Aerobic Digester Feed Pump

Bar Screen

Equalization Basin

Anaerobic Digester

Aerobic Lagoon Agitator

Filter Precoat System

Aerobic Sludge recycle Pump

Aerobic Sludge Pump

Aerobic Digestion Outlet Pump

Sludge Filtrate Recycle Pump

Treated Water Pump

Belt Filter Press

Aerobic Digester

Clarifier

The design for the wastewater treatment section mirrors that of the ethanol report, which relied upon the analysis of Merrick Engineering. Their design was carefully scaled and optimized for their flow rates, which differ slightly from ours. We have scaled linearly the components of the system to match our increased flow rate. The subassembly components are show in Figure 21-21. 
Figure 21-21. Wastewater Treatment Subassembly Design

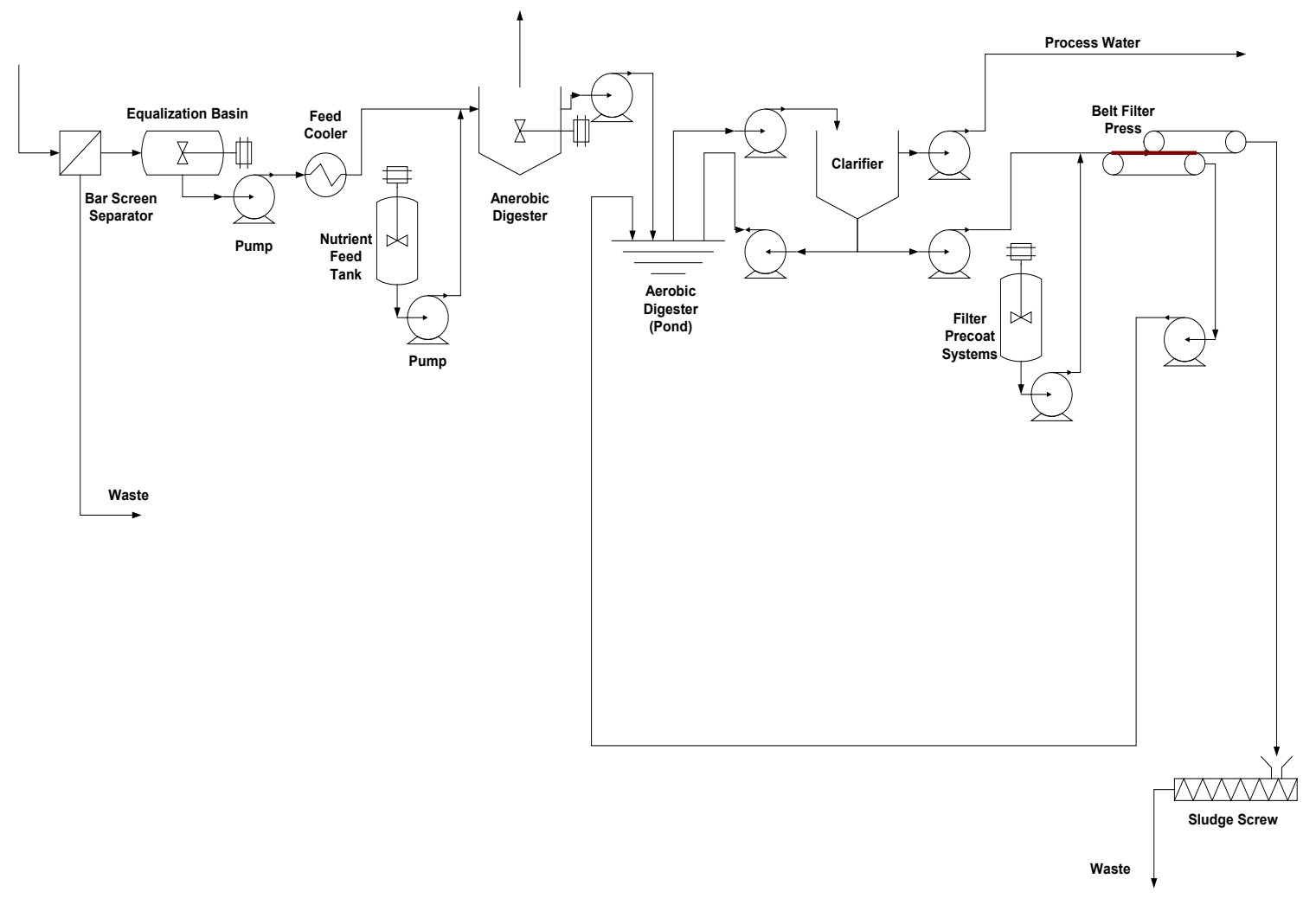

The equipment in Figure 21-21 is all very commonly available within the agricultural industry. Thus pricing for the equipment was easily located in reference documents and through discussions with suppliers. The capital cost of the subassembly is $\$ 12,039,997$ as shown in Figure 21-22. 
Figure 21-22. Capital Cost of Wastewater Treatment Subassembly

\section{Storage Components \\ Material Chosen}

Total

Pricing

Equalization Basin Agitator

SS. 38 HP each, Fixed Prop, 0.1 HP/1000 gal

$\$ 94,624$

Anaerobic Agitator

SS. Fixed Prop, 41 HP, 0.05 hp/1000 gal

$\$ 100,955$

Anaerobic Digester Feed

Cooler

SS316. TEMA BES type, floating head

$\$ 428,475$

Nutrient Feed System

CS. 5 tanks and pumps

$\$ 71,301$

Biogas Emergency Flare

SS. Flare and Pilot

$\$ 69,099$

Anaerobic Reactor Feed

Pump

CS. Centrifugal Pump, 876 GPM, 150 ft. head

$\$ 37,983$

Aerobic Digester Feed Pump

CS. Centrifugal Pump, 830 GPM, 150 ft. head

$\$ 35,651$

Bar Screen

CS. 0.5" Mehc. Cleaned Screen

$\$ 392,551$

Equalization Basin

Anaerobic Digester

Aerobic Lagoon Agitator

Concrete. 377516 Gal. Residence time $7.2 \mathrm{hr}$

Expoxy Lined. 810250 gal each, space velocity $12 \mathrm{~g} / \mathrm{COD} / \mathrm{day}$

$\$ 1,168,809$

$\$ 2,935,620$

CS. Twister Surface Aerators, 50 HP each

$\$ 1,665,920$

Filter Precoat System

Cs. Tank, Agitator, Pump

Aerobic Sludge recycle Pump

Aerobic Sludge Pump

Aerobic Digestion Outlet

Pump

Sludge Filtrate Recycle Pump

Treated Water Pump

Belt Filter Press

Aerobic Digester

Clarifier

SS316. Slurry Pump 2.5 GPM, $150 \mathrm{ft}$. head

$\$ 9,996$

$\$ 36,983$

SS316. Slurry Pump 25.3 GPM, 150 ft. head

$\$ 36,983$

CS. Centrifugal Pump, 828 GPM, 150 ft. head

$\$ 35,651$

CS. Centrifugal Pump, 22 GPM, 150 ft. head

$\$ 20,324$

CS. Centrifugal Pump, 803 GPM, 100 ft. head

$\$ 35,317$

304SS. Filter Press Separator

Polymer Lined Pit. 19500000 gal, 16.3 day residence time.

$\$ 2,166,438$

$\$ 2,116,294$

Concrete. 195,289 gal, residence time $3.9 \mathrm{hr}$

$\$ 581,023$

$\$ 12,039,997$

\subsection{Gas Compression and Separation Subassembly}

The function of the gas compression and separation subassembly is to compress the gaseous outputs from the fermentor to $300 \mathrm{psi}$, separate the product hydrogen from water vapor and $\mathrm{CO}_{2}$, and deliver the hydrogen to the production facility limits. The outlet pressure of hydrogen 
at the plant gate is $300 \mathrm{psi}$. This pressure was selected to provide with a system comparable to other DOE H2A Production Plants. The components of this subassembly in general terms are listed in Figure 21-23.

Figure 21-23. Gas Compression and Separation Components

\begin{tabular}{|l|}
\multicolumn{1}{l}{ Gas Capture Subassembly Components } \\
\hline Fermentor Compressor \\
\hline Fermentor PSA Separator \\
\hline Fermentor Condenser 1 \\
\hline Fermentor Intercooler 1 \\
\hline Fermentor Intercooler 2 \\
\hline Hydrogen Flow Meter \\
\hline
\end{tabular}

The hydrogen $/ \mathrm{CO}_{2} /$ water vapor mixture is at atmospheric pressure and $55^{\circ} \mathrm{C}$ at the outlet from the fermentor:

- $\mathrm{H}_{2} \quad 46,477 \mathrm{~kg} /$ day

- $\mathrm{CO}_{2} \quad 507,340 \mathrm{~kg} /$ day

- $\mathrm{H}_{2} \mathrm{O} 113,542 \mathrm{~kg} /$ day

The gas mixture is initially sent to a condenser to cool the gas to $45^{\circ} \mathrm{C}$ condense about $40 \%$ of the water. This counter-flow gas/water heat exchanger has been scaled from a comparable condenser used in the Ethanol Report.

After the condenser, the gas enters a 2-stage compressor, which compresses the gas to 302 psi. to accommodate pressure losses in the PSA gas separation unit and the pipeline runs, which are estimated as 2 psi. A gas/water intercooler (FIC-1) is used between first and second stage compression to reduce the compressed gas temperature to $45^{\circ} \mathrm{C}$ and to condense additional water. A second intercooler (FIC-2) is used between second stage compression and the PSA to reduce the gas temperature to $45^{\circ} \mathrm{C}$ and to condense additional water. In the condenser and intercoolers, a total of $97 \%$ of the water vapor from the fermentor output is condensed out before the fermentor PSA, with the remaining water vapor mole fraction reduced to 0.00460 . The gas/water intercoolers were scaled from a comparable heat exchanger used in the Ethanol Report. The subassembly components are shown in Figure 21-24. 
Figure 21-24. Gas Compression and Separation Subassembly Design

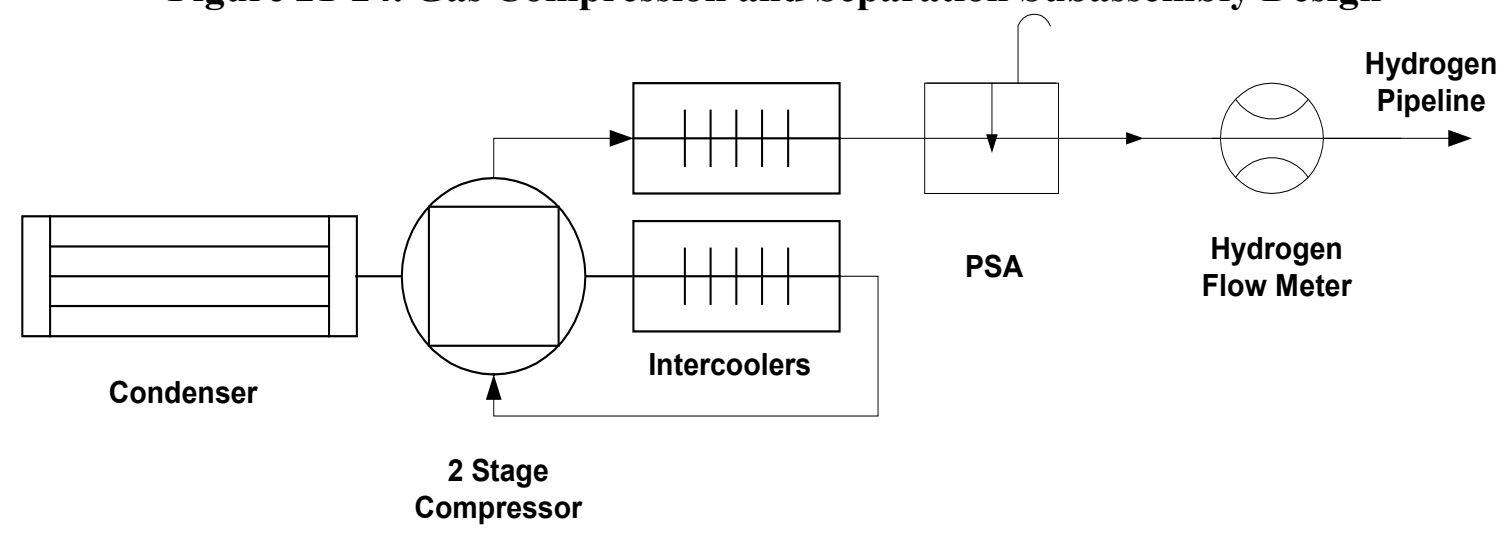

The equipment in Figure 21-24 has been priced previously in several reports. Thus pricing for the equipment was easily located in reference documents and through discussions with suppliers. The capital cost of the subassembly components are shown in Figure 21-25.

Figure 21-25. Capital Cost of Gas Compression and Separation Subassembly

\begin{tabular}{|l|l|c|}
\hline $\begin{array}{l}\text { Gas Compression and } \\
\text { Separation Components }\end{array}$ & Material Chosen & Pricing \\
\hline Compressor & Source: Using H2A Cost guidelines and scaling factors & $\$ 15,729,564$ \\
\hline PSA Separator & Source: Using H2A Cost guidelines and scaling factors & $\$ 1,527,494$ \\
\hline Fermentor Condensor 1 & Shell -Tube, SS304, atmospheric & $\$ 29,623$ \\
\hline Fermentor Intercooler 1 & Shell-Tube, SS304, 4 atmospheres & $\$ 57,651$ \\
\hline Fermentor Intercooler 2 & Shell-Tube, SS304, 20 atmospheres & $\$ 311,057$ \\
\hline Hydrogen Flow Meter & Information from Emerson Process Management & $\$ 5,000$ \\
\hline Total & & $\$ 17,660,889$ \\
\hline
\end{tabular}

\subsection{Bill of Materials}

The flow chart outlining mass flows and subsystem parameters is shown in Figure 21-26. The detailed mass and energy balance data is included in Part III, Appendix A. The full bill of materials for the lignocellulosic hydrogen production plant is shown in Figure 21-27. The system described in this section of the report has a capital cost of $\$ 44,944,078$. 


\section{Figure 21-26. Lignocellulosic Fermentation Flow Chart}

Fermentation System - Batch Process

Efficiencies- Hydrolysis: 90\%, Fermentation: 90\%

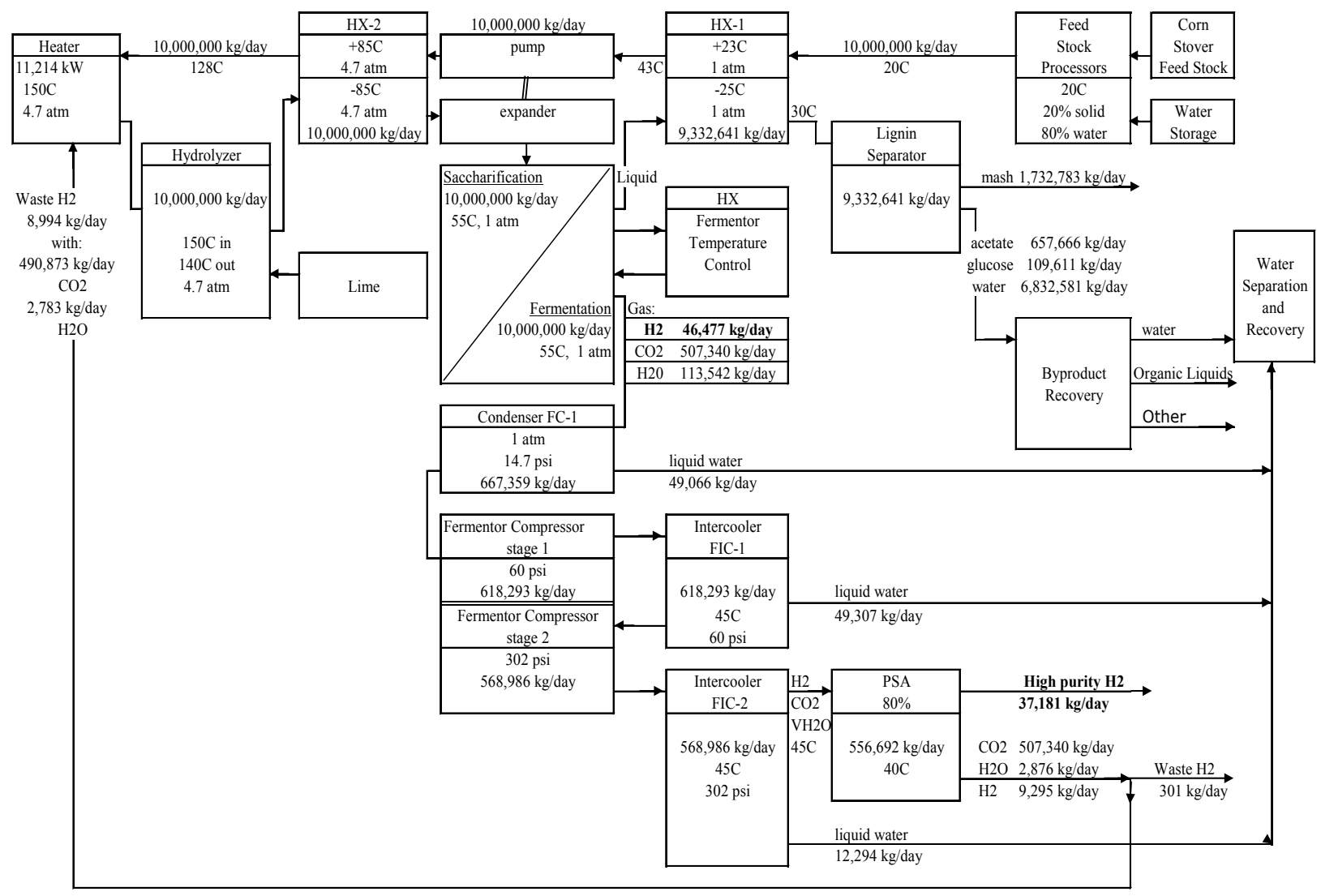


Figure 21-27. Bill of Materials Lignocellulosic Fermentation

\begin{tabular}{|c|c|c|c|c|}
\hline Description & Install Factor & Size Req'd Units & & Unit cost \\
\hline Corn Stover Prep Subassembly & & & & \\
\hline Bale Transport Conveyor & 1.62 & & $\$$ & 400,000 \\
\hline Bale Unwrapping Conveyor & 1.19 & & $\$$ & 150,000 \\
\hline Belt Press Discharge Conveyor & 1.89 & & $\$$ & 50,000 \\
\hline Shredder Feed Conveyor & 1.38 & & $\$$ & 60,000 \\
\hline Truck Scales & 2.47 & & $\$$ & 34,000 \\
\hline Truck Unloading Forklift & 1 & & $\$$ & 18,000 \\
\hline Bale Moving Forklift & 1 & & $\$$ & 18,000 \\
\hline Corn Stover Wash Table & 2.39 & & $\$$ & 104,000 \\
\hline Shredder & 1.38 & & s & 302,000 \\
\hline Concrete Feedstock-Storage Slab & 2.2 & & $\$$ & 450,655 \\
\hline Polymer Feed System & 2.28 & & $\$$ & 30,000 \\
\hline Wash Table Pump & 3.87 & & $\$$ & 20,000 \\
\hline Wash water Pump & 5.19 & & ș & 15,000 \\
\hline $\begin{array}{l}\text { Clarifier Underflow Pump } \\
\text { Clarified Water Pump }\end{array}$ & $\begin{array}{l}13.41 \\
7.07\end{array}$ & & \$ & 6,000 \\
\hline $\begin{array}{l}\text { Clarified Water Pump } \\
\text { Belt Press Sump Pump }\end{array}$ & 2.92 & & s & $\begin{array}{l}15,000 \\
19,000\end{array}$ \\
\hline $\begin{array}{l}\text { Clarifier Thickener } \\
\text { Belt Press }\end{array}$ & 1.51 & & s & 135,000 \\
\hline $\begin{array}{l}\text { Belt Press } \\
\text { Magnetic Separator }\end{array}$ & $\begin{array}{l}1.25 \\
1.3\end{array}$ & & \$ & $\begin{array}{r}100,000 \\
10,335\end{array}$ \\
\hline $\begin{array}{l}\text { Magne Wateparator } \\
\text { Wash Water } \\
\text { Clarifier Thickener Tank }\end{array}$ & $\begin{array}{l}1.3 \\
2.8\end{array}$ & & s & $\begin{array}{l}100,000 \\
50\end{array}$ \\
\hline Clarifier Thickener Tank & 3.04 & & $\$$ & 135,000 \\
\hline Pretreatment/Hydrolysis Subassembly & & & & \\
\hline $\begin{array}{l}\text { Hydrozylate Mix Tank Agitator } \\
\text { Hydrozylate Mixing Tank }\end{array}$ & $\begin{array}{l}1.2 \\
1.2\end{array}$ & & \$ & $\begin{array}{l}28,421 \\
32,237\end{array}$ \\
\hline $\begin{array}{l}\text { In-line Sulfuric Acid Mixer } \\
\text { Sulfuric Acid Pump }\end{array}$ & 18 & & \$ & 2,542 \\
\hline $\begin{array}{l}\text { Sulfuric Acid Pump } \\
\text { Sulfuric Acid Tank }\end{array}$ & $\begin{array}{l}2.8 \\
1.4\end{array}$ & & $\begin{array}{l}\$ \\
\$\end{array}$ & $\begin{array}{l}8,289 \\
9,441\end{array}$ \\
\hline Lime Solids Feeder & 1.3 & & \$ & 3,900 \\
\hline Lime Unloading Blower & 1.4 & & $\$$ & 99,594 \\
\hline Lime Dust Vent Baghouse & 1.5 & & $\$$ & 140,707 \\
\hline Lime Storage Bin & 1.3 & & $\$$ & 136,370 \\
\hline Hydrolysis Tank Pump & 2.8 & & $\$$ & 69,516 \\
\hline Boiler & 1.3 & & $\$$ & 316,000 \\
\hline Fermentation Subassembly & & & & \\
\hline Fermentation Tank & 1.2 & & $\$$ & 493,391 \\
\hline Fermentation Agitator & 1.2 & & $\$$ & 19,676 \\
\hline Fermentation Recirculation Pump & 2.8 & & $\$$ & 13,666 \\
\hline Lignin Wet Cake Screw & 1.4 & & $\$$ & 16,837 \\
\hline Acetate Product Storage Tank & 1.4 & & $\$$ & 160,829 \\
\hline Acetate Transfer Pump & 1.3 & & $\$$ & 53,737 \\
\hline Pneumapress filter & 1.4 & & $\$$ & $1,285,736$ \\
\hline$H X-1$ & 1.3 & & $\$$ & 22,346 \\
\hline$H X-2$ & 1.3 & & $\$$ & 194,618 \\
\hline FTC & 1.3 & & $\$$ & 6,781 \\
\hline Seed Production Subassembly & & & & \\
\hline Seed Hold Tank & 1.2 & & $\$$ & 160,829 \\
\hline Seed Hold Tank Agitator & 1.2 & & $\$$ & 12,492 \\
\hline Seed Hold Transfer Pump & 1.4 & & $\$$ & 22,050 \\
\hline 1st Seed Fermentor & 2.8 & & $\$$ & 14,700 \\
\hline 2nd Seed Fermentor & 2.8 & & $\$$ & 32,600 \\
\hline 3rd Seed Fermentor & 2.8 & & $\$$ & 81,100 \\
\hline 4th Seed Fermentor & 1.2 & & \$ & 39,160 \\
\hline $\begin{array}{l}\text { 5th Seed Fermentor } \\
\text { 4th Seed Agitator }\end{array}$ & 1.2 & & \$ & $\begin{array}{r}146,549 \\
11,645\end{array}$ \\
\hline $\begin{array}{l}\text { 4h Seed Agitator } \\
\text { 5th Seed Agitator }\end{array}$ & $\begin{array}{l}1.2 \\
1.2\end{array}$ & & \$ & $\begin{array}{l}11,645 \\
10,291\end{array}$ \\
\hline $\begin{array}{l}\text { thi Seed Agitator } \\
\text { 4th Seed Fermentor Coil }\end{array}$ & 1.2 & & s & $\begin{array}{r}10,291 \\
4,658\end{array}$ \\
\hline 5th Seed Fermentor Coil & 1.2 & & 象 & 28,238 \\
\hline Seed Transfer Pump & 1.4 & & $\$$ & 53,737 \\
\hline Storage Subassembly & & & & \\
\hline $\begin{array}{l}\text { CSL Storage tank Agitator } \\
\text { CSL Pump }\end{array}$ & $\frac{1.2}{2.8}$ & & & $\begin{array}{l}2,143 \\
6,188\end{array}$ \\
\hline CSL Storage Tank & 1.4 & & & $\begin{array}{l}61,949 \\
28,470\end{array}$ \\
\hline $\begin{array}{l}\text { CSL/DAP Day Tank } \\
\text { CSL/DAP Pump }\end{array}$ & $\frac{1.4}{2.8}$ & & & $\begin{array}{r}28,470 \\
6,188\end{array}$ \\
\hline CSL/DAP Day Tank Agitator & 1.2 & & & 12,348 \\
\hline $\begin{array}{l}\text { DAP Solids Feeder } \\
\text { DAP Unloading Blower }\end{array}$ & $\begin{array}{l}1.3 \\
1.4\end{array}$ & & & $\begin{array}{r}3,900 \\
49,014\end{array}$ \\
\hline DAP Vent Baghouse & 1.5 & & & 9,595 \\
\hline $\begin{array}{l}\text { DAP Storage Bin } \\
\text { Sulfuric Acid Pump }\end{array}$ & $\begin{array}{l}1.3 \\
2.8\end{array}$ & & & $\begin{array}{r}34,255 \\
13,814\end{array}$ \\
\hline $\begin{array}{l}\text { Sulfuric Acid Pump } \\
\text { Sulfuric Acid Storage Tank }\end{array}$ & $\begin{array}{l}2.8 \\
1.2\end{array}$ & & & $\begin{array}{l}13,814 \\
60,470\end{array}$ \\
\hline Propane Storage Tank & 1.4 & & & 30,825 \\
\hline Cooling Water Pump/MEC Pumps & 2.8 & & & 242,216 \\
\hline $\begin{array}{l}\text { Make-up Water Pump } \\
\text { Process Water Circulating Pump }\end{array}$ & 2.8 & & & $\begin{array}{r}8,735 \\
8,818\end{array}$ \\
\hline $\begin{array}{l}\text { Process Water Circulating Pump } \\
\text { Process Water Tank }\end{array}$ & $\begin{array}{l}2.8 \\
1.4\end{array}$ & & & $\begin{array}{r}8,818 \\
168,502\end{array}$ \\
\hline Wastewater Treatment Subassembly & & & & \\
\hline Equalization Basin Agitator & 1.2 & & & 28,400 \\
\hline Anaerobic Agitator & 1.2 & & & 30,300 \\
\hline Anaerobic Digestor Feed Cooler & 2.1 & & & 128,600 \\
\hline Nutrient Feed System & 2.58 & & & 21,400 \\
\hline Biogas Emergency Flare & 1.68 & & & 20,739 \\
\hline Anaerobic Reactor Feed Pump & 2.8 & & & 11,400 \\
\hline Aerobic Digestor Feed Pump & 2.8 & & & 10,700 \\
\hline Bar Screen & 1.2 & & & 117,818 \\
\hline Equalization Basin & 1.42 & & & 350,800 \\
\hline Anaerobic Digestor & 1.04 & & & 881,081 \\
\hline Aerobic Lagoon Agitator & 1.4 & & & 31,250 \\
\hline Filter Precoat System & 1.4 & & & 3,000 \\
\hline Aerobic Sludge Recycle Pump & 1.4 & & & 11,100 \\
\hline Aerobic Sludge Pump & 1.4 & & & 11,100 \\
\hline Aerobic Digestion Outlet Pump & 2.8 & & & 10,700 \\
\hline Sludge Filtrate Recycle Pump & 2.8 & & & 6,100 \\
\hline Treated Water Pump & 2.8 & & & 10,600 \\
\hline Belt Filter Press & 1.8 & & & 650,223 \\
\hline Aerobic Digestor & 1 & & & 635,173 \\
\hline Clarifier & 1.96 & & & 174,385 \\
\hline & & & & \\
\hline $\begin{array}{l}\text { Compressor Fermentor } \\
\text { FC-1 }\end{array}$ & & $1704 \mathrm{kgmol} / \mathrm{hr}$ & \$ & $\begin{array}{r}9,233 \\
29,623\end{array}$ \\
\hline $\begin{array}{l}\text { FC-1 } \\
\text { FIC }-1\end{array}$ & 1.3 & & s & $\begin{array}{r}59,623 \\
31,651\end{array}$ \\
\hline PSA Fermentor & 1.3 & & s & 311,057 \\
\hline Hydrogen Flow Meter & 1.3 & & $\$$ & 5,500 \\
\hline
\end{tabular}




\section{Microbial Electrolyis Cell (MEC) Hydrogen Production}

A Microbial Electrolysis Cell (MEC), also referred to as a Bio-Electrochemically Assisted Microbial Reactor (BEAMR) can be used to generate $\mathrm{H}_{2}$ from simple organic liquids, such as acetic acid and ethanol, using electrolysis enhanced by a microbial reaction at the anode. The $\mathrm{H}_{2}$ gas is evolved at the cathode and $\mathrm{CO}_{2}$ gas is evolved at the anode.

In this section we will consider the MEC as a stand-alone hydrogen production unit, with a purchased acetic acid feedstock. Integration of the MEC system with the fermentation system to utilize the fermentator byproducts will be discussed in a later section.

\subsection{Theoretical Reaction and Assumptions}

Assuming an acetic acid input and MEC electrode voltages above 0.4 Volts, a complete reaction in the MEC would be:

\section{$\mathrm{C}_{2} \mathrm{H}_{4} \mathrm{O}_{2}+2 \mathrm{H}_{2} \mathrm{O}=>4 \mathrm{H}_{2}+2 \mathrm{CO}_{2}$}

The MEC process has been extensively researched and demonstrated at Penn State University. Output from a MEC using an acetic acid feedstock has been demonstrated in lab-scale tests to be as high as $96 \% \pm 1 \%{ }^{89}$. With $95 \%$ reacted into $\mathrm{H}_{2}$ and $\mathrm{CO}_{2}, 3.8$ moles $\mathrm{H}_{2}$ is generated per mole acetic acid. For this reaction, the input acetic acid was diluted with water to 1 gram per liter. For our calculations we assumed an average of $90 \%$ efficiency due to scale-up losses and anode/cathode degredation. This leads to an estimated acetic acid to hydrogen conversion ratio of $12.08 \%$ (gram $\mathrm{H}_{2} /$ gram acetic acid).

The following major MEC assumptions are used in the analysis:

- Both the anode and cathode materials are low cost and sufficiently durable for long-term operation (20 years)

- External electrical power will be provided to sustain the reactions.

- The volume of acetic acid feedstock chosen for use was chosen based on the amount of acetic acid and glucose that would be used in an integrated system utilizing the fermentation effluent

- The cost of the acetic acid feedstock is $\$ 0.595 / \mathrm{kg}$ based on the international market price as reported by the Korean Chemical Journal ${ }^{90}$

\subsection{MEC Operating Parameters}

For this study the baseline MEC system was sized so that it could be integrated with the fermentation system described in the previous section. The baseline conditions that have been used for MEC hydrogen production using an acetic acid feedstock are summarized in Figure 22-1.

\footnotetext{
89 Call, Douglas and Logan, Bruce, "Hydrogen Production in a single Chamber Microbial Electrolysis Cell Lacking a Membrane.” Environmental Scientific Technology 42 (2008): 3401-3406.

90 Lee, Sang Yup. "Plastic Bacteria? Progress and Prospects for Polyhydroxyalkanoate Production in Bacteria." Trends in Biotechnology 14 (1996): 431-438.
} 
Figure 22-1. Parameters for MEC System

\begin{tabular}{|c|c|}
\hline \multicolumn{2}{|c|}{ MEC (0.9V) } \\
\hline Acetic Acid Usage (kg/day) & 767,277 \\
\hline $\mathrm{H}_{2}$ Production Rate $\left(\mathrm{kgH}_{2} /\right.$ day $)$ & $88,085^{91}$ \\
\hline Plant Area (Acres) & 10 \\
\hline $\begin{array}{l}\text { Land Utilization }\left(\mathrm{kg} \mathrm{H}_{2} / \mathrm{acre} /\right. \\
\text { year) }\end{array}$ & $2,788,553$ \\
\hline 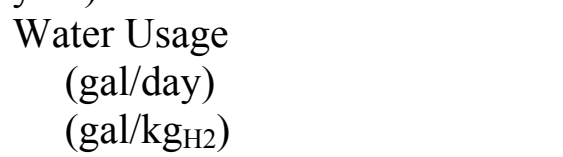 & $\begin{array}{l}9,242,555 \\
105\end{array}$ \\
\hline $\begin{array}{l}\text { Electricity Required } \\
\mathrm{kWhr} / \text { day } \\
\mathrm{kWh} / \mathrm{kgH}_{2} \\
\mathrm{kWh} / \mathrm{kWh} \mathrm{H}_{2}\end{array}$ & $\begin{array}{l}3,288,962 \\
37.34 \\
1.12\end{array}$ \\
\hline \multicolumn{2}{|c|}{ MEC Parameters } \\
\hline Bacteria Cell lines (anode) & $\begin{array}{l}\text { Pseudomonas spp. And Shewanella } \\
\text { spp. }^{92}\end{array}$ \\
\hline Duration of Cycle (hrs) & 24 \\
\hline Target Temperature $\left({ }^{\circ} \mathrm{C}\right)$ & 30 \\
\hline Assumed Reaction Efficiency & $90 \%$ \\
\hline $\begin{array}{l}\text { Feedstock - to }-\mathrm{H}_{2} \text { Conversion } \\
\text { Ratio }\end{array}$ & \\
\hline $\begin{array}{l}\text { gram } \mathrm{H}_{2} / \text { gram acetic acid } \\
\text { Reactant Volume }\end{array}$ & $12.08 \%$ \\
\hline Gallons & $91,524,080$ \\
\hline $\begin{array}{l}\text { Liters } \\
\text { Reactor Volume }{ }^{93}\end{array}$ & $346,682,121$ \\
\hline Gallons & $96,100,285$ \\
\hline Liters & $364,016,227$ \\
\hline Theoretical Product Ratio & $\begin{array}{l}4 \mathrm{~mol} \mathrm{H}_{2} \\
2 \mathrm{~mol} \mathrm{CO}_{2}\end{array}$ \\
\hline Assumed Actual Product Ratio & $\begin{array}{l}3.6 \mathrm{~mol} \mathrm{H}_{2} \\
1.8 \mathrm{~mol} \mathrm{CO}_{2}\end{array}$ \\
\hline
\end{tabular}

${ }^{91}$ Assumes $95 \% \mathrm{H}_{2}$ recovery in the PSA.

92 Logan, Bruce et al. "Microbial Enectorlysis Cells for High Yield Hydrogen Gas Production from Organic Matter." Environmental Scientific Technology 42 (2008): 8630-8640.

${ }^{93}$ Including electrode volume and spare capacity of 5\% 


\subsection{MEC System Description}

The MEC hydrogen production plant has been divided into 3 interconnected subassemblies, namely,

- MEC Subassembly,

- Storage Subassembly, and

- Gas Compression and Separation Subassembly

\subsubsection{MEC Plant Layout}

The interfaces between the subassemblies are shown in Figure 22-2. The subassemblies have several components that will be identified in later sections of this document.

Figure 22-2. Simplified MEC Hydrogen Production Unit

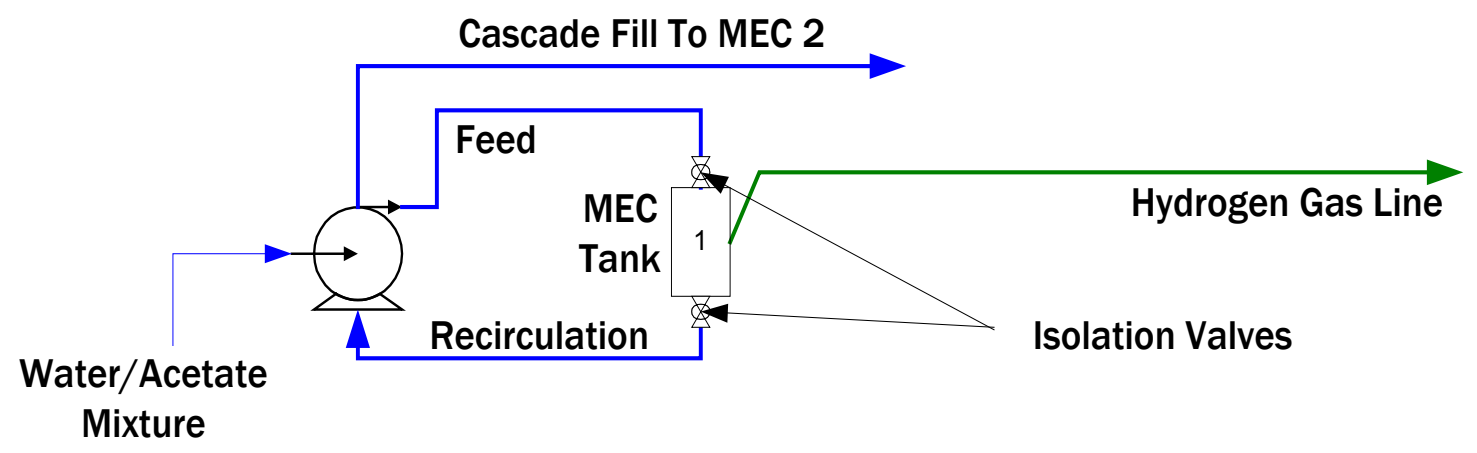

For the hydrogen production rate shown in the previous section, a large number of units, each comprised of a million gallon reactant tank and electrodes, are necessary. Residence time in the reactor at $0.9 \mathrm{~V}$ potential is 24 hours per electrolysis cycle. Each reactant tank can be operated in a semi-continuous process, with daily replenishment of acetate and water. With the MEC system designed to consume $690,549 \mathrm{~kg}$ acetate and 414,314 $\mathrm{kg}$ water per day, these amounts will be replenished daily. Periodically, after an appropriate number of cycles, a tank would be emptied, cleaned and replenished with new electrolyte, and also anode organisms if necessary. A representative tank field layout is shown inFigure 22-3. 
Figure 22-3. MEC Unit Field Layout

Water From Storage

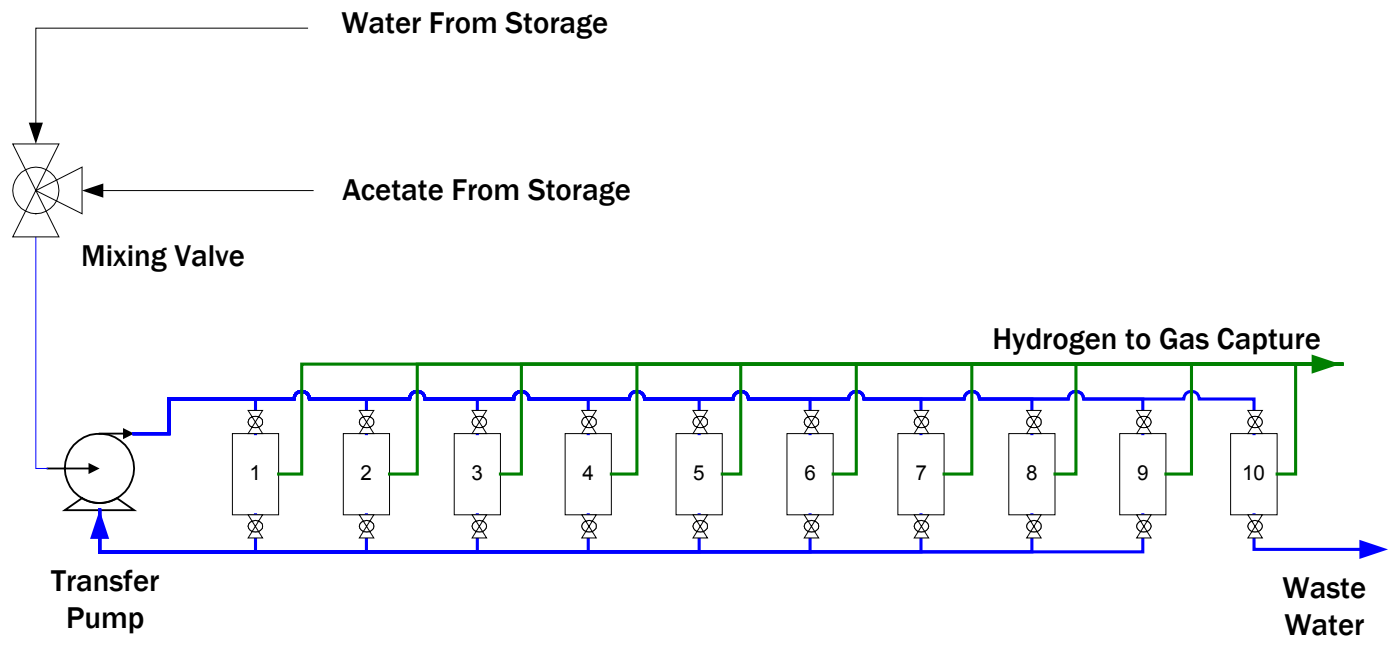

MEC Bank

10 MEC and 1 Transfer Pump

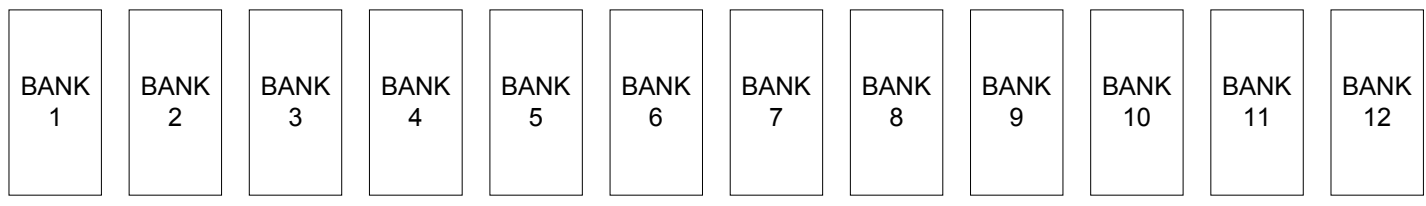

MEC Module $=\sim 12$ MEC Banks

\subsubsection{MEC Reactor Subassembly}

As mentioned, to generate $\mathrm{H}_{2}$ from acetic acid or from the acetic acid, succinic acid, lactic acid, formic acid, glucose, and alcohol liquid byproducts of a fermentation reaction, a Microbial Electrolysis Cell (MEC) also referred to as a Bio-Electrochemically Assisted Microbial Reactor (BEAMR), can be used to electrolyze the mix of organic materials and water to produce hydrogen.

Ordinarily, a water electrolysis unit requires about $1.8 \mathrm{~V}$ to electrolyze water. The MEC uses microbe reactions at the anode with the organic materials, and water to generate a significant voltage. This is supplemented with an externally applied anode-to-cathode voltage to initiate and sustain an electrolysis process to generate $\mathrm{H}_{2}$ and $\mathrm{CO}_{2}$ from the organics and water. The current generated provides the electrons to produce $\mathrm{H}_{2}$ at the cathode, with $\mathrm{CO}_{2}$ produced at the anode. The microbes on the anode develop sufficient voltage such that the additional potential needed for the electrolysis of organic byproduct is only $0.2-0.9 \mathrm{~V}$.

With acetic acid input, a complete redox reaction in the MEC would be:

$$
\mathrm{C}_{2} \mathrm{H}_{4} \mathrm{O}_{2}+2 \mathrm{H}_{2} \mathrm{O}=>4 \mathrm{H}_{2}+2 \mathrm{CO}_{2}
$$


The components of the subassembly in general terms are listed in Figure 22-4.

Figure 22-4. MEC Components

\begin{tabular}{|l|}
\multicolumn{1}{|c|}{ MIEC Subassembly Components } \\
\hline MEC Tank \\
\hline Cathode \\
\hline Anode \\
\hline Power Supply \\
\hline Process Water Circulating Pump \\
\hline MEC Transfer Pumps \\
\hline MEC Intercooler 1 \\
\hline MEC Intercooler 2 \\
\hline
\end{tabular}

\subsubsection{MEC Cell Description}

A representative MEC reactor cell is shown in Figure 22-5. Though the cell is shown with a PEM membrane, it can be operated without one, resulting in a small amount of gas dilution.

Figure 22-5. MEC Cell

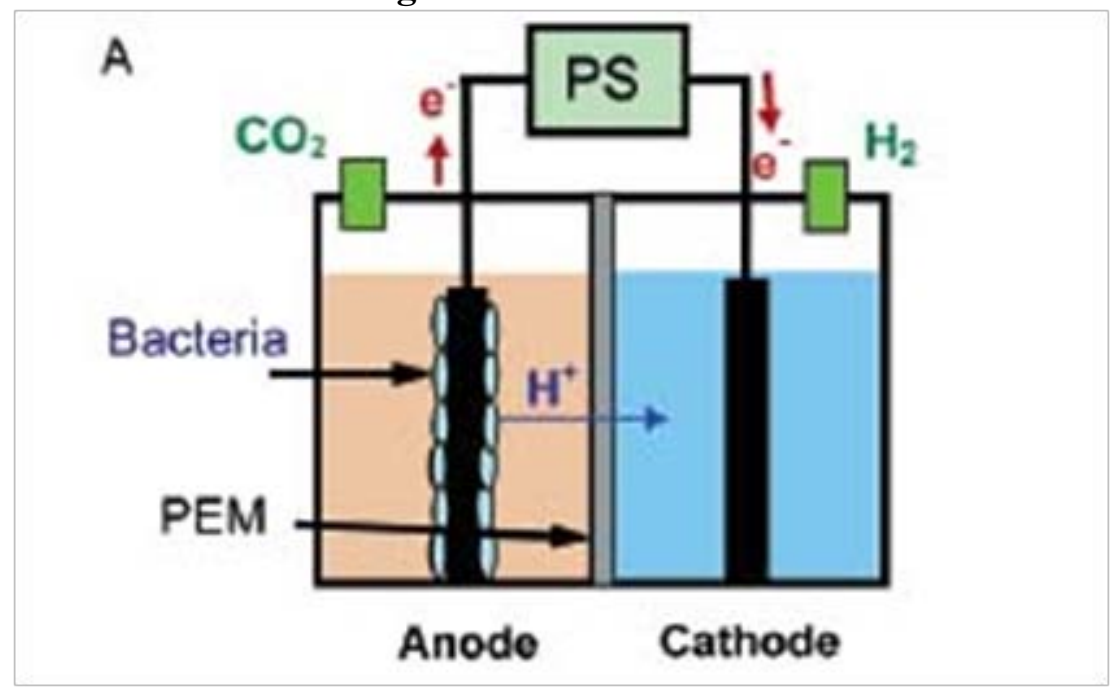

Tests have been run by PSU with a high surface area brush anode (brush fiber surface area/brush envelope volume $=18,200 \mathrm{~m}^{2} / \mathrm{m}^{3}$ ) and a cathode made from carbon cloth loaded at $0.5 \mathrm{mg} / \mathrm{cm}^{2} \mathrm{Pt}^{94}$. Data from these tests in Figure 22-5 shows the linear relationship between $\mathrm{H}_{2}$ output $\mathrm{Q}\left(\mathrm{m}^{3}\right.$-hydrogen per day $\left./ \mathrm{m}^{3} \mathrm{MEC}\right)$ as a factor of applied voltage with $\mathrm{Q}=0$ at $\mathrm{V}=0.2$. The figure also shows energy efficiency increasing with decreasing voltage. However, at lower voltage, the reaction is slower and system size increases substantially. These tests run without a membrane provided good separation of the $\mathrm{H}_{2}$ and $\mathrm{CO}_{2}$.

94 Call Douglas and Bruce E. Logan. "Hydrogen Production in a single Chamber Microbial Electrolysis Cell Lacking a Membrane.” Environmental Scientific Technology 42 (2008): 3401-3406. 


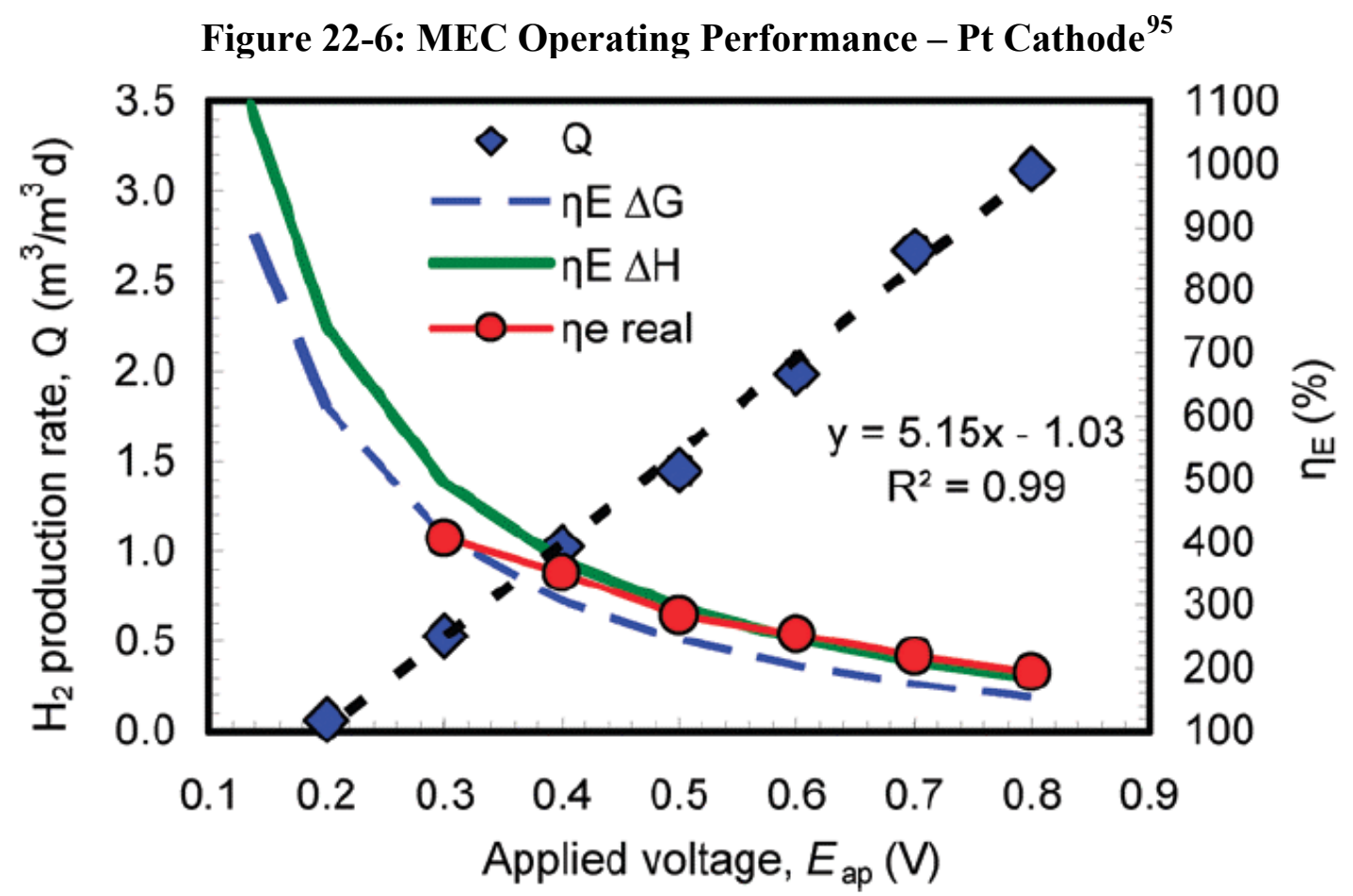

Because of the high cost of Pt cathodes, additional research has been carried out by PSU, substituting a stainless steel brush for the carbon/Pt cathode ${ }^{96}$. With a very high surface area brush cathode, the $\mathrm{H}_{2}$ production rate was only slightly less than with the Pt loaded cathode. These tests demonstrated a $\mathrm{Q}$ of 1.7 at a voltage of $0.6 \mathrm{~V}$. Assuming that the $\mathrm{Q}$ vs. $\mathrm{V}$ relationship for the brush cathode is also linear with a zero output at $0.2 \mathrm{~V}$, a line for the cell output through Q of 1.7 and $\mathrm{V}$ of 0.6 can be superimposed on Figure 22-6. The resulting performance line is the solid blue line labeled "brush cathode" in Figure 22-7. The equation for the Pt Cathode Q is:

$$
\mathrm{Q}=5.15 \mathrm{~V}-1.03
$$

And the similar equation for the Brush Cathode (the solid blue line in Figure 22-7) is:

$$
\mathrm{Q}=4.25 \mathrm{~V}-0.85
$$

\footnotetext{
95 Logan, Bruce et al. "Microbial Electrolysis Cells for High Yield Hydrogen Gas Production from Organic Matter." Environmental Scientific Technology 42 (2008): 8630-8640.

96 Call, Douglas et al. "High Surface Area Stainless Steel Brushes as Cathodes in Microbial Electrolysis Cells." Environmental Scientific Technology (2008)
} 
Figure 22-7. MEC Operating Performance - Brush Cathode

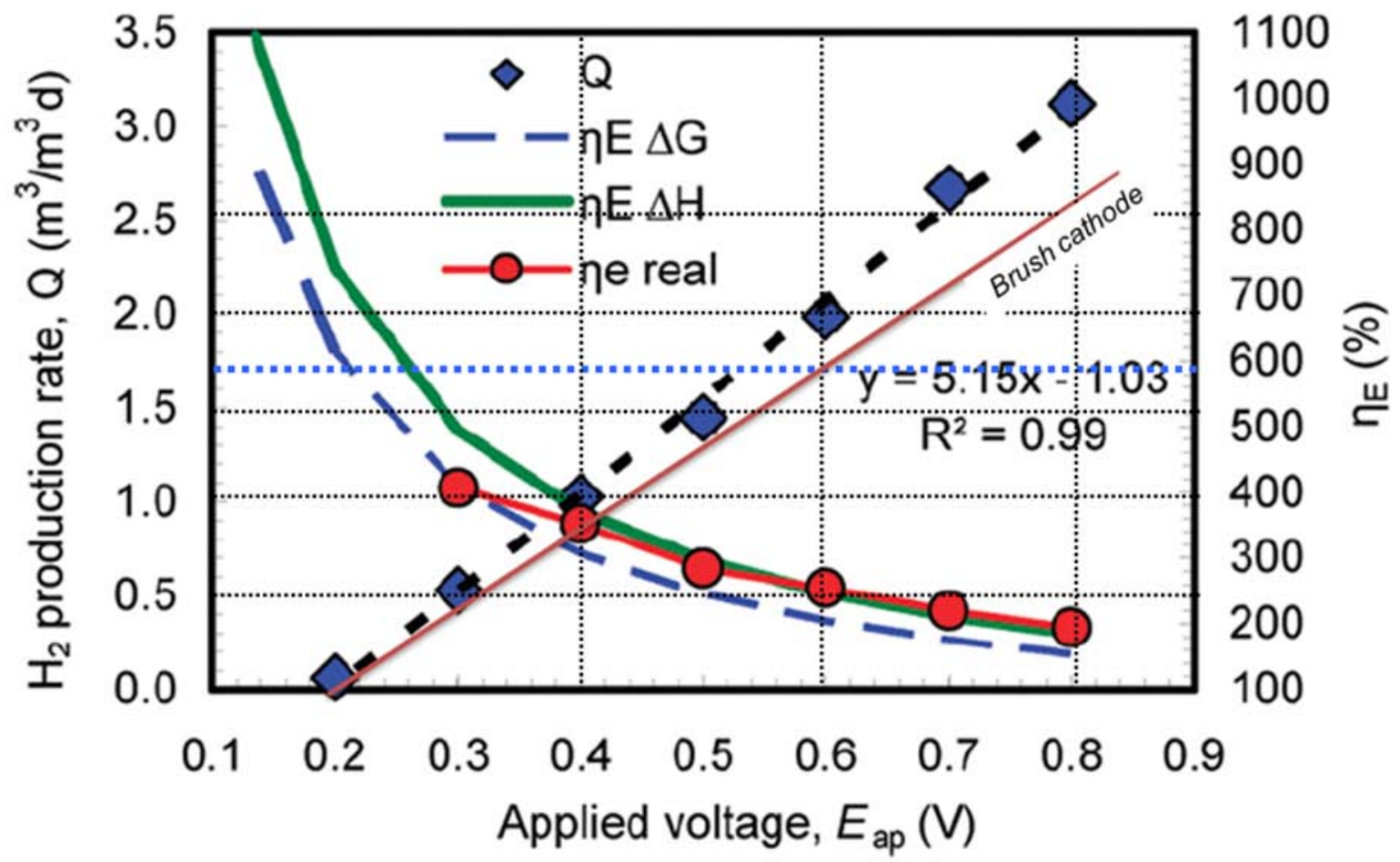

The conclusion drawn from these performance graphs is that while a low voltage is more efficient from a power consumption standpoint, a high voltage results in a markedly smaller MEC volume for a given volume of $\mathrm{H}_{2}$ product, thus reducing capital costs significantly.

\subsubsection{MEC Hydrogen Production Cost Optimization}

MEC capital costs decrease with increased voltage, due to higher production rate. However, electrical costs increase with voltage. Thus, higher electrical costs go along with lower tank and electrode costs. These costs were modeled as a function of voltage to examine the minimum $\mathrm{H}_{2}$ cost design for the MEC. The five primary $\mathrm{H}_{2}$ production cost components are:

- MEC Tank

- Brush Cathode

- Brush Anode ${ }^{97}$,

- Power Supply, and

- Electric Power

Figure 22-8 plots the cumulative $\mathrm{H}_{2}$ production cost buildup from these five components. We used component sizing methodology used by PSU. The most dominant factor was the cost of stainless steel brush wires (based on SS wire costs from various suppliers). Though we looked at wire diameters down at $0.02 \mathrm{~mm}$, the best cost-to-surface-area ratio was with $0.08 \mathrm{~mm}$ wire. To reduce brush costs, we reduced the surface area required by a factor of 2 relative to the

\footnotetext{
${ }^{97}$ Logan, Bruce et al. "Graphite Fiber Brush Anodes for Increased Power Production in Air Cathode Microbial Fuel Cells.” Environmental Scientific Technology (2007)
} 
brushes used in the PSU tests, per the suggestion of Bruce Logan who pointed out that the brush size is not yet optimized.

The results shown in Figure 22-8 indicate that $0.9 \mathrm{~V}$ achieves the lowest cost. We therefore used this point in our cost analyses.

Figure 22-8. MEC Cost Optimization

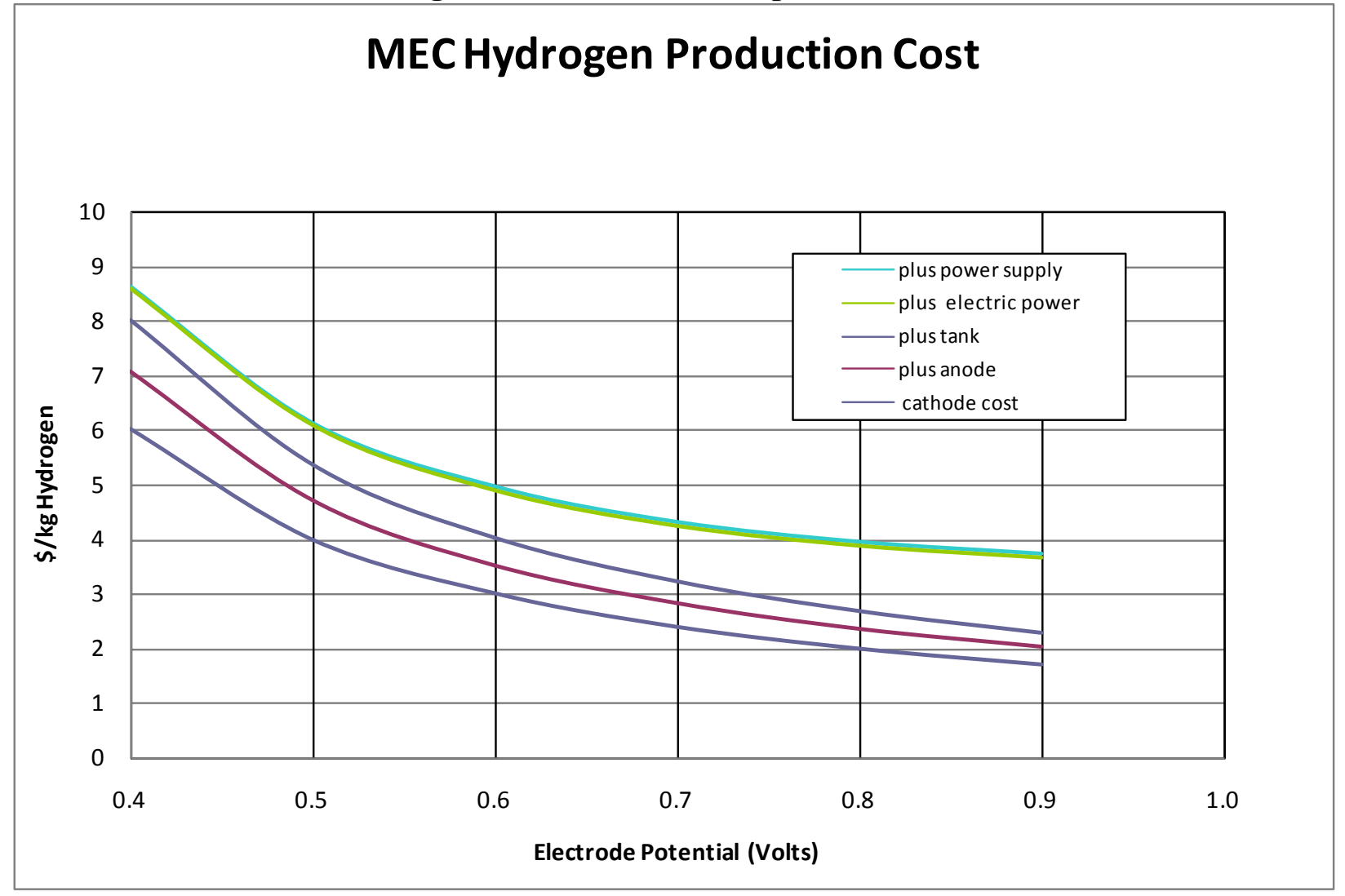

\subsubsection{MEC Brush Cathode}

For the brush cathode, the ratio of its surface area to the brush envelope volume, $\mathrm{S} / \mathrm{Ve}$, was approximately $2500 \mathrm{~m}^{2} / \mathrm{m}^{3}$. For the PSU test cells, the ratio of brush cathode surface area to the reactor volume, $\mathrm{S} / \mathrm{Vr}$, was between 650 and $810 \mathrm{~m}^{2} / \mathrm{m}^{3}$. A top view of the MEC cell with a half-brush anode and half-brush cathode which gave the best performance is shown in Figure 22-9. The brushes are semicircular to improve the packing density and reduce the ion transport distance relative to circular brushes. 
Figure 22-9: MEC Test Unit Top view with Half-Brush Cathode and Anode

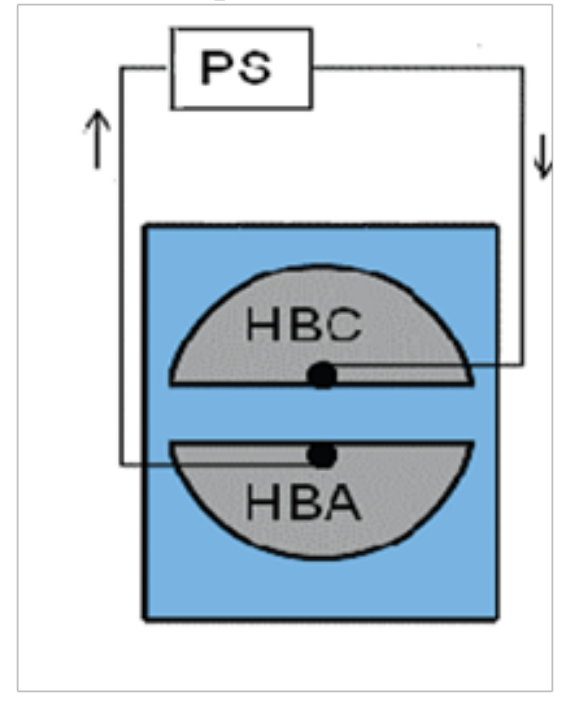

For the MEC design and costing analysis, carbon fiber brush anodes and 304 stainless steel brush cathodes as discussed in the references were assumed. Cell performance was based on the test results but reduced from $95 \%$ to $90 \%$ to account for scale-up losses and brush degradation. The specific brush sizes used in the PSU tests were laboratory scale (1 inch length by 0.5 inch radius) and are obviously not appropriate for large-scale production cells. For this analysis, the surface area ratio used was reduced to half of that used in the small scale tests. Using this ratio for a large system the materials requirements are quite substantial, and effort will have to be dedicated in the future to designing lower cost high effective area cathodes and anodes amenable to a large scale system.

In addition, to reduce costs, the cells were operated without an ion exchange membrane. Potential future developments future for a scaled-up MEC system would include:

- reduced reactor volume per hydrogen generation, increased reactant concentration

- lower cost cathodes

- additional bacteria-generated voltage

- minimized $\mathrm{CH} 4$ output

- optimized solution electrolyte \& conductivity

- addressal of long term corrosion issues

- cathode and anode scale-up for large cells

\subsubsection{Total Hydrogen Production Cost}

The system size was chosen to be compatible with the fermentation system output reactable organic liquids. For the stand-alone MEC, a similar mass flow of acetate was substituted for the output organic liquid mass flow of the fermentor. Thus, the feedstock reacted for the standalone MEC was:

- Acetic Acid: 767,277 kg/day (12,788 moles/day) 
For the overall system layout, the output $\mathrm{H}_{2}$ gas from the multiple MEC units feed a manifold that feeds a single gas compression and separation subassembly, discussed in the following section.

For this effluent, the capital cost of the subassembly is $\$ 541,705,673$ as shown in Figure $22-10$.

Figure 22-10. Capital Costs of MEC Subassembly

\begin{tabular}{lcr}
\multicolumn{1}{c}{$\begin{array}{c}\text { Seed Production } \\
\text { Components }\end{array}$} & Material Chosen & Total Pricing \\
\hline MEC Tanks & $\begin{array}{c}\text { SS304. 962,651 gal. each, 7 day residence } \\
\text { total, } 90 \% \mathrm{wV} \text {, API, atmospheric }\end{array}$ & $\$ 57,488,911$ \\
Brush Cathode & $0.08 \mathrm{~mm} \mathrm{SS316} \mathrm{Wire}$ & $\$ 400,686,098$ \\
Brush Anode & $0.0072 \mathrm{~mm}$ Carbon Threads & $\$ 62,316,288$ \\
Power Supply & Based on Electrolyzer Power Supply, & $\$ 18,550,000$ \\
& Scaled for 122,184 kW & $\$ 2,906,592$ \\
MEC Transfer Pumps & CS. 41000 gpm, 70 ft head. & $\$ 541,705,673$
\end{tabular}

\subsubsection{Storage Subassembly}

The storage subassembly for the MEC system is substantially smaller than for the fermentation system. The only storage needed is for the acetate feedstock and process water. The components of this subassembly in general terms are listed in Figure 22-11 and shown in Figure 22-12.

Figure 22-11. Storage Components

\section{Storage Subassembly Components}

Acetate Storage Tank

Acetate Transfer Pump

Process Water Circulating Pump

Process Water Tank

Process Water Transfer Pump 
Figure 22-12. Storage Subassembly Design
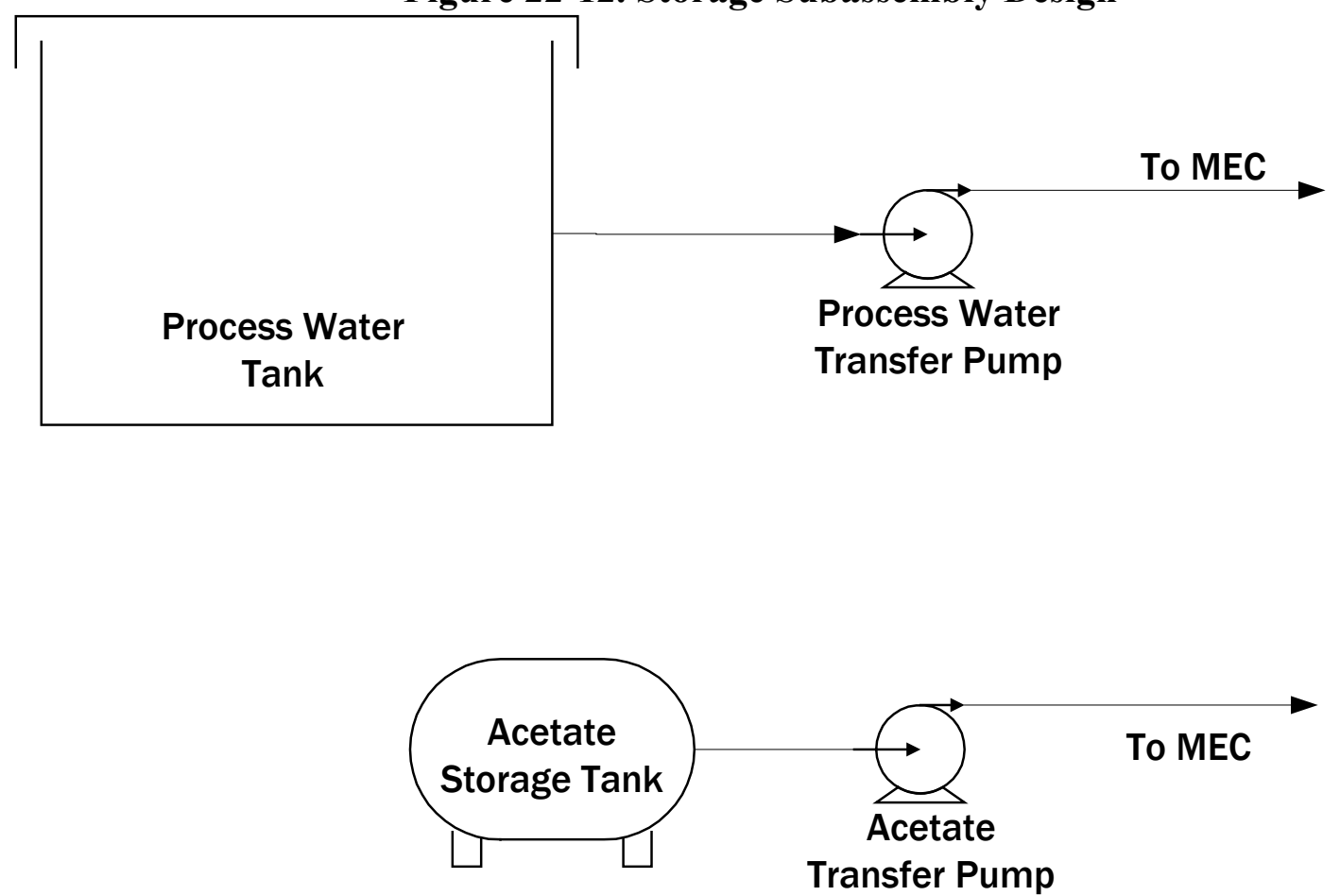

The equipment in Figure 22-12 is all very commonly available within the agricultural industry. Thus pricing for the equipment was easily located in reference documents and through discussions with suppliers. The capital cost of the subassembly is $\$ 884,167$ as shown in Figure 22-13.

Figure 22-13. Capital Costs of Storage Subassembly

\section{Storage Components}

Acetate Storage Tank

Acetate Transfer Pump

Process Water Circulating Pump

Process Water Tank

Process Water Transfer Pump

TOTAL

\section{Material Chosen} SS316. 18697 gal, 90\% wv, 12' dia x 22'

high, atmospheric

SS316. $215 \mathrm{gpm}, 150 \mathrm{ft}$ head

CS. 1199 gpm ea, 75 ft. head

CS. 756000 gal. $8 \mathrm{hr}$ res time

CS. 41000 gpm, $70 \mathrm{ft}$ head.
$\$ 35,270$

\section{Total Pricing}

$\$ 391,000$

$\$ 161,593$

$\$ 54,088$

$\$ 242,216$

$\$ 884,167$

\subsubsection{Gas Compression and Separation Subassembly}

The function of gas compression and separation subassembly of the MEC is to compress the gaseous outputs from the MEC, to separate the product hydrogen, and to deliver it to the production facility limits at $300 \mathrm{psi}$. The components of this subassembly in general terms are listed in Figure 22-14. 


\section{Figure 22-14. Gas Compression and Separation Components}

\begin{tabular}{|l|}
\multicolumn{1}{|c|}{ Gas Capture Subassembly Components } \\
\hline MEC Compressor (2 stage) \\
\hline MEC PSA \\
\hline MEC Compressor Intercooler 1 \\
\hline MEC Compressor Intercooler 2 \\
\hline Hydrogen Flow Meter \\
\hline
\end{tabular}

The outlet pressure of hydrogen at the plant gate of 300 psi was selected to provide with a system comparable to other DOE H2A Production Plants.

At the MEC hydrogen outlet, the gas is at atmospheric pressure and $30^{\circ} \mathrm{C}$. Since the temperature is only $30^{\circ} \mathrm{C}$, there is a substantially lower mole fraction of water than is in the outlet gas from the fermentor, so no condenser is needed. In addition, the MEC electrolysis process separates most of the hydrogen from the $\mathrm{CO}_{2}$. It is estimated that only $5 \%$ of the MECproduced $\mathrm{CO}_{2}$ is mixed in the output hydrogen stream. The MEC-exit stream into the compressor is:
- $\mathrm{H}_{2} \quad 92,721 \mathrm{~kg} /$ day
- $\mathrm{CO}_{2} \quad 50,607 \mathrm{~kg} /$ day
- $\mathrm{H}_{2} \mathrm{O} \quad 36,752 \mathrm{~kg} /$ day

The gas mixture is sent to the 2-stage compressor. After the compressor and two intercoolers, the remaining gas mixture at 302 psi enters the PSA. Pressure loss in the PSA and the pipeline is estimated as 2 psi. A gas/water intercooler (MIC-1) is used between first and second stage compression to reduce the gas temperature to $45^{\circ} \mathrm{C}$ and to condense out water. A second intercooler (MIC-2) is used between second stage compression and the PSA to reduce the gas temperature to $45^{\circ} \mathrm{C}$ and to condense additional water, so that a total of $89 \%$ of the water vapor from the MEC output is removed before the MEC PSA., with the remaining water vapor mole fraction reduced to 0.00460 . The gas/water intercoolers were scaled from a comparable heat exchanger used in the Ethanol Report.

Since the PSA input is 1,914 moles $/ \mathrm{hr} \mathrm{H}_{2}, 48$ moles $/ \mathrm{hr} \mathrm{CO}_{2}$, and 9 moles $/ \mathrm{hr}_{2} \mathrm{O}$, we have assumed that the PSA can recover $95 \%$ of the inlet $\mathrm{H}_{2}$. Thus the PSA output is:

- $\mathrm{H}_{2}$ (high purity) $88,085 \mathrm{~kg} /$ day

- Waste:

$$
\begin{array}{lll}
\circ & \mathrm{CO}_{2} & 50,607 \mathrm{~kg} / \text { day } \\
\circ & \mathrm{H}_{2} \mathrm{O} & 3,921 \mathrm{~kg} / \text { day } \\
\circ & \mathrm{H}_{2} \text { (loss) } & 4,636 \mathrm{~kg} / \text { day }
\end{array}
$$

Subassembly components are shown in Figure 22-15. 
Figure 22-15. Gas Compression and Separation Subassembly Design

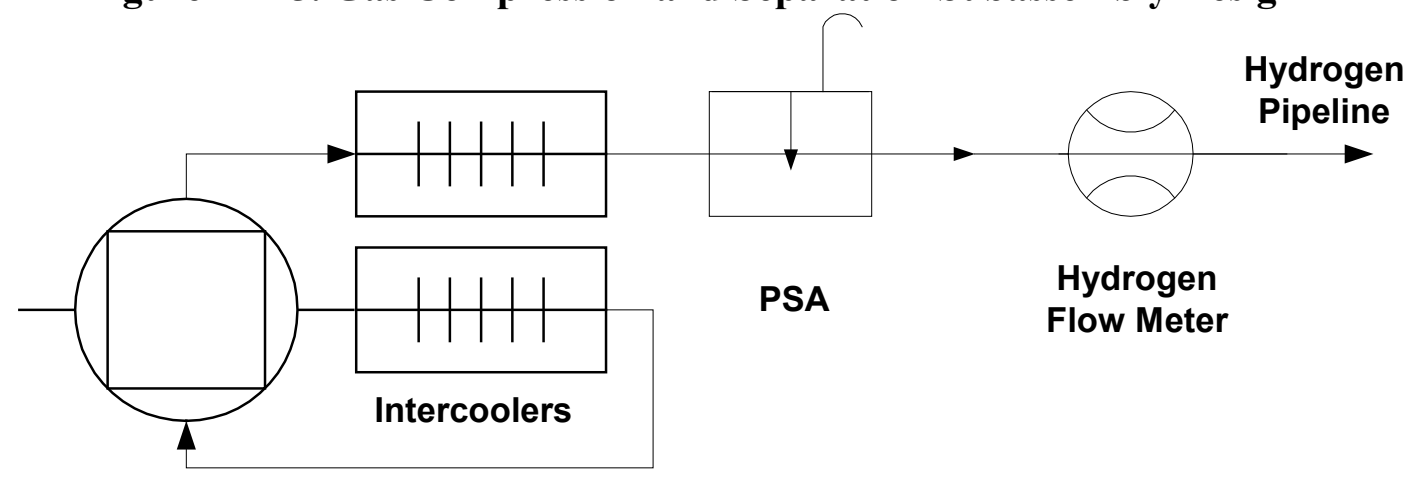

\section{Stage}

Compressor

Gas compression and separation is has been priced previously in several reports. Thus pricing for the equipment was easily located in reference documents and through discussions with suppliers. The capital cost of the subassembly components is $\$ 16,099,326$ as shown in Figure 22-16.

Figure 22-16. Capital Cost of Gas Compression and Separation Subassembly

\begin{tabular}{llc}
\multicolumn{1}{c}{$\begin{array}{c}\text { Gas Compression and } \\
\text { Separation Components }\end{array}$} & \multicolumn{1}{c}{ Material Chosen } & Pricing \\
\hline Compressor & $\begin{array}{l}\text { Source: Using H2A Cost guidelines } \\
\text { and scaling factors }\end{array}$ & $\$ 15,267,690$ \\
\hline PSA & Pressure Swing Adsorption & $\$ 182,960$ \\
& Source: Using H2A Cost guidelines and scaling factors \\
\hline MEC Intercooler 1 & Shell-Tube, SS304, 4 atmospheres & $\$ 88,542$ \\
\hline MEC Intercooler 2 & Shell-Tube, SS304, 20 atmospheres & $\$ 554,634$ \\
\hline Hydrogen Flow Meter & $\begin{array}{l}\text { Information from Emerson Process } \\
\text { Management }\end{array}$ & $\$ 5,500$ \\
\hline Total & & $\$ 16,099,326$
\end{tabular}

\subsection{Bill of Materials}

The flow chart outlining mass flows and subsystem parameters is shown in Figure 22-17. The detailed mass and energy balance is included in Part III, Appendix B. 
Figure 22-17. MEC System Flow Chart

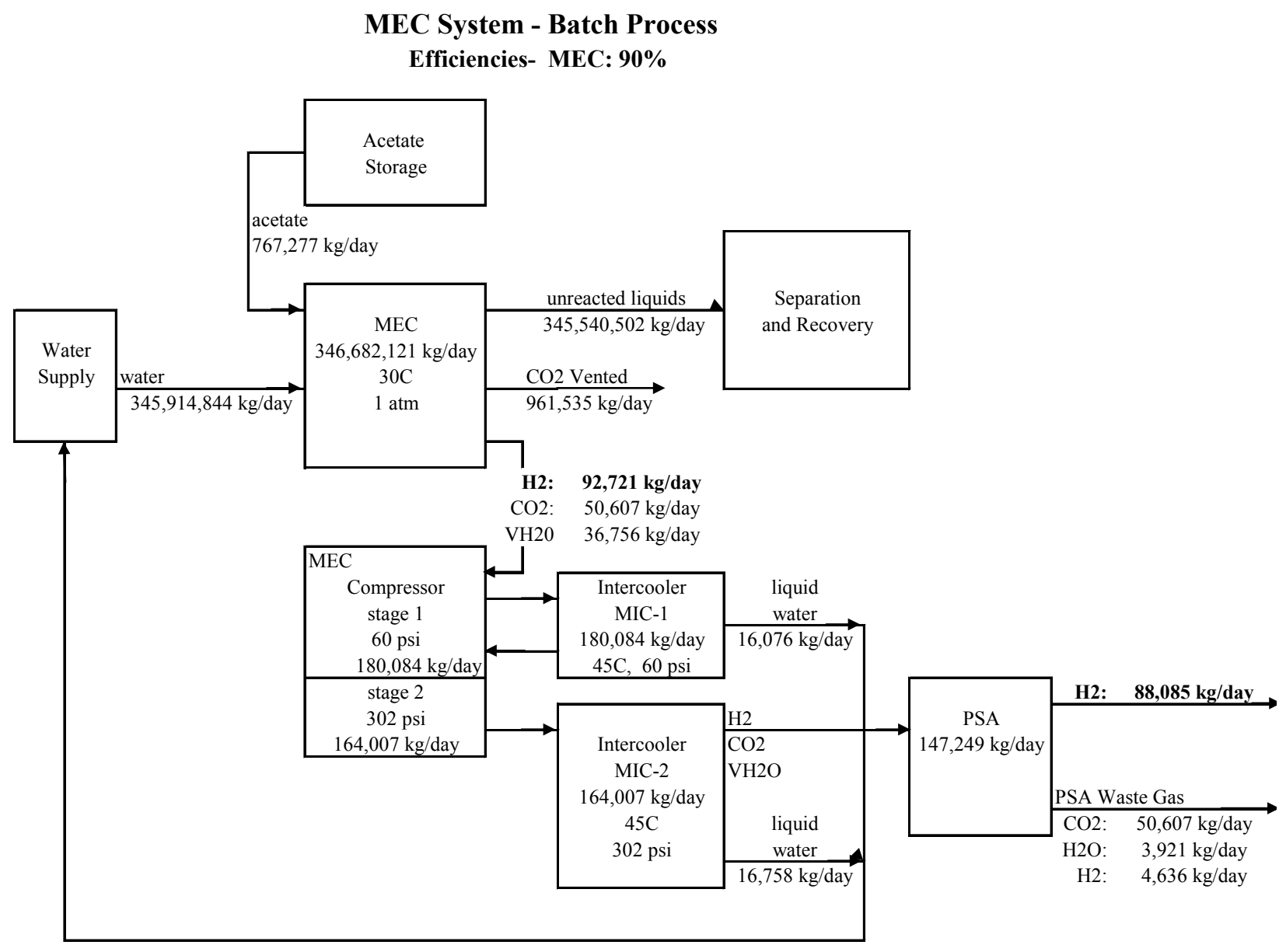

The full bill of materials for the MEC stand-alone hydrogen production plant is shown in Figure 22-18. The MEC system described in this section of the report has a capital cost of $\$ 558,689,165$.

Figure 22-18. MEC Stand-Alone Bill of Materials

\begin{tabular}{|c|c|c|c|c|c|c|c|c|}
\hline Description & Install Factor & Size Reg'd & Unit Size & Units & & Unit cost & Qty Req'd & Total Cost \\
\hline \multicolumn{9}{|l|}{ MEC Subassembly } \\
\hline MEC Tanks & 1.3 & & & & $\$$ & 0.51 & $1.13 E+08 \$$ & $57,488,911$ \\
\hline Brush Cathode & 1.2 & & & & $\$$ & 14.60 & $27436736 \$$ & $400,686,098$ \\
\hline Brush Anode & 1.2 & & & & $\$$ & 7.92 & $7868218 \$$ & $62,316,288$ \\
\hline Power Supply & 1.3 & & & & $\$$ & $350,000.00$ & $53 \$$ & $18,550,000$ \\
\hline MEC Pumps & 2.8 & & & & & 242,216 & $11 \$$ & $2,664,376$ \\
\hline \multicolumn{9}{|l|}{ Storage Subassembly } \\
\hline Process Water Circulating Pump & 2.8 & & & & & 17,635 & $2 \$$ & 35,270 \\
\hline Process Water Tank & 1.4 & & & & & 195,500 & $2 \$$ & 391,000 \\
\hline Acetate Product Storage Tank & 1.4 & & & & $\$$ & 161,593 & $1 \$$ & 161,593 \\
\hline Acetate Transfer Pump & 1.3 & & & & $\$$ & 54,088 & $1 \$$ & 54,088 \\
\hline Process Water Transfer Pump & 2.8 & & & & & 242,216 & $1 \$$ & 242,216 \\
\hline \multicolumn{9}{|l|}{ Gas Capture Subassembly } \\
\hline Compressor MEC & 1.3 & $1654 \mathrm{kgmol} / \mathrm{hr}$ & 1654 & $\mathrm{kgmol} / \mathrm{hr}$ & $\$$ & 9,233 & $1 \$$ & $15,267,690$ \\
\hline MIC - 1 & 1.3 & & & & $\$$ & 88,542 & $1 \$$ & 88,542 \\
\hline MIC - 2 & 1.3 & & & & $\$$ & 554,634 & $1 \$$ & 554,634 \\
\hline PSA MEC & 1.3 & & & & & & $1 \$$ & 182,960 \\
\hline Hydrogen Flow Meter & 1.3 & & 1 & & $\$$ & 5,500 & $1 \$$ & $5,500.00$ \\
\hline
\end{tabular}




\section{Cost Assumptions and Calculations}

In addition to the capital costs which have been described in the previous sections, there are some additional costs associated with this system, mostly electricity, labor, and various feedstock costs. These costs for both the MEC system and the Fermentation system are explained in detail in this section.

\subsection{Variable Costs}

Aside from the fixed capital costs, there are numerous variable costs including electricity, labor, water usage, and additional consumables. The usage and associated costs of these will each be defined in the following sections.

\subsubsection{Electric Power Requirements}

There are numerous elements of the Lignocellulosic Fermentation System requiring power, but they mostly center around pumps, conveyors and agitators. However, the largest power needs comes from the compressor, which is compressing an enormous amount of gas. PSA power is minimal as it is only needed to actuate valves. The gas compressor is a 2-stage piston compressor $(\mathrm{N}=2)$ with interstage cooling. Its power was calculated by assuming compression from $45^{\circ} \mathrm{C}$ inlet temperature with efficiency of $75 \%$. Overall pressure ratio was 20.5 for an outlet pressure of $302 \mathrm{psi}$.

$$
P=\frac{d m}{d t} \operatorname{CpTN} \frac{1}{\eta}\left(\frac{P}{P 1}^{\frac{\gamma-1}{\gamma N}}-1\right)
$$

Figure 23-1 lists the electricity usage anticipated for each of the Fermentor components previously described and provides a total consumption value for the Fermentor to be used in further analysis. The previously mentioned duty cycles and operational cycle have been taken into account in these computations. We have assumed a pump efficiency of $80 \%$ and a density of all liquids as $1 \mathrm{~g} / \mathrm{cc}$. H2A accounts for electricity usage and costs in the "Other Variable Costs" section. 
Figure 23-1. Power Requirements for Fermentor without MEC

\begin{tabular}{|c|c|c|c|c|c|c|c|}
\hline \multicolumn{8}{|c|}{ Power Requirements } \\
\hline Conveyors & Power & Unit & & & & & kW \\
\hline Bale Transport Conveyor & 50 & HP & & & & & 37 \\
\hline Bale Unwrapping Conveyor & 50 & HP & & & & & 37 \\
\hline Belt Press Discharge Conveyor & 50 & HP & & & & & 37 \\
\hline Shredder Feed Conveyor & 50 & HP & & & & & 37 \\
\hline Lignin Wet Cake Screw & 50 & HP & & & & & 37 \\
\hline DAP Solids Feeder & 50 & HP & & & & & 37 \\
\hline Agitators & Power & Unit & & & & & \\
\hline Fermentation Agitator & 75 & HP & & & & & 56 \\
\hline Hydrozylate Mix Tank Agitator & 50 & HP & & & & & 37 \\
\hline Seed Hold Tank Agitator & 23 & HP & & & & & 17 \\
\hline 4th Seed Agitator & 6 & HP & & & & & 4 \\
\hline 5th Seed Agitator & 19 & HP & & & & & 14 \\
\hline CSL Storage tank Agitator & 23 & HP & & & & & 17 \\
\hline CSL/DAP Day Tank Agitator & 5 & HP & & & & & 4 \\
\hline Pumps & Throughput & Unit & Head & & $\mathrm{M} 3 / \mathrm{hr}$ & Meter & \\
\hline Wash Table Pump & 2500 & GPM & 50 & $\mathrm{ft}$ & 568 & 15 & 29 \\
\hline Wash Water Pump & 5000 & GPM & 50 & $\mathrm{ft}$ & 1136 & 15 & 59 \\
\hline Clarifier Underflow Pump & 100 & GPM & 50 & $\mathrm{ft}$ & 23 & 15 & 1 \\
\hline Clarified Water Pump & 5000 & GPM & 50 & $\mathrm{ft}$ & 1136 & 15 & 59 \\
\hline Belt Press Sump Pump & 100 & GPM & 40 & $\mathrm{ft}$ & 23 & 12 & 1 \\
\hline Sulfuric Acid Pump & 4 & GPM & 245 & $\mathrm{ft}$ & 1 & 75 & 0.2 \\
\hline Process Tank Pump & 737 & GPM & 200 & $\mathrm{ft}$ & 168 & 61 & 35 \\
\hline Fermentation Recirculation Pump & 1060 & GPM & 150 & $\mathrm{ft}$ & 241 & 46 & 38 \\
\hline CSL Pump & 431 & GPM & 150 & $\mathrm{ft}$ & 98 & 46 & 15 \\
\hline Sulfuric Acid Pump & 215 & GPM & 150 & $\mathrm{ft}$ & 49 & 46 & 8 \\
\hline Cooling Water Pump & 41000 & GPM & 70 & $\mathrm{ft}$ & 9318 & 21 & 677 \\
\hline Make-up Water Pump & 1083 & GPM & 75 & $\mathrm{ft}$ & 246 & 23 & 19 \\
\hline Process Water Circulating Pump & 1199 & GPM & 75 & $\mathrm{ft}$ & 273 & 23 & 21 \\
\hline CSL/DAP Pump & 431 & GPM & 150 & $\mathrm{ft}$ & 98 & 46 & 15 \\
\hline Seed Hold Transfer Pump & 172 & GPM & 150 & $\mathrm{ft}$ & 39 & 46 & 6 \\
\hline Seed Transfer Pump & 1231 & GPM & 100 & $\mathrm{ft}$ & 280 & 30 & 29 \\
\hline Miscellaneous & Throughput & Unit & & & & & \\
\hline DAP Unloading Blower & 253 & HP & & & & & 189 \\
\hline Compressor & & & & & & & 4535 \\
\hline PSA & & & & & & & 50 \\
\hline Lime Unloading Blower & 253 & HP & & & & & 189 \\
\hline Total Power Usage (kW) & & & & & & & 6,350 \\
\hline kWhr/day & & & & & & & 152,389 \\
\hline kWhr/year & & & & & & & $55,621,907$ \\
\hline$\$ /$ year & & & & & & $\$$ & $2,781,095$ \\
\hline$\$ / \mathrm{kg} \mathrm{H}_{2}$ & & & & & & $\$$ & 0.23 \\
\hline $\mathrm{kWhr} / \mathrm{kg} \mathrm{H}$ & & & & & & & 4.10 \\
\hline kwhr/kwhr $\mathrm{H}_{2}$ & & & & & & & 0.12 \\
\hline
\end{tabular}

The power requirement of the MEC system comes primarily from the MEC cell itself. The power draw of the MEC electrolysis process is estimated from the electron current required to reduce the $\mathrm{H}+$ and the applied voltage and the system electric efficiencies experimentally 
determined in Penn State tests ${ }^{98}$. Figure 23-2 lists the electricity usage anticipated for the MEC system.

Figure 23-2. Power Requirements MEC System

\begin{tabular}{|c|c|c|c|c|c|c|c|c|}
\hline \multicolumn{9}{|c|}{ Power Requirements } \\
\hline & & & & & & & \multicolumn{2}{|r|}{ kW } \\
\hline MEC & & & & & & & & 122184 \\
\hline Compressor MEC & & & & & & & & 6619 \\
\hline PSA & & & & & & & & 50 \\
\hline Pumps & Throughput & Unit & Head & & $\mathrm{M} 3 / \mathrm{hr}$ & Meter & & kW \\
\hline Cooling Water Pump & 41000 & GPM & 70 & $\mathrm{ft}$ & 9318 & & 21 & 8125 \\
\hline Acetate Transfer Pump & 1083 & GPM & 75 & $\mathrm{ft}$ & 246 & & 23 & 19 \\
\hline Process Water Circulating Pump & 1199 & GPM & 75 & $\mathrm{ft}$ & 273 & & 23 & 42 \\
\hline kW & & & & & & & & 137,040 \\
\hline kWhr/day & & & & & & & & $3,288,962$ \\
\hline kWhr/year & & & & & & & & $1,200,471,198$ \\
\hline \$/year & & & & & & & $\$$ & $60,023,560$ \\
\hline$\$ / \mathrm{kg} \mathrm{H} 2$ & & & & & & & $\$$ & 2.07 \\
\hline kWh/kg H2 & & & & & & & & 37.34 \\
\hline kWh/kWh H2 & & & & & & & & 1.12 \\
\hline
\end{tabular}

\subsubsection{Labor}

Labor rates for the fermentation system are similar to those in the ethanol report. We eliminated lab technicians and managers, since we will not require use of a lab. We also removed clerks and secretaries, who are accounted for separately in the H2A spreadsheet. Due to the vastly smaller and less complex plant as compared to an ethanol plant, the resulting labor numbers are probably somewhat high. However, given the relatively small impact that labor has on the cost of produced hydrogen, we felt that this was an acceptable overestimation. Figure 23-3 shows labor categories and number of personnel. The same number of personnel is assumed for the fermentation-only alone plant as is assumed for the fermentor with MEC plant. $\mathrm{H} 2 \mathrm{~A}$ accounts for labor costs in the fixed O\&M.

Figure 23-3. Labor Breakdown - Fermentor

\begin{tabular}{|lc|}
\multicolumn{1}{|c}{ Position } & Number of Personnel \\
\hline Plant Manager & 1 \\
\hline Plant Engineer & 1 \\
\hline Maintenance Supervisor & 1 \\
\hline Shift Supervisor & 5 \\
\hline Maintenance Technician & 8 \\
\hline Shift Operators & 20 \\
\hline Yard Employees & 32 \\
\hline General Manager & 1 \\
\hline Total FTEs & $\mathbf{6 8}$ \\
\hline
\end{tabular}

${ }^{98}$ Call, Douglas et al. "High Surface Area Stainless Steel Brushes as Cathodes in Microbial Electrolysis Cells." Environmental Scientific Technology (2008) table 1. 
For MEC labor, due to the similar size but reduced complexity, we have assumed $1 / 4$ of the labor is required.

\subsubsection{Additional Chemical Consumables}

There are many consumables that are needed for full operation of the lignocellulosic fermentation plant. The rates and costs of these consumables for the fermentation system are listed in Figure 23-4. Rates and costs for these consumables are derived from the ethanol production report.

Figure 23-4. Additional Consumables Costs - Fermentation system

\begin{tabular}{|c|c|c|c|c|c|c|c|}
\hline \multicolumn{8}{|c|}{ Additional Consumables Cost } \\
\hline Raw Material & Unit & Rate & & $/ \mathrm{kg})$ & & \$/year & \$/kg H2 \\
\hline CSL & $\mathrm{kg} /$ day & 31,344 & $\$$ & 0.18 & $\$$ & $2,023,606$ & $\$ 0.165678$ \\
\hline Sulfuric Acid & $\mathrm{kg} /$ day & 78,912 & $\$$ & 0.03 & $\$$ & 785,743 & $\$ 0.064331$ \\
\hline Lime & $\mathrm{kg} / \mathrm{day}$ & 57,480 & $\$$ & 0.08 & $\$$ & $1,606,244$ & $\$ 0.131508$ \\
\hline DAP & $\mathrm{kg} / \mathrm{day}$ & 3,912 & $\$$ & 0.16 & $\$$ & 221,778 & $\$ 0.018158$ \\
\hline Propane & $\mathrm{kg} / \mathrm{day}$ & 480 & $\$$ & 0.005 & $\$$ & 848 & $\$ 0.000069$ \\
\hline Clarifier Polymer & $\mathrm{kg} /$ day & 672 & $\$$ & 2.75 & $\$$ & 674,520 & $\$ 0.055225$ \\
\hline Totals & & & & & $\$$ & $5,312,739$ & $\$ \quad 0.43$ \\
\hline
\end{tabular}

Given that these consumables are not options within the H2A Modeling tool, we have calculated the cost per kilogram of hydrogen from these variable operating costs and manually added these to the results obtained from $\mathrm{H} 2 \mathrm{~A}$ for levelized hydrogen costs.

The MEC consumable for the stand-alone system is acetic acid at $\$ 0.595 / \mathrm{kg}$ and costing $\$ 5.70$ per kg of produced hydrogen.

\subsubsection{Water Consumption}

There are several sources of water loss within each system. For the fermentation system, water is primarily lost in the fermentation reaction. Further water is trapped in solids that are removed as waste. Most of the process water vapor is returned by condensation in the condenser and intercoolers. Using the molar ratios of the fermentation equation and the volume of hydrogen gas generated, we are able to calculate the daily use of reactant water in hydrogen production. In addition, substantial water is recovered from liquid byproducts.

For the MEC developed by PSU, the substrate is much more dilute than the fermentor output. Further, additional water is needed because we have assumed that after going through ten cycles of MEC acetate replenishment, the system will be flushed and the process water will need to be replaced. Thus, every day, $10 \%$ of the overall process water will need to be replaced in addition to the water used up in the production of hydrogen.

The water losses for the Fermentor and MEC is shown in Figure 23-5. 
Figure 23-5. Water Use

$\begin{array}{lcc} & \text { Water Loss (gal/day) } & \text { MEC } \\ & \text { Fermentor } & \text { 88 TPD } \\ \text { Size } & 37 \text { TPD } & 109,375 \\ \text { Water Used in reaction } & 54,826 & \\ \text { Water Loss in Lignin } & 223,397 & \text { NA } \\ \text { Separator } & \text { NA } & 9,132,152 \\ \text { MEC Waste Water (10\%) } & 759 & 1,035 \\ \text { Water Lost in PSA } & \mathbf{2 7 8 , 9 8 3} & \mathbf{9 , 2 4 1 , 5 5 1} \\ \text { Net Loss } & \mathbf{7 . 5} & \mathbf{1 0 5} \\ \text { Net Loss }\left(\mathbf{g a l} / \mathbf{k g H}_{\mathbf{2}}\right) & & \end{array}$

\subsubsection{Total Variable Feed Costs}

The sum of all the variable costs, excluding labor, for the Fermentation system is indicated in the Figure 23-6. The variable costs for the MEC system are shown in Figure 23-7.

Figure 23-6. Total Variable Costs for Fermentor

\begin{tabular}{|c|c|c|c|c|c|c|c|c|}
\hline \multicolumn{9}{|c|}{ Variable Operating Costs } \\
\hline Raw Material & Unit & Rate & & $\$ / \mathrm{kg})$ & & $\$ /$ year & & /kg H2 \\
\hline Corn Stover & $\mathrm{kg} /$ day & $2,000,000$ & $\$$ & 0.03 & $\$$ & $24,090,000$ & $\$$ & 1.972317 \\
\hline Process Water & gal/day & 278,983 & $\$$ & 0.004 & $\$$ & 373,089 & $\$$ & 0.030546 \\
\hline CSL & $\mathrm{kg} /$ day & 31,344 & $\$$ & 0.18 & $\$$ & $2,023,606$ & $\$$ & 0.165678 \\
\hline Sulfuric Acid & $\mathrm{kg} /$ day & 78,912 & $\$$ & 0.03 & $\$$ & 785,743 & $\$$ & 0.064331 \\
\hline Lime & $\mathrm{kg} /$ day & 57,480 & $\$$ & 0.08 & $\$$ & $1,606,244$ & $\$$ & 0.131508 \\
\hline DAP & $\mathrm{kg} /$ day & 3,912 & $\$$ & 0.16 & $\$$ & 221,778 & $\$$ & 0.018158 \\
\hline Propane & $\mathrm{kg} /$ day & 480 & $\$$ & 0.005 & $\$$ & 848 & $\$$ & 0.000069 \\
\hline Clarifier Polymer & $\mathrm{kg} /$ day & 672 & $\$$ & 2.75 & $\$$ & 674,520 & $\$$ & 0.055225 \\
\hline Totals & & & & & $\$$ & $29,775,828$ & $\$$ & 2.44 \\
\hline
\end{tabular}

Figure 23-7. Total Variable Costs for MEC

\begin{tabular}{|c|c|c|c|c|c|c|c|}
\hline \multicolumn{8}{|c|}{ Variable Operating Costs } \\
\hline Raw Material & Unit & Rate & & (\$/kg) & $\$ /$ year & & $\$ / \mathrm{kg} \mathrm{H} 2$ \\
\hline Acetic Acid & $\mathrm{kg} / \mathrm{day}$ & 767,277 & $\$$ & 0.595 & $\$ 166,633,382$ & $\$$ & 5.758714 \\
\hline Process Water & gal/day & $9,242,551$ & $\$$ & 0.002 & $5,618,279$ & $\$$ & 0.194163 \\
\hline Totals & & & & & $\$ 172,251,661$ & $\overline{\$}$ & 5.95 \\
\hline
\end{tabular}




\section{Hydrogen Production Costs for Fermentor and MEC}

The summation of the various costs per kg of hydrogen produced is listed in Figure 24-1. Note that due to slight differences in H2A costing methodology, the prices shown in these subtotals might be different from those shown in the final results. The primary components of the levelized cost of hydrogen are capital costs, fixed O\&M and other variable costs as shown in Figure 24-2.

Figure 24-1: Total Hydrogen Cost

\begin{tabular}{|r|c|c|}
\hline \multicolumn{3}{|c|}{ Total Cost of Produced $\mathbf{H}_{\mathbf{2}}$} \\
\hline Cost Component & Hydrogen Production Cost Contribution (\$/kg) \\
\hline System & $\begin{array}{c}\text { Fermentor-Only } \\
\text { (37 TPD Production) }\end{array}$ & $\begin{array}{c}\text { MEC Alone (88 TPD) } \\
\text { (at 0.9V/cell) }\end{array}$ \\
\hline Cost Component & $\begin{array}{c}\text { Hydrogen Production Cost } \\
\text { Contribution (\$/kg) }\end{array}$ & $\begin{array}{c}\text { Hydrogen Production Cost } \\
\text { Contribution (\$/kg) }\end{array}$ \\
\hline Capital Costs & $\$ 1.19$ & $\$ 4.37$ \\
\hline Decommissioning Costs & $\$ 0.01$ & $\$ 0.05$ \\
\hline Fixed O\&M & $\$ 0.87$ & $\$ 0.71$ \\
\hline Feedstock Costs & $\$ 1.60$ & $\$ 5.18$ \\
\hline Other Raw Material Costs & $\$ 0.00$ & $\$ 0.00$ \\
\hline Byproduct Credits & $\$ 0.00$ & $\$ 0.00$ \\
\hline Additional Consumables & $\$ 0.23$ & $\$ 2.12$ \\
\hline Total & $\$ 0.43$ & $\$ 0.00$ \\
\hline
\end{tabular}

Figure 24-2. Comparison of Levelized Cost Components

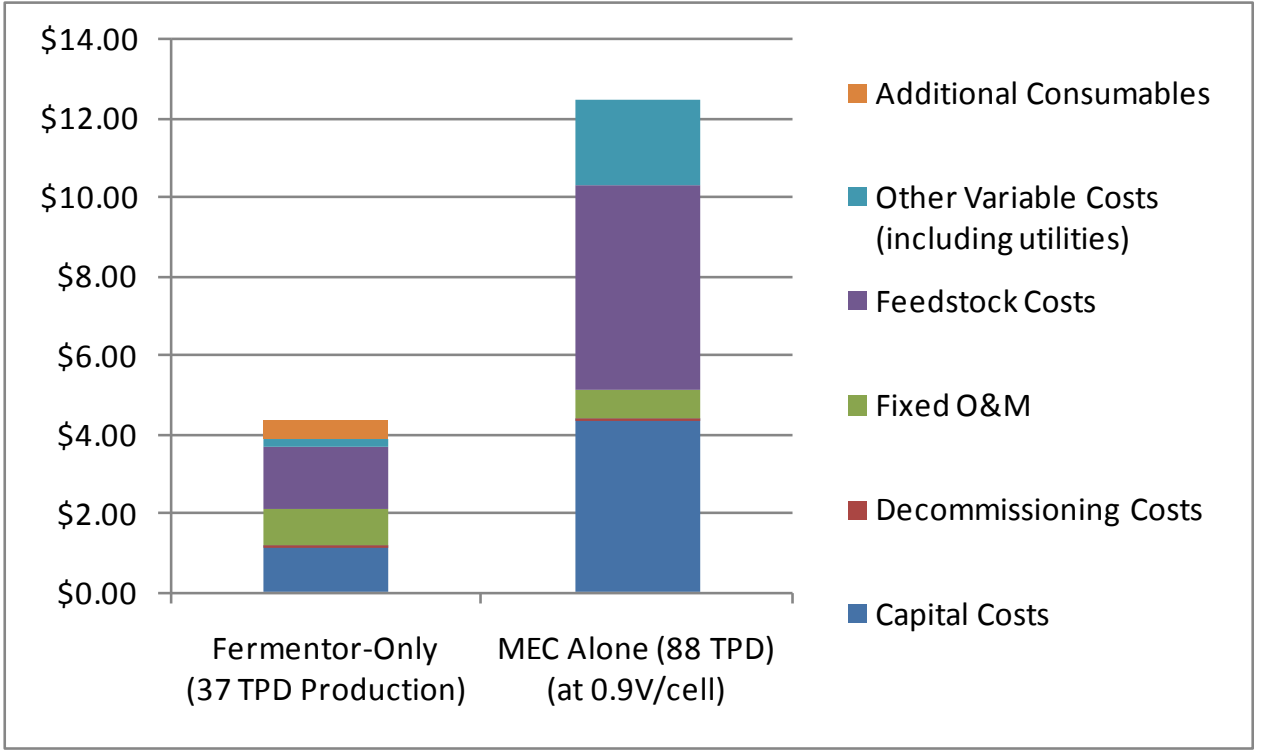

For the Stand-alone Fermentor system, there is a substantial liquid organic byproduct which has value, but for which we have not taken a cost credit due to the uncertainty of the constituents 
and the market values. From NREL testing, the fermentor byproduct (section 2.3.2) is as shown in Figure 24-3.

Figure 24-3. Fermentor Liquid-Organic Output Value

\begin{tabular}{|lcccc|}
\hline \multicolumn{1}{|c}{ Fermentor Product } & mM & MW & Mass fraction & Market Cost per kg \\
\hline Acetic Acid & 26.0 & 60.05 & $51.1 \%$ & $\$ 0.57$ \\
\hline Ethanol & 14.0 & 46.06 & $21.1 \%$ & $\$ 0.54$ \\
\hline Succinic Acid & 5.6 & 118.10 & $21.6 \%$ & NA \\
\hline Lactic Acid & 1.8 & 90.08 & $5.3 \%$ & $\$ 2.03$ \\
\hline Formic Acid & 0.6 & 43.03 & $0.8 \%$ & NA \\
\hline
\end{tabular}

Thus, after a distillation separation process, the resulting components would have a current average market value of about $\$ 0.55 / \mathrm{kg}$. However, any large addition to the world market would reduce prices, so the actual cost benefit of the organic byproduct is difficult to estimate. With the fermentor organic liquid byproduct of about $700,000 \mathrm{~kg} / \mathrm{day}$, if the value of this raw byproduct were $\$ 0.20 / \mathrm{kg}$, the byproduct value would be $\$ 140,000$ per day. This would yield a credit of $\$ 3.78 / \mathrm{kg} \mathrm{H}$, substantially driving down the $\mathrm{H}_{2}$ cost $/ \mathrm{kg}$ to $\$ 0.60 / \mathrm{kg}$. Even with a byproduct value as low as $\$ 0.12 / \mathrm{kg}$, the $\mathrm{H}_{2}$ cost $/ \mathrm{kg}$ is $\$ 2.09 / \mathrm{kg}$, near the goal of $\$ 2.00 / \mathrm{kg} \mathrm{H}$.

\section{Lignocellulose Fermenation and MEC System Conclusions and Recommendations}

\subsection{Lignocellulose Fermentation System}

The lignocellulose fermentation system used corn stover at 2,000 tonnes/day as a feedstock to generate 37 tonne/day purified $\mathrm{H}_{2}$. The process is complex and involves feedstock preprocessing, hydrolysis, saccharification, fermentation, solid/liquid separation, and $\mathrm{H}_{2}$ gas separation. The unique $150^{\circ} \mathrm{C}$ acid hydrolysis process used to convert cellulose and hemicellulose into complex sugars has been demonstrated by NREL. The subsequent saccharification process utilizes organisms developed at NREL to rapidly convert the hydrolysis products into simple sugars. The ensuing fermentation process occurs in the same reactor and uses separate NREL-developed bacteria to produce $\mathrm{H}_{2}$ and $\mathrm{CO}_{2}$ gases plus simple organic liquids, such as acetic acid and ethanol.

In the initial calculation, with no value recovered from the byproducts, the lignocellulosic processing achieved a moderately low $\mathrm{H}_{2}$ cost of $\$ 4.33 / \mathrm{kg} \mathrm{H}_{2}$. For this system producing 37 tonnes of pure $\mathrm{H}_{2}$, these byproducts are essentially: 692 tonnes of organic acid and alcohol liquids, 115 tonnes of unreacted sugars, and 846 tonnes of solids including lignin and a small amount of unreacted xylan. The liquid organic byproducts, equaling $35 \%$ of the input organic feedstock by weight, include $51 \%$ acetate and $21 \%$ ethanol which have intrinsic value, but require a subsequent separation process such as distillation. As an alternative to byproduct recovery, the liquid organics can be processed in an MEC to produce additional hydrogen.

There is high potential for $\mathrm{H}_{2}$ cost reduction from sales of the liquid organic byproduct. If this byproduct had a market value of $\$ 0.12 / \mathrm{kg}$ (as compared to the acetic acid market price of $\$ 0.60 / \mathrm{kg}$ ), the net $\mathrm{H}_{2}$ cost would be reduced to $\$ 2.09 / \mathrm{kg}$. 
In addition to the liquid byproducts, the remaining solids, lignin and some residual xylan, (42\% of the organic feedstock by weight) have additional value, as they can be used as a low grade fuel for industrial processes.

Recommendations:

- Conduct further analysis to verify the values of the lignocellulose fermentation liquid and solid organic byproducts to significantly reduce the cost of the hydrogen.

- Conduct further analysis to address the separation of byproduct components (acids, ethanol, etc.), such as in a distillation process

- Examine in greater detail the current experimental efficiencies and reaction times for the hydrolysis, saccharification, and fermentation processes, and propose potential future testing to verify these quantities.

\subsection{Microbial Electrolysis Cell (MEC) System}

For the MEC electrolysis process the microbial electrolysis voltage is supplemented by an external voltage. Low external voltage results in highest efficiency, but increases reaction times, thus increasing system size and cost. For lowest $\mathrm{H}_{2}$ production cost, the system should be operated at a higher than normal voltage $(0.9 \mathrm{~V})$ to minimize capital plant costs. The very low concentration of the input acetic acid $\sim 2 \mathrm{~g}$ acetate/liter of water, (as opposed to the fermentor at $200 \mathrm{~g}$ organics/liter of water) resulted in a very large system, i.e., 96,000,000 gallons of total reactor volume for 88 tonnes pure $\mathrm{H}_{2}$ /day. These volumes, based on current PSU research results, resulted in large tankage and the resultant large area anodes and cathodes, which were the major cost drivers. In addition, the effective operation of these electrodes in a very large scale reactor tank has not yet been analyzed or demonstrated.

For the MEC system, the $\mathrm{H}_{2}$ cost using pure acetic acid feedstock was a moderately high $\$ 12.43 / \mathrm{kg} \mathrm{H}_{2}$. This was primarily a product of the use of a very dilute acetic acid/water reactant, which necessitated very large reactor volumes and very large, costly anodes and cathodes. Along with the high capital cost was high acetate feedstock cost, which could be reduced by using a low purity simple organic feedstock such as the fermentor byproduct. However, the current large system size dominates the costs. The immaturity of the full scale system concepts and components indicated that there is extensive potential for future cost reductions.

Recommendations:

- Develop optimized production process and components for low capital cost systems, addressing issues such as:

- Increased solution density,

- Pressurized operation (to minimize separate compressor costs)

- Lower cost cathodes

- Lower cost anodes

- Cathode and anode geometry optimization for large reactors

- Determine the extent of ion transport losses as reactor size grows to production scale

- Examine potential efficiencies of the process carried out at large scale 
26. Part III Appendix A: Fermentor Mass/Heat Balance

\begin{tabular}{|c|c|c|c|c|c|c|c|c|c|c|c|c|c|}
\hline \multicolumn{3}{|l|}{ Process } & \multirow[b]{2}{*}{$\%$} & \multicolumn{2}{|l|}{ Mass flow } & \multirow{2}{*}{$\begin{array}{l}\text { mole flow } \\
\mathrm{kgM} / \mathrm{hr}\end{array}$} & \multirow{2}{*}{$\begin{array}{l}\mathrm{T} \\
{ }^{\circ} \mathrm{C}\end{array}$} & \multirow{2}{*}{$\begin{array}{c}\text { Tave } \\
{ }^{\circ} \mathrm{C}\end{array}$} & \multirow{2}{*}{$\begin{array}{l}\cong T \\
{ }^{\circ} \mathrm{T}\end{array}$} & \multirow{2}{*}{$\begin{array}{l}\mathrm{P} \\
\mathrm{psi}\end{array}$} & $\mathrm{Cp}$ & $\mathrm{h}$ & dq/dt \\
\hline & & & & kg/day & $\mathrm{kg} / \mathrm{hr}$ & & & & & & $\mathrm{kJ} / \mathrm{kg}^{\circ} \mathrm{C}$ & $\mathrm{kJ} / \mathrm{kg}$ & $\mathrm{kJ} / \mathrm{hr}$ \\
\hline Feedstock & Corn stover & & $20.0 \%$ & $2,000,000$ & 83,333 & & 20 & & & 14.7 & & & \\
\hline Inputs & & \begin{tabular}{|l|} 
cellulose \\
\end{tabular} & $36.7 \%$ & 734,000 & 30,583 & & & & & & & & \\
\hline & & hemicell & $27.4 \%$ & 548,000 & 22,833 & & & & & & & & \\
\hline & & Lignin,etc & $35.9 \%$ & 718,000 & 29,917 & & & & & & & & \\
\hline & & & $100.0 \%$ & $2,000,000$ & 83,333 & & & & & & & & \\
\hline & water & & $80.0 \%$ & $8,000,000$ & 333,333 & & 20 & & & 14.7 & & & \\
\hline & total slurry & & $100.0 \%$ & $10,000,000$ & 416,667 & & 20 & & & 14.7 & & & \\
\hline HX-1 & $\begin{array}{l}\text { from feedstock } \\
\text { to HX-2 }\end{array}$ & & & $\begin{array}{l}10,000,000 \\
10,000,000\end{array}$ & $\begin{array}{l}416,667 \\
416,667\end{array}$ & & $\frac{20.0}{43.3}$ & 31.7 & 23.3 & 14.7 & 4.180 & & $40,655,319$ \\
\hline & \begin{tabular}{|l} 
from fermentor \\
to Ligsep
\end{tabular} & & & $9,332,641$ & $388,860.06$ & & 55.0 & 125 & 250 & 14.7 & 4.182 & & 10655310 \\
\hline HX-2 & from $\mathrm{HX}-1$ primary & & & $10,000,000$ & 416,667 & & 43.3 & & & 68.8 & 4.206 & & \\
\hline & to hydrolyzer heater & & & $10,000,000$ & 416,667 & & 128.5 & 85.9 & 85.2 & & & & $149,281,250$ \\
\hline & \begin{tabular}{|l|} 
from hydrolyzer \\
to
\end{tabular} & & & $\begin{array}{l}10,000,000 \\
10,000,00\end{array}$ & $\begin{array}{l}416,667 \\
416,667\end{array}$ & & $\begin{array}{l}140.0 \\
550\end{array}$ & 975 & 85.0 & 68.8 & 4.215 & & -149281250 \\
\hline Hydolyzer & heating of slurry from & $H X-2$ & & $10,000,000$ & 416,667 & & 128.5 & & & & & & \\
\hline Heater & & & & $10,000,000$ & 416,667 & & 150.0 & 139.3 & 21.5 & 68.8 & 4.290 & & $38,387,188$ \\
\hline & heating of $\mathrm{CO} 2$ from & & & 490,873 & 20,453 & & 45.0 & & & & & & \\
\hline & $\mathrm{CO} 2 / \mathrm{H} 2 \mathrm{mas}$ & 54.58 & & 490,873 & 20,453 & & 150.0 & 97.5 & 105.0 & 14.7 & 0.913 & & $1,960,729$ \\
\hline & heating of $\mathrm{H} 2 \mathrm{O}$ from & & & 2,783 & 116 & & 45.0 & & & & & & \\
\hline & $\mathrm{H} 2 \mathrm{O} / \mathrm{H} 2 \mathrm{mas}$ & 0.31 & & 2,783 & 116 & & 150.0 & 97.5 & 105.0 & 14.7 & 1.970 & & 23,985 \\
\hline & Total heat input r & quired (neg & lecting $\mathrm{H} 2$ & & & & & & & & & & $40,371,902$ \\
\hline & Waste $\mathrm{H} 2$ burner & heating & effic $=$ & & & & & & & & & & \\
\hline & H2 LHV kJ/kg & $=119,705$ & $90 \%$ & 8,994 & 375 & & & & & 14.7 & & & $40,371,902$ \\
\hline & & & & $10,000,000$ & 416,667 & & & & & & & & \\
\hline Total heating from $\mathrm{HX}-1$ & + HX-2 + Heater & & & & & & & & & & & & $230,308,471$ \\
\hline Hydrolyzer & II from Heater & & & $10,000,000$ & $\begin{array}{lll}416,667 \\
\end{array}$ & & 150.0 & & & $\begin{array}{lll}68.8 \\
\end{array}$ & & & \\
\hline & inputs & \begin{tabular}{|c|} 
cellulose \\
\end{tabular} & $36.7 \%$ & 734,000 & 30,583 & & & & & psi & & & \\
\hline & & hemicell & $27.4 \%$ & 548,000 & 22,833 & & & & & 4.68 & & & \\
\hline & & Lignin,etc & $35.9 \%$ & 718,000 & 29,917 & & & & & $\mathrm{~atm}$ & & & \\
\hline & & \begin{tabular}{|l|} 
water \\
\end{tabular} & $80.0 \%$ & $8,000,000$ & 333,333 & & & & & & & & \\
\hline & & total & & $10,000,000$ & 416,667 & & & & & & & & \\
\hline efficiency= & output & complex sug & & $1,153,800$ & 48,075 & & 140.0 & & & 68.8 & & & \\
\hline $90 \%$ & & xylan & & 128,200 & 5,342 & & & & & & & & \\
\hline & & Lignin,etc & & 718,000 & 29,917 & & & & & & & & \\
\hline & & \begin{tabular}{|l|} 
organics \\
\end{tabular} & & $2,000,000$ & 83,333 & & & & & & & & \\
\hline & & water & & $8,000,000$ & 333,333 & & & & & & & & \\
\hline & & total & & $10,000,000$ & 416,667 & & & & & & & & \\
\hline & Endothermic heat ab & orption $\cong T$ & & & & & 10.0 & & & & & & \\
\hline & to $\mathrm{HX}-2$ & & & $10,000,000$ & 416,667 & & 140.0 & & & 68.8 & & & \\
\hline Saccharification & from HX-2 & & & $10,000,000$ & 4416,667 & & 55.0 & & & 14.7 & & & \\
\hline in fermentor tank & to fermentation proce & & & $10,000,000$ & 416,667 & & 55.0 & & & & & & \\
\hline Fermentor & Jin from & Jotal & & $\overline{10,000,000}$ & 416,667 & & $\overline{55.0}$ & & & 14.7 & & & \\
\hline efficiency $=$ & sacchrification & simple sugar & & $1,153,800$ & 48,075 & 267 & & & & & & & \\
\hline $90 \%$ & process & Lignin,xylan, & & 846,200 & 35,258 & & & & & & & & \\
\hline & & water & & $8,000,000$ & 333,333 & & & & & & & & \\
\hline & & reactants & & $10,000,000$ & 416,667 & & & & & & & & \\
\hline & H2O reacted in ferme & tation & & 207,676 & 8,653 & & & & & & & & \\
\hline & gas out & H2 & & $46,476.6$ & 1,937 & 961 & 55 & & & 14.7 & & & \\
\hline & & $\mathrm{CO} 2$ & & $507,339.5$ & 21,139 & 480 & 55 & & & & & & \\
\hline & & \begin{tabular}{|l|}
$\mathrm{VH} 2 \mathrm{O}$ \\
\end{tabular} & & 113,542 & $\begin{array}{l}4,731 \\
4,73\end{array}$ & 263 & 55 & & & & & & \\
\hline & & total gas & & 667,359 & 27,807 & 1,704 & & & & & & & \\
\hline & slurry out to HX-1 & slurry total & & $9,332,641$ & 388,860 & & 55 & & & & & & \\
\hline & & Lignin,xylan, & & 846,200 & 35,258 & & & & & & & & \\
\hline & & Acetate & & 692,280 & 28,845 & & & & & & & & \\
\hline & & Glucose & $10 \%$ & 115,380 & 4,808 & & & & & & & & \\
\hline & & L-H2O & & $7,678,781$ & 319,949 & & & & & & & & \\
\hline & & \begin{tabular}{|l|l|} 
total \\
\end{tabular} & & $9,332,641$ & 388,860 & & & & & & & & \\
\hline & total mass out & & & $10,000,000$ & 416,667 & & & & & & & & \\
\hline$\overline{\text { Condenser }}$ & gases in & $\mathrm{H} 2$ & & 466,477 & $\begin{array}{ll}1,937 \\
\end{array}$ & & $\overline{55}$ & & & 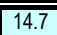 & 14.496 & & \\
\hline FC-1 & from fermentor & $\mathrm{CO} 2$ & & 507,340 & 21,139 & & 55 & & & 14.7 & 0.953 & & \\
\hline & & V H2O & & 113,542 & 4,731 & & 55 & & & 14.7 & 1.912 & & \\
\hline & & total & & 667,359 & 27,807 & & & & & & & & \\
\hline & gases out to & $\mathrm{H} 2$ & & 46,477 & 1,937 & 960.6 & 45 & 50 & -10 & 14.7 & 14.496 & & $-280,719$ \\
\hline & Compressor-F-1 & CO2 & & 507,340 & 21,139 & 480.3 & 45 & 50 & -10 & 14.7 & 0.953 & & $-201,350$ \\
\hline & & V H2O & & 64,477 & $2,686.5$ & 149.1 & 45 & 50 & -10 & 14.7 & 1.912 & & $-51,367$ \\
\hline & & total gas & & 618,293 & 25,762 & & & & & & & & $-533,436$ \\
\hline & liquids out & L H2O & & 49,066 & 2,044 & & 45 & & -10 & 14.7 & 4.200 & & $\begin{array}{r}-62,477 \\
\end{array}$ \\
\hline & & V-L Phase & change heat & & & & & & & & & -2222 & $-4,542,656$ \\
\hline
\end{tabular}




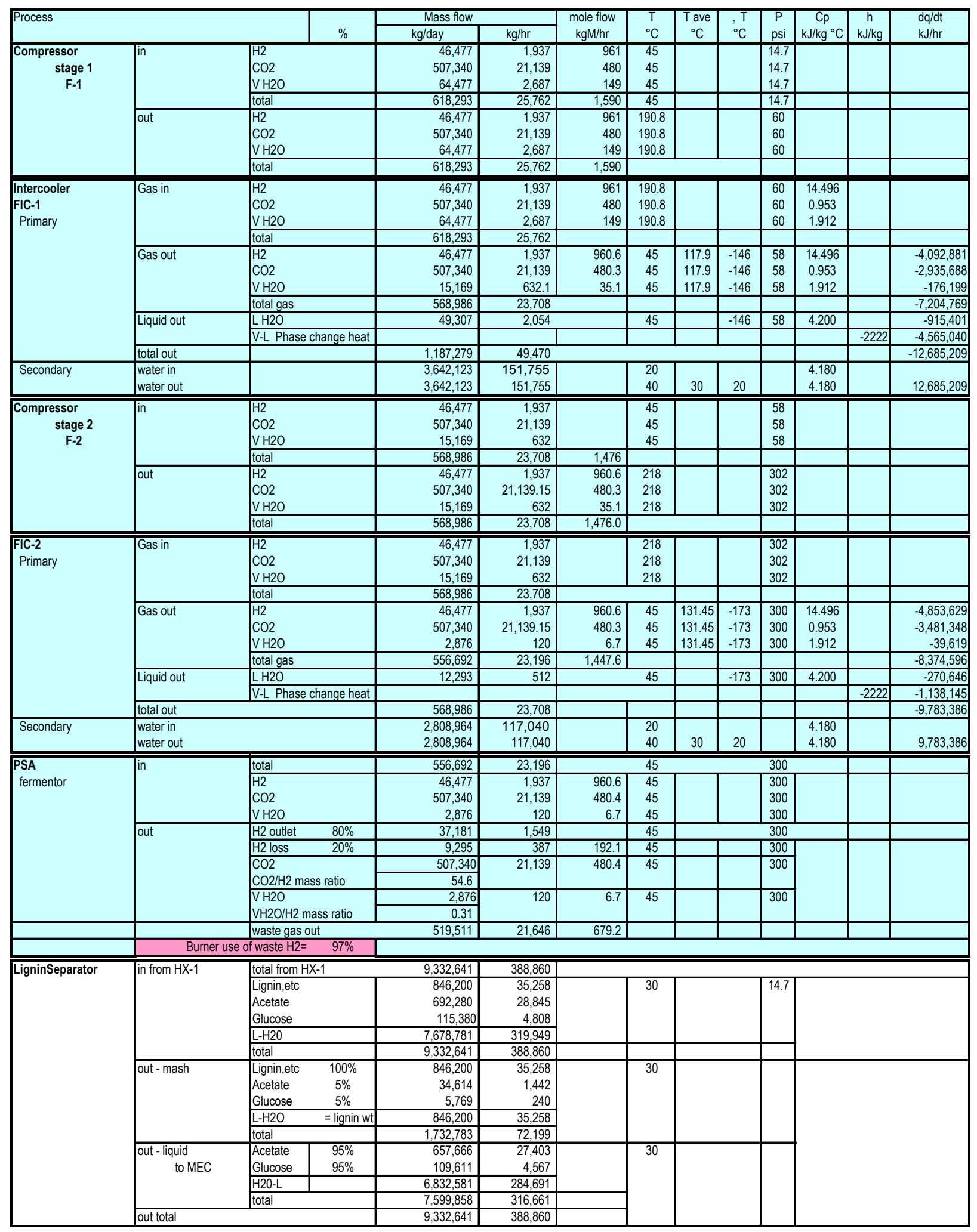


27. Part III Appendix B: MEC Mass/Heat Balance

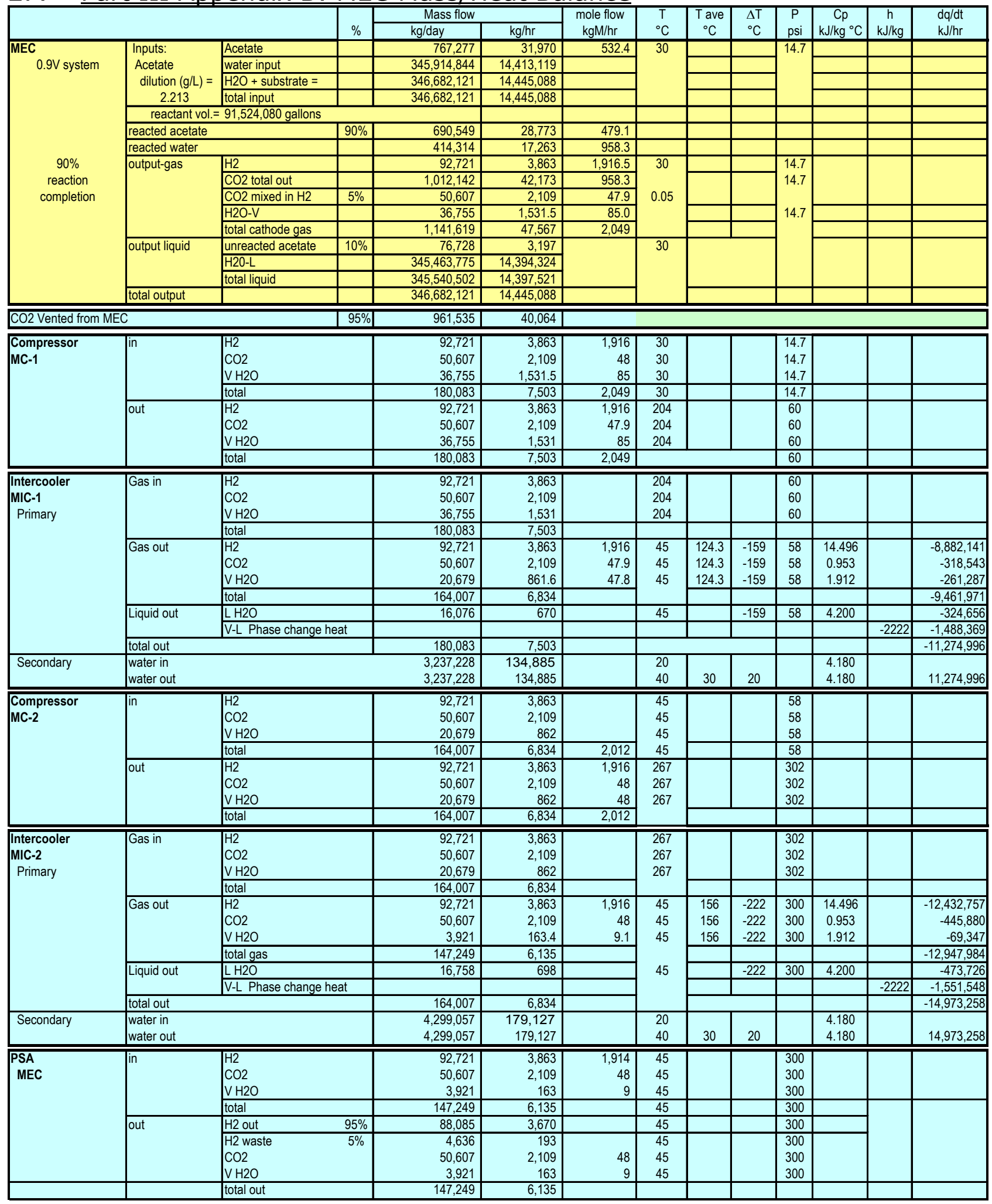




\section{Part IV: Integrated Systems}




\section{Systems Integration}

Having characterized and assessed costs for several pathways for biological hydrogen production, it is important to consider how combinations of different pathways could enhance hydrogen production and potentially lower costs. Combining capital costs, making use of waste products and increasing solar capture makes it possible to improve the cost-effectiveness of the overall system. This report is focused on examining different combinations of the biological hydrogen production pathways and evaluating costs associated with these integrations as compared to the individual systems.

There are three types of biological systems that have been evaluated in this effort: photobiological, fermentation, and Microbial Electrolysis. These types can be used in integrated systems. Integrations are shown in Figure 28-1. Combinations can occur within the photobiological subset of systems, within the fermentation subset of systems or a combination of a photobiological and fermentation system. While other combinations may exist, our task required the evaluation of four systems. We have chosen to study the four that are most representative and have sufficient synergies to make integration a possibility. Higher multiples of the systems could be possible but are not considered necessary to evaluate in the boundary analysis. Those could be reviewed in more detail if any of these combinations prove fruitful.

Figure 28-1. Potential Biological Integration Methods

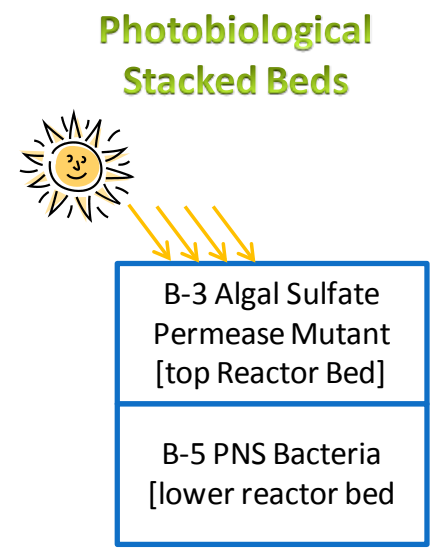

\section{Fermentor/MEC Integration}

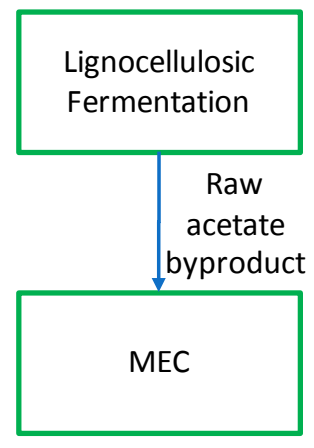

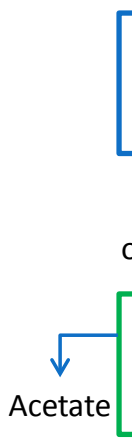

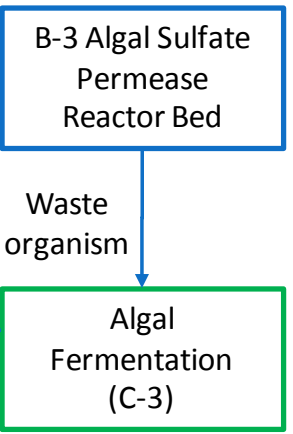

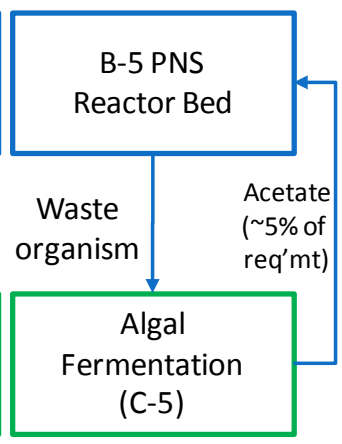

The four potential system combinations analyzed are as follows:

- stacked photobiological systems (B-3/B-5) to capture a greater portion of the solar spectrum

- photobiological $\mathrm{H}_{2}$ production (B-1) combined with algal fermentation (C-1)

- photobiological PNS $\mathrm{H}_{2}$ production (B-5) combined with waste PNS fermentation (C-5) and waste acetate consumption in the PNS photosynthesis

- lignocellolosic fermentation combined with microbial electrolysis

For more details on the specifics of each of the systems mentioned please refer to Part I, Part II and Part III of this report. 


\subsection{Stacked Photobiological Pathway}

The best way to evaluate integrated photobiological beds is by considering them vertically stacked. Side-by-side integration would increase the land requirements and only share auxiliary subsystem costs. Organisms and bed designs as defined would not absorb the full spectrum or intensity of solar light available. Thus, it seems probable that a stacked system would take advantage of this and allow for greater hydrogen production per area. In order to stack systems the organisms chosen for the top and bottom reactor must have sufficiently different PAR spectra to produce significant increases in hydrogen production in a stacked configuration. As has been noted before, the PNS bacteria in the B-5 pathway utilize a different PAR spectrum than the Chlamydomonas algae and Cyanobacteria in systems B-1, B-2, B-3, and B-4. Thus stacking one of these beds on top of a B-5 photobio bed could improve $\mathrm{H}_{2}$ production by increasing the range of the solar spectrum captured by the beds. For the upper bed, B-3 was chosen rather than the B-1 and B-2 systems because of the additional greater precautions necessary in handling the stoichiometric $\mathrm{H}_{2} / \mathrm{O} 2$ mix from the latter systems. The B-4 system was not used because the polypropylene mats used for the immobilized algae, combined with the high algae density on these mats, would block the transmission of photons to the lower layer. Therefore, the stacked system we chose to investigate consisted of a sulfate permease mutant B-3 system stacked on top of a B-5 PNS bed, increasing the effective PAR of the integrated system from $44 \%$ to $71 \%$, leading to an increase in hydrogen production relative to the B-3 system by itself. Furthermore, many hardware components can be combined for the two systems, including most of the reactor bed subassembly, control system subassembly, and gas capture subassembly costs. The assumptions and changes from the B-3 system to create a stacked bed include:

- A second layer of film to separate the two beds

- The components of the Organism Feed Subassembly and Recycle Subassembly are all doubled in order to provide nutrients and maintain concentration in both beds

- In order to capture the additional photons, roughly $1 / 5$ of the normal concentration of PNS will be needed, and thus the acetate nutrient requirements are $1 / 5$ of the full B-5 system

- Since the B-5 system will be stacked below the B-3 system, it will be impossible to provide paddlewheel mixing. Thus, we have added recirculation pumps and perforated pipe that extends the length of the raceways every 10 feet

\section{A process diagram of the integrated system is shown in}

Figure 28-2. The conceptual design of a tiered reactor bed system is illustrated in Figure 28-3. Overall cost for the B-3/B-5 stacked system for a 1 ton per day (TPD) plant is $\$ 4,274,085$. The bill of materials for the B-3/B-5 stacked system is shown in Figure 28-4. 
Figure 28-2. Process Diagram - Integrated Photobiological Systems

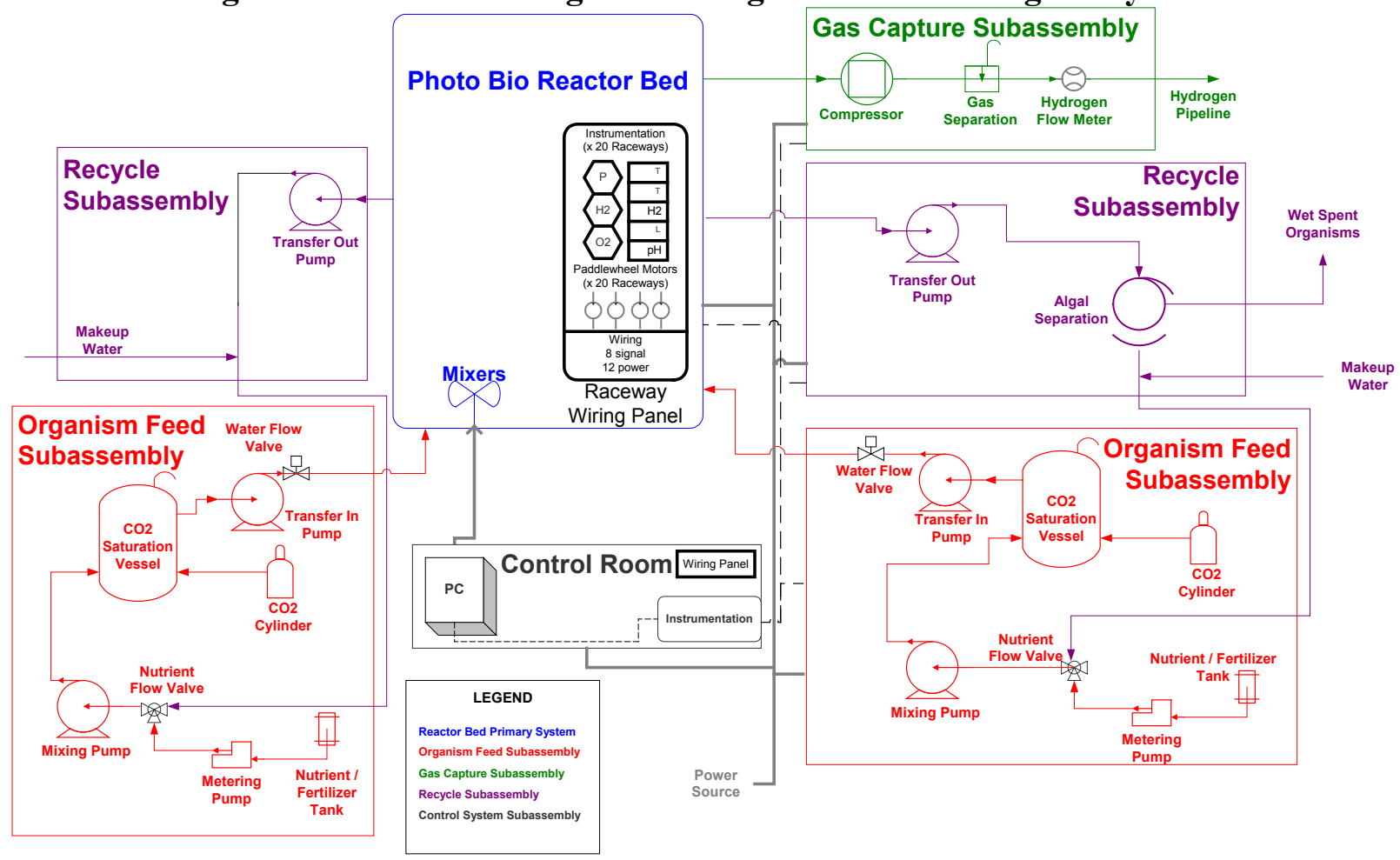

Figure 28-3. Tiered Reactor Bed Conceptual Design

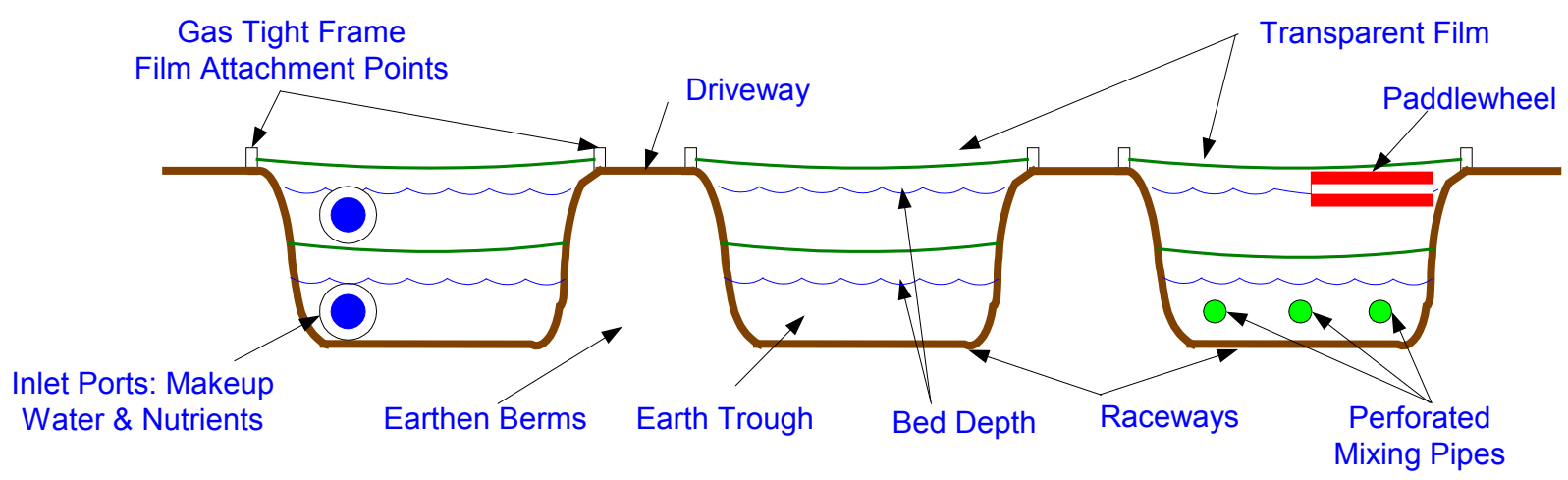

FRONT VIEW 
Figure 28-4. Bill of Materials for B-3/B-5 Stacked Beds

\begin{tabular}{|c|c|c|c|c|c|c|c|c|}
\hline \multirow{3}{*}{$\begin{array}{l}\text { Description } \\
\text { Photo Bio Reactor Bed Subassembly } \\
\text { Transparent Film }\end{array}$} & \multirow[t]{2}{*}{ Size Req'd Units } & \multirow[t]{2}{*}{ Unit Size } & \multirow[t]{2}{*}{ Units } & \multicolumn{2}{|r|}{ Unit cost } & \multirow[t]{2}{*}{ Qty Req'd } & Total Cost & \multirow{2}{*}{ Material / Part Description } \\
\hline & & & & & & & & \\
\hline & $165452 \mathrm{~m} 2$ & 1 & m2 & $\$$ & 0.54 & 165,452 & 89,054 & Polyethylene price quote at $\$ 0.54 / \mathrm{mz}(\$ 0.05 / \mathrm{ft} 2)$ \\
\hline Film Layer 2 & $165452 \mathrm{~m} 2$ & 1 & $\mathrm{~m} 2$ & $\$$ & 0.54 & 165,452 & 89,054 & Polyethylene price quote at $\$ 0.54 / \mathrm{m} 2(\$ 0.05 / \mathrm{tt} 2)$ \\
\hline Pond Lining & $178597 \mathrm{~m} 2$ & 1 & $\mathrm{~m} 2$ & $\$$ & 0.47 & 178,597 & 84,382 & Butyl rubber, PVC, and LDPE (low density polyethylene) based on quote of $\$ 175.56$ for \\
\hline Pond Edging & $26566 \mathrm{~m}$ & 1 & $\mathrm{~m}$ & $\$$ & 7.00 & 26,566 & 185,965 & Unit Cost is engineering estimate at $\$ 7 / \mathrm{m}$ \\
\hline Installation of Ponds & & 1 & raceway & $\$$ & $26,083.00$ & 38 & 991,154 & Based on California labor rates. \\
\hline Paddlewheel Mixers & & 1 & each & $\$$ & $5,000.00$ & 76 & 380,000 & Est. paddlewheel cost. 4 per raceway. 18 raceways. \\
\hline Inlet Water Valve & 0.5 in & 1 & each & $\$$ & 43.46 & 38 & 1,651 & Price from ValveStore.com (http://www.valvestore.com/prodinfo.asp?number=551032) \\
\hline Outlet Water Valve & $0.5 \mathrm{in}$ & 1 & each & $\$$ & 43.46 & 38 & 1,651 & Price from Valvestore.com (http://www.valvestore.com/prodinfo.asp?number=551032) \\
\hline Outlet Gas Valve & $1.0 \mathrm{in}$ & 1 & each & $\$$ & 67.23 & 38 & 2,555 & Price from Valvestore.com (http://www.valvestore.com/prodinfo.asp?number=551032) \\
\hline Flanges & $0.5 \mathrm{in}$ & 1 & each & $\$$ & 8.00 & 114 & 912 & Price from http://www.ancorp.com/line.aspx?id=819 \\
\hline PNS Recicirculaiton Pump & 76 & & & $\$$ & 187.99 & 76 & 14,287 & \\
\hline PNS Perforated Piping & 248900 & & & $\$$ & 0.24 & 248,900 & 59,736 & \\
\hline \multicolumn{9}{|l|}{ Gas Capture Subassembly } \\
\hline Compressor & $67 \mathrm{kgmol} / \mathrm{hr}$ & 67 & $\mathrm{kgmol} / \mathrm{hr}$ & $\$$ & $9,233.00$ & 1 & 622,078 & Using H2A Unit cost \\
\hline PSA & & & & $\$$ & 78,900 & 1 & 78,900 & \\
\hline Raceway Collection Pipe & $76 \mathrm{ft}$ & 1 & $\mathrm{ft}$ & $\$$ & 1.00 & 76 & 76 & Sized for Peak Hydrogen production. Assuming Plastic Gas piping, $100 \mathrm{ft} / \mathrm{s}$ velocity, \\
\hline Main Collection Pipe & $2160 \mathrm{ft}$ & 1 & $\mathrm{ft}$ & $\$$ & 6.18 & 2160 & 13,349 & Sized for Peak Hydrogen production. Assuming Plastic Gas piping, $100 \mathrm{ft} / \mathrm{s}$ velocity, \\
\hline Gas Capture Pipe & $350 \mathrm{ft}$ & 1 & $\mathrm{ft}$ & $\$$ & 6.18 & 350 & 2,163 & Sized for Peak Hydrogen production. Assuming Plastic Gas piping, $100 \mathrm{ft} / \mathrm{s}$ velocity, \\
\hline PNS Gas Collection Pipe & & & & $\$$ & 1.00 & 380 & 380 & Diverts PNS gas to Main Gas Piping \\
\hline \multicolumn{9}{|l|}{ Organism Feed Subassembly } \\
\hline Transfer In Pump & $150 \mathrm{gpm}$ & 150 & gpm & $\$$ & 10,252 & 18 & 184,536 & Est. Based on Perry's Chemical Handbook, Plant Design and Economics \\
\hline Nutrient Metering Pumps & & 1468 & $\mathrm{Gal} / \mathrm{Hr}$. & $\$$ & 2,594 & 2 & 5,188 & Est. Based on Perry's Chemical Handbook, Plant Design and Economics \\
\hline Mixing Pump & $150 \mathrm{gpm}$ & 150 & $\mathrm{gpm}$ & $\$$ & 10,252 & 18 & 184,536 & Est. Based on Perry's Chemical Handbook, Plant Design and Economics \\
\hline CO2 Cylinder & $50 \mathrm{lb}$ & 50 & $\mathrm{lb}$ & $\$$ & 360 & 1 & 360 & (http://kegman.net/carbon.htm) \\
\hline CO2 Saturation Vessel & $15000 \mathrm{gal}$ & 15000 & gal & $\$$ & 30,000 & 10 & 300,000 & Economics \\
\hline Nutrient Tank & $14 \mathrm{gal}$ & 10 & gal & $\$$ & 30.00 & 2 & 60 & 085 (http://www.watertanks.com/products/0275-085.asp) \\
\hline Raceway Slurry Collection Pipe (B3 and B5) & $184 \mathrm{ft}$ & 1 & $\mathrm{ft}$ & $\$$ & 2.12 & 184 & 390 & Pricing based off of Estimates from PVC Plastic Corp. Assumes $10 \mathrm{ft} /$ second flow rate and \\
\hline Main Slurry Collection Pipe (B3 and B5) & $5280 \mathrm{ft}$ & 1 & $\mathrm{ft}$ & $\$$ & 8.51 & 5280 & 44,933 & Pricing based off of Estimates from PVC Plastic Corp. Assumes $10 \mathrm{ft} /$ /second flow rate and \\
\hline Recycle-Feed Transfer Pipe (B3 and B5) & $360 \mathrm{ft}$ & 1 & $\mathrm{ft}$ & $\$$ & 8.51 & 360 & 3,064 & Pricing based off of Estimates from PVC Plastic Corp. Assumes $10 \mathrm{ft} /$ second flow rate and \\
\hline \multicolumn{9}{|l|}{ Recycle Subassembly } \\
\hline Rotary Drum filter & $17980 \mathrm{gph}$ & 3750 & gph & $\$$ & $87,000.00$ & 5 & 435,000 & Information from Dana Kent at Advanced Aquaculture Inc. on Hydrotech Drum Filter \\
\hline Transfer Out Pump & $150 \mathrm{gpm}$ & 150 & $\mathrm{gpm}$ & $\$$ & 10,252 & 18 & 184,531 & Timmerhaus \\
\hline Main Slurry Feed Pipe (B3 and B5) & $5280 \mathrm{ft}$ & 1 & $\mathrm{ft}$ & $\$$ & 6.18 & 2040 & 12,607 & Pricing based off of Estimates from PVC Plastic Corp. Assumes $10 \mathrm{ft} /$ second flow rate and \\
\hline Raceway Slurry Feed Pipe (B3 and B5) & $184 \mathrm{ft}$ & 1 & $\mathrm{ft}$ & $\$$ & 1.00 & 72 & 72 & Pricing based off of Estimates from PVC Plastic Corp. Assumes $10 \mathrm{ft} /$ second flow rate and \\
\hline \multicolumn{9}{|l|}{ Consumables } \\
\hline Initial $\mathrm{CO} 2$ & $41629 \mathrm{lb}$ & 50 & Ib & $\$$ & 35.00 & 833 & 29,155 & Cost based on average fertilizer use for Aquaculture and average fertilizer costs from the \\
\hline Initial Nutrients & $2 \mathrm{lb}$ & 1 & $\mathrm{lb}$ & $\$$ & 0.20 & 2 & 0 & NFC Company, Chicago, IL (800) 7344515 \\
\hline Initial Water & 7991266 gal & 1 & gal & $\$$ & 0.00 & 7583248.679 & 12,626 & H2A Feedstock Costs \\
\hline Initial Acetate & $5442 \mathrm{~kg}$ & 1 & $\mathrm{~kg}$ & $\$$ & 0.60 & 5442 & 3,238 & \\
\hline \multicolumn{9}{|l|}{ Control System } \\
\hline Control Room & $160 \mathrm{ft} 2$ & 1 & $\mathrm{ft} 2$ & $\$$ & 50.00 & 160 & 8,000 & http://www.buyerzone.com/industrial/modular_buildings/prefab_guide.html \\
\hline Control Room Wiring Panel & & 1 & & $\$$ & $3,000.00$ & 1 & $3,000.00$ & Consultation with Innomation Systems Inc. \\
\hline Raceway wiring Panel & & 1 & & $\$$ & 146.00 & 38 & 5,548 & Information from Tessco Technologies Inc. \\
\hline Computer and Monitor & & 1 & & $\$$ & $1,500.00$ & 1 & $1,500.00$ & Information from Emerson Process Management \\
\hline Labview Software & & 1 & & $\$$ & $4,299.00$ & 1 & $4,299.00$ & Information from Emerson Process Management \\
\hline Level Indicators & & 1 & & $\$$ & 714.00 & 38 & $27,132.00$ & Omega Engineering Inc. LVR51 Liquid Level Float Transmitter + DPi32 Meter \\
\hline Pressure Sensors & & 1 & & $\$$ & 345.00 & 38 & $13,110.00$ & Omega Engineering Inc. PX209 Pressure Trnasducer + DPi32 Meter \\
\hline Hydrogen Area Sensors & & 1 & & $\$$ & $7,600.00$ & 19 & $\$ 144,400.00$ & Honeywell 7866 Gas Analyzer (http://www.lesman.com/unleashd/catalog/analytical/anal \\
\hline Air Temperature Meter & & 1 & & $\$$ & 599.00 & 1 & $\$ 599.00$ & Omega DP81T Meter \\
\hline Air Temperature Indicator & & 1 & & $\$$ & 38.00 & 38 & $1,444.00$ & Omega TH-10-44000 Thermistor Probe \\
\hline Water Temperature Indicator & & 1 & & $\$$ & - & 38 & - & Comes with the PH sensor \\
\hline pH level Indicator & & 1 & & $\$$ & 435.00 & 38 & $16,530.00$ & Omega Engineering Inc. PHE - 6510 PH electrode + DP24 -PH Meter \\
\hline Oxygen Area Sensors & & 1 & & $\$$ & - & 38 & - & Comes with $\mathrm{H} 2$ Sensor \\
\hline Nutrient Flow Valve & & 1 & & $\$$ & $5,500.00$ & 1 & $5,500.00$ & Information from Emerson Process Management \\
\hline Water Flow Valve & & 1 & & $\$$ & $5,500.00$ & 1 & $5,500.00$ & Information from Emerson Process Management \\
\hline Hydrogen Flow Meter & & 1 & & $\$$ & $5,500.00$ & 1 & $5,500.00$ & Information from Emerson Process Management \\
\hline Instrument Wiring & $213180 \mathrm{ft}$ & 1 & $\mathrm{ft}$ & $\$$ & 0.02 & 213180 & $4,135.69$ & Information from Waytek Inc. at waytekwire.com \\
\hline Power Wiring & $264360 \mathrm{ft}$ & 1 & $\mathrm{ft}$ & $\$$ & 0.02 & 264360 & $5,128.58$ & Information from Waytek Inc. at waytekwire.com \\
\hline Conduit & $8820 \mathrm{ft}$ & 1 & $\mathrm{ft}$ & $\$$ & 0.58 & 8820 & $5,113.84$ & Information from Waytek Inc. at waytekwire.com \\
\hline
\end{tabular}

\subsection{Photobiological-Fermentor Integration}

In the current photobiological pathway configurations, algae and bacteria filtered out of the photobiological systems by the rotary drum filters are discarded as waste. However, as analyzed in Part II, this waste biomass can be utilized in a fermentation reactor to generate additional hydrogen. This integration combines a photobiological pathway in series with a fermentation pathway, thus little capital cost efficiencies are expected. Due to the small additional hydrogen generated from the fermentation system, it is possible to route the fermentation hydrogen produced into the gas capture subassembly of the photobiological system to improve costs slightly. As mentioned in Part II, the major cost component of the stand-alone algae fermentation systems is the labor cost, which is enormous relative to the minimal hydrogen produced. However, the minimal size of the fermentation unit will require no additional labor from that already needed for the photobiological plant, leading to massive cost savings relative to the stand-alone fermentation system. The process diagram for the photobiological-fermentor integration is shown in Figure 28-5. 
Figure 28-5. Photobio-Fermentor Process Diagram

Photobiological-Fermentor Integration

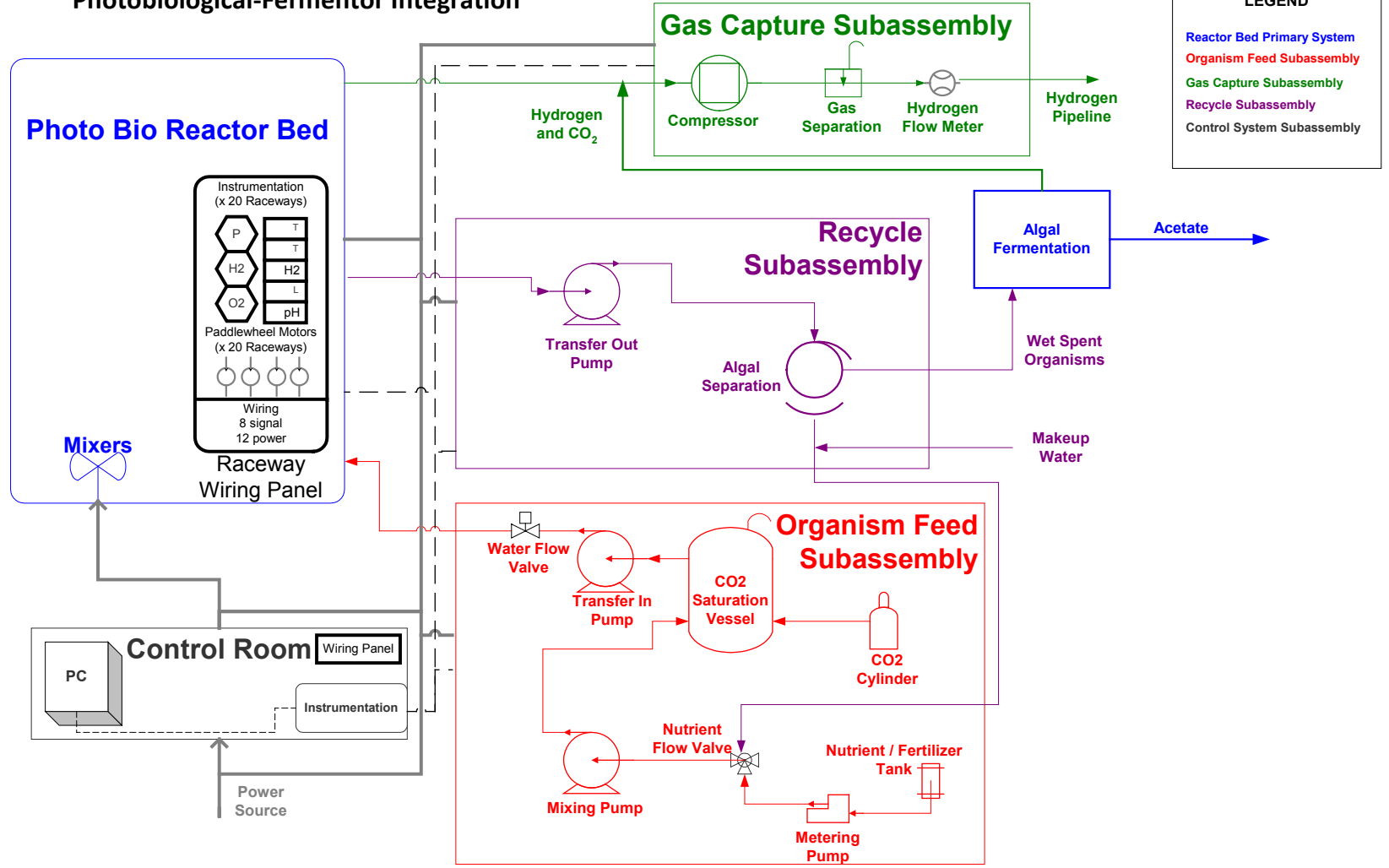

Our analysis combines the waste organisms of the B-1, B-2 and B-5 systems with fermentation. Since the capital costs and the reactor specifications for B-1 are the same as B-2, we have assumed the results for both systems to be the same. Neither the B-3 nor the B-4 systems produce any waste algae, since all the algae mass is needed for respiration to keep the systems anaerobic. Additionally, the algae in the B-4 system are mounted on an immobilized mat, and its waste organisms would to require additional processing which would not result in an economically beneficial integration. The B-5 system is similar conceptually to the B-1 and B-2 system with the exception that it is able to use the waste acetate stream from fermentation to feed the photosynthetic organisms. Because of this additional requirement there is an acetate retrieval pump required, making the B-5 Photobio-Fermentor Integration a separate integration pathway. The Bill of Materials for the B-5 with Fermentation is shown as an example in Figure 28-6. The Bill of Materials for B-1and B-2 with fermentation would be similar. 
Figure 28-6. BOM for B-5/C-5 Integrated System

\begin{tabular}{|c|c|c|c|c|c|c|c|c|}
\hline Description & Size Req'd & Unit Size & Units & & Unit cost & Qty Req'd & Total Cost & Material / Part Description \\
\hline \multicolumn{9}{|l|}{ Photo Bio Reactor Bed Subassembly } \\
\hline Transparent Film & $235116 \mathrm{~m} 2$ & 1 & $\mathrm{~m} 2$ & $\$$ & 0.54 & $235,116 \$$ & 126,551 & Polyethylene price quote at $\$ 0.54 / \mathrm{mz} 2(\$ 0.05 / \mathrm{tt} 2)$ \\
\hline Pond Lining & $253795 \mathrm{~m} 2$ & 1 & $\mathrm{~m} 2$ & $\$$ & 0.47 & $253,795 \$$ & 119,912 & Butyl rubber, PVC, and LDPE (low density polyethylene)based on quote of $\$ 175.56$ for 4,000 oftz. \\
\hline Pond Edging & $37752 \mathrm{~m}$ & 1 & m & $\$$ & 7.00 & $37,752 \$$ & 264,266 & Unit Cost is engineering estimate at $\$ 7 / \mathrm{m}$ \\
\hline Installation of Ponds & & 1 & raceway & $\$$ & $26,083.00$ & $54 \$$ & $1,408,482$ & Based on California labor rates. \\
\hline Paddlewheel Mixers & & 1 & each & $\$$ & $5,000.00$ & $108 \$$ & 540,000 & Est. paddlewhel cost. 4 per raceway. 18 raceways. \\
\hline Inlet Water Valve & $0.5 \mathrm{in}$ & 1 & each & $\$$ & 43.46 & $54 \$$ & 2,347 & Price from Valvestore.com (http://www.valvestore.com//rodinfo.asp?number=551032) \\
\hline Outlet Water Valve & $0.5 \mathrm{in}$ & 1 & each & $\$$ & 43.46 & $54 \$$ & 2,347 & Price from Valvestore.com (http://www.valvestore.com/rrodinfo.asp?number=551032) \\
\hline Outlet Gas Valve & $1.0 \mathrm{in}$ & 1 & each & $\$$ & 67.23 & $54 \$$ & 3,630 & Price from Valvestore.com (http://www.valvestore.com//rodinfo.asp?number=551032) \\
\hline Flanges & $0.5 \mathrm{in}$ & 1 & each & $\$$ & 8.00 & $162 \$$ & 1,296 & Price from http://www.ancorp.com/line.aspx?:id=819 \\
\hline \multicolumn{9}{|l|}{ Gas Capture Subassembly } \\
\hline Compressor & $45 \mathrm{kgmol} / \mathrm{hr}$ & 45 & $\mathrm{kgmol} / \mathrm{hr}$ & $\$$ & $9,233.00$ & $1 \$$ & 414,241 & Using H2A Unit cost \\
\hline PSA & & & & $\$$ & 26,895 & $1 \$$ & 30,542 & Using H2A scaling \\
\hline Raceway Collection Pipe & $108 \mathrm{ft}$ & 1 & $\mathrm{ft}$ & $\$$ & 1.00 & $108 \$$ & 108 & $\begin{array}{l}\text { Sized for Peak k } 1 \text { ydrogen production. Assuming Plastic Gas piping, } 100 \text { ft/s velocity, uniform pipe diameter (can be } \\
\text { altered) and } 2 \text { to } 1 \text { molar ratio of hydrogen to oxygen. Pricing from PVC Plastic Corp. }\end{array}$ \\
\hline Main Collection Pipe & $3120 \mathrm{ft}$ & 1 & $\mathrm{ft}$ & $\$$ & 6.18 & $3120 \$$ & 19,282 & $\begin{array}{l}\text { Sized for Peak Hydrogen production. Assuming Plastic Gas piping, } 100 \mathrm{ft} / \mathrm{s} \text { velocity, uniform pipe diameter (can be } \\
\text { altered) and } 2 \text { to } 1 \text { molar ratio of hydrogen to oxygen. Pricing from PVC Plastic Corp. }\end{array}$ \\
\hline Gas Capture Pipe & $50 \mathrm{ft}$ & 1 & $\mathrm{ft}$ & $\$$ & 6.18 & $50 \$$ & 309 & altered) and 2 to 1 molar ratio of hydrogen to oxygen. Pricing from PVC Plastic Corp. \\
\hline \multicolumn{9}{|l|}{ Organism Feed Subassembly } \\
\hline Transfer In Pump & $150 \mathrm{gpm}$ & 150 & $\mathrm{gpm}$ & $\$$ & 10,252 & $3 \$$ & 30,755 & Est. Based on Perry's Chemical Handbook, Plant Design and Economics \\
\hline Nutrient Metering Pumps & & 1468 & $\mathrm{Gal} / \mathrm{Hr}$. & $\$$ & 2,594 & $1 \$$ & 2,594 & Est. Based on Perry's Chemical Handbook, Plant Design and Economics \\
\hline Mixing Pump & $150 \mathrm{gpm}$ & 150 & gpm & $\$$ & 10,252 & $3 \$$ & 30,755 & Est. Based on Perry's Chemical Handbook, Plant Design and Economics \\
\hline Nutrient Tank & $21 \mathrm{gal}$ & 10 & gal & $\$$ & 30.00 & $3 \$$ & 90 & 10 gallon Cylindrical Process Tank, Part \#0275-085 (http://www.watertanks.com/products/0275-085.asp) \\
\hline Raceway Slurry Collection Pipe & $108 \mathrm{ft}$ & 1 & $\mathrm{ft}$ & $\$$ & 1.00 & $108 \$$ & 108 & Pricing based off of Estimates from PVC Plastic Corp. Assumes $10 \mathrm{ft} / \mathrm{sec}$ cond flow rate and Density of $1 \mathrm{~g} / \mathrm{mm}$ \\
\hline Main Slurry Collection Pipe & $3120 \mathrm{ft}$ & 1 & $\mathrm{ft}$ & $\$$ & 4.31 & $3120 \$$ & 13,447 & Pricing based off of Estimates from PVC Plastic Corp. Assumes $10 \mathrm{ft} / \mathrm{sec}$ cond flow rate and Density of $1 \mathrm{~g} / \mathrm{ml}$ \\
\hline Recycle-Feed Transfer Pipe & $180 \mathrm{ft}$ & 1 & $\mathrm{ft}$ & $\$$ & 6.18 & $180 \$$ & 1,112 & Pricing based off of Estimates from PVC Plastic Corp. Assumes $10 \mathrm{ft} / \mathrm{sec}$ cond flow rate and Density of $1 \mathrm{~g} / \mathrm{mm}$ \\
\hline \multicolumn{9}{|l|}{ Consumables } \\
\hline Initial Nutrients & $1 \mathrm{lb}$ & 1 & lb & $\$$ & 0.20 & $1.112714485 \$$ & 0 & NFC Company, Chicago, IL (800) 7344515 \\
\hline Initial Water & $5720312 \mathrm{gal}$ & 1 & gal & $\$$ & 0.00 & $5720311.865 \$$ & 9,524 & H2A Feedstock Costs \\
\hline Initial Acetate & $7793 \mathrm{~kg}$ & 1 & $\mathrm{~kg}$ & $\$$ & 0.60 & $7792.757824 \$$ & 4,637 & Chemical Journal of Korea. Assumes consumption to be four times more to account for full growth conditions. \\
\hline \multicolumn{9}{|l|}{ Recycle Subassembly } \\
\hline Rotary Drum filter & $25,741 \mathrm{gph}$ & 3750 & $\mathrm{gph}$ & $\$$ & $87,000.00$ & $7 \$$ & 609,000 & Information from Dana Kent at Advanced Aquaculture Inc. on Hydrotech Drum Filter \\
\hline Transfer Out Pump & $150 \mathrm{gpm}$ & 150 & $\mathrm{gpm}$ & $\$$ & 10,252 & $3 \$$ & 30,755 & Est. Based on Perry's chemical Handbook, Plant Design and Economics \\
\hline Main Slurry Feed Pipe & $3120 \mathrm{ft}$ & 1 & $\mathrm{ft}$ & $\$$ & 4.31 & $3120 \$$ & 13,447 & Pricing based off of Estimates from PVC Plastic Corp. Assumes $10 \mathrm{ft} / \mathrm{sec}$ cond flow rate and Density of $1 \mathrm{~g} / \mathrm{ml}$ \\
\hline Raceway Slurry Feed Pipe & $108 \mathrm{ft}$ & 1 & $\mathrm{ft}$ & $\$$ & 1.00 & $108 \$$ & 108 & Pricing based off of Estimates from PVC Plastic Corp. Assumes $10 \mathrm{ft} / \mathrm{sec}$ cond flow rate and Density of $1 \mathrm{~g} / \mathrm{ml}$ \\
\hline \multicolumn{9}{|l|}{ Fermentation Subassembly } \\
\hline Tank & $6173 \mathrm{gal}$ & 1 & gal & $\$$ & 2.00 & $24,693 \$$ & 49,386 & This is a scaled cost based on the capital costs from NREL Report TP-510-32438 \\
\hline Slurry Piping - $0.5^{\prime \prime}$ & $500 \mathrm{ft}$ & 1 & $\mathrm{ft}$ & $\$$ & 0.52 & $500 \$$ & 260 & Sized using Continuity Equation. Assumed a velocity of 1 t//sec. \\
\hline Slurry Piping - 1" & $5077 \mathrm{ft}$ & 1 & $\mathrm{ft}$ & $\$$ & 1.00 & $5,077 \$$ & 5,077 & Sized using Continuity Equation. Assumed a velocity of 1 t $/$ /sec. \\
\hline Pump & $6173 \mathrm{gal} / \mathrm{day}$ & 4 & $\mathrm{gal} / \mathrm{min}$ & $\$$ & 198.50 & $1 \$$ & 199 & http://mwwe.grainger.com//rainger/titems/19795 \\
\hline Inlet Valves & 1 in & 1 & each & $\$$ & 67.23 & $4 \$$ & 269 & 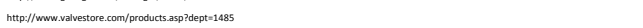 \\
\hline Outlet Valves & $0.5 \mathrm{in}$ & 1 & each & $\$$ & 46.85 & $4 \$$ & 187 & 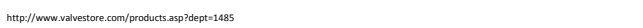 \\
\hline \multicolumn{9}{|l|}{ Control System } \\
\hline Control Room & $160 \mathrm{ft} 2$ & 1 & $\mathrm{ft} 2$ & $\$$ & 50.00 & $160 \$$ & 8,000 & comes from price quote of $\$ 50 / \mathrm{ft} 2$ from http://www.buyerzone.com/industrial/modular_buildings/prefab_guide.html \\
\hline Control Room Wiring Panel & & 1 & & $\$$ & $3,000.00$ & $1 \$$ & $3,000.00$ & Consultation with Innomation Systems Inc. \\
\hline Raceway wiring Panel & & 1 & & $\$$ & 146.00 & $54 \$$ & 7,884 & Information from Tessco Technologies Inc. \\
\hline Computer and Monitor & & 1 & & $\$$ & $1,500.00$ & $1 \$$ & $1,500.00$ & Information from Emerson Process Management \\
\hline Labview Software & & 1 & & $\$$ & $4,299.00$ & $1 \$$ & $4,299.00$ & Information from Emerson Process Management \\
\hline Level Indicators & & 1 & & $\$$ & 714.00 & $54 \$$ & $38,556.00$ & Omega Engineering Inc. LVR51 Liquid Level Float Transmitter + DPi32 Meter \\
\hline Pressure Sensors & & 1 & & $\$$ & 345.00 & $54 \$$ & $\$ 18,630.00$ & Omega Engineering Inc. PX209 Pressure Trnasducer + DPi32 Meter \\
\hline Hydrogen Area Sensors & & 1 & & $\$$ & $7,600.00$ & $27 \$$ & $\$ 205,200.00$ & Honeywell 7866 Gas Analyzer_hhtp://www.lesman.com/unleashd/catalog/analytical//analyt hwhydrogengas.htm) \\
\hline Air Temperature Meter & & 1 & & $\$$ & 599.00 & $1 \$$ & $\$ 599.00$ & Omega DP81T Meter \\
\hline Air Temperature Indicator & & 1 & & $\$$ & 38.00 & $54 \$$ & $2,052.00$ & Omega TH-10-44000 Thermistor Probe \\
\hline Water Temperature Indicator & & 1 & & $\$$ & - & $54 \$$ & - & Comes with the PH sensor \\
\hline $\mathrm{pH}$ level Indicator & & 1 & & $\$$ & 435.00 & $54 \$$ & $23,490.00$ & Omega Engineering Inc. PHE - 6510 PH electrode + DP24-PH Meter \\
\hline Oxygen Area Sensors & & 1 & & $\$$ & - & $54 \$$ & - & Comes with H2 Sensor \\
\hline Nutrient Flow Valve & & 1 & & $\$$ & $5,500.00$ & $1 \$$ & $5,500.00$ & Information from Emerson Process Management \\
\hline Water Flow Valve & & 1 & & $\$$ & $5,500.00$ & $1 \$$ & $5,500.00$ & Information from Emerson Process Management \\
\hline Hydrogen Flow Meter & & 1 & & $\$$ & $5,500.00$ & $1 \$$ & $5,500.00$ & Information from Emerson Process Management \\
\hline Instrument Wiring & $406380 \mathrm{ft}$ & 1 & $\mathrm{ft}$ & $\$$ & 0.02 & $406380 \$$ & $7,883.77$ & Information from Waytek Inc. at waytekwire.com \\
\hline Power Wiring & $505080 \mathrm{ft}$ & 1 & $\mathrm{ft}$ & $\$$ & 0.02 & $505080 \$$ & $9,798.55$ & Information from Waytek Inc. at waytekwire.com \\
\hline Conduit & $12340 \mathrm{ft}$ & 1 & $\mathrm{ft}$ & $\$$ & 0.58 & $12340 \$$ & $7,154.73$ & Information from Waytek Inc. at waytekwire.com \\
\hline
\end{tabular}

\subsection{Lignocellulosic Fermentation/MEC Integration}

The output from a lignocellulosic fermentor would be primarily a mix of acetic acid and ethanol with lesser amounts of other organic acids and glucose. NREL fermentor research on the corn stover $\mathrm{H}_{2}$ fermentor resulted in the following byproduct:

$\begin{array}{lr}\text { acetic acid } & 26.0 \mathrm{mM} \\ \text { succinic acid } & 5.6 \mathrm{mM} \\ \text { lactic acid } & 1.8 \mathrm{mM} \\ \text { formic acid } & 0.6 \mathrm{mM} \\ \text { ethanol } & 14.0 \mathrm{mM}\end{array}$


Subsequently, research at Penn State operated the MEC on this product mix. ${ }^{99}$

The fermentation integration evaluated was that of lignocellose fermentation with MEC. This integration occurs in series providing little overlap in equipment. The process diagram is shown in Figure 28-7.

Figure 28-7. Process Diagram for Fermentation-MEC Integration Integrated Lignocellosic Fermentation with MEC

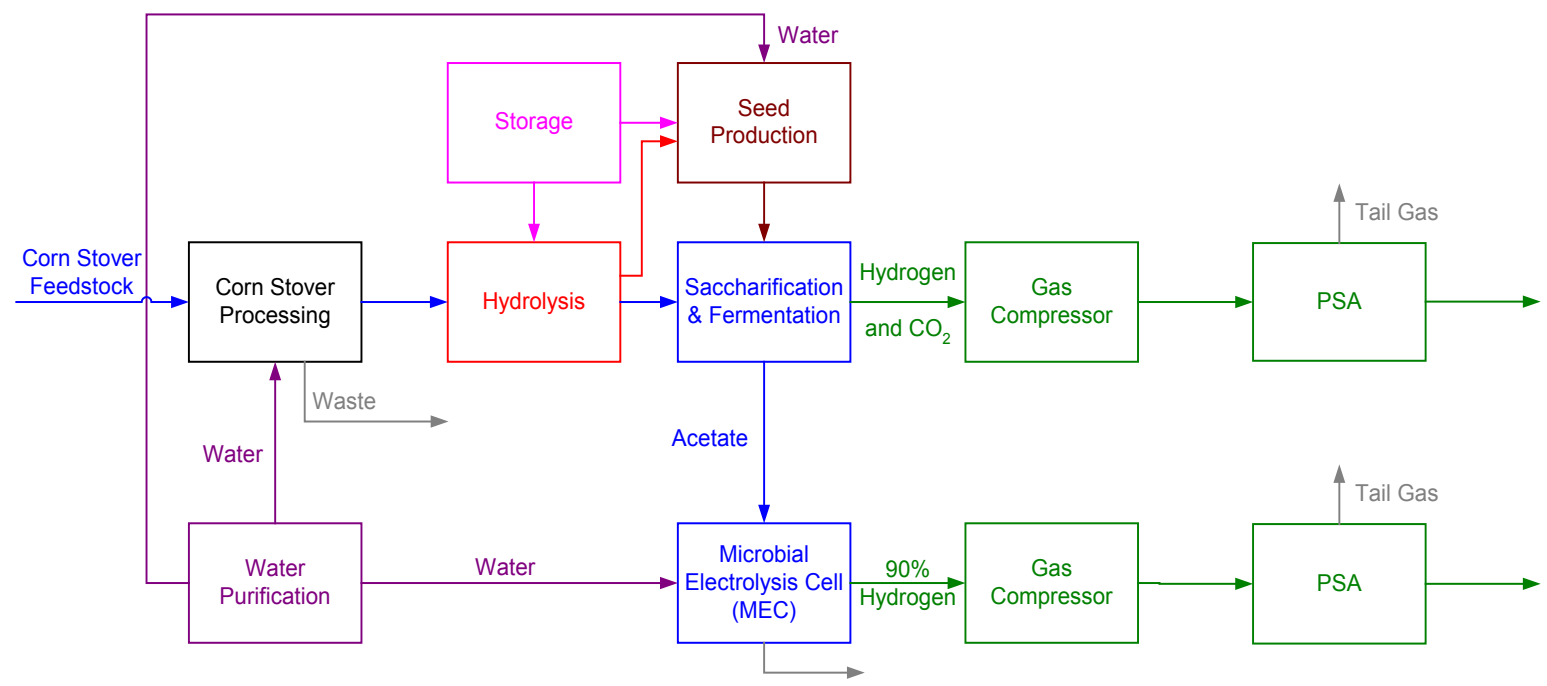

The MEC component of this integrated system as defined in Part III has been sized to consume $100 \%$ of the lignocellose fermentation waste acetate and other organics. We have assumed no extra labor will be needed for the integrated system. Because the hydrogen volumes are large and the output gas compositions are different in each case system, separate gas capture systems are used for the fermentor and MEC. The Bill of Materials for the Integrated FermentationMEC is shown in Figure 28-8.

99 Logan, Bruce. "Electrochemically Assisted Microbial Fermentation of Acetate."ZFH-8-77623-01. NREL. Colorado. Janurary 2009. 
Figure 28-8. Bill of Materials for Integrated Fermentation-MEC

\begin{tabular}{|c|c|}
\hline Description & Install Factor \\
\hline Corn Stover Prep Subassembly & \\
\hline Bale Transport Conveyor & 1.62 \\
\hline Bale Unwrapping Conveyor & 1.19 \\
\hline Belt Press Discharge Conveyor & 1.89 \\
\hline Shredder Feed Conveyor & 1.38 \\
\hline Truck Scales & 2.47 \\
\hline Truck Unloading Forklift & 1 \\
\hline Bale Moving Forklift & 1 \\
\hline Corn Stover Wash Table & 2.39 \\
\hline Shredder & 1.38 \\
\hline Concrete Feedstock-Storage Slab & 2.2 \\
\hline Polymer Feed System & 2.28 \\
\hline Wash Table Pump & 3.87 \\
\hline Wash Water Pump & 5.19 \\
\hline Clarifier Underflow Pump & 13.41 \\
\hline Clarified Water Pump & 7.07 \\
\hline Belt Press Sump Pump & 2.92 \\
\hline $\begin{array}{l}\text { Clarifier Thickener } \\
\text {. }\end{array}$ & 1.51 \\
\hline Belt Press & 1.25 \\
\hline Magnetic Separator & 1.3 \\
\hline Wash Water Tank & 2.8 \\
\hline Clarifier Thickener Tank & 3.04 \\
\hline Pretreatment/Hydrolysis Subassembly & \\
\hline Hydrozylate Mix Tank Agitator & 1.2 \\
\hline Hydrozylate Mixing Tank & 1.2 \\
\hline Hydrozylate Cooler & 2.1 \\
\hline In-line Sulfuric Acid Mixer & 1 \\
\hline Sulfuric Acid Pump & 2.8 \\
\hline Sulfuric Acid Tank & 1.4 \\
\hline Lime Solids Feeder & 1.3 \\
\hline Lime Unloading Blower & 1.4 \\
\hline Lime Dust Vent Baghouse & 1.5 \\
\hline Lime Storage Bin & 1.3 \\
\hline Hydrolysis Tank Pump & 2.8 \\
\hline Methane Boiler & 1.3 \\
\hline Fermentation Subassembly & \\
\hline Fermentation Tank & 1.2 \\
\hline Fermentation Agitator & 1.2 \\
\hline Fermentation Cooler & 2.1 \\
\hline Fermentation Recirculation Pump & 2.8 \\
\hline Lignin Wet Cake Screw & 1.4 \\
\hline Acetate Product Storage Tank & 1.4 \\
\hline Acetate Transfer Pump & 1.3 \\
\hline Pneumapress filter & 1.4 \\
\hline$H X-1$ & 1.3 \\
\hline$H X-2$ & 1.3 \\
\hline FTC & 1.3 \\
\hline Seed Production Subassembly & \\
\hline Seed Hold Tank & 1.2 \\
\hline Seed Hold Tank Agitator & 1.2 \\
\hline Seed Hold Transfer Pump & 1.4 \\
\hline 1st Seed Fermentor & 2.8 \\
\hline 2nd Seed Fermentor & 2.8 \\
\hline 3rd Seed Fermentor & 2.8 \\
\hline 4th Seed Fermentor & 1.2 \\
\hline 5th Seed Fermentor & 1.2 \\
\hline 4th Seed Agitator & 1.2 \\
\hline 5th Seed Agitator & 1.2 \\
\hline 4th Seed Fermentor Coil & 1.2 \\
\hline 5th Seed Fermentor Coil & 1.2 \\
\hline Seed Transfer Pump & 1.4 \\
\hline MEC Subassembly & \\
\hline MEC Tanks & 1.3 \\
\hline Brush Cathode & 1.2 \\
\hline Brush Anode & 1.2 \\
\hline Power Supply & 1.3 \\
\hline Process Water Circulating Pump & 2.8 \\
\hline MIC - 1 & 1.3 \\
\hline MIC - 2 & 1.3 \\
\hline Cooling Water Pump/MEC Pumps & 2.8 \\
\hline Storage Subassembly & \\
\hline CSL Storage tank Agitator & 1.2 \\
\hline CSL Pump & 2.8 \\
\hline CSL Storage Tank & 1.4 \\
\hline CSL/DAP Day Tank & 1.4 \\
\hline CSL/DAP Pump & 2.8 \\
\hline CSL/DAP Day Tank Agitator & 1.2 \\
\hline DAP Solids Feeder & 1.3 \\
\hline DAP Unloading Blower & 1.4 \\
\hline DAP Vent Baghouse & 1.5 \\
\hline DAP Storage Bin & 1.3 \\
\hline Sulfuric Acid Pump & 2.8 \\
\hline Sulfuric Acid Storage Tank & 1.2 \\
\hline Propane Storage Tank & 1.4 \\
\hline Make-up Water Pump & 2.8 \\
\hline Process Water Circulating Pump & 2.8 \\
\hline Process Water Tank & 1.4 \\
\hline Gas Capture Subassembly & \\
\hline Compressor Fermentor & \\
\hline FC-1 & 1.3 \\
\hline FIC -1 & 1.3 \\
\hline FIC -2 & 1.3 \\
\hline Compressor MEC & 1.3 \\
\hline PSA Fermentor & 1.3 \\
\hline PSA MEC & 1.3 \\
\hline Hydrogen Flow Meter & 1.3 \\
\hline
\end{tabular}




\subsubsection{Flow Chart}

The combined system mass flows and flow properties are diagramed in Figure 28-9. Details of these components and the reactions are included in the Part II discussions. A detailed Mass and energy balance is included in Part IV, Appendix A.

\section{Figure 28-9. Fermentor/MEC Mass Balance Flow Chart}

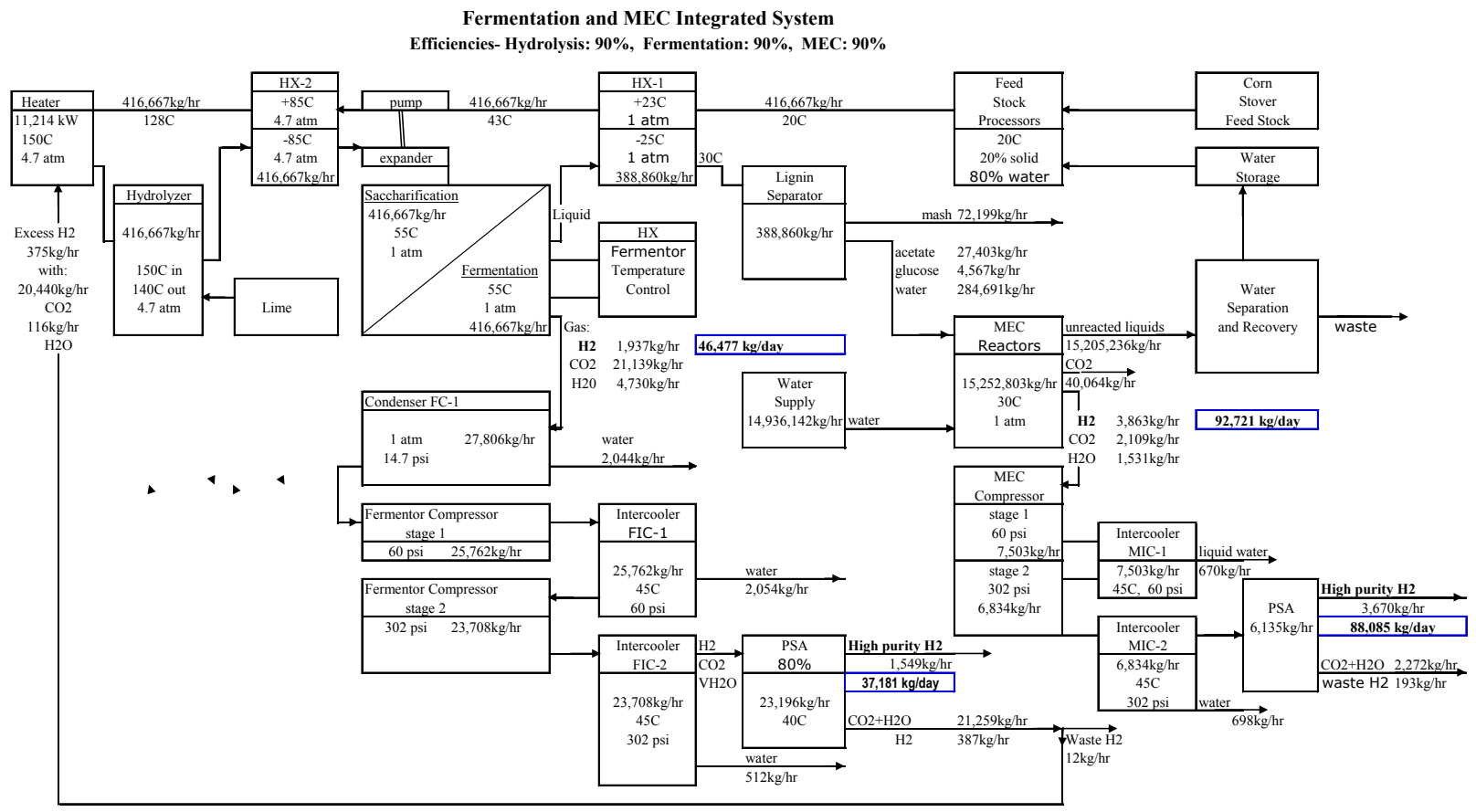

29. Results and Discussion for Integrated Systems

The hydrogen production costs for the previously described system combinations are discussed below. By comparing the hydrogen production costs from the integrated systems to the individual systems we can determine if there is any benefit to systems integration. A cost comparison for the integrated systems is shown in Figure 29-1. 
Figure 29-1. Integrated Systems Results

\begin{tabular}{|c|c|c|c|}
\hline Systems & Capital Costs & $\begin{array}{c}\text { H2 Production } \\
\text { (kg/day) }\end{array}$ & H2 Cost $(\$ / \mathrm{kg})$ \\
\hline \multicolumn{4}{|l|}{ Stacked Photobio Beds } \\
\hline Stand alone B-3 & $\$ 39,485,240$ & 10,000 & $\$ 4.17$ \\
\hline Stand alone B-5 & $\$ 34,196,970$ & 10,000 & $\$ 10.36$ \\
\hline Integrated & $\$ 41,485,500$ & 10,600 & $\$ 5.25$ \\
\hline \multicolumn{4}{|l|}{ Photobio-Fermentor Integration } \\
\hline Stand Alone B-1/B-2 & $\$ 21,880,470$ & 10,000 & $\$ 2.99$ \\
\hline Stand Alone Algae Fermentation ( $\mathrm{C} 1 / \mathrm{C} 2)$ & $\$ 37,142$ & 7 & $\$ 172.73$ \\
\hline Integrated & $\$ 22,272,680$ & 10,007 & $\$ 3.21$ \\
\hline \multicolumn{4}{|l|}{ Photobio-Fermentor Integration } \\
\hline Stand Alone B-5 & $\$ 34,196,970$ & 10,000 & $\$ 10.36$ \\
\hline Stand Alone Algae Fermentation (C5) & $\$ 86,211$ & 13 & $\$ 66.17$ \\
\hline Integrated & $\$ 34,591,120$ & 10,013 & $\$ 11.04$ \\
\hline \multicolumn{4}{|l|}{ Lignocellulosic Fermentor and MEC } \\
\hline Lignocellulosic Alone & $\$ 44,944,078$ & 37,181 & $\$ 4.33$ \\
\hline MEC Alone & $\$ 558,689,165$ & 88,055 & $\$ 12.43$ \\
\hline Integrated & $\$ 593,317,371$ & 125,266 & $\$ 6.61$ \\
\hline
\end{tabular}

The cost change between the stand-alone systems and the integrated systems is shown in Figure 29-2.

Figure 29-2. Comparison of Integrated System Costs

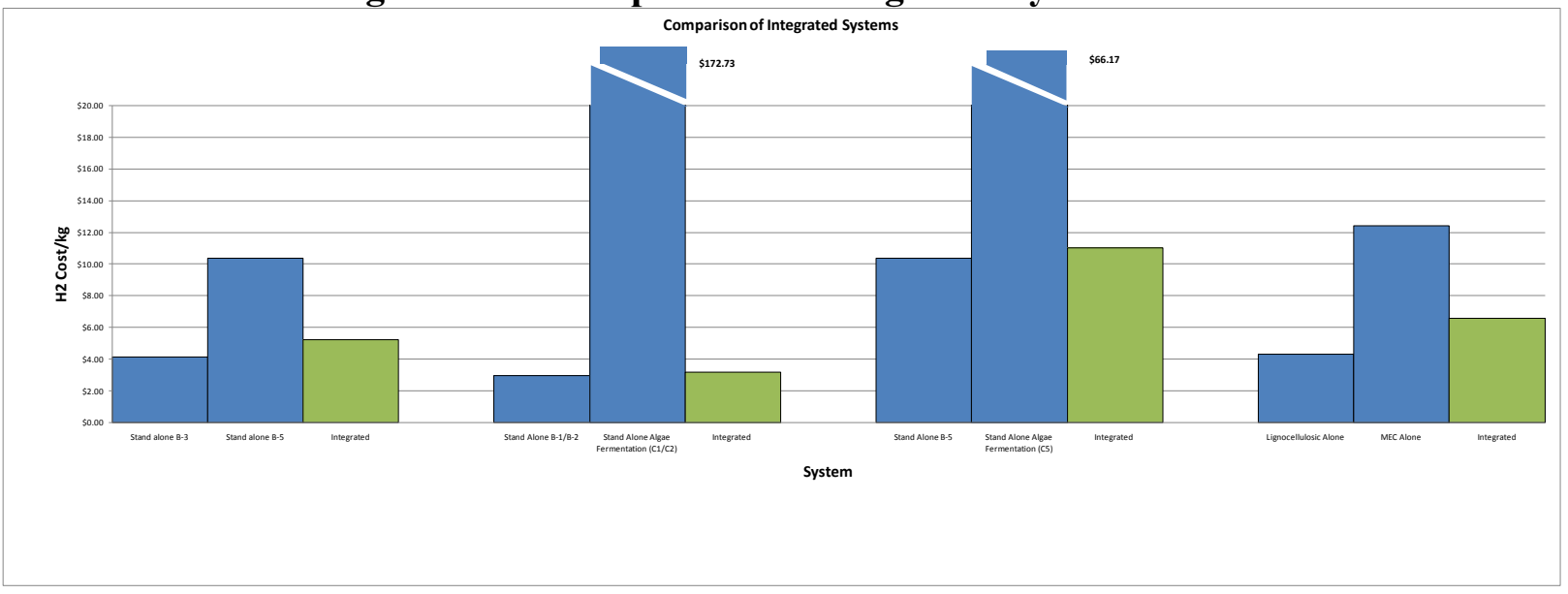


30. Integrated System Conclusions and Recommendations

Integrating hydrogen producing systems can yield greater hydrogen production per area of land, however, it is not necessarily the most cost effective method of producing hydrogen for the following reasons:

- The increase in capital costs for the stacked photobioreactor beds and the photobioreactor plus fermentor, while less than the systems alone, are still substantial enough to outweigh the increase in hydrogen output.

- For the Fermentor/MEC combination, the high cost of $\mathrm{H}_{2}$ from the MEC makes the combination uneconomic. This is partly due to the current immature and unoptimized status of the MEC, and the results could be markedly improved with additional MEC developments and cost optimization. 
31. Part IV Appendix A: Integrated Fermentor/MEC Mass/Heat Balance

\begin{tabular}{|c|c|c|c|c|c|c|c|c|c|c|c|c|c|}
\hline \multicolumn{3}{|l|}{ Processes } & \multirow[b]{2}{*}{$\%$} & \multicolumn{2}{|l|}{ Mass flow } & \multirow{2}{*}{$\begin{array}{c}\text { mole flow } \\
\mathrm{kgM} / \mathrm{hr}\end{array}$} & \multirow{2}{*}{${ }^{\mathrm{T}} \mathrm{C}$} & \multirow{2}{*}{$\begin{array}{c}\text { Tave } \\
{ }^{\circ} \mathrm{C}\end{array}$} & \multirow{2}{*}{$\begin{array}{l}\Phi T \\
{ }^{\circ} \mathrm{C}\end{array}$} & \multirow{2}{*}{$\begin{array}{l}P \\
\mathrm{psi}\end{array}$} & \multirow{2}{*}{$\underset{\mathrm{Cp}}{\mathrm{CJ} / \mathrm{kg}}{ }^{\circ} \mathrm{C}$} & \multirow{2}{*}{$\begin{array}{c}\mathrm{h} \\
\mathrm{kJ} / \mathrm{kg}\end{array}$} & \multirow{2}{*}{$\begin{array}{l}\text { dq/dt } \\
\mathrm{kJ} / \mathrm{hr}\end{array}$} \\
\hline \multirow{7}{*}{\begin{tabular}{|l|} 
Feedstock \\
Inputs
\end{tabular}} & & & & kg/day & $\mathrm{kg} / \mathrm{hr}$ & & & & & & & & \\
\hline & \multirow[t]{4}{*}{ Corn stover } & & $20.0 \%$ & $2,000,000$ & 83,333 & & 20 & & & 14.7 & & & \\
\hline & & cellulose & $36.7 \%$ & 734,000 & 30,583 & & & & & & & & \\
\hline & & hemicell & $27.4 \%$ & 548,000 & 22,833 & & & & & & & & \\
\hline & & \begin{tabular}{|l} 
Lignin,etc \\
total
\end{tabular} & $\frac{35.9 \%}{100 \%}$ & $\frac{718,000}{200000}$ & $\frac{29,917}{8333}$ & & & & & & & & \\
\hline & water & & $80.0 \%$ & $8,000,000$ & 333,333 & & 20 & & & 14.7 & & & \\
\hline & total slurry & & $100.0 \%$ & $10,000,000$ & 416,667 & & 20 & & & 14.7 & & & \\
\hline \multirow[t]{4}{*}{ HX-1 } & \multirow{2}{*}{\multicolumn{2}{|c|}{$\begin{array}{l}\text { from feedstock } \\
\text { to } \mathrm{HX}-2\end{array}$}} & & $10,000,000$ & 416,667 & & 20.0 & & & 14.7 & 4.180 & & \\
\hline & & & & $10,000,000$ & 416,667 & & 43.3 & 31.7 & 23.3 & & & & $40,655,319$ \\
\hline & \multirow{2}{*}{\multicolumn{2}{|c|}{$\begin{array}{l}\text { from fermentor } \\
\text { to LigSep }\end{array}$}} & & $9,332,641$ & $388,860.06$ & & 55.0 & & & 14.7 & 4.182 & & \\
\hline & & & & $9,332,641$ & 388,860 & & 30.0 & 42.5 & -25.0 & & & & $-40,655,319$ \\
\hline \multirow[t]{4}{*}{ HX-2 } & \multirow{2}{*}{\multicolumn{2}{|c|}{$\begin{array}{l}\text { from HX-1 primary } \\
\text { to hydrolyzer heater }\end{array}$}} & & $10,000,000$ & 416,667 & & 43.3 & & & 68.8 & 4.206 & & \\
\hline & & & & $10,000,000$ & 416,667 & & 128.5 & 85.9 & 85.2 & & & & $149,281,250$ \\
\hline & \multirow{2}{*}{\multicolumn{2}{|c|}{$\begin{array}{l}\text { from hydrolyzer } \\
\text { to sacchrification }\end{array}$}} & & $10,000,000$ & 416,667 & & 140.0 & & 85.0 & 68.8 & 4.215 & & \\
\hline & & & & $10,000,000$ & 416,667 & & 55.0 & 97.5 & & & & & $-149,281,250$ \\
\hline \multirow{10}{*}{$\begin{array}{r}\begin{array}{l}\text { Hydolyzer } \\
\text { Heater }\end{array} \\
\end{array}$} & \multirow{2}{*}{\multicolumn{2}{|c|}{ heating of slurry from $\mathrm{HX}-2$}} & & $10,000,000$ & 416,667 & & 128.5 & & & & & & \\
\hline & & & & $10,000,000$ & 416,667 & & 150.0 & 139.3 & 21.5 & 68.8 & 4.290 & & $38,387,188$ \\
\hline & \multirow{2}{*}{\multicolumn{2}{|c|}{\begin{tabular}{|c|} 
heating of $\mathrm{CO} 2$ from PSA \\
$\mathrm{CO} 2 / \mathrm{H} 2$ mass 54.58 \\
\end{tabular}}} & & 490,873 & 20,453 & & 45.0 & & & & & & \\
\hline & & & & 490,873 & 20,453 & & 150.0 & 97.5 & 105.0 & 14.7 & 0.913 & & $1,960,729$ \\
\hline & \multirow{2}{*}{\multicolumn{2}{|c|}{$\begin{array}{l}\text { heating of } \mathrm{H} 2 \mathrm{O} \text { from PSA } \\
\mathrm{H} 2 \mathrm{O} / \mathrm{H} 2 \text { mass } 0.31\end{array}$}} & & 2,783 & 116 & & 45.0 & & & & & & \\
\hline & & & & 2,783 & 116 & & 150.0 & 97.5 & 105.0 & 14.7 & 1.970 & & 23,985 \\
\hline & \multicolumn{3}{|c|}{ Total heat input required (neglecting H2 $\Phi T$ ) } & & & & & & & & & & $40,371,902$ \\
\hline & \multicolumn{2}{|c|}{\begin{tabular}{|l|} 
Waste $\mathrm{H} 2$ burner heating \\
\end{tabular}} & & & & & & & & & & & \\
\hline & H2 LHV kJ/kg = & 119,705 & $90 \%$ & 8,994 & 375 & & & & & 14.7 & & & $40,371,902$ \\
\hline & & & & $10,000,000$ & 416,667 & & & & & & & & \\
\hline
\end{tabular}

\begin{tabular}{|c|c|c|c|c|c|c|c|c|c|c|c|c|}
\hline \multicolumn{3}{|c|}{ Total heating from $\mathrm{HX}-1+\mathrm{HX}-2+$ Heater } & & & & & & & & & & $230,308,471$ \\
\hline \multirow{14}{*}{$\begin{array}{l}\text { efficiency= } \\
90 \%\end{array}$} & \multicolumn{2}{|l|}{ In from Heater } & & $10,000,000$ & 416,667 & & \multirow[t]{6}{*}{150.0} & & & \multirow{6}{*}{$\begin{array}{l}68.8 \\
\begin{array}{c}6.68 \\
\mathrm{~atm}\end{array} \\
\end{array}$} & & \\
\hline & \multirow[t]{5}{*}{ inputs } & cellulose & $36.7 \%$ & 734,000 & 30,583 & & & & & & & \\
\hline & & hemicell & $27.4 \%$ & 548,000 & 22,833 & & & & & & & \\
\hline & & Lignin,etc & & 718,000 & 29,917 & & & & & & & \\
\hline & & water & $80.0 \%$ & $8,000,000$ & 333,333 & & & & & & & \\
\hline & & total & & $10,000,000$ & 416,667 & & & & & & & \\
\hline & \multirow[t]{6}{*}{$=$ output } & \multicolumn{2}{|c|}{ complex sugars } & $1,153,800$ & 48,075 & & \multirow[t]{6}{*}{140.0} & & & & & \\
\hline & & xylan & & 128,200 & 5,342 & & & & & & & \\
\hline & & \multirow{2}{*}{\multicolumn{2}{|c|}{\begin{tabular}{|l} 
Lignin,etc \\
organics
\end{tabular}}} & 718,000 & 29,917 & & & & & & & \\
\hline & & & & $2,000,000$ & 83,333 & & & & & & & \\
\hline & & \multirow{2}{*}{\multicolumn{2}{|c|}{\begin{tabular}{|l} 
water \\
total
\end{tabular}}} & $8,000,000$ & 333,333 & & & & & & & \\
\hline & & & & $10,000,000$ & 416,667 & & & & & & & \\
\hline & \multirow{2}{*}{\multicolumn{2}{|c|}{\begin{tabular}{|l} 
Endothermic heat absorption $\Phi T$ \\
to HX-2
\end{tabular}}} & & & & & 10.0 & & & & & \\
\hline & & & & $10,000,000$ & 416,667 & & 140.0 & & & 68.8 & & \\
\hline $\begin{array}{l}\text { Saccharification } \\
\text { in fermentor }\end{array}$ & \multicolumn{3}{|l|}{$\begin{array}{l}\text { from HX-2 } \\
\text { to fermentation }\end{array}$} & $\begin{array}{l}10,000,000 \\
10,000,000\end{array}$ & $\begin{array}{l}416,667 \\
416,667\end{array}$ & & $\begin{array}{l}55.0 \\
55.0\end{array}$ & & & & & \\
\hline \multirow{17}{*}{$\begin{array}{c}\text { Fermentor } \\
\text { efficiency }=\end{array}$} & \multirow{5}{*}{$\begin{array}{l}\text { in from } \\
\text { sacchrification }\end{array}$} & \multirow{2}{*}{\multicolumn{2}{|c|}{\begin{tabular}{|l} 
total \\
simple suars
\end{tabular}}} & $10,000,000$ & 416,667 & & 55.0 & & & & & \\
\hline & & & & $1,153,800$ & 48,075 & 267 & & & & & & \\
\hline & & Lignin,xylan,etc & & 846200 & 35258 & & & & & & & \\
\hline & & \multirow{2}{*}{\multicolumn{2}{|c|}{\begin{tabular}{|l} 
water \\
reactants
\end{tabular}}} & $8.000,000$ & 333,333 & & & & & & & \\
\hline & & & & $10,000,000$ & 416,667 & & & & & & & \\
\hline & \multicolumn{3}{|c|}{ H2O reacted in fermentation } & 207,676 & 8,653 & & & & & & & \\
\hline & \multirow[t]{4}{*}{ gas out } & \multirow{3}{*}{\multicolumn{2}{|c|}{\begin{tabular}{|l}
$\mathrm{H} 2$ \\
$\mathrm{CO} 2$ \\
$\mathrm{VH} 2 \mathrm{O}$
\end{tabular}}} & $46,476.6$ & 1,937 & 961 & 55 & & & & & \\
\hline & & & & $507,339.5$ & 21,139 & 480 & 55 & & & & & \\
\hline & & & & 113,542 & 4,731 & 263 & 55 & & & 14.7 & & \\
\hline & & & & 667,359 & 27,807 & 1,704 & & & & & & \\
\hline & slurry out to $\mathrm{HX}-1$ & slurry total & & $9,332,641$ & 388,860 & & 55 & & & & & \\
\hline & & Lignin,xylan,etc & & 846,200 & 35,258 & & & & & & & \\
\hline & & Acetate & & 692,280 & 28,845 & & & & & & & \\
\hline & & Glucose & $10 \%$ & 115,380 & 4,808 & & & & & & & \\
\hline & & L-H2O & & $7,678,781$ & 319,949 & & & & & & & \\
\hline & & total & & $9,332,641$ & 388,860 & & & & & & & \\
\hline & total mass out & & & $10,000,000$ & 416,667 & & & & & & & \\
\hline Condenser & gases in & H2 & & "46,477 & $\begin{array}{ll}1,937 \\
\end{array}$ & & 55 & & & 14.7 & 14.496 & \\
\hline FC-1 & from fermentor & $\mathrm{co} 2$ & & 507,340 & 21,139 & & 55 & & & 14.7 & 0.953 & \\
\hline & & $\mathrm{VH} 2 \mathrm{O}$ & & 113,542 & 4,731 & & 55 & & & 14.7 & 1.912 & \\
\hline & & total & & 667,359 & 27,807 & & & & & & & \\
\hline & gases out to & $\mathrm{H} 2$ & & 46,477 & $\begin{array}{ll}1,937 \\
\end{array}$ & 960.6 & 45 & 50 & -10 & 14.7 & 14.496 & $-280,719$ \\
\hline & Compressor-F-1 & CO2 & & 507,340 & 21,139 & 480.3 & 45 & 50 & -10 & 14.7 & 0.953 & $-201,350$ \\
\hline & & V H2O & & 64,477 & $2,686.5$ & 149.1 & 45 & 50 & -10 & 14.7 & 1.912 & $-51,367$ \\
\hline & & total gas & & 618,293 & 25,762 & & & & & & & $-533,436$ \\
\hline & liquids out & $\mathrm{LH} 2 \mathrm{O}$ & & 49,066 & 2,044 & & 45 & & -10 & 14.7 & 4.200 & $\begin{array}{r}-62,477 \\
\end{array}$ \\
\hline
\end{tabular}




\begin{tabular}{|c|c|c|c|c|c|c|c|c|c|c|c|c|c|}
\hline \multirow[t]{2}{*}{ Processes } & & & \multirow[b]{2}{*}{$\%$} & \multicolumn{2}{|l|}{ Mass flow } & \multirow{2}{*}{$\begin{array}{c}\text { mole flow } \\
\mathrm{kgM} / \mathrm{hr}\end{array}$} & \multirow{2}{*}{$\begin{array}{l}\mathrm{T} \\
{ }^{\circ} \mathrm{C}\end{array}$} & \multirow{2}{*}{\begin{tabular}{|c|}
$\mathrm{T}$ ave \\
${ }^{\circ} \mathrm{C}$
\end{tabular}} & \multirow{2}{*}{$\begin{array}{l}<\mathrm{T} \\
{ }^{\circ} \mathrm{C}\end{array}$} & \multirow{2}{*}{$\begin{array}{l}\mathrm{P} \\
\mathrm{psi}\end{array}$} & \multirow{2}{*}{\begin{tabular}{|c|}
$\mathrm{Cp}$ \\
$\mathrm{kJ} / \mathrm{kg}{ }^{\circ} \mathrm{C}$
\end{tabular}} & \multirow{2}{*}{$\begin{array}{c}\mathrm{h} \\
\mathrm{kJ} / \mathrm{kg}\end{array}$} & \multirow{2}{*}{$\begin{array}{l}\mathrm{dq} / \mathrm{dt} \\
\mathrm{kJ} / \mathrm{hr}\end{array}$} \\
\hline & & & & $\mathrm{kg} / \mathrm{day}$ & $\mathrm{kg} / \mathrm{hr}$ & & & & & & & & \\
\hline \multirow[t]{4}{*}{$\begin{array}{c}\text { Compressor } \\
\text { stage } 1 \\
\text { F-1 }\end{array}$} & \multirow[t]{2}{*}{ in } & \begin{tabular}{|l}
$\mathrm{H} 2$ \\
$\mathrm{CO} 2$ \\
$\mathrm{~V} \mathrm{H} 2 \mathrm{O}$
\end{tabular} & & $\begin{array}{r}46,477 \\
507,340 \\
64,477\end{array}$ & \begin{tabular}{r|}
1,937 \\
21,139 \\
2,687 \\
\end{tabular} & $\begin{array}{l}961 \\
480 \\
149\end{array}$ & $\begin{array}{l}45 \\
45 \\
45\end{array}$ & & & $\begin{array}{l}14.7 \\
14.7 \\
14.7\end{array}$ & & & \\
\hline & & total & & 618,293 & 25,762 & 1,590 & 45 & & & 14.7 & & & \\
\hline & \multirow[t]{2}{*}{ out } & \begin{tabular}{|l}
$\mathrm{H} 2$ \\
$\mathrm{CO} 2$ \\
$\mathrm{~V} \mathrm{H} 2 \mathrm{O}$
\end{tabular} & & $\begin{array}{r}46,477 \\
507,340 \\
64,477 \\
\end{array}$ & $\begin{array}{r}1,937 \\
21,139 \\
2,687\end{array}$ & $\begin{array}{l}961 \\
480 \\
149\end{array}$ & $\begin{array}{l}190.8 \\
190.8 \\
190.8\end{array}$ & & & $\begin{array}{l}60 \\
60 \\
60\end{array}$ & & & \\
\hline & & total & & 618,293 & 25,762 & 1,590 & & & & & & & \\
\hline \multirow[t]{9}{*}{$\begin{array}{l}\text { Intercooler } \\
\text { FIC-1 } \\
\text { Primary }\end{array}$} & \multirow[t]{2}{*}{ Gas in } & \begin{tabular}{|l}
$\mathrm{H} 2$ \\
$\mathrm{CO} 2$ \\
$\mathrm{VH} 2 \mathrm{O}$ \\
\end{tabular} & & $\begin{array}{r}46,477 \\
507,340 \\
64,477 \\
\end{array}$ & $\begin{array}{r}1,937 \\
21,139 \\
2,687 \\
\end{array}$ & $\begin{array}{l}961 \\
480 \\
149 \\
\end{array}$ & $\begin{array}{l}190.8 \\
190.8 \\
190.8 \\
\end{array}$ & & & $\begin{array}{l}60 \\
60 \\
60 \\
\end{array}$ & $\begin{array}{c}14.496 \\
0.953 \\
1.912 \\
\end{array}$ & & \\
\hline & & total & & 618,293 & 25,762 & & & & & & & & \\
\hline & \multirow[t]{4}{*}{ Gas out } & $\mathrm{H} 2$ & & 46,477 & 1,937 & 960.6 & 45 & 117.9 & -146 & 58 & 14.496 & & $-4,092,881$ \\
\hline & & CO2 & & 507,340 & 21,139 & 480.3 & 45 & 117.9 & -146 & 58 & 0.953 & & $-2,935,688$ \\
\hline & & $\mathrm{VH} 2 \mathrm{O}$ & & 15,169 & 632.1 & 35.1 & 45 & 117.9 & -146 & 58 & 1.912 & & $-176,199$ \\
\hline & & total gas & & 568,986 & 23,708 & & & & & & & & $-7,204,769$ \\
\hline & Liquid out & $\mathrm{LH} 2 \mathrm{O}$ & & 49,307 & 2,054 & & 45 & & -146 & 58 & 4.200 & & $-915,401$ \\
\hline & & V-L Phase chan & e heat & & & & & & & & & -2222 & $-4,565,040$ \\
\hline & total out & & & $1,187,279$ & 49,470 & & & & & & & & $-12,685,209$ \\
\hline Secondary & $\begin{array}{l}\text { water in } \\
\text { water out }\end{array}$ & & & $\begin{array}{l}3,642,123 \\
3,642,123 \\
\end{array}$ & $\begin{array}{r}151,755 \\
151,755 \\
\end{array}$ & & $\begin{array}{l}20 \\
40 \\
\end{array}$ & 30 & 20 & & $\begin{array}{l}4.180 \\
4.180 \\
\end{array}$ & & $12,685,209$ \\
\hline $\begin{array}{c}\text { Compressor } \\
\text { stage } 2 \\
\text { F-2 }\end{array}$ & in & \begin{tabular}{|l}
$\mathrm{H} 2$ \\
$\mathrm{CO} 2$ \\
$\mathrm{VH} 2 \mathrm{O}$ \\
\end{tabular} & & $\begin{array}{r}46,477 \\
507,340 \\
15,169 \\
\end{array}$ & $\begin{array}{r}1,937 \\
21,139 \\
632 \\
\end{array}$ & & $\begin{array}{l}45 \\
45 \\
45 \\
\end{array}$ & & & $\begin{array}{l}58 \\
58 \\
58 \\
\end{array}$ & & & \\
\hline & & total & & 568,986 & 23,708 & 1,476 & & & & & & & \\
\hline & out & \begin{tabular}{|l}
$\mathrm{H} 2$ \\
$\mathrm{CO} 2$ \\
$\mathrm{~V} \mathrm{H} 2 \mathrm{O}$
\end{tabular} & & $\begin{array}{r}46,477 \\
507,340 \\
15,169 \\
\end{array}$ & $\begin{array}{r}1,937 \\
21,139 \\
632\end{array}$ & $\begin{array}{r}960.6 \\
480.3 \\
35.1 \\
\end{array}$ & $\begin{array}{l}218 \\
218 \\
218\end{array}$ & & & $\begin{array}{l}302 \\
302 \\
302\end{array}$ & & & \\
\hline & & total & & 568,986 & 23,708 & $1,476.0$ & & & & & & & \\
\hline \begin{tabular}{|l} 
FIC-2 \\
Primary
\end{tabular} & Gas in & \begin{tabular}{|l|}
$\mathrm{H} 2$ \\
$\mathrm{CO} 2$ \\
$\mathrm{VH} 2 \mathrm{O}$ \\
\end{tabular} & & $\begin{array}{r}46,477 \\
507,340 \\
15,169 \\
\end{array}$ & $\begin{array}{r}1,937 \\
21,139 \\
632 \\
\end{array}$ & & $\begin{array}{l}218 \\
218 \\
218 \\
\end{array}$ & & & $\begin{array}{l}302 \\
302 \\
302 \\
\end{array}$ & & & \\
\hline & & total & & 568,986 & 23,708 & & & & & & & & \\
\hline & Gas out & $\mathrm{H} 2$ & & 46,477 & 1,937 & 960.6 & 45 & 131.45 & -173 & 300 & 14.496 & & $-4,853,629$ \\
\hline & & CO2 & & 507,340 & 21,139 & 480.3 & 45 & 131.45 & -173 & 300 & 0.953 & & $-3,481,348$ \\
\hline & & $\mathrm{V} \mathrm{H} 2 \mathrm{O}$ & & 2,876 & 120 & 6.7 & 45 & 131.45 & -173 & 300 & 1.912 & & $-39,619$ \\
\hline & & total gas & & 556,692 & 23,196 & & & & & & & & $-8,374,596$ \\
\hline & Liquid out & $\mathrm{L} \mathrm{H} 2 \mathrm{O}$ & & 12,293 & 512 & & 45 & & -173 & 300 & 4.200 & & $-270,646$ \\
\hline & & V-L Phase chan & e heat & & & & & & & & & -2222 & $-1,138,145$ \\
\hline & total out & & & 568,986 & 23,708 & & & & & & & & $-9,783,386$ \\
\hline Secondary & $\begin{array}{l}\text { water in } \\
\text { water out }\end{array}$ & & & $\begin{array}{l}2,808,964 \\
2,808,964 \\
\end{array}$ & $\begin{array}{r}117,040 \\
117,040 \\
\end{array}$ & & $\begin{array}{l}20 \\
40 \\
\end{array}$ & 30 & 20 & & $\begin{array}{l}4.180 \\
4.180\end{array}$ & & $9,783,386$ \\
\hline PSA & jin & total & & 556,692 & 23,196 & & 45 & & & 300 & & & \\
\hline fermentor & & \begin{tabular}{|l}
$\mathrm{H} 2$ \\
$\mathrm{CO} 2$ \\
$\mathrm{~V} \mathrm{H} 2 \mathrm{O}$
\end{tabular} & & $\begin{array}{r}46,477 \\
507,340 \\
2,876\end{array}$ & $\begin{array}{r}1,937 \\
21,139 \\
120\end{array}$ & $\begin{array}{r}960.6 \\
480.4 \\
6.7\end{array}$ & $\begin{array}{l}45 \\
45 \\
45\end{array}$ & & & $\begin{array}{l}300 \\
300 \\
300\end{array}$ & & & \\
\hline & out & $\mathrm{H} 2$ outlet & $80 \%$ & 37,181 & 1,549 & & 45 & & & 300 & & & \\
\hline & & H2 loss & $20 \%$ & 9,295 & 387 & 192.1 & 45 & & & 300 & & & \\
\hline & & \begin{tabular}{|l|}
$\mathrm{CO} 2$ \\
$\mathrm{CO} / \mathrm{H} 2$ mass ra
\end{tabular} & & $\begin{array}{r}507,340 \\
54.6\end{array}$ & 21,139 & 480.4 & 45 & & & 300 & & & \\
\hline & & $\begin{array}{l}\mathrm{V} \mathrm{H} 2 \mathrm{O} \\
\mathrm{VH} 2 \mathrm{O} / \mathrm{H} 2 \text { mass }\end{array}$ & & $\begin{array}{r}2,876 \\
0.31\end{array}$ & 120 & 6.7 & 45 & & & 300 & & & \\
\hline & & waste gas out & & 519,511 & 21,646 & 679.2 & & & & & & & \\
\hline & Burner us & se of waste $\mathrm{H} 2=$ & $97 \%$ & & & & & & & & & & \\
\hline LigninSeparator & in from $\mathrm{HX}-1$ & & & $9,332,641$ & 388,860 & & & & & & & & \\
\hline & (from fermentor) & Lignin, etc & & 846,200 & 35,258 & & 30 & & & 14.7 & & & \\
\hline & & $\begin{array}{l}\text { Acetate } \\
\text { Glucose }\end{array}$ & & $\begin{array}{r}692,280 \\
115,380\end{array}$ & $\begin{array}{r}28,845 \\
4,808\end{array}$ & & & & & & & & \\
\hline & & \begin{tabular}{|l}
$\mathrm{L}-\mathrm{H} 20$ \\
\end{tabular} & & $\frac{1,0,000}{7,678,781}$ & $\begin{array}{r}4,000 \\
319,949\end{array}$ & & & & & & & & \\
\hline & & total & & $9,332,641$ & 388,860 & & & & & & & & \\
\hline & out - mash & $\begin{array}{l}\text { Lignin, etc } \\
\text { Acetate } \\
\text { Glucose }\end{array}$ & $\begin{array}{c}100 \% \\
5 \% \\
5 \%\end{array}$ & $\begin{array}{r}846,200 \\
34,614 \\
5,769\end{array}$ & $\begin{array}{r}35,258 \\
1,442 \\
240 \\
\end{array}$ & & 30 & & & 14.7 & & & \\
\hline & & LH2O/lignin & $100 \%$ & & & & & & & & & & \\
\hline & & \begin{tabular}{|l}
$\mathrm{LH} 2 \mathrm{O}$ \\
total
\end{tabular} & & 846,200 & 35,258 & & & & & & & & \\
\hline & out - liquid & Acetate & $95 \%$ & $\begin{array}{r}1,732,783 \\
657,666\end{array}$ & $\begin{array}{l}12,199 \\
27,403\end{array}$ & & 30 & & & 147 & & & \\
\hline & to MEC & Glucose & $95 \%$ & $\begin{array}{l}05 /, 000 \\
109,611\end{array}$ & 4,567 & & 00 & & & & & & \\
\hline & & $\mathrm{H} 20-\mathrm{L}$ & & $6,832,581$ & 284,691 & & & & & & & & \\
\hline & & total & & $7,599,858$ & 316,661 & & & & & & & & \\
\hline
\end{tabular}




\begin{tabular}{|c|c|c|c|c|c|c|c|c|c|c|c|c|c|}
\hline \multicolumn{3}{|l|}{ Processes } & $\%$ & \multirow{2}{*}{\multicolumn{2}{|c|}{ Mass flow }} & \multirow{2}{*}{$\begin{array}{c}\text { mole flow } \\
\mathrm{kgM} / \mathrm{hr}\end{array}$} & \multirow{2}{*}{$\begin{array}{l}\mathrm{T} \\
{ }^{\circ} \mathrm{C}\end{array}$} & \multirow{2}{*}{$\begin{array}{c}\text { Tave } \\
{ }^{\circ} \mathrm{C}\end{array}$} & \multirow{2}{*}{$\begin{array}{l}9 \mathrm{~T} \\
{ }^{\circ} \mathrm{C}\end{array}$} & \multirow{2}{*}{$\begin{array}{c}\mathrm{P} \\
\mathrm{psi}\end{array}$} & \multirow{2}{*}{$\mathrm{Cp}_{\mathrm{KJ}}$} & \multirow{2}{*}{$\begin{array}{c}\mathrm{h} \\
\mathrm{kJ} / \mathrm{kg}\end{array}$} & \multirow{2}{*}{$\begin{array}{l}\mathrm{dq} / \mathrm{dt} \\
\mathrm{kJ} / \mathrm{hr}\end{array}$} \\
\hline & & & & & & & & & & & & & \\
\hline MEC water addition & & & & $339,082,263$ & $14,128,428$ & & & & & & & & \\
\hline MEC & from LigSep & Acetate & & 657,666 & 27,403 & 456.3 & 30 & & & & & & \\
\hline $0.9 \mathrm{~V}$ system & & Glucose & & 109,611 & 4,567 & 25.4 & & & & & & & \\
\hline & & total substrat & & 767,277 & 31,970 & $\begin{array}{lll}481.7 & \\
\end{array}$ & & & & & & & \\
\hline & & H20-L & & $6,832,581$ & 284,691 & & & & & & & & \\
\hline & Water addition: & total input & & $\begin{array}{l}7,0599,858 \\
\end{array}$ & 316,661 & & & & & & & & \\
\hline & Acetate & $\mathrm{H} 2 \mathrm{O}+$ substr & & $346,682,121$ & $14,445,088$ & & & & & & & & \\
\hline & dilution $(g / L)=$ & Total H20 ne & & $345,914,844$ & $14,413,119$ & & & & & & & & \\
\hline $90 \%$ & 2.213 & Water Additic & & $339,082,263$ & $14,128,428$ & & & & & & & & \\
\hline reaction & & total water & & $345,914,844$ & $14,413,119$ & & & & & & & & \\
\hline completion & total input & & & $346,682,121$ & $14,445,088$ & & & & & & & & \\
\hline & \begin{tabular}{|l} 
reactant vol. $=$ \\
\end{tabular} & $91,524,080 \mathrm{~g}$ & & & & & & & & & & & \\
\hline & reacted acetate+gluc & & $90 \%$ & 690,549 & 28,773 & & & & & & & & \\
\hline & reacted water & & & 414,314 & 17,263 & 958.3 & & & & & & & \\
\hline & output-gas & $\mathrm{H} 2$ & & 92,721 & 3,863 & $1,916.5$ & 30 & & & 14.7 & & & \\
\hline & calculation & CO2 total & & $1,012,142$ & 42,173 & 958.3 & 30 & & & 14.7 & & & \\
\hline completion & & $\mathrm{CO} 2$ in $\mathrm{H} 2$ & $5 \%$ & 50,607 & 2,109 & 47.9 & 0.05001 & & & & & & \\
\hline & (process chart) & $\mathrm{H} 2 \mathrm{O}-\mathrm{V}$ & & 36,752 & $1,531.3$ & 85.0 & $\frac{0.00}{30}$ & & & 14.7 & & & \\
\hline & & total cathode & & $1,141,615$ & 47,567 & 2,049 & 30 & & & & & & \\
\hline & output-liquid waste & Acetate & $10 \%$ & 65,767 & 2,740 & & 30 & & & & & & \\
\hline & & Glucose & $10 \%$ & 10,961 & & & 30 & & & & & & \\
\hline & & H20-L & & $345,463,778$ & $14,394,324$ & & & & & & & & \\
\hline & & total liquids & & $345,540,506$ & $14,397,521$ & & & & & & & & \\
\hline & total output & & & 346682121 & 14,445088 & & & & & & & & \\
\hline
\end{tabular}

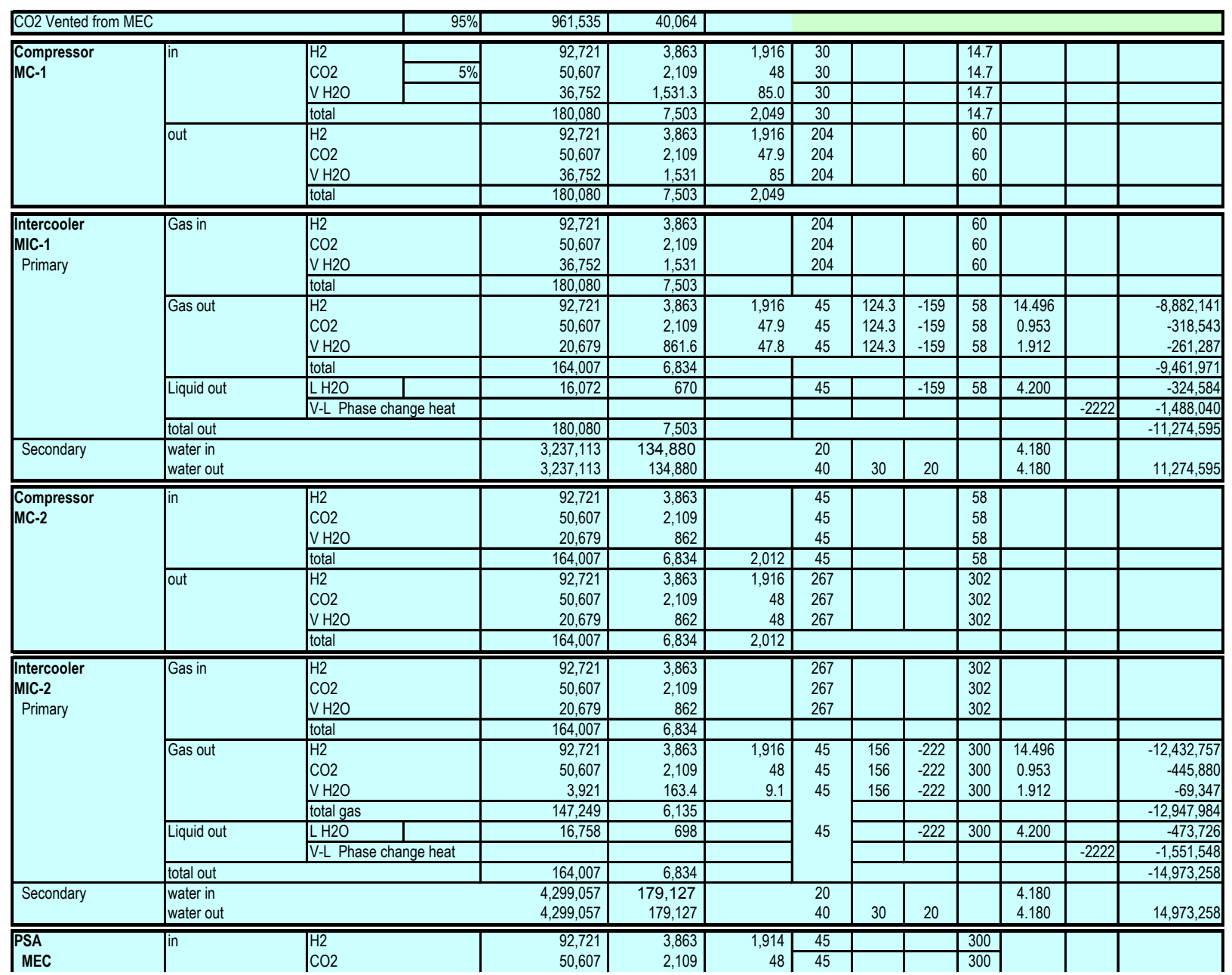




\section{Part V: Discussion of Project Results}




\section{Summary of Results and Conclusions}

This report consists of technoeconomic boundary analyses conducted for thirteen different biological hydrogen production systems. Eight were stand-alone systems:

- Five photosynthesis systems using algae and bacteria

- A fermentation system for waste algae

- A fermentation system for lignocellulose

- A Microbial Electrolysis Cell (MEC)

Five integrated systems were examined, each combining two of the above systems:

- A vertically stacked photosynthesis system using algae and PNS bacteria

- Three systems combining photobiological and fermentor systems

- A lignocellulose fermentation system combined with an MEC to process the organic byproduct of the fermentor

\subsection{Photosynthesis systems}

Each photosynthesis system used a series of large ponds or beds for organism growth and subsequent hydrogen production. The reactor beds were covered with a non-porous transparent cover to capture the $\mathrm{H}_{2}$ and other gaseous products. Multiple configuration approaches were considered including single bed, dual bed, and chemostat configurations. The best single configuration for reach system was selected for more detailed study. Cost analysis suggests that large shallow reactor beds with thin film LDPE covers are the most economic approach. Such reactor configurations were selected for all photobiological $\mathrm{H}_{2}$ production.

The five photosynthesis systems were:

- B-1: Chlamydomonas reinhardtii mutant with $\mathrm{O}_{2}$ tolerant hydrogenase

- B-2: Cyanobacterium mutant with $\mathrm{O}_{2}$-tolerant hydrogenase

- B-3: Chlamydomonas reinhardtii with mutated sulfate permease

- B-4: Chlamydomonas reinhardtii, immobilized on a porous mat and sulfur deprived

- B-5: Rhodobacter sphoeroides RV Purple Non-Sulfur (PNS) Bacteria

The B-1, B-2 and B-5 systems were used in a chemostat II configuration, which is able to continuously generate $\mathrm{H}_{2}$ while the organisms are regenerated using a portion of the solar radiation. The B-3 system alternated between $\mathrm{H}_{2}$ generation (3 days) and algae regeneration (4 days). The B-4 system was immobilized on a polypropylene film, thus minimizing the algae's energy requirements. This system operated cyclically, alternating 3 days production and 1 days regeneration.

For the hydrogen production calculations, the following key assumptions were made affecting solar-to-hydrogen (STH) energy efficiency for the upper bound of organism functioning:

1. PAR (Photosyntheticaly Active Radiation): $44 \%$ for B-1 through B-4 and $71 \%$ for B-5 
2. Antennas: Mutants are developed with highly truncated antennas for maximal solar utilization (mutants have been developed with moderately truncated antennas but these have not produced significant amounts of hydrogen)

3. Light saturation: Mutants are developed that do not have ETR (Electron Transfer Rate) limitations in sunlight up to maximum intensity, thus allowing $12.2 \% \mathrm{STH}$ energy efficiency. (Current mutants are saturated at low sunlight levels, limiting STH efficiency to $2-3 \%$ )

4. Chemostat II: A continuously operating Chemostat II is feasible, allowing simultaneous growth and $\mathrm{H}_{2}$ production. (This continuous operation has not yet been demonstrated in comprehensive experiments)

Near term STH energy conversion efficiencies were also estimated for the photobiological systems. The key assumptions listed above for the upper bound cases generally apply with the exception of an imposition of light saturation affects (ie. ETR limitations). These near term efficiencies are somewhat subjective and are higher than performance currently demonstrated in the lab but much lower than upper bound performance.

Figure 32-1summarizes the solar-to-hydrogen energy conversion efficiency assumed for both upper bound performance and near term performance.

Figure 32-1. Photobiological System STH Energy Efficiency ${ }^{100}$

\begin{tabular}{|lccccc|}
\hline STH Efficiency & B1 & B2 & B3 & B4 & B5 \\
\hline Upper Bound & $9.2 \%$ & $9.2 \%$ & $5.2 \%$ & $2.25 \%$ & $3.5 \%$ \\
\hline Near Term & $2 \%$ & $2 \%$ & $1.3 \%$ & $1.5 \%$ & $1.5 \%$ \\
\hline
\end{tabular}

\subsection{Algae Fermentation Systems}

Fermentation systems were designed to carry out dark fermentation of waste organisms as would be generated in the B-1 through B-5 systems. The maximum potential output from glucose is 4 moles $\mathrm{H}_{2}$ per mole glucose. The fermentation converts the organisms into $\mathrm{H}_{2}, \mathrm{CO}_{2}$, acetic acid, and other organic compounds. The algae fermentation process has been experimentally demonstrated at lab scale by NREL using NREL-developed bacteria consortia. These initial tests at NREL partially converted cell starches, and subsequently, using the same consortium, additionally converted lipids. The high starch algae (sulfur deprived for 21 hours and $32 \%$ glucose) yielded 1.7 moles $\mathrm{H}_{2}$ per mole glucose, or $\mathrm{H}_{2}$ mass of $0.618 \%$ of algae mass.

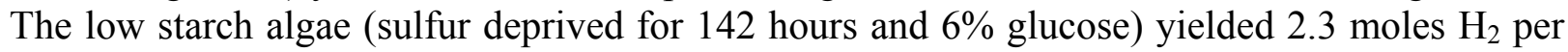
mole glucose, or $\mathrm{H}_{2}$ mass of $0.155 \%$ of algae mass. With additional experimental developments, near term future mass conversion rates are expected to be $0.4 \mathrm{wt} \%$ from sulfur depleted algae.

For this study, the fermentor unit was sized based on the waste algae output from the photosynthesis systems. With this relatively small feedstock, the ferment output was low, resulting in high $\mathrm{H}_{2}$ production cost.

100 STH Efficiency =Solar to Hydrogen conversion efficiency = ratio of hydrogen net energy produced (lower heating value) to total solar energy incident on reactor bed. 
For the algae fermentor production calculations, the following key assumptions were made:

1. Mass conversion rate of sulfur deprived algae was $0.4 \% \mathrm{H}_{2}$ mass/algae mass. (Current test achievements include: $0.154 \%$ for sulfur deprived $142 \mathrm{hrs}$ and $0.613 \%$ for sulfur deprived $21 \mathrm{hrs}$ )

Only an upper bound performance estimate was made for the fermentation system since the system is at a much more developed level than the photobiological system.

\subsection{Lignocellulose Fermentation System}

The lignocellulose fermentation system used corn stover as a feedstock to generate hydrogen via a dark fermentation process. The process is quite complex and involves extensive feedstock pre-processing, hydrolysis, saccharification, and fermentation. Portions of the process design and capital costs were based on an NREL corn stover-to-ethanol plant cost analysis. The unique $150^{\circ} \mathrm{C}$ hydrolysis process used for this study is one that has been demonstrated by NREL. The unique organisms for the saccharification process and for the fermentation-to- $\mathrm{H}_{2}$ process have been developed by NREL at lab scale. The saccharification process utilizes organisms to convert the hydrolysis products into simple sugars in a short time. The subsequent fermentation process uses the same bacteria to produce $\mathrm{H}_{2}$ and $\mathrm{CO}_{2}$ gas plus simple organic liquids

For the lignocellulose fermentor production calculations, the following assumptions were made:

1. Acid hydrolysis to break down biomass to hemicellulose and cellulose components of complex sugars can be effectively carried out at a temperature of $150^{\circ} \mathrm{C}$ and pressure of $4.7 \mathrm{~atm}$. with an efficiency of $90 \%$ conversion of the components.

2. Saccharification and fermentation can be effectively carried out sequentially in the same reactor vessel at a temperature of $55^{\circ} \mathrm{C}$, at atmospheric pressure, and using $40 \mathrm{hr}$ batch cycle with an efficiency of $90 \%$ conversion.

The saccharification process utilizes bacteria to convert the hydrolysis products into simple sugars in a short time. The subsequent fermentation process uses the same bacteria to produce $\mathrm{H}_{2}$ and $\mathrm{CO}_{2}$ gas plus organic liquids, requiring approximately 40 hours. Efficiency for these processes in combination was $90 \%$ conversion to $\mathrm{H}_{2}$ and simple liquid organic byproducts.

Costs of 37 tonne/day $\mathrm{H}_{2}$ production were initially calculated assuming zero value of the byproducts. These byproducts are essentially: 692 tonnes of organic acid and alcohol liquids plus 846 tonnes of lignin and xylan solids. The liquid byproducts comprising $51 \%$ acetate and $21 \%$ ethanol have intrinsic value, but would require a subsequent separation process such as distillation. Taking credit for the value of the large amount of byproduct would substantially reduce net $\mathrm{H}_{2}$ costs. A more rigorous assessment of this effect should be conducted. As an alternative to byproduct recovery, the liquid organics can be processed in an MEC to produce additional hydrogen.

In addition to the liquid byproducts, the extracted lignin solids can be used as a low grade fuel for industrial processes. 
Like the algae fermentation system, only an upper bound performance estimate was made for the lignocellulosic fermentation system.

\subsection{Microbial electrolysis Cell (MEC) System}

The MEC has been developed at Penn State University to break down simple liquid organics such as acetic acid and ethanol mixed with water into $\mathrm{H}_{2}$ and $\mathrm{CO}_{2}$, with the gasses being separated by the electrolysis process.

For the electrolysis process, the anode microbes generate a voltage which is supplemented with an external voltage to generate an electrolysis current. A lower external voltage results in higher efficiency, but increases reaction times, thus increasing system size and cost. It was determined that for lowest cost $\mathrm{H}_{2}$, the system should be operated at a higher than normal voltage $(0.9 \mathrm{~V})$ to minimize capital plant costs. The very low concentration of the input acetic acid $(\sim 2 \mathrm{~g}$ acetate/Liter of water as opposed to the fermentor at $200 \mathrm{~g} / \mathrm{L})$ resulted in a very large system, i.e., $96,000,000$ gallons of total reactor volume for 88 tonnes $\mathrm{H}_{2} /$ day. These volumes and the required high area anodes and cathodes were based on specifications from lab tests by Penn State. The anode used was a carbon brush with the microbe layer and the cathode was a stainless steel brush. The details of utilization of these electrodes in a large scale reactor tank have not been fully worked out. Since the MEC separates most of the $\mathrm{H}_{2}$ from the $\mathrm{CO}_{2}$, its PSA requirements are greatly reduced and there is reduced loss of $\mathrm{H}_{2}$ in the PSA process.

Key assumptions for the MEC system were:

1. Conversion efficiency of acetate to $\mathrm{H}_{2}$ is $90 \%$ of the theoretical 4 moles of $\mathrm{H}_{2} / \mathrm{mole}^{2}$ acetate (lab tests have achieved as high as 95\%)

2. The lab-scale system design will function equally well for very large scale reactors.

3. Acetate feedstock for the stand-alone MEC was $\$ 0.60 / \mathrm{kg}$, (which is a significant component of the resultant $\mathrm{H}_{2}$ cost).

Only an upper bound performance estimate was made for the MEC system given its currently very low stage of development.

\subsection{Integrated Stacked Photosynthesis System}

This system employs two different photosynthesis systems having different, but overlapping, PAR wavelength bands. The narrower band system is stacked on top of the wider band system so that the lower system can utilize photons not utilized by the upper system. For this case, the more efficient (4 photons $/ \mathrm{H}_{2}$ ), but narrower band Chlamydomonas reinhardtii was above the less efficient (11 long wavelength photons $\left./ \mathrm{H}_{2}\right)$, but wider band (PAR $\left.=0.71\right)$ PNS bacteria. For the top bed, the B-3 system was used, since the B-1 and B-2 mixtures of $\mathrm{O}_{2}$ and $\mathrm{H}_{2}$ raised safety concerns for this application and the B-4 mat and high cell density absorbed too much sunlight. The stacked system has the benefit of reduced land area requirement. 


\subsection{Integrated Photosynthesis and Fermentor System}

This system used the algae or bacteria waste from the photosynthesis beds as feedstock to an algal/organism fermentor. The B-1, B-2 and B-5 systems were chosen as the best adapted for the integration, since, in chemostat operation, they will be filtering waste algae from a slip stream of water to maintain bed concentration. In the B-3 and B-4 system, no waste algae is removed due to the need for the system to respire enough glucose to keep the system anaerobic. In all cases, the quantity of feedstock was so low that very little $\mathrm{H}_{2}$ was produced as compared with the 10 tonne/day photosynthesis beds. For the B-1 and B-2 integrations, output was $\sim 7 \mathrm{~kg} / \mathrm{day}$ and for the B-5 integration, output was $\sim 18 \mathrm{~kg} /$ day. An additional benefit of the B-5 integration was that the fermentor produced acetic acid byproduct, providing $3 \%$ of the B-5 acetic acid requirement.

\subsection{Integrated Lignocellulosic Fermentor and MEC}

The baseline lignocellulosic fermentor and baseline MEC were sized to allow integration of the two such that the organic liquid byproduct of the fermentor could be used as the entire feedstock for the MEC. This byproduct has been shown in NREL experiments to be $51 \%$ acetic acid and $21 \%$ ethanol, with the remainder being other organic acids. Thus, the 2,000 tonnes/day corn stover plus water produced 37 tonnes $\mathrm{H}_{2} /$ day from the fermentor and 88 tonnes $\mathrm{H}_{2} /$ day from the MEC.

\subsection{Gas Processing}

For each of these systems, the reactor gaseous outputs were ducted to compression and gas separation systems. The compressors were two stage units, using intercoolers to reduce gas temperature and to condense water vapor, thus minimizing compression power requirement. The final separation was carried out with PSA (Pressure Swing Adsorption) units that would produce $99.9 \%$ pure $\mathrm{H}_{2}$.

\subsection{Hydrogen Production Cost Comparisons}

Given the systems and performance assumptions listed above, the feasibility, performance, capital cost, and resultant $\$ / \mathrm{kg} \mathrm{H}_{2}$ were evaluated for each system and integrated system. System hydrogen production costs are summarized in Figure 32-2. 
Figure 32-2. $\mathrm{H}_{2}$ Production Costs

\begin{tabular}{|c|c|c|c|}
\hline \multirow[b]{2}{*}{ System } & \multirow{2}{*}{$\begin{array}{c}\mathrm{H}_{2} \\
\text { Production } \\
\text { kg/day }\end{array}$} & \multicolumn{2}{|c|}{ Hydrogen Cost, \$/kg } \\
\hline & & $\begin{array}{l}\text { Near Term } \\
\text { Performance }\end{array}$ & $\begin{array}{l}\text { Upper Bound } \\
\text { Performance }\end{array}$ \\
\hline \multicolumn{4}{|l|}{ Photobiological $\mathrm{H}_{2}$ Production } \\
\hline B-1: Algal $\mathrm{O}_{2}$-tolerant Hydrogenase & 10,000 & $\$ 8.15$ & $\$ 2.99$ \\
\hline B-2: Cyanobacterium $\mathrm{O}_{2}$-tolerant Hydrogenase & 10,000 & $\$ 8.15$ & $\$ 2.99$ \\
\hline B-3: Algal Sulfate Permease & 10,000 & $\$ 10.48$ & $\$ 4.17$ \\
\hline B-4: Immobi lized A lgal, Sulfer de prived & 10,000 & $\$ 8.44$ & $\$ 6.02$ \\
\hline B-5: PNS Bacteria & 10,000 & $\$ 13.95$ & $\$ 10.36$ \\
\hline \multicolumn{4}{|l|}{ Fermentation of Waste Algae/Photobacteria } \\
\hline $\mathrm{C}-1$ or C-2 (Effluent from B-1 or B-2) & 7 & -- & $\$ 172.73$ \\
\hline C-5 (Effluent from B-5) & 19 & -- & $\$ 66.17$ \\
\hline \multicolumn{2}{|l|}{ Fermentation of Lignocellulose } & -- & \\
\hline System with no byproduct credit & 37,181 & -- & $\$ 4.33$ \\
\hline System with byproduct sales ( $\$ 0.12 / \mathrm{kg}$ acetate byproduct) & 37,181 & & $\$ 2.09$ \\
\hline MEC - Microbial Electrolysis Cell (Acetic Acid Feedstock) & 88,055 & -- & $\$ 12.43$ \\
\hline \multicolumn{4}{|l|}{ Integrated Sys tems } \\
\hline Integrated Photobiological - Stacked System (B-3 over B-5) & 10,600 & -- & $\$ 5.25$ \\
\hline Integrated Photobiologica/Fermentor & & & \\
\hline $\mathrm{B} 1-\mathrm{C} 1$ or $\mathrm{B} 2-\mathrm{C} 2$ Integration & 10,007 & -- & $\$ 3.21$ \\
\hline B5-C5 Integration & 10,019 & -- & $\$ 11.04$ \\
\hline Integrated Lignocellulosic Fermentor/MEC & 125,266 & -- & $\$ 6.61$ \\
\hline
\end{tabular}

For the pure photobiological systems, the upper bound performance B-1/B-2 system ${ }^{101}$ achieved the lowest hydrogen cost, however, these results are predicated on major improvements in organism mutations achieving truncated antenna reductions, elimination of cell light saturation due to Electron Transfer Rate (ETR) limits, and satisfactory chemostat II operation. The B-3 and B-4 system costs are slightly higher and the systems are more complex, but the components have been more completely demonstrated. The B-5 system has the highest cost of the photobiological systems due the larger amount of photons needed (11 to 15 vs. 4) and the high

${ }^{101}$ While the B-1 and B-2 pathways utilize different organisms, all system engineering parameters are identical. Consequently, predicted hydrogen cost is the same. 
cost of the acetic acid feedstock. This system definition also assumed a satisfactory Chemostat II.

Not surprisingly, the photobiological systems achieving near term STH energy efficiency are observed to be substantially higher cost than those achieving upper bound STH efficiency. The cost difference is a function of both required reactor area and scaling affects of non-bed components, thus the cost difference cannot be determined by simply ratioing STH efficiencies.

The algae/bacteria fermentation systems have high costs due to the low organism feedstock input resulting in low $\mathrm{H}_{2}$ output. A large part of the resulting $\mathrm{H}_{2}$ cost is due to the labor costs, (94-96\% of total cost) since we are analyzing it as a stand-alone system. The cost contribution of the labor drops drastically when integrated with the Photobiological system. The current results are based on a projected fermentation output of highly sulfur-deprived organisms and do not exploit fully the organic components of the algae feedstock. It is expected that future bacteria and processing developments can facilitate more extensive conversion of the starch, lipid and protein content of the algae into $\mathrm{H}_{2}$. Note that lignocellulose was not added to the algal fermentor to supplement the feedstock due to different bacterium needed and significant transportation costs from lignocellulosic sources to the high solar intensity photobiological sites.

The lignocellulosic fermentation achieved a moderately low $\mathrm{H}_{2}$ cost, using bacteria and processing that has been proven in lab environments, but not in large scale demonstrations. There is also high potential for cost reduction from sales of the $51 \%$ acetic acid content liquid byproduct. If the byproduct had a market value of $\$ 0.12 / \mathrm{kg}$ (as compared to the market price of $\sim \$ 0.60 / \mathrm{kg}$ for acetic acid), the net $\mathrm{H}_{2}$ cost would be reduced to near $\$ 2.00 / \mathrm{kg}$.

For the MEC system, the moderately high $\mathrm{H}_{2}$ cost resulted from the very dilute acetic acid/water reactant, and necessitated a very large reactor volume and correspondingly very large anode and cathode areas. This high capital cost was coupled with high acetate market price, which could potentially be reduced by lowering acetic acid purity, which is not marketed, but is available as a fermentor byproduct. The immaturity of the full scale system concepts and components indicated that there is extensive potential for future cost reductions. Cost saving could also arise from higher concentration of electrolyte and higher pressure operation.

For the integrated stacked photobiological system, the $\mathrm{H}_{2}$ cost is between the cost of the individual stand-alone systems. This indicates that there is no cost benefit to integration as a scaled-up version of the lowest cost non-integrated configuration is most preferable.

For the integrated photobiological algae/fermentor system, the resulting $\mathrm{H}_{2}$ costs are higher than the stand-alone photobiological system, also indicated that integration is not preferred.

For the integrated fermentor/MEC system, the MEC's $\mathrm{H}_{2}$ production cost is reduced significantly due to supply of a "free" feedstock. However, due to high MEC capital costs, the cost of the combined system is still significantly higher than the fermentor alone. 


\section{Recommendations for Future Work}

Key recommendations for future work are summarized below:

Photobiological Systems

- Conduct research to further reduce the truncated antenna of mutants

- Conduct research to eliminate or alleviate the current Electron Transfer Rate (ETR) limitations for organisms and resulting light saturation

- Conduct sensitivity testing on advanced mutants to more fully assess the effects of algae photon utilization rate saturation

- Demonstrate the Chemostat II operation at larger scale

- Evaluate alternative reactor bed concepts

- Consider the use of an alternative immobilization mat for use in the B-4 system. As currently postulated, B-4 uses a fibrous, high surface area polypropylene mat on which to cultivate algae. This mat has been shown to work well with other algal organisms and can be purchased at low cost as opposed to having to be fabricated on-site (at an anticipated high cost). However, alternate mats, perhaps made of alginate, offer several advantages: they can be used as a nutrient source for the algae and/or used as feedstock for the fermentor when the photobiological system is integrated with an algal fermentor. For these reasons, consideration of alternate B-4 systems is warranted.

- Conduct more comprehensive systems designs, addressing details of mixing, $\mathrm{pH}$ control, bed temperature control, and $\mathrm{CO}_{2}$ absorption

Future Algae Fermentation Systems

- Evaluate feedstock algae pre-treatment processes (e.g. hydrolysis and saccharification) to significantly increase the algae-to-hydrogen conversion rate (by greater conversion of lipids and other components)

- Consider stand-alone large-scale hydrogen production using high glucose content, rapid growing, denser concentration algae as a substrate, grown specifically for fermentation

- Use non-sulfur deprived algae, greatly increasing the easily fermentable glucose content

- Reduce fermentation time from 72 hours to at least the 40 hour batch time characteristic of the lignocellulosic fermentation

Lignocellulose Fermentation Systems

- Conduct further analysis to verify the benefit of the lignocellulose fermentation liquid organic byproduct sale to dramatically reduce the cost of hydrogen. This would include evaluation of potential byproduct component selling price reductions due to increases in worldwide supply from fermentation processors

- Conduct further analysis to address the separation of byproduct components (acids, ethanol, etc.), as in a distillation process 
MEC Systems

- Through research and analysis, develop optimized production process and components for low capital cost systems, addressing issues such as:

- Increased solution density

- Higher pressure operation

- Low cost cathodes and anodes

- Cathode and anode optimization for large reactors

- Determine the extent of ion transport loss increases as reactor size grows to production scales

Integrated Systems

- Postulate additional synergistic integrated system combinations to achieve reduced hydrogen cost

- Analyze integration of reactor bed configurations (dual beds, other) that may not be optimal for stand-alone photobiological reactors, but are advantageous when combined in an integrated system 


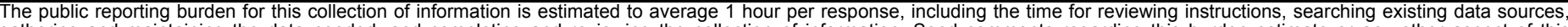

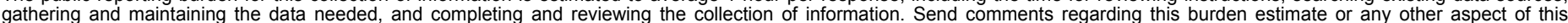

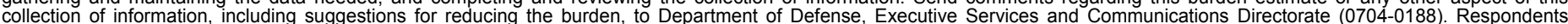

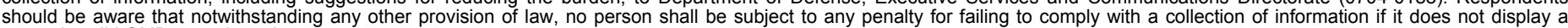

should be aware that notwithstanding

PLEASE DO NOT RETURN YOUR FORM TO THE ABOVE ORGANIZATION.

\begin{tabular}{l|ll} 
1. & REPORT DATE $(D D-M M-Y Y Y Y)$ \\
September 2009 & 2. & $\begin{array}{l}\text { REPORT TYPE } \\
\text { Subcontract Report }\end{array}$ \\
\hline
\end{tabular}

4. TITLE AND SUBTITLE

Technoeconomic Boundary Analysis of Biological Pathways to

Hydrogen Production: March 27, 2008 - August 31, 2009
3. DATES COVERED (From - To)

3/27/08 - 8/31/09

5a. CONTRACT NUMBER

DE-AC36-08-GO28308

5b. GRANT NUMBER

5c. PROGRAM ELEMENT NUMBER

5d. PROJECT NUMBER

NREL/SR-560-46674

5e. TASK NUMBER

H2714000

5f. WORK UNIT NUMBER
7. PERFORMING ORGANIZATION NAME(S) AND ADDRESS(ES)

Directed Technologies, Inc.

One Virginia Square

3601 Wilson Boulevard, Suite 650

Arlington, Virginia 22201

9. SPONSORING/MONITORING AGENCY NAME(S) AND ADDRESS(ES)

National Renewable Energy Laboratory

1617 Cole Blvd.

Golden, CO 80401-3393
8. PERFORMING ORGANIZATION REPORT NUMBER

AFH-8-88601-01
10. SPONSOR/MONITOR'S ACRONYM(S) NREL

11. SPONSORING/MONITORING AGENCY REPORT NUMBER NREL/SR-560-46674

12. DISTRIBUTION AVAILABILITY STATEMENT

National Technical Information Service

U.S. Department of Commerce

5285 Port Royal Road

Springfield, VA 22161

13. SUPPLEMENTARY NOTES

NREL Technical Monitor: Ali Jalalzadeh-Azar

14. ABSTRACT (Maximum 200 Words)

Report documenting the biological and engineering characteristics of five algal and bacterial hydrogen production systems selected by DOE and NREL for evaluation.

\section{SUBJECT TERMS}

technoeconomic analysis; boundary analysis; biological pathways; hydrogen production; Directed Technologies, Inc.

\begin{tabular}{|c|c|c|c|c|}
\hline \multicolumn{3}{|c|}{ 16. SECURITY CLASSIFICATION OF: } & \multirow{2}{*}{$\begin{array}{l}\text { 17. LIMITATION } \\
\text { OF ABSTRACT } \\
\text { UL }\end{array}$} & \multirow{2}{*}{$\begin{array}{l}\text { 18. NUMBER } \\
\text { OF PAGES }\end{array}$} \\
\hline $\begin{array}{l}\text { a. REPORT } \\
\text { Unclassified }\end{array}$ & $\begin{array}{l}\text { b. ABSTRACT } \\
\text { Unclassified }\end{array}$ & $\begin{array}{l}\text { c. THIS PAGE } \\
\text { Unclassified }\end{array}$ & & \\
\hline
\end{tabular}

19a. NAME OF RESPONSIBLE PERSON

19b. TELEPHONE NUMBER (Include area code) 